\title{
Showerhead Film Cooling Performance of a Turbine Vane at High Freestream Turbulence in a Transonic Cascade
}

\author{
Shakeel Nasir \\ Dissertation submitted to the faculty of the \\ Virginia Polytechnic Institute and State University \\ in partial fulfillment of the requirements for the degree of
}

\section{Doctor of Philosophy \\ in \\ Mechanical Engineering}

\author{
Dr. Wing Ng, Advisor and Chair \\ Dr. Karen Thole \\ Dr. Thomas Diller \\ Dr. Saad Ragab \\ Dr. Clinton Dancey \\ Dr. Walter O'Brien
}

June 30, 2008

Blacksburg, Virginia Tech

Keywords: Gas Turbines, High Freestream Turbulence, Film Cooling, Heat Transfer, Aerodynamics, Transonic Cascade

Copyright (C2008, Shakeel Nasir 


\title{
Showerhead Film Cooling Performance of Turbine Vane at High Freestream Turbulence in a Transonic Cascade
}

\author{
Shakeel Nasir
}

\begin{abstract}
One way to increase cycle efficiency of a gas turbine engine is to operate at higher turbine inlet temperature (TIT). In most engines, the turbine inlet temperatures have increased to be well above the metallurgical limit of engine components. Film cooling of gas turbine components (blades and vanes) is a widely used technique that allows higher turbine inlet temperatures by maintaining material temperatures within acceptable limits. In this cooling method, air is extracted from the compressor and forced through internal cooling passages within turbine blades and vanes before being ejected through discrete cooling holes on the surfaces of these airfoils. The air leaving these cooling holes forms a film of cool air on the component surface which protects the part from hot gas exiting the combustor.

Design optimization of the airfoil film cooling system on an engine scale is a key as increasing the amount of coolant supplied yields a cooler airfoil that will last longer, but decreases engine core flow-diminishing overall cycle efficiency. Interestingly, when contemplating the physics of film cooling, optimization is also a key to developing an effective design. The film cooling process is shown to be a complex function of at least two important mechanisms: Increasing the amount of coolant injected reduces the driving temperature (adiabatic wall temperature) of convective heat transfer-reducing heat load to the airfoil, but coolant injection also disturbs boundary layer and augments convective heat transfer coefficient due to local increase in freestream turbulence.

Accurate numerical modeling of airfoil film cooling performance is a challenge as it is complicated by several factors such as film cooling hole shape, coolant-to-freestream blowing ratio, coolant-to-freestream momentum ratio, surface curvature, approaching boundary layer state, Reynolds number, Mach number, combustor-generated high freestream turbulence, turbulence length scale, and secondary flows just to name a few. Until computational methods are able to accurately simulate these factors affecting film cooling performance, experimental studies are required to assist engineers in designing effective film cooling schemes.
\end{abstract}


The unique contribution of this research work is to experimentally and numerically investigate the effects of coolant injection rate or blowing ratio and exit Reynolds number/Mach number on the film cooling performance of a showerhead film cooled first stage turbine vane at high freestream turbulence $(\mathrm{Tu}=16 \%)$ and engine representative exit flow conditions. The vane was arranged in a two-dimensional, linear cascade in a heated, transonic, blow-down wind tunnel. The same facility was also used to conduct experimental and numerical study of the effects of freestream turbulence, and Reynolds number on smooth (without film cooling holes) turbine blade and vane heat transfer at engine representative exit flow conditions. The showerhead film cooled vane was instrumented with single-sided platinum thin film gauges to experimentally determine the Nusselt number and film cooling effectiveness distributions over the surface from a single transient-temperature run. Showerhead film cooling was found to augment Nusselt number and reduce adiabatic wall temperature downstream of injection. The adiabatic effectiveness trend on the suction surface was also found to be influenced by a favorable pressure gradient due to Mach number and boundary layer transition region at all blowing ratio and exit Mach number conditions.

The experimental study was also complimented with a 3-D CFD effort to calculate and explain adiabatic film cooling effectiveness and Nusselt number distributions downstream of the showerhead film cooling rows of a turbine vane at high freestream turbulence $(\mathrm{Tu}=16 \%)$ and engine design exit flow condition $\left(\mathrm{M}_{\mathrm{ex}}=0.76\right)$. The research work presents a new threesimulations technique to calculate vane surface recovery temperature, adiabatic wall temperature, and surface Nusselt number to completely characterize film cooling performance in a high speed flow. The RANS based $v^{2}-f$ turbulence model was used in all numerical calculations. CFD calculations performed with experiment-matched boundary conditions showed an overall good trend agreement with experimental adiabatic film cooling effectiveness and Nusselt number distributions downstream of the showerhead film cooling rows of the vane. 


\section{Preface}

This dissertation is organized in a manuscript format that mainly includes three individual research papers that document the main focus of the work. The author was primarily responsible for all aspects of experimentation, including designing test section and modifying wind tunnel facility, instrumentation, executing experiments, reducing and analyzing data with extensive literature review. The author was also involved in conducting 2-D CFD (FLUENT and TEXSTAN) study of gas turbine aerodynamics and heat transfer in an uncooled environment and developing three-simulations technique for 3-D CFD calculations in film cooling environment in high speed flow. The author was also responsible for the analysis of 3-D CFD results in film cooling environment.

The first paper experimentally and numerically investigates the effects of large scale high freestream turbulence intensity and exit Reynolds number on the surface heat transfer distribution of a turbine vane in a 2-D linear cascade at realistic engine Mach numbers. The second paper experimentally investigates the effect of blowing ratio and exit Reynolds number/Mach number on the film cooling performance of a showerhead film cooled first stage turbine vane. The main objective of the third paper is to use 3-D CFD to calculate and explain adiabatic film cooling effectiveness and Nusselt number distributions downstream of the showerhead film cooling rows of a turbine vane at high freestream turbulence and realistic exit Reynolds number/Mach number condition. The author would like to extend his appreciation to Dr. Hong Wu from Beijing University of Aeronautics and Astronautics for conducting 3-D CFD (FLUENT) calculations of this research work. The three research papers are followed by a fourth paper (updated version) with research colleague and primary author, Jeffrey Carullo, which relates to experimental investigation of the effect of high freestream turbulence intensity, turbulence length scale, and exit Reynolds number on the surface heat transfer distribution of a turbine blade at realistic engine Mach numbers. A series of appendices then follows which provides additional information on several topics including extensive literature review of airfoil film cooling, instrumentation, experimental setup, heat transfer and aerodynamic testing, experimental data, uncertainty analysis, and computational work, all of which were used in the process of pursuing this research endeavor. 


\section{Acknowledgments}

I deeply feel a gratitude to Almighty Allah, THE MOST GRACIOUS AND MERCIFUL, who capacitated me to complete my Ph.D. degree. Almighty Allah provided me strength and enthusiasm, without of which nothing could have been done. Although the feelings are deep, but the words too little, to illustrate completely the depth of feelings.

This research work owes its existence to the help, support, and encouragement of many people. I would like to express my deepest sense of gratitude to my advisor Dr. Wing Ng for his patient guidance, inspiration and excellent advice throughout this study. I am deeply indebted to my committee members Dr. Karen Thole, Dr. Thomas Diller, Dr. Saad Ragab, Dr. Clinton Dancey, and Dr. Walter O'Brien for their time and effort in reviewing this work. This research work was sponsored by Solar Turbines Inc. I would like to thank Dr. Hee Koo Moon, and Dr. Luzeng Zhang of Solar Turbines Inc. for their help and support of this work. I would also like to thank Dr. Jiang Luo of Solar Turbines Inc. for useful discussions. Special thanks go to Dr. Richard Anthony and Dr. Marcus Polanka of the Air Force Research Laboratory, WrightPatterson AFB for their help with manufacturing and implementation of the thin film gauges.

I am also indebted to the members of research group Jeffrey Carullo, Ronald Cress, Ashley Guy, and Trey Bolchoz for their hard work and dedication in successfully completing different phases of the Solar Turbines research project. Jeffrey Carullo conducted heat transfer measurements on an uncooled turbine blade. Ronald Cress was primarily responsible in developing heat flux data reduction codes for thin film gauges. Trey Bolchoz documented film cooling measurements on showerhead film cooled vane at low freestream turbulence. I am also grateful to all the members of the group for the cooperative spirit and the excellent working atmosphere, creating a unique setting for intellectual exploration. I would also like to extend my gratitude to Dr. Hong Wu from Beijing University of Aeronautics and Astronautics for participating in the CFD study of this research work. I also extend my appreciation to all staff members of the Mechanical Engineering Department for their assistance and support.

Special thanks to all the members of Mechanical Engineering Machine Shop. I am grateful to Bill Songer for his recommendations, quality of work, and selfless support. A thank you also goes out to Steve Edwards in teaching us how to operate, troubleshoot and update the wind tunnel facility. 
Finally, I owe special gratitude to my parents, Muhammad Nasir Iqbal and Zahida Anjum, my siblings, Ayesha Naveed, Ahmad Ali, and Muhammad Ali, and my beloved wife, Madiha Shakeel, for their continuous and unconditional love and support of all my undertakings, scholastic and otherwise.

SHAKEEL NASIR

Virginia Polytechnic Institute and State University

June 2008 


\section{Table of Contents}

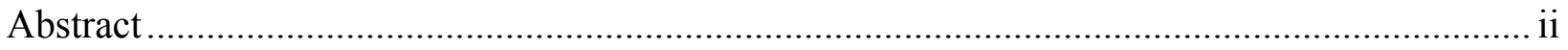

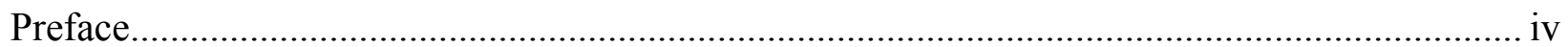

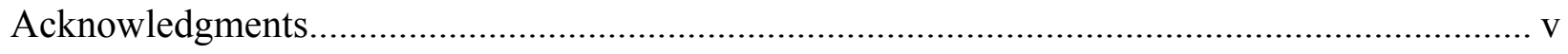

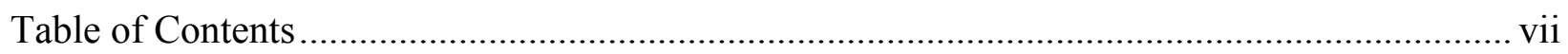

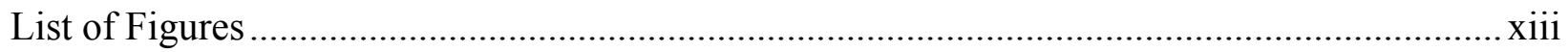

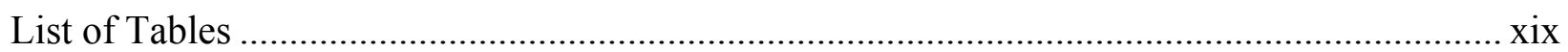

\section{Paper 1:}

Effects of Large Scale High Freestream Turbulence, and Exit Reynolds Number on Turbine Vane Heat Transfer in a Transonic Cascade

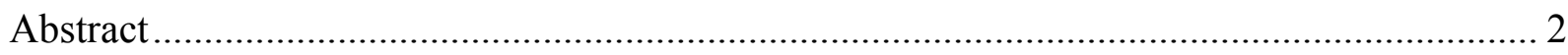

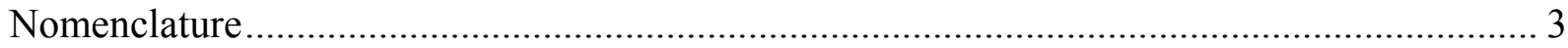

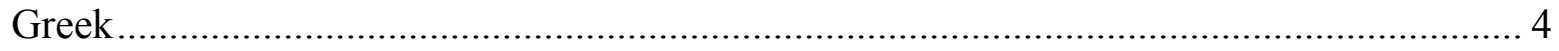

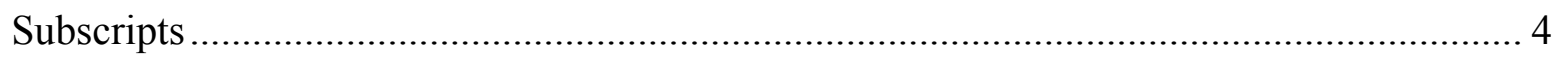

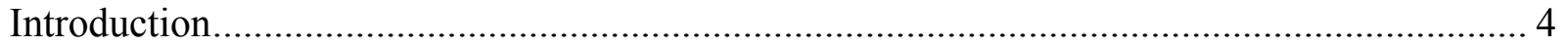

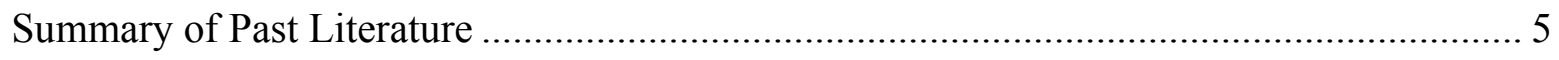

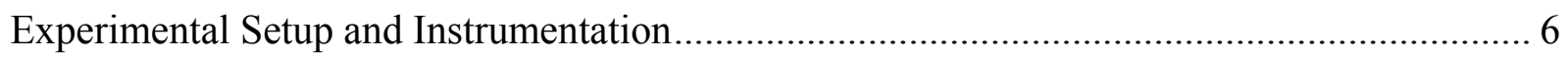

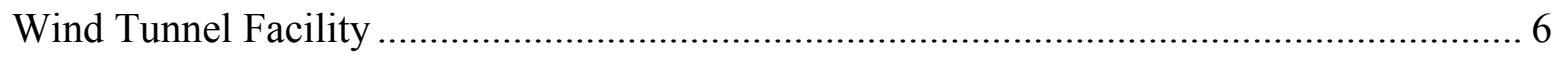

Static Pressure Measurements................................................................................. 7

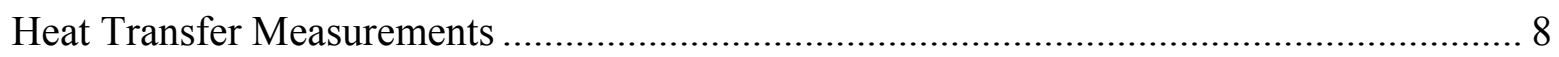

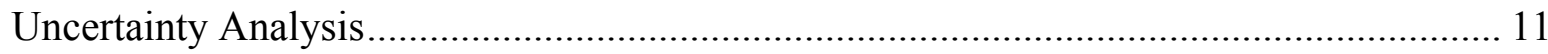

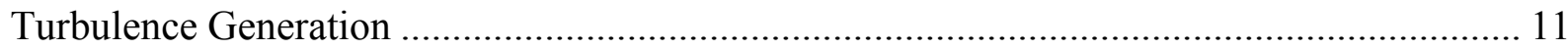

Vane Static Pressure Distribution ................................................................................ 14

Vane Heat Transfer Distribution................................................................................... 16

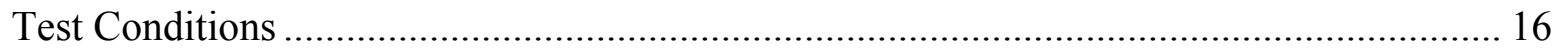

Effect of Freestream Turbulence ............................................................................... 17

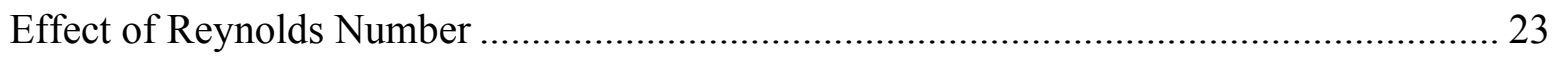

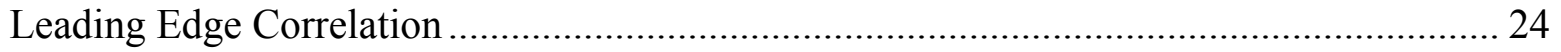

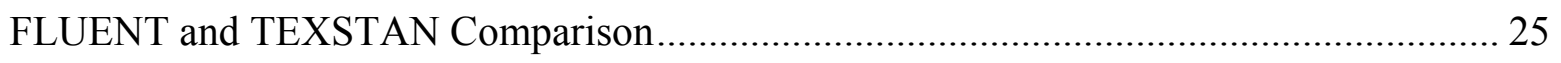

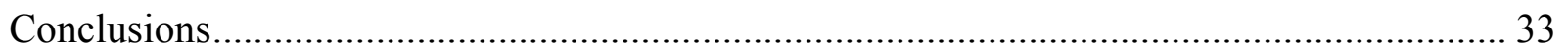

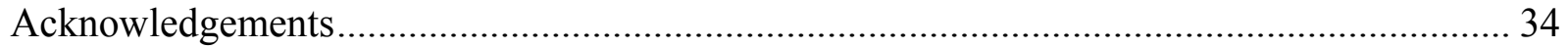


References

\section{Paper 2:}

Showerhead Film Cooling Performance of Turbine Vane at High Freestream Turbulence in a Transonic Cascade

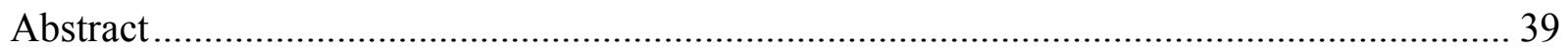

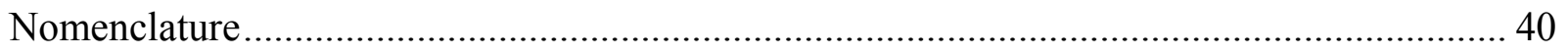

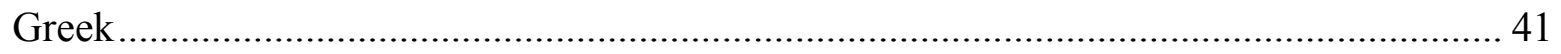

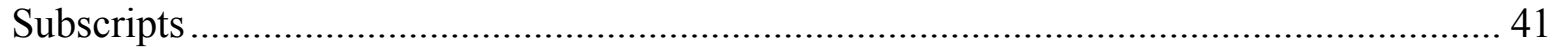

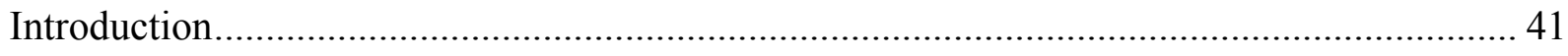

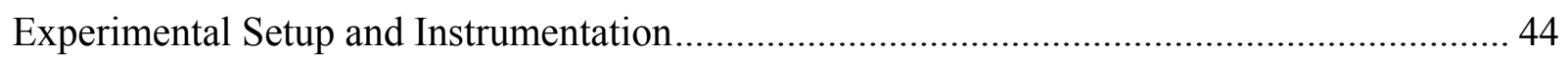

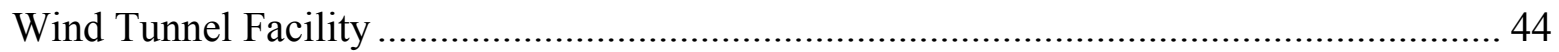

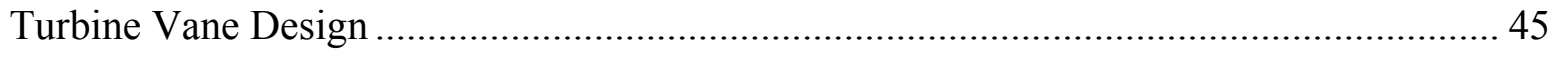

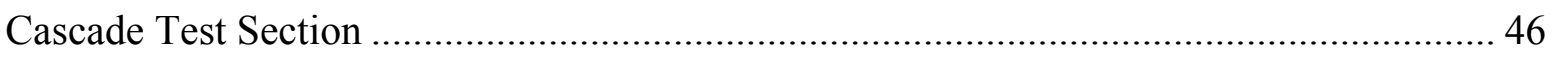

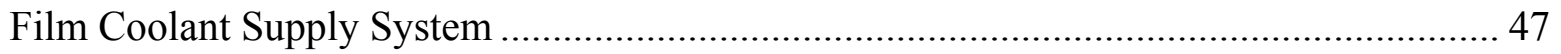

Single-Sided Thin Film Gauge in Film Cooling Environment ......................................... 48

Determination of Heat Transfer Coefficient and Adiabatic Film Cooling Effectiveness........ 49

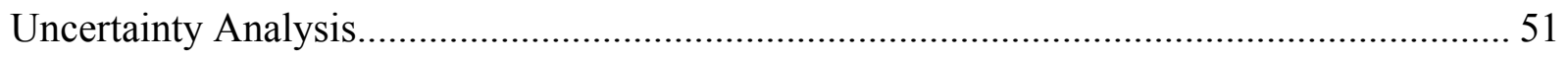

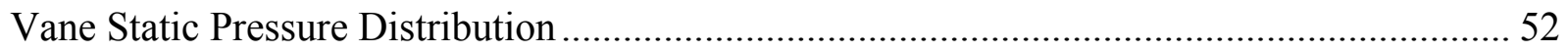

Vane Heat Transfer and Adiabatic Effectiveness Distribution........................................... 53

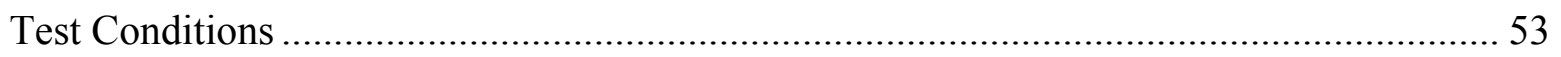

Effect of Blowing Ratio on Nusselt Number ....................................................... 54

Effect of Blowing Ratio on Adiabatic Effectiveness ................................................... 57

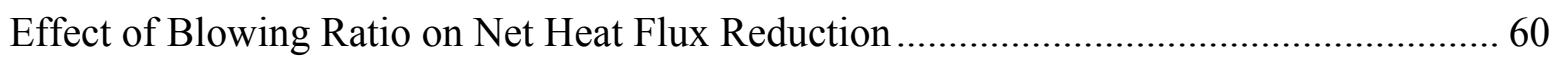

Effect of Re/Mach Number on Nusselt Number........................................................ 63

Effect of Re/Mach Number on Adiabatic Effectiveness............................................... 66

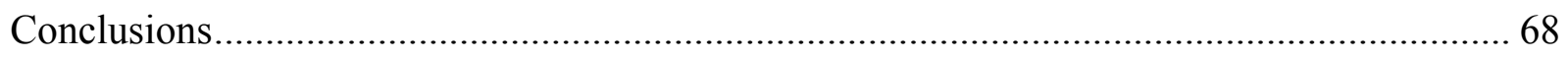

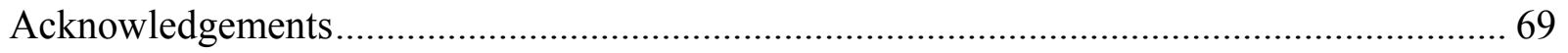

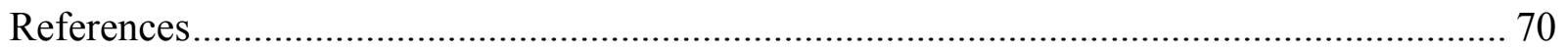

\section{Paper 3:}

Showerhead Film Cooling Performance of a Transonic Turbine Vane at High Freestream Turbulence (Tu =16\%): 3-D CFD and Comparison with Experiment 


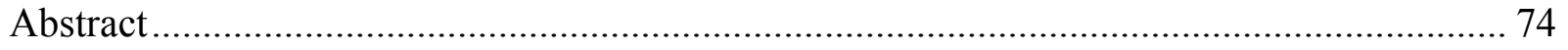

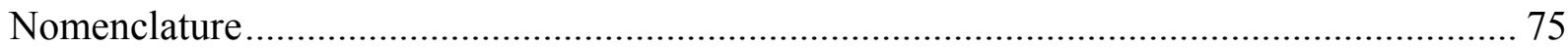

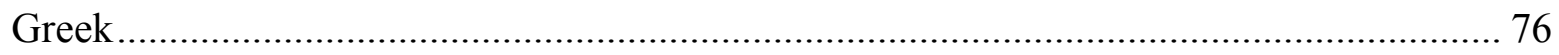

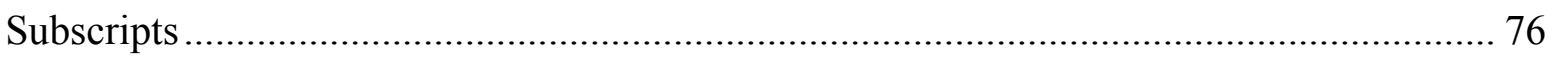

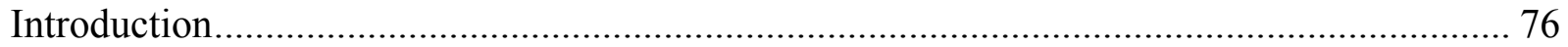

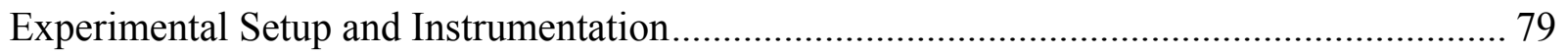

Determination of Heat Transfer Coefficient and Adiabatic Film Cooling Effectiveness......... 83

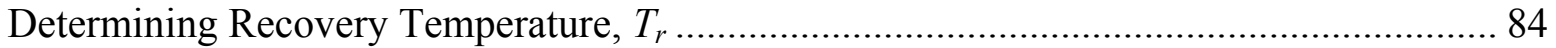

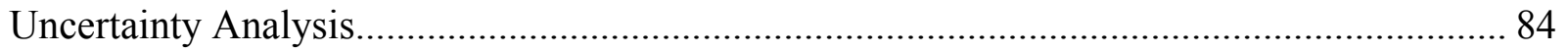

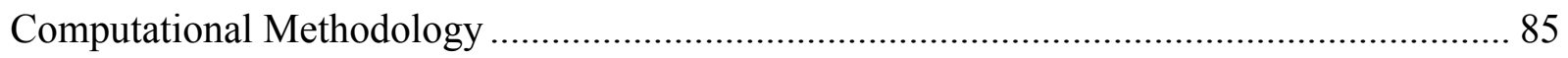

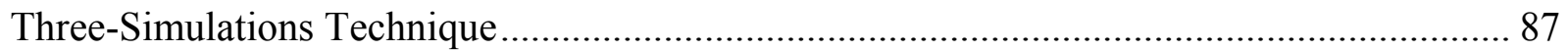

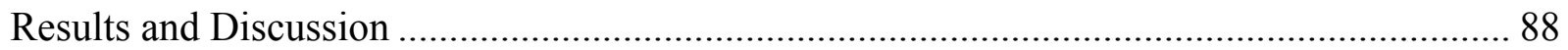

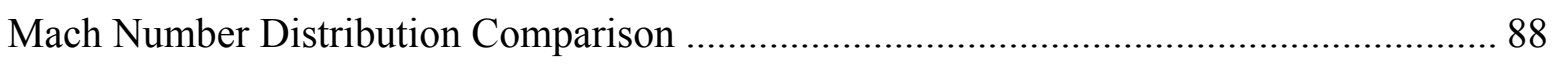

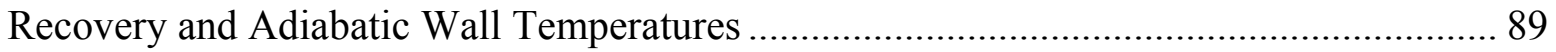

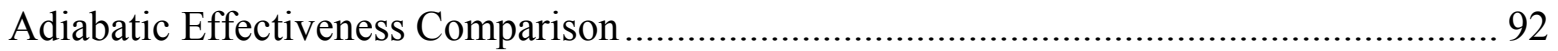

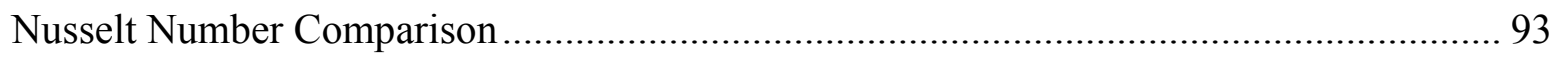

Boundary Layer CFD Analysis on Suction Surface ………........................................ 95

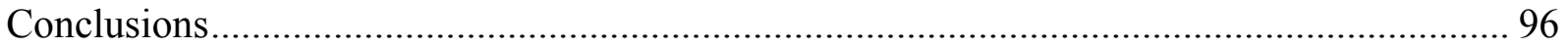

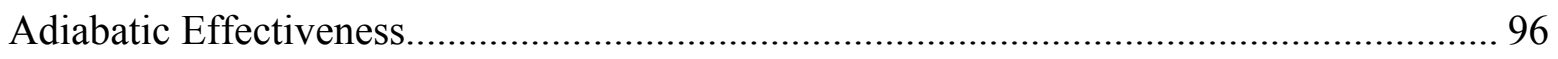

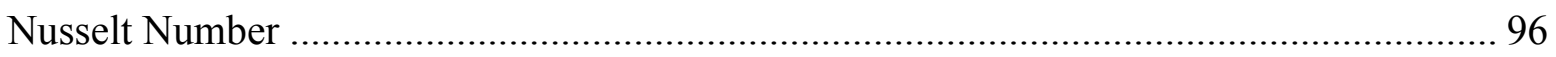

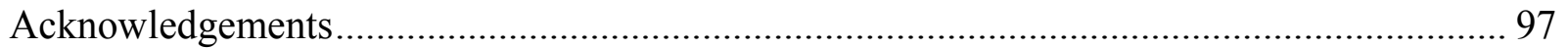

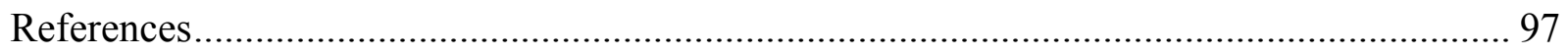

\section{Paper 4:}

The Effects of Freestream Turbulence, Turbulence Length Scale, and Exit Reynolds Number on Turbine Blade Heat Transfer in a Transonic Cascade
Abstract. 102

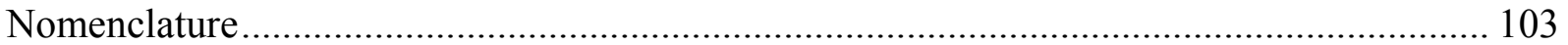

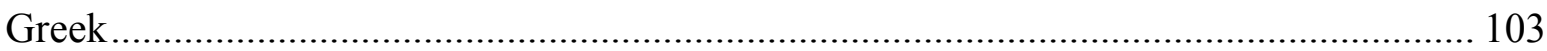

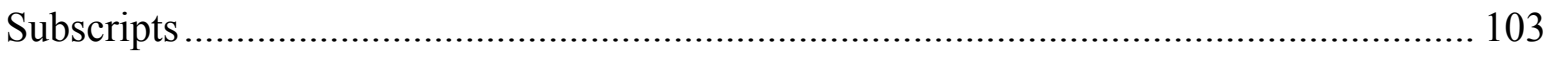

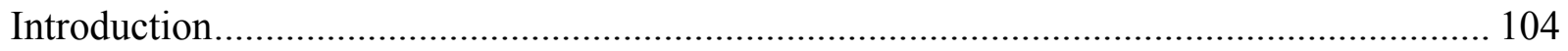

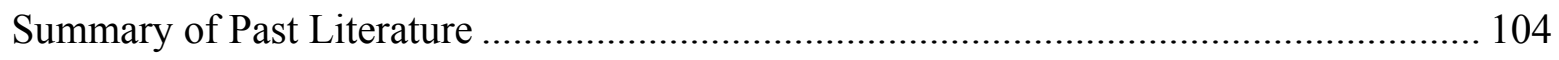


Experimental Setup and Instrumentation...................................................................... 105

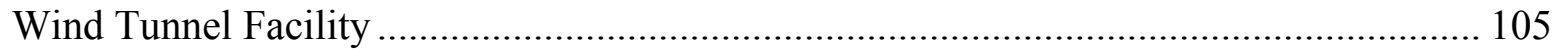

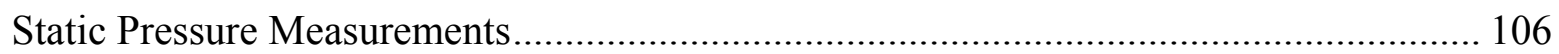

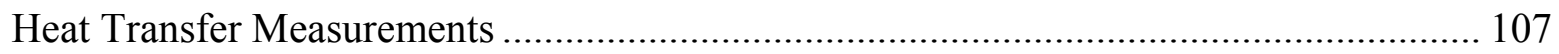

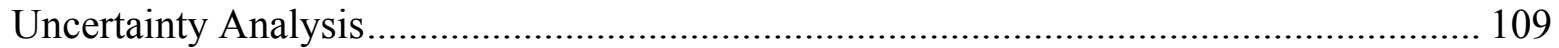

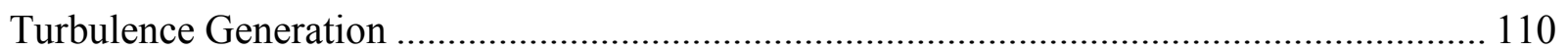

Blade Static Pressure Distribution ................................................................................ 115

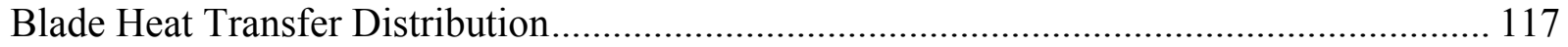

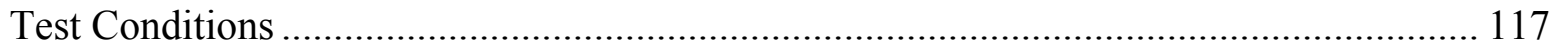

Effect of Freestream Turbulence .................................................................................. 117

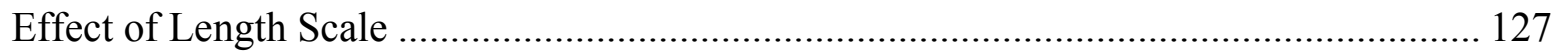

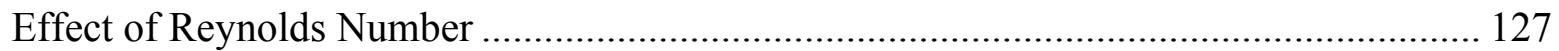

Leading Edge Correlation .............................................................................................. 129

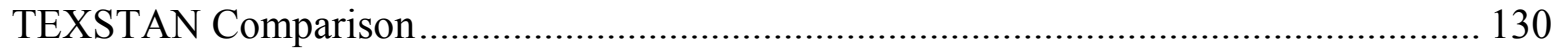

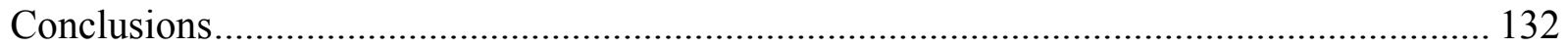

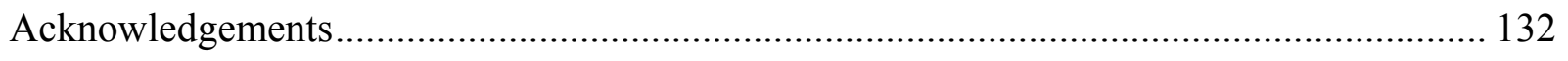

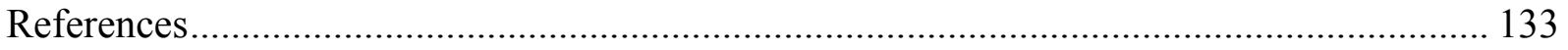

\section{Conclusions of Research Work}

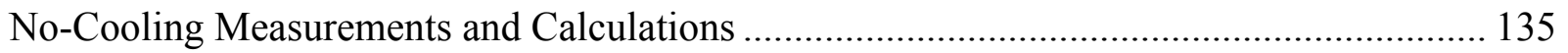

Showerhead Film Cooling Measurements and Calculations ............................................... 136

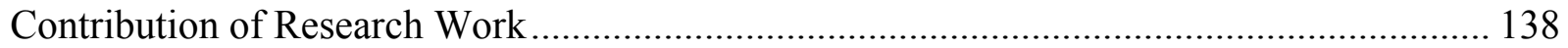

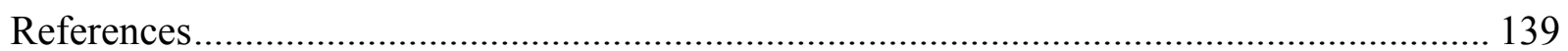

\section{Appendix A Literature Review - Airfoil Film Cooling}

Experimental Work ........................................................................................................ 141

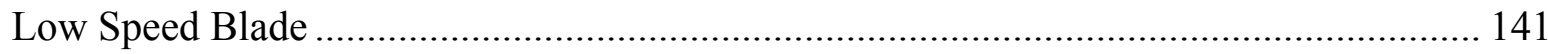

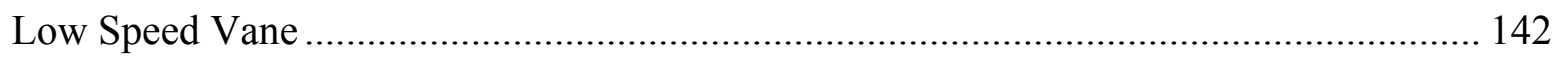

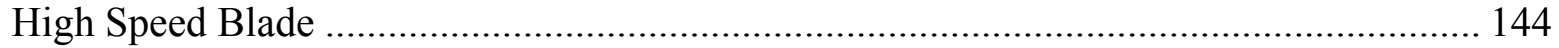

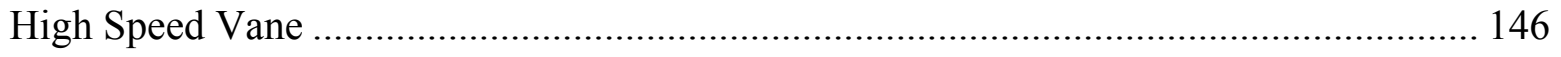

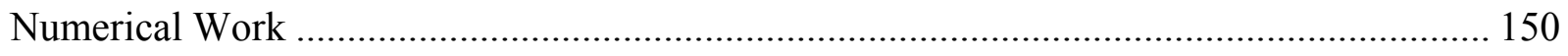

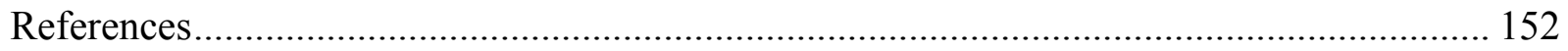

Appendix B Film Cooling System 
Film Cooling System Setup and Operation .................................................................... 157

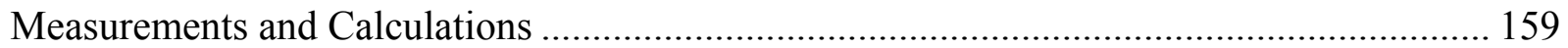

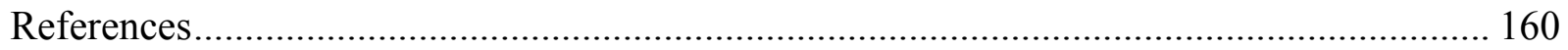

\section{Appendix C Thin Film Gauge Overview - Film Cooling Measurements}

Thin Film Gauge Mounting on Vane.................................................................................. 161

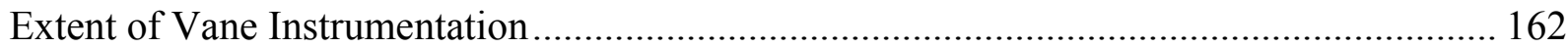

Thermocouple Mounting on Vane................................................................................ 163

Thin Film Gauge Lead Wire Attachment …………………........................................... 164

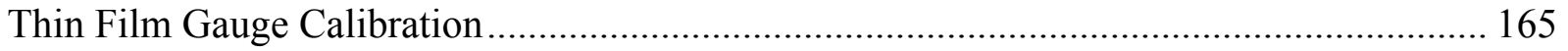

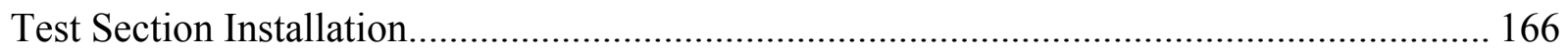

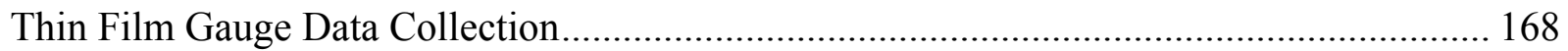

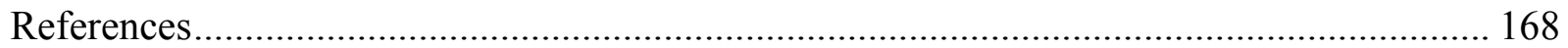

\section{Appendix D Sample Data Analysis - Film Cooling Measurements}

Determination of Surface Heat Flux............................................................................ 169

Determination of Heat Transfer Coefficient and Adiabatic Effectiveness .............................. 171

Determination of Recovery Temperature …………….................................................. 172

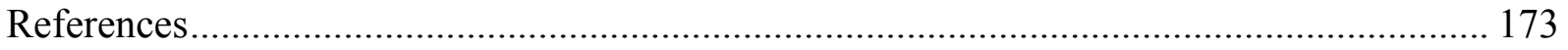

Appendix E Uncertainty Analysis - Film Cooling Measurements

Heat Transfer Coefficient and Adiabatic Effectiveness …………………........................... 174

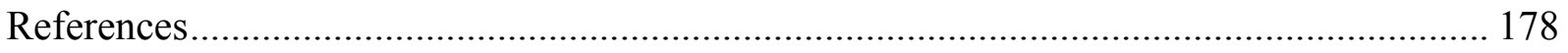

Appendix F Turbulence Generation and Instrumentation

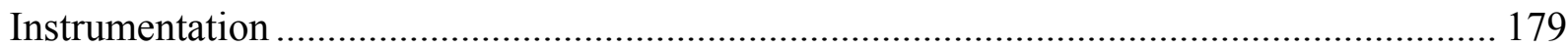

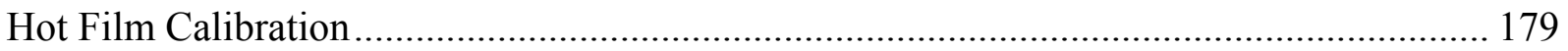

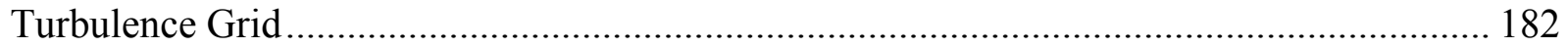

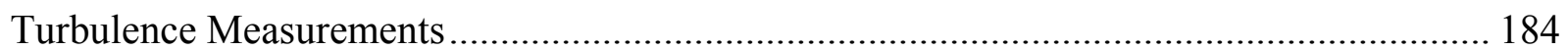

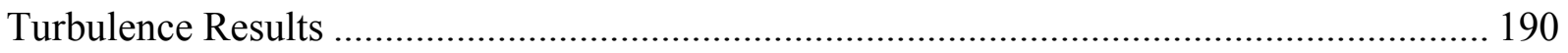

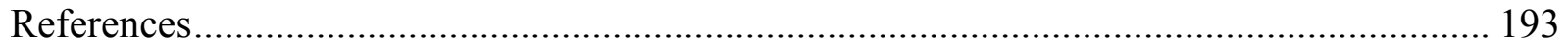

Appendix G Vane Aerodynamic Tests

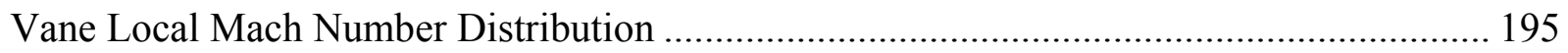

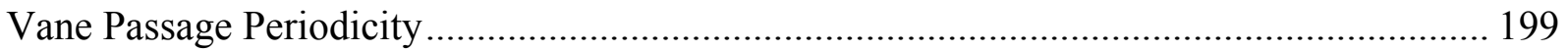

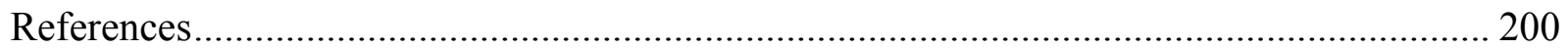




\section{Appendix H Tabulated Results - Film Cooling Measurements}

Vane Heat Transfer and Adiabatic Effectiveness at Exit Mach 0.57 .................................. 201

Vane Heat Transfer and Adiabatic Effectiveness at Exit Mach 0.76 .................................. 205

Vane Heat Transfer and Adiabatic Effectiveness at Exit Mach 1.0 ................................... 209

Appendix I Tabulated Results - No-Cooling Measurements

Smooth Vane Heat Transfer at Exit Mach 0.55 ............................................................... 213

Smooth Vane Heat Transfer at Exit Mach 0.75 ................................................................ 214

Smooth Vane Heat Transfer at Exit Mach 1.01 ................................................................ 215

Smooth Vane Mach Number Distribution ..................................................................... 216

\section{Appendix J Sample TEXSTAN Input Files}

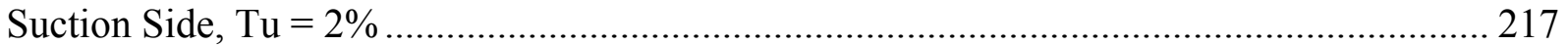

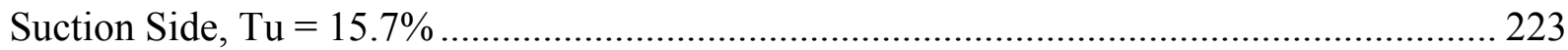

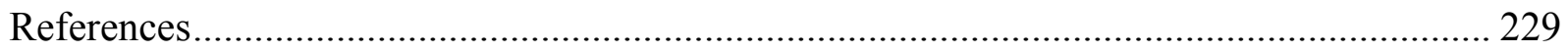




\section{List of Figures}

\section{Paper 1:}

\section{Effects of Large Scale High Freestream Turbulence, and Exit Reynolds Number on Turbine Vane Heat Transfer in a Transonic Cascade}

Figure 1.1. Virginia Tech transonic cascade wind tunnel............................................. 6

Figure 1.2. Cascade diagram showing the vanes and the axis orientation for measurements with

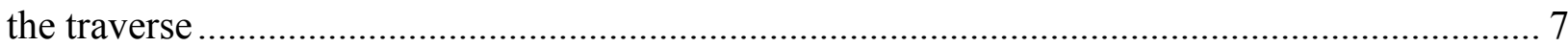

Figure 1.3. Cascade inlet temperature and Mach number history ….................................... 8

Figure 1.4. Photograph of thin film gauges in wind tunnel ............................................... 9

Figure 1.5. Typical vane surface and adiabatic wall temperature history .............................. 10

Figure 1.6. Typical vane surface heat flux and heat transfer coefficient history ...................... 11

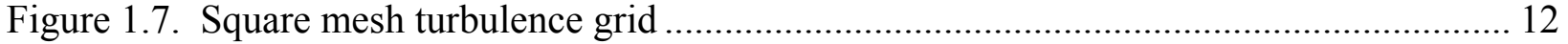

Figure 1.8. Square mesh turbulence grid location relative to the test section quare mesh ......... 12

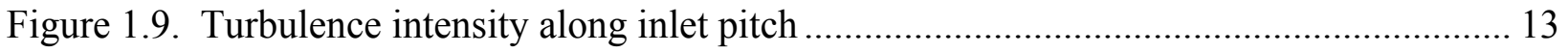

Figure 1.10. Turbulence length scale along inlet pitch ..................................................... 13

Figure 1.11. Velocity ratio variation along inlet pitch.................................................. 14

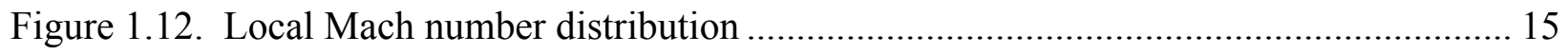

Figure 1.13. Flow periodicity through vane passages................................................... 15

Figure 1.14. Acceleration parameter distribution ............................................................. 16

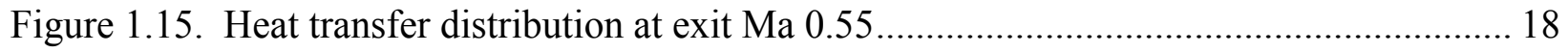

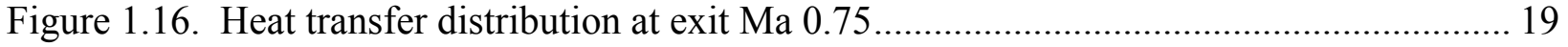

Figure 1.17. Heat transfer distribution at exit Ma 1.01 ........................................................ 19

Figure 1.18. Heat transfer augmentation at all exit Ma cases ................................................ 20

Figure 1.19. Suction side data compared to the flat plate correlations at exit Ma $0.75 \ldots \ldots \ldots \ldots . . .22$

Figure 1.20. Pressure side data compared to the flat plate correlations at exit Ma $0.75 \ldots . . . . . . .22$

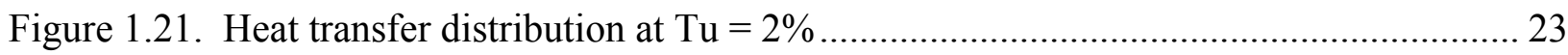

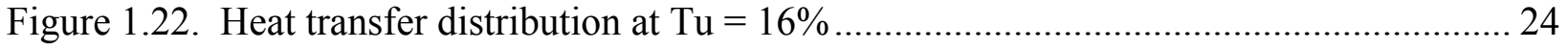

Figure 1.23. Stagnation region data compared to Dullenkopf and Mayle's correlation............. 25

Figure 1.24. Computational domain for CFD predictions ................................................... 26

Figure 1.25. Local Mach number distribution comparison................................................. 27

Figure 1.26. FLUENT prediction at exit Ma 0.55, 2\% Tu................................................. 28 


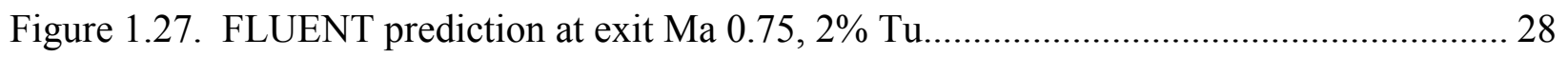

Figure 1.28. FLUENT prediction at exit Ma 1.01, 2\% Tu....................................................... 29

Figure 1.29. FLUENT prediction at exit Ma 0.75, 16\% Tu.................................................... 29

Figure 1.30. TEXSTAN prediction at exit Ma 0.55, 2\% Tu................................................ 30

Figure 1.31. TEXSTAN prediction at exit Ma 0.75, 2\% Tu....................................................... 31

Figure 1.32. TEXSTAN prediction at exit Ma 1.01, 2\% Tu.................................................... 31

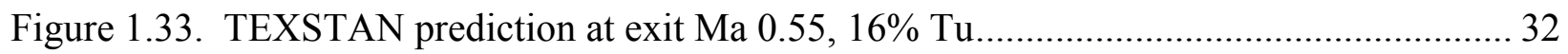

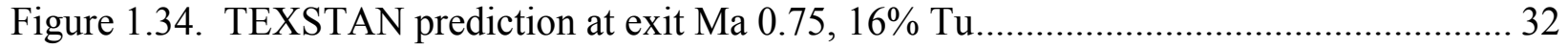

Figure 1.35. TEXSTAN prediction at exit Ma 1.01, 16\% Tu..................................................... 33

\section{Paper 2:}

\section{Showerhead Film Cooling Performance of Turbine Vane at High Freestream Turbulence in a Transonic Cascade}

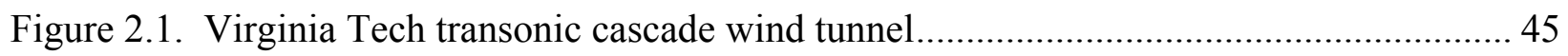

Figure 2.2. Profile view of showerhead film cooled vane .......................................................... 46

Figure 2.3. Section view of the stagnation row of holes......................................................... 46

Figure 2.4. Cascade diagram showing the vanes and the axis orientation for measurements with

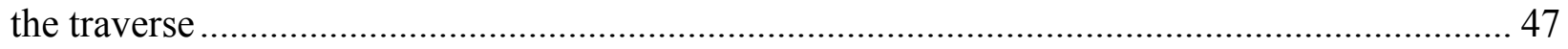

Figure 2.5. Gauges mounted on the vane before installation in wind tunnel............................... 49

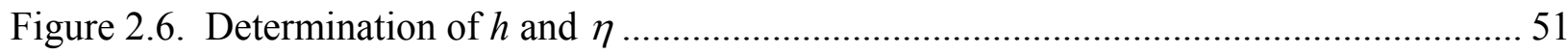

Figure 2.7. Local Mach number distribution ...................................................................... 52

Figure 2.8. Acceleration parameter distribution …………………………………………….... 53

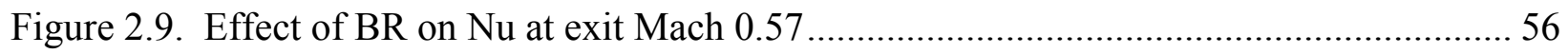

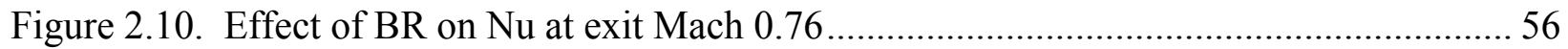

Figure 2.11. Effect of $\mathrm{BR}$ on $\mathrm{Nu}$ at exit Mach 1.0 ……............................................................. 57

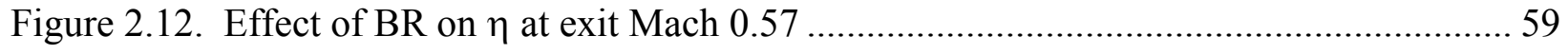

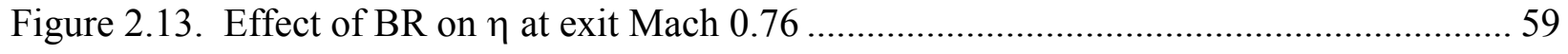

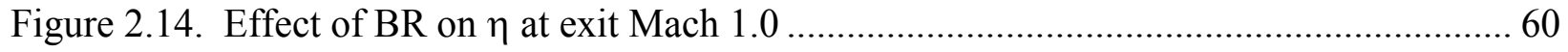

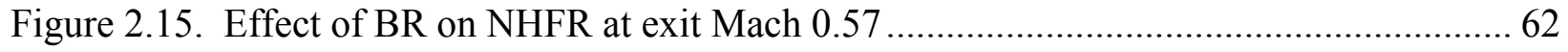

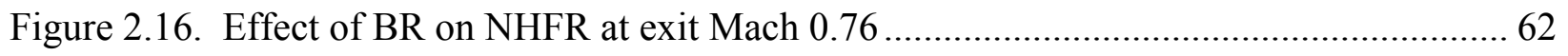

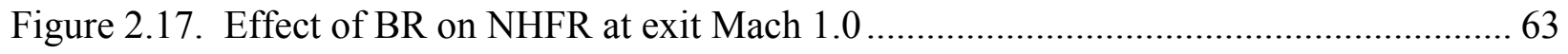

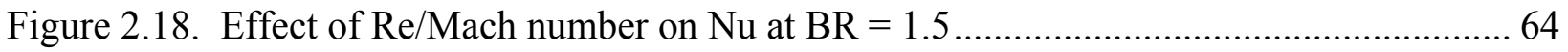




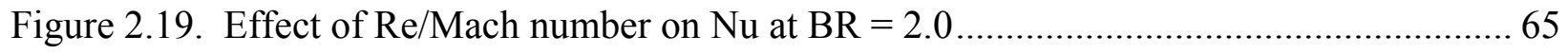

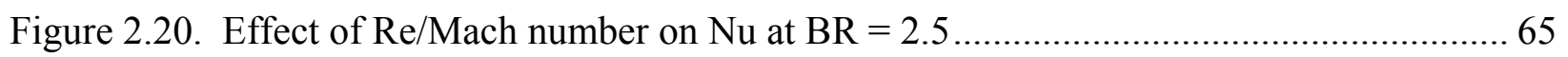

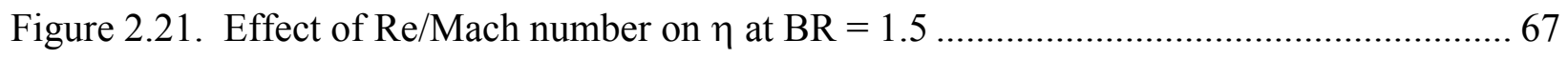

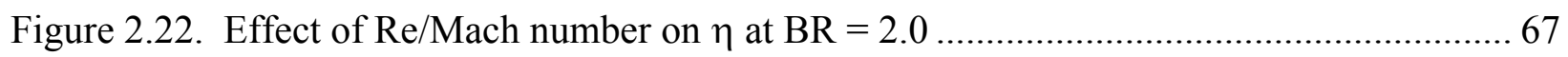

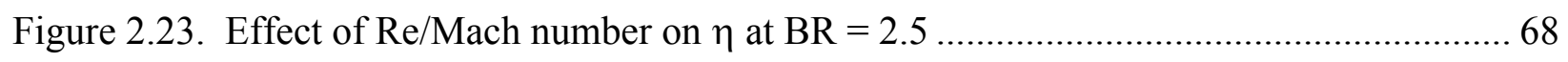

\section{Paper 3:}

Showerhead Film Cooling Performance of a Transonic Turbine Vane at High Freestream

Turbulence ( $\mathrm{Tu}=16 \%)$ : 3-D CFD and Comparison with Experiment

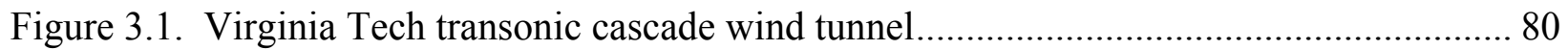

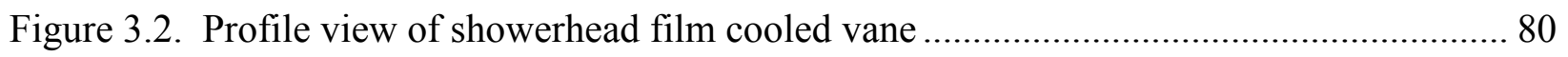

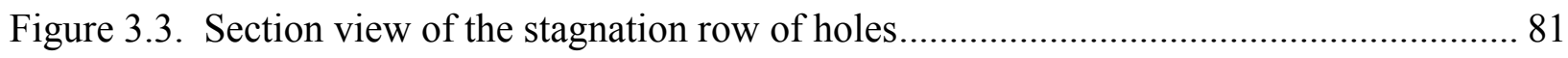

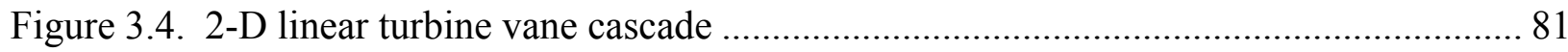

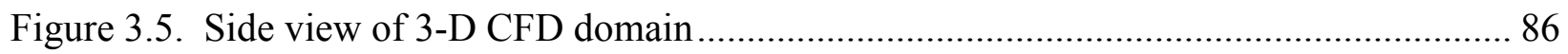

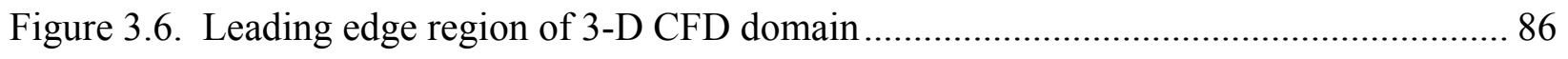

Figure 3.7. O-shape mesh in the vicinity of film cooling holes.................................................. 87

Figure 3.8. Midspan Mach number distribution comparison....................................................... 89

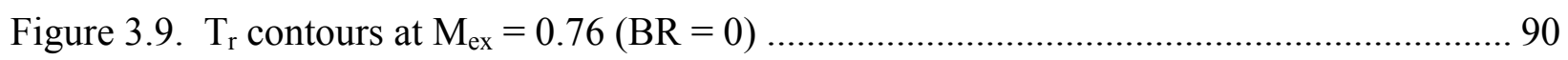

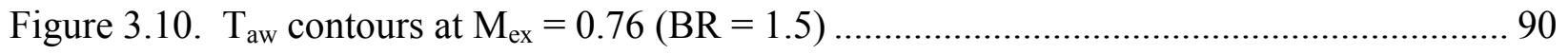

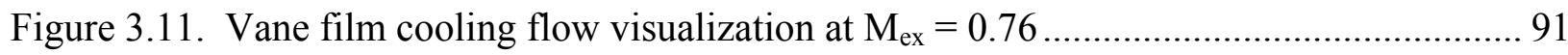

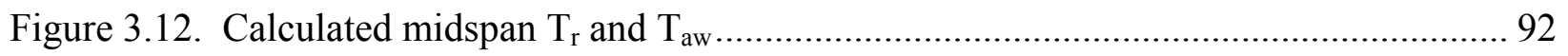

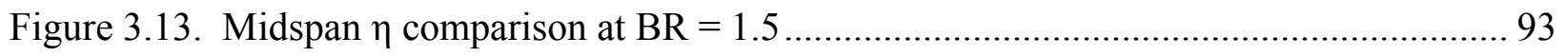

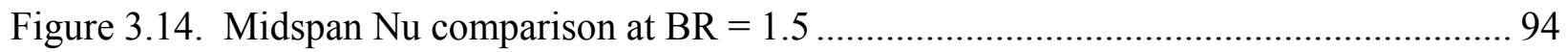

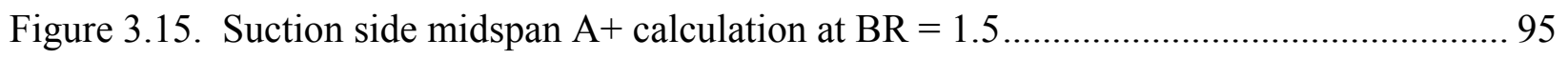

\section{Paper 4:}

The Effects of Freestream Turbulence, Turbulence Length Scale, and Exit Reynolds

Number on Turbine Blade Heat Transfer in a Transonic Cascade

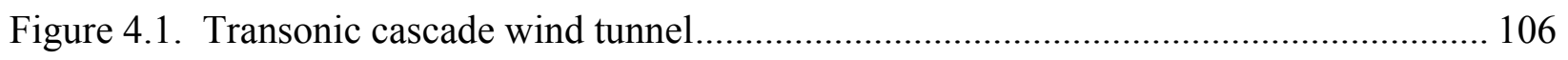

Figure 4.2. Cascade diagram showing the blades and the axis orientation for measurements with

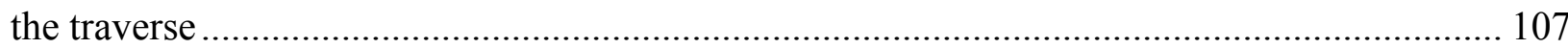

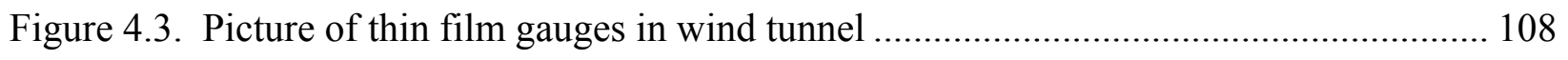

Figure 4.4. Turbulence grids (a) mesh grid, $\mathrm{Tu}=12 \%$ and (b) bar grid, $\mathrm{Tu}=14 \% \ldots \ldots \ldots \ldots \ldots . . .110$ 
Figure 4.5. Turbulence grid location relative to the test section for the (a) mesh grid and (b) bar grid 111

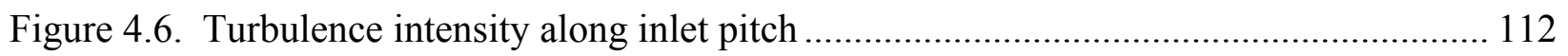

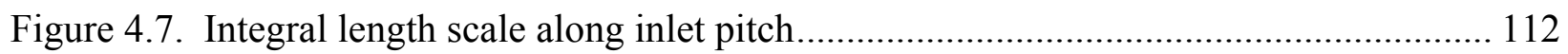

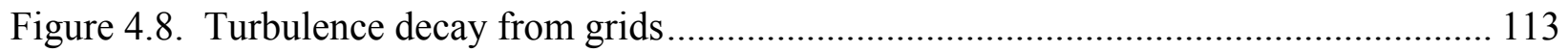

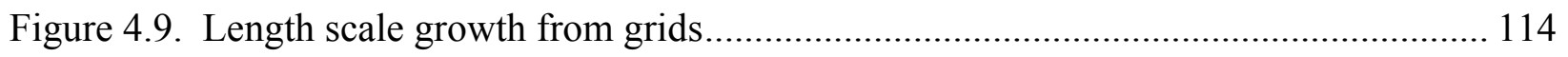

Figure 4.10. Velocity ratio distribution along inlet pitch........................................................... 114

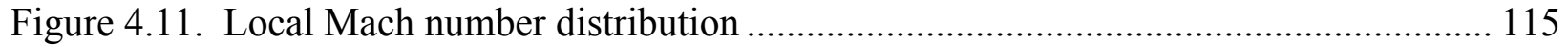

Figure 4.12. Flow periodicity through blade passages ............................................................... 116

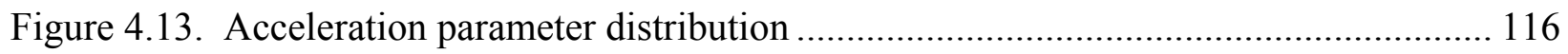

Figure 4.14. Heat transfer distribution at exit Ma 0.55 ...................................................... 119

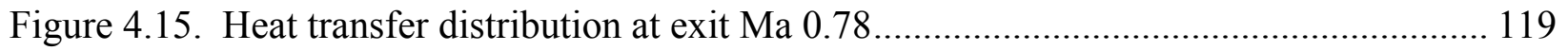

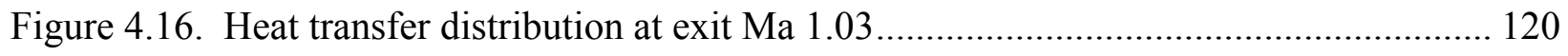

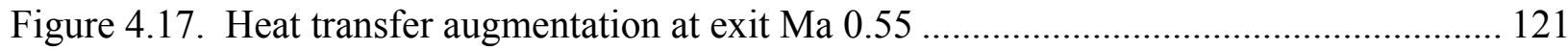

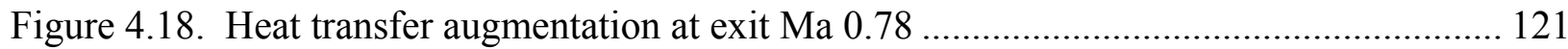

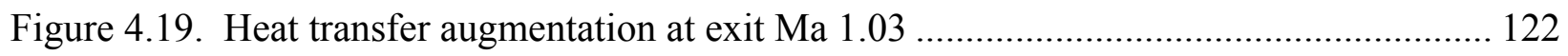

Figure 4.20. Suction side data compared to the flat plate correlations at exit Ma 0.55 ............. 124

Figure 4.21. Suction side data compared to the flat plate correlations at exit Ma 0.78 ............. 124

Figure 4.22. Suction side data compared to the flat plate correlations at exit Ma 1.03 ............. 125

Figure 4.23. Pressure side data compared to the flat plate correlations at exit Ma 0.55 ........... 125

Figure 4.24. Pressure side data compared to the flat plate correlations at exit Ma 0.78 ........... 126

Figure 4.25. Pressure side data compared to the flat plate correlations at exit Ma 1.03 ........... 126

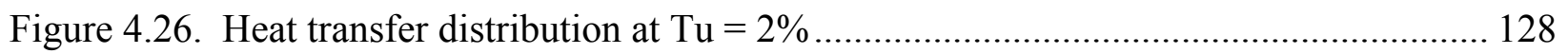

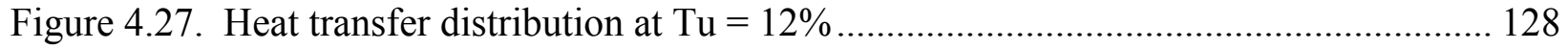

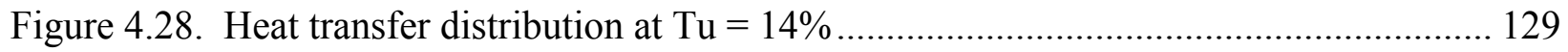

Figure 4.29. Van Fossen correlation comparison .................................................................... 130

Figure 4.30. TEXSTAN prediction at exit Ma 0.78, 2\% Tu.................................................... 131

Figure 4.31. TEXSTAN prediction at exit Ma 0.78, 12\% Tu................................................. 131

\section{Appendix B Thin Film Gauge Overview - Film Cooling Measurements}

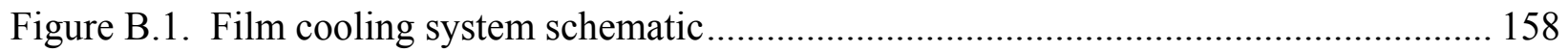

Figure B.2. Photograph of film cooling system ............................................................... 158 
Figure B.3. Coolant supply fitting .... 159

Appendix C Thin Film Gauge Overview - Film Cooling Measurements

Figure C.1. Gauges mounted on the vane before installation in wind tunnel ......................... 162

Figure C.2. Film cooling holes drilled through the thin film gauge sheet ............................. 162

Figure C.3. Location of thin film gauges on the vane surface ............................................. 163

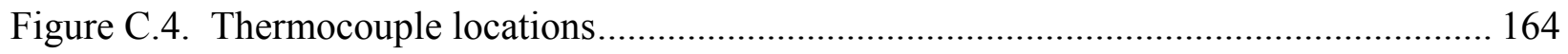

Figure C.5. Calibration curve for two of the thin film gauges installed on the turbine vane ... 165

Figure C.6. Schematic of the Wheatstone bridge circuit for the thin film gauges................... 166

Figure C.7. Film cooled vane assembled with test section windows and insert .................... 167

Figure C.8. Picture on instrumented vane installed in test section ................................... 167

Appendix D Sample Data Analysis - Film Cooling Measurements

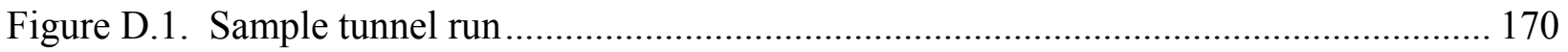

Figure D.2. Gauge 7 and plenum temperature history ............................................... 170

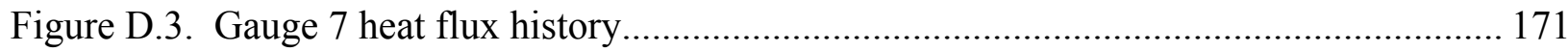

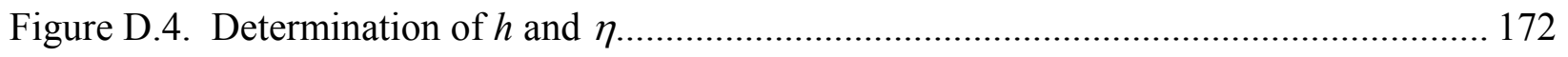

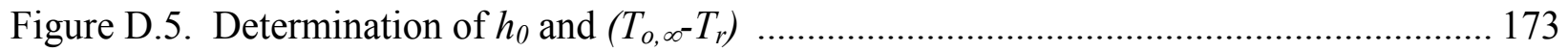

\section{Appendix E Uncertainty Analysis - Film Cooling Measurements}

Figure E.1. Determination of $h$ and $\eta$

Figure E.2. Showerhead film cooled vane surface heat transfer coefficient distribution with

uncertainty band. The data correspond to Figure 2.10 of the thesis

Figure E.3. Showerhead film cooled vane surface adiabatic effectiveness distribution with

uncertainty band. The data correspond to Figure 2.13 of the thesis 178

\section{Appendix F Turbulence Generation and Instrumentation}

Figure F.1. Plot of the calibration curve of a hot film (Courtesy of Carullo [F-1])................ 182

Figure F.2. Square mesh turbulence grid

Figure F.3. Schematic showing the position of the square mesh turbulence grid relative to the test section.

Figure F.4. Schematic showing the location of the measurement slot in the test section......... 184

Figure F.5. Sample time history of the instantaneous velocity measured by hot film probe..... 185

Figure F.6. Sample plot of the velocity histogram of the flow ......................................... 186

Figure F.7. PSD of velocity signal at discrete location along vertical slot ........................... 187 
Figure F.8. Plot of the normalized power spectral density .................................................... 188

Figure F.9. Plot of the autocorrelation for the hot film signal ................................................. 189

Figure F.10. Turbulence intensity along inlet pitch.......................................................... 190

Figure F.11. Turbulence length scale along inlet pitch........................................................... 191

Figure F.12. Turbulence decay from the mesh grid............................................................... 192

Figure F.13. Length scale dispersion from the mesh grid...................................................... 192

Figure F.14. Velocity ratio variation along inlet pitch.......................................................... 193

\section{Appendix G Vane Aerodynamic Tests}

Figure G.1. Pictures showing the vane pressure taps (a) front view and (b) back view ............ 196

Figure G.2. Schematic of the pressure tap locations with the taps shown in red........................ 196

Figure G.3. Run to run repeatability of exit Mach 0.8 distribution .......................................... 197

Figure G.4. Local Mach number distribution .................................................................... 198

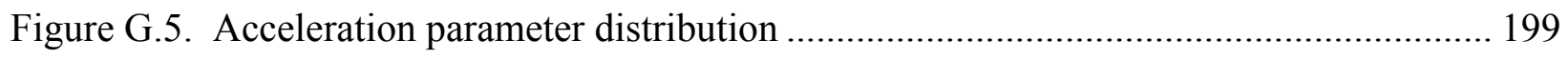

Figure G.6. Flow periodicity through vane passages............................................................... 200 


\section{List of Tables}

\section{Paper 1:}

Effects of Large Scale High Freestream Turbulence, and Exit Reynolds Number on

\section{Turbine Vane Heat Transfer in a Transonic Cascade}

Table 1.1. Turbine vane geometrry ................................................................................. 7

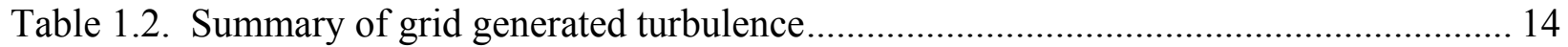

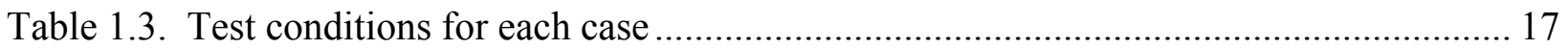

Paper 2:

Showerhead Film Cooling Performance of Turbine Vane at High Freestream Turbulence in a Transonic Cascade

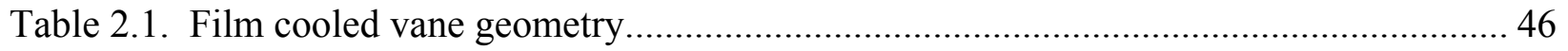

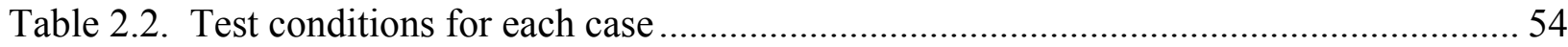

\section{Paper 3:}

Showerhead Film Cooling Performance of a Transonic Turbine Vane at High Freestream

Turbulence (Tu = 16\%): 3-D CFD and Comparison wirh Experiment

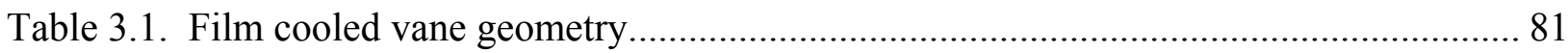

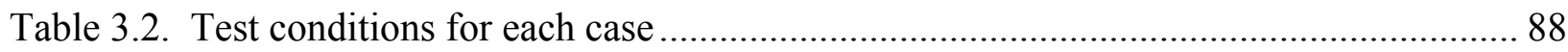

\section{Paper 4:}

The Effects of Freestream Turbulence, Turbulence Length Scale, and Exit Reynolds

Number on Turbine Blade Heat Transfer in a Transonic Cascade

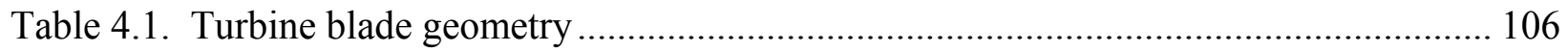

Table 4.2. Summary of grid generated turbulence ........................................................... 112

Table 4.3. Test conditions for each case ........................................................................ 117

Appendix C Thin Film Gauge Overview - Film Cooling Measurements

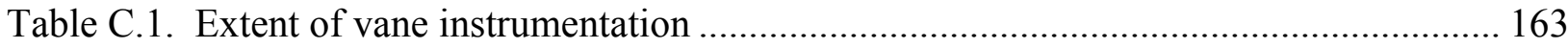

Appendix E Uncertainty Analysis - Film Cooling Measurements

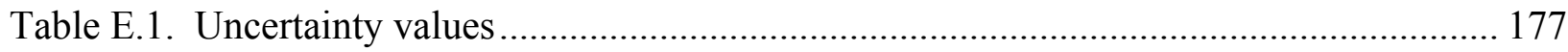

Appendix F Turbulence Generation and Instrumentation

Table F.1. Summary of grid generated turbulence

Appendix H Tabulated Results - Film Cooling Measurements

Table H.1. Nusselt number, $\mathrm{Nu}$, for $\mathrm{M}_{\mathrm{ex}}=0.57$ 
Table H.2. Nusselt number augmentation, $\mathrm{Nu} / \mathrm{Nu}_{0}$, for $\mathrm{M}_{\mathrm{ex}}=0.57$............................... 202

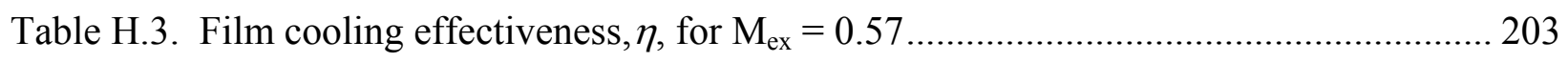

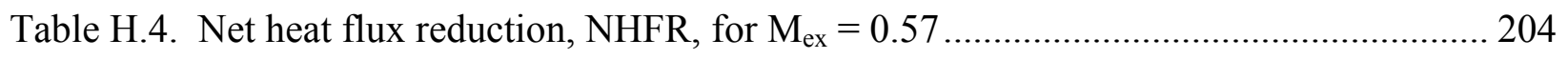

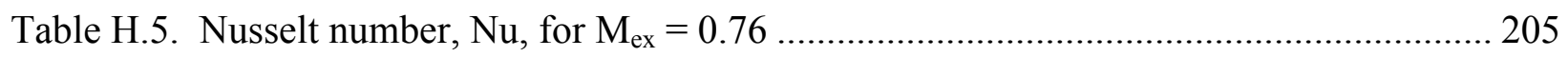

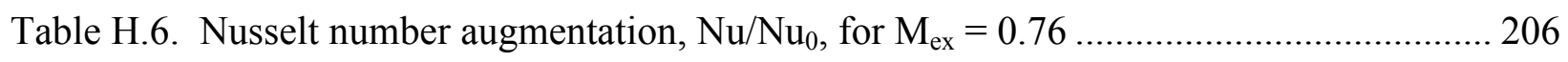

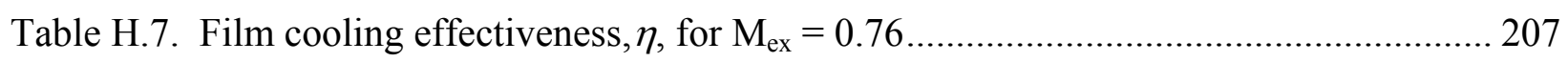

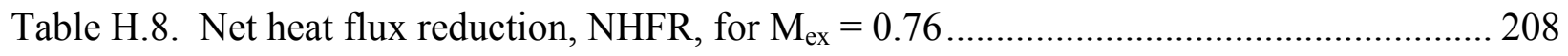

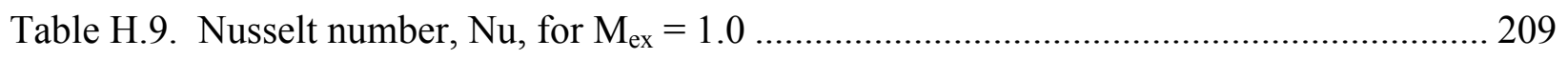

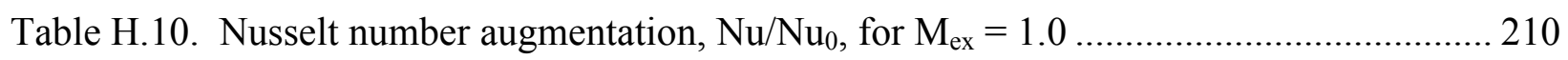

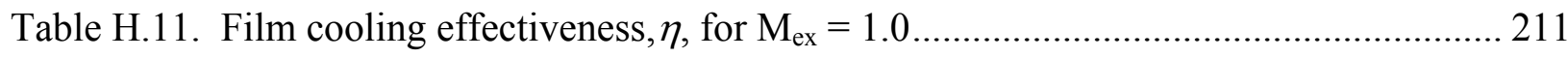

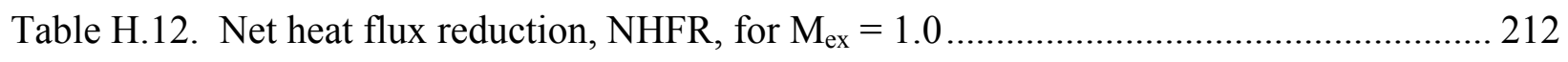

\section{Appendix I Tabulated Results - No-Cooling Measurements}

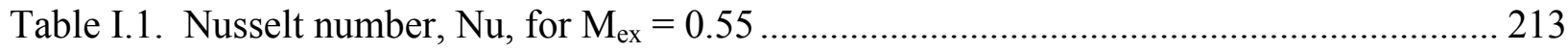

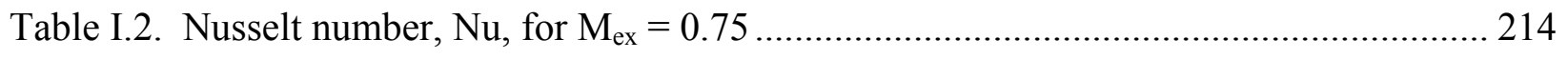

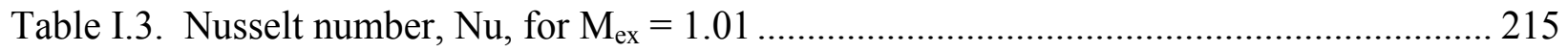

Table I.4. Vane local Mach number.............................................................................. 216 


\section{Preface Paper 1}

Paper 1 experimentally and numerically investigates the effects of large scale high freestream turbulence intensity and exit Reynolds number on the surface heat transfer distribution of a turbine vane in a 2-D linear cascade at realistic engine Mach numbers. The paper has been accepted to ASME Journal of Turbomachinery (Turbo-07-1136). For more details regarding this paper, please refer to Appendices F, G, I and J. 


\title{
Effects of Large Scale High Freestream Turbulence, and Exit Reynolds Number on Turbine Vane Heat Transfer in a Transonic Cascade
}

\author{
S. Nasir, J.S. Carullo, H. Wu, W.F. Ng and K.A. Thole \\ Mechanical Engineering Department \\ Virginia Polytechnic Institute and State University \\ Blacksburg, VA 24061 \\ L.J. Zhang and H.K. Moon \\ Solar Turbines Inc. \\ San Diego, CA 92101
}

IMECE Paper 2007-44098

Accepted to the Journal of Turbomachinery

\begin{abstract}
This paper experimentally and numerically investigates the effects of large scale high freestream turbulence intensity and exit Reynolds number on the surface heat transfer distribution of a turbine vane in a 2-D linear cascade at realistic engine Mach numbers. A passive turbulence grid was used to generate a freestream turbulence level of $16 \%$ and integral length scale normalized by the vane pitch of 0.23 at the cascade inlet. The baseline turbulence level and integral length scale normalized by the vane pitch at the cascade inlet were measured to be $2 \%$ and 0.05 , respectively. Surface heat transfer measurements were made at the midspan of the vane using thin film gauges. Experiments were performed at exit Mach numbers of 0.55, 0.75 and 1.01 which represent flow conditions below, near, and above nominal conditions. The exit Mach numbers tested correspond to exit Reynolds numbers of $9 \times 10^{5}, 1.05 \times 10^{6}$, and $1.5 \times 10^{6}$, based on vane chord.
\end{abstract}

The experimental results showed that the large scale high freestream turbulence augmented the heat transfer on both the pressure and suction sides of the vane as compared to the 
low freestream turbulence case and promoted slightly earlier boundary layer transition on the suction surface for exit Mach 0.55 and 0.75. At nominal conditions, exit Mach 0.75, average heat transfer augmentations of $52 \%$ and $25 \%$ were observed on the pressure and suction side of the vane, respectively. An increased Reynolds number was found to induce an earlier boundary layer transition on the vane suction surface and to increase heat transfer levels on the suction and pressure surfaces. On the suction side, the boundary layer transition length was also found to be affected by increase changes in Reynolds number. The experimental results also compared well with analytical correlations and CFD predictions.

\section{Nomenclature}

$\begin{array}{ll}a_{1} & \text { dimensionless strain rate } \\ B & \text { bar width of turbulence grid } \\ C & \text { vane chord } \\ C_{p} & \text { constant pressure specific heat } \\ D & \text { effective leading edge diameter of vane } \\ f & \text { elliptic operator in V2F model } \\ h & \text { heat transfer coefficient } \\ k_{a} & \text { thermal conductivity of air } \\ k & \text { acceleration parameter / thermal conductivity/turbulent kinetic energy } \\ L_{a} & \text { dimensionless length scale } \\ L S & \text { integral turbulence length scale } \\ M a & \text { Mach number } \\ N u & \text { Nusselt number } \\ N u_{a} & \text { Effective Nusselt Number } \\ N u_{0} & \text { Nusselt Number at Tu }=2 \% \\ N u_{D} & \text { Nusselt Number based on D } \\ P & \text { pitch of vane } \\ P r & \text { Prandtl number } \\ q & \text { heat flux } \\ r_{c} & \text { recovery factor } \\ R e & \text { Reynolds number } \\ R e_{D} & \text { Reynolds number based on D, evaluated at inlet conditions } \\ S & \text { vane surface distance from stagnation point } \\ S t & \text { Stanton number } \\ T & \text { temperature } \\ T u & \text { streamwise freestream turbulence intensity } \\ T u_{a} & \text { modified turbulence intensity } \\ T u_{\lambda} & \text { effective turbulence intensity } \\ U & \text { local velocity } \\ V R & \text { velocity ratio } \\ & \end{array}$




$\begin{array}{ll}v^{2} & \text { wall normal Reynolds stress component } \\ x & \text { streamwise distance from turbulence grid } \\ y^{+} & \text {equivalent normal distance }\end{array}$

\section{Greek}

$\Lambda_{x} \quad$ integral turbulence length scale

$\rho \quad$ local density of air

$\mu \quad$ dynamic viscosity of air

\section{Subscripts}

$\begin{array}{ll}1,2 & \text { inlet conditions, exit conditions } \\ \text { aw, w } & \text { adiabatic wall, wall } \\ \text { gauge } & \text { thin film gauge (surface) measurement } \\ \text { init } & \text { initial } \\ \text { L } & \text { local conditions } \\ \text { o } & \text { stagnation }\end{array}$

\section{Introduction}

One way to increase the cycle efficiency of a gas turbine engine is to operate at higher turbine inlet temperature (TIT). In most engines, the turbine inlet temperatures have increased to be well above the metallurgical limit of engine components. Cooling of turbine engine components (blades and vanes) is a widely used technique that allows higher TITs by maintaining material temperatures within acceptable limits. Accurate turbine section heat transfer modeling can lead to an optimized cooling design and therefore higher turbine inlet temperatures.

Numerical modeling of heat transfer through turbine passages is a challenge as it is complicated by several factors such as Reynolds number, Mach number, combustor-generated high freestream turbulence, turbulence length scale, hot streaks, and secondary flows just to name a few. The efforts of this work are to experimentally and numerically investigate the effects of large scale high freestream turbulence on first stage turbine vane heat transfer at realistic engine Mach number conditions. 


\section{Summary of Past Literature}

While measuring the turbulence level in a gas turbine is extremely difficult, researchers have found that combustion systems typically produce turbulence levels between $7 \%$ and $30 \%$ $[1,2]$. Ames et al. [3] reported that the exit turbulence levels depend on combustor core flow to vane inlet contraction ratio and the residence time of the flow in the combustor.

Several research groups have performed heat transfer experiments on turbine vane geometries in low speed cascade facilities. Ames et al. [3-4-5] investigated the effects of freestream turbulence and length scale on vane heat transfer at different exit Reynolds number conditions. In all these studies with different turbulence generators, Ames et al. observed that turbulence augmented the heat transfer in the laminar region with the highest augmentation in the stagnation region and on the pressure side. An earlier transition to a turbulent boundary layer was also observed on the suction side of the vane when the turbulence level was increased. The length scale effect was also observed with the augmentation on pressure side heat transfer increased as the length scale was decreased. Radomsky and Thole [6] documented surface heat transfer and the highly turbulent flowfield around a scaled-up stator vane. Their observations of the heat transfer augmentation on the vane surface were also consistent with Ames [4].

Several experimental studies have also been performed in transonic cascade facilities to investigate the effect of freestream turbulence, Mach number and exit Reynolds number on vane heat transfer. Nealy et al. [7] found that turbulence augmented heat transfer on the vane surface. He also found that an increase in Reynolds number increased heat transfer levels on the vane surface and the exit Mach number controlled the heat transfer distribution on the suction side of the vane. Arts and Lambert de Rouvroit [8] found augmentation levels of up to $100 \%$ on the laminar portion of the vane subjected to $6 \%$ turbulence levels.

Hoffs et al. [9] investigated the effects of Reynolds number and turbulence on smooth vane heat transfer in a high speed facility and found that the boundary layer on the pressure side started transition with an increase in the heat transfer coefficient near the trailing edge. Bunker [10] also investigated the effects of high freestream turbulence (13\%) and Reynolds number on the vane heat transfer in a linear cascade. He found that pressure side heat transfer was less affected by turbulence, but showed a consistent increase with turbulence over the whole pressure surface. He found that increased turbulence hastened suction side transition. Bunker also found 
that heat transfer on the suction side of the vane aft of transition followed a proportionality of $\operatorname{Re}^{1.0}$.

\section{Experimental Setup and Instrumentation}

\section{Wind Tunnel Facility}

The two-dimensional Virginia Tech transonic cascade wind tunnel, shown in Figure 1.1, is a blow-down facility that is capable of sustaining a constant inlet pressure in the test section for up to 25 seconds. Prior heat transfer research that has been performed in this facility includes work of Carullo et al. [11], Nix et al. [12], Holmberg and Diller [13], Smith et al. [14], and Popp et al. [15]. Air is supplied from high pressure air tanks that are charged up to $1380 \mathrm{kPa}$ (200 psig) prior to testing. A control valve regulates the flow from the air tanks to the test section. Cascade inlet pressures range from $20.7 \mathrm{kPa}$ (3 psig) to $69.0 \mathrm{kPa}(10 \mathrm{psig})$ depending on the objective test conditions. Between the control valve and the test section, the air passes through a passive heat exchanger, which heats the cascade inlet flow up to $120^{\circ} \mathrm{C}$. After the air passes through the heat exchanger, the air goes through a contraction and enters the test section before being exhausted to the atmosphere.

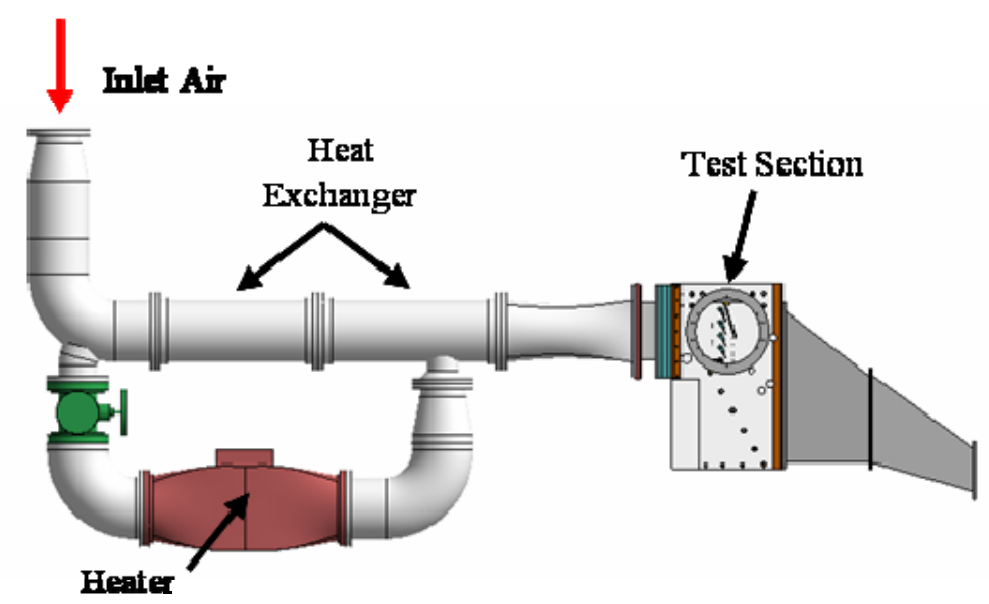

Figure 1.1. Virginia Tech transonic cascade wind tunnel

The turbine vane tested in these experiments is similar in geometry to a first stage turbine vane for a small industrial gas turbine. The vane was scaled one-and-half times so that the nominal exit Reynolds number would be at the desired value. Table 1 summarizes the geometry of the turbine vane. 
Table 1.1. Turbine vane geometry

\begin{tabular}{|c|c|}
\hline Chord & $91.2 \mathrm{~mm}(3.59$ in.) \\
\hline Axial Chord & $50.0 \mathrm{~mm}(1.97$ in.) \\
\hline Pitch & $83.0 \mathrm{~mm}(3.27$ in.) \\
\hline Span & $152.4 \mathrm{~mm}(6.00$ in.) \\
\hline Inlet and Exit Angle & $0^{\circ}$ and $73.5^{\circ}$ \\
\hline
\end{tabular}

A diagram of the vane cascade is provided in Figure 1.2. From the vane geometry and the test section size, the vane cascade consists of four full vanes and two partial vanes, which result in four full passages and one partial passage. A tailboard placed at the vane exit angle aids in creating periodic flow through the cascade. The full vanes are numbered starting from the lower bottom of the cascade with Vane 2 being the vane that is fully instrumented to make static pressure and heat transfer measurements. The slot located $0.45 \mathrm{C}$ upstream of the cascade is used to measure the turbulence and velocity distributions at the inlet of the cascade.

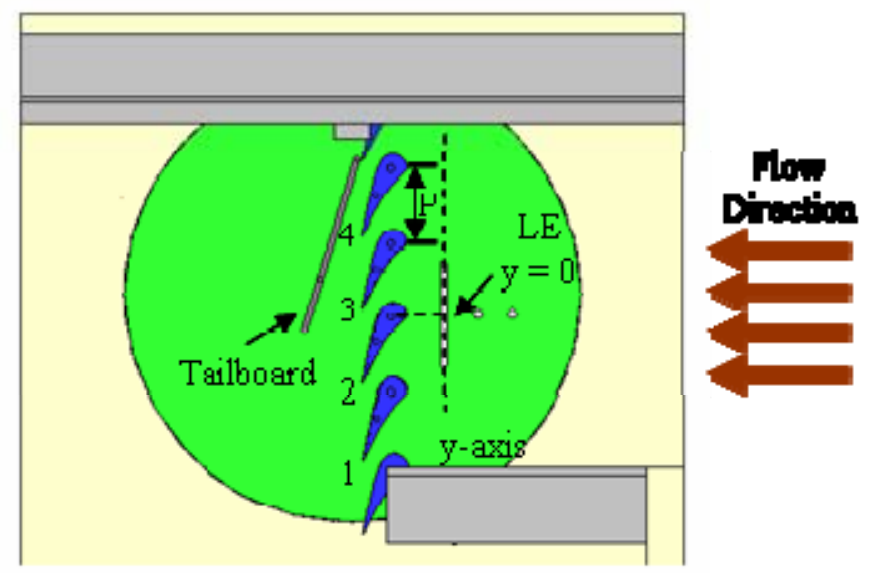

Figure 1.2. Cascade diagram showing the vanes and the axis orientation for measurements with the traverse

\section{Static Pressure Measurements}

To calculate the isentropic Mach number distribution on the vane surface, the turbine vane was instrumented with static pressure taps placed at the midspan of the vane. Vane 2 was instrumented with 7 taps on the pressure side, 18 taps on the suction side and 1 tap near the leading edge. Static pressure taps were also instrumented on suction side of Vane 1 and on the pressure side of Vane 3 to check the periodicity of the flow. The static pressure measurements were made through experiments conducted independently of the heat transfer experiments. In 
addition to calculating the isentropic Mach number distribution, the acceleration parameter distribution on the vane surface was calculated.

Static pressure taps on the end wall of the cascade were used to measure the inlet and exit static pressures and characterize the inlet and exit flow. Fourteen inlet static taps were located $0.45 \mathrm{C}$ upstream of the vane passages and 14 exit static taps were located $0.45 \mathrm{C}$ downstream of the vane passages. Figure 1.3 provides typical cascade inlet temperature, inlet and exit Mach number time histories during a blowdown test run.

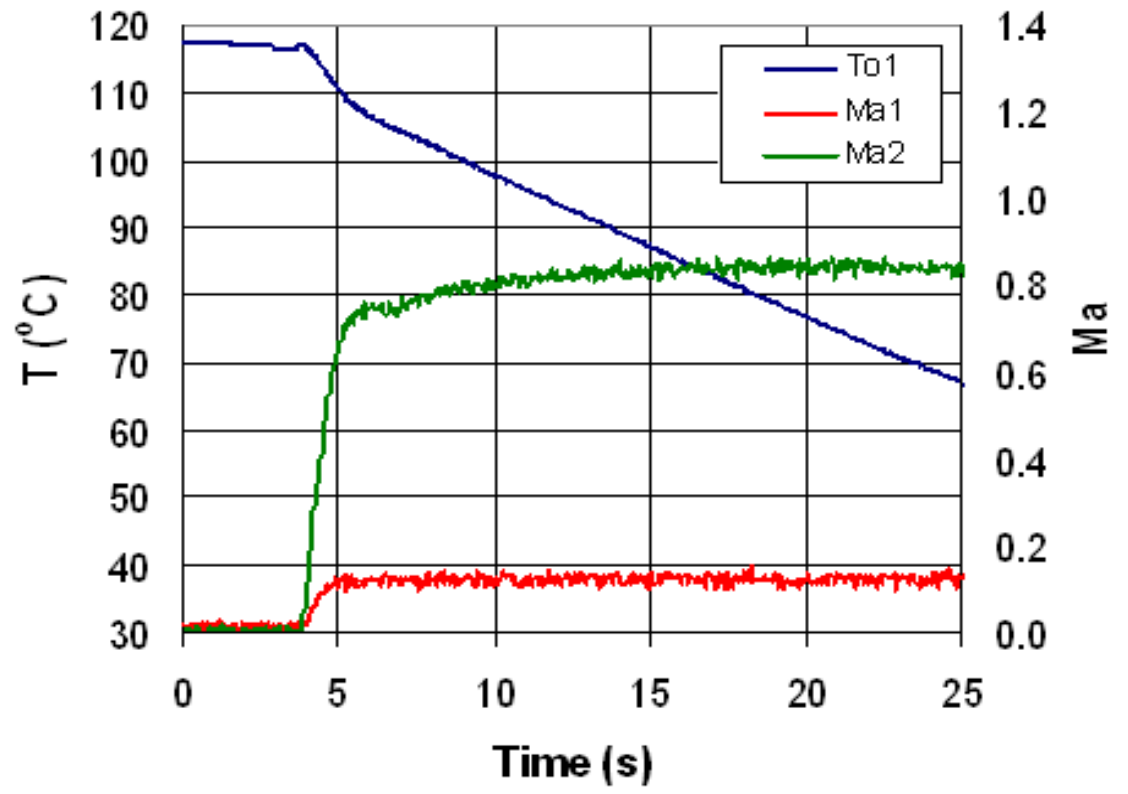

Figure 1.3. Cascade inlet temperature and Mach number history

\section{Heat Transfer Measurements}

Heat transfer measurements Heat transfer measurements were made with thin film gauges that allow for high spatial resolution measurements on the vane surface with minimal flow disruption. Thin film gauges were originally developed by Schultz and Jones [16] and variations of the original design have been used by Doorly and Oldfield [17] and Dunn [18]. The thin film gauges that were used in these experiments are two-layer thin film gauges similar to the gauges developed by Doorly and Oldfield [17]. The gauges were manufactured according to the procedure described by Joe [19].

Each thin film gauge consists of a $3.18 \mathrm{~mm}$ (0.125 in.) long platinum sensor attached to copper leads which are sputtered to a Kapton $(k=0.12 \mathrm{~W} / \mathrm{mK})$ sheet that is $50 \mu \mathrm{m}$ thick. The Kapton sheet with the gauges is attached to a vane manufactured from a low thermal 
conductivity ceramic material, Macor $(k=1.46 \mathrm{~W} / \mathrm{mK})$. A photograph of the gauges installed on the vane is shown in Figure 1.4. Forty-three thin film gauges were instrumented on the vane with platinum sensors placed at the midspan of the vane. Thin film gauges are used to measure a change in temperature on the surface of the vane. The platinum sensor of the thin film gauge changes resistance with temperature and therefore is calibrated for temperature coefficient of resistivity prior to testing. Since the gauge changes resistance with temperature, the gauge is used as one arm of a Wheatstone bridge circuit. The Wheatstone bridge used in these experiments is described by Joe [19]. The change in voltage across the bridge during the experiment is sampled at $1 \mathrm{kHz}$ during the experiment using a 16-Bit NI SCXI-1600 data acquisition system. The data from up to 31 gauges can be recorded in this facility during a single test.

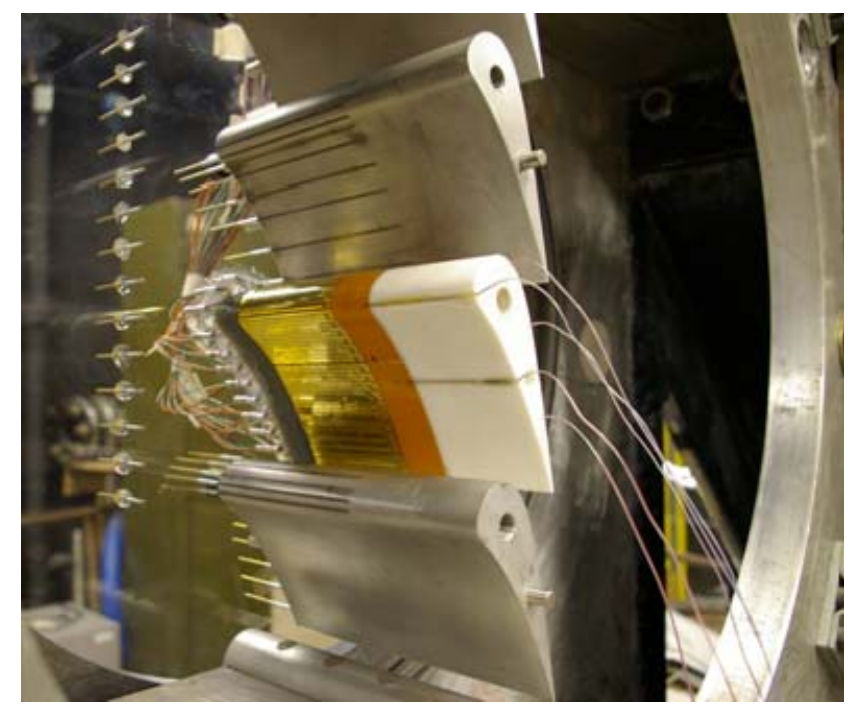

Figure 1.4. Photograph of thin film gauges in wind tunnel

To reduce the heat transfer data, several steps must be taken. The voltage output from each Wheatstone bridge is converted into surface temperature using the gauge calibration and basic Wheatstone bridge operating principles. Next, the heat flux for each gauge is calculated by using a finite-difference code developed by Cress [20]. The finite-difference code uses the time history of the surface temperature of the gauge as a boundary condition and solves the onedimensional, transient heat conduction equation. Over the majority of the vane, the conduction is assumed to be semi-infinite since the Macor conducts heat very slowly. Near the trailing edge, the heat flux is calculated over a finite material thickness with the surface temperature measured by the gauges on each side of the vane used as the boundary conditions to calculate heat flux. Once the heat flux is determined, the heat transfer coefficient can then be calculated by using, 


$$
h=\frac{q^{\prime \prime}}{\left(T_{\text {aw }}-T_{\text {gauge }}\right)}
$$

where the adiabatic wall temperature is defined as,

$$
T_{a w}=T_{o 1} \cdot\left(\frac{1+r_{c} \cdot \frac{\gamma-1}{2} M a^{2}}{1+\frac{\gamma-1}{2} M a^{2}}\right)
$$

It was assumed that the boundary layer was turbulent everywhere, so a recovery factor of $r_{c}=\operatorname{Pr}^{1 / 3}$ was applied to all of the gauges. The heat transfer coefficient can then be nondimensionalized by calculating Nusselt number as,

$$
N u=\frac{h \cdot C}{k_{a}}
$$

The heat transfer coefficient can also be nondimensionalized in terms of the Stanton number given by,

$$
S t=\frac{h}{\rho_{L} \cdot U_{L} \cdot C_{p}}
$$

Figure 1.5 shows typical vane surface temperature and adiabatic wall temperature time histories, and Figure 1.6 shows the calculated heat flux and heat transfer coefficient time histories during a blow-down test run.

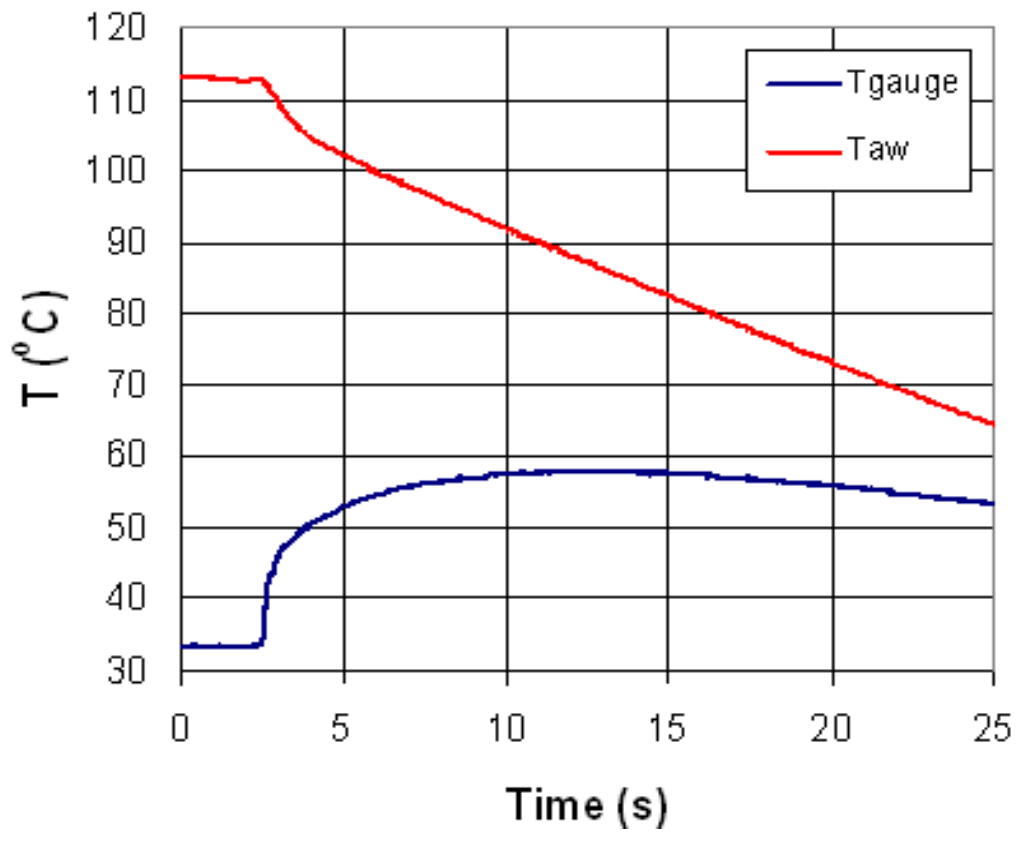

Figure 1.5. Typical vane surface and adiabatic wall temperature history 


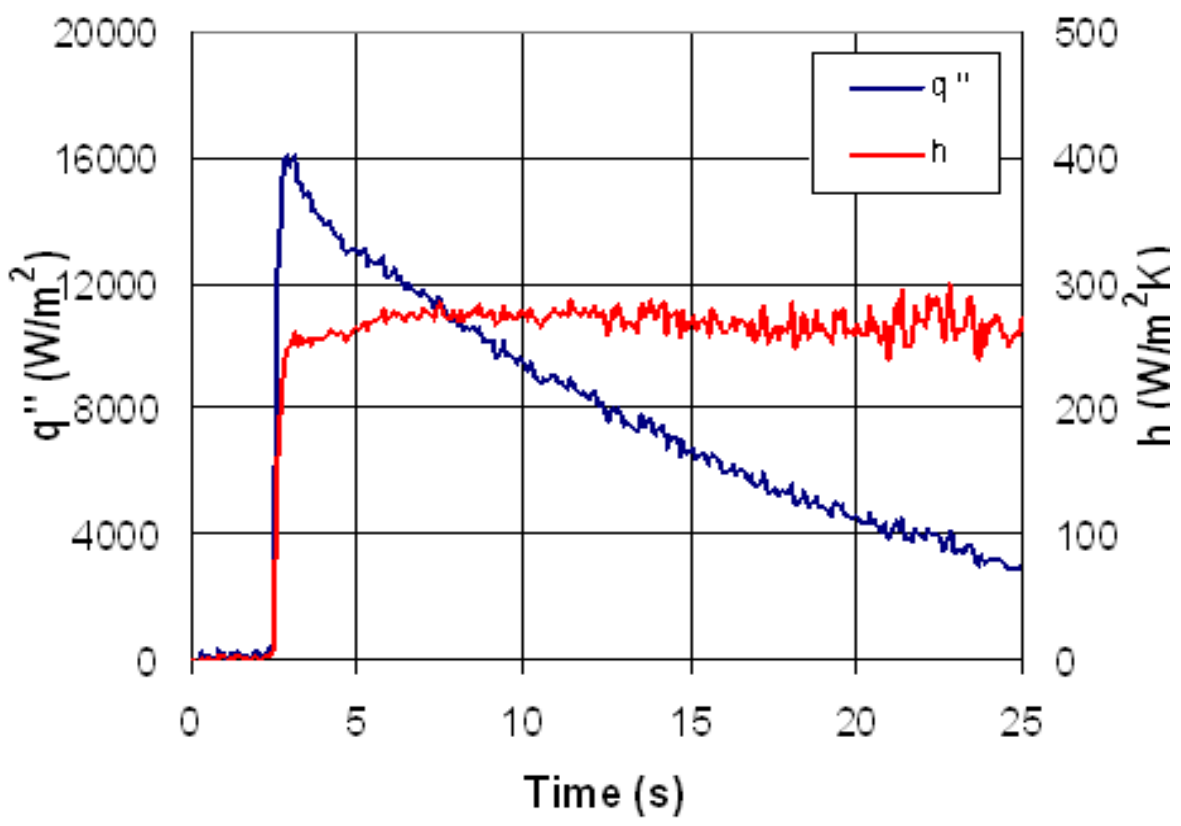

Figure 1.6. Typical vane surface heat flux and heat transfer coefficient history

\section{Uncertainty Analysis}

The experimental uncertainty of the heat transfer measurements was calculated by using the perturbation method described by Moffat [21]. The analysis took into account the bias error and precision error. An uncertainty was calculated for each gauge at every test condition. The total uncertainty of the heat transfer coefficient for the gauges ranged between $\pm 8.5 \%$ and $\pm 11.0 \%$ with the bias error contributing to the majority of the total uncertainty. For each test condition, measurements were performed at least three times to establish repeatability.

\section{Turbulence Generation}

To generate freestream turbulence levels of $16 \%$, a passive square mesh turbulence grid was used. A schematic of the turbulence grid is provided in Figure 1.7. The grid design was based on the correlations reported by Baines and Peterson [22] and research performed by Nix et al. [23] on turbulence grids in the cascade wind tunnel. The square mesh grid has bar widths of $1.91 \mathrm{~cm}(0.75 \mathrm{in}$.) and spaced to create $3.81 \mathrm{~cm} \times 3.81 \mathrm{~cm}(1.5$ in. $\times 1.5$ in.) square openings. The porosity of the square mesh grid is $52 \%$. 


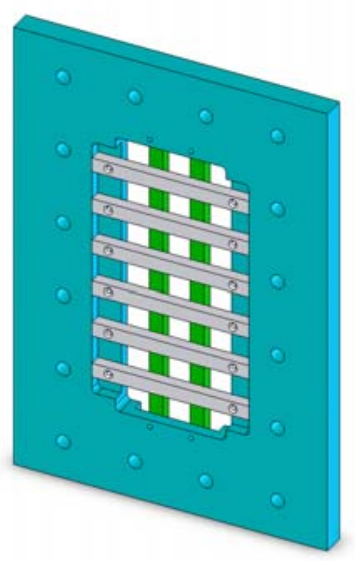

Figure 1.7. Square mesh turbulence grid

The location of turbulence grid relative to the test section is provided in Figure 1.8. The turbulence grid is oriented so that the flow is perpendicular to the grid bars. The mesh grid was placed downstream of the two-dimensional contraction with a spacer (1.25 in. thick) placed between the contraction and test section. The non-dimensional streamwise distance from turbulence grid to the turbulence measurement slot is given by $\mathrm{x} / \mathrm{B}=16$.

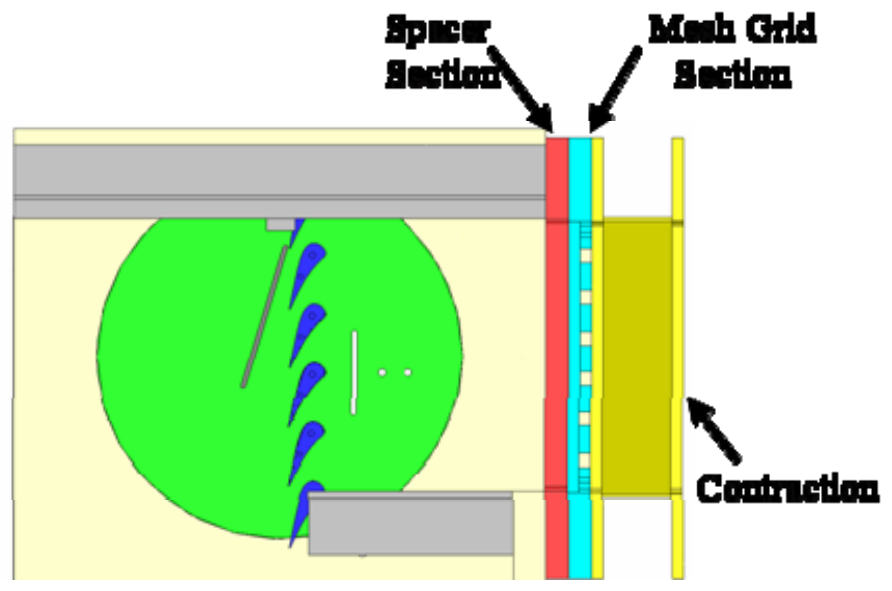

Figure 1.8. Square mesh turbulence grid location relative to the test section

The velocity fluctuations in the streamwise direction were measured using a single hotfilm probe with a $50 \mu \mathrm{m}$ diameter and roughly $1.5 \mathrm{~mm}$ long film that was connected to a constant-temperature anemometer. Hot-film data were sampled for approximately 1.3 seconds at $100 \mathrm{kHz}$ and filtered at $40 \mathrm{kHz}$. The hot-film probe was discretely traversed over one vane pitch along the vertical slot as shown in Figure 2. The turbulence intensity and integral turbulence length scales were calculated at each measurement location. The turbulence length scales were 
calculated using the methods described by Nix et al. [23] that applies Taylor's Hypothesis of frozen turbulence. The turbulence levels and length scales were measured for the square mesh grid and a baseline case where no turbulence grid was installed in the tunnel. The turbulence intensity and the normalized integral length scale distributions along the vane inlet pitch are provided in Figures 1.9 and 1.10, respectively. The summary of turbulence measurements is provided in Table 2 .

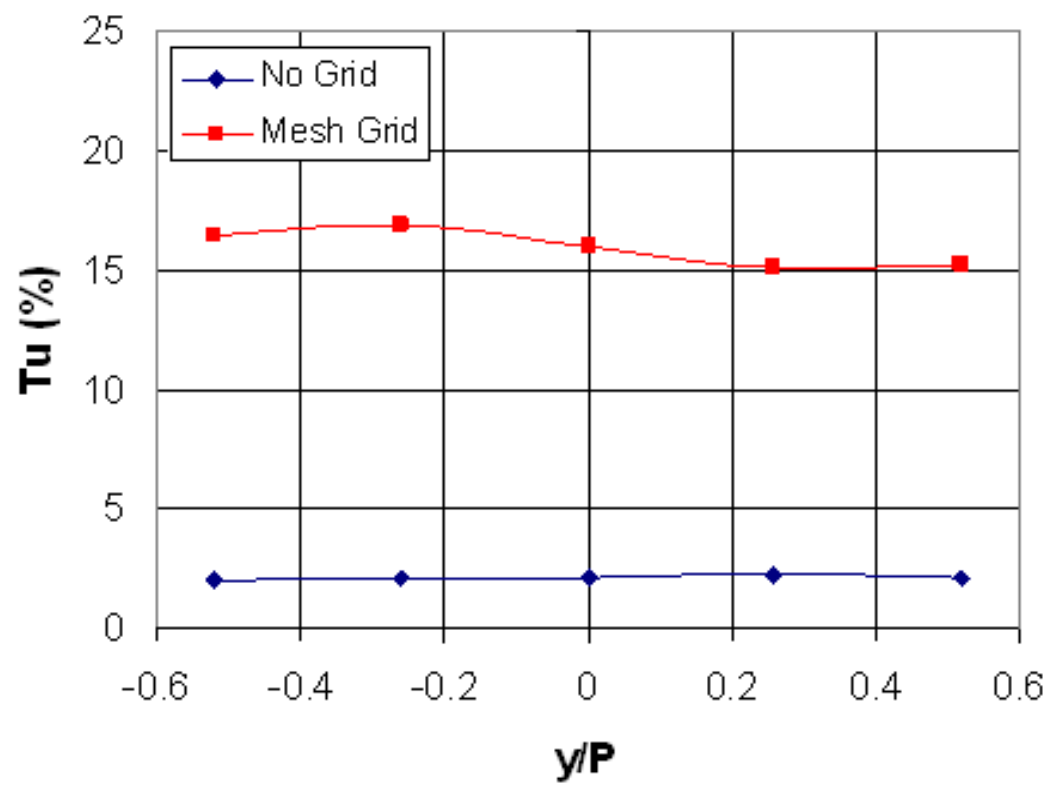

Figure 1.9. Turbulence intensity along inlet pitch

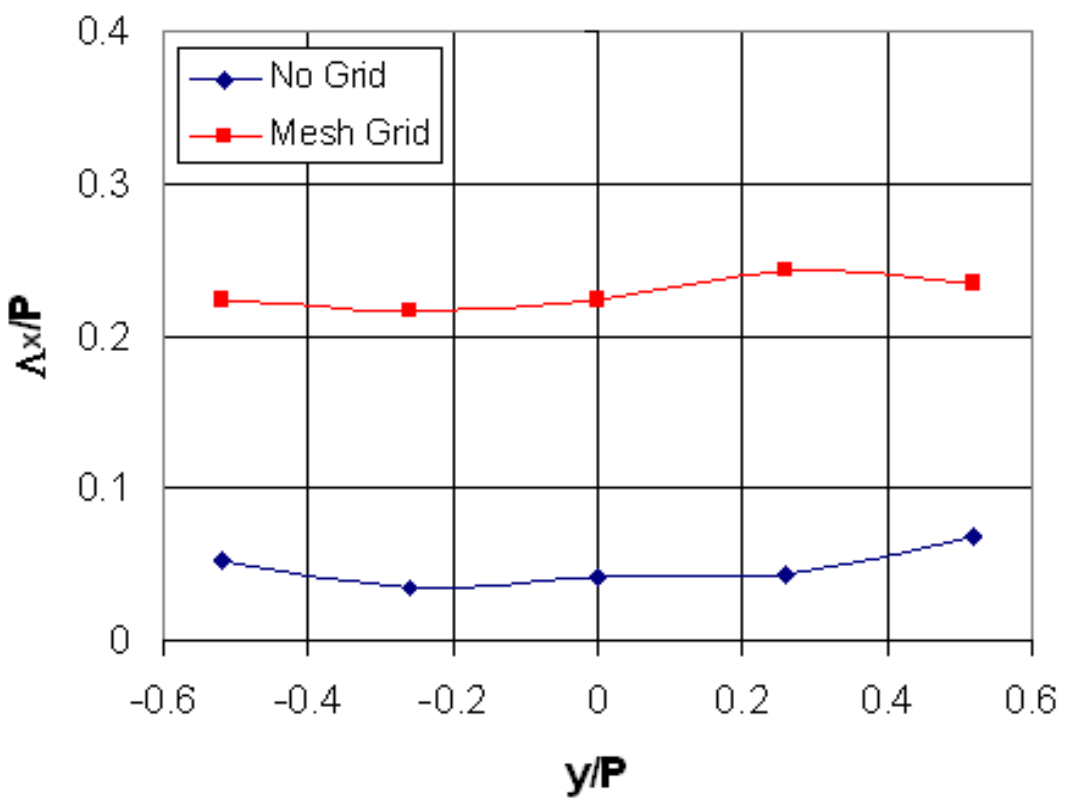

Figure 1.10. Turbulence length scale along inlet pitch 
Table 1.2. Summary of grid generated turbulence

\begin{tabular}{|c|c|c|c|}
\hline & Tu Intensity & $\begin{array}{c}\text { Length Scale } \\
\left(\Lambda_{\mathrm{x}} / \mathrm{P}\right)\end{array}$ & $\begin{array}{c}\text { Turbulent KE } \\
\left(\mathrm{k} / \mathrm{U}_{1}^{2}\right)\end{array}$ \\
\hline Baseline & $2 \%$ & 0.05 & 0.0002 \\
\hline Mesh Grid & $16 \%$ & 0.23 & 0.0128 \\
\hline
\end{tabular}

To check uniformity of the inlet flow to the vane passages downstream of the turbulence grid, a Kiel probe was continuously traversed at low speed along the measurement slot shown in Figure 1.2. A velocity ratio was obtained by dividing the velocity measured from the Kiel probe to the velocity measured from a stationary Pitot probe. The velocity ratio for the square mesh grid and a baseline configuration tested is provided in Figure 1.11.

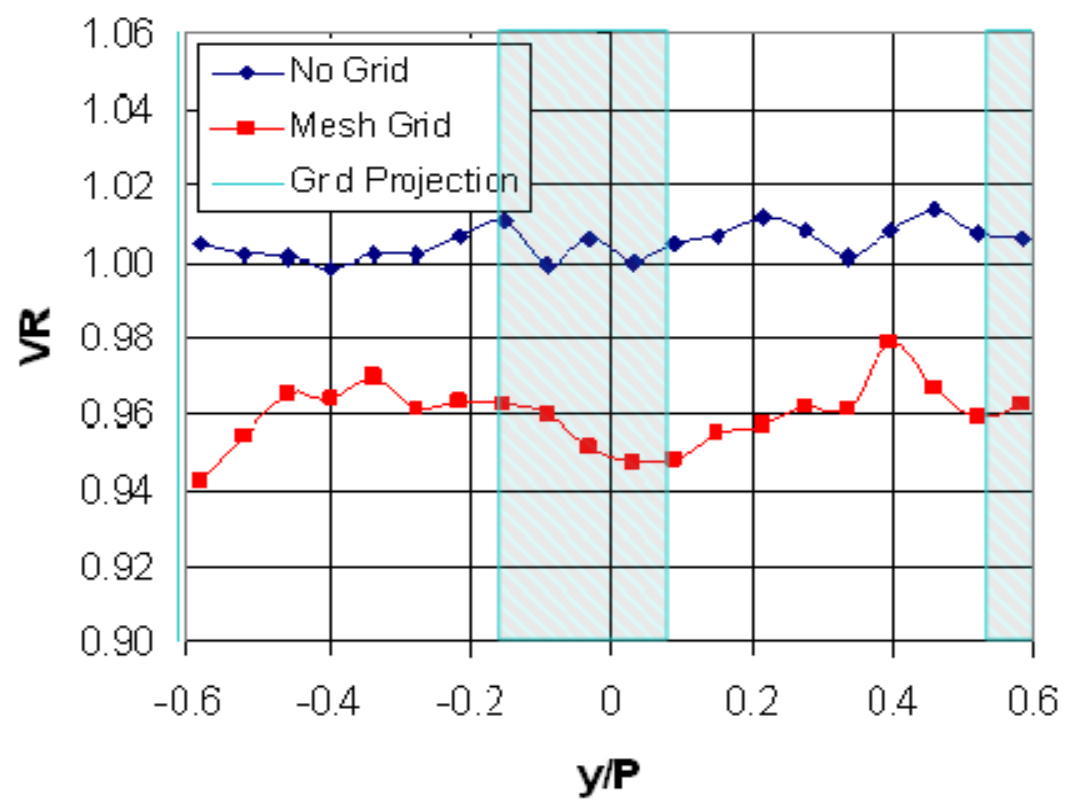

Figure 1.11. Velocity ratio variation along inlet pitch

\section{Vane Static Pressure Distribution}

Figure 1.12 shows the local Mach number distributions on the vane surface for three exit Mach number conditions. The Mach number distribution varies smoothly along the pressure side, and does not exhibit any velocity peak downstream of the stagnation region. The flow on the suction side continuously accelerates up to the geometric throat area $(\mathrm{s} / \mathrm{C}=0.51)$. The exit Mach 0.6 and 0.8 cases decelerate immediately after the throat, whereas the exit Mach 1.0 case continues to accelerate and becomes supersonic. A trailing edge shock from the adjacent vane 
impinging on the suction surface $(\mathrm{s} / \mathrm{C}=0.58)$ causes the multi flow decelerations after the throat for the exit Mach 1.0 case.

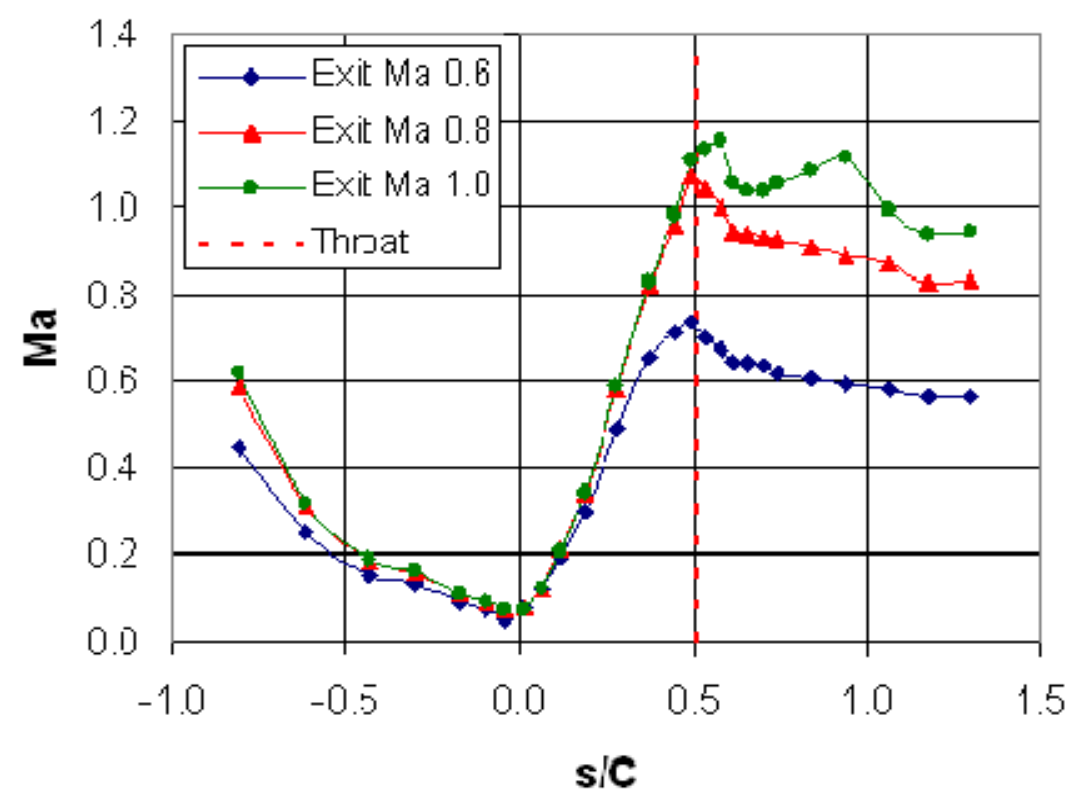

Figure 1.12. Local Mach number distribution

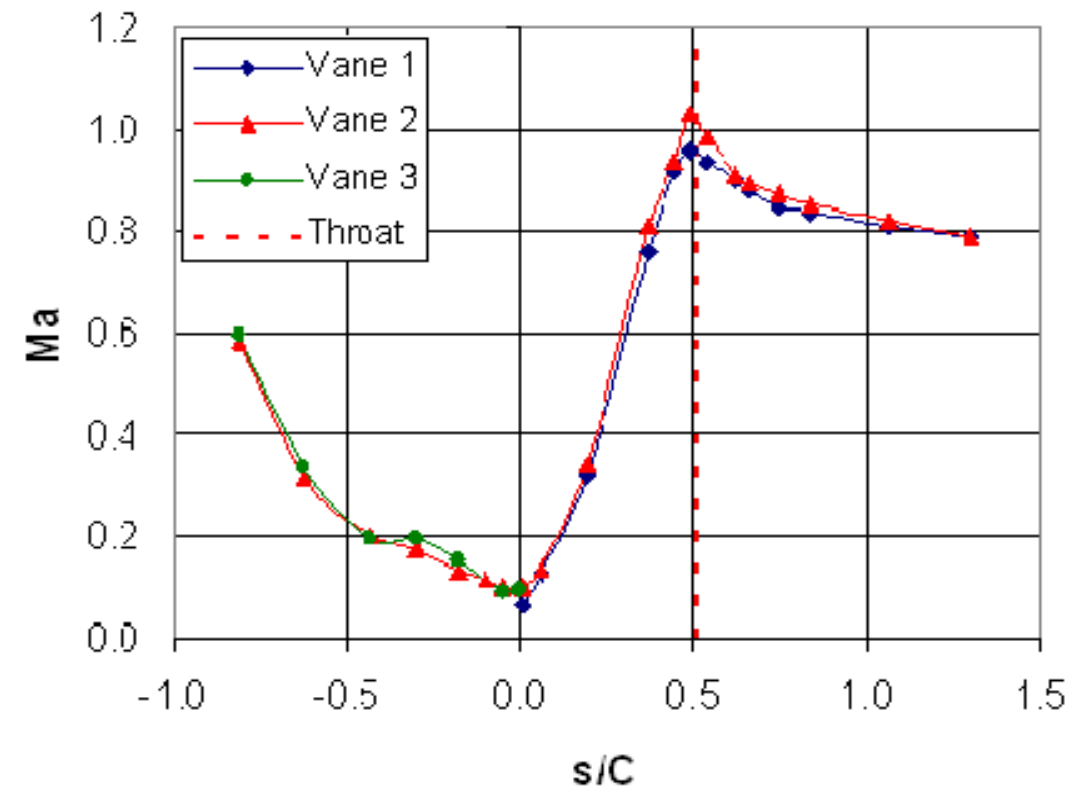

Figure 1.13. Flow periodicity through vane passages

The periodicity of the flow at exit Mach 0.8 is provided in Figure 1.13. The flow periodicity is shown by comparing the local Mach number distribution over the vane surfaces. The suction sides of vane 1 and vane 2 show the same local Mach number distributions over the majority of the suction surface. There is a slight variation in the local Mach numbers near the 
geometric throat. The pressure side of vane 2 and vane 3 shows almost identical local Mach number distributions with very small variation downstream of the stagnation region.

The distribution of acceleration parameter, $k$, on the vane surface for each exit Mach number is provided in Figure 1.14. A positive acceleration parameter indicates that the flow is accelerating and a negative value indicates that the flow is decelerating. On the pressure side of the vane, the acceleration parameter for exit Mach 0.6 case barely reaches the critical value of 3 $\times 10^{-6}$ after $\mathrm{s} / \mathrm{C}=-0.43$. This critical value of $k$ has been observed by Jones and Launder [24] and Mayle [25] as a criterion for boundary layer relaminarization.

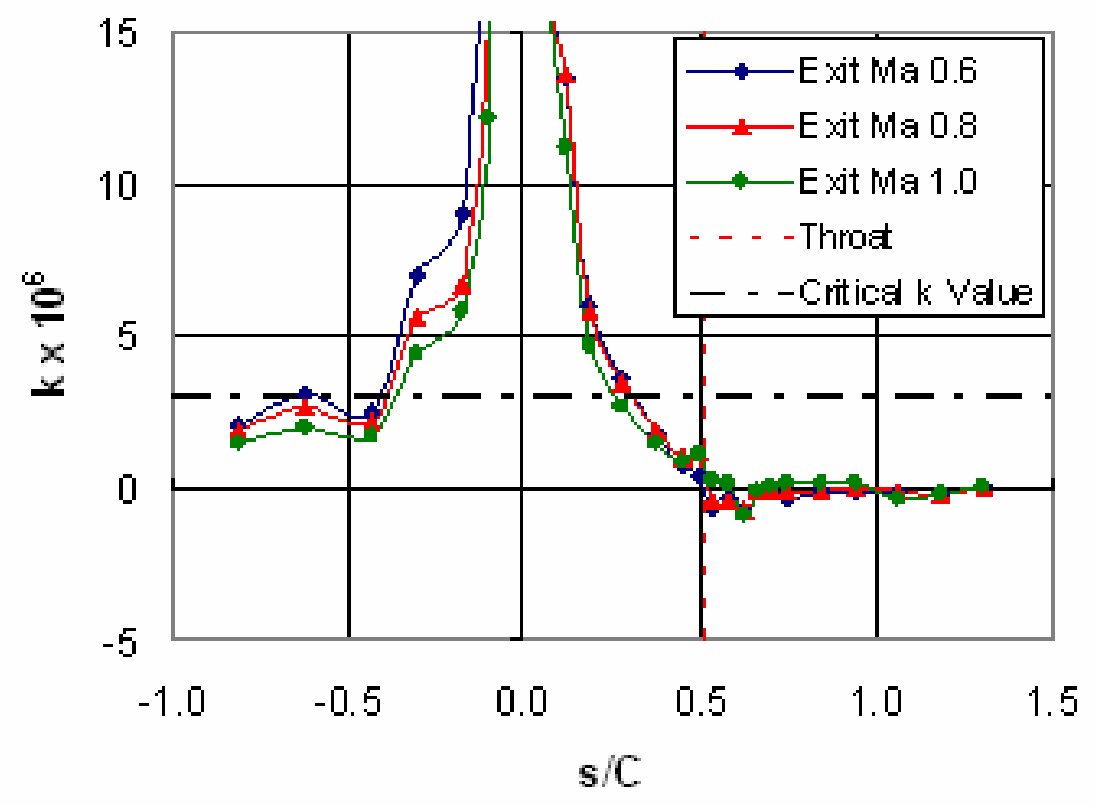

Figure 1.14. Acceleration parameter distribution

\section{Vane Heat Transfer Distribution}

\section{Test Conditions}

Heat transfer Heat transfer measurements were performed at exit Mach numbers of 0.55, 0.75 and 1.01. The turbulence levels were varied between $2 \%$, and $16 \%$ at each exit Mach number. The test matrix produced heat transfer data for six different flow conditions. For each test condition, measurements were performed at least three times to establish repeatability. Table 1.3 provides the flow and heat transfer conditions for each test. The exit Reynolds number coupled with the exit Mach number is based on vane chord and is defined by, 


$$
\mathrm{Re}_{2}=\frac{\rho_{2} \cdot U_{2} \cdot C}{\mu_{2}}
$$

where the average pressure and temperature data during the test run were used to calculate the exit Reynolds number.

Table 1.3. Test conditions for each case

\begin{tabular}{|l|c|c|c|c|c|}
\hline & Exit Ma & $\mathbf{T u}$ & Exit Re & $\mathbf{T}_{\mathbf{0 1}}\left({ }^{\mathbf{0}} \mathbf{C}\right)$ & $\mathbf{T}_{\text {init,w }}\left({ }^{\mathbf{0}} \mathbf{C}\right)$ \\
\hline Case 1 & 0.55 & $2 \%$ & 900,000 & 105 & 30.4 \\
\hline Case 2 & 0.55 & $16 \%$ & 908,000 & 107 & 28.2 \\
\hline Case 3 & 0.74 & $2 \%$ & $1,050,000$ & 102 & 33.4 \\
\hline Case 4 & 0.75 & $16 \%$ & $1,060,000$ & 107 & 33.3 \\
\hline Case 5 & 1.02 & $2 \%$ & $1,520,000$ & 103 & 29.0 \\
\hline Case 6 & 1.01 & $16 \%$ & $1,500,000$ & 104 & 32.0 \\
\hline
\end{tabular}

\section{Effect of Freestream Turbulence}

This section discusses the effect that increasing freestream turbulence has on the heat transfer distribution over the turbine vane surface. Plots of the heat transfer distribution over the vane surface are shown in terms of Nusselt number and the Nusselt number augmentation relative to the low freestream turbulence cases.

Figures $1.15,1.16$, and 1.17 provide the heat transfer distributions for each freestream turbulence level at exit Mach 0.55, 0.75 and 1.01, respectively. The large scale high freestream turbulence augments the heat transfer at the leading edge, on the pressure side, and on the suction side of the vane where the boundary layer is laminar. The general shape of the heat transfer distribution over the vane surface is the same for all cases. After having achieved a relatively high heat transfer value at the leading edge, the heat transfer decreases as the flow proceeds down the suction and pressure sides due to the development of a laminar boundary layer. The heat transfer on the suction surface also responds to the pressure gradient along the surface and decreases until the boundary layer transitions, where a large increase in heat transfer occurs. The heat transfer on the pressure surface shows a decrease until s/C $=-0.25$ and then a continuous increase until s/C $=-0.86$.

On the suction side, the transition to a turbulent boundary layer occurs downstream of throat at $\mathrm{s} / \mathrm{C}=0.57$ for the low turbulence level at exit Mach 0.55 and 0.75 . The boundary layer transition length over the vane surface is short for the exit Mach 0.55 and 0.75 cases because the flow is decelerating downstream of the throat. The boundary layer transition for the low 
turbulence at exit Ma 1.01 occurs at $\mathrm{s} / \mathrm{C}=0.40$. Since the flow is still accelerating at this point, the transition length is affected. The effect of acceleration on the transition length was also noted in the study performed by Zhang and Han [26].

The start of transition for the high turbulence tests at exit Mach 0.55 and 0.75 appears to begin slightly earlier at $\mathrm{s} / \mathrm{C}=0.51$. Again, the boundary layer transition length over the vane surface is short for the exit Mach 0.55 and 0.75 cases because of flow deceleration downstream of the throat. The boundary layer transition for the high turbulence at exit Ma 1.01 occur also at $\mathrm{s} / \mathrm{C}=0.40$. For the exit Mach 1.01 case, the transition location is observed to be not influenced by the large scale high freestream turbulence. The transition length for both turbulence cases at exit Mach 1.01 is interrupted around $\mathrm{s} / \mathrm{C}=0.57$ which corresponds to the location where trailing edge shock from the adjacent vane is impinging on the suction surface. The slow transition could be attributed to the interaction of the shock with the transitioning boundary layer. Once the boundary layer goes turbulent on the suction side, the effect of large scale high freestream turbulence level on heat transfer diminishes. This observation is consistent with Ames and Moffat [27] and Thole and Bogard [28] who have shown that relatively large scale turbulence has a reduced effect on turbulent boundary layer heat transfer augmentation.

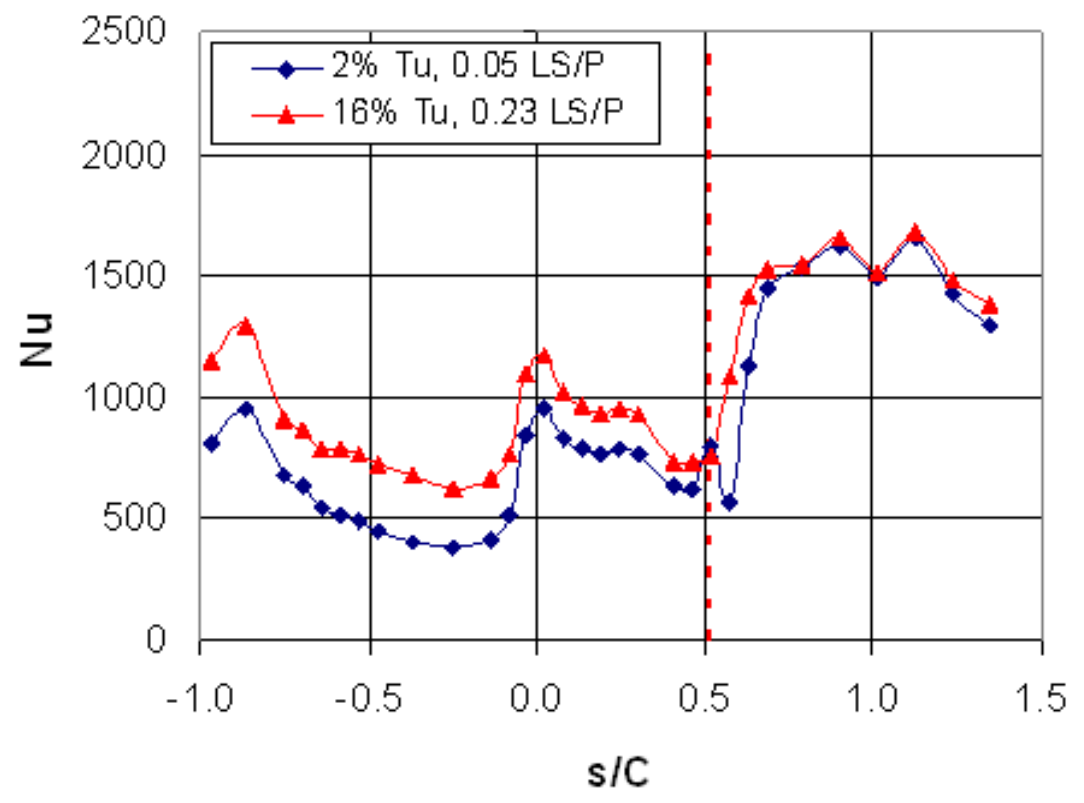

Figure 1.15. Heat transfer distribution at exit Ma 0.55 


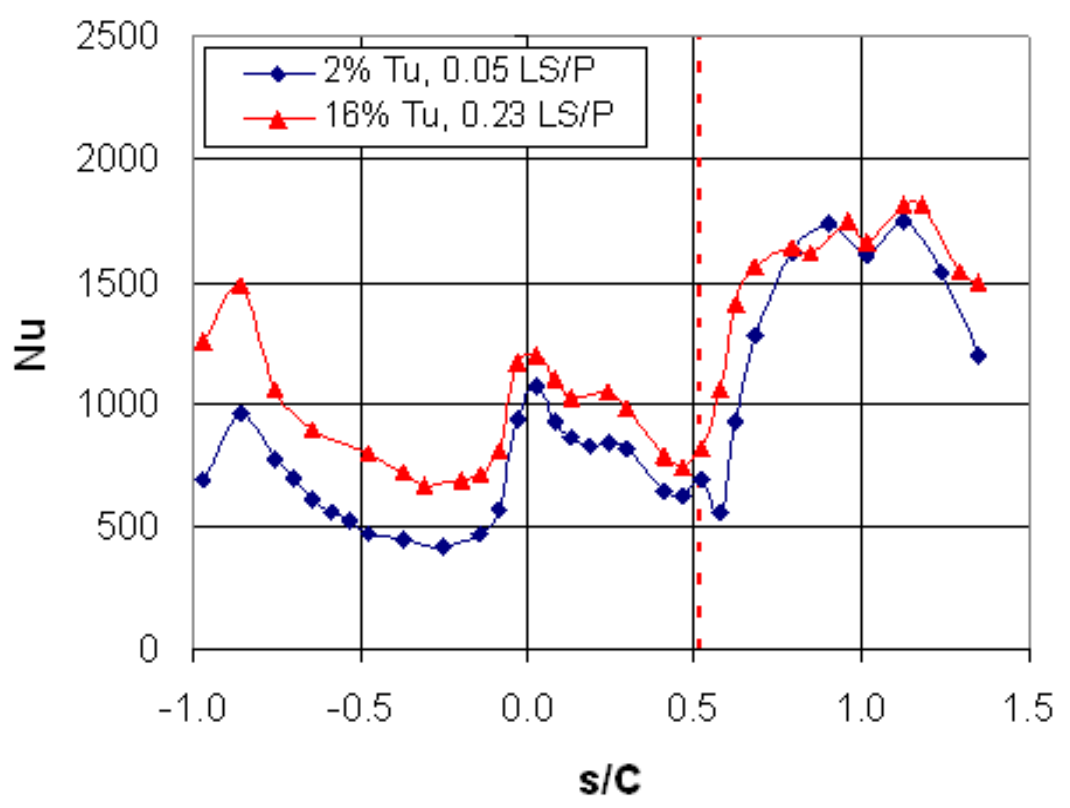

Figure 1.16. Heat transfer distribution at exit Ma 0.75

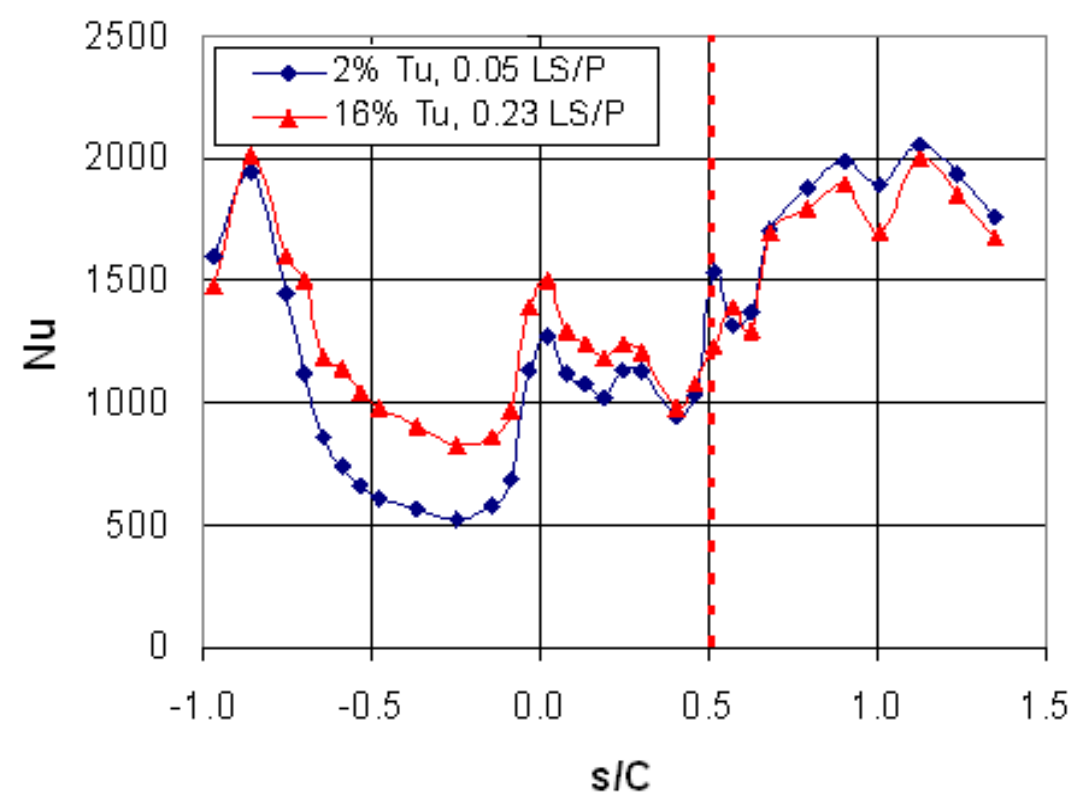

Figure 1.17. Heat transfer distribution at exit Ma 1.01

The heat transfer data at high turbulence level were also normalized with the $2 \%$ turbulence data to show the augmentation levels due to turbulence. The augmentation plots for exit Mach 0.55, 0.75, and 1.01 are shown in Figure 1.18. There is a peak in the augmentation plot on the suction side for the exit Mach 0.55 and 0.75 cases because the transition occurs slightly earlier than low freestream turbulence. Relatively higher augmentation levels can be 
seen over the majority of the pressure surface as compared to the suction surface. For instance, at exit Mach 0.75, average heat transfer augmentations of $52 \%$ and $25 \%$ were observed on the pressure and suction sides of the vane, respectively.

The heat transfer augmentation trends are similar over the majority of vane pressure surface for all exit Mach conditions. However, these augmentation plots show a change in shape at the aft end of the pressure surface. The upturn in the augmentation plot at exit Mach 0.55 and 0.75 shows a boundary layer transition behavior on the pressure surface. This upturn in the augmentation plot goes away at exit Mach 1.01, which shows that the low freestream turbulence case achieves complete boundary layer transition on the pressure surface.

In the stagnation region, relatively lower augmentation levels are observed at exit Mach 0.75 and 1.01 than for the exit Mach 0.55 case. Since the Mach number and the Reynolds number are coupled in our facility, this behavior is consistent with the stagnation region heat transfer study of Radomsky and Thole [6] that indicates very little heat transfer augmentation with increasing Reynolds number at high freestream turbulence. The augmentation levels are similar over the majority of vane suction surface for exit Mach 0.55 and 0.75 . However, at exit Mach 1.01, the augmentation level is lower in the laminar region than at exit Mach 0.55 and 0.75 . This might be due to the diminishing influence of large scale high freestream turbulence on heat transfer augmentation with increasing Reynolds number.

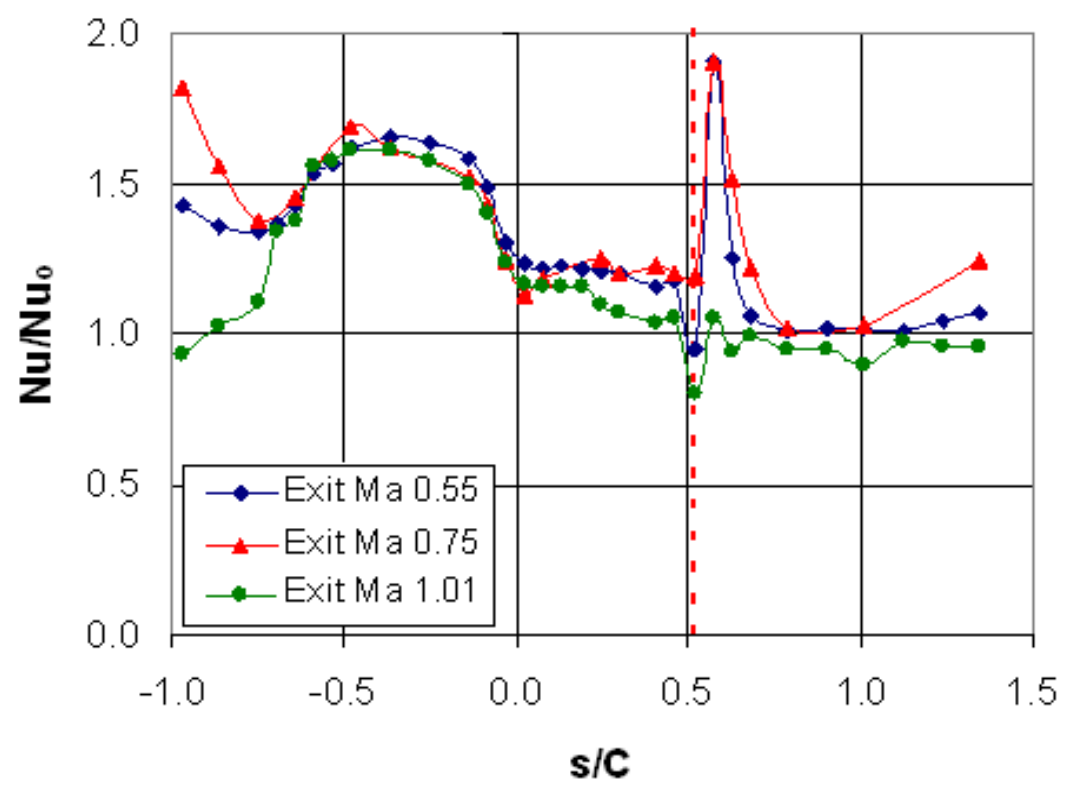

Figure 1.18. Heat transfer augmentation at all exit Ma cases 
The heat transfer data were also compared to the flat plate correlations for a laminar and turbulent boundary layer. While the flat plate correlations do not take into account the effect of pressure gradient or curvature on heat transfer, the correlations do provide insight on boundary layer behavior. The flat plate correlations reported by Incropera and DeWitt [29] in terms of the local Nusselt number are,

$$
\begin{array}{ll}
\text { Laminar: } & N u_{L}=0.332 \mathrm{Re}_{L}^{1 / 2} \cdot \operatorname{Pr}^{1 / 3} \\
\text { Turbulent: } & N u_{L}=0.0296 \mathrm{Re}_{L}^{4 / 5} \cdot \operatorname{Pr}^{1 / 3}
\end{array}
$$

The local Reynolds number given by,

$$
\operatorname{Re}_{L}=\frac{\rho_{L} \cdot U_{L} \cdot s}{\mu}
$$

was used to find the Nusselt number distribution of the correlation. Averaged pressure and temperature data taken during the test run were used to calculate the local Reynolds number. The local Nusselt number was converted into a heat transfer coefficient at each measurement location by using,

$$
h=\frac{N u_{L} \cdot k_{a}}{s}
$$

and then the Stanton number is calculated by using equation 1.4.

Figure 1.19 shows how the experimental data compares with the laminar and turbulent flat plate heat transfer correlations on the suction side of the vane at exit Mach 0.75. Before transition occurs, the boundary layer data lie between the laminar and turbulent boundary layer correlations for each case and follows the trend of laminar correlation. The difference between the laminar correlation and the low freestream turbulence data in the laminar region can be attributed to the effect of favorable pressure gradient. The augmentation due to turbulence can also be seen on the suction side. A good agreement between the turbulent flat plate correlation and the experimental data is shown for all of the data once the flow goes turbulent on the suction surface. Similar trends were also observed for the exit Mach 0.55 and 1.01 cases.

The comparison of the experimental data at exit Mach 0.75 with the laminar and turbulent flat plate correlations on the pressure side is provided in Figure 1.20. For low freestream turbulence, the data initially follow the trend of the laminar correlation and then approach the turbulent correlation towards the end of the pressure surface. At high freestream turbulence the data follow the trend of the turbulent correlation. Similar trends were also 
observed for exit Mach 0.55 and 1.01 cases. From the acceleration parameter in Figure 1.14, the acceleration parameter barely reaches the critical value over the pressure side after $\mathrm{s} / \mathrm{C}=-0.43$, so there was no evidence of boundary layer relaminarization at any exit Mach condition.

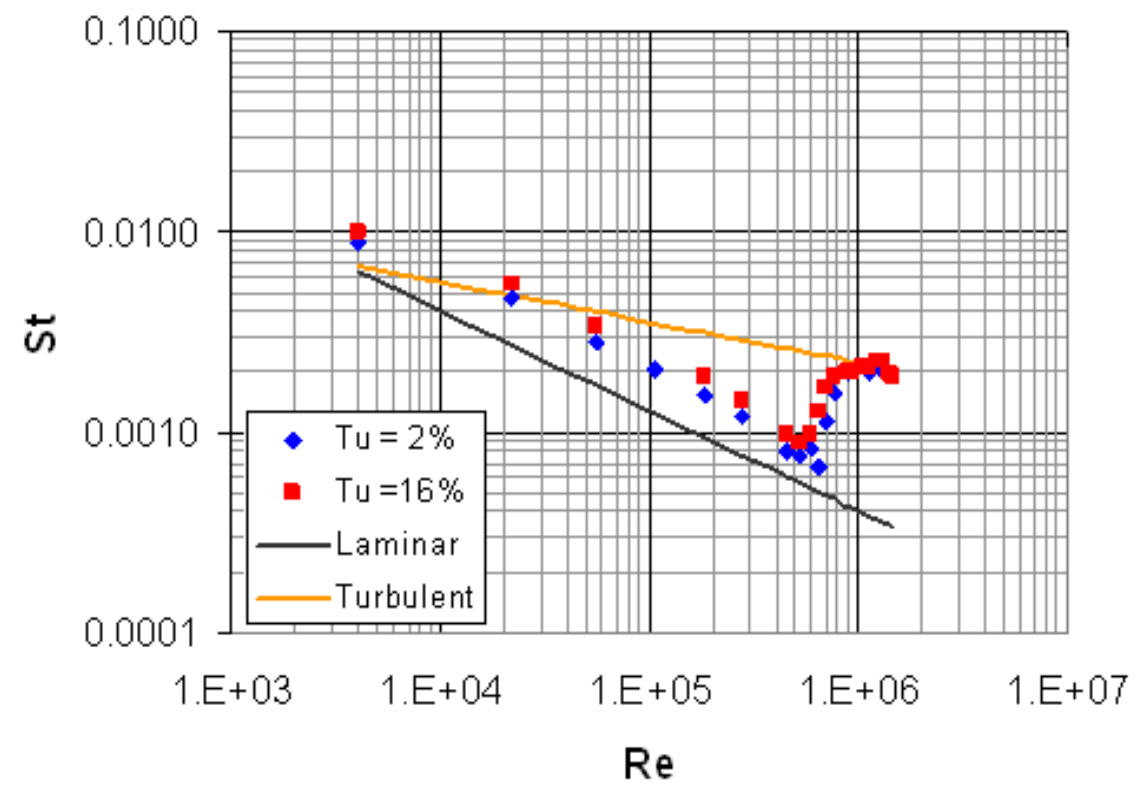

Figure 1.19. Suction side data compared to the flat plate correlations at exit Ma 0.75

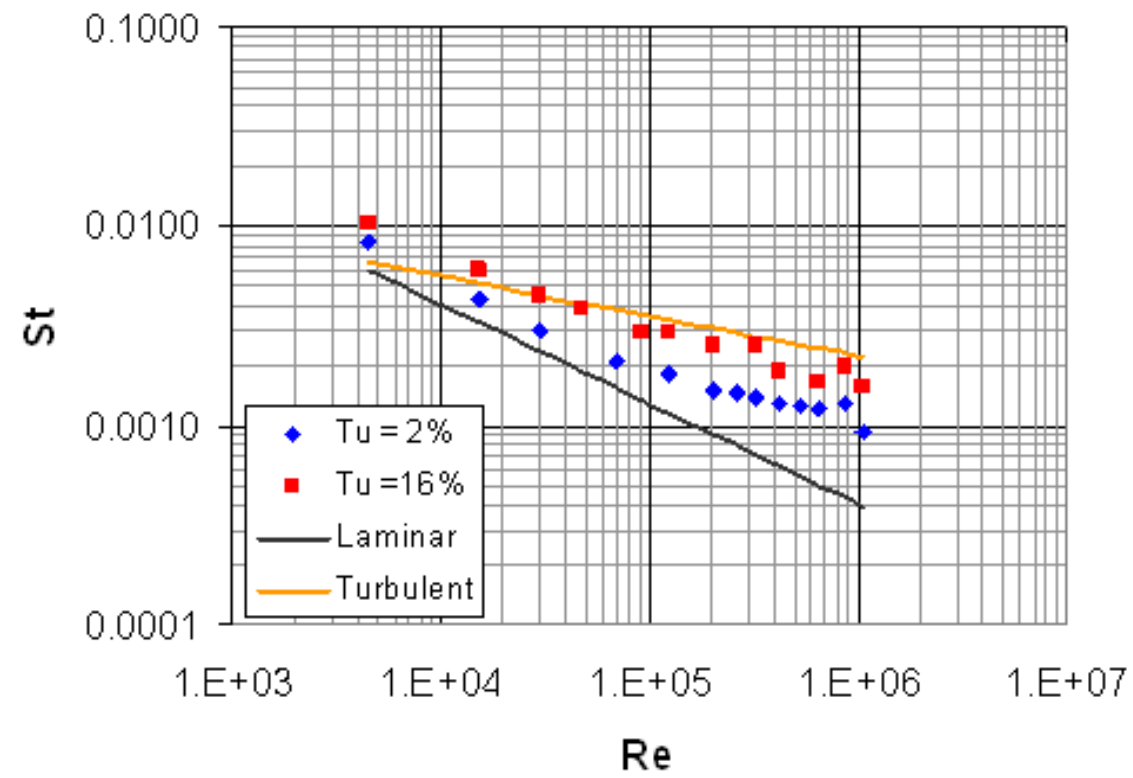

Figure 1.20. Pressure side data compared to the flat plate correlations at exit Ma 0.75 


\section{Effect of Reynolds Number}

The primary objective of this work was to examine the effect of freestream turbulence on heat transfer at three exit Mach number conditions. Because of this objective, the exit Mach number was not decoupled from the exit Reynolds number. An increase in exit Mach number corresponds to an increase in the exit Reynolds number. To remain consistent with the previous sections, the data will be compared by stating the Mach number. The actual exit Reynolds numbers measured for each test is provided in Table 1.3.

The Nusselt number distributions showing the effect of increasing the Reynolds number at turbulence levels of $2 \%$ and $16 \%$ are shown in Figures 1.21 and 1.22, respectively. As expected, there is an overall increase in heat transfer due to the increase in Reynolds number. The increase in heat transfer level is most noticeable at the highest Reynolds number (Mach 1.01). Another effect that the highest Reynolds number has on the heat transfer is to promote early boundary layer transition $(\mathrm{s} / \mathrm{C}=0.40)$ on the suction side. An earlier boundary layer transition on the suction side is observed at both turbulence levels.

On the pressure side, steeper streamwise Nusselt number gradients are observed at the highest Reynolds number. These Nusselt number gradients are more noticeable at the low freestream turbulence indicating a boundary layer transition at the aft end of the pressure side.

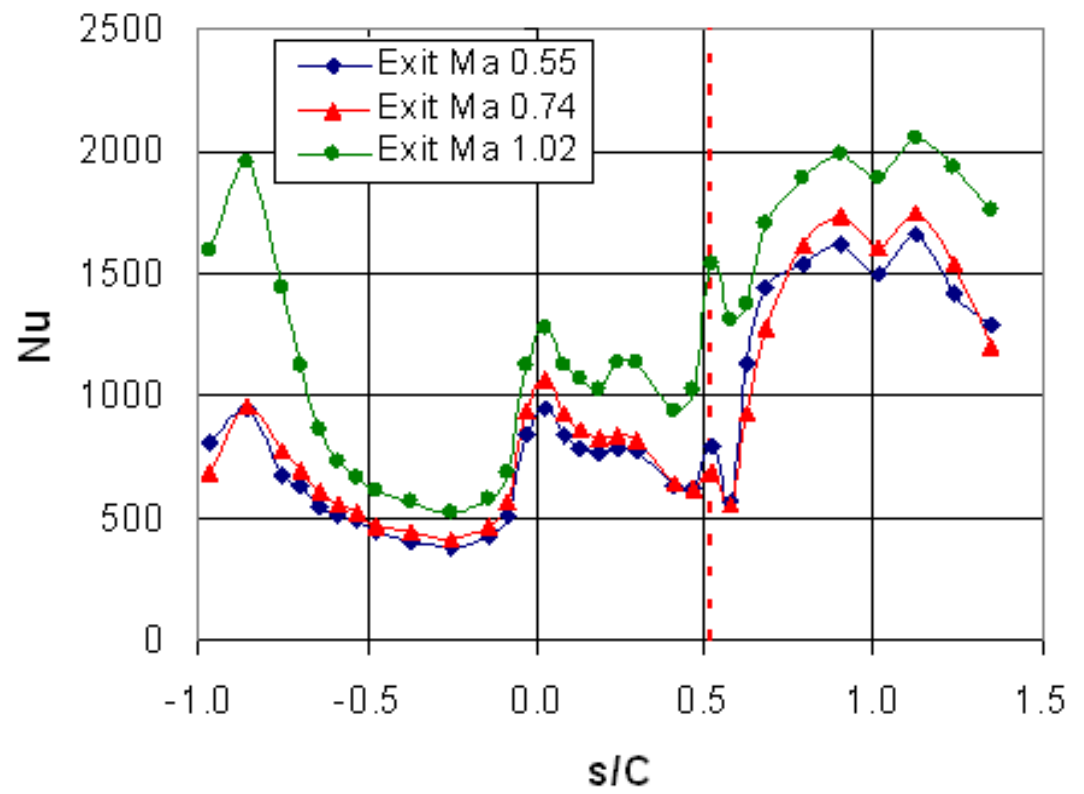

Figure 1.21. Heat transfer distribution at $\mathrm{Tu}=2 \%$ 


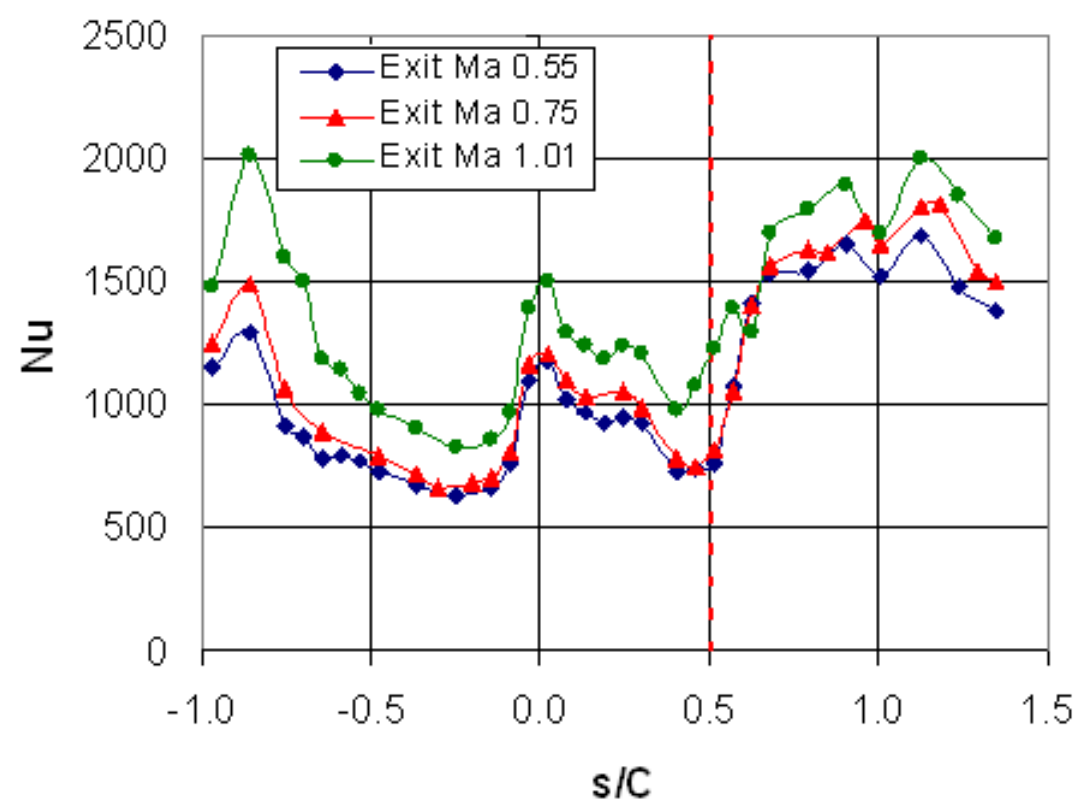

Figure 1.22. Heat transfer distribution at $\mathrm{Tu}=16 \%$

\section{Leading Edge Correlation}

The experimental data at the leading edge was compared to the correlation developed by Dullenkopf and Mayle [30]. The correlation takes into account the effects of freestream turbulence and integral length scale on stagnation region heat transfer. The correlation requires the determination of an "effective" leading edge diameter of the vane. The effective leading edge diameter of the vane is determined by fitting the velocity distribution around the suction side of the vane to a potential flow theory for a cylinder in crossflow. The correlation uses an "effective" turbulence level and also takes into account the strain rate. The effective Nusselt number is presented as a function of this effective turbulence level $T u_{\lambda}$ by,

$$
N u_{a} \operatorname{Pr}^{-0.37}=0.571+0.01 . T u_{\lambda}
$$

where

$$
N u_{a}=\frac{N u_{D}}{\sqrt{a_{1} \operatorname{Re}_{D}}}
$$

and the value of $T u_{\lambda}$ is determined by,

$$
T u_{\lambda}=\frac{T u_{a} \sqrt{L_{a}}}{\left(1+0.004 L_{a}^{2}\right)^{5 / 12}}
$$

The dimensionless length scale $L_{a}$ is given by, 


$$
L_{a}=\left(\Lambda_{x} / D\right) \sqrt{a_{1} \operatorname{Re}_{D}}
$$

and

$$
T u_{a}=T u \sqrt{a_{1} \operatorname{Re}_{D}}
$$

It must be mentioned that the dimensionless strain rate $a_{1}=4$ was used for the stagnation data. Figure 1.23 shows the comparison of current heat transfer data and the previous literature investigations with Dullenkopf and Mayle's correlation for stagnation region heat transfer. The experimental data at the leading edge compare rather well with the correlation. All of the data follow the same trend as the correlation and lies within $\pm 9 \%$ (bias error) of the correlation.

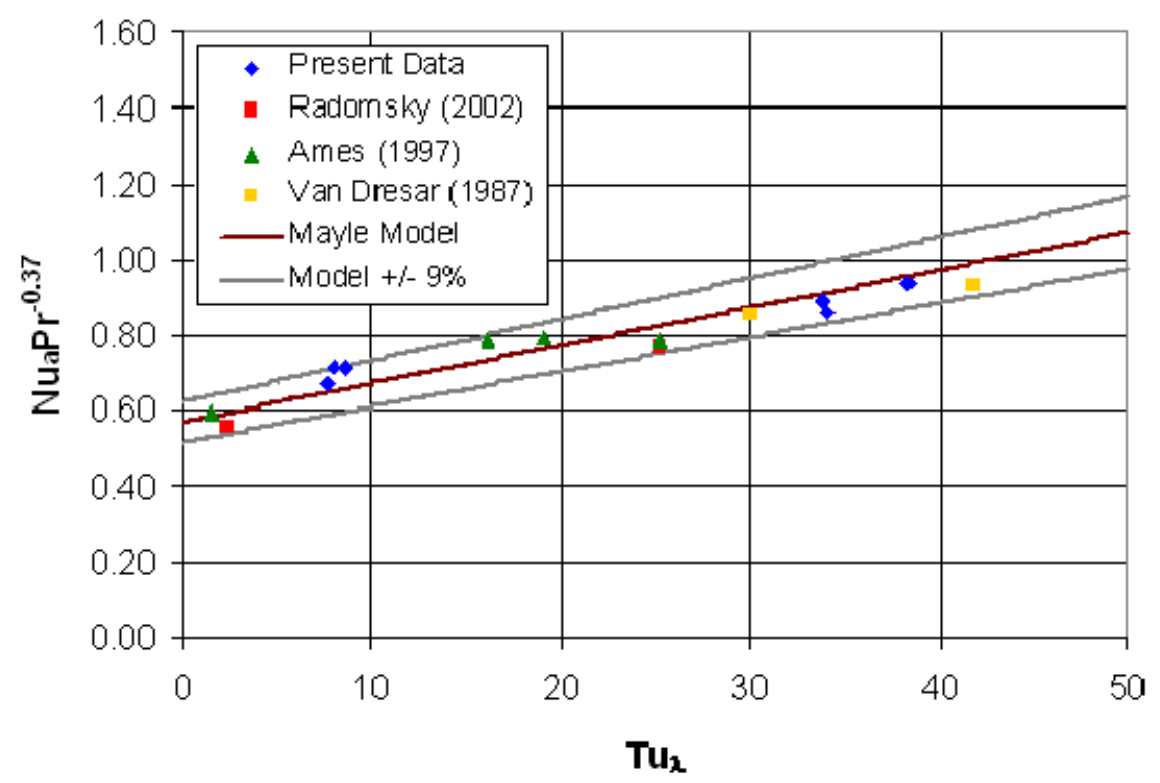

Figure 1.23. Stagnation region data compared to Dullenkopf and Mayle's correlation

\section{FLUENT and TEXSTAN Comparison}

CFD heat transfer predictions at low freestream turbulence were performed using a commercially available software package (FLUENT 6.2.6). A 2-D computational domain representing one full vane passage with periodic boundary conditions was employed to simulate the cascade test condition. The computational inlet was located at $0.45 \mathrm{C}$ upstream of the vane leading edge. For all tests cases, total pressure and total temperature were specified at the inlet and static pressure was specified at the outlet. The vane geometry was simulated with constant wall temperature boundary condition. Freestream turbulence level and length scale were also specified at the inlet for all test cases. Fluid specific heat, thermal conductivity and molecular viscosity were kept constant for all test cases. 
For the FLUENT solver, coupled implicit solution method with second-order upwind discretization scheme was chosen. The RANS based $v^{2}-f$ turbulence model, originally suggested by Durbin [32], was used in all numerical predictions. A 2-D hexahedral mesh consisted of 73300 cells and was refined near the wall to better capture the wall heat transfer as shown in Figure 1.24. This was achieved by adjusting the near-wall spacing $y^{+}$to be less than 1 . The convergence of calculation was assumed to be reached when all normalized residuals were smaller than $10^{-5}$, except energy smaller than $10^{-7}$. In general, 3000 iterations were required for full convergence.

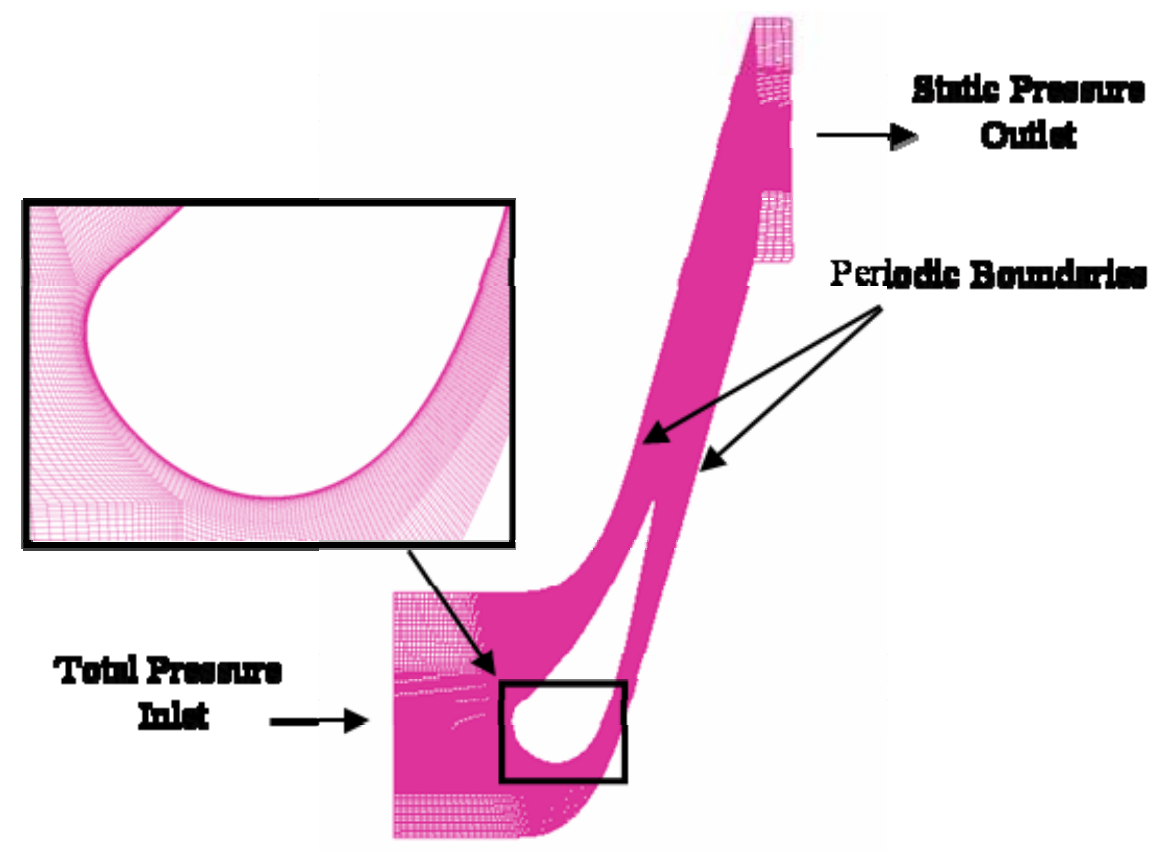

Figure 1.24. Computational domain for CFD predictions

Figure 1.25 shows the comparison of predicted and measured Mach number distributions around the vane surface for three exit Mach number conditions. Overall, the FLUENT results compare very well with the experimental data on the pressure side at all exit Mach conditions. On the suction side, the FLUENT predictions also compare well with the experimental data at exit Mach 0.6 and 0.8. For the exit Mach 1.0 case, the FLUENT prediction matches the experimental data up to $\mathrm{s} / \mathrm{C}=0.58$ but then the FLUENT model is unable to reasonably predict multi flow decelerations caused by the shock wave on suction side Mach number distribution. 


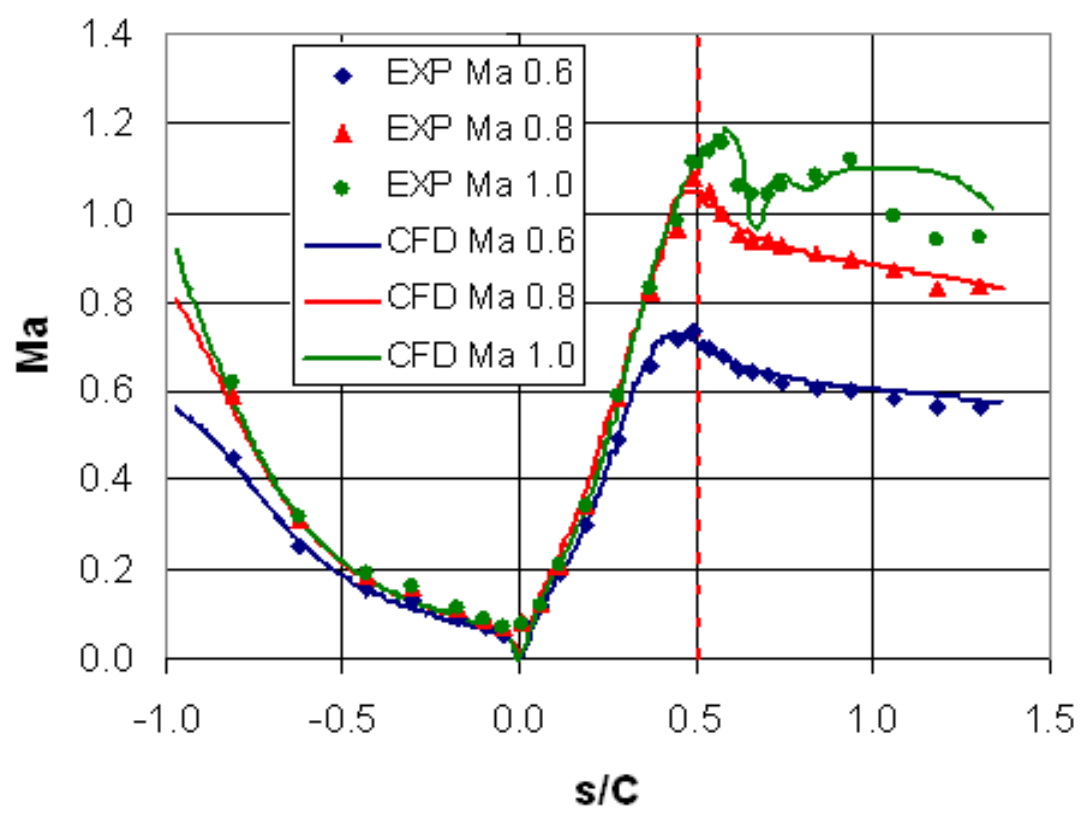

Figure 1.25. Local Mach number distribution comparison

Figures 1.26, 1.27, and 1.28 provide the comparison of measured and predicted Nusselt number distributions for low freestream turbulence level at exit Mach 0.55, 0.75, and 1.01, respectively. The $v^{2}-f$ model compares generally well over the majority of the vane pressure surface at all exit Mach conditions as observed by other authors [33-34]. The model overpredicts the heat transfer at the leading edge and in the laminar region on the suction side for the exit Mach 0.55 and 0.75 cases. The $v^{2}-f$ model also predicts an early boundary layer transition on the suction side and overpredicts the heat transfer at the end of transition for the exit Mach 0.55 and 0.75 cases. An early boundary layer prediction and overprediction of the heat transfer at the end of transition has also been observed by Luo and Razinsky [34]. At exit Mach 1.01, $v^{2}-f$ model overpredicts heat transfer at the leading edge but then underpredicts it in the region from s/C $=$ 0.25 to $\mathrm{s} / \mathrm{C}=0.5$. Also the $v^{2}-f$ model underpredicts turbulent boundary layer heat transfer on the suction and pressure sides of the vane at exit Mach 1.01.

An attempt was also made to perform FLUENT $v^{2}-f$ heat transfer predictions at high freestream turbulence level but the $v^{2}-f$ model profoundly overpredicted heat transfer at high freestream turbulence on the entire surface of the vane at all exit Mach conditions. Figure 1.29 provides the comparison of measured and predicted Nusselt number distributions for high freestream turbulence level at exit Mach 0.75 . The leading edge heat transfer is profoundly overpredicted and seems to affect the heat transfer levels on the entire surface of the vane. 
Modeling freestream turbulence eddy viscosity as a function of large length scale, proper scaling of high freestream turbulence near the wall, and developing correct models to account for the heat transfer augmentation in the leading edge region and both surfaces of the vane at high freestream turbulence is a challenging problem and requires more work.

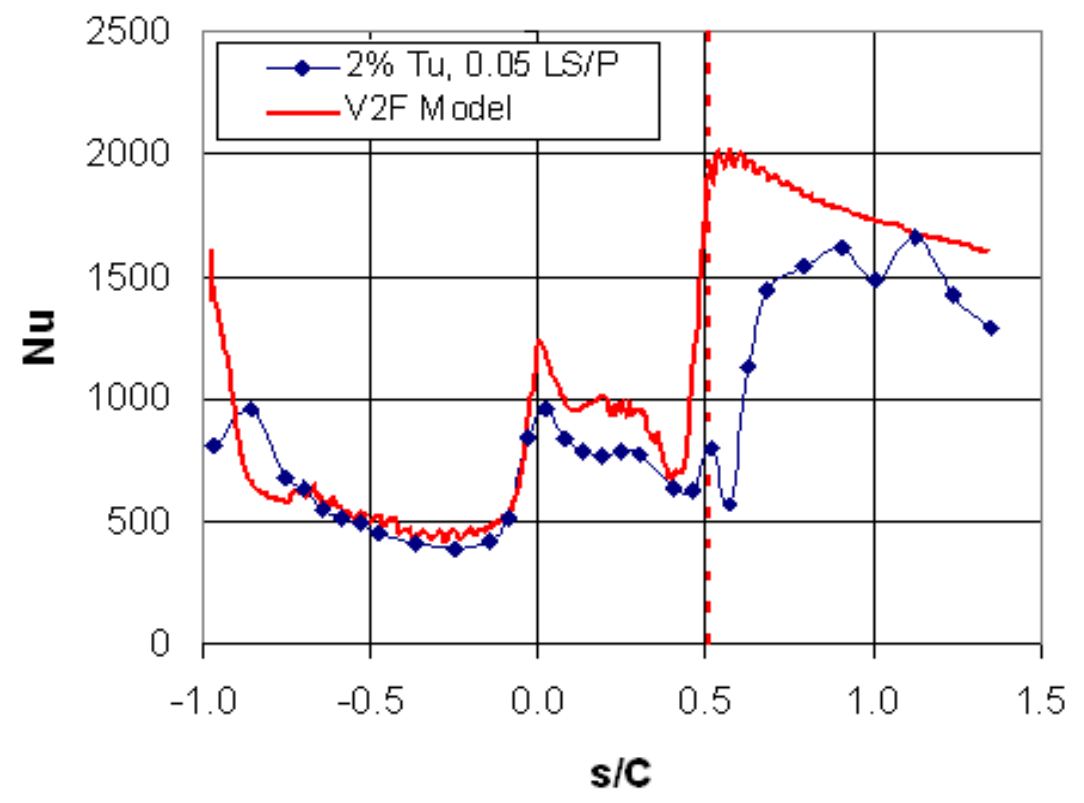

Figure 1.26. FLUENT prediction at exit Ma $0.55,2 \% \mathrm{Tu}$

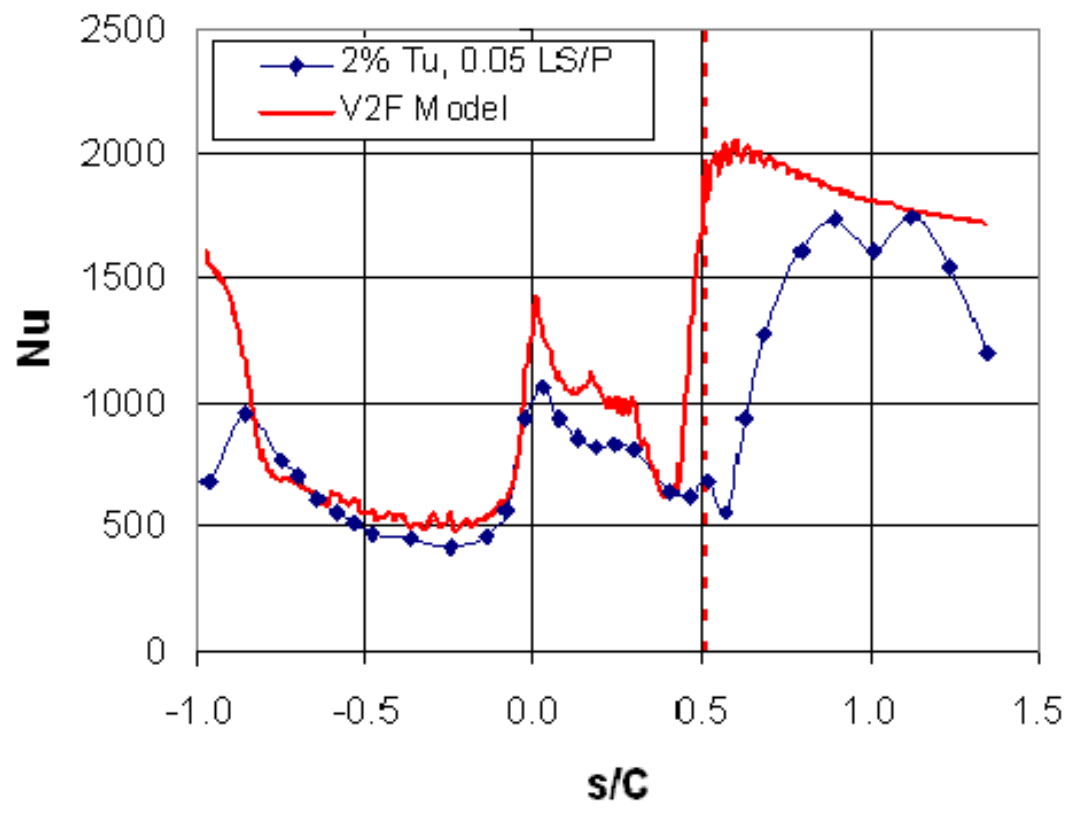

Figure 1.27. FLUENT prediction at exit Ma $0.75,2 \% \mathrm{Tu}$ 


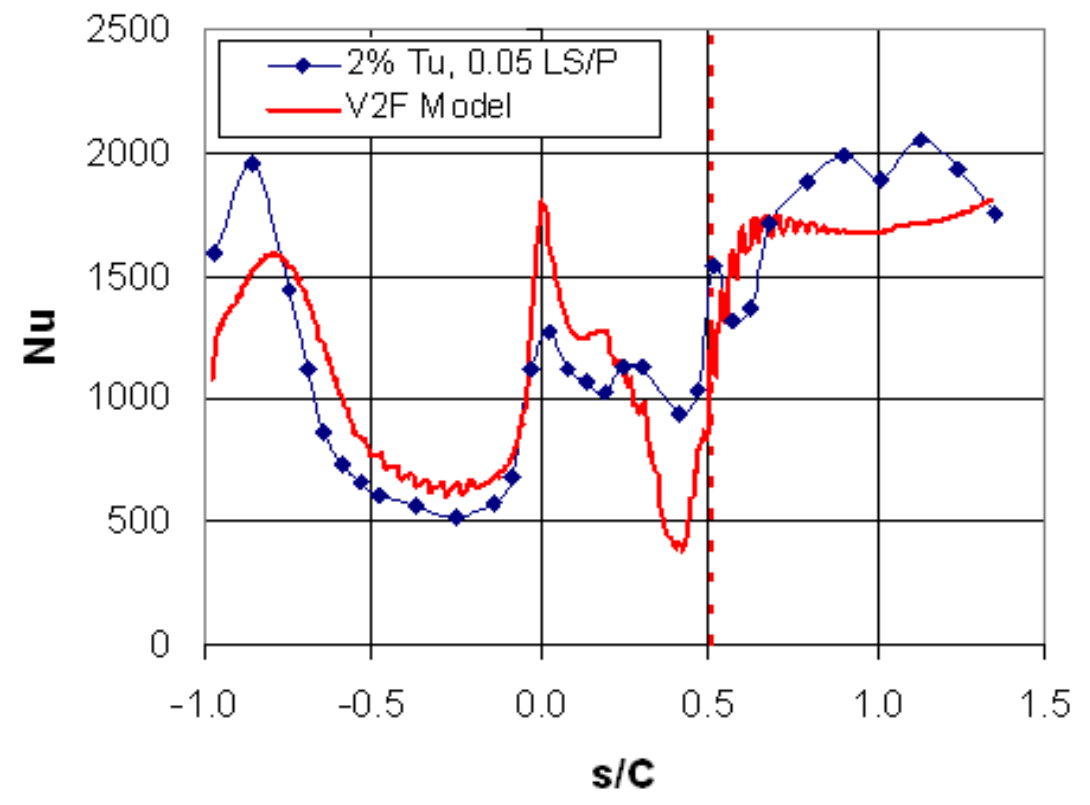

Figure 1.28. FLUENT prediction at exit Ma 1.01, $2 \% \mathrm{Tu}$

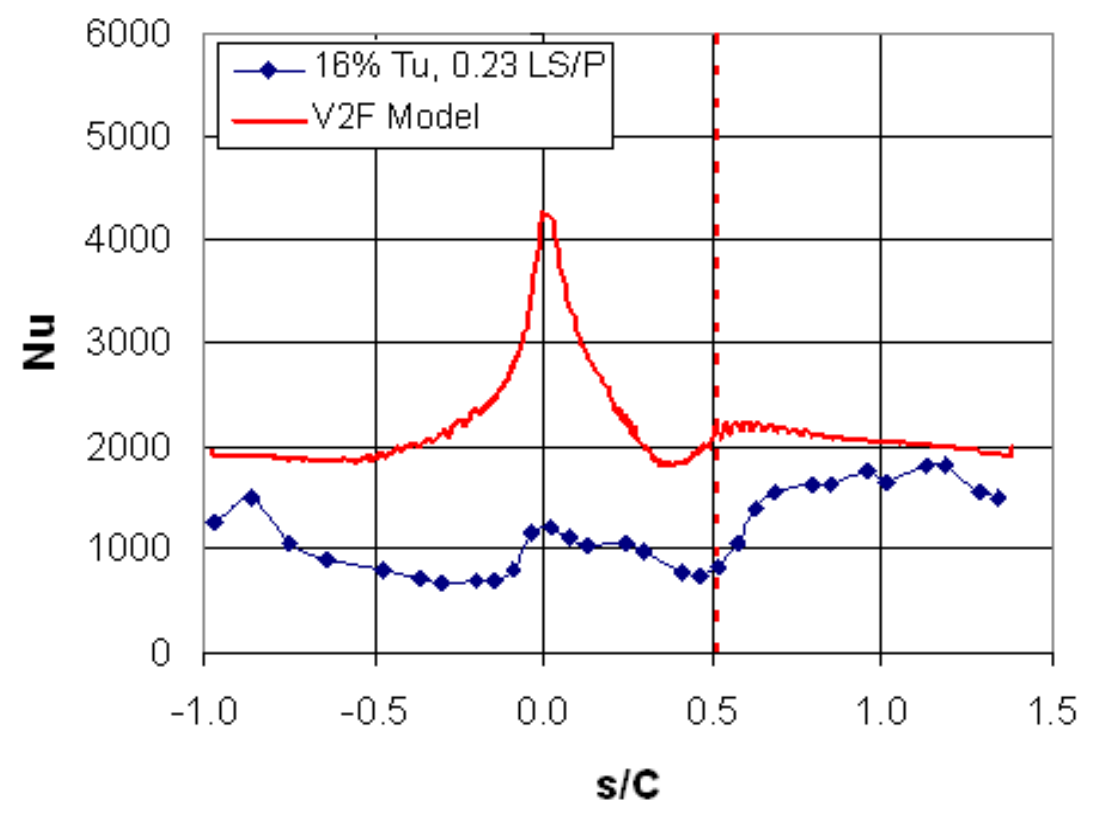

Figure 1.29. FLUENT prediction at exit Ma $0.75,16 \% \mathrm{Tu}$

The experimental data was also compared with the numerical predictions of academic version of TEXSTAN developed by Crawford [35]. To model the flow through the vane passages, the two-equation Lam-Bremhorst turbulence model was used with the SchmidtPatankar transition model. A constant surface temperature boundary condition was applied to the vane and the constant freestream turbulence kinetic energy was set throughout the computational domain by freezing the turbulence dissipation rate. 
At low freestream turbulence, the TEXSTAN predictions match well with the experimental data at all exit Mach conditions on the pressure side till $\mathrm{s} / \mathrm{C}=-0.53$ but then starts deviating from the measurements as shown in Figures 1.30, 1.31, and 1.32. On the suction side, the predictions match well with the data in the laminar region downstream of the leading edge but the above mentioned turbulence and transition models did not predict boundary layer transition. For the low freestream turbulence case at all exit Mach conditions only, the TEXSTAN was forced to transition at the location where the experimental data indicated transition by using an abrupt transition model.

At high freestream turbulence, TEXSTAN overpredicted the heat transfer on both the pressure and suction sides of the vane at all exit Mach conditions as shown in Figures 1.33, 1.34, and 1.35. The leading edge heat transfer is also overpredicted at all exit Mach conditions. However, the suction side predictions show similar trend in the laminar region with the data only coming close to the prediction after the transition. The pressure side predictions at all exit Mach conditions also show a similar trend with the data coming close to prediction at the aft end of the pressure surface.

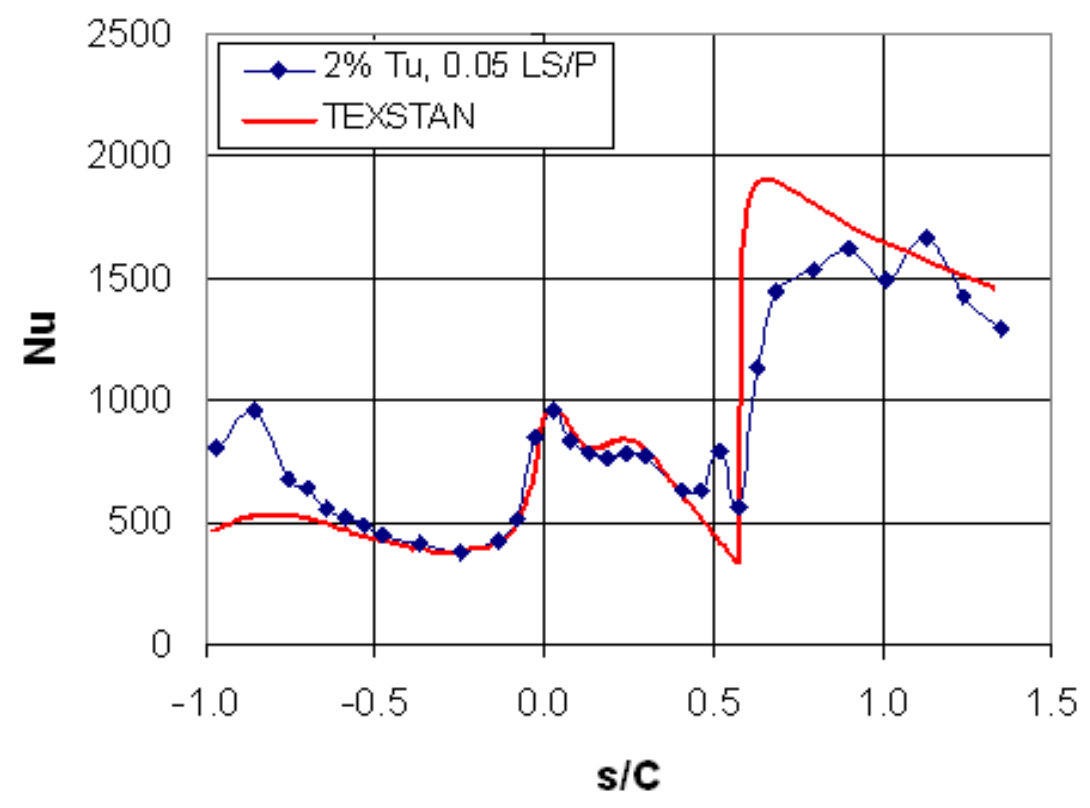

Figure 1.30. TEXSTAN prediction at exit Ma $0.55,2 \% \mathrm{Tu}$ 


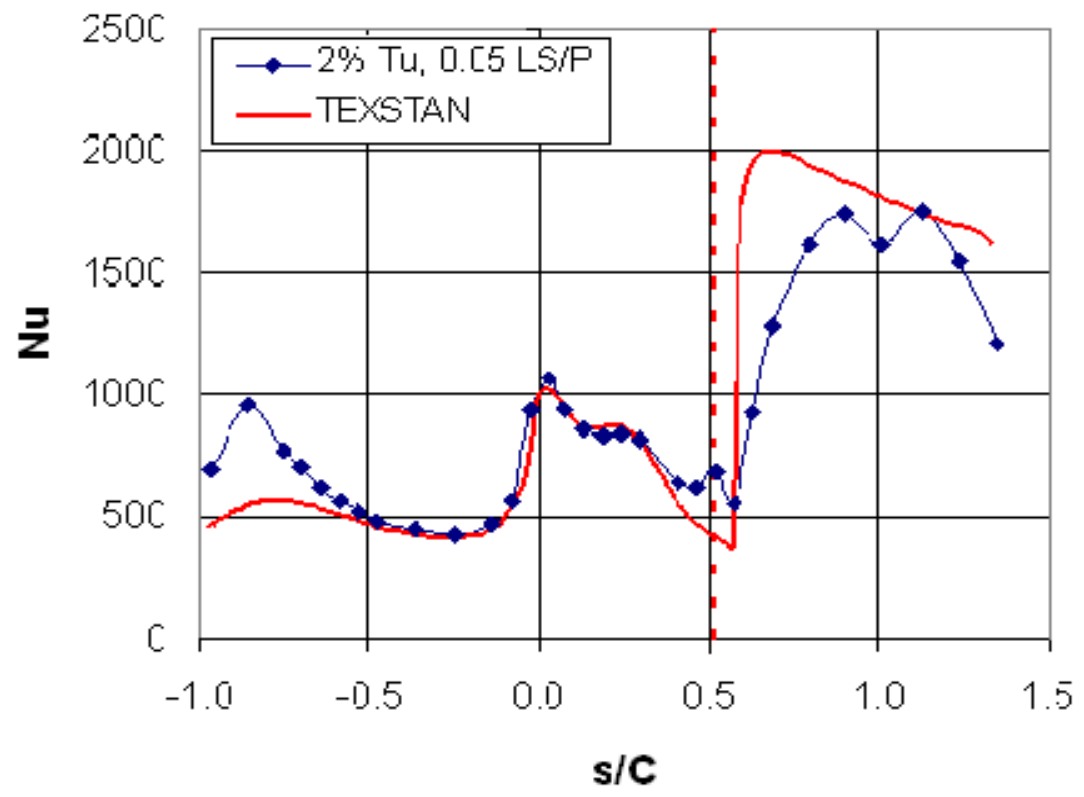

Figure 1.31. TEXSTAN prediction at exit Ma $0.75,2 \% \mathrm{Tu}$

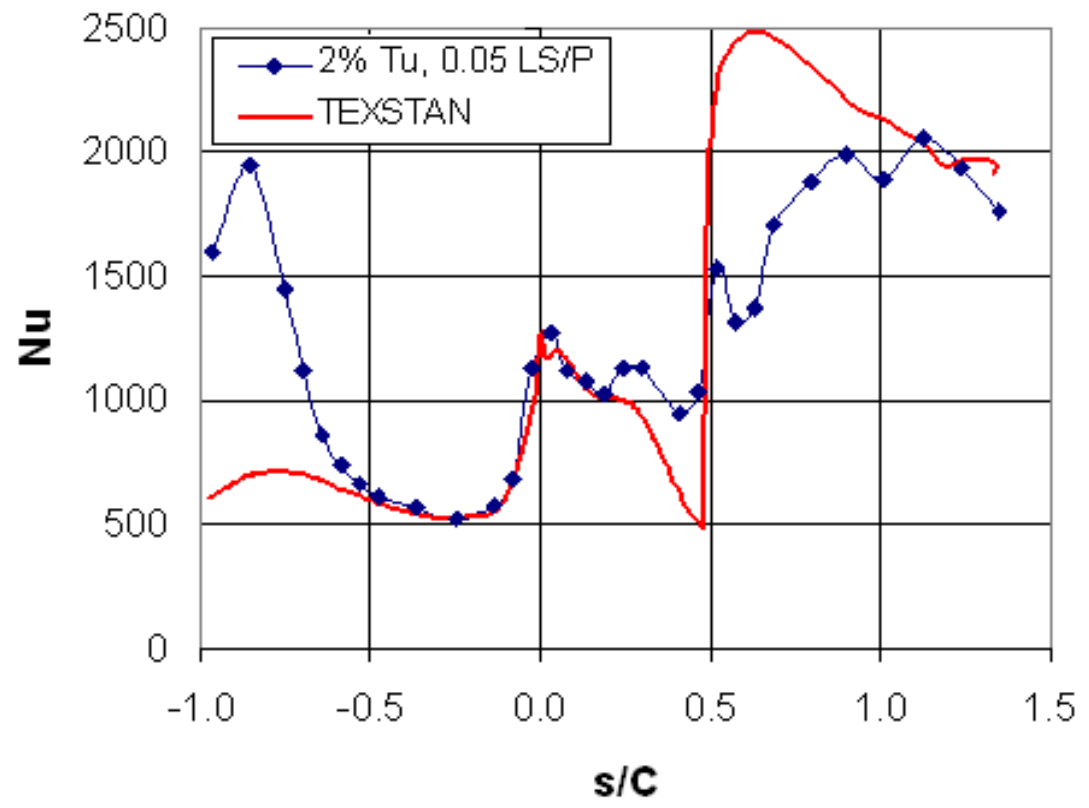

Figure 1.32. TEXSTAN prediction at exit Ma 1.01, 2\% Tu 


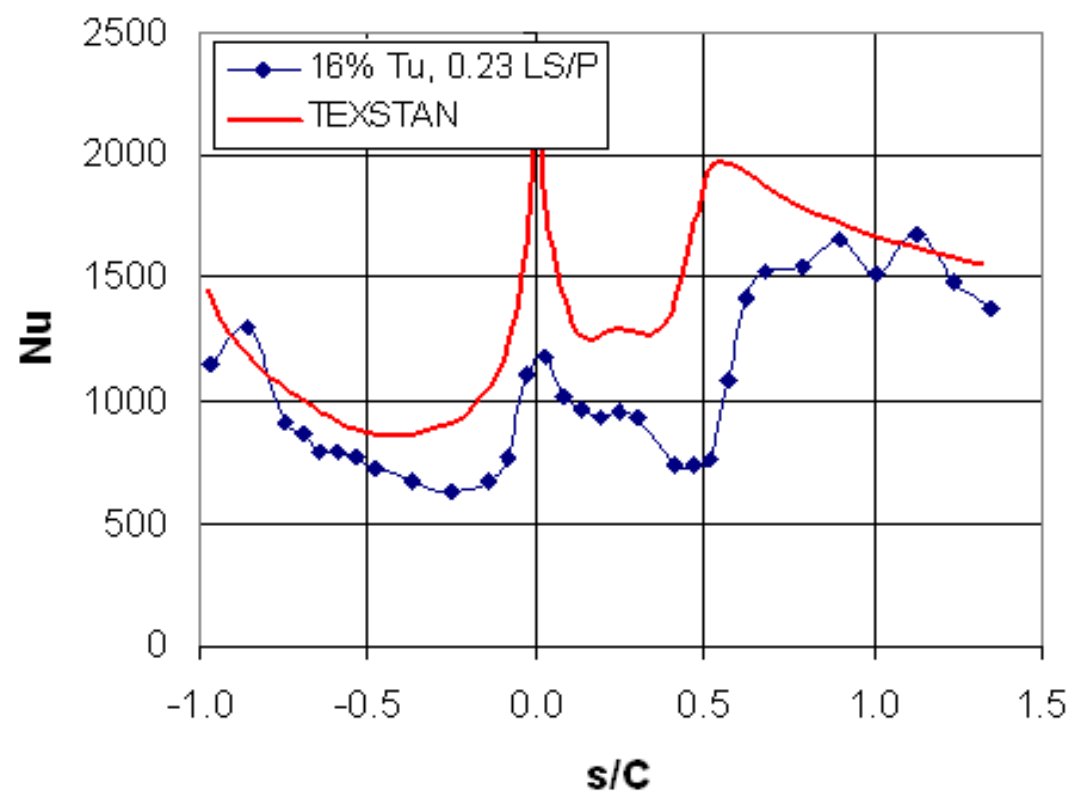

Figure 1.33. TEXSTAN prediction at exit Ma $0.55,16 \% \mathrm{Tu}$

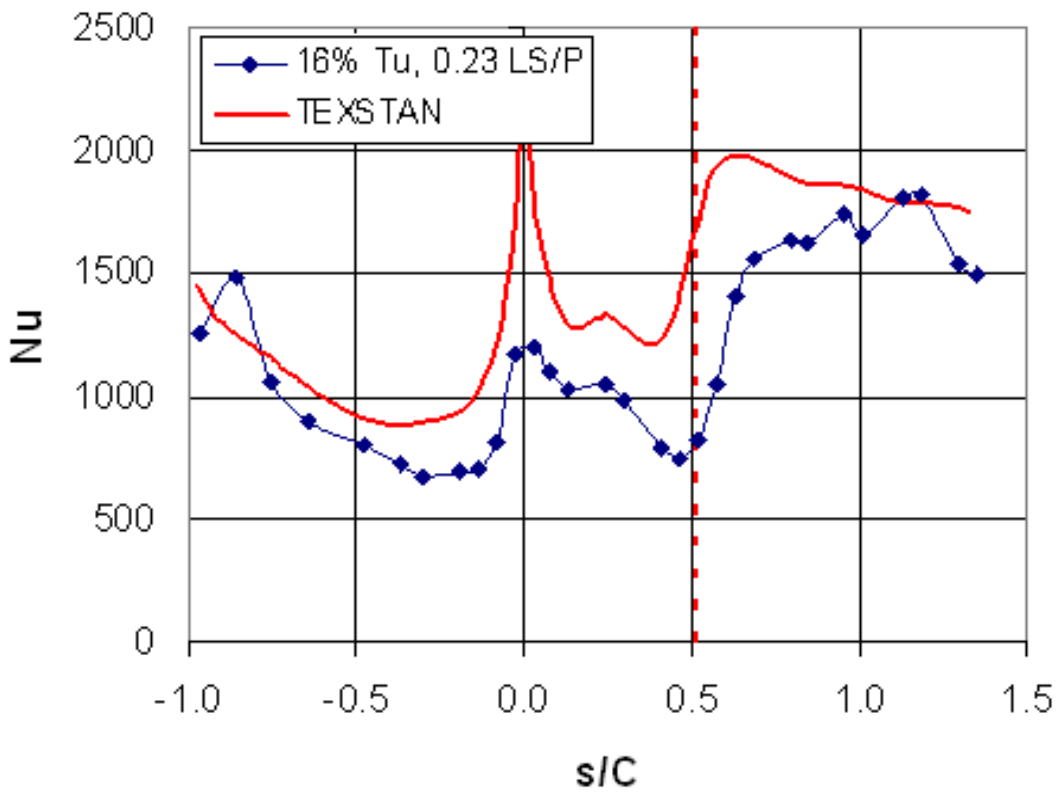

Figure 1.34. TEXSTAN prediction at exit Ma $0.75,16 \% \mathrm{Tu}$ 


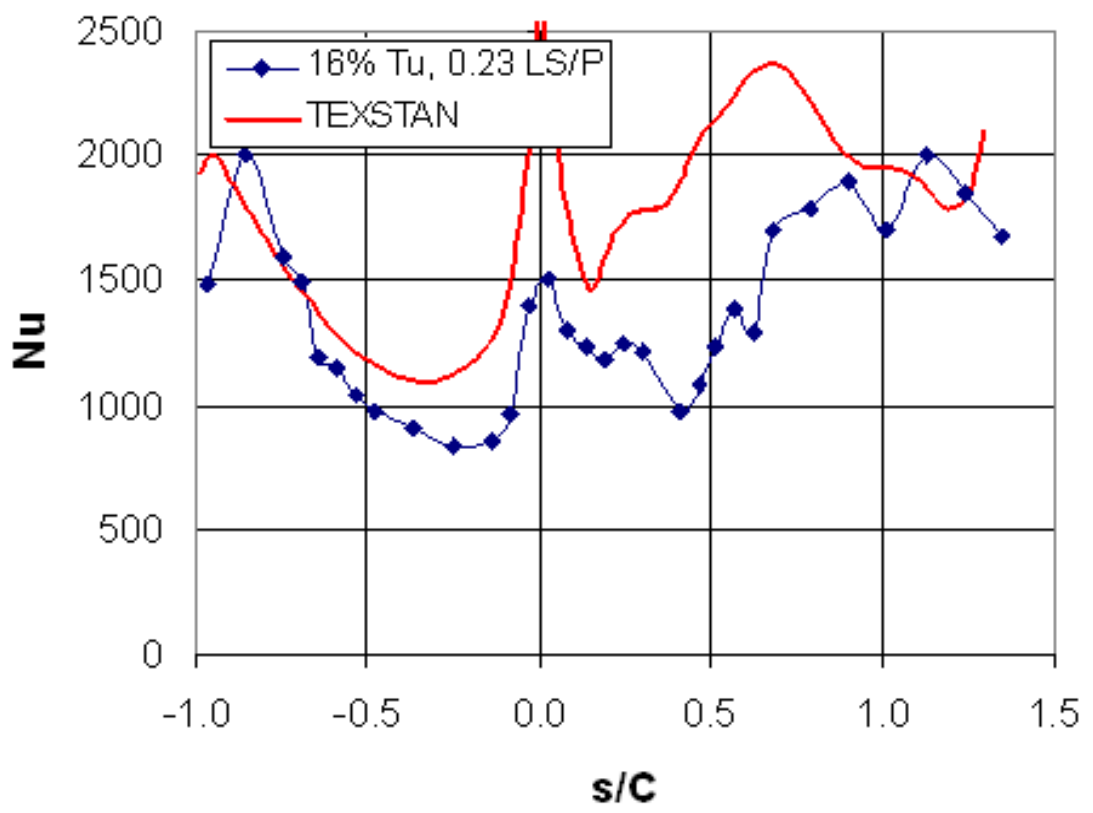

Figure 1.35. TEXSTAN prediction at exit Ma $1.01,16 \% \mathrm{Tu}$

\section{Conclusions}

Aerodynamic and heat transfer measurements were made on a turbine vane at flow conditions representative of engine operating conditions. Large scale high free stream turbulence was generated by using a passive turbulence grid. Increasing the turbulence level was observed to augment the heat transfer over the vane surface.

Relatively higher augmentation levels were seen over the majority of the pressure surface as compared to the suction surface for all exit Mach conditions. High freestream turbulence hastened boundary layer transition on the suction side for the exit Mach 0.55 and 0.75 cases. For the exit Mach 1.01 case, the turbulence augmentation was small on the suction surface as compared to the exit Mach 0.55 and 0.75 cases. Also for exit Mach 1.01 case, increasing the freestream turbulence was observed to not influence the location of boundary layer transition on the suction surface.

As expected, increasing the exit Reynolds number was shown to increase the heat transfer levels and cause earlier boundary layer transition on the suction side for the highest Reynolds number $\left(1.5 \times 10^{6}\right)$. On the pressure side, steeper streamwise Nusselt number gradients were observed at the highest Reynolds number. These Nusselt number gradients were more noticeable 
at the low freestream turbulence indicating a boundary layer transition to turbulent flow at the aft end of the pressure side.

Several comparisons were made between the data using the analytical flat plate correlations, leading edge correlation developed by Dullenkopf and Mayle [30], FLUENT $v^{2}-f$ model and TEXSTAN predictions. The heat transfer data showed good agreement with flat plate and leading edge correlations. The $v^{2}-f$ model and TEXSTAN resulted in overall reasonable prediction of the heat transfer at low freestream turbulence levels. At high freestream turbulence, FLUENT $v^{2}-f$ model and TEXSTAN was found to significantly overpredict the heat transfer levels on the vane surface.

\section{Acknowledgements}

This work was sponsored by Solar Turbines Inc. We would also like to express our gratitude to Dr. Richard Anthony and Dr. Marcus Polanka of the Air Force Research Laboratory, Wright-Patterson AFB for their help with manufacturing and implementation of the thin film gauges.

\section{References}

[1] Zimmermann, D. R., 1979, "Laser anemometer measurements at the exit of a T63-C20 combustor," NASA CR-159623.

[2] Van Fossen, G. J. and Bunker, R. S., 2001 "Augmentation of stagnation heat transfer due to turbulence from a DLN can combustor,” ASME J. Turbomach., 123, pp. 140-146.

[3] Ames, F.E., Wang, C., and Barbot, P.A., 2003, "Measurement and Prediction of the Influence of Catalytic and Dry Low NOx Combustor Turbulence on Vane Surface Heat Transfer," ASME J. Turbomach., 125, pp. 221-231.

[4] Ames, F.E., 1997, "The Influence of Large-Scale High Intensity Turbulence on Vane Heat Transfer," ASME J. Turbomach., 119, pp. 23-30.

[5] Ames, F.E., Argenziano, M., and Wang, C., 2004, "Measurement and Prediction of Heat Transfer Distributions on an Aft Loaded Vane Subjected to the Influence of Catalytic and Dry Low NOx Combustor Turbulence," ASME J. Turbomach., 126, pp. 139-149. 
[6] Radomsky, R., and Thole, K.A., 2002, "Detailed Boundary Layer Measurements on a Turbine Stator Vane at Elevated Freestream Turbulence Levels," ASME J. Turbomach., 124, pp. 107-118.

[7] Nealy, D.A., Mihelc, M.S., Hylton, L.D., and Gladden, H.J, 1990, "Measurements of Heat Transfer Distribution Over the Surfaces of Highly Loaded Turbine Nozzle Guide Vanes," ASME J. Eng for Gas Turbine and Power, 106, pp. 149-158.

[8] Arts, T., Lambert de Rouvroit, M., 1992, “Aero-Thermal Performance Measurements and Analysis of a Two-Dimensional Highly Loaded Transonic Turbine Nozzle Guide Vane: A Test Case for Inviscid and Viscous Flow Computations," ASME J. Turbomach., 114, pp. 147-154.

[9] Hoffs, A., Drost, U. and Bolcs, A., 1996, "Heat Transfer Measurements on a Turbine Airfoil at Various Reynolds Numbers and Turbulence Intensities Including Effects of Surface Roughness," ASME GT-1996-169.

[10] Bunker, R.S., 1997, "Separate and Combined Effects of Surface Roughness and Turbulence Intensity on Vane Heat Transfer," ASME GT-1997-135.

[11] Carullo, J.S., Nasir, S., Cress, R.D., Ng, W.F., Thole, K.A., Zhang, L.J., and Moon, H.K., 2007, "The Effects of Freestream Turbulence, Turbulence Length Scale, and Exit Reynolds Number on Turbine Blade Heat Transfer in a Transonic Cascade," ASME GT-2007-27859.

[12] Nix, A.C., Diller, T.E., and Ng, W.F., 2007, "Experimental Measurements and Modeling of the Effects of Large-Scale Freestream Turbulence on Heat Transfer," ASME J. Turbomach., 129, pp. 542-550.

[13] Holmberg, D.G., and Diller, T.E., 2005, "Simultaneous Heat Flux and Velocity Measurements in a Transonic Turbine Cascade," ASME J. Turbomach., 127, pp. 502-506.

[14] Smith, D.E., Bubb, J.V., Popp, O., Grabowski, H.C., Diller, T.E. Schetz, J.A. and Ng. W.F., 2000, "An Investigation of Heat Transfer in a Film Cooled Transonic Turbine Cascade, Part I: Steady Heat Transfer," ASME GT-2000-202.

[15] Popp, O., Smith, D.E., Bubb, J.V., Grabowski, H.C., Diller, T.E. Schetz, J.A. and Ng. W.F., 2000, "An Investigation of Heat Transfer in a Film Cooled Transonic Turbine Cascade, Part II: Unsteady Heat Transfer,” ASME GT-2000-203.

[16] Schultz, D.L., and Jones, T.V., 1973, "Heat Transfer Measurements in Short Duration Hypersonic Facilities," AGARD AG-165.

[17] Doorly, J.E., and Oldfield, M.L.G., 1987, "The Theory of Advanced Multi-Layer Thin Film Heat Transfer Gages," Intl. J. Heat and Mass Transfer, 30, pp. 1159-1168.

[18] Dunn, M.G., 1995, “The Thin-Film Gauge," Von Karman Institute for Fluid Dynamics, Lecture Series 1995-01. 
[19] Joe, C.R., 1997, "Unsteady Heat Transfer on the Turbine Research Facility at Wright Laboratory," Ph.D. Thesis, Syracuse University.

[20] Cress, R.D., 2006, “Turbine Blade Heat Transfer Measurements in a Transonic Flow Using Thin Film Gages," MS Thesis, Virginia Polytechnic Institute and State University.

[21] Moffat, R. J., 1988, "Describing Uncertainties in Experimental Results," Exp. Thermal and Fluid Science, 1, pp. 3-17.

[22] Baines, W.D. and Peterson, E.G., 1951, "An Investigation of Flow Through Screens," Trans. of the ASME, 73, pp. 467-480.

[23] Nix, A.C., Smith, A.C., Diller, T.E., Ng, W.F. and Thole, K.A., 2002, "High Intensity, Large Length-Scale Freestream Turbulence Generation in a Transonic Turbine Cascade," ASME GT-2002-30523.

[24] Jones, W.P., and Launder, B. E., 1972, "The Prediction of Laminarization with a TwoEquation Model of Turbulence," Intl. J. Heat and Mass Transfer, 15, pp. 301-314.

[25] Mayle, R.E., 1991, "The Role of Laminar-Turbulent Transition in Gas Turbine Engines," ASME J. Turbomach., 113, pp. 509-537.

[26] Zhang, J., and Han, J.-C., 1994, "Influence of Mainstream Turbulence on Heat Transfer Coefficient from a Gas Turbine Blade," ASME J. Heat Transfer, 116, pp. 896-903.

[27] Ames, F.E., and Moffat, R.J., 1990, "Heat Transfer with High Intensity, Large Scale Turbulence: The Flat Plate Turbulent Boundary Layer and the Cylindrical Stagnation Point" Report No. HMT-44, Thermosciences Division of Mechanical Engineering, Stanford University, Stanford, CA.

[28] Thole, K.A. and Bogard, D.G., 1995, "Enhanced Heat Transfer and Skin Friction due to High Freestream Turbulence,” ASME J. Turbomach., 117, pp. 418-424.

[29] Incropera, F.P. and DeWitt, D.P., 2002, Fundamentals of Heat and Mass Transfer, 5th Ed., John Wiley and Sons, New York.

[30] Dullenkopf, K., and Mayle, R.E., 1995, “An Account of Free-Stream-Turbulence Length Scale on Laminar Heat Transfer," ASME J. Turbomach., 117, pp. 401-406.

[31] Van Dresar, N.T., and Mayle, R.E., 1989, “A Quasi-Steady Approach to Leading Edge Heat Transfer Rates," ASME J. Turbomach., 111, pp. 483-490.

[32] Durbin, P., 1991, "Near-Wall Turbulence Closure Modeling Without "damping functions"," Theor. Comput. Fluid Dyn., 3, pp. 1-13. 
[33] Pecnik, R., Pieringer, P., and Sanz, W., 2005, "Numerical Investigation of the Secondary Flow of a Transonic Turbine Stage Using Various Turbulence Closures," ASME GT-200568754 .

[34] Luo, J., and Razinsky, E.H., 2007, "Conjugate Heat Transfer Analysis of a Cooled Turbine Vane Using the v2-f Turbulence Model," ASME J. Turbomach., 129, pp. 773-781.

[35] Crawford, M.E., 1986, "Simulation Codes for Calculation of Heat Transfer to ConvectivelyCooled Turbine Blades," A Set of 4 lectures in Convective Heat Transfer and Film Cooling in Turbomachinery, VKI Lecture Series 1986-06. 


\section{Preface Paper 2}

Paper 2 experimentally investigates the effect of blowing ratio and exit Reynolds number/Mach number on the film cooling performance of a showerhead film cooled first stage turbine vane. The paper has been submitted to ASME IMECE 2008 (IMECE-2008-66528) and will also be submitted to ASME Journal of Turbomachinery. For more details regarding this paper, please refer to Appendices A-E, and $\mathrm{H}$. 


\title{
Showerhead Film Cooling Performance of Turbine Vane at High Freestream Turbulence in a Transonic Cascade
}

\author{
S. Nasir, T. Bolchoz, and W.F. Ng \\ Mechanical Engineering Department \\ Virginia Polytechnic Institute and State University \\ Blacksburg, VA 24061 \\ L.J. Zhang and H.K. Moon \\ Solar Turbines Inc. \\ San Diego, CA 92101 \\ R.J. Anthony \\ Propulsion Directorate \\ Air Force Research Laboratory \\ Wright-Patterson AFB, OH 45433 \\ IMECE Paper 2008-66528 \\ To be submitted to the Journal of Turbomachinery
}

\begin{abstract}
This paper experimentally investigates the effect of blowing ratio and exit Reynolds number/Mach number on the film cooling performance of a showerhead film cooled first stage turbine vane. The vane midspan was instrumented with single-sided platinum thin film gauges to experimentally characterize the Nusselt number and film cooling effectiveness distributions over the surface. The vane was arranged in a two-dimensional, linear cascade in a heated, transonic, blow-down wind tunnel. Three different exit Mach numbers of $\mathrm{M}_{\mathrm{ex}}=0.57,0.76$ and 1.0corresponding to exit Reynolds numbers based on vane chord of $9.7 \times 10^{5}, 1.1 \times 10^{6}$ and $1.5 \mathrm{x}$ $10^{6}$, respectively-were tested with an inlet free stream turbulence intensity $(\mathrm{Tu})$ of $16 \%$ and an integral length scale normalized by vane pitch $\left(\Lambda_{\mathrm{x}} / \mathrm{P}\right)$ of 0.23 . A showerhead cooling scheme with five rows of cooling holes was tested at blowing ratios of $\mathrm{BR}=0,1.5,2.0$, and 2.5 and a density ratio of $\mathrm{DR}=1.3$. Nusselt number and adiabatic film cooling effectiveness distributions
\end{abstract}


were presented on the vane surface over a range of $\mathrm{s} / \mathrm{C}=-0.58$ on the pressure side to $\mathrm{s} / \mathrm{C}=0.72$ on the suction side of the vane.

The primary effects of coolant injection were to augment Nusselt number and reduce adiabatic wall temperature downstream of the injection on the vane surface as compared to no film injection case $(\mathrm{BR}=0)$ at all exit Mach number conditions. In general, an increase in blowing ratio $(\mathrm{BR}=1.5$ to 2.5$)$ showed noticeable Nusselt number augmentation on pressure surface as compared to suction surface at exit Mach 0.57 and 0.75 ; however, Nusselt number augmentation for these blowing ratios was found to be negligible on the vane surface for exit Mach 1.0 case. At exit Mach 1.0, an increase in blowing ratio $(\mathrm{BR}=1.5$ to 2.5$)$ was observed to have an adverse effect on adiabatic effectiveness on the pressure surface but had negligible effect on suction surface. The effectiveness trend on the suction surface was also found to be influenced by a favorable pressure gradient due to Mach number in the region $\mathrm{s} / \mathrm{C}=0.28$ to $\mathrm{s} / \mathrm{C}=$ 0.45 at all blowing ratio and exit Mach number conditions. An increase in Reynolds number from exit Mach 0.76 to 1.0 increased heat transfer levels on the vane surface at all blowing ratio conditions. A large increase in Reynolds number adversely affected adiabatic effectiveness on the pressure surface at all blowing ratio conditions. On the suction surface, a large increase in Reynolds number also affected adiabatic effectiveness in the favorable pressure gradient and boundary layer transition region.

\section{Nomenclature}

$\begin{array}{ll}A & \text { area } \\ B R & \text { blowing ratio } \\ C & \text { vane chord } \\ d & \text { cooling hole diameter } \\ D R & \text { density ratio } \\ h & \text { heat transfer coefficient } \\ k & \text { acceleration parameter / thermal conductivity } \\ M & \text { Mach number } \\ \dot{m} & \text { mass flow rate } \\ N H F R & \text { Net heat flux reduction } \\ N u & \text { Nusselt number } \\ P & \text { vane pitch } \\ p & \text { cooling hole pitch } \\ P r & \text { Prandt number }\end{array}$




$\begin{array}{ll}q ” & \text { heat flux } \\ R e & \text { Reynolds number } \\ s & \text { vane surface distance from stagnation point } \\ T & \text { temperature } \\ T u & \text { streamwise freestream turbulence intensity } \\ U & \text { local velocity }\end{array}$

\section{Greek}

$\begin{array}{ll}\alpha & \text { spanwise hole cooling angle } \\ \gamma & \text { compound injection angle } \\ \phi & \text { overall film cooling effectiveness } \\ \eta & \text { adiabatic film cooling effectiveness } \\ \Lambda_{x} & \text { integral turbulence length scale } \\ \rho & \text { local density of air }\end{array}$

\section{Subscripts}

$\begin{array}{ll}0 & \text { no film cooling } \\ \infty, \mathrm{a} & \text { freestream, air } \\ \mathrm{aw}, \mathrm{w} & \text { adiabatic wall, wall } \\ \mathrm{c} & \text { coolant } \\ \mathrm{ex}, \mathrm{i} & \text { exit, inlet } \\ \mathrm{o} & \text { stagnation } \\ \mathrm{r} & \text { recovery } \\ \text { red } & \text { reduction }\end{array}$

\section{Introduction}

One way to increase cycle efficiency of a gas turbine is to operate at higher turbine inlet temperature (TIT). In most engines, the turbine inlet temperatures have increased well above the metallurgical limit of engine components. Film cooling of gas turbine components (blades and vanes) is a widely used technique that allows higher turbine inlet temperatures by maintaining material temperatures within acceptable limits. In this cooling method, air is extracted from the compressor and forced through internal cooling passages within turbine blades and vanes before being ejected through discrete cooling holes on the airfoil surfaces. The air leaving these cooling holes forms a film of cool air on the component surface which protects the components from hot gas exiting the combustor.

Accurate numerical modeling of airfoil film cooling performance is a challenge as it is complicated by several factors such as film cooling hole shape, blowing ratio, momentum ratio, 
surface curvature, approach boundary layer state, Reynolds number, Mach number, combustorgenerated high freestream turbulence, turbulence length scale, and secondary flows just to name a few. Until computational methods are able to accurately simulate these factors affecting film cooling performance, experimental studies are required to assist engineers in designing effective film cooling schemes.

Film cooling is a broad, mature topic and its various applications have been studied in literature for some time. The basic film cooling physics on flat plates are described by Goldstein [1]. Bogard and Thole [2] and Han et al. [3] have compiled much of the current work on film cooling as it applies to the gas turbine field. One of the earliest gas turbine vane film cooling studies in a high speed facility comes from the work of Turner et al. [4], who studied the effects of varying Reynolds number, Mach number, coolant injection rate, and coolant to freestream temperature ratio on a showerhead cooled $\mathrm{C} 3 \mathrm{X}$ vane at freestream turbulence of $6.5 \%$ in a transonic, linear cascade wind tunnel. They found that increasing the rate of coolant injection was seen to increase the heat transfer coefficient. Increases in Reynolds number in the film cooled case were also seen to increase heat transfer levels. It was noted that the addition of film cooling had a definite effect on heat transfer coefficient in the laminar region, but after boundary layer transition the effect of film cooling was negligible. Film cooling was shown to move the location of laminar to turbulent transition slightly further upstream.

Arts and Bourguignon [5] investigated the effect of exit Reynolds number, blowing ratio, and location of a pair of film cooling rows on heat transfer coefficient and film cooling effectiveness along the pressure side of a high-pressure nozzle guide vane in a transonic linear cascade. They found that increasing blowing ratio from 0.4 to 2.0 increased film cooling effectiveness and heat transfer coefficient downstream of injection. For $\mathrm{BR}=1.0$ and $\mathrm{Tu}=4 \%$, an increase in Reynolds number adversely affected film effectiveness and reduced heat transfer augmentation downstream of injection for near-stagnation pair of rows.

Abuaf et al. [6] performed heat transfer coefficient and film cooling effectiveness measurements on a heavily film cooled nozzle guide vane in a linear cascade with realistic flow conditions. They had 14 rows of film cooling holes - nine in the stagnation region and five on the suction side. The cooling blowing ratio was as high as 2.7 in the showerhead region and as low as 1.2 on the suction surface. Vane suction side heat transfer coefficient showed significant increase due to film cooling as compared to the pressure surface. The accumulated effect of the 
showerhead and suction side rows also produced significantly higher values of film effectiveness far downstream on the suction surface.

Drost and Bölcs [7] investigated the effects of blowing ratio, incoming boundary layer state, and Reynolds number/Mach number on a film cooled high speed vane. The transient liquid crystal technique was used to determine heat transfer coefficient and film cooling effectiveness. For a single row of film cooling holes on the pressure surface, best effectiveness near the hole was obtained for blowing ratio of 1.3. For a pair of rows of film cooling holes on the suction surface, a jet lift-off was observed between blowing ratios of 1.11 and 1.77. They also found that the film effectiveness was strongly influenced by the nature of incoming boundary layer. Variation in exit Reynolds number/Mach number was found to affect the film cooling performance on the suction side due to changes of boundary layer thickness and flow acceleration.

Guo et al. [8] used platinum thin film gauges on a semi-infinite substrate (Perspex) in a transonic annular cascade to measure the effect of film cooling on a fully film cooled nozzle guide vane. Foreign gas with specific heat properties similar to air was used to match the density ratio seen in a gas turbine. For a nominal pressure ratio of 1.02, an augmentation of heat transfer coefficient due to cooling was observed over the entire pressure surface and some of the suction surface. Heat transfer coefficient levels below that of uncooled data were reasoned to be the result of a thicker boundary layer. Film cooling effectiveness was higher on the pressure side where more rows of coolant injection were present, and it decreased after the last row of cooling holes.

Zhang et al. [9] researched vane film cooling at high freestream turbulence of $\mathrm{Tu}=12 \%$ with one row of shaped holes on the suction side using the PSP technique in a high speed wind tunnel. They found that adiabatic film cooling effectiveness increased with an increase in blowing ratio from 0.5 to 1.5 . Despite high freestream turbulence at the nozzle inlet, significant spanwise variation of film cooling effectiveness was observed. This spanwise variation was attributed to the effect of secondary flow and insufficient mixing on the suction surface. Other important conclusions from their study were that film cooling effectiveness decreased with an increase in exit Reynolds number and a decrease in exit Mach number. These flow condition effects (independent variation of exit Reynolds number and Mach number) were less pronounced at the highest blowing ratio. 
Reiss and Bölcs [10] studied the influence of boundary layer state and Reynolds number/Mach number on the suction side of film cooled nozzle guide vane with transient liquid crystal technique. They found that the incoming turbulent boundary layer decreased the effectiveness values for single injection location as compared to a laminar boundary layer at actual engine conditions. It was also shown that higher Mach and Reynolds number may increase or decrease the film cooling effectiveness, depending on the surface location and the intensity of injection.

Recently, Haldeman et al. [11] conducted aerodynamic and heat flux measurements on a fully film cooled, high-work, single stage HP turbine operating in a short duration blow-down rig. Double-sided Kapton thin film gauges were used for both time-averaged and time-accurate heat flux measurements. Data was presented only for a low Reynolds number, low coolant mass flow case within a large experimental matrix. The vane measurements for the $50 \%$ span showed lower heat flux on the pressure side where the gauges were more heavily influenced by the cooling holes. The differences in the heat flux between the suction and pressure surfaces were minimal because of low cooling injection rates.

The objective of the present work is to experimentally investigate the effects of coolant injection rate or blowing ratio on film cooling performance of a showerhead film cooled first stage turbine vane at high freestream turbulence and three different exit Reynolds numbers or Mach numbers in a transonic cascade wind tunnel. Showerhead film cooling performance is characterized by Nusselt number and adiabatic film cooling effectiveness along the surface of the vane. Another important objective of present study is to document the effect of favorable pressure gradient due to Mach number on vane suction surface adiabatic effectiveness through changes in local recovery and adiabatic wall temperatures at all blowing ratio and exit flow conditions.

\section{Experimental Setup and Instrumentation}

\section{Wind Tunnel Facility}

The two-dimensional Virginia Tech transonic cascade wind tunnel, shown in Figure 2.1, is a blow-down facility that is capable of sustaining a constant inlet pressure in the test section for up to 25 seconds. Prior heat transfer research that has been performed in this facility includes 
work of Nasir et al. [12], Nix et al. [13], Holmberg and Diller [14], Smith et al. [15], and Popp et al. [16]. Air is supplied from high pressure air tanks that are charged up to $1380 \mathrm{kPa}$ (200 psig) prior to testing. A control valve regulates the flow from the air tanks to the test section. Cascade inlet pressures range from $20.7 \mathrm{kPa}$ ( $3 \mathrm{psig}$ ) to $69.0 \mathrm{kPa}$ (10 psig) depending on the objective test conditions. Between the control valve and the test section, the air passes through a passive heat exchanger, which heats the cascade inlet flow up to $120^{\circ} \mathrm{C}$. After the air passes through the heat exchanger, the air goes through a contraction and enters the test section before being exhausted to the atmosphere.

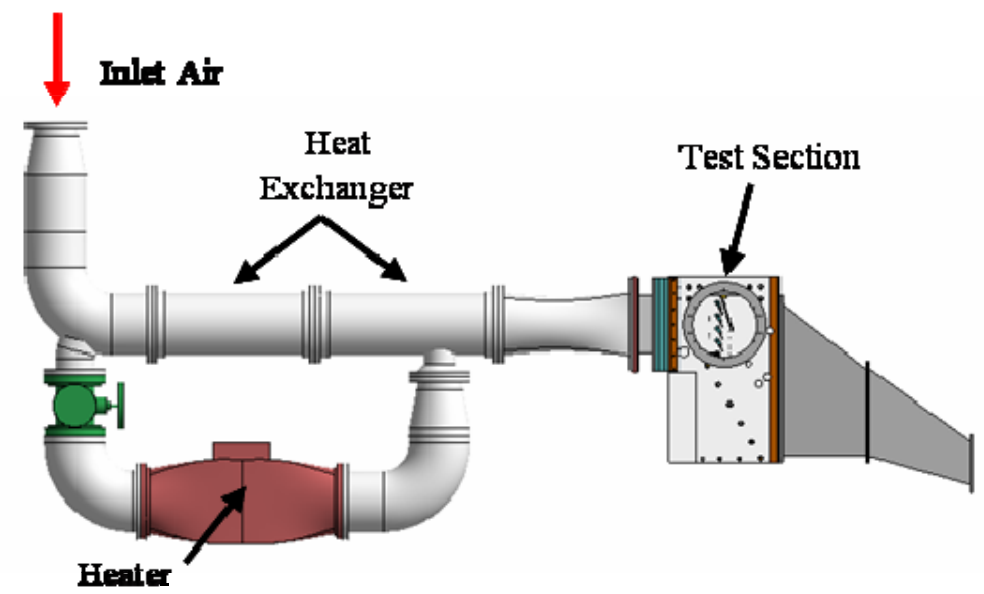

Figure 2.1. Virginia Tech transonic cascade wind tunnel

\section{Turbine Vane Design}

A showerhead film cooled vane with five rows of staggered cylindrical cooling holes is used in this study. The exit of the center row of cooling holes is placed at the geometric stagnation point on the vane. There are a total of 83 holes in all five rows. The number of cooling holes on the stagnation region row is 17 . The nearest downstream rows on either side have 16 holes each, and the farthest downstream rows have 17 holes each. The spacing between rows is 4 hole diameters on the vane surface and 3 hole diameters in the plenum as shown in Figure 2.2. Cooling flow is injected at $90^{\circ}$ angle to the freestream and $45^{\circ}$ angle to the span of the vane as shown in Figure 2.3. All cooling hole rows have the same spanwise injection angle. The turbine vane tested in these experiments is similar in geometry to a first stage turbine vane for a small industrial gas turbine. The vane is scaled one-and-half times so that the nominal exit Reynolds number would be at the desired value. Table 2.1 summarizes the geometry of the showerhead film cooled turbine vane. 


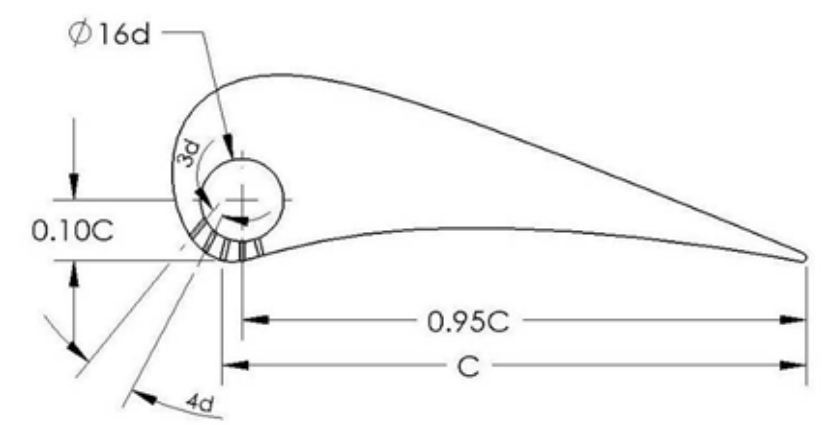

Figure 2.2. Profile view of showerhead film cooled vane

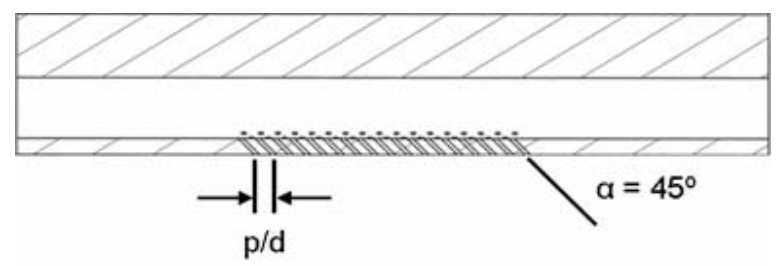

Figure 2.3. Section view of the stagnation row of holes

Table 2.1. Film cooled vane geometry

\begin{tabular}{|c|c|c|}
\hline Vane Chord (see Figure 2.2.) & $C$ & $91.2 \mathrm{~mm}(3.59$ in.) \\
\hline Vane Pitch & $P$ & $83.0 \mathrm{~mm}(3.27 \mathrm{in})$. \\
\hline Cooling Hole Diameter & $d$ & $0.787 \mathrm{~mm}(0.031 \mathrm{in})$. \\
\hline Cooling Hole Spacing & $p / d$ & 4.35 \\
\hline Hole Spanwise Angle & $\alpha$ & $45^{\circ}$ \\
\hline Compound angle (streamwise) & $\gamma$ & $90^{\circ}$ \\
\hline Vane Span & & $152.4 \mathrm{~mm}(6.00 \mathrm{in})$. \\
\hline Cooled Span & & $59.2 \mathrm{~mm}(2.33 \mathrm{in})$. \\
\hline Vane Inlet and Exit Angle & & $0^{\circ}$ and $73.5^{\circ}$ \\
\hline
\end{tabular}

\section{Cascade Test Section}

A diagram of the vane cascade is provided in Figure 2.4. From the vane geometry and the test section size, the vane cascade consists of four full vanes and two partial vanes, which result in four full passages and one partial passage. A tailboard placed at the vane exit angle aids in creating periodic flow through the cascade. The full vanes are numbered starting from the lower bottom of the cascade with Vane 2 being the vane that is fully instrumented to make static pressure and heat transfer measurements. The static pressure measurements are made on a smooth vane (without film cooling holes) through experiments conducted independently of the heat transfer experiments to calculate isentropic Mach number and acceleration parameter distribution on the vane surface. End wall static pressure taps are instrumented at $0.45 \mathrm{C}$ upstream 
and downstream of the cascade to measure the inlet and exit static pressures and characterize the inlet and exit flow. The vertical slot located $0.45 \mathrm{C}$ upstream of the cascade is used to measure the turbulence and velocity distributions at the inlet of the cascade. Inlet freestream turbulence is generated by a passive, mesh grid. All film cooling measurements are performed at a freestream turbulence levels of $\mathrm{Tu}=16 \%$ with an integral length scale normalized by vane pitch of $\Lambda_{\mathrm{x}} / \mathrm{P}=$ 0.23 . The transonic blow-down wind tunnel performance, turbulence grid geometry and measurements of turbulence are described further by Nasir et al. [12].

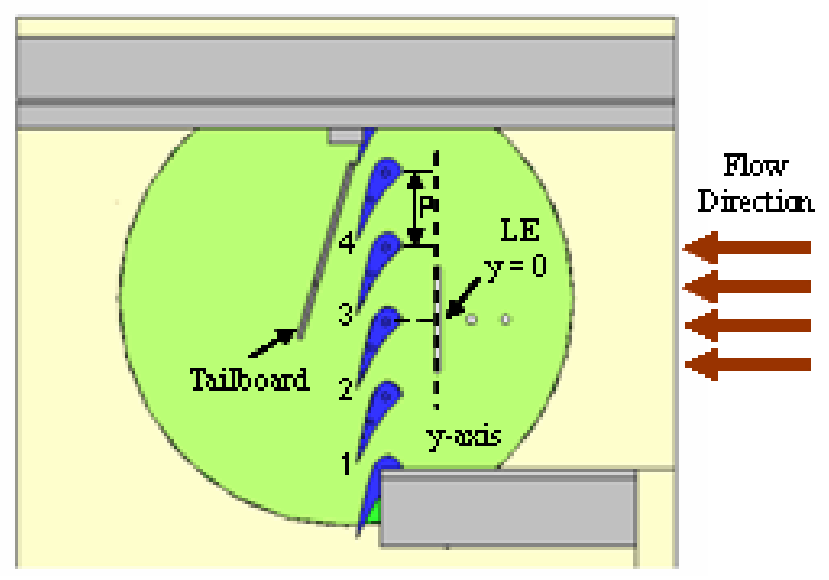

Figure 2.4. Cascade diagram showing the vanes and the axis orientation for measurements with the traverse

\section{Film Coolant Supply System}

Coolant is supplied to the showerhead film cooled vane plenum from a storage tank pressurized to 120 psig with filtered, dried air. The air is dried to a relative humidity less than $4 \%$. The air exiting the tank is regulated by a control valve and passed through a coil of pipe immersed in water bath. The temperature of the water bath is adjusted in such a way that the air temperature flowing through the vane plenum matches the initial vane temperature $\left(\sim 26^{\circ} \mathrm{C}\right)$ before every experimental run. The coolant to freestream density ratio, DR, is defined as:

$$
D R=\frac{\rho_{c}}{\rho_{\infty}}
$$

The freestream density $\left(\rho_{\infty}\right)$ is calculated from cascade inlet conditions measured by a Pitot-static probe and a T-type stagnation temperature measurement probe. The coolant density $\left(\rho_{c}\right)$ is determined from a T-type thermocouple inserted near midspan at the center of the vane plenum and a Pitot-static probe near the entrance to the plenum. The density ratio, DR, is 
between $1.33-1.44$ for all of the tested conditions. According to Bogard and Thole [2], typical gas turbine engine density ratios are $\mathrm{DR} \approx 2$, but coolant density ratio has a secondary effect on the predictability of film cooling performance.

The coolant to freestream mass flux or blowing ratio, $\mathrm{BR}$, is defined as:

$$
B R=\frac{\rho_{c} U_{c}}{\rho_{\infty} U_{\infty}}=\frac{\dot{m}_{c}}{A_{\text {holes }} \rho_{i} U_{i}}
$$

where the mass flow rate of the coolant is measured with an orifice plate meter and divided by the area of the film cooling holes to find the coolant mass flux. Freestream mass flux is calculated from cascade inlet flow conditions. Blowing ratio is calculated for the entire showerhead region using the definition outlined by Colban et al. [17]. Because of local pressure variations at each of the cooling row locations, blowing ratio will vary from row to row, but this variation is small. Blowing ratios of $1.5,2.0$, and 2.5 are tested by manipulating the control valve to increase or decrease the supply of coolant. Heat transfer tests with $\mathrm{BR}=0$ are also conducted, and these correspond to no coolant flow with a film cooled vane.

\section{Single-Sided Thin Film Gauge in Film Cooling Environment}

Heat transfer measurements on a film cooled vane are made with single-sided platinum thin film gauges that allow for high spatial resolution temperature and heat flux measurements with minimal flow disruption. The thin film gauges used in these experiments are Kapton-Glue based two-layer $(k=0.12 \mathrm{~W} / \mathrm{mK}$, thickness $=75 \mu \mathrm{m})$ thin film gauges similar to the gauges developed by Doorly and Oldfield [18]. The gauges were manufactured by Air Force Research Laboratories according to the procedure described by Joe [19]. Once properly calibrated for the temperature coefficient of resistivity, each gauge gives a unique surface temperature history during transient temperature blow-down run. The gauges are installed on the low thermally conductive Macor $(k=1.46 \mathrm{~W} / \mathrm{mK})$ vane midspan and the coolant temperature in the vane plenum is controlled to match the initial vane temperature. This allows 1-D semi-infinite assumption to be used for all the gauges installed on the film cooled vane to calculate normal heat flux $\left(q^{\prime \prime}\right)$ into the vane during transient temperature blow-down run. The working principle, physical properties, calibration and data acquisition procedures of these gauges have been described further by Nasir et al. [12], Nasir [20], and Cress [21]. Application of single-sided thin film gauges in film cooling environment has also been documented by Guo et al. [8]. 
The film cooled Macor vane is instrumented with 20 single-sided platinum thin film gauges. The vane has 11 gauges on the suction side and 9 gauges on the pressure side. Eight miniature T-type $(0.0005$ in.) RdF thermocouples are also installed on the vane surface to monitor the initial temperature of the vane before the experimental run. Figure 2.5 shows the gauges and thermocouples on the vane before its installation in the wind tunnel.

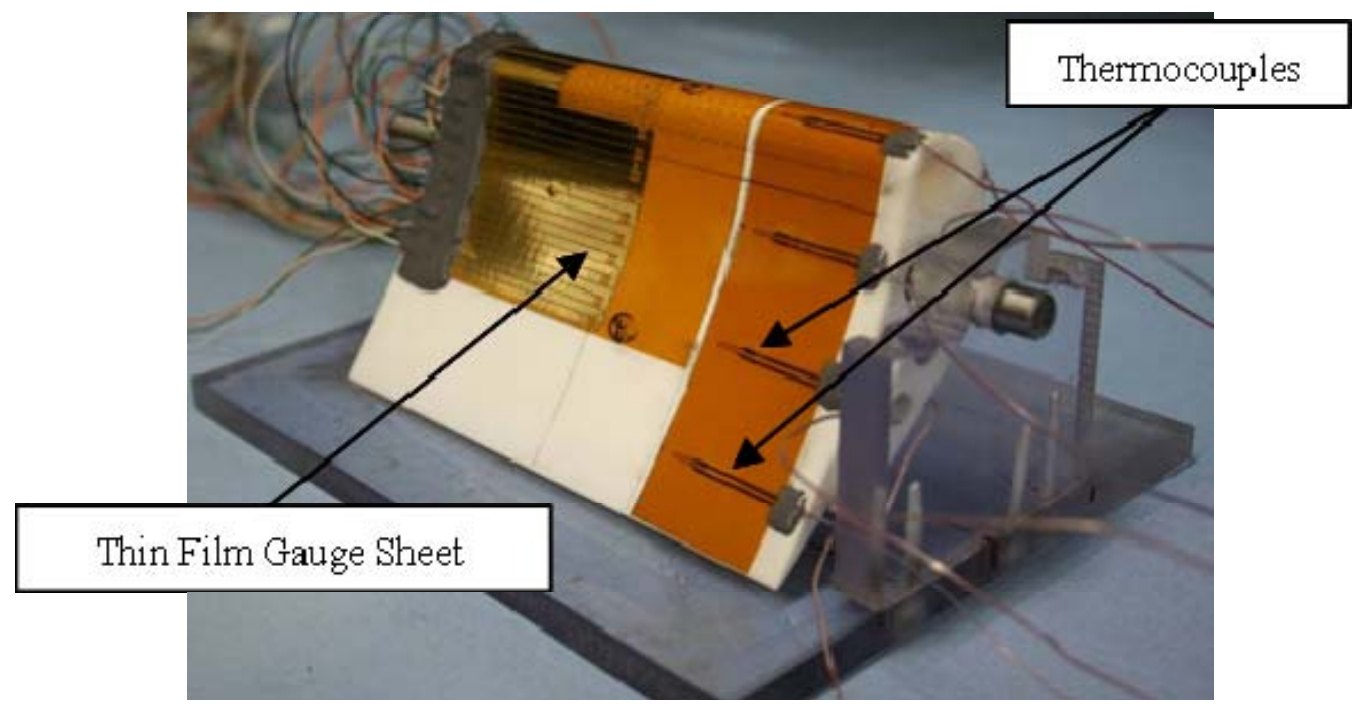

Figure 2.5. Gauges mounted on the vane before installation in wind tunnel

\section{Determination of Heat Transfer Coefficient and Adiabatic Film Cooling Effectiveness}

Heat Transfer in a high speed film cooled environment can be described by:

$$
q^{\prime \prime}=h\left(T_{a w}-T_{w}\right)
$$

where $T_{w}$ is measured on the surface of the vane using the platinum thin film gauge and $T_{a w}$ is the temperature of an assumed adiabatic wall that is the driving temperature of heat transfer. The adiabatic wall temperature defines heat transfer coefficient as a function of aerodynamic character of the flowfield alone and makes it independent of temperature boundary conditions. The adiabatic wall temperature can be nondimensionalized into adiabatic film cooling effectiveness for high speed flow as:

$$
\eta=\frac{T_{a w}-T_{r}}{T_{c}-T_{r}}
$$


In film cooling, $h$ and $\eta$ are the two quantities of interest. It is often necessary to determine these quantities from separate experiments as suggested by Vedula and Metzger [22]. In the Virginia Tech facility, flow conditions are at quasi-steady state while the temperatures of the freestream and vane surface are transient. This allows for determination of heat transfer coefficient and film cooling effectiveness during a single tunnel run. This data analysis procedure is outlined in Smith et al. [15]. Equations 2.3 and 2.4 can be arranged to yield:

$$
\frac{q^{\prime \prime}}{T_{r}-T_{c}}=h\left(\frac{T_{r}-T_{w}}{T_{r}-T_{c}}\right)-h \eta
$$

where $q$ " is calculated with the single-sided thin film gauge.

In this form, Equation 2.5 is equivalent to the standard line equation of $y=m x+b$. The nondimensional temperature variable multiplied by $h$ in Equation 2.5 is plotted as the $x$-axis and the left side of the equation is plotted as the y-axis for the quasi-steady portion of the sample run. The slope of the line is the heat transfer coefficient and the $\mathrm{x}$-intercept is the adiabatic film cooling effectiveness. The slope is determined using a least squares linear regression fit of the plotted data. The effectiveness is given by the intersection of the $\mathrm{x}$-axis-where $q$ " goes to zero. The heat transfer coefficient and effectiveness were determined at each instrumented location for each tunnel run. An example of this plotting is shown in Figure 2.6. The heat transfer coefficient result is nondimensionalized in terms of Nusselt number described by:

$$
N u=\frac{h \cdot C}{k_{a}}
$$

The recovery temperature $\left(T_{r}\right)$ in Equation 2.5 is experimentally measured in a high speed flow from the no film injection $(\mathrm{BR}=0)$ case. With the $\mathrm{BR}=0$ data, the following equation is used to determine $T_{r}$ for the film cooled runs.

$$
q_{0} "=h_{0}\left(T_{o, \infty}-T_{w}\right)-h_{0}\left(T_{o, \infty}-T_{r}\right)
$$

Using Equation 2.7, we can determine $h_{0}$ and $T_{r}$ by plotting $q_{0}$ " versus $\left(T_{o, \infty}-T_{w}\right)$ for the quasi-steady portion of the run. The result gives us a line of the form $y=m x+b$, where the slope of the line is heat transfer coefficient without film cooling and the $\mathrm{x}$-intercept of the line is $\left(T_{0, \infty^{-}}\right.$ $\left.T_{r}\right)$. $\left(T_{o, \infty}-T_{r}\right)$ was determined at each measurement location and then used to find the recovery temperature using $T_{o, \infty}$ from the film cooled runs. More explanation of this technique can be seen in Smith et al. [15] and Popp et al. [16]. 


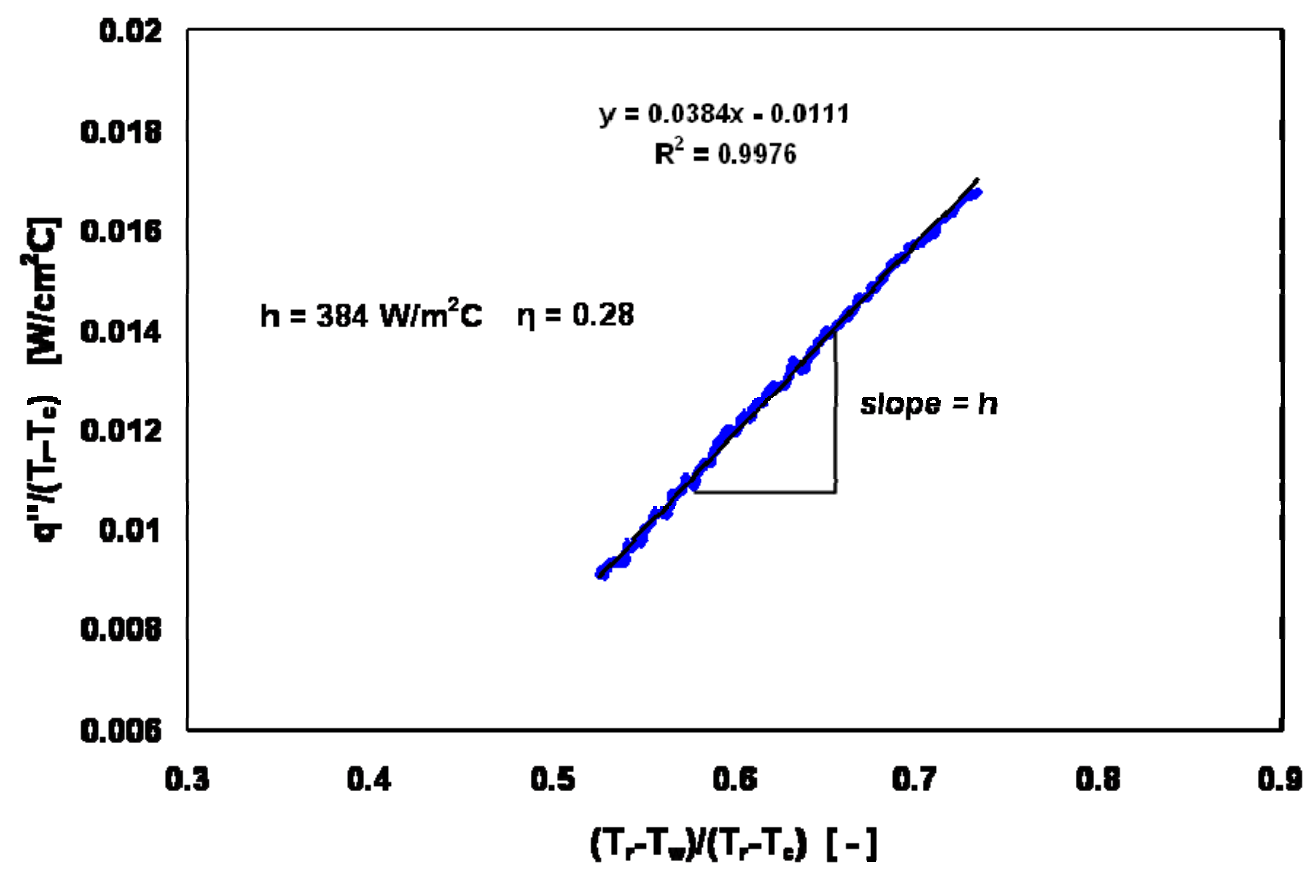

Figure 2.6. Determination of $h$ and $\eta$

\section{Uncertainty Analysis}

The overall uncertainty of the quantities of interest, $h$ and $\eta$, is determined with the aid of two methods. First, Moffat's [23] small perturbation uncertainty method is used to estimate the bias and precision uncertainties of the x-values and y-values plotted in Figure 2.6. Brown and Coleman's [24] linear regression analysis is used to obtain the uncertainty of the fit ( $h$ and $\eta$ ) based upon the $\mathrm{x}$ and $\mathrm{y}$ uncertainties of each gauge during the useful data reduction time. All uncertainties are reported within $95 \%$ confidence interval. For each test condition, measurements were performed at least three times to establish repeatability. The overall average uncertainty of the heat transfer coefficient is determined to be $\pm 6.5 \%$. Because $\eta$ is determined from extrapolating the data shown in Figure 6, its uncertainty is higher. The overall average uncertainty in $\eta$ is \pm 0.032 . 


\section{Vane Static Pressure Distribution}

Figure 2.7 shows the local Mach number distributions on the smooth vane (without film cooling holes) surface for three exit Mach number conditions. The local Mach number is plotted against non-dimensional surface distance, $\mathrm{s} / \mathrm{C}$. Positive and negative values of $\mathrm{s} / \mathrm{C}$ correspond to suction and pressure sides, respectively. The Mach number distribution varies smoothly along the pressure side, and does not exhibit any velocity peak downstream of the stagnation region. The flow on the suction side continuously accelerates up to the geometric throat area $(\mathrm{s} / \mathrm{C}=$ 0.51). The exit Mach 0.6 and 0.8 cases decelerate immediately after the throat, whereas the exit Mach 1.0 case continues to accelerate and becomes supersonic. A trailing edge shock from the adjacent vane impinging on the suction surface $(\mathrm{s} / \mathrm{C}=0.58)$ causes the multi flow decelerations after the throat for the exit Mach 1.0 case.

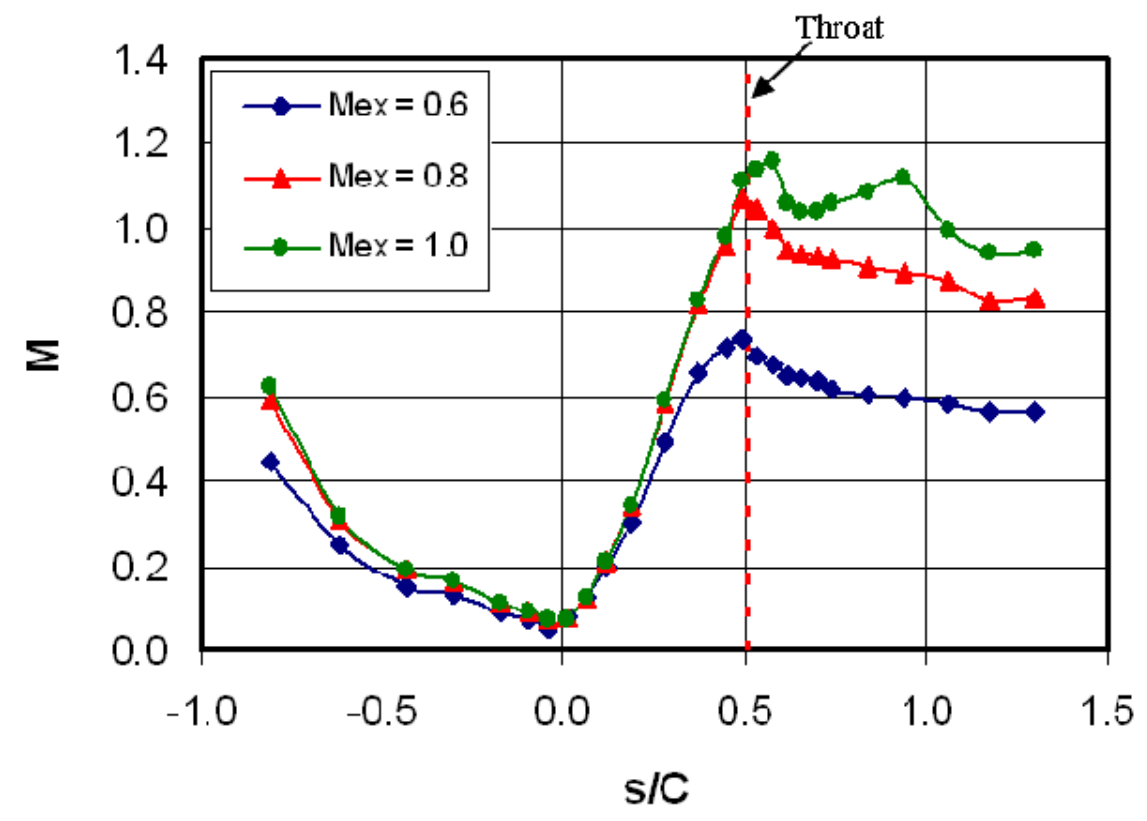

Figure 2.7. Local Mach number distribution

The distribution of acceleration parameter, $k$, on the smooth vane surface for each exit Mach number is provided in Figure 2.8. A positive acceleration parameter indicates that the flow is accelerating and a negative value indicates that the flow is decelerating. On the pressure side of the vane, the acceleration parameter for exit Mach 0.6 case barely reaches the critical value of $3 \times 10^{-6}$ after $\mathrm{s} / \mathrm{C}=-0.43$. This critical value of $k$ has been observed by Jones and Launder [25] and Mayle [26] as a criterion for boundary layer relaminarization. 


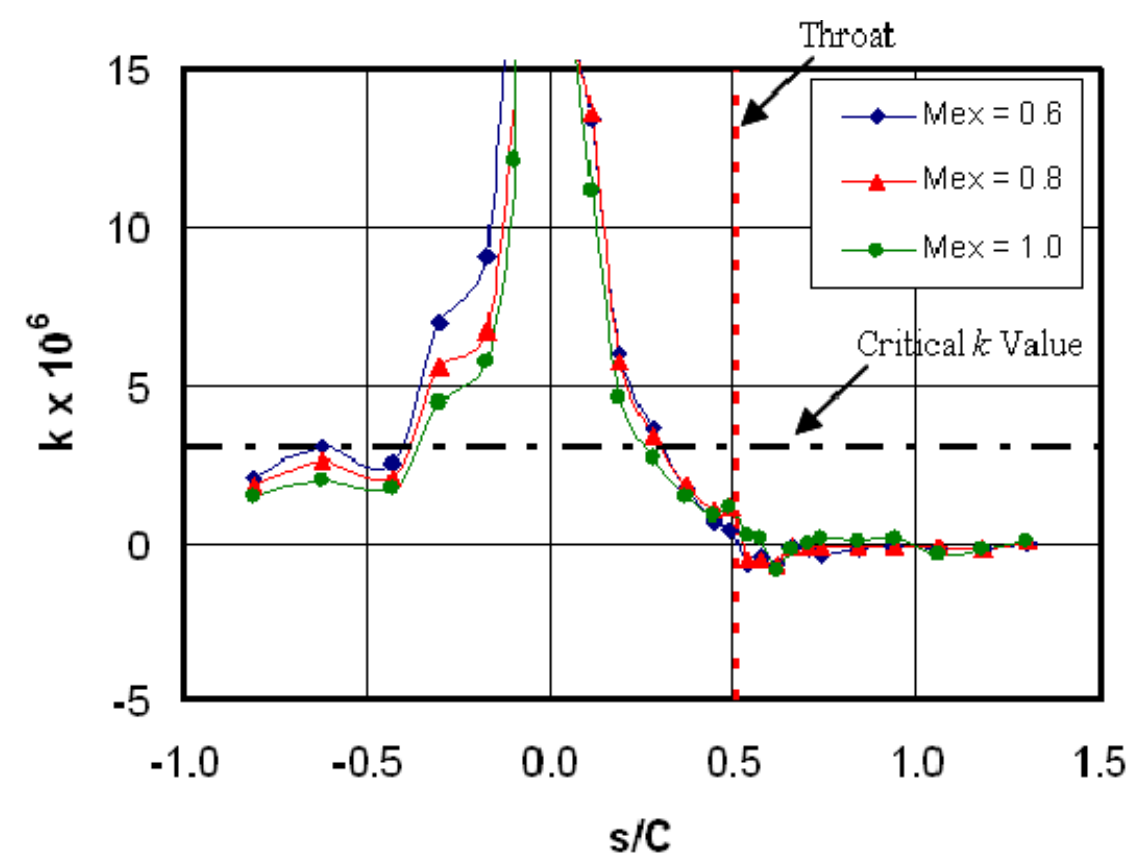

Figure 2.8. Acceleration parameter distribution

\section{Vane Heat Transfer and Adiabatic Effectiveness Distribution}

\section{Test Conditions}

Film cooling heat transfer and adiabatic effectiveness measurements were preformed at exit Mach numbers of $0.57,0.76$, and 1.0 with inlet free stream turbulence intensity (Tu) of $16 \%$ and an integral length scale normalized by vane pitch $\left(\Lambda_{\mathrm{x}} / \mathrm{P}\right)$ of 0.23 . The blowing ratio conditions studied at each Mach number were 0, 1.5, 2.0, and 2.5. The test matrix produced heat transfer coefficient and film cooling effectiveness data for 12 different flow conditions. In this study, the exit Mach and Reynolds numbers were coupled due to facility limitation. Mach numbers and Reynolds numbers are calculated based on exit flow conditions. Reynolds number is based on the vane chord. For each test condition, measurements were performed at least three times to establish repeatability. The test conditions are provided in Table 2.2. 
Table 2.2. Test conditions for each case

\begin{tabular}{|c|c|c|c|c|}
\hline & $\mathbf{M}_{\mathrm{ex}}$ & Tu & $\mathbf{R e}_{\mathrm{ex}}$ & BR \\
\hline Case 1 & \multirow{4}{*}{0.57} & \multirow{12}{*}{$16 \%$} & \multirow{4}{*}{970,000} & 0 \\
\hline Case 2 & & & & 1.5 \\
\hline Case 3 & & & & 2.0 \\
\hline Case 4 & & & & 2.5 \\
\hline Case 5 & \multirow{4}{*}{0.76} & & \multirow{4}{*}{$1,080,000$} & 0 \\
\hline Case 6 & & & & 1.5 \\
\hline Case 7 & & & & 2.0 \\
\hline Case 8 & & & & 2.5 \\
\hline Case 9 & \multirow{4}{*}{1.0} & & \multirow{4}{*}{$1,500,000$} & 0 \\
\hline Case 10 & & & & 1.5 \\
\hline Case 11 & & & & 2.0 \\
\hline Case 12 & & & & 2.5 \\
\hline
\end{tabular}

\section{Effect of Blowing Ratio on Nusselt Number}

The effect of blowing ratio on showerhead film cooled vane Nusselt number at exit Mach 0.57, 0.76, and 1.0 is shown in Figures 2.9, 2.10, and 2.11, respectively. The Nusselt number $\mathrm{N} \mathrm{Nu}$ ) for each gauge, averaged over the quasi-steady portion of the run, is plotted against nondimensional surface distance, $\mathrm{s} / \mathrm{C}$ and $\mathrm{s} / \mathrm{d}$. Here the Nusselt number for no film injection $(\mathrm{BR}=$ 0 ) at respective Mach number is also plotted for comparison. The primary effect of coolant injection is to augment Nusselt number downstream of injection on the vane surface as compared to $\mathrm{BR}=0$ case at all exit Mach number conditions. The Nusselt number augmentation is due to more mixing and local increase in turbulence levels within the boundary layer.

At exit Mach 0.57 (Figure 2.9), an increase in blowing ratio from 1.5 to 2.0 augments Nusselt number downstream of the film cooling rows on the vane surface. Further increase in blowing ratio from 2.0 to 2.5 shows a marginal increase in Nusselt number augmentation downstream of injection. An increase in heat transfer augmentation due to increase in blowing ratio has been documented widely in literature such as references [4, 5, 27-29]. The effect of blowing ratio on Nusselt number augmentation is clearly more noticeable on the pressure surface as compared to the suction surface. Though augmented, Nusselt number distributions follow the same trend as the $\mathrm{BR}=0$ case on the suction side at all blowing ratio conditions. On the suction surface, the Nusselt number shows a peak and a valley downstream of the film cooling rows for all blowing ratio conditions. The reasons for this peak and valley can be attributed to the effect of favorable pressure gradient $\left(k>3 \times 10^{-6}\right)$ on a pseudo-turbulent boundary layer to possibly relaminarize in the region $(\mathrm{s} / \mathrm{C}=0.2-0.3)$ or the effect of favorable pressure gradient on the 
inner sublayer thickness of the pseudo-turbulent boundary layer accompanied by a bypass transition again to a fully turbulent boundary layer at $\mathrm{s} / \mathrm{C}=0.34$. This type of peak and valley on vane suction side heat transfer distribution with showerhead film cooling has also been noted by Turner et al. [4]. Also, the suction side boundary layer transition location $(\mathrm{s} / \mathrm{C}=0.34)$ seems to be unaffected by an increase in blowing ratio. Once the boundary layer becomes turbulent on the suction side, the effect of coolant injection on the Nusselt number diminishes.

At exit Mach 0.76 (Figure 2.10), an increase in blowing ratio from 1.5 to 2.5 shows a noticeable Nusselt number on the pressure surface as compared to the suction surface. On the pressure surface, the highest Nusselt number augmentation occurs at the first measurement location downstream of the stagnation region and then augmentation decreases further downstream of the injection location. On the suction surface, an increase in blowing ratio from 1.5 to 2.5 shows marginal augmentation downstream of injection. The suction side boundary layer transition location $(\mathrm{s} / \mathrm{C}=0.34)$ seems to be unaffected by an increase in blowing ratio at exit Mach 0.76 .

At exit Mach 1.0 (Figure 2.11), an increase in blowing ratio from 1.5 to 2.5 shows a reduction in Nusselt number downstream of the stagnation region $(\mathrm{s} / \mathrm{C}<-0.20)$ on the pressure surface. This reduction in Nusselt number can be attributed to partial or complete jet lift-off causing reduction in jet vorticity interaction in the boundary layer at higher blowing ratios $(\mathrm{BR}=$ 2.0 and 2.5) on the pressure surface. The exact reason of jet lift-off at exit Mach 1.0 and blowing ratios $\mathrm{BR}=2.0$ and 2.5 is not completely known at this point and requires more future research work. On the suction side, the effect of blowing ratio $(B R=1.5,2.0$ and 2.5) on Nusselt number is negligible. Also, the boundary layer on the suction side seems to be fully turbulent downstream of the injection at blowing ratios 1.5, 2.0 and 2.5 due to high Nusselt number levels, but again seems to be affected by a favorable pressure gradient in the region $(\mathrm{s} / \mathrm{C}=0.2-0.3)$. Overall, the negligible effect of coolant injection rate on vane surface Nusselt number at exit Mach 1.0 can be attributed to the diminishing influence of local turbulence augmentation due to the injection process as the Reynolds number increases. It must be noted that the last two gauges located on the suction side at $\mathrm{s} / \mathrm{C}=0.67$ and 0.72 were discarded at exit Mach 1.0 because they showed a possible shockwave interaction with the turbulent boundary layer. The linear regression technique showed unsteadiness and unrepeatability of heat transfer coefficient and effectiveness due to this interaction. 


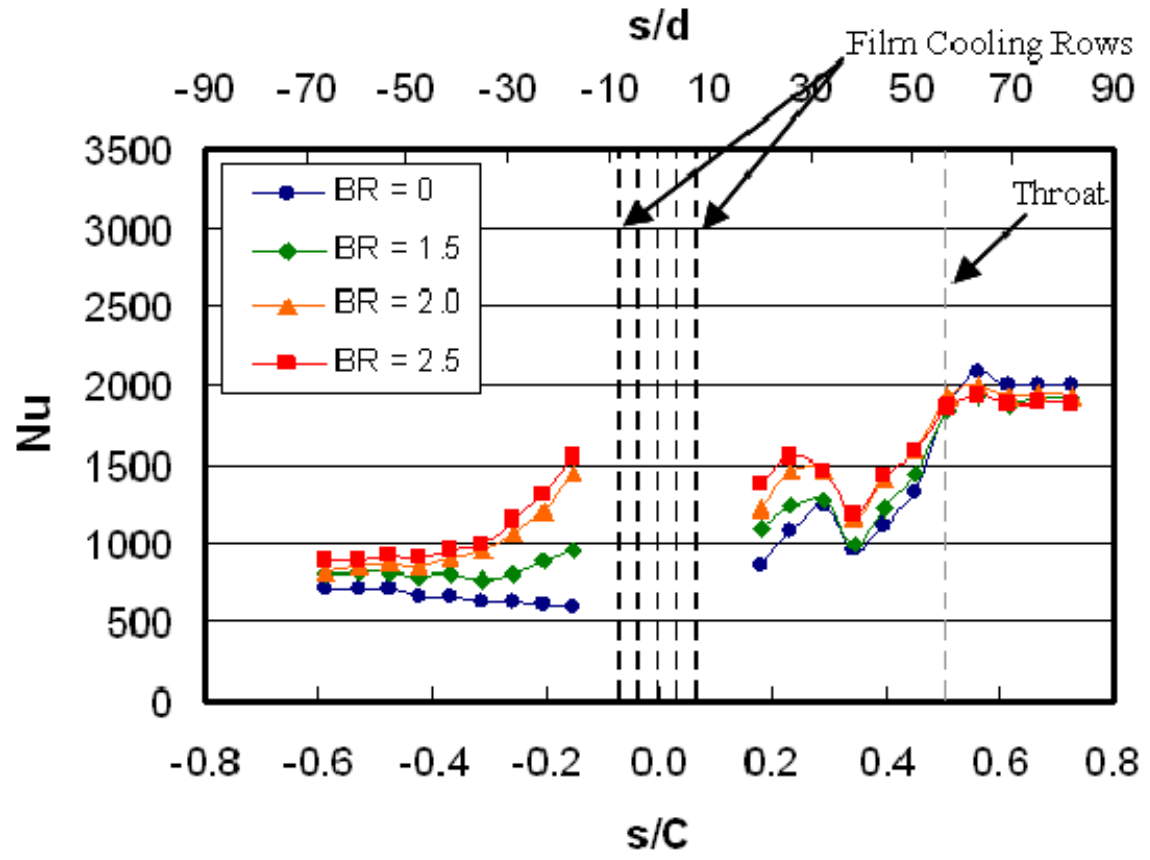

Figure 2.9. Effect of $\mathrm{BR}$ on $\mathrm{Nu}$ at exit Mach 0.57

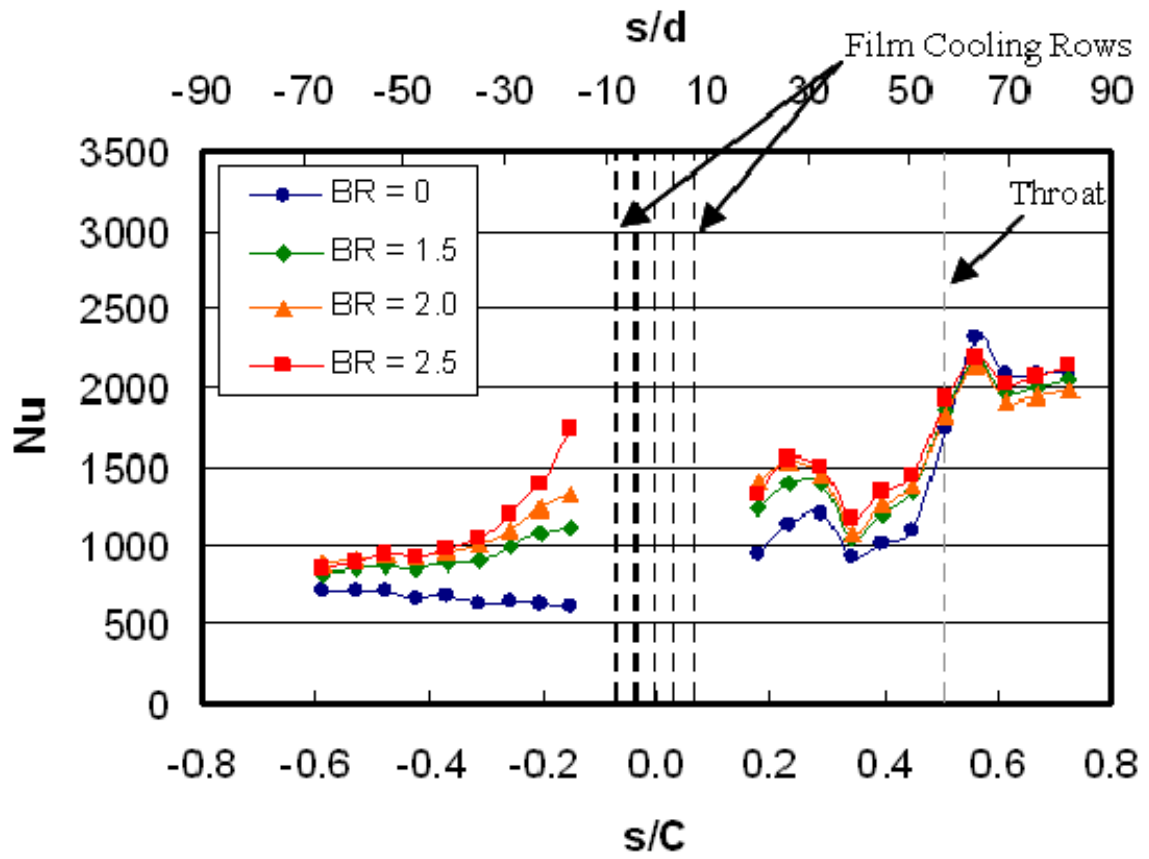

Figure 2.10. Effect of BR on $\mathrm{Nu}$ at exit Mach 0.76 


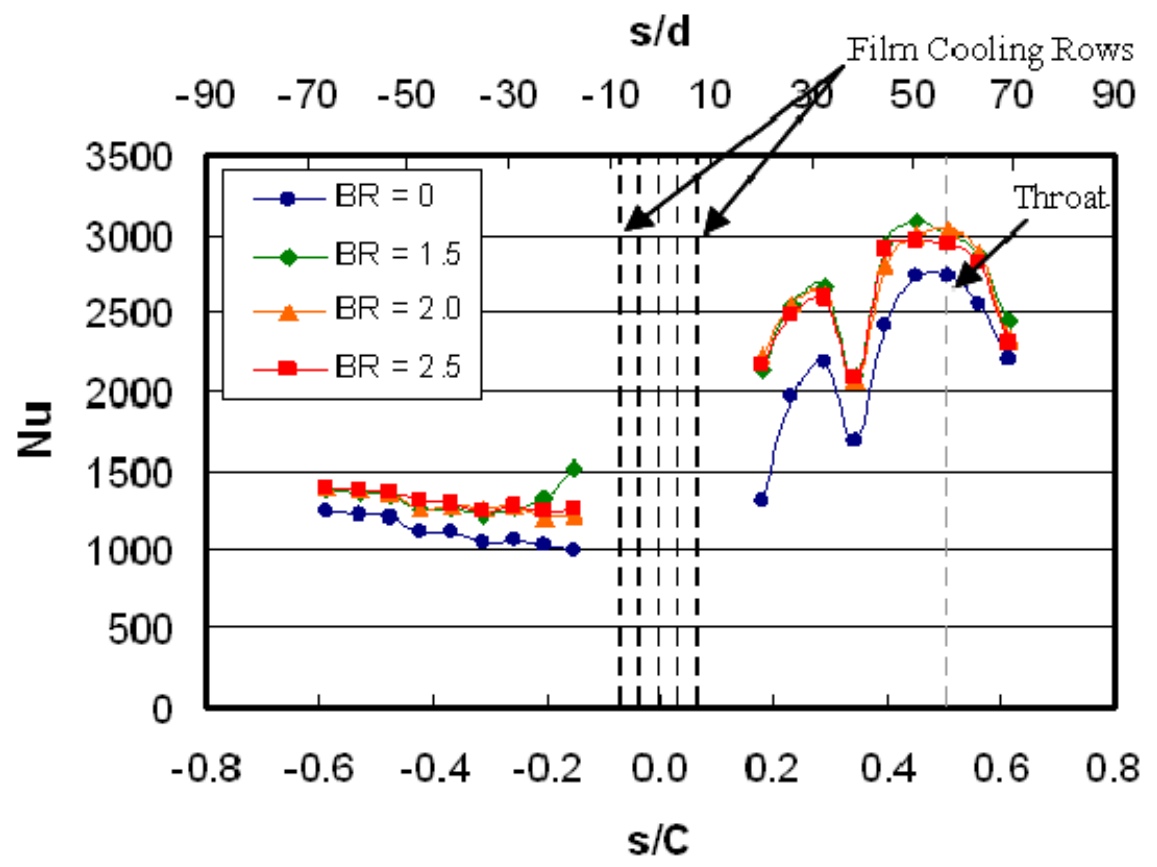

Figure 2.11. Effect of $\mathrm{BR}$ on $\mathrm{Nu}$ at exit Mach 1.0

\section{Effect of Blowing Ratio on Adiabatic Effectiveness}

Another important effect of coolant injection was to reduce adiabatic wall temperature downstream of injection on both vane surfaces. The change in adiabatic temperature was measured by a nondimensional parameter-adiabatic effectiveness. The effect of blowing ratio on adiabatic film cooling effectiveness $(\eta)$ at exit Mach $0.57,0.76$, and 1.0 is shown in Figures $2.12,2.13$, and 2.14 , respectively.

At exit Mach 0.57 (Figure 2.12), the effectiveness trend shows decay downstream of coolant injection on both surfaces at all blowing ratio conditions. On the pressure surface, an increase in blowing ratio from 1.5 to 2.0 increases adiabatic effectiveness on the measurement surface up to $\mathrm{s} / \mathrm{C}=-0.47$. Further increase in blowing ratio results in similar values on the pressure surface. On the suction surface, an increase in blowing ratio from 1.5 to 2.0 increases adiabatic effectiveness up to the throat region $(\mathrm{s} / \mathrm{C}=0.51)$. Further increase in blowing ratio results in similar values on the suction surface. In general, the suction surface effectiveness trend does not exhibit a continuous decay downstream of the coolant injection as does the pressure surface. The effectiveness trend on the suction surface seems to be influenced by a favorable pressure gradient due to Mach number in the region $\mathrm{s} / \mathrm{C}=0.28$ to $\mathrm{s} / \mathrm{C}=0.45$ through changes in local recovery and adiabatic wall temperatures. The favorable pressure gradient effect due to 
Mach number results in nearly steady adiabatic effectiveness values in the region $\mathrm{s} / \mathrm{C}=0.28$ to $\mathrm{s} / \mathrm{C}=0.40$. The effect of favorable pressure gradient in combination with a direct Mach number on vane surface recovery temperature was found to be significantly different from assumed recovery temperature based on local Mach number and turbulent boundary layer recovery factor $\left(r=\operatorname{Pr}^{1 / 3}\right)$. A possible reason is a compressibility effect on recovery factor for gases with Prandtl number $\operatorname{Pr}<1$, as hinted by Oudheusden [30].

At exit Mach 0.76 (Figure 2.13), the effectiveness trends show similar values downstream of the stagnation region on the pressure surface at all blowing ratio conditions. On the suction surface, an increase in blowing ratio from 1.5 to 2.0 shows similar adiabatic effectiveness on the entire measurement surface. Further increase in blowing ratio results in slightly higher effectiveness values in the region $\mathrm{s} / \mathrm{C}=0.28$ to $\mathrm{s} / \mathrm{C}=0.40$. Mhetras et al. [31] observed that higher blowing ratios did not affect the effectiveness values on the suction side but did show higher effectiveness values on the pressure side at similar exit Mach number conditions. Similar to exit Mach 0.57, the suction surface effectiveness trend seems to be influenced by the favorable pressure gradient due to Mach number in the region $\mathrm{s} / \mathrm{C}=0.28$ to $\mathrm{s} / \mathrm{C}$ $=0.45$.

At exit Mach 1.0 (Figure 2.14), an increase in blowing ratio from 1.5 to 2.5 shows a significant decrease in adiabatic effectiveness values on the pressure surface. This decrease in effectiveness with the increase in blowing ratio on the pressure surface can be attributed to partial or complete coolant jet lift-off accompanied by jet dissipation in the higher momentum freestream at exit Mach 1.0 condition. On the suction surface, an increase in blowing ratio from 1.5 to 2.5 shows very similar effectiveness values at all measurement locations. The effectiveness trend on the suction surface again seems to be influenced by high favorable pressure gradient due to Mach number in the region $\mathrm{s} / \mathrm{C}=0.28$ to $\mathrm{s} / \mathrm{C}=0.40$, but this influence is less pronounced as compared to other exit Mach conditions. 


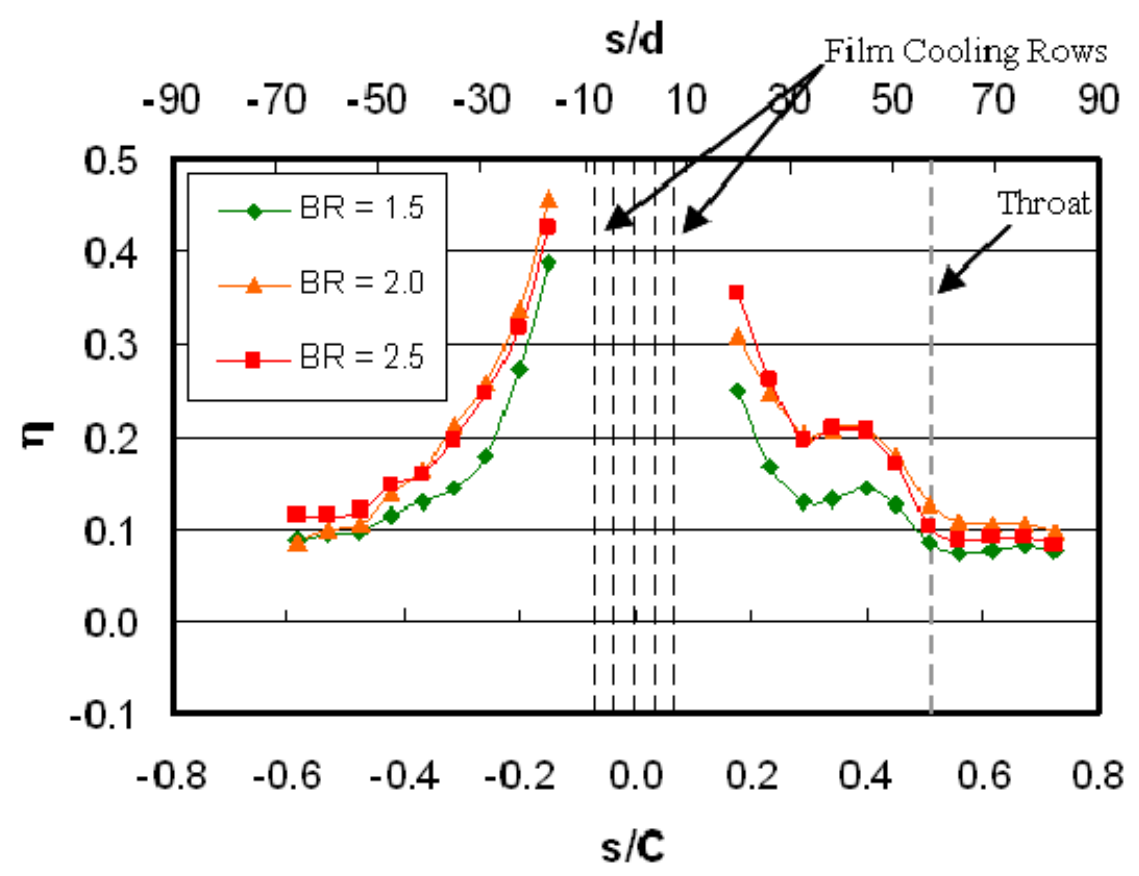

Figure 2.12. Effect of BR on $\eta$ at exit Mach 0.57

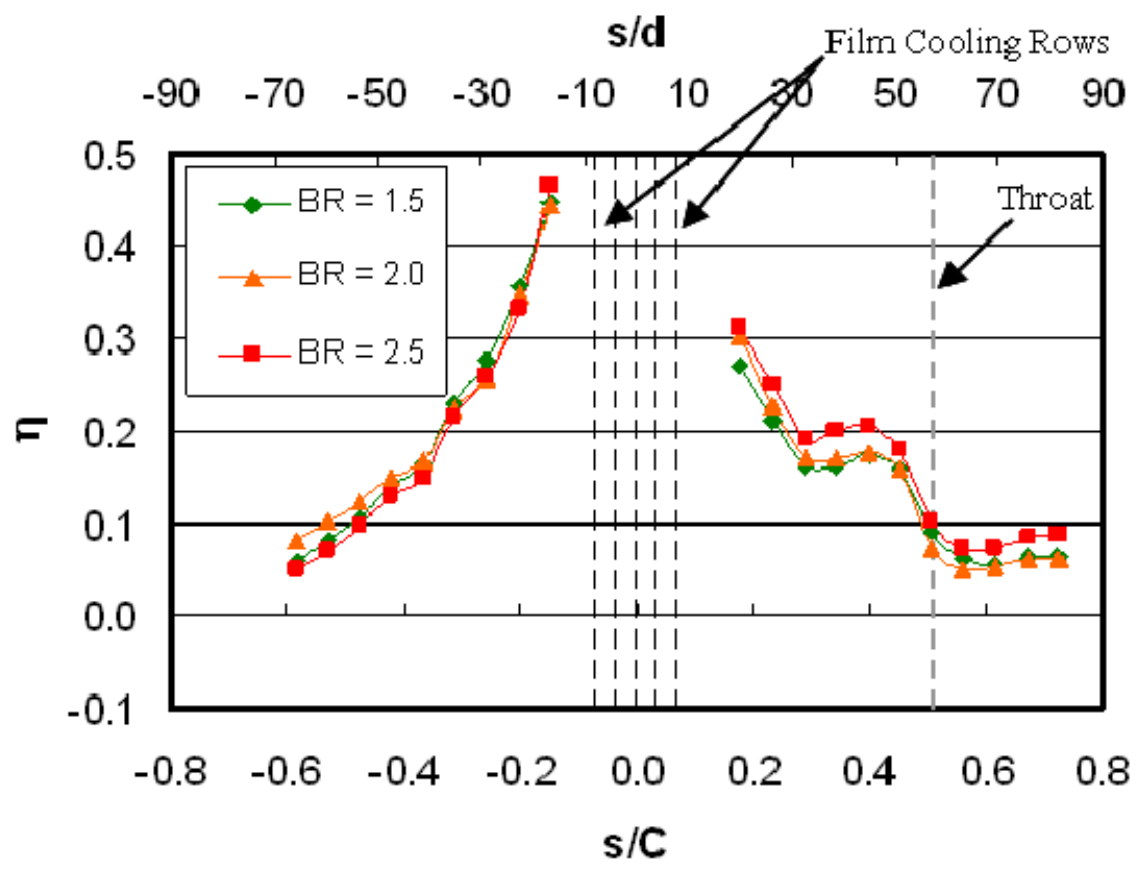

Figure 2.13. Effect of BR on $\eta$ at exit Mach 0.76 


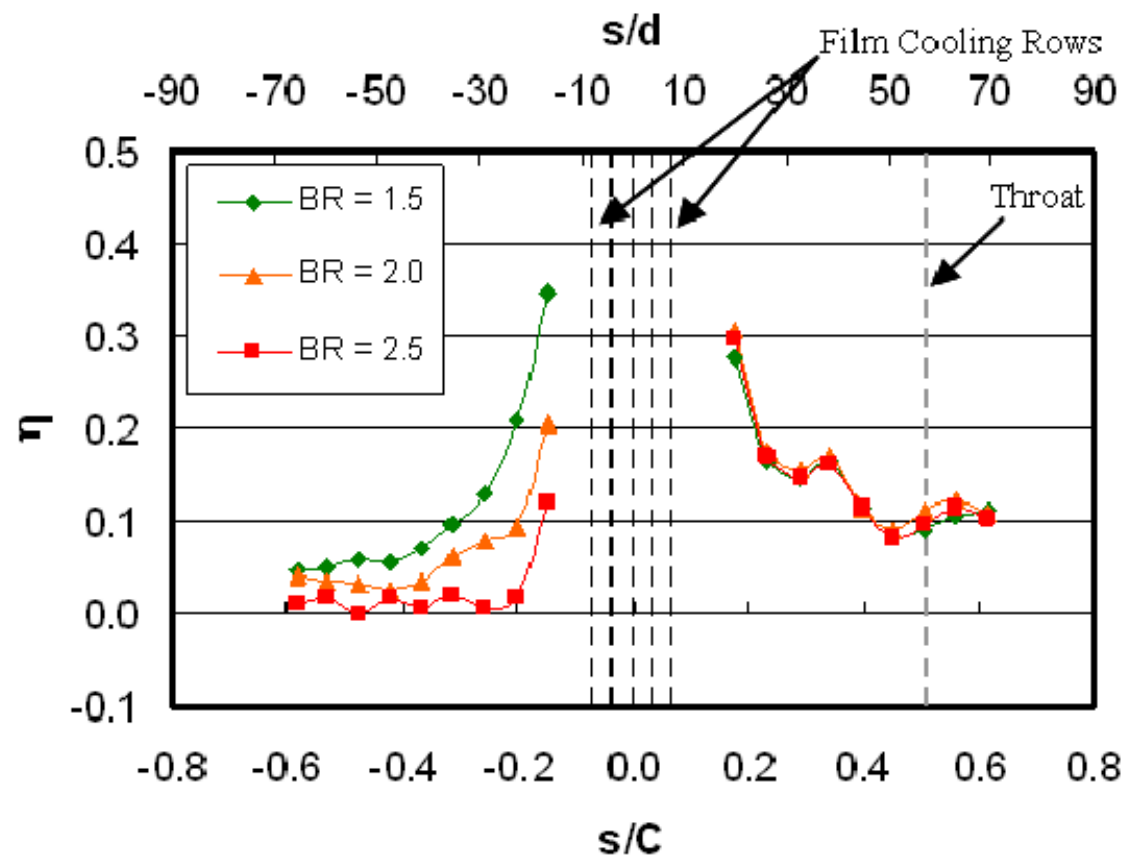

Figure 2.14. Effect of $B R$ on $\eta$ at exit Mach 1.0

\section{Effect of Blowing Ratio on Net Heat Flux Reduction}

Although film cooling serves to reduce convective heat flux into the airfoil, it is always used in conjunction with internal airfoil cooling in real engine applications. In this case, showerhead cooling can be used as a sink for internal cooling air. Therefore, the net heat flux reduction due to showerhead film cooling may not be a vital tool in overall design, but it still illustrates the balance between heat transfer augmentation and film cooling effectiveness due to coolant injection. Net heat flux reduction, NHFR is described by:

$$
N H F R=\Delta q_{r e d}^{\prime \prime}=1-\frac{q^{\prime \prime}}{q_{0}^{\prime \prime}}=1-\frac{h}{h_{0}}\left(1-\frac{\eta}{\phi}\right)
$$

With the overall cooling effectiveness $\phi$ defined as:

$$
\phi=\frac{T_{w}-T_{r}}{T_{c}-T_{r}}
$$

From Equation 2.8, if the value of NHFR is positive, the effect of film cooling is beneficial. If the value of NHFR is negative, then the effect of film cooling is detrimental. Overall film cooling performance in Equation 2.9 can vary over the surface of the vane, but typically is within the range of 0.5-0.7. A value of $\phi=0.6$ has been chosen for this analysis. 
This value has also been used by Drost et al. [7] in a high speed testing facility and Lu et al. [32] in a low speed testing facility.

The effect of blowing ratio on net heat flux reduction (NHFR) at exit Mach 0.57, 0.76, and 1.0 is shown in Figures 2.15, 2.16, and 2.17, respectively. At exit Mach 0.57 (Figure 2.15), highest positive NHFR is obtained just downstream of the coolant injection on both surfaces because of very high values of adiabatic effectiveness. On the pressure surface, $B R=1.5$ shows the best film cooling performance at all measurement locations as compared to higher blowing ratios $(\mathrm{BR}=2.0$ and 2.5$)$, but still does not protect the entire pressure surface. In order to operate at higher blowing ratios and also provide full surface film cooling coverage, more injection locations are required on the pressure surface. On the suction surface, NHFR is positive on the entire measured surface and has very similar values at all blowing ratio conditions. The reason for positive NHFR at all measurement locations on the suction surface is low heat transfer coefficient augmentation due to film cooling at all blowing ratio conditions. On the suction surface, the NHFR trend is also affected by the high flow acceleration and boundary layer transition for all blowing ratio cases.

At exit Mach 0.76 (Figure 2.16) and 1.0 (Figure 2.17), an increase in blowing ratio from 1.5 to 2.5 reduces net heat flux reduction and film coverage on the pressure surface. The decrease in NHFR with an increase in blowing ratio is due to much higher heat transfer coefficient augmentation with little or no increase in the film effectiveness. On the suction surface, NHFR is positive on the entire measured surface and has very similar values at all blowing ratio conditions. Also, on the suction surface, the NHFR trend is seen to be affected by the high flow acceleration and boundary layer state for all blowing ratio cases. 


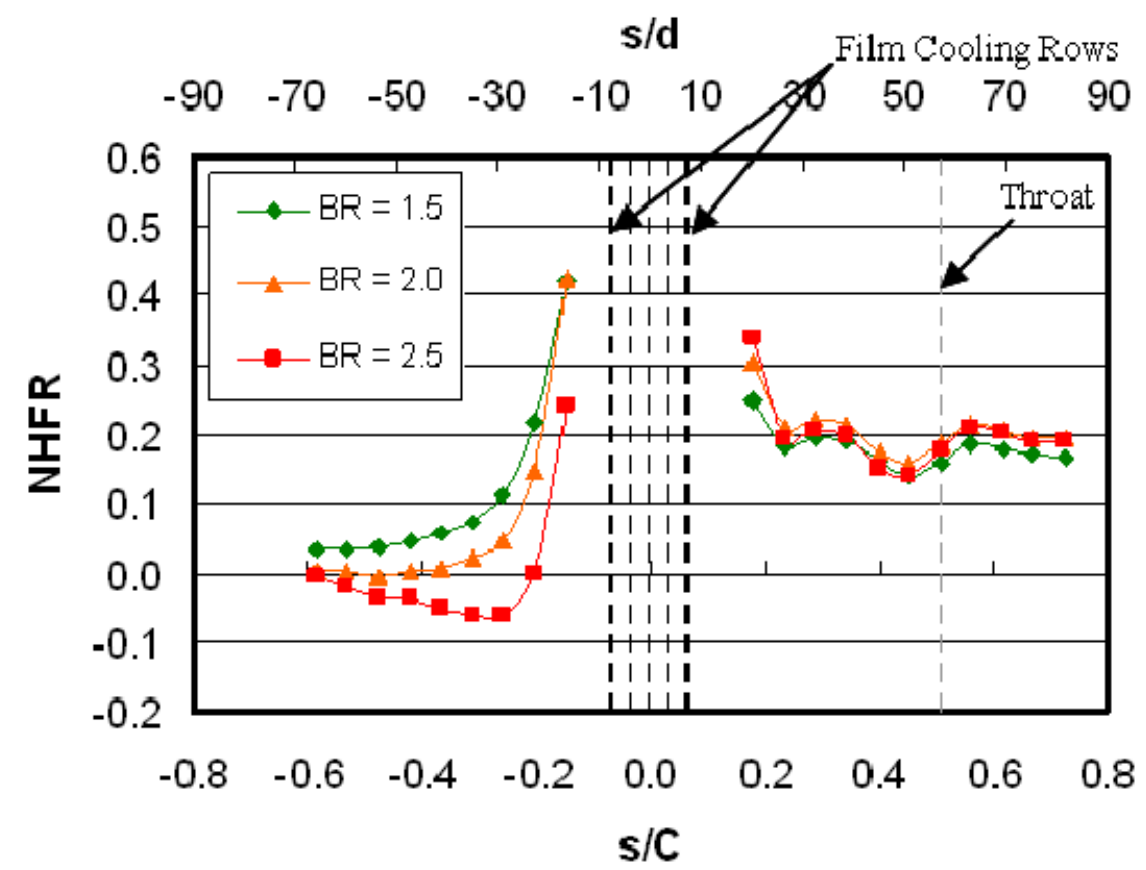

Figure 2.15. Effect of BR on NHFR at exit Mach 0.57

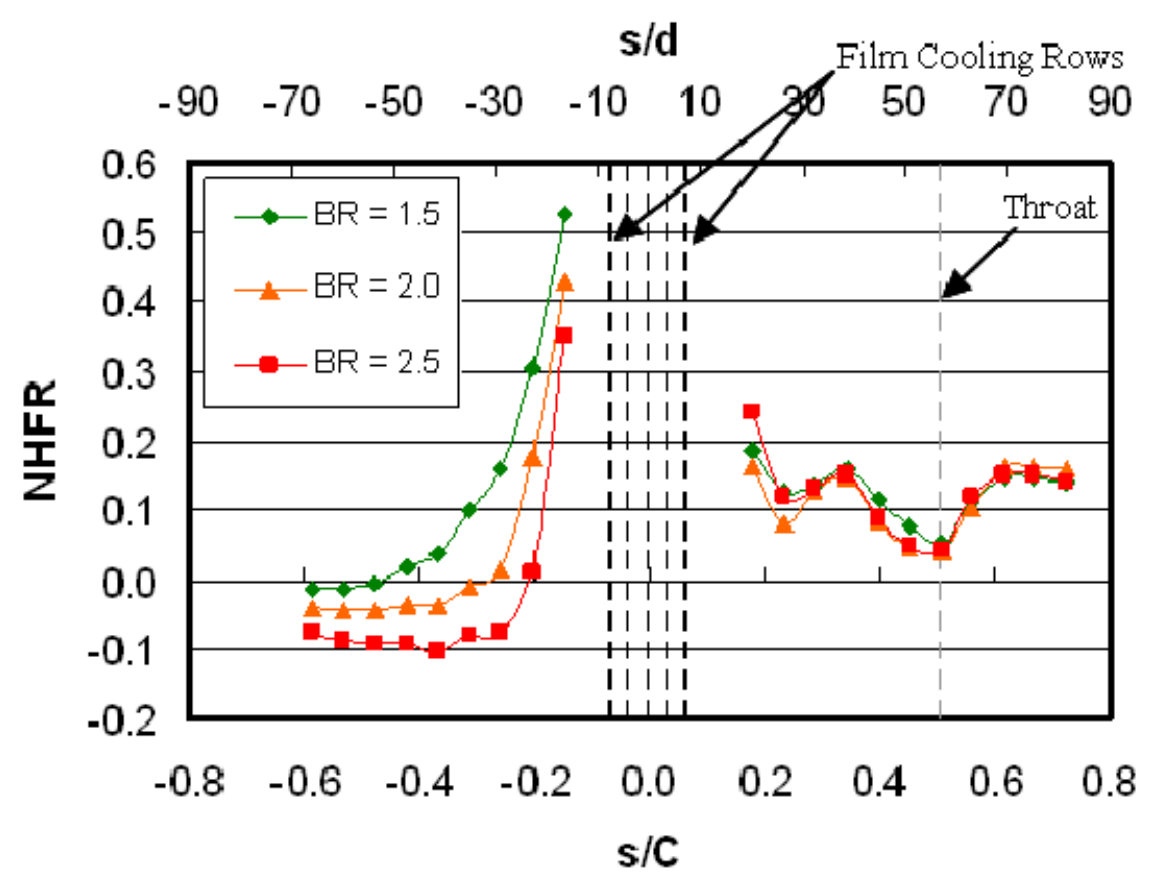

Figure 2.16. Effect of BR on NHFR at exit Mach 0.76 


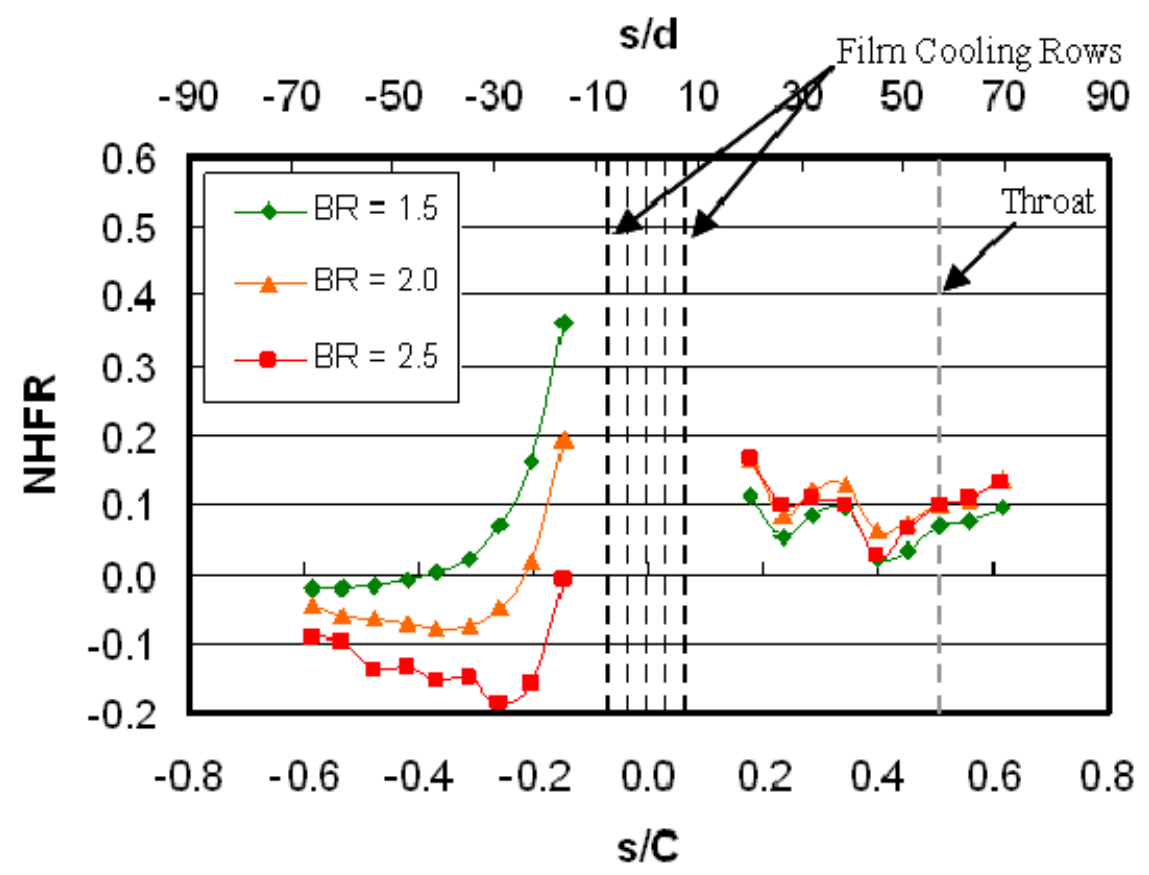

Figure 2.17. Effect of BR on NHFR at exit Mach 1.0

\section{Effect of Re/Mach Number on Nusselt Number}

Showerhead vane film cooling Nusselt number was seen to be affected by changing exit Reynolds number/Mach number conditions. In the Virginia Tech transonic wind tunnel facility, exit Mach number and the exit Reynolds number were not decoupled, so an increase in exit Mach number corresponds to an increase in exit Reynolds number. To remain consistent with the previous sections, the data will be compared by stating the Mach number. Due to small change in Reynolds number from exit Mach 0.57 to $0.76\left(9.7 \times 10^{5}\right.$ to $\left.1.1 \times 10^{6}\right)$ the effect of Reynolds number/Mach number on film cooling Nusselt number is only discussed for large increase in Reynolds number $\left(1.1 \times 10^{6}\right.$ to $\left.1.5 \times 10^{6}\right)$ from exit Mach 0.76 to 1.0.

The Nusselt number distributions showing the effect of increasing the Reynolds number /Mach number at all three blowing ratio conditions $(\mathrm{BR}=1.5,2.0$, and 2.5) are shown in Figures 2.18, 2.19, and 2.20, respectively. Consistent with Reiss and Bölcs [10], a large increase in exit Reynolds number and Mach number was found to increase film cooling Nusselt number levels on the vane surface due to the change in the boundary layer thickness and/or state at higher momentum exit flow condition. On the pressure surface, beyond $\mathrm{s} / \mathrm{C}=-0.20$, the Nusselt number levels increase with the increase in exit Reynolds number for all blowing ratio conditions. Also 
on the pressure surface, upstream of $\mathrm{s} / \mathrm{C}=-0.20$, the Nusselt number levels decrease with an increase in Reynolds number from exit Mach 0.76 to exit Mach 1.0 because of possible partial or complete jet lift-off causing reduction in jet vorticity interaction in the boundary layer near the surface at higher blowing ratio conditions ( $\mathrm{BR}=2.0$ and 2.5) for exit Mach 1.0 condition.

On the suction surface, the Nusselt number levels also increase with an increase in exit Reynolds number from exit Mach 0.76 to 1.0 on the entire measurement surface for all blowing ratio conditions. Also at the highest Reynolds number case (Mach 1.0), the boundary layer seems to be entirely turbulent downstream of injection on the suction surface at all blowing ratio conditions due to high heat transfer levels, but seems to be affected by high favorable pressure gradient due to Mach number in the region $(\mathrm{s} / \mathrm{C}=0.2-0.3)$.

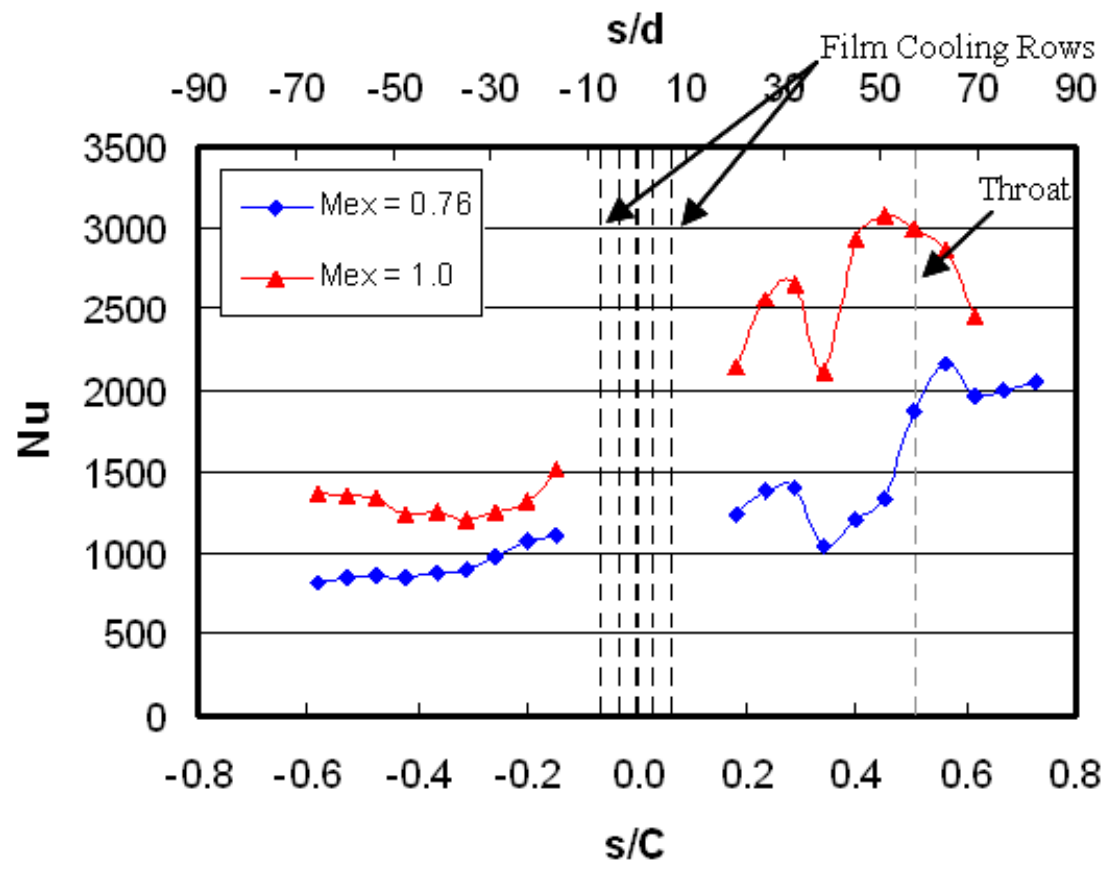

Figure 2.18. Effect of Re/Mach number on $\mathrm{Nu}$ at $\mathrm{BR}=1.5$ 


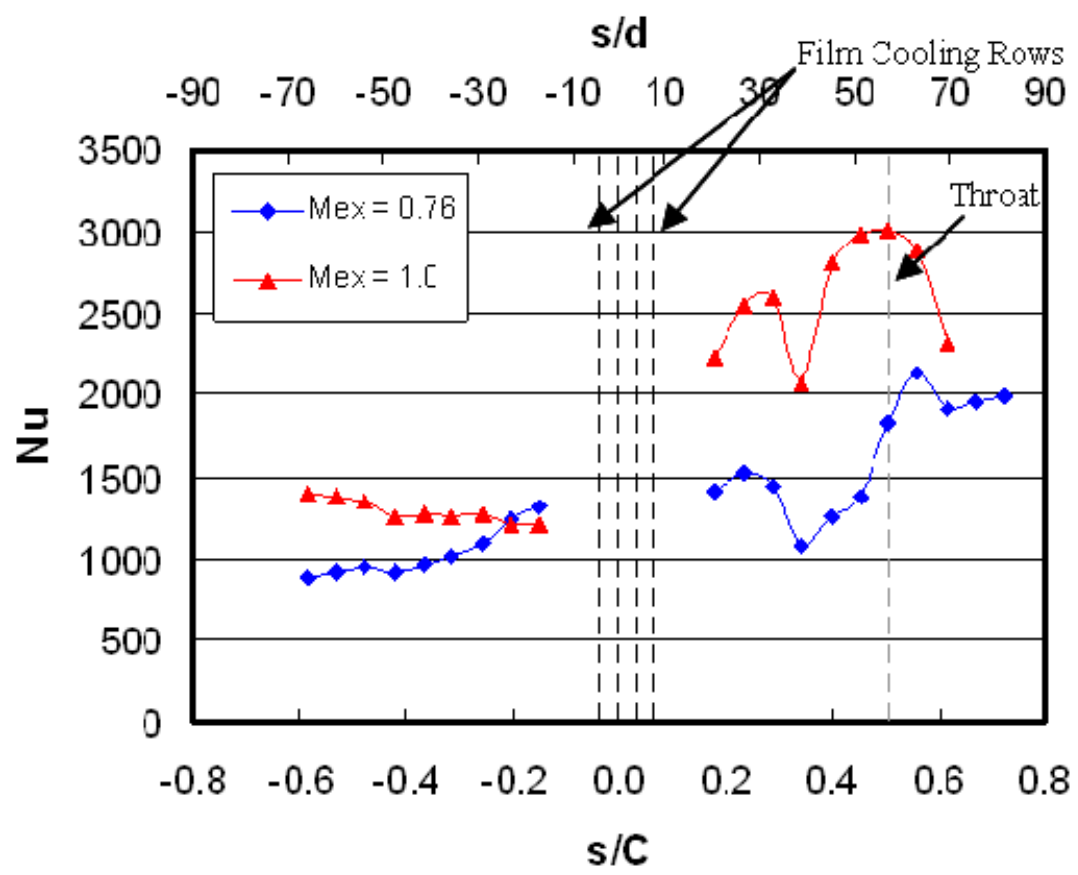

Figure 2.19. Effect of $\mathrm{Re} / \mathrm{Mach}$ number on $\mathrm{Nu}$ at $\mathrm{BR}=2.0$

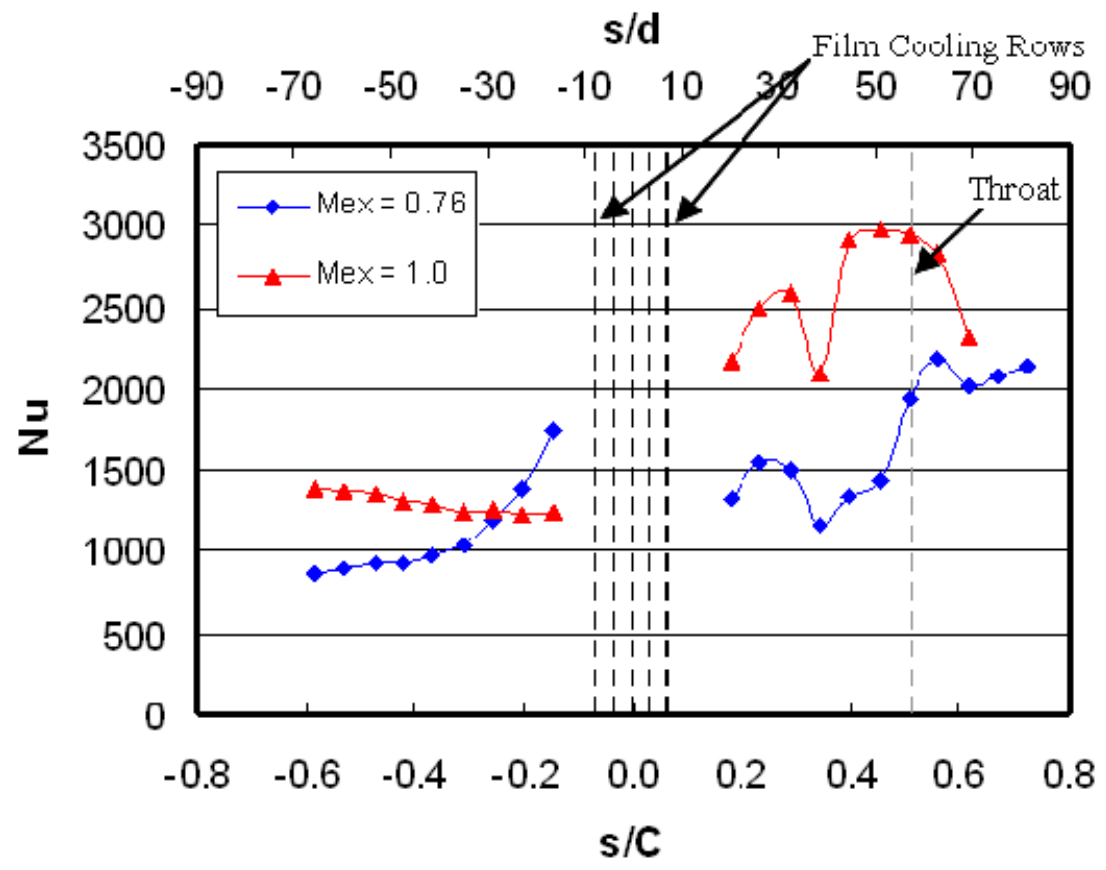

Figure 2.20. Effect of $\mathrm{Re} / \mathrm{Mach}$ number on $\mathrm{Nu}$ at $\mathrm{BR}=2.5$ 


\section{Effect of Re/Mach Number on Adiabatic Effectiveness}

Showerhead vane film cooling effectiveness was also seen to be affected by changing exit Reynolds number/Mach number conditions. Drost and Bölcs [7] observed that two essential flow field parameters: flow acceleration and boundary layer displacement thickness as a function of Reynolds number can have an impact on film effectiveness. The effect of Reynolds number on film cooling effectiveness found in literature is contradictory. Mehendale and Han [33] reported slightly increase in effectiveness for higher Reynolds number while Arts and Bourguignon [5] and Reiss and Bölcs [10] reported decrease in effectiveness with an increase in Reynolds number. The adiabatic effectiveness distributions showing the effect of increasing the Reynolds number at all three blowing ratio conditions $(B R=1.5,2.0$, and 2.5) are shown in Figures 2.21, 2.22 , and 2.23, respectively.

On the pressure surface, effectiveness levels decrease with the increase in exit Reynolds number from exit Mach 0.76 to 1.0 at all measurement locations for all blowing ratio conditions. A possible explanation of the adverse effect of large increase in Reynolds number on film cooling effectiveness is a reduction in coolant jet interaction with a relatively thinner boundary layer and thus dissipation of bigger portion of the coolant jet to the freestream at exit Mach 1.0 condition. An adverse affect of Reynolds number on the film cooling effectiveness is more pronounced as the blowing ratio increases because of partial or complete coolant jet lift-off further facilitating jet dissipation in the higher momentum freestream at exit Mach 1.0 condition.

On the suction surface, for blowing ratios 1.5 and 2.0, the adiabatic effectiveness levels remain similar downstream of injection with the increase in exit Reynolds number from exit Mach 0.76 to 1.0 , but then depreciate from $\mathrm{s} / \mathrm{C}=0.34$ to $\mathrm{s} / \mathrm{C}=0.51$ for the highest exit Reynolds number condition (Mach 1.0). At blowing ratio 2.5, an increase in exit Reynolds number from exit Mach 0.76 to 1.0 shows a decrease in effectiveness values downstream of injection and in a favorable pressure gradient and boundary layer transition region on the suction surface. 


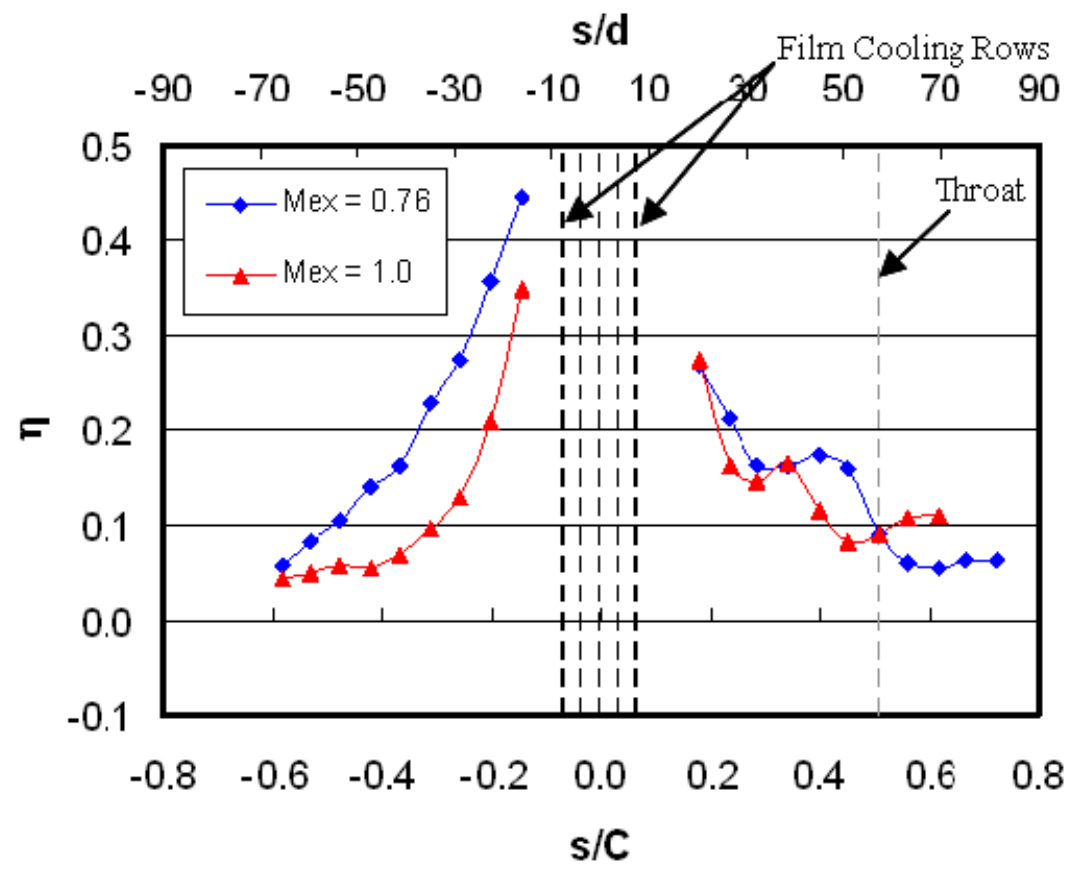

Figure 2.21. Effect of Re/Mach number on $\eta$ at $B R=1.5$

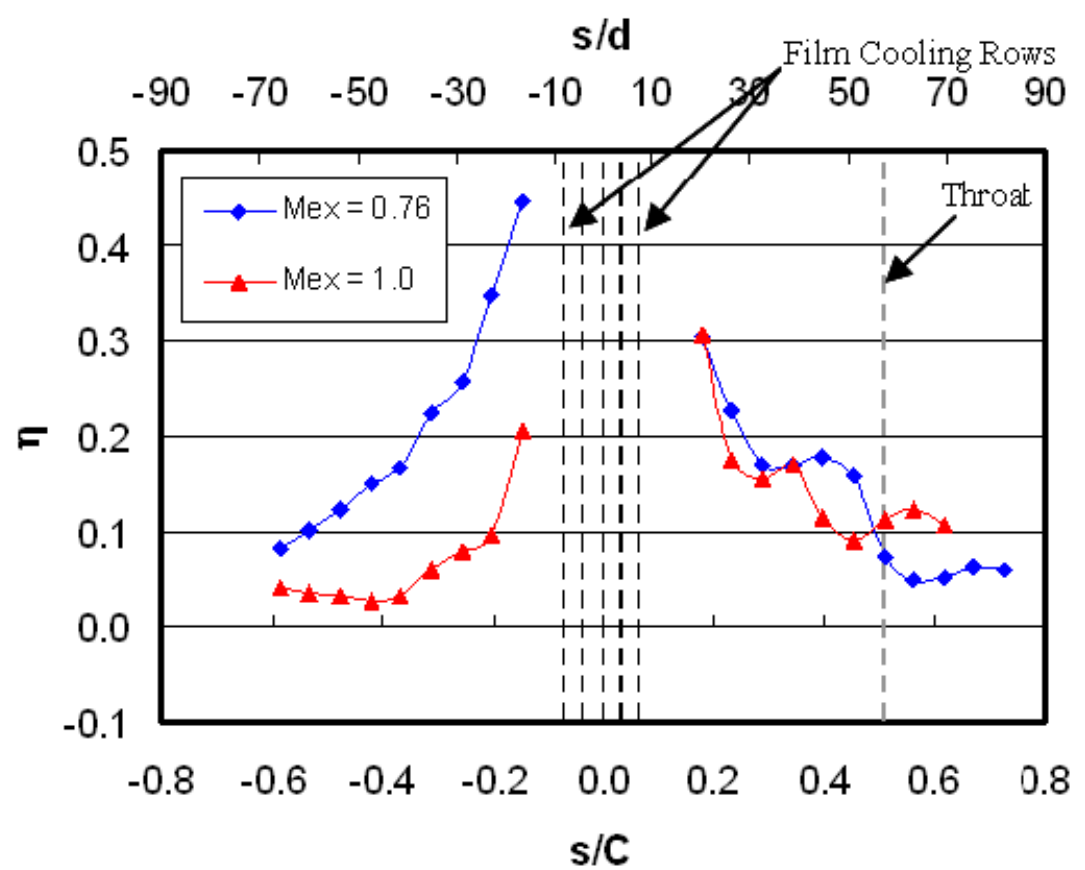

Figure 2.22. Effect of $\mathrm{Re} / \mathrm{Mach}$ number on $\eta$ at $\mathrm{BR}=2.0$ 


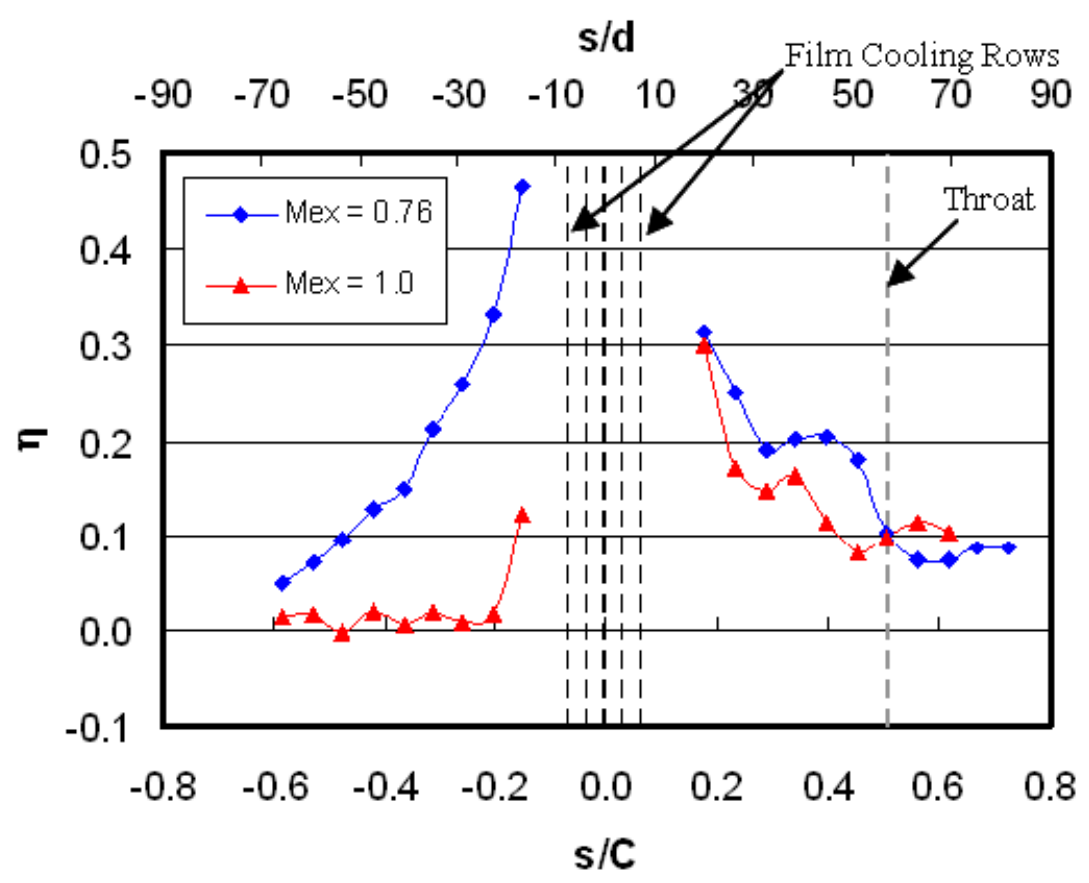

Figure 2.23. Effect of Re/Mach number on $\eta$ at $B R=2.5$

\section{Conclusions}

Experimental film cooling performance tests were performed on a showerhead film cooled vane at engine representative conditions in a transient, heated, blow-down transonic wind tunnel. Three different exit Mach numbers of $\mathrm{M}_{\mathrm{ex}}=0.57,0.76$ and 1.0-corresponding to exit Reynolds numbers based on vane chord of $9.7 \times 10^{5}, 1.1 \times 10^{6}$ and $1.5 \times 10^{6}$, respectivelywere tested with an inlet free stream turbulence intensity $(\mathrm{Tu})$ of $16 \%$ and an integral length scale normalized by vane pitch $\left(\Lambda_{\mathrm{x}} / \mathrm{P}\right)$ of 0.23 . A showerhead cooling scheme with five rows of cooling holes was tested at blowing ratios of $B R=0,1.5,2.0$, and 2.5 and a density ratio of $D R=$ 1.3. Nusselt number and adiabatic film cooling effectiveness distributions were presented on the vane surface over a range of $\mathrm{s} / \mathrm{C}=-0.58$ on the pressure side to $\mathrm{s} / \mathrm{C}=0.72$ on the suction side of the vane.

One of the primary effects of coolant injection was to augment Nusselt number downstream of the injection on the vane surface as compared to no film injection case $(B R=0)$ at all exit Mach number conditions. At exit Mach 0.57 and 0.76, an increase in blowing ratio from 1.5 to 2.5 showed a noticeable Nusselt number augmentation on the pressure surface as compared to the suction surface. At exit Mach 1.0, an increase in blowing ratio from 1.5 to 2.5 
showed negligible effect of Nusselt number augmentation on suction surface and showed partial/complete jet lift off downstream of coolant injection on the pressure surface.

Film cooling injection also reduced adiabatic wall temperature downstream of the injection on the vane surface as compared to no film injection case $(\mathrm{BR}=0)$ at all exit Mach number conditions. At exit Mach 0.57 and 0.76, an increase in blowing ratio was observed to either result in similar or slightly higher adiabatic effectiveness values on each surface (pressure and suction). At exit Mach 1.0, an increase in blowing ratio (1.5 to 2.5) was observed to have an adverse effect on adiabatic effectiveness on the pressure surface but had a negligible effect on the suction surface. The adiabatic effectiveness trend on the suction surface was also found to be influenced by a favorable pressure gradient due to Mach number in the region $\mathrm{s} / \mathrm{C}=0.28$ to $\mathrm{s} / \mathrm{C}=$ 0.45 at all blowing ratio and exit Mach number conditions.

An increase in blowing ratio from 1.5 to 2.5 had a noticeable effect on neat heat flux reduction and film coverage on the pressure surface as compared to the suction surface at all exit Mach conditions. Overall, the blowing ratio of 1.5 provided superior net heat flux reduction at all exit Mach number conditions.

An increase in Reynolds number from exit Mach 0.76 to 1.0 increased Nusselt number levels on the vane surface at all blowing ratio conditions. Large increase in Reynolds number adversely affected adiabatic effectiveness on the pressure surface at all blowing ratio conditions. On the suction surface, a large increase in Reynolds number also affected adiabatic effectiveness in a favorable pressure gradient and boundary layer transition region.

\section{Acknowledgements}

This work was sponsored by Solar Turbines Inc. We would also like to express our gratitude to Dr. Marcus Polanka of the Air Force Research Laboratory, Wright-Patterson AFB for his help with manufacturing and implementation of the thin film gauges. We would also like to thank Ashley Guy and Bill Songer for their valuable assistance in setting up the experiments. 


\section{References}

[1] Goldstein, R.J., 1971, “Film Cooling,” Advances in Heat Transfer, 7, pp. 321-380.

[2] Bogard, D.G., and Thole, K.A., 2006, "Gas Turbine Film Cooling," ASME J. Propulsion and Power, 22, pp. 249-270.

[3] Han, J.-C., Dutta, S., and Ekkad, S.V., 2000, Gas Turbine Heat Transfer and Cooling Technology, Taylor \& Francis, New York.

[4] Turner, E.R., Wilson, M.D., Hylton, L.D., and Kaufman, R.M., 1985, “Turbine Vane External Heat Transfer: Vol. 1: Analytical and Experimental Evaluation of Surface Heat Transfer Distributions with Leading Edge Showerhead Film Cooling," NASA CR-174827.

[5] Arts, T., and Bourguignon, A.E., 1990, "Behavior of a Coolant Film with Two rows of Holes along the Pressure Side of a High Pressure Nozzle Guide Vane," ASME J. Turbomach., 112, pp. 512-520.

[6] Abuaf, N., Bunker, R., and Lee, C.P., 1997, "Heat Transfer and Film Cooling Effectiveness in a Linear Airfoil Cascade," ASME J. Turbomach., 119, pp. 302-309.

[7] Drost, U., and Bölcs, A., 1999, "Investigation of Detailed Film Cooling Effectiveness and Heat Transfer Distribution on a Gas Turbine Airfoil," ASME J. Turbomach., 121, pp. 233-242.

[8] Guo, S.M., Lai, C.C., Jones, T.V., Oldfield, M.L.G., Lock, G.D., and Rawlinson, A.J., 1998, "The Application of Thin-film Technology to Measure Turbine-Vane Heat Transfer and Effectiveness in a Film-Cooled, Engine-Simulated Environment," Intl. J. Heat and Fluid Flow, 19, pp. 594-600.

[9] Zhang, L. J., Baltz, M., Pudupatty, R., and Fox, M., 1999, "Turbine Nozzle Film Cooling Study Using the Pressure Sensitive Paint (PSP) Technique,” ASME GT-1999-196.

[10] Reiss, H., and Bölcs, A., 2000, "The Influence of the Boundary Layer State and Reynolds Number on Film Cooling and Heat Transfer on a Cooled Nozzle Guide Vane," ASME GT-2000205.

[11] Haldeman, C.W., Mathison, R.M., Dunn, M.G., Southworth, S., Harral, J.W., and Heitland, G., 2006, "Aerodynamic and Heat Flux Measurements in a Single Stage Fully Cooled Turbine Part II: Experimental Results,” ASME GT-2006-90968.

[12] Nasir, S., Carullo, J.S., Ng, W.F., Thole, K.A., Wu, H., Zhang, L.J., and Moon, H.K., 2007, "Effects of Large Scale High Freestream Turbulence, and Exit Reynolds Number on Turbine Vane Heat Transfer in a Transonic Cascade," ASME IMECE-2007-44098.

[13] Nix, A.C., Diller, T.E., and Ng, W.F., 2007, "Experimental Measurements and Modeling of the Effects of Large-Scale Freestream Turbulence on Heat Transfer," ASME J. Turbomach., 129, pp. $542-55$ 
[14] Holmberg, D.G., and Diller, T.E., 2005, "Simultaneous Heat Flux and Velocity Measurements in a Transonic Turbine Cascade," ASME J. Turbomach., 127, pp. 502-506.

[15] Smith, D.E., Bubb, J.V., Popp, O., Grabowski, H.C., Diller, T.E. Schetz, J.A. and Ng. W.F., 2000, "An Investigation of Heat Transfer in a Film Cooled Transonic Turbine Cascade, Part I: Steady Heat Transfer," ASME GT-2000-202.

[16] Popp, O., Smith, D.E., Bubb, J.V., Grabowski, H.C., Diller, T.E. Schetz, J.A. and Ng. W.F., 2000, "An Investigation of Heat Transfer in a Film Cooled Transonic Turbine Cascade, Part II: Unsteady Heat Transfer,” ASME GT-2000-203.

[17] Colban, W., Gratton, A., and Thole, K.A., 2006, "Heat Transfer and Film-Cooling Measurements on a Stator Vane with Fan-Shaped Cooling Holes," ASME J. Turbomach., 128, pp. 53-61.

[18] Doorly, J.E., and Oldfield, M.L.G., 1987, "The Theory of Advanced Multi-Layer Thin Film Heat Transfer Gages," Intl. J. Heat and Mass Transfer, 30, pp. 1159-1168.

[19] Joe, C.R., 1997, "Unsteady Heat Transfer on the Turbine Research Facility at Wright Laboratory," Ph.D. Dissertation, Syracuse University.

[20] Nasir, S., 2008, "Showerhead Film Cooling Performance of a Turbine Vane at High Freestream Turbulence in a Transonic Cascade," Ph.D. Dissertation, Virginia Polytechnic Institute and State University.

[21] Cress, R.D., 2006, "Turbine Blade Heat Transfer Measurements in a Transonic Flow Using Thin film Gages," Master's Thesis, Virginia Polytechnic Institute and State University.

[22] Vedula, R. P., and Metzger, D. E., 1991, "A Method for the Simultaneous Determination of Local Effectiveness and Heat Transfer Distributions in a Three Temperature Convective Situations," ASME GT-1991-345.

[23] Moffat, R. J., 1988, "Describing Uncertainties in Experimental Results," Exp. Thermal and Fluid Science, 1, pp. 3-17.

[24] Brown, K.H., Coleman, H.W., and Steele, W.G., 1995, "Estimating Uncertainty Intervals for Linear Regression," AIAA-1995-0796.

[25] Jones, W.P., and Launder, B. E., 1972, "The Prediction of Laminarization with a TwoEquation Model of Turbulence," Intl. J. Heat and Mass Transfer, 15, pp. 301-314.

[26] Mayle, R.E., 1991, "The Role of Laminar-Turbulent Transition in Gas Turbine Engines," ASME J. Turbomach., 113, pp. 509-537. 
[27] Ou, S., Han, J.-C., Mehendale, A.B., and Lee, C.P., 1994, "Unsteady Wake Over a Linear Turbine Blade Cascade with Air and $\mathrm{CO}_{2}$ Film Injection: Part I-Effect on Heat Transfer Coefficients," ASME J. Turbomach., 116, pp. 721-729.

[28] Ekkad, S.V., Mehendale, A.B., Han, J.-C., and Lee, C.P., 1997, “Combined Effect of Grid Turbulence and Unsteady Wake on Film Effectiveness and Heat Transfer Coefficient of a Gas Turbine Blade with Air and $\mathrm{CO}_{2}$ Film Injection," ASME J. Turbomach., 119, pp. 594-600.

[29] Ames, F.E., 1996, "Experimental Study of Vane Heat Transfer and Film Cooling at Elevated Levels of Turbulence," NASA CR-198525.

[30] van Oudheusden, B.W., 2004, "Compressibility Effects on the Extended Crocco Relation and the Thermal Recovery Factor in Laminar Boundary Layer Flow," ASME J. Turbomach., 126, pp. 32-41.

[31] Mhetras, S., Han, J.-C., and Rudolph, R., 2007, "Effect of Flow Parameter Variations on Full Coverage Film-Cooling Effectiveness for a Gas Turbine Blade,” ASME GT-2007-27071.

[32] Lu, Y., Dhungel, A., Ekkad, S.V., and Bunker, R.S., 2007, "Effect of Trench Width and Depth on Film Cooling from Cylindrical Holes Embedded in Trenches," ASME GT-2007-27388.

[33] Mehendale, A.B., and Han, J.-C., 1993, "Reynolds number Effect on Leading Edge Film Effectiveness and Heat Transfer Coefficient," Intl. J. Heat and Mass Transfer, 36, pp. 37233730 . 


\section{Preface Paper 3}

Paper 3 presents 3-D CFD study to calculate and explain adiabatic film cooling effectiveness and Nusselt number distributions downstream of the showerhead film cooling rows of a turbine vane at high freestream turbulence and realistic exit Reynolds number/Mach number condition. The paper has been submitted to ASME IMECE 2008 (IMECE-2008-67782) and will also be submitted to ASME Journal of Turbomachinery. For more details regarding this paper, please refer to Appendices A-E, and H. 


\title{
Showerhead Film Cooling Performance of a Transonic Turbine Vane at High Freestream Turbulence (Tu =16\%): 3-D CFD and Comparison with Experiment
}

\author{
Hong $\mathrm{Wu}$ \\ School of Jet Propulsion \\ Beihang University \\ Beijing, 100083, China \\ S. Nasir and W.F. Ng \\ Mechanical Engineering Department \\ Virginia Polytechnic Institute and State University \\ Blacksburg, VA 24061 \\ H.K. Moon \\ Solar Turbines Inc. \\ San Diego, CA 92101 \\ IMECE Paper 2008-67782 \\ To be submitted to the Journal of Turbomachinery
}

\begin{abstract}
The main objective of the study reported here is to use 3-D CFD to calculate and explain adiabatic film cooling effectiveness and Nusselt number distributions downstream of the showerhead film cooling rows of a turbine vane at high freestream turbulence and realistic exit Reynolds number/Mach number condition. The paper discusses a new three-simulations technique to calculate vane surface recovery temperature, adiabatic wall temperature, and surface Nusselt number to completely characterize film cooling performance in a high speed flow. The RANS based $v^{2}-f$ turbulence model, originally suggested by Durbin [1], is used in all numerical predictions. The vane midspan numerical calculations are compared with the experimental results obtained with the showerhead film cooled vane instrumented with single-sided platinum thin film gauges at the midspan and arranged in a two-dimensional, linear cascade in a heated, transonic, blow-down wind tunnel. Exit Mach number of $\mathrm{M}_{\mathrm{ex}}=0.76-$ corresponding to exit
\end{abstract}


Reynolds numbers based on vane chord of $1.1 \times 10^{6}$-was tested with an inlet free stream turbulence intensity $(\mathrm{Tu})$ of $16 \%$ and an integral length scale normalized by vane pitch $\left(\Lambda_{\mathrm{x}} / \mathrm{P}\right)$ of 0.23. A showerhead cooling scheme with five rows of cooling holes was tested at blowing ratios of $\mathrm{BR}=0$ and 1.5 , and a density ratio of $\mathrm{DR}=1.3$.

CFD calculations performed with experiment-matched boundary conditions show an overall good agreement with experimental adiabatic film cooling effectiveness and Nusselt number distributions downstream of the showerhead film cooling rows of the vane. For the experimental data, the primary effects of coolant injection are to augment Nusselt number and reduce adiabatic wall temperature downstream of the injection on the vane surface as compared to no film injection case $(\mathrm{BR}=0)$ at $\mathrm{M}_{\mathrm{ex}}=0.76$. Similar to experimental results, the adiabatic film cooling effectiveness prediction on the suction surface at $\mathrm{BR}=1.5$ is found to be influenced by favorable pressure gradient due to Mach number through changes in local adiabatic wall and recovery temperature. The Nusselt number prediction on the suction surface shows a peak and a valley downstream of the film cooling rows in a favorable pressure gradient region for both tested blowing ratio conditions. This trend is also observed in the experimental results.

\section{Nomenclature}

$\begin{array}{ll}A & \text { area } \\ A+ & \text { effective sublayer thickness } \\ B R & \text { blowing ratio } \\ C & \text { vane chord } \\ d & \text { cooling hole diameter } \\ D R & \text { density ratio } \\ f & \text { elliptic operator in V2F model } \\ h & \text { heat transfer coefficient } \\ k & \text { acceleration parameter / thermal conductivity } \\ M & \text { Mach number } \\ \dot{m} & \text { mass flow rate } \\ N u & \text { Nusselt number } \\ P & \text { vane pitch } \\ p & \text { cooling hole pitch } \\ P r & \text { Prandtl number } \\ q ” & \text { heat flux } \\ R e & \text { Reynolds number } \\ S & \text { vane surface distance from stagnation point } \\ T & \text { temperature }\end{array}$




$\begin{array}{ll}T u & \text { streamwise freestream turbulence intensity } \\ U & \text { local velocity } \\ v^{2} & \text { wall normal Reynolds stress component } \\ y^{+} & \text {equivalent normal distance }\end{array}$

\section{Greek}

$\begin{array}{ll}\alpha & \text { spanwise hole cooling angle } \\ \varepsilon & \text { turbulent dissipation } \\ \gamma & \text { compound injection angle } \\ \eta & \text { adiabatic film cooling effectiveness } \\ \Lambda_{x} & \text { integral turbulence length scale } \\ \rho & \text { local density } \\ \mu & \text { dynamic viscosity } \\ \nu & \text { kinematic viscosity } \\ \tau & \text { shear stress } \\ \omega & \text { specific turbulent dissipation }\end{array}$

\section{Subscripts}

$\begin{array}{ll}0 & \text { no film cooling } \\ \infty, \mathrm{a} & \text { freestream, air } \\ \text { aw, w } & \text { adiabatic wall, wall } \\ \mathrm{c} & \text { coolant } \\ \mathrm{ex}, \mathrm{i} & \text { exit, inlet } \\ \mathrm{g} & \text { gas } \\ \mathrm{o} & \text { stagnation } \\ \mathrm{r} & \text { recovery } \\ \mathrm{t} & \text { turbulent }\end{array}$

\section{Introduction}

Film cooling of high pressure gas turbine components (blades and vanes) is a widely used technique that allows higher turbine inlet temperatures for improved engine cycle performance. In this cooling method, air is extracted from the compressor and forced through internal cooling passages within turbine blades and vanes before being ejected through discrete cooling holes on the surfaces of these airfoils. The air leaving these cooling holes forms a film of cool air on the component surface which protects the components from hot gas exiting the combustor.

CFD is an essential design tool to predict film cooling performance of gas turbine components but in order to ensure computational reliability, it is imperative to validate the predictions with experimental studies. One of the earliest gas turbine blade film cooling studies 
in high speed facility come from the experimental work of Camci and Arts [2-4], who measured heat transfer coefficient over a film cooled VKI rotor in a short duration, transonic wind tunnel facility. Measurements were performed at engine representative exit Mach, $\mathrm{M}_{\mathrm{ex}}=0.90$ and varying inlet freestream turbulence intensities from $0.8 \%$ to $5.2 \%$. They found that increasing the coolant mass flow decreased the heat transfer coefficient levels below the uncooled case. An increase in freestream turbulence did not have a significant effect on heat transfer coefficient and the existence of cooling holes without injection lead to an earlier boundary layer transition on the suction surface.

The effects of varying Reynolds number, Mach number, coolant injection rate, and coolant to temperature ratio were experimentally investigated on a showerhead film cooled NASA C3X vane at medium freestream turbulence $(\mathrm{Tu}=6.5 \%)$ in a transonic, linear cascade wind tunnel by Turner et al. [5]. Increasing the rate of coolant injection was seen to increase the heat transfer coefficient. Increases in Reynolds number in the film cooled case were also seen to augment the heat transfer coefficient. It was noted that the addition of film cooling had a definite effect on heat transfer coefficient in the laminar region, but after transition the effect of film cooling was negligible. Film cooling was shown to move the location of laminar to turbulent transition slightly further upstream.

Later, Nirmalan and Hylton [6] studied the effects of various operating parameters investigated by Turner et al. [5] on a fully film cooled C3X vane. Typical results were presented at exit Mach number condition of $\mathrm{M}_{\mathrm{ex}}=0.90$ and exit Reynolds number of $2.0 \times 10^{6}$. This study did not have any instrumentation in the region between the showerhead and downstream rows. The downstream film cooling was shown to be a complex function of mainly two competing mechanisms: (i) the thermal dilution due to injection of relatively cold fluid, and (ii) turbulence augmentation due to injection process. The pressure surface showed higher variance in heat transfer reduction due to parameters such as thermal dilution, exit Mach number, and turbulence augmentation. This investigation was a fairly good representation of actual engine conditions.

Several computational studies have been performed to explain and predict film cooling on turbine blades and vanes at engine realistic flow conditions. Garg and Ameri [7] used 3-D RANS code with Coakley's $q-\omega$ model, Chien's $k-\varepsilon$ model and Wilcox's $k-\omega$ model to predict heat transfer coefficient at low freestream turbulence on the film cooled VKI rotor with six rows of cooling holes including three rows in the showerhead and the NASA C3X vane with nine 
rows of holes including five rows in the showerhead. Later, Garg [8] used a multi-block 3-D RANS code with Wilcox's $k$ - $\omega$ model to study with-in hole and near-hole physics in relation to heat transfer on the showerhead film cooled VKI rotor blade. He found a reasonably good agreement with the experimental data over the whole surface but found that near hole heat transfer coefficient distribution was dependent on velocity and temperature distribution profiles inside the cooling holes.

Heidmann et al. [9] performed 3-D coupled internal/external heat transfer simulation of Allied Signal's film cooled vane using the LeRC-HT code at engine representative exit Mach number condition of $\mathrm{M}_{\mathrm{ex}}=0.876$ and freestream turbulence intensity of $8 \%$. The turbulence closure was done by means of modified Wilcox's $k$ - $\omega$ model as implemented by Chima [10]. Two computations were performed for different isothermal wall temperatures to allow independent determination of heat transfer coefficient and film cooling effectiveness values. The numerical results were not validated with the experiments but showed that the shaped holes on the pressure surface provided a reduction in heat flux through the reduction in heat transfer coefficient and increase in film cooling effectiveness as compared to showerhead region circular shaped holes.

Ginibre et al. [11] computed wall heat flux on a 3-D slice of high pressure film cooled NGV with multiple rows of injections to evaluate 3D Navier-Stokes solver developed by Snecma Moteurs. The turbulence closure was done by means of algebraic mixing length model and Spalart-Allmaras one-transport equation model. Ginibre et al. found that both the models predicted similar span averaged heat flux values but Spalart-Allmaras model was more appropriate for industrial use because of its generality and robustness.

Medic and Durbin [12] presented flow and heat transfer coefficient predictions for a high pressure film cooled VKI rotor blade with turbulent time-scale bound $k$ - $\varepsilon$ model, standard and modified $k-\omega$ model, and $v^{2}-f$ model. All the simulations were performed at exit Mach number condition of $\mathrm{M}_{\mathrm{ex}}=0.92$ and freestream turbulence of 5\%. They found that for low blowing ratios, the modified $k-\varepsilon$ model and $v^{2}-f$ model gave satisfactory predictions of overall heat transfer coefficient levels on the film cooled vane surface. For higher blowing ratios, on the suction surface, the modified $k-\varepsilon$ model and $v^{2}-f$ model overpredicted film cooling in the vicinity of film cooling holes. For higher blowing ratios, on the pressure surface, the $v^{2}-f$ model predicted stronger jet lateral spreading as compared to the other models. 
Montomoli et al. [13] upgraded the finite volume CFD solver Hybflow, to perform conjugate heat transfer simulations of QinetiQ MT1 high pressure NGV at freestream turbulence of $5.5 \%$. The heat transfer coefficient distribution over the vane surface showed good agreement with the experimental data of Chana and Mole [14].

Recently, Laskowski et al. [15] obtained coupled 3-D CFD heat transfer simulations for a high pressure film cooled VKI rotor blade and high pressure film cooled C3X vane with the shear stress transport (SST) turbulence model of Menter [16]. Laskowski et al. found that film cooling simulations consistently underpredicted heat transfer coefficient downstream of the film cooling holes. They also noted better lateral film cooling coverage for the VKI rotor as compared to the $\mathrm{C} 3 \mathrm{X}$ vane.

The unique contribution of this work is to experimentally and numerically investigate the effects of coolant injection on film cooling performance of a showerhead film cooled first stage turbine vane at high freestream turbulence $(\mathrm{Tu}=16 \%)$ and realistic exit Mach number condition $\left(\mathrm{M}_{\mathrm{ex}}=0.76\right)$. Showerhead film cooling performance is characterized by Nusselt number and adiabatic film cooling effectiveness along the surface of the vane. The paper discusses a new three-simulations technique to calculate vane surface recovery temperature, adiabatic wall temperature, and surface Nusselt number to completely characterize film cooling performance in a high speed flow.

\section{Experimental Setup and Instrumentation}

Vane showerhead film cooling measurements are performed in a two-dimensional Virginia Tech transonic cascade wind tunnel facility shown in Figure 3.1. The detail discussion of experimental setup, instrumentation and film cooling data analysis procedure is given by Nasir et al. [17] but for completeness of this paper, is briefly repeated here. Virginia Tech transonic cascade wind tunnel is a blow-down facility capable of sustaining a constant inlet pressure in the test section for up to 25 seconds. Air is supplied from high pressure air tanks that are charged up to $1380 \mathrm{kPa}$ (200 psig) prior to testing. A control valve regulates the flow from the air tanks to the test section. Cascade inlet pressures range from $20.7 \mathrm{kPa}$ (3 psig) to $69.0 \mathrm{kPa}$ (10 psig) depending on the objective test conditions. Between the control valve and the test section, the air passes through a passive heat exchanger, which heats the cascade inlet flow up to $120^{\circ} \mathrm{C}$. After 
the air passes through the heat exchanger, the air goes through a contraction and enters the test section before being exhausted to the atmosphere.

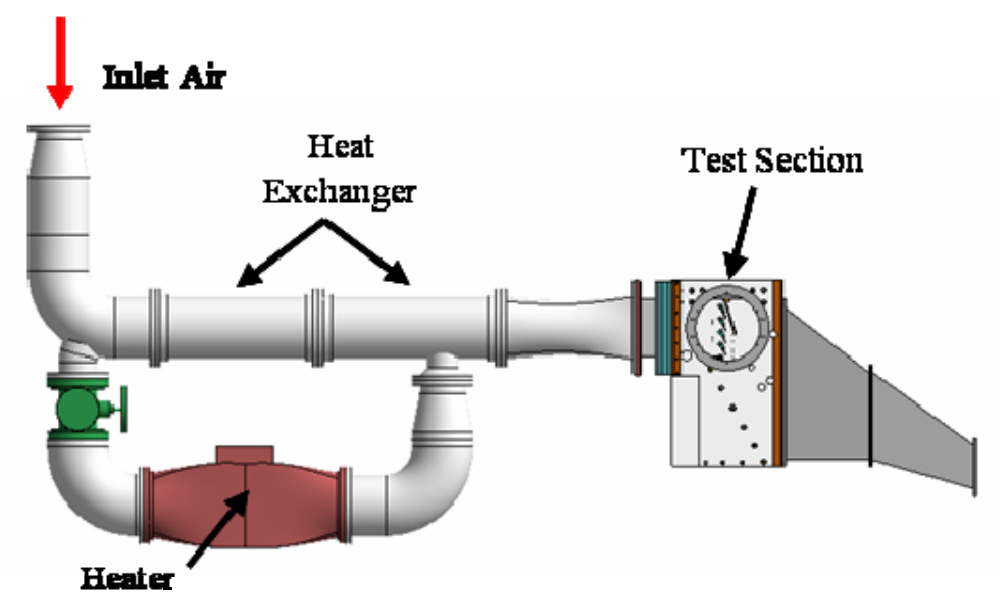

Figure 3.1. Virginia Tech transonic cascade wind tunnel

A showerhead film cooled vane with five rows of staggered cylindrical cooling holes is used in this study. The exit of the center row of cooling holes is placed at the geometric stagnation point on the vane. There are a total of 83 holes in all five rows. The number of cooling holes on the stagnation region row is 17 . The nearest downstream rows on either side have 16 holes each, and the farthest downstream rows have 17 holes each. The spacing between rows is 4 hole diameters on the vane surface and 3 hole diameters in the plenum as shown in Figure 3.2. Cooling flow is injected at $90^{\circ}$ angle to the freestream and $45^{\circ}$ angle to the span of the vane as shown in Figure 3.3. The turbine vane tested in these experiments is similar in geometry to a first stage turbine vane for a small industrial gas turbine. The vane is scaled one-and-half times so that the nominal exit Reynolds number would be at the desired value. Table 3.1 summarizes the geometry of the showerhead film cooled turbine vane.

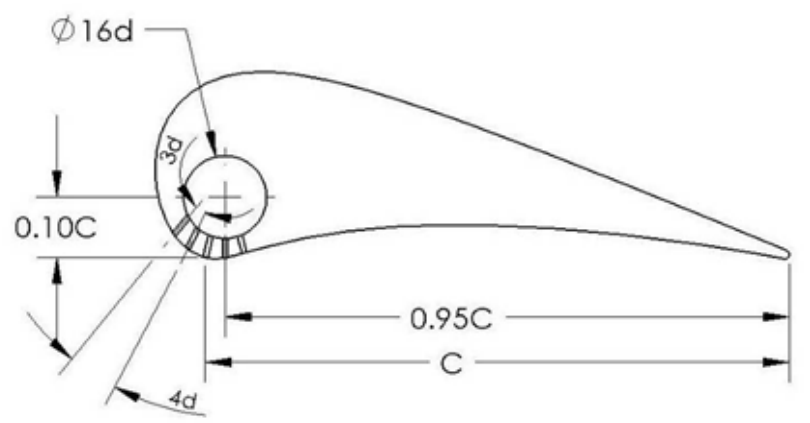

Figure 3.2. Profile view of showerhead film cooled vane 


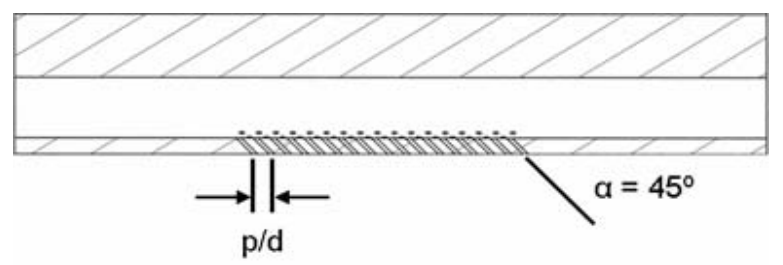

Figure 3.3. Section view of the stagnation row of holes

Table 3.1. Film cooled vane geometry

\begin{tabular}{|c|c|c|}
\hline Vane Chord (see Figure 2.2.) & $C$ & $91.2 \mathrm{~mm}(3.59 \mathrm{in})$. \\
\hline Vane Pitch & $P$ & $83.0 \mathrm{~mm}(3.27 \mathrm{in})$. \\
\hline Cooling Hole Diameter & $d$ & $0.787 \mathrm{~mm}(0.031 \mathrm{in})$. \\
\hline Cooling Hole Spacing & $p / d$ & 4.35 \\
\hline Hole Spanwise Angle & $\alpha$ & $45^{\circ}$ \\
\hline Compound angle (streamwise) & $\gamma$ & $90^{\circ}$ \\
\hline Vane Span & & $152.4 \mathrm{~mm}(6.00 \mathrm{in})$. \\
\hline Cooled Span & & $59.2 \mathrm{~mm}(2.33 \mathrm{in})$. \\
\hline Vane Inlet and Exit Angle & & $0^{\circ}$ and $73.5^{\circ}$ \\
\hline
\end{tabular}

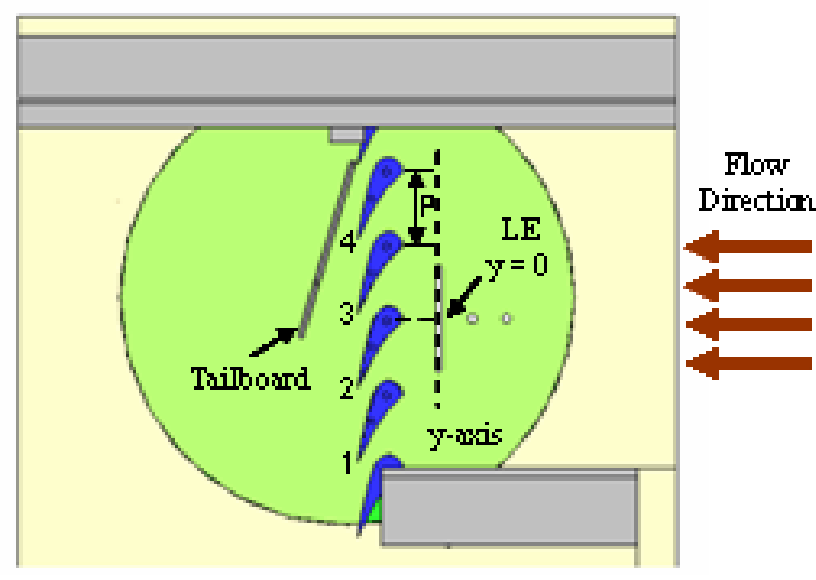

Figure 3.4. 2-D linear turbine vane cascade

The vane cascade shown in Figure 3.4 consists of four full vanes and two partial vanes, which result in four full passages and one partial passage. Vane 2 is instrumented to make independent static pressure and heat transfer measurements. The vertical slot located $0.45 \mathrm{C}$ upstream of the cascade is used to measure the turbulence and velocity distributions at the inlet of the cascade. Inlet freestream turbulence is generated by a passive, square mesh grid. The film cooling measurements are performed at a freestream turbulence levels of $\mathrm{Tu}=16 \%$ with an integral length scale normalized by vane pitch of $\Lambda_{\mathrm{X}} / \mathrm{P}=0.23$. The transonic blow-down wind 
tunnel performance, turbulence grid geometry and measurements of turbulence are described further by Nasir et al. [18].

Coolant is supplied to the showerhead film cooled vane plenum from a storage tank pressurized to $120 \mathrm{psig}$ with filtered, dried air. The air is dried to a relative humidity less than $4 \%$. The air exiting the tank is regulated by a control valve and passed through a coil of pipe immersed in water bath. The temperature of the water bath is adjusted in such a way that the air temperature flowing through the vane plenum matches the initial vane temperature $\left(\sim 26^{\circ} \mathrm{C}\right)$ before every experimental run. The coolant to freestream density ratio, DR, is defined as:

$$
D R=\frac{\rho_{c}}{\rho_{\infty}}
$$

The freestream density $\left(\rho_{\infty}\right)$ is calculated from cascade inlet conditions measured by a Pitot-static probe and a T-type stagnation temperature measurement probe. The coolant density $\left(\rho_{c}\right)$ is determined from a T-type thermocouple inserted near midspan at the center of the vane plenum and a Pitot-static probe near the entrance to the plenum. The density ratio, DR, is between 1.3 for all of the tested conditions.

An average coolant to freestream blowing ratio, BR, for the entire showerhead region as outlined by Colban et al. [19] is defined as:

$$
B R=\frac{\rho_{c} U_{c}}{\rho_{\infty} U_{\infty}}=\frac{\dot{m}_{c}}{A_{\text {holes }} \rho_{i} U_{i}}
$$

where the mass flow of the coolant is measured with an orifice plate meter and divided by the area of the film cooling holes to find the coolant mass flux. Freestream mass flux is calculated from cascade inlet flow conditions.

Heat transfer measurements on a film cooled vane are made with single-sided platinum thin film gauges manufactured by Air Force Research Laboratories according to the procedure described by Joe [20]. The film cooled vane is instrumented with 20 single-sided platinum thin film gauges with measurement extent of $\mathrm{s} / \mathrm{C}=-0.58$ on the pressure side to $\mathrm{s} / \mathrm{C}=0.72$ on the suction side of the vane. Once properly calibrated for the temperature coefficient of resistivity, each gauge gives a unique surface temperature history during transient temperature blow-down run. The gauges are installed on a low thermally conductive Macor $(k=1.46 \mathrm{~W} / \mathrm{mK})$ vane midspan and the coolant temperature in the vane plenum is controlled to match the initial vane temperature $\left(\sim 26^{\circ} \mathrm{C}\right)$. This allows 1-D semi-infinite assumption to be used for all the gauges 
installed on the film cooled vane to calculate normal heat flux ( $\left.q^{\prime \prime}\right)$ into the vane during transient temperature blow-down run. The working principle, physical properties, calibration and data acquisition procedures of these gauges have been described further by Nasir et al. [18], Nasir [21], and Cress [22].

\section{Determination of Heat Transfer Coefficient and Adiabatic Film Cooling Effectiveness}

Heat Transfer in a high speed film cooled environment can be described by:

$$
q^{\prime \prime}=h\left(T_{a w}-T_{w}\right)
$$

where $T_{w}$ is measured on the surface of the vane using the platinum thin film gauge and $T_{a w}$ is the temperature of an assumed adiabatic wall that is the driving temperature of heat transfer. The adiabatic wall temperature can be nondimensionalized into adiabatic film cooling effectiveness for high speed flow as:

$$
\eta=\frac{T_{a w}-T_{r}}{T_{c}-T_{r}}
$$

In film cooling, $h$ and $\eta$ are the two quantities of interest. It is often necessary to determine these quantities from separate experiments as suggested by Vedula and Metzger [23]. In the Virginia Tech facility, flow conditions are at quasi-steady state while the temperatures of the freestream and vane surface are transient. This allows for determination of heat transfer coefficient and film cooling effectiveness during a single tunnel run. This data analysis procedure is outlined in Smith et al. [24]. Equations 3.3 and 3.4 can be arranged to yield:

$$
\frac{q^{\prime \prime}}{T_{r}-T_{c}}=h\left(\frac{T_{r}-T_{w}}{T_{r}-T_{c}}\right)-h \eta
$$

where $q$ " is calculated with the single-sided thin film gauge.

In this form, Equation 3.5 is equivalent to the standard line equation of $y=m x+b$. The nondimensional temperature variable multiplied by $h$ in Equation 3.5 is plotted as the x-axis and the left side of the equation is plotted as the y-axis for the quasi-steady portion of the sample run. The slope of the line is the heat transfer coefficient and the x-intercept is the adiabatic film cooling effectiveness. The slope is determined using a least squares linear regression fit of the plotted data. The effectiveness is given by the intersection of the x-axis-where $q$ " goes to zero. 
The heat transfer coefficient and effectiveness were determined at each instrumented location for each tunnel run. The heat transfer coefficient result is nondimensionalized in terms of Nusselt number described by:

$$
N u=\frac{h \cdot C}{k_{a}}
$$

\section{Determining Recovery Temperature, $T_{r}$}

In the experiment, instead of assuming local freestream recovery temperature, $T_{r}$, based on local Mach number and recovery factor, it is measured in a high speed flow from the no film injection $(\mathrm{BR}=0)$ case. With no film cooling, heat transfer in a high speed environment can be described by:

$$
q_{0} "=h_{0}\left(T_{r}-T_{w}\right)
$$

where $T_{w}$ is measured on the surface of the vane using the platinum thin film gauge and $h_{0}$ is the heat transfer coefficient for no film injection $(\mathrm{BR}=0)$ case. Equation 3.7 can be rewritten as:

$$
q_{0} "=h_{0}\left(T_{o, \infty}-T_{w}\right)-h_{0}\left(T_{o, \infty}-T_{r}\right)
$$

Using Equation 3.8, we can determine $h_{0}$ and $T_{r}$ by plotting $q_{0}$ " versus $\left(T_{o, \infty}-T_{w}\right)$ for the quasi-steady portion of the run. The result gives us a line of the form $y=m x+b$, where the slope of the line is heat transfer coefficient without film cooling and the $\mathrm{x}$-intercept of the line is $\left(T_{o, \infty}-\right.$ $\left.T_{r}\right)$. $\left(T_{o, \infty}-T_{r}\right)$ was determined at each measurement location and then used to find the recovery temperature using $T_{o, \infty}$ from the film cooled runs. More explanation of this technique can be seen in Smith et al. [24] and Popp et al. [25].

\section{Uncertainty Analysis}

The overall uncertainty of the quantities of interest, $h$ and $\eta$, is determined with the aid of two methods. First, Moffat's [26] small perturbation uncertainty method is used to estimate the bias and precision uncertainties of the $q^{\prime \prime} /\left(T_{r}-T_{c}\right)$ and $\left(T_{r}-T_{w}\right) /\left(T_{r}-T_{c}\right)$ values plotted in Equation 3.5. Brown and Coleman's [27] linear regression analysis is used to obtain the uncertainty of the fit ( $h$ and $\eta$ ) based upon uncertainties determined by Moffat's method for each gauge during the useful data reduction time. All uncertainties are reported within $95 \%$ 
confidence interval. For each test condition, measurements were performed at least three times to establish repeatability. The overall average uncertainty in heat transfer coefficient and adiabatic effectiveness is determined to be $\pm 6.5 \%$ and \pm 0.032 , respectively.

\section{Computational Methodology}

Film cooling CFD simulations were performed using a commercially available software package (FLUENT 6.3.26). A 3-D computational domain representing one full vane passage with periodic boundary conditions was employed to simulate the cascade test condition. A side view of 3-D computational domain for external and internal flow is shown in Figure 3.5. The freestream inlet was located at $0.45 \mathrm{C}$ upstream of the vane leading edge. For all tests cases, total pressure, total temperature, freestream turbulence level, and integral length scale were specified at the freestream inlet and static pressure was specified at the domain outlet. Total pressure and temperature were set at the plenum inlet boundary depending on the particular coolant injection rate being investigated. The exit end of the plenum was closed off. In addition, adiabatic no-slip wall boundary conditions were specified along the plenum and film cooling hole walls and also along the end walls of the 3-D vane in the spanwise direction. Fluid specific heat, thermal conductivity and molecular viscosity were kept constant for all test cases. For energy Prandtl number, a constant value of 0.85 was used. Figure 3.6 shows the leading edge region of the 3-D computational domain.

For the FLUENT solver, coupled implicit solution method with second-order upwind discretization scheme was chosen. The RANS based $v^{2}-f$ turbulence model from CASCADE Inc. was used in all numerical predictions. Unlike conventional two-equation eddy viscosity models, $v^{2}-f$ model solves two additional turbulence transport equations-one for the wall-normal Reynolds stress component $\left(v^{2}\right)$ and other for an elliptic relaxation function $(f)$ - to incorporate near-wall turbulence anisotropic behavior and remove the necessity of wall damping functions. The $v^{2}-f$ turbulence model was selected because of its proven ability to produce reasonable heat transfer predictions on airfoil surface with and without the presence of film cooling $[12,17$, and 28-32]. 


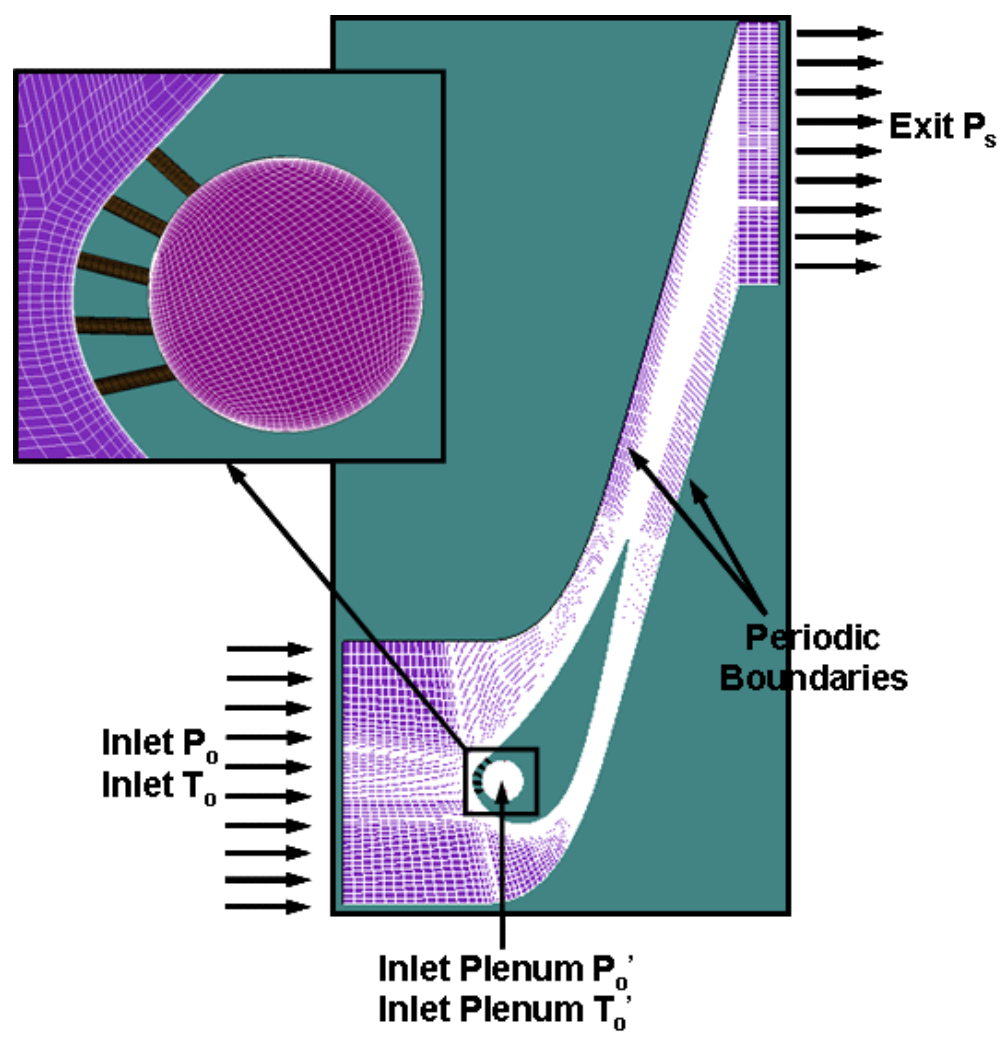

Figure 3.5. Side view of 3-D CFD domain

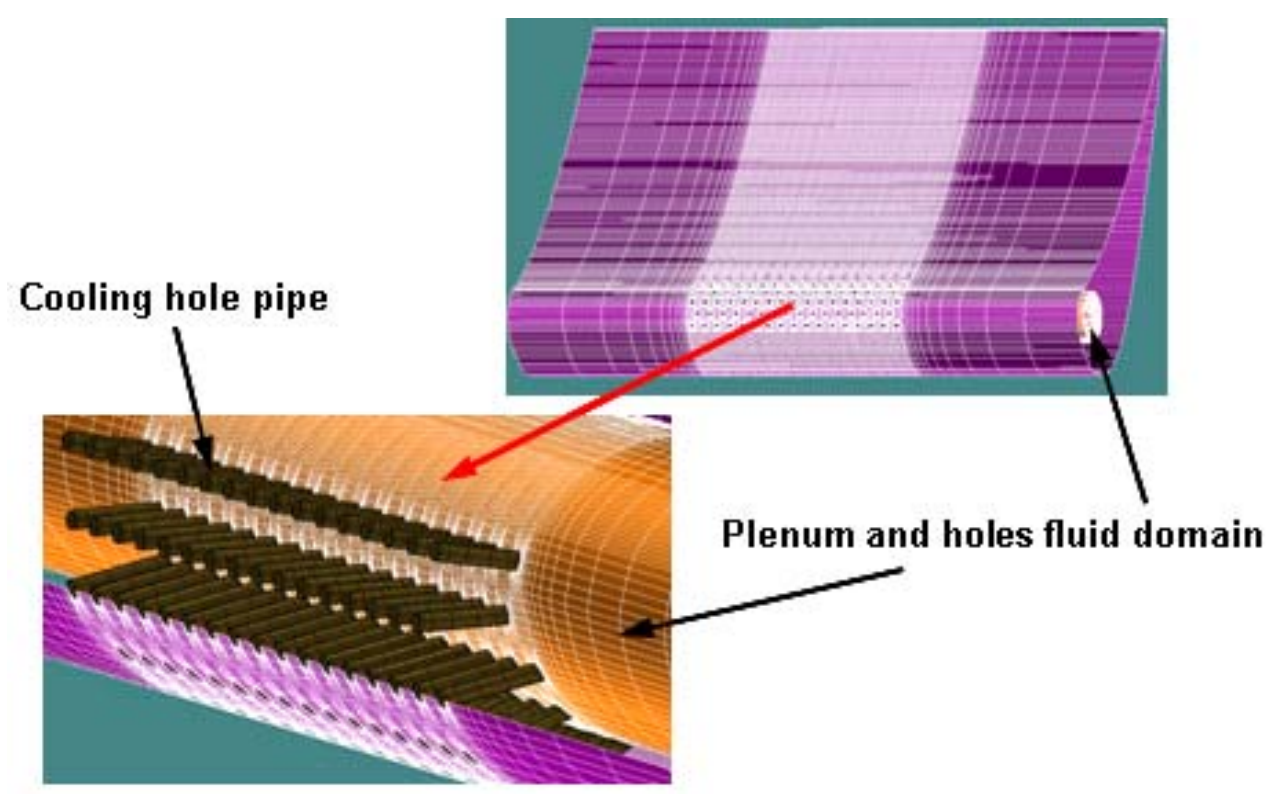

Figure 3.6. Leading edge region of 3-D CFD domain 
A 3-D multi-block structured hexahedral mesh consisting of approximately 4.1 million cells for external and internal flow was selected after gird independence study and was refined near the wall to better capture the wall heat transfer. This was achieved by adjusting the nearwall spacing $y^{+}$to be less than 1 . Dense mesh with O-shape grid was used in the vicinity of film cooling holes to improve grid quality and to better capture flow physics in the region as shown in Figure 3.7. The convergence of the $v^{2}-f$ model prediction was assumed to be reached when all normalized residuals were smaller than $10^{-5}$, except energy smaller than $10^{-6}$. All $v^{2}-f$ model simulations were performed on Intel Core $(\mathrm{TM}) 2 \mathrm{CPU}(2.66 \mathrm{GHz})$ and each simulation required approximately five days to reach convergence. In general, 6500 iterations were required for full convergence.

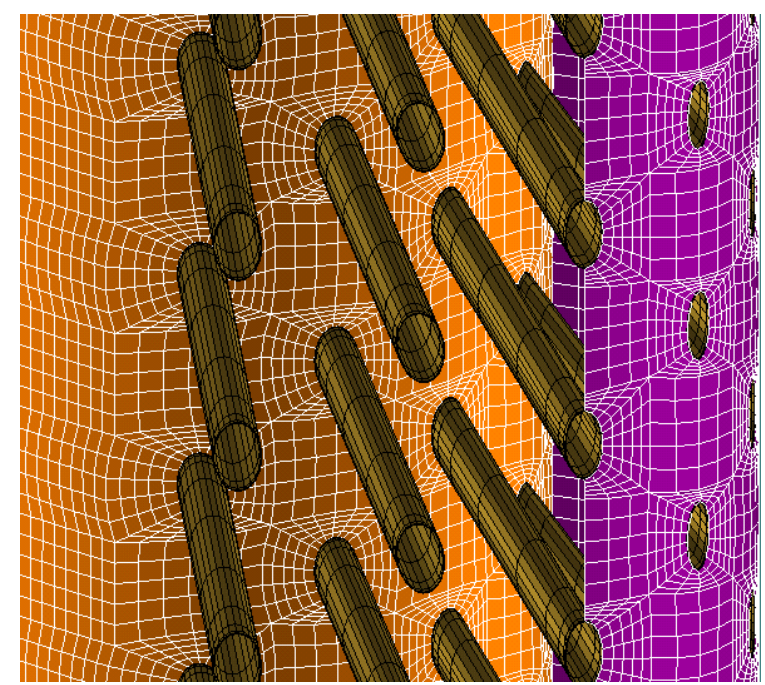

Figure 3.7. O-shape mesh in the vicinity of film cooling holes

\section{Three-Simulations Technique}

Three independent simulations were performed for a particular blowing ratio $(\mathrm{BR}>0)$ condition to completely characterize the film cooling performance of showerhead film cooled vane in a transonic flow. The notion of three-simulations technique to calculate adiabatic effectiveness and heat transfer coefficient in a film cooling environment is an extension of twosimulations technique documented in literature such as [9, 33, and 34] by adding a third simulation to predict freestream recovery temperature on an airfoil surface in a high speed flow. 
First simulation was performed with no blowing $(\mathrm{BR}=0)$ and no-slip adiabatic vane surface boundary condition to find local freestream recovery temperature $\left(T_{r}\right)$. The local freestream recovery temperature is actually a local adiabatic wall temperature for a two-temperature problem (freestream and surface). This is similar to the experiment discussed in the previous section. Second simulation was performed for a particular blowing ratio $(\mathrm{BR}>0)$ with no-slip adiabatic vane surface boundary condition to find adiabatic wall temperature $\left(T_{a w}\right)$ for a threetemperature problem (freestream, coolant, and surface). Once recovery and adiabatic wall temperatures were known, film cooling adiabatic effectiveness was found using Equation 3.4. A third simulation with no-slip constant vane surface temperature boundary condition was performed to predict vane surface heat transfer coefficient $(h)$ for a particular blowing ratio (BR $>0)$ using Equation 3.3. Heat transfer coefficient for no blowing $(\mathrm{BR}=0)$ is also predicted with no-slip constant vane surface temperature boundary condition and is defined on the basis of freestream recovery temperature $\left(T_{r}\right)$. Table 3.2 summarizes the external flow and heat transfer boundary conditions for each test case.

Table 3.2. Test conditions for each case

\begin{tabular}{|c|c|c|c|c|c|c|}
\hline & $\mathbf{M}_{\mathbf{i}}$ & $\mathbf{M}_{\mathbf{e x}}$ & $\mathbf{T u}$ & $\mathbf{R e}_{\mathbf{e x}}$ & $\mathbf{B R}$ & $\mathbf{T}_{\mathbf{w}} / \mathbf{T}_{\mathbf{0}}$ \\
\hline Case 1 & 0.12 & 0.76 & $16 \%$ & $1,050,000$ & 0 & 0.86 \\
\hline Case 2 & 0.12 & 0.76 & $16 \%$ & $1,050,000$ & 1.5 & 0.86 \\
\hline
\end{tabular}

\section{Results and Discussion}

\section{Mach Number Distribution Comparison}

Figure 3.8 shows the comparison of calculated and measured Mach number distribution along the vane midspan at exit Mach 0.76. The local Mach number is plotted against nondimensional surface distance, $\mathrm{s} / \mathrm{C}$. Positive and negative values of $\mathrm{s} / \mathrm{C}$ correspond to suction and pressure sides, respectively. Overall, the $v^{2}-f$ model calculation compare very well with the experimental data on the vane surface except for slight underprediction in the geometric throat region on the suction side. The Mach number distribution varies smoothly along the pressure side, and does not exhibit any velocity peak downstream of the stagnation region. The flow on the suction side continuously accelerates up to the geometric throat area $(\mathrm{s} / \mathrm{C}=0.51)$ and then decelerates up to the measurement extent $(\mathrm{s} / \mathrm{C}=1.3)$. 


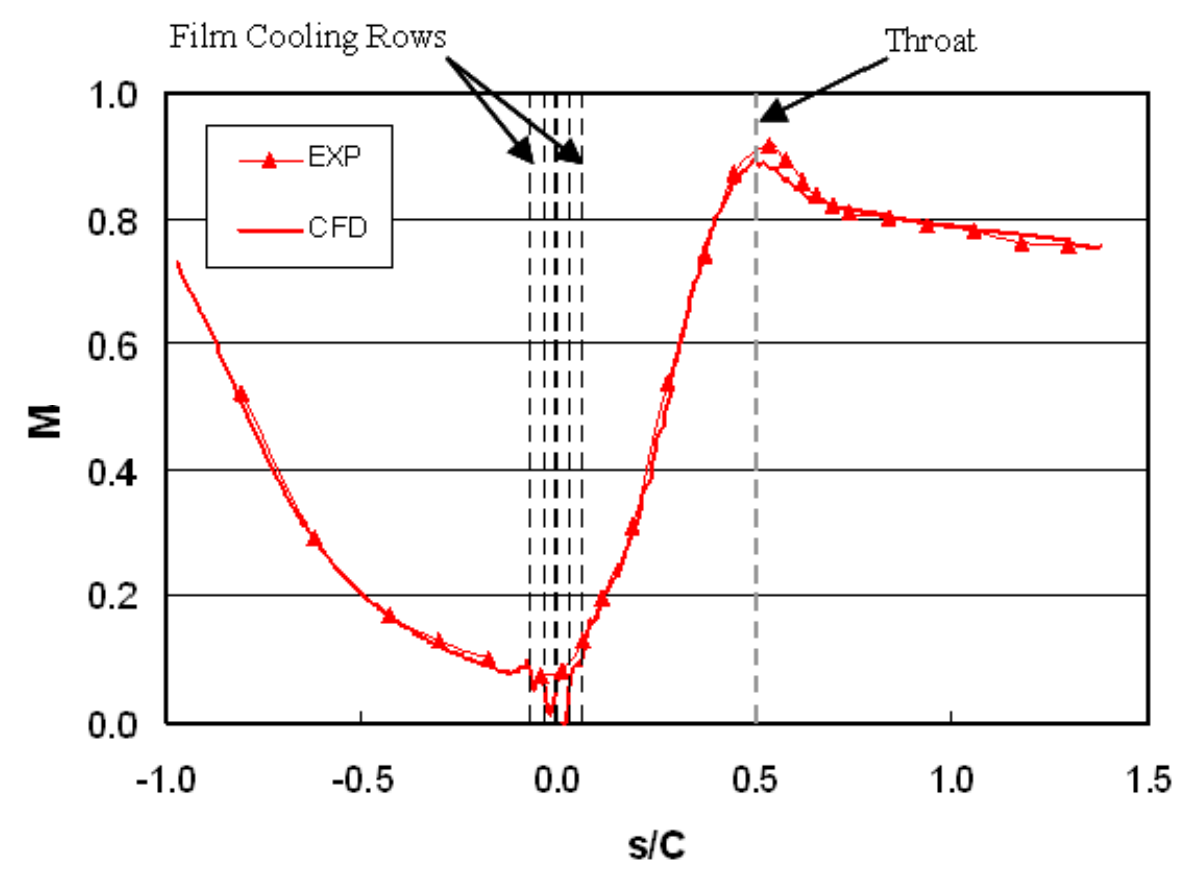

Figure 3.8. Midspan Mach number distribution comparison

\section{Recovery and Adiabatic Wall Temperatures}

Figures 3.9 and 3.10 present 3-D vane recovery and adiabatic wall temperatures contours for $\mathrm{BR}=0$ and 1.5 , respectively. The vane recovery temperature contours $(\mathrm{BR}=0)$ are affected by flow acceleration on the vane surface and show slight fluid ejection from the extreme film cooling rows on both surfaces due to small pressure variation between rows. The vane adiabatic wall temperature contours $(\mathrm{BR}=1.5)$ are also affected by flow acceleration on the vane surface and show coolant accumulation in the jet exit direction. This coolant accumulation is more evident on the pressure surface and can also be qualitatively observed in vane film cooling surface oil flow visualization test in Figure 3.11. 


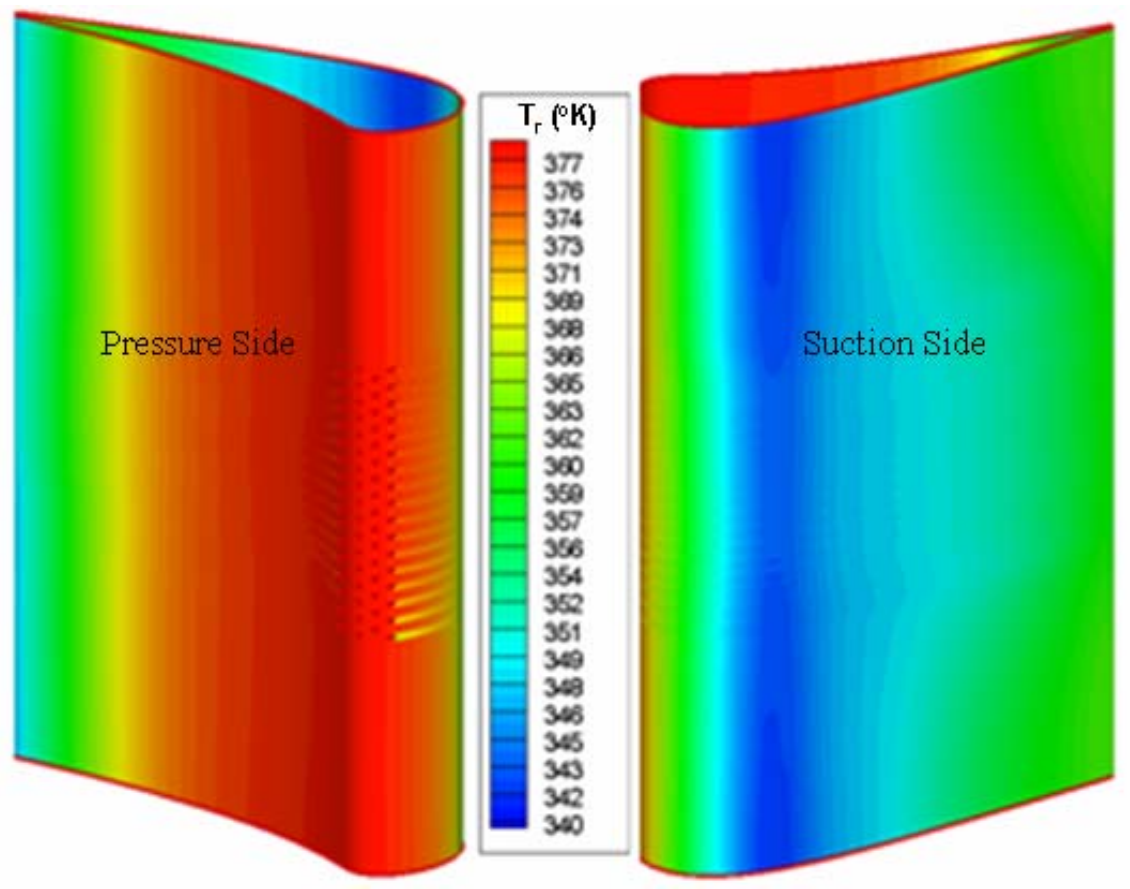

Figure 3.9. $\mathrm{T}_{\mathrm{r}}$ contours at $\mathrm{M}_{\mathrm{ex}}=0.76(\mathrm{BR}=0)$
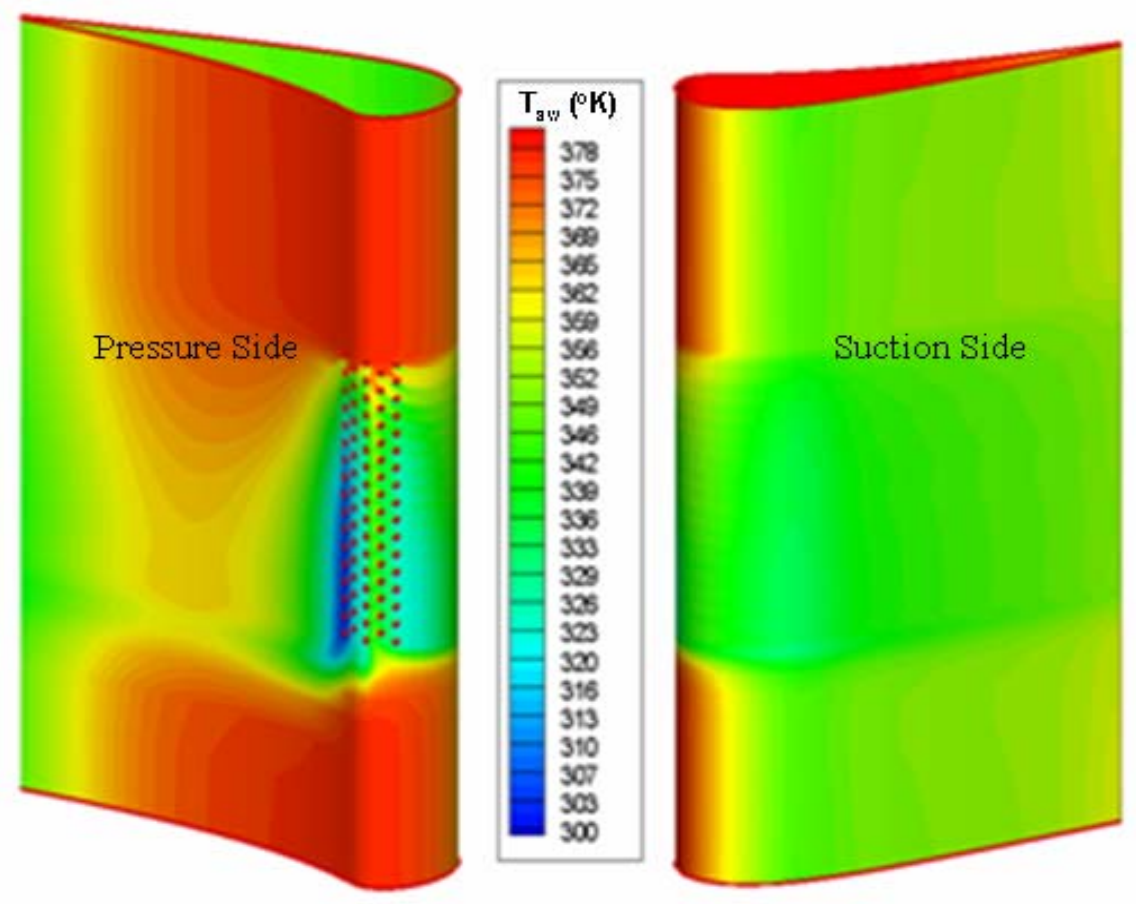

Figure 3.10. $\mathrm{T}_{\mathrm{aw}}$ contours at $\mathrm{M}_{\mathrm{ex}}=0.76(\mathrm{BR}=1.5)$ 

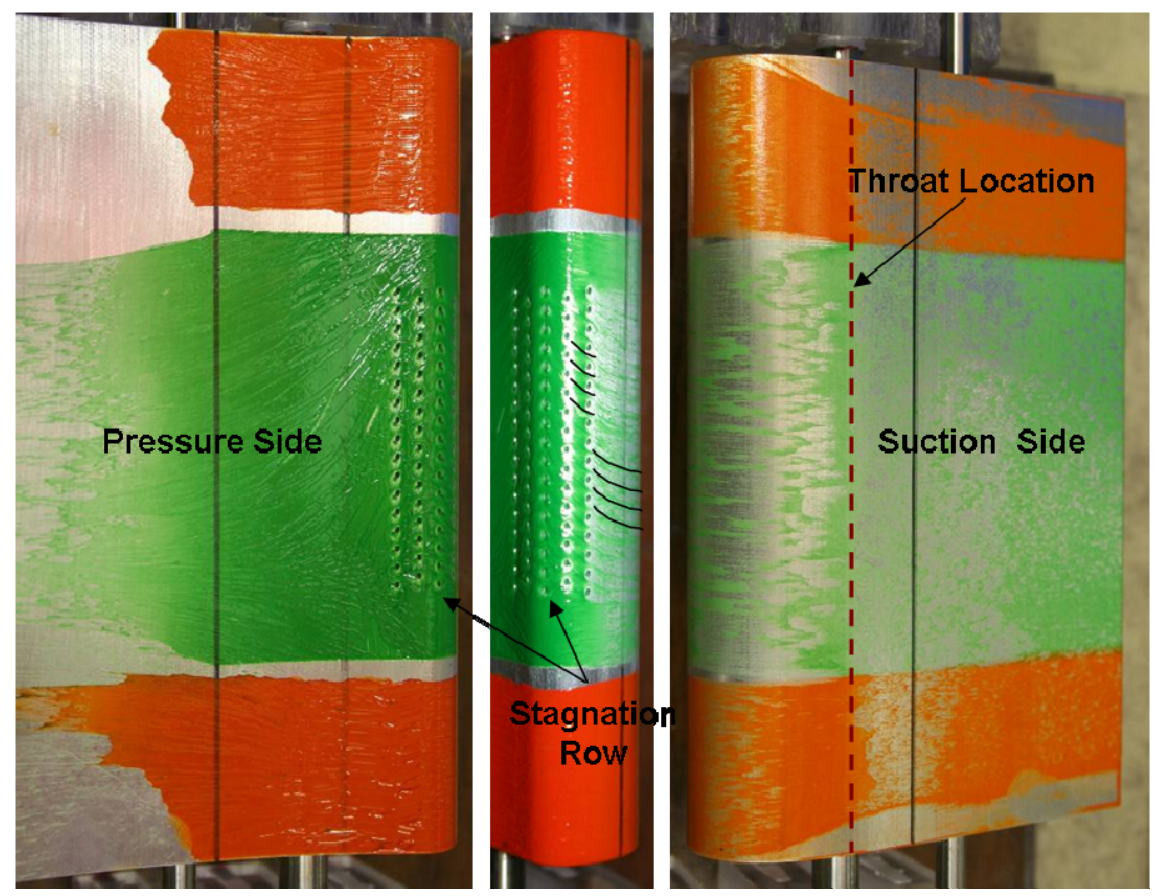

Figure 3.11. Vane film cooling flow visualization at $\mathrm{M}_{\mathrm{ex}}=0.76$

Figure 3.12 presents calculated non-dimensional vane recovery and adiabatic wall temperatures along the vane midspan for $\mathrm{BR}=0$ and 1.5 , respectively. The non-dimensional temperatures are plotted against non-dimensional surface distance $(\mathrm{s} / \mathrm{C}$ and $\mathrm{s} / \mathrm{d})$. On the pressure surface, the vane recovery temperature $(B R=0)$ decreases slowly downstream of the stagnation region because of low favorable pressure gradient (Mach number) along the surface. The pressure surface clearly shows the effect of coolant injection $(B R=1.5)$ on adiabatic wall temperature reduction downstream of the stagnation region. The effect of coolant on adiabatic wall temperature remains up to $\mathrm{s} / \mathrm{C}=-0.50$ on the pressure surface, but then the adiabatic wall temperature follows the trend of local recovery temperature due to high favorable pressure gradient (Mach number) beyond $\mathrm{s} / \mathrm{C}=-0.50$. On the suction surface, the vane recovery temperature decreases downstream of the stagnation region up to the geometric throat due to high favorable pressure gradient (Mach number) but then increases downstream of throat due to the adverse pressure gradient. It is also important to mention that the calculated recovery temperature was significantly different from assumed recovery temperature based on local Mach number and turbulent boundary layer recovery factor $\left(r=\operatorname{Pr}^{1 / 3}\right)$. An assumed recovery temperature was unable to provide reasonable effectiveness distribution on vane suction surface. A possible reason is a compressibility effect on recovery factor for gases with Prandtl number Pr 
$<1$, as hinted by Oudheusden [35]. The suction surface also shows the effect of coolant injection $(\mathrm{BR}=1.5)$ on adiabatic wall temperature reduction downstream of the stagnation region. The adiabatic wall temperature increases due to jet dissipation from $\mathrm{s} / \mathrm{C}=0.15$ to $\mathrm{s} / \mathrm{C}=0.28$ but then responds to high flow acceleration downstream of $\mathrm{s} / \mathrm{C}=0.28$ and follows the trend of local recovery temperature up to $\mathrm{s} / \mathrm{C}=0.80$.

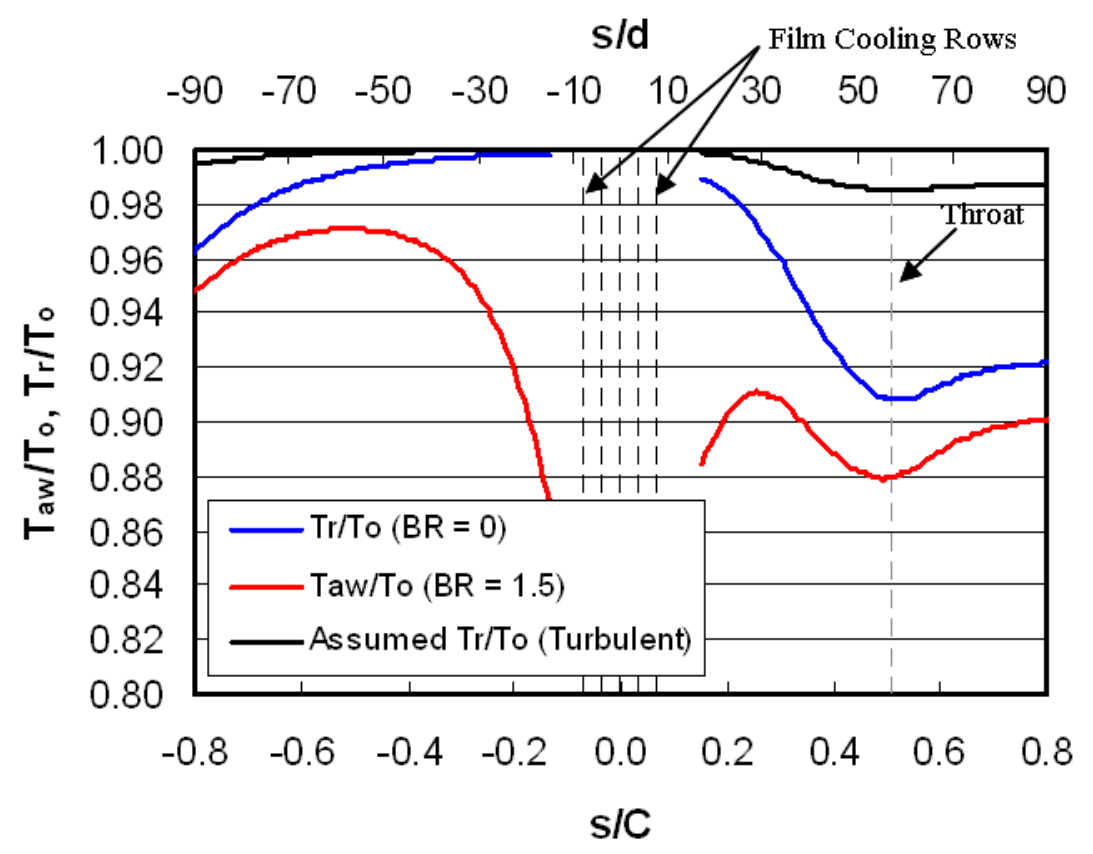

Figure 3.12. Calculated midspan $\mathrm{T}_{\mathrm{r}}$ and $\mathrm{T}_{\mathrm{aw}}$

\section{Adiabatic Effectiveness Comparison}

Comparison of vane midspan calculated and measured adiabatic wall effectiveness at BR $=1.5$ and exit Mach 0.76 is shown in Figure 3.13. For the experimental data, the adiabatic effectiveness decays downstream of coolant injection on both surfaces due to jet dissipation. The suction surface effectiveness does not exhibit a continuous decay downstream of the coolant injection as does the pressure surface and is influenced by a favorable pressure gradient due to Mach number in the region $\mathrm{s} / \mathrm{C}=0.28$ to $\mathrm{s} / \mathrm{C}=0.40$. On the pressure surface, the $v^{2}-f$ model shows an overall very reasonable adiabatic effectiveness distribution comparison with the experimental data. On the suction surface, the $v^{2}-f$ model overpredicts adiabatic film cooling effectiveness but captures the experimental data trend on the entire surface. The effect of favorable pressure gradient due to Mach number on freestream recovery and adiabatic wall temperature results in nearly steady adiabatic effectiveness data from $\mathrm{s} / \mathrm{C}=0.28$ to $\mathrm{s} / \mathrm{C}=0.40$ 
but then it decays through the geometric throat. Unlike pressure surface, the overprediction of adiabatic film cooling effectiveness is possibly due to the overprediction of local recovery temperature and adiabatic wall temperature in a highly favorable pressure gradient flow. The authors are most interested in the trend of vane surface adiabatic effectiveness at this time and would like to research and discuss the differences between measured and calculated levels of vane surface adiabatic effectiveness in detail in future.

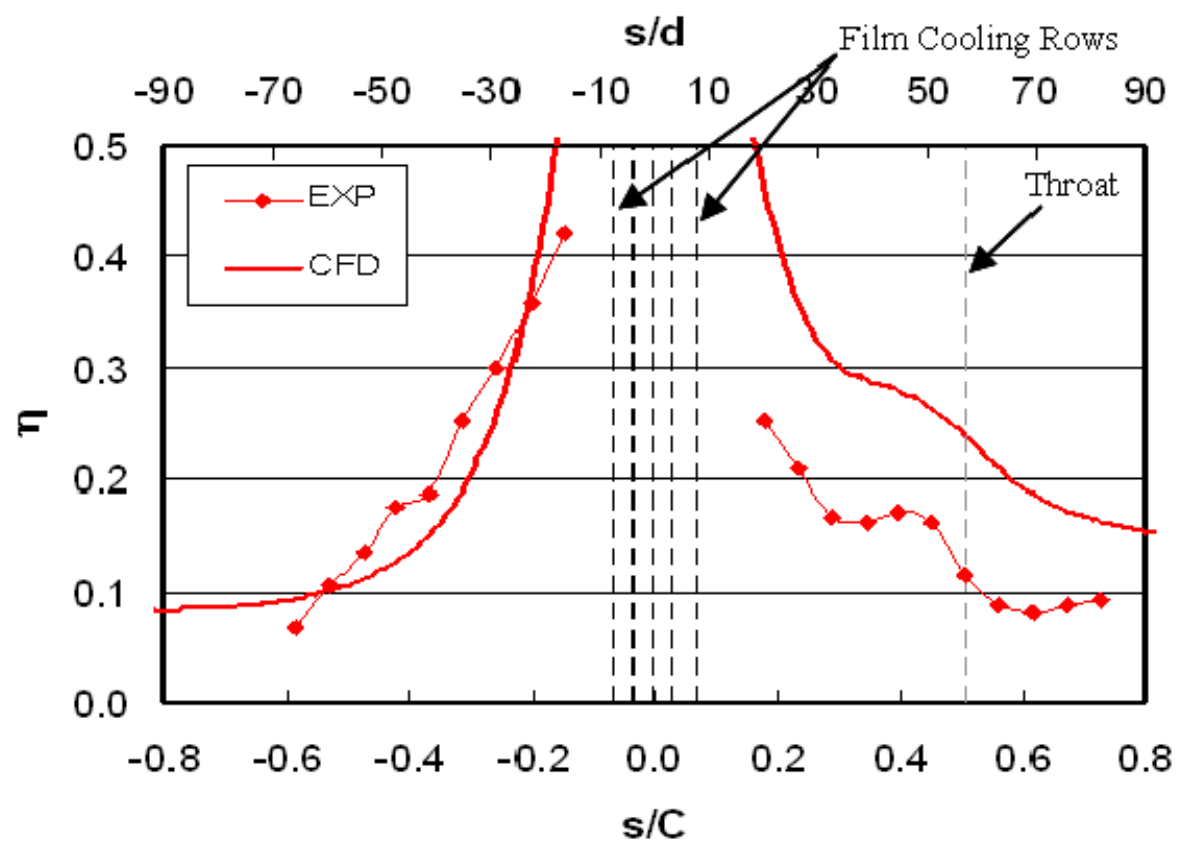

Figure 3.13. Midspan $\eta$ comparison at $\mathrm{BR}=1.5$

\section{Nusselt Number Comparison}

Figure 3.14 provide the comparison of measured and calculated Nusselt number distribution along the vane midspan for $\mathrm{BR}=0$ and 1.5 at exit Mach 0.76 . For the experimental data, the primary effect of coolant injection at $\mathrm{BR}=1.5$ is to augment Nusselt number downstream of injection on the vane surface as compared to no film injection case $(\mathrm{BR}=0)$. The Nusselt number augmentation is due to more mixing and local increase in turbulence levels within the boundary layer. The effect of blowing ratio on Nusselt number augmentation is clearly more noticeable on the pressure surface as compared to the suction surface. Though augmented, Nusselt number distribution follow the same trend as the $\mathrm{BR}=0$ case on the suction side. Airfoil surface heat transfer augmentation due to film cooling injection has been documented widely in literature such as references [8, 36-39]. The $v^{2}-f$ model overpredicts Nusselt number on the vane 
pressure surface for $\mathrm{BR}=0$ and 1.5. The vane pressure surface predictions appear to be fully turbulent for both blowing ratio cases and show negligible effect of coolant injection. The Nusselt number overprediction on the vane pressure surface can be attributed to the difficulty of $v^{2}-f$ model to accurately calculate the effects of large scale high freestream turbulence on a pressure surface (low favorable pressure gradient due to low Mach number) Nusselt number and has also been observed by Luo and Razinsky [32].

On the suction surface, the $v^{2}-f$ model also overpredicts Nusselt number downstream of the stagnation region for $\mathrm{BR}=0$ and 1.5, but unlike pressure surface, it does show Nusselt number augmentation downstream of stagnation region due to coolant injection $(\mathrm{BR}=1.5)$. Also on the suction surface, the measured and calculated Nusselt number show a peak and a valley downstream of the film cooling rows for $\mathrm{BR}=0$ and 1.5. The reasons for this peak and valley can be attributed to the effect of favorable pressure gradient due to Mach number on a pseudoturbulent (highly perturbed and augmented) boundary layer to possibly relaminarize or the effect of favorable pressure gradient on the inner sublayer thickness of the pseudo-turbulent boundary accompanied by a bypass transition again to a fully turbulent boundary layer. The authors are encouraged to see that the $v^{2}-f$ model captures the Nusselt number trend on the suction surface for $\mathrm{BR}=0$ and 1.5 and would like to explain the effect of favorable pressure gradient due to Mach number on a pseudo-turbulent boundary layer downstream of film cooling rows by a boundary layer analysis below.

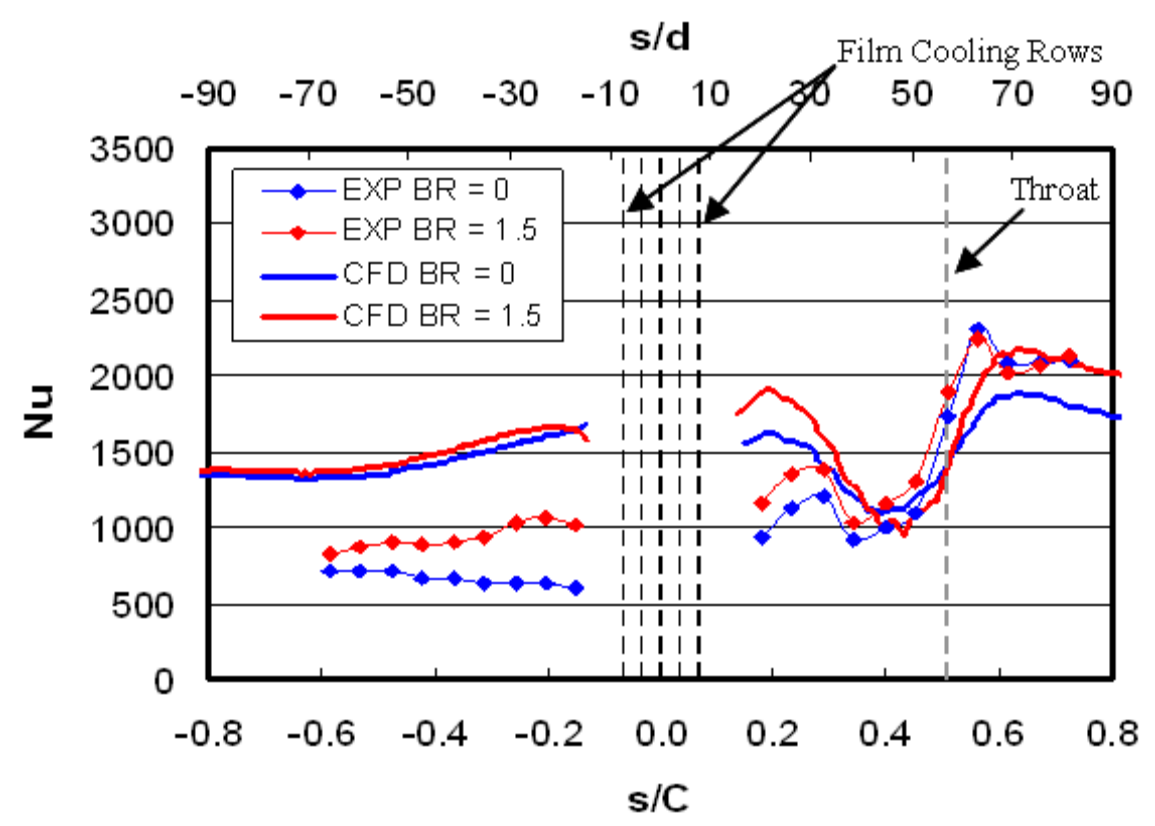

Figure 3.14. Midspan $\mathrm{Nu}$ comparison at $\mathrm{BR}=1.5$ 


\section{Boundary Layer CFD Analysis on Suction Surface}

According to Weigand et al. [40], high favorable pressure gradient induces a thicker laminar sublayer by delaying the critical momentum thickness Reynolds number for laminar to turbulent transition. A thick sublayer results in an increase in heat transfer resistance and a decrease in Nusselt number. An effective sublayer thickness $(\mathrm{A}+)$ was estimated from the CFD solution for $\mathrm{BR}=1.5$ case as a critical value of $y^{+}$where turbulent eddy diffusivity $\left(\varepsilon_{t}\right)$ is of the same scale as that of molecular diffusivity ( $v)$. Figure 3.15 shows the effective sublayer thickness along the suction side for $\mathrm{BR}=1.5$ case. The plot shows that the effective sublayer thickness increases along the suction side in a favorable pressure gradient region $(\mathrm{s} / \mathrm{C}=0.23-$ 0.37 ), and then decreases due to increase in turbulent eddy transport and possible local breakdown of sublayer near critical momentum thickness Reynolds number. This increase in turbulent eddy transport and local instability in the sublayer leads to boundary layer transition to a fully turbulent boundary layer in the geometric throat region $(\mathrm{s} / \mathrm{C}=0.51)$. This type of peak and valley on vane suction side heat transfer distribution with showerhead film cooling has also been noted by the experimental study of Turner et al. [5]. The authors believe that the effect of high favorable pressure gradient on effective sublayer thickness also impacts the adiabatic effectiveness through changes in local adiabatic wall and recovery temperatures.

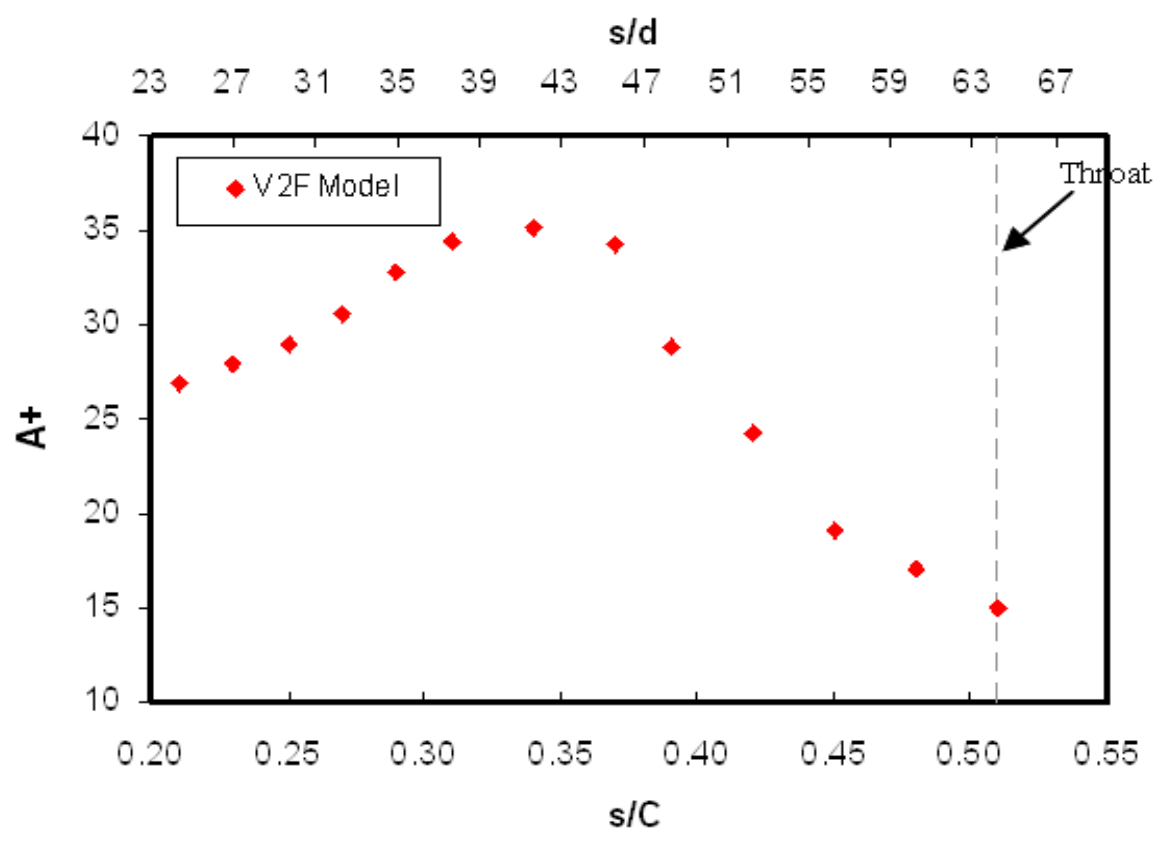

Figure 3.15. Suction side midspan $\mathrm{A}+$ calculation at $\mathrm{BR}=1.5$ 
Regarding suction side boundary layer transition, the experimental data shows that the boundary layer transition location $(\mathrm{s} / \mathrm{C}=0.34)$ is unaffected by coolant injection $(\mathrm{BR}=1.5)$. The experimental data also shows that once the boundary layer becomes turbulent on the suction side, the effect of coolant injection on the heat transfer diminishes. The $v^{2}-f$ model predicts a slight delay in the boundary layer transition on the suction surface for both blowing ratio cases, and also shows an augmentation in a fully turbulent boundary layer for the $\mathrm{BR}=1.5$ case as compared to $\mathrm{BR}=0$ case.

\section{Conclusions}

This paper presents an experimental and numerical investigation of the effects of coolant injection on film cooling performance of a showerhead film cooled first stage turbine vane at high freestream turbulence $(\mathrm{Tu}=16 \%)$ and realistic exit Mach number condition $\left(\mathrm{M}_{\mathrm{ex}}=0.76\right)$. The paper discusses a new three-simulations technique to calculate vane surface recovery temperature, adiabatic wall temperature, and surface Nusselt number to completely characterize film cooling performance in a high speed flow. For the experimental data, the primary effects of coolant injection $(\mathrm{BR}=1.5)$ are to augment Nusselt number and reduce adiabatic wall temperature downstream of the injection on the vane surface as compared to no film injection case $(\mathrm{BR}=0)$ at high freestream turbulence of $\mathrm{Tu}=16 \%$ and exit Mach number of $\mathrm{M}_{\mathrm{ex}}=0.76$.

\section{Adiabatic Effectiveness}

On the pressure surface, at $\mathrm{BR}=1.5$, the $v^{2}-f$ model shows an overall good adiabatic effectiveness distribution comparison with the experimental data. On the suction surface, at $\mathrm{BR}=$ 1.5 , the $v^{2}-f$ model overpredicts adiabatic effectiveness but captures the experimental data trend on the entire surface. Also on the suction surface, the adiabatic effectiveness calculation on the suction surface is found to be influenced by favorable pressure gradient due to Mach number through changes in local adiabatic wall and recovery temperature.

\section{Nusselt Number}

On the pressure surface, at BR $=0$ and 1.5 , the $v^{2}-f$ model overpredicts Nusselt number and shows negligible effect of coolant injection. On the suction surface, the $v^{2}-f$ model also 
overpredicts Nusselt number downstream of the stagnation region for $\mathrm{BR}=0$ and 1.5 , but unlike the pressure surface, it does show Nusselt number augmentation downstream of stagnation region due to coolant injection $(\mathrm{BR}=1.5)$. Similar to experimental results, the Nusselt number calculation on the suction surface shows a peak and a valley downstream of the film cooling rows in a favorable pressure gradient region for both tested blowing ratio conditions. The reason for this peak and valley is attributed to the effect of favorable pressure gradient due to Mach number on the inner sublayer thickness of the pseudo-turbulent boundary accompanied by a bypass transition again to a fully turbulent boundary layer.

\section{Acknowledgements}

This work was sponsored by Solar Turbines Inc. We would like to thank Dr. Luzeng Zhang of Solar Turbine Inc. for his help and support of this project. We would also like to express our gratitude to Dr. Richard Anthony and Dr. Marcus Polanka of the Air Force Research Laboratory, Wright-Patterson AFB for their help with manufacturing and implementation of the thin film gauges.

\section{References}

[1] Durbin, P., 1991, "Near-Wall Turbulence Closure Modeling Without "damping functions"," Theor. Comput. Fluid Dyn., 3, pp. 1-13

[2] Camci, C., 1985, “Theoretical and Experimental Investigation of Film Cooling Heat Transfer on a Gas Turbine Blade, Ph.D. Thesis, Von Karman Institute for Fluid Dynamics and University of Leuven, Belgium.

[3] Camci, C., and Arts, T., 1985a, "Short Duration Measurements and Numerical Simulation of Heat Transfer Along the Suction Side of a Film-Cooled Gas Turbine Blade," ASME J. Eng. Power, 107, pp. 991-997.

[4] Camci, C., and Arts, T., 1985b, "Experimental Heat Transfer Investigation around the FilmCooled Leading Edge of a High-Pressure Gas Turbine Rotor Blade," ASME J. Eng. Power, 107, pp. 1016-1021.

[5] Turner, E.R., Wilson, M.D., Hylton, L.D., and Kaufman, R.M., 1985, “Turbine Vane External Heat Transfer: Vol. 1: Analytical and Experimental Evaluation of Surface Heat Transfer Distributions with Leading Edge Showerhead Film Cooling," NASA CR-174827. 
[6] Nirmalan, N.V., and Hylton, L.D., 1990, “An Experimental Study of Turbine Vane Heat Transfer with Leading edge and Downstream Film Cooling," ASME J. Turbomach., 112, pp. 477487.

[7] Garg, V.K., and Ameri, A.A., 1997. "Comparison of Two-Equation Turbulence Models for Prediction of Heat Transfer on Film-Cooled Turbine Blades," Numerical Heat Transfer, Part A $32,347-371$.

[8] Garg, V.K., 2001, "Modeling Film Coolant Flow Characteristics at the Exit of Shower Head Holes", Intl. J. Heat and Fluid Flow, 22, pp. 134-142.

[9] Heidmann, J.D., Rigby, D.L., and Ameri, A.A., 2000, "A Three-Dimensional Coupled Internal/External Simulation of a Film-Cooled Turbine Vane," ASME J. Turbomach., 122, pp. 348-359.

[10] Chima, R. V., 1996, "A k- $\omega$ Turbulence Model for Quasi-Three-Dimensional Turbomachinery Flows," NASA TM-107051.

[11] Ginibre, P., Lefebre, and M., Liamis, N., 2001, "Numerical Investigation of Heat Transfer on Film-Cooled Turbine Blades", Annals New York Academy of Sciences, 934, pp. 377-384.

[12] Medic, G., and Durbin, P.A., 2002, “Toward Improved Film Cooling Prediction”, ASME J. Turbomach., 124, pp. 193-199.

[13] Montomoli, F., Adami, P., Della Gatta, S., and Martelli, F., 2004, "Conjugate Heat Transfer Modeling in Film Cooled Blades," ASME GT2004-53177.

[14] Chana, K.S., and Mole, A.H., 2002, "Summary of Cooled NGV and Uncooled Rotor Measurements from the MT1 Single Stage High Pressure Turbine in the DERA Isentropic Light Piston Facility", Brite-EuRam Turbine Aero-Thermal External Flow project (BRPR-CT97-0519).

[15] Laskowski, G.M., Tolpadi, A.K., and Ostrowski, M.C., 2007, "Heat Transfer Predictions of Film Cooled Stationary Turbine Airfoils," ASME GT2007-27497.

[16] Menter, F. R., 1994, "Two-Equation Eddy-Viscosity Turbulence Models for Engineering Applications," AIAA-Journal, 32, pp.1598-1605.

[17] Nasir, S., Bolchoz, T., Ng, W.F., Zhang, L.J., Moon, H.K., and Anthony, R.J., 2008, "Showerhead Film Cooling Performance of a Turbine Vane at High Freestream Turbulence in a Transonic Cascade," ASME IMECE-2008-66528.

[18] Nasir, S., Carullo, J.S., Ng, W.F., Thole, K.A., Wu, H., Zhang, L.J., and Moon, H.K., 2007, "Effects of Large Scale High Freestream Turbulence, and Exit Reynolds Number on Turbine Vane Heat Transfer in a Transonic Cascade,” ASME IMECE-2008-44098. 
[19] Colban, W., Gratton, A., and Thole, K.A., 2006, "Heat Transfer and Film-Cooling Measurements on a Stator Vane with Fan-Shaped Cooling Holes," ASME J. Turbomach., 128, pp. 53-61.

[20] Joe, C.R., 1997, "Unsteady Heat Transfer on the Turbine Research Facility at Wright Laboratory," Ph.D. Dissertation, Syracuse University.

[21] Nasir, S., 2008, "Showerhead Film Cooling Performance of a Turbine Vane at High Freestream Turbulence in a Transonic Cascade," Ph.D. Dissertation, Virginia Polytechnic Institute and State University.

[22] Cress, R.D., 2006, "Turbine Blade Heat Transfer Measurements in a Transonic Flow Using Thin film Gages,” Master's Thesis, Virginia Polytechnic Institute and State University.

[23] Vedula, R. P., and Metzger, D. E., 1991, "A Method for the Simultaneous Determination of Local Effectiveness and Heat Transfer Distributions in a Three Temperature Convective Situations," ASME GT-1991-345.

[24] Smith, D.E., Bubb, J.V., Popp, O., Grabowski, H.C., Diller, T.E. Schetz, J.A. and Ng. W.F., 2000, "An Investigation of Heat Transfer in a Film Cooled Transonic Turbine Cascade, Part I: Steady Heat Transfer,” ASME GT-2000-202.

[25] Popp, O., Smith, D.E., Bubb, J.V., Grabowski, H.C., Diller, T.E. Schetz, J.A. and Ng. W.F., 2000, "An Investigation of Heat Transfer in a Film Cooled Transonic Turbine Cascade, Part II: Unsteady Heat Transfer,” ASME GT-2000-203.

[26] Moffat, R. J., 1988, "Describing Uncertainties in Experimental Results," Exp. Thermal and Fluid Science, 1, pp. 3-17.

[27] Brown, K.H., Coleman, H.W., and Steele, W.G., 1995, "Estimating Uncertainty Intervals for Linear Regression," AIAA-1995-0796.

[28] Medic, G., and Durbin, P. A., 2002, "Toward Improved Prediction of Heat Transfer on Turbine Blades," ASME J. Turbomach., 124, pp. 187-192.

[29] Ameri, A. A., and Ajmani, K., 2004, "Evaluation of Predicted Heat Transfer on a Transonic Blade Using v²-f Models," ASME GT-2004-53572.

[30] Pecnik, R., Pieringer, P., and Sanz, W., 2005, "Numerical Investigation of the Secondary Flow of a Transonic Turbine Stage Using Various Turbulence Closures," ASME GT-2005-68754.

[31] Luo, J., and Razinsky, E.H., 2007, "Conjugate Heat Transfer Analysis of a Cooled Turbine Vane Using the $\mathrm{v}^{2}$-f Turbulence Model,” ASME J. Turbomach., 129, pp. 773-781.

[32] Luo, J., and Razinsky, E.H., 2008, "Prediction of Heat Transfer and Flow Transition on Transonic Turbine Airfoils under High Freestream Turbulence,” ASME GT-2008-50868. 
[33] Heidmann, J.D., and Ekkad, S., 2007, “A Novel Anti-Vortex Turbine Film Cooling Hole Concept," ASME GT-2007-27528.

[34] Rozati, A., and Tafti, D.K., 2007, "Large Eddy Simulation of Leading Edge Film Cooling Part-II: Heat Transfer and Effect of Blowing Ratio,” ASME GT-2007-27690.

[35] van Oudheusden, B.W., 2004, "Compressibility Effects on the Extended Crocco Relation and the Thermal Recovery Factor in Laminar Boundary Layer Flow," ASME J. Turbomach., 126, pp. 32-41.

[36] Arts, T., and Bourguignon, A.E., 1990, "Behavior of a Coolant Film with Two rows of Holes along the Pressure Side of a High Pressure Nozzle Guide Vane," ASME J. Turbomach., 112, pp. 512-520.

[37] Ou, S., Han, J.-C., Mehendale, A.B., and Lee, C.P., 1994, "Unsteady Wake Over a Linear Turbine Blade Cascade with Air and $\mathrm{CO}_{2}$ Film Injection: Part I-Effect on Heat Transfer Coefficients," ASME J. Turbomach., 116, pp. 721-729.

[38] Ekkad, S.V., Mehendale, A.B., Han, J.-C., and Lee, C.P., 1997, “Combined Effect of Grid Turbulence and Unsteady Wake on Film Effectiveness and Heat Transfer Coefficient of a Gas Turbine Blade with Air and $\mathrm{CO}_{2}$ Film Injection," ASME J. Turbomach., 119, pp. 594-600.

[39] Ames, F.E., 1996, "Experimental Study of Vane Heat Transfer and Film Cooling at Elevated Levels of Turbulence," NASA CR-198525.

[40] Weigand, B., Crawford, M.E., and Kays, W.M., 2004, "Convective Heat and Mass Transfer," $4^{\text {th }}$ Ed., McGraw-Hill Inc., New York. 


\section{Preface Paper 4}

Paper 4 is an updated version of research paper with research colleague and primary author, Jeffrey Carullo, which relates to experimental investigation of the effect of high freestream turbulence intensity, turbulence length scale, and exit Reynolds number on the surface heat transfer distribution of a turbine blade at realistic engine Mach numbers. The paper was submitted to ASME IGTI 2007 (GT-2007-27859) and has also been submitted to ASME Journal of Turbomachinery (Turbo-08-1001). 


\title{
The Effects of Freestream Turbulence, Turbulence Length Scale, and Exit Reynolds Number on Turbine Blade Heat Transfer in a Transonic Cascade
}

\author{
J.S. Carullo, S. Nasir, R.D. Cress, W.F. Ng and K.A. Thole \\ Mechanical Engineering Department \\ Virginia Polytechnic Institute and State University \\ Blacksburg, VA 24061 \\ L.J. Zhang and H.K. Moon \\ Solar Turbines Inc. \\ San Diego, CA 92101 \\ IGTI Paper GT-2007-27859 \\ Submitted to the Journal of Turbomachinery
}

\begin{abstract}
This paper experimentally investigates the effect of high freestream turbulence intensity, turbulence length scale, and exit Reynolds number on the surface heat transfer distribution of a turbine blade at realistic engine Mach numbers. Passive turbulence grids were used to generate freestream turbulence levels of $2 \%, 12 \%$, and $14 \%$ at the cascade inlet. The turbulence grids produced length scales normalized by the blade pitch of $0.02,0.26$, and 0.41 , respectively. Surface heat transfer measurements were made at the midspan of the blade using thin film gauges. Experiments were performed at exit Mach numbers of $0.55,0.78$ and 1.03 which represent flow conditions below, near, and above nominal conditions. The exit Mach numbers tested correspond to exit Reynolds numbers of $6 \times 10^{5}, 8 \times 10^{5}$, and $11 \times 10^{5}$, based upon blade chord.

The experimental results showed that the high freestream turbulence augmented the heat transfer on both the pressure and suction sides of the blade as compared to the low freestream turbulence case. At nominal conditions, exit Mach 0.78, average heat transfer augmentations of $23 \%$ and $35 \%$ were observed on the pressure side and suction side of the blade, respectively.
\end{abstract}




\section{Nomenclature}

$B \quad$ bar width of turbulence grid

$C \quad$ chord of blade

$C_{p} \quad$ constant pressure specific heat

$d \quad$ leading edge diameter of blade

$\mathrm{Fr} \quad$ Frossling number

$h \quad$ heat transfer coefficient

$k_{a} \quad$ thermal conductivity of air

$k \quad$ acceleration parameter

$\mathrm{Ma} \quad$ Mach number

$\mathrm{Nu} \quad$ Nusselt number

$\mathrm{Nu}_{0} \quad$ Nusselt number at $\mathrm{Tu}=2 \%$

$P \quad$ pitch of blade

$\mathrm{Pr} \quad$ Prandtl number

$q " \quad$ heat flux

$r_{c}$

Re

recovery factor

Reynolds number

$S$

St

$T$

blade surface distance from stagnation point

Stanton number

temperature

Tu

$U$

$V R$

$x$

streamwise freestream turbulence intensity

velocity

velocity ratio

streamwise distance from turbulence grid

\section{Greek}

$\gamma$

$\Lambda_{\mathrm{x}}$

specific heat ratio of air

$\rho$

integral turbulence length scale (LS)

local density of air

$\mu$

dynamic viscosity of air

\section{Subscripts}

2

aw

gauge

init, $\mathrm{w}$

$\mathrm{L}$

inlet conditions

exit conditions

adiabatic wall

thin film gauge (surface) measurement

initial wall

local conditions

o stagnation 


\section{Introduction}

The components in the turbine section of a gas turbine engine present several complex problems to engine designers. One of the problems that designers face is the high gas path temperatures that pass through the turbine section. The gas path temperatures continue to be increased in order to increase the gas turbine power output and efficiency. In most engines, the gas path temperature has increased to be well above the melting temperature of most engine components. These high temperatures can drastically decrease the operating life of an engine component if not cooled properly.

To increase the component operating life, designers typically use CFD and other analysis tools to predict the regions of a component that will require a cooling scheme to be used. The heat transfer models used in these predictions can be complicated since the heat transfer is affected by several factors which include Reynolds number, turbulence intensity, turbulence

length scale, blade curvature, and pressure gradient just to name a few. The efforts of this work are to examine the effects of high freestream turbulence levels and turbulence length scales on heat transfer from a turbine blade at realistic engine Mach number conditions.

\section{Summary of Past Literature}

The freestream turbulence in the turbine section of an engine is due to the velocity fluctuations of the flow created by the combustor system and vane wakes upstream of the blade passages. While measuring the turbulence level in a gas turbine is extremely difficult, researchers have found that combustion systems typically produce turbulence levels between $7 \%$ and $30 \%$ [1-2]. The turbulence produced by the combustor decays as the flow passes through the vanes, but additional velocity fluctuations will be created by the vane wakes.

Several experimental studies have been performed in transonic cascades that investigate the effects of exit Reynolds number and freestream turbulence on the surface heat transfer distribution over a turbine blade. Consigny and Richards [3] measured the blade surface heat transfer distribution by varying the freestream turbulence between $0.8 \%$ and $5.2 \%$. Consigny and Richards observed that increasing the turbulence level augmented the heat transfer on the pressure and suction sides and at the leading edge. An earlier transition to a turbulent boundary layer was observed on the suction side of the blade when the turbulence level was increased. 
Another study by Arts et al. [4] examined the effect of Mach number, Reynolds number and incidence angle while varying the turbulence levels between $1 \%$ and $6 \%$. Similarly to Consigny and Richards, Arts et al. observed an earlier boundary layer transition on the suction side when the freestream turbulence level increased. In addition, Arts et al. noted a local peak in heat transfer on the pressure side near the leading edge. The local peak amplitude diminished as the turbulence level increased. The location of the local peak corresponds to a deceleration of the flow downstream of the leading edge on the pressure surface. They hypothesized that a small recirculation bubble occurred in the decelerating region and caused the local peak in heat transfer. Arts et al. also observed that increasing the exit Reynolds number increased the heat transfer levels.

More recent studies by Giel et al. [5] examined the effects of Reynolds number and cascade end wall boundary layers on surface heat transfer at turbulence levels of $9 \%$ with an integral lengths scale of $26 \mathrm{~mm}$ (1.02 in.). Giel et al. also observed a local peak on the pressure side of the blade near the leading edge. From these experiments and other similar experiments, turbulence models have been created and validated.

\section{Experimental Setup and Instrumentation}

\section{Wind Tunnel Facility}

The two-dimensional transonic cascade wind tunnel, shown in Figure 4.1, is a blow-down facility that is capable of sustaining a constant test section pressure for up to 25 seconds. Prior heat transfer research that has been performed in this facility includes work by Holmberg [6], Nix et al. [7], Smith et al. [8], and Popp et al. [9]. Air is supplied from high pressure air tanks that are charged up to $1380 \mathrm{kPa}$ (200 psig) prior to testing. A control valve regulates the flow from the air tanks to the test section. Cascade inlet pressures range from $20.7 \mathrm{kPa}$ ( $3 \mathrm{psig}$ ) to 69.0 $\mathrm{kPa}$ (10 psig) depending on the objective test conditions. Between the control valve and the test section, the air passes through a passive heat exchanger, which heats the cascade inlet flow up to $120^{\circ} \mathrm{C}$. After the air passes through the heat exchanger, the air goes through a contraction and enters the test section before being exhausted to the atmosphere. 


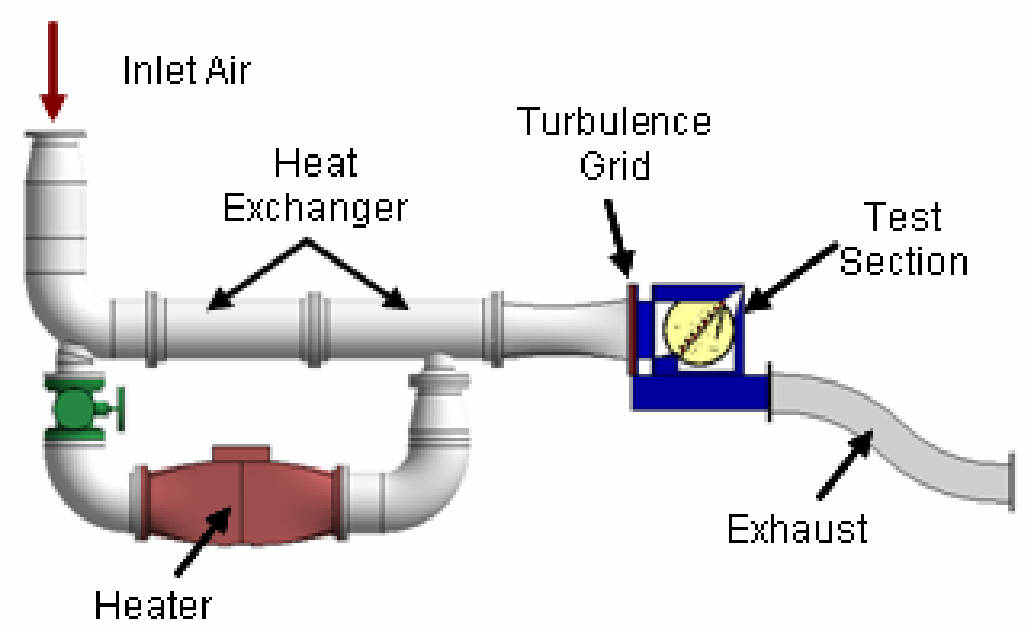

Figure 4.1. Transonic cascade wind tunnel

The turbine blade tested in these experiments is similar in geometry to a first stage turbine blade. The blade was scaled two times so that the nominal exit Reynolds number would be at the desired value. Table 4.1 summarizes the geometry of the turbine blade.

Table 4.1. Turbine blade geometry

\begin{tabular}{|c|c|}
\hline Chord & $69.9 \mathrm{~mm}(2.75 \mathrm{in})$. \\
\hline Axial Chord & $35.2 \mathrm{~mm}(1.39 \mathrm{in})$. \\
\hline Pitch & $58.2 \mathrm{~mm}(2.29 \mathrm{in})$. \\
\hline Span & $152.4 \mathrm{~mm}(6.00 \mathrm{in})$. \\
\hline Turning Angle & $107.5^{\circ}$ \\
\hline
\end{tabular}

A diagram of the blade cascade is provided in Figure 4.2. From the blade geometry and the test section size, the blade cascade consists of seven full blades and two partial blades, which result in seven full passages and one partial passage. A tailboard placed at the blade exit angle aids in creating periodic flow through the cascade. The blades are numbered starting from the lower left of the cascade with blade 4 being the blade that is fully instrumented to make static pressure and heat transfer measurements. The slot located $0.6 \mathrm{C}$ upstream of the cascade is used to measure the turbulence and velocity distributions at the inlet of the cascade.

\section{Static Pressure Measurements}

To calculate the isentropic Mach number distribution on the blade surface, the turbine blade was instrumented with static pressure taps placed at the midspan of the blade. Blade 4 was instrumented with a total of 27 pressure taps with 9 taps on the pressure side, 17 taps on the 
suction side and 1 tap near the leading edge. Static pressure taps were also instrumented on suction side of blade 3 and on the pressure side of blade 5 to check the periodicity of the flow. The total pressure of the flow was measured using a Pitot static probe located upstream of the cascade inlet. The static pressure measurements were made through independently conducted experiments relative to the heat transfer experiments. In addition to calculating the isentropic Mach number distribution, the acceleration parameter distribution on the blade surface was also calculated.

Static pressure taps on the end wall of the cascade were used to measure the inlet and exit static pressures and characterize the inlet and exit flow. The static pressures measured by these taps are also used to calculate the inlet and exit flow conditions. 12 inlet static taps were located $0.6 \mathrm{C}$ upstream of the blade passages and 12 exit static taps were located $0.6 \mathrm{C}$ downstream of the blade passages.

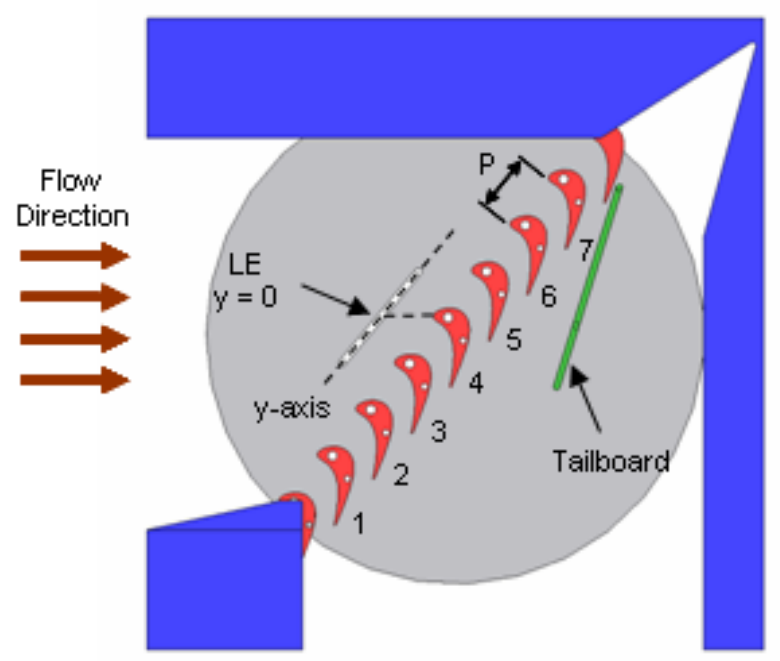

Figure 4.2. Cascade diagram showing the blades and the axis orientation for measurements with the traverse

\section{Heat Transfer Measurements}

Heat transfer measurements were made with thin film gauges that allow for high spatial resolution measurements on the blade surface with minimal flow disruption. Thin film gauges were originally developed by Schultz and Jones [10] and variations of the original design have been used by Doorly and Oldfield [11] and Dunn [12]. The thin film gauges that were used in these experiments are two-layer thin film gauges similar to the gauges developed by Doorly and Oldfield [11]. The gauges were manufactured according to the procedure described by Joe [13]. 
Each thin film gauge consists of a platinum sensor that is $3.18 \mathrm{~mm}(0.125 \mathrm{in}$.) long that attach copper leads which are sputtered to a Kapton $(k=0.12 \mathrm{~W} / \mathrm{mK})$ sheet that is $50 \mu \mathrm{m}$ thick. The Kapton sheet with the gauges is attached to a blade manufactured from a low thermal conductivity ceramic material called Macor $(k=1.46 \mathrm{~W} / \mathrm{mK})$. A photograph of the gauges installed on the blade is shown in Figure 4.3. The platinum sensor was placed at the midspan of the blade and a total of 36 thin film gauges were instrumented on the blade.

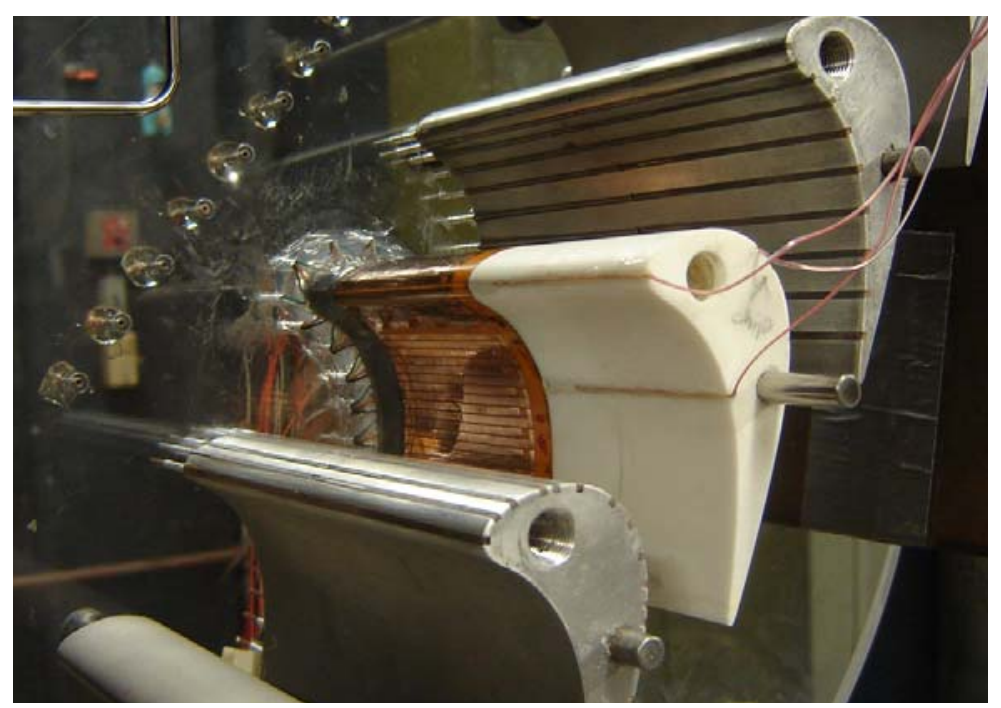

Figure 4.3. Picture of thin film gauges in wind tunnel

Thin film gauges are used to measure a change in temperature on the surface of the blade. The platinum sensor of the thin film gauge changes resistance with temperature and each gauge is calibrated prior to testing. Since the gauge changes resistance with temperature, the gauge is used as one arm of a Wheatstone bridge circuit. The Wheatstone bridge use in these experiments is described by Joe [13]. The change in voltage across the bridge during the experiment is sampled at $1 \mathrm{kHz}$ during the experiment using a 16 Bit NI SCXI-1600 data acquisition system. The data from up to 31 gauges can be recorded in this facility during a single test.

To reduce the heat transfer data, several steps must be taken. The voltage output from each Wheatstone bridge is converted into surface temperature using the gauge calibration and basic Wheatstone bridge operating principles. Next, the heat flux for each gauge is calculated by using a finite-difference code developed by Cress [14]. The finite-difference code uses the time history of the surface temperature of a gauge as a boundary condition and solves the onedimensional, transient heat conduction equation. Over the majority of the blade, the conduction is assumed to be semi-infinite since the Macor conducts heat very slowly. Near the trailing edge, 
the heat flux is calculated over a finite material thickness with the surface temperatures measured by the gauges on each side of the blade used as the boundary conditions to calculate the heat flux. Once the heat flux is determined, the heat transfer coefficient can then be calculated by using,

$$
h=\frac{q^{\prime \prime}}{\left(T_{\text {aw }}-T_{\text {gauge }}\right)}
$$

where the adiabatic wall temperature is provided by,

$$
T_{a w}=T_{o 1} \cdot\left(\frac{1+r_{c} \cdot \frac{\gamma-1}{2} M a^{2}}{1+\frac{\gamma-1}{2} M a^{2}}\right)
$$

It was assumed that the boundary layer was turbulent everywhere, so a recovery factor of $r_{c}=\operatorname{Pr}^{1 / 3}$ was applied to all of the gauges. The heat transfer coefficient can then be nondimensionalized by calculating the Nusselt number by using,

$$
N u=\frac{h \cdot C}{k_{a}}
$$

The heat transfer coefficient can also be nondimensionalized in terms of the Stanton number given by,

$$
S t=\frac{h}{\rho_{L} \cdot U_{L} \cdot C_{p}}
$$

\section{Uncertainty Analysis}

The experimental uncertainty of the heat transfer measurements was calculated by using the procedure developed by Moffat [15]. The analysis took into account the bias error and precision error. An uncertainty was calculated for each gauge at every test condition. The total uncertainty of the heat transfer coefficient for the gauges ranged between $8.5 \%$ and $11.5 \%$ with the bias error contributing the majority to the total uncertainty. For each test condition, measurements were performed at least three times to establish repeatability. 


\section{Turbulence Generation}

To generate freestream turbulence levels of $12 \%$ and $14 \%$, passive turbulence grids were used. A schematic of the turbulence grids is provided in Figure 4.4. The grid designs were based on the correlations reported by Baines and Peterson [16] and research performed by Nix et al. [17] on turbulence grids in the cascade wind tunnel. The first turbulence grid is a square mesh grid. The square mesh grid has bar widths of $1.91 \mathrm{~cm}(0.75 \mathrm{in}$.) and spaced to create $3.81 \mathrm{~cm} \mathrm{x}$ $3.81 \mathrm{~cm}$ (1.5 in. x 1.5 in.) square openings. The solidity of the square mesh grid is $48 \%$. The second turbulence grid is a parallel bar grid. This grid has bars that are $6.35 \mathrm{~cm}$ (2.5 in.) wide and spaced $4.76 \mathrm{~cm}$ (1.875 in.) apart to create a solidity of $50 \%$.

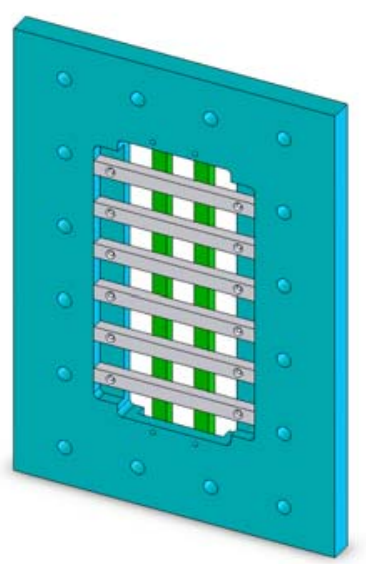

(a)

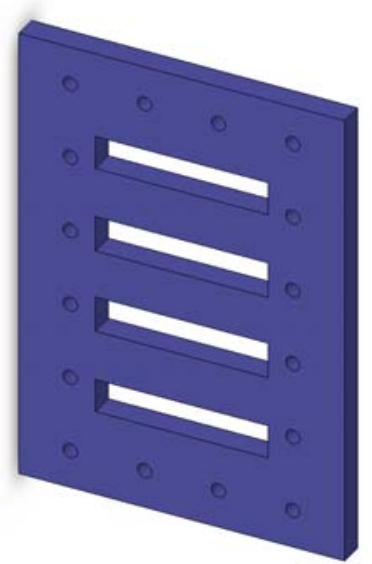

(b)

Figure 4.4. Turbulence grids (a) mesh grid, $\mathrm{Tu}=12 \%$ and (b) bar grid, $\mathrm{Tu}=14 \%$

The location of the turbulence grids relative to the test section are provided in Figure 4.5. Both grids are oriented so that the flow is perpendicular to the bars. Spacers that were $3.18 \mathrm{~cm}$ (1.25 in.) thick were added or removed to achieve the desired turbulence level in the test section. The mesh grid was placed downstream of the two-dimensional contraction with two spacers placed between the mesh grid and the test section. The bar grid was placed upstream of the contraction and four spacers were placed between the contraction and the test section. 


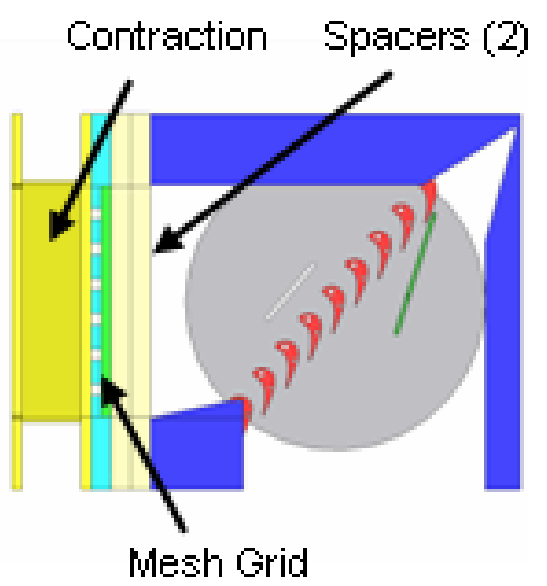

(a)

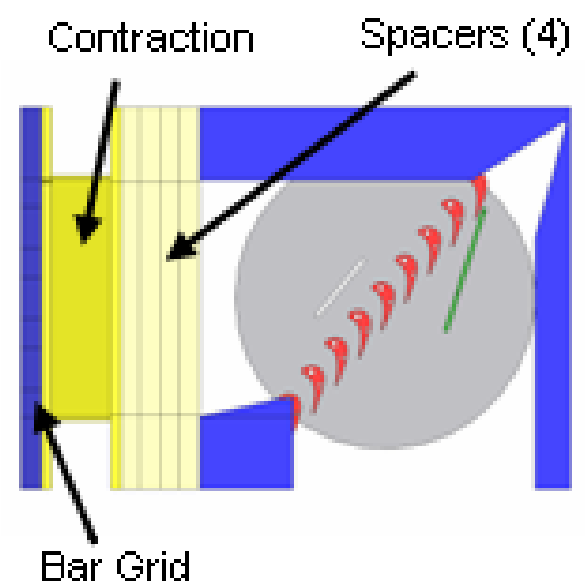

(b)

Figure 4.5. Turbulence grid location relative to the test section for the (a) mesh grid and (b) bar grid

The velocity fluctuations in the streamwise direction were measured using a single hotfilm probe with a $50 \mu \mathrm{m}$ diameter film that was roughly $1.5 \mathrm{~mm}$ long that was connected to a constant-temperature anemometer. Hot-film data was sampled for approximately 1.3 seconds at $100 \mathrm{kHz}$ and filtered at $40 \mathrm{kHz}$. The hot-film probe was discretely traversed over one blade pitch along the slot parallel to the blade inlet plane as shown in Figure 4.2. The turbulence intensity and integral turbulence length scales were calculated at each measurement location. The turbulence length scales were calculated using the methods described by Nix et al. [17] that applies Taylor's Hypothesis of frozen turbulence. The turbulence levels and length scales were measured for the square mesh grid, the bar grid and a baseline case where no turbulence grid was installed in the tunnel. The turbulence intensity and the normalized integral length scale distributions along the blade inlet pitch are provided in Figures 4.6 and 4.7, respectively. The turbulence levels and normalized length scales are provided in Table 4.2. 


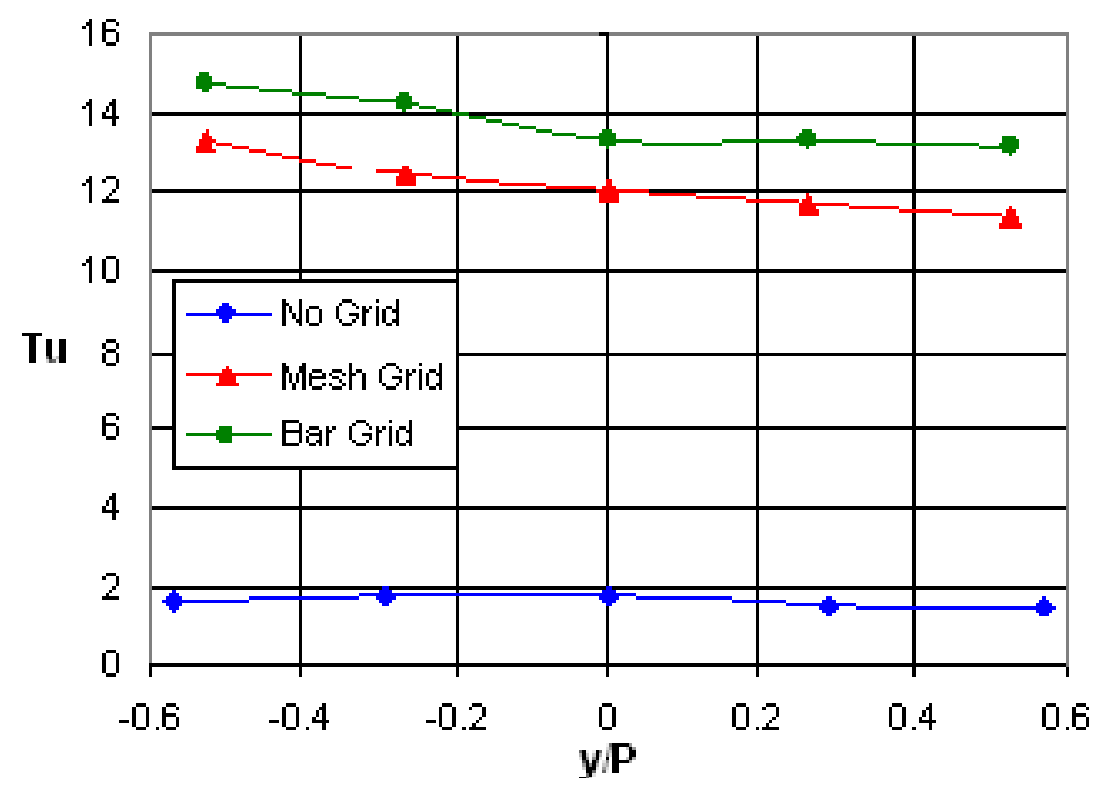

Figure 4.6. Turbulence intensity along inlet pitch

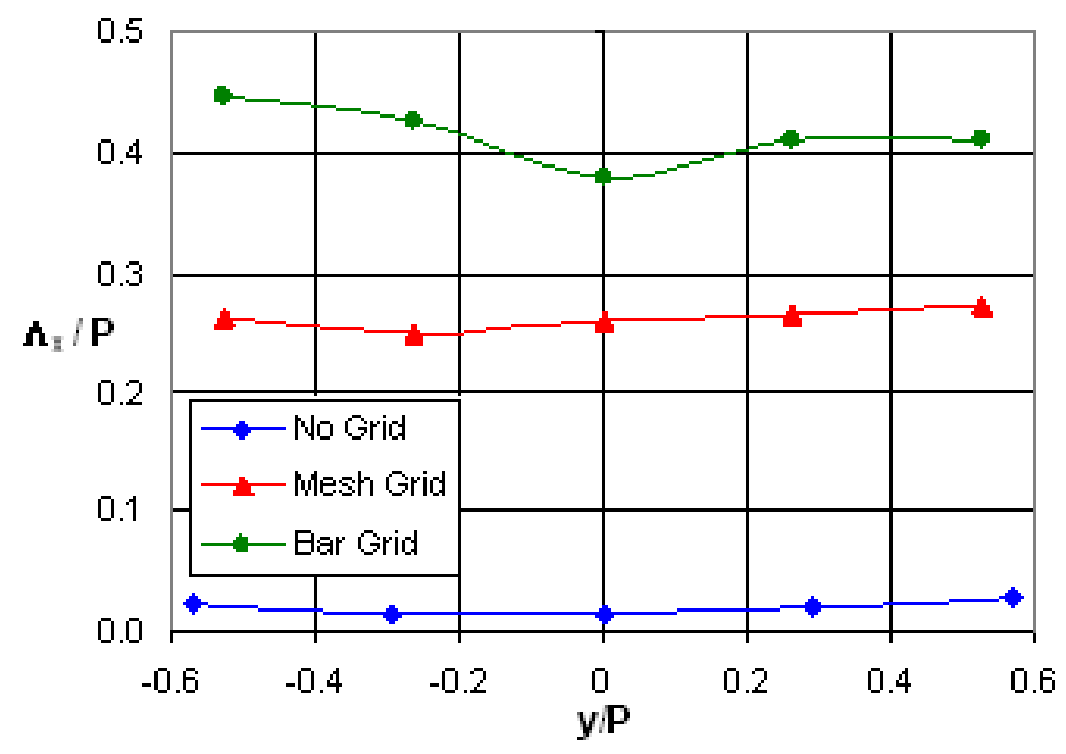

Figure 4.7. Integral length scale along inlet pitch

Table 4.2. Summary of grid generated turbulence

\begin{tabular}{|c|c|c|}
\hline & Tu Intensity & $\begin{array}{c}\text { Length Scale } \\
\left(\Lambda_{\mathrm{x}} / \mathrm{P}\right)\end{array}$ \\
\hline Baseline & $2 \%$ & 0.02 \\
\hline Mesh Grid & $12 \%$ & 0.26 \\
\hline Mesh Grid & $14 \%$ & 0.41 \\
\hline
\end{tabular}


The turbulence intensity and length scale measurements were also compared to the literature correlations for grid generated turbulence in the streamwise direction using the coefficient values reported by Roach [18]. The turbulence decay for both grid geometries is given by,

$$
T u=1.13 \cdot\left(\frac{x}{B}\right)^{-5 / 7}
$$

and the increase in length scale is provided by,

$$
\frac{\Lambda_{x}}{B}=0.2 \cdot\left(\frac{x}{B}\right)^{1 / 2}
$$

The turbulence decay for the mesh and bar grids is provided in Figure 4.8. The turbulence decay for both the grids show similar trends to the correlation, but are at lower turbulence levels as compared to the correlation. The measured turbulence levels being lower than the correlation were also observed by Nix et al. [17] in this facility.

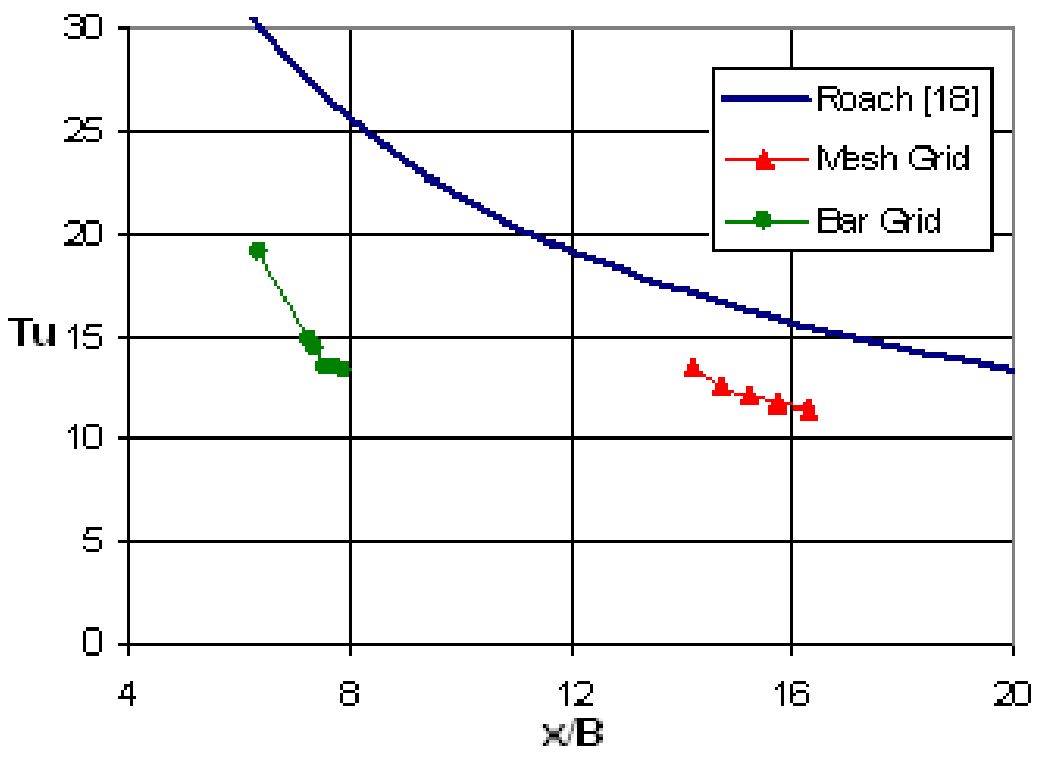

Figure 4.8. Turbulence decay from grids

The increase in the diameter of the length scale for the mesh and bar girds is provided in Figure 4.9. The measured turbulence length scales show similar trends to the correlation. The mesh grid matches the correlation almost exactly, whereas, the bar grid lies below the correlation. The turbulence length scale for the bar grid lies below the correlation since the flow passes through a contraction after the bar grid. 
To check that the inlet flow to the blade passages downstream of the turbulence grids was uniform, a Kiel probe was traversed along the measurement slot shown in Figure 4.2. A velocity ratio was creating by dividing the velocity measured from the Kiel probe by the velocity measured from a stationary Pitot probe was calculated. The velocity ratio for the each configuration tested is provided in Figure 4.10. The bar grid shows a slight variation of inlet velocity along the angled slot. The trade off of generating high turbulence levels with the bar grid was that the inlet velocity was slightly nonuniform.

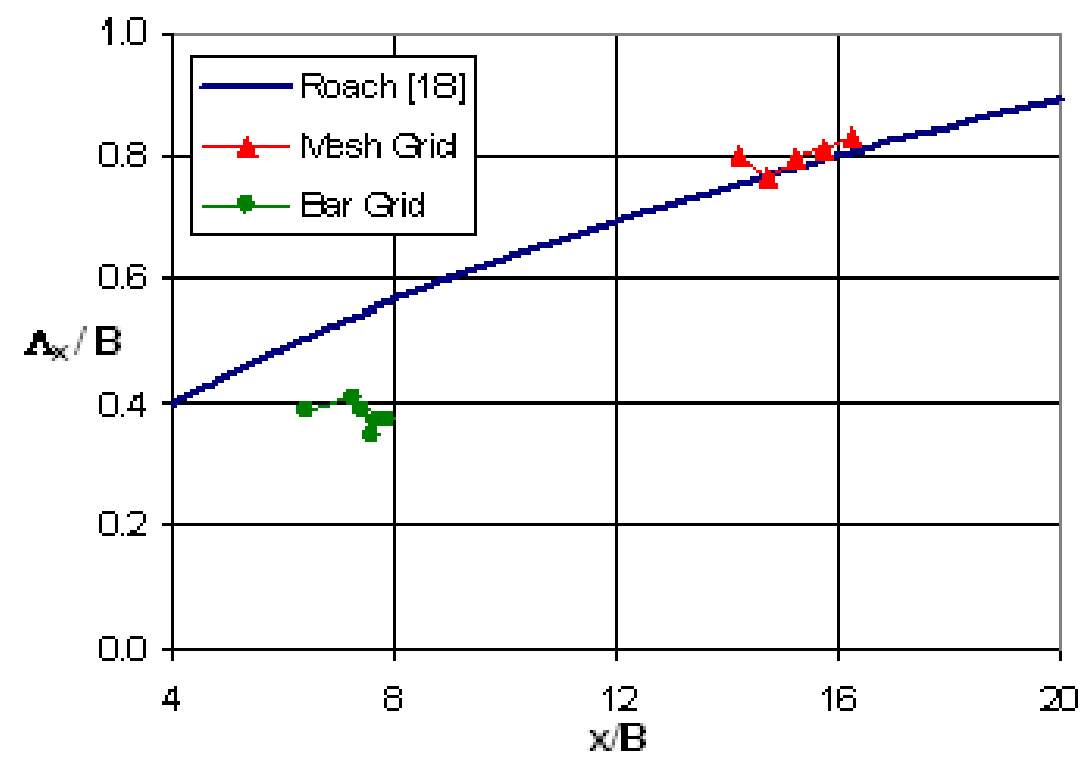

Figure 4.9. Length scale growth from grids

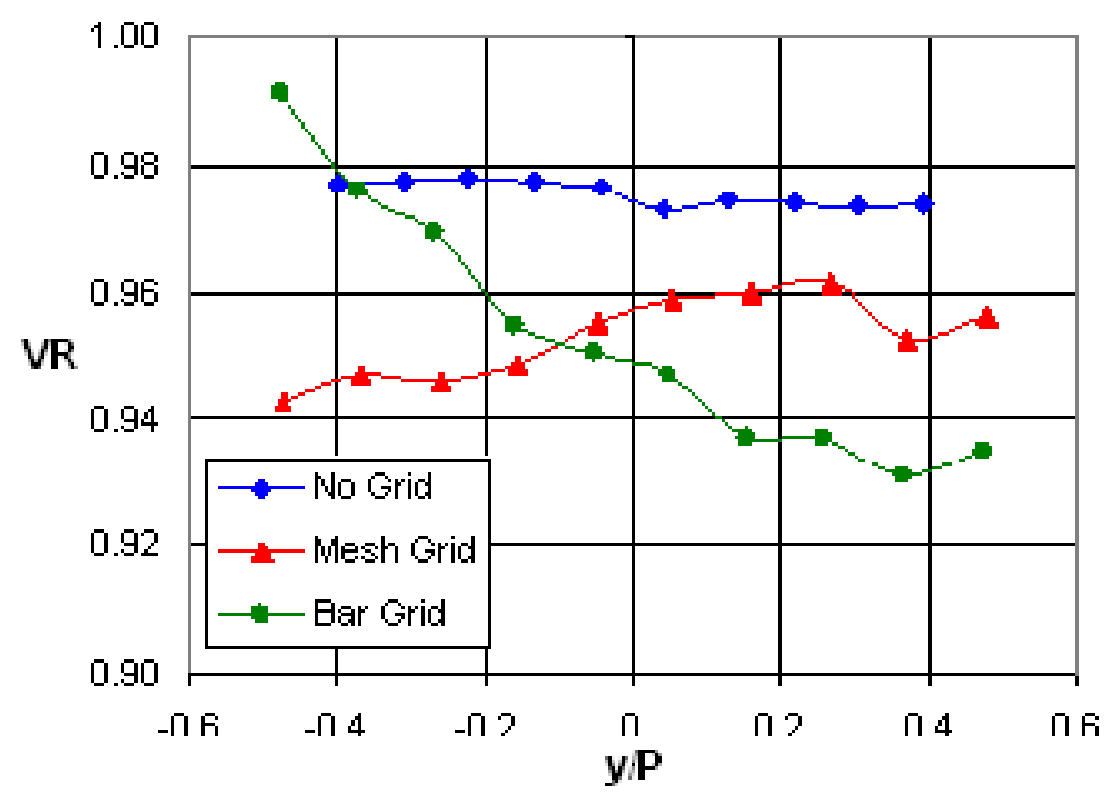

Figure 4.10. Velocity ratio distribution along inlet pitch 


\section{Blade Static Pressure Distribution}

Figure 4.11 shows the local Mach number distributions on the blade surface for three exit Mach number conditions. The flow accelerates over most of the pressure side except for a short deceleration region just downstream of the stagnation point $(\mathrm{s} / \mathrm{C}=-0.25)$. The flow on the suction side continuously accelerates up to the geometric throat area $(\mathrm{s} / \mathrm{C}=0.84)$. The exit Mach 0.62 and 0.8 cases decelerate immediately after the throat, whereas the exit Mach 1.09 case continues to accelerate and becomes supersonic. A trailing edge shock from the adjacent blade impinging on the suction surface $(\mathrm{s} / \mathrm{C}=1.01)$ causes the sudden flow deceleration after the throat at exit Mach 1.09.

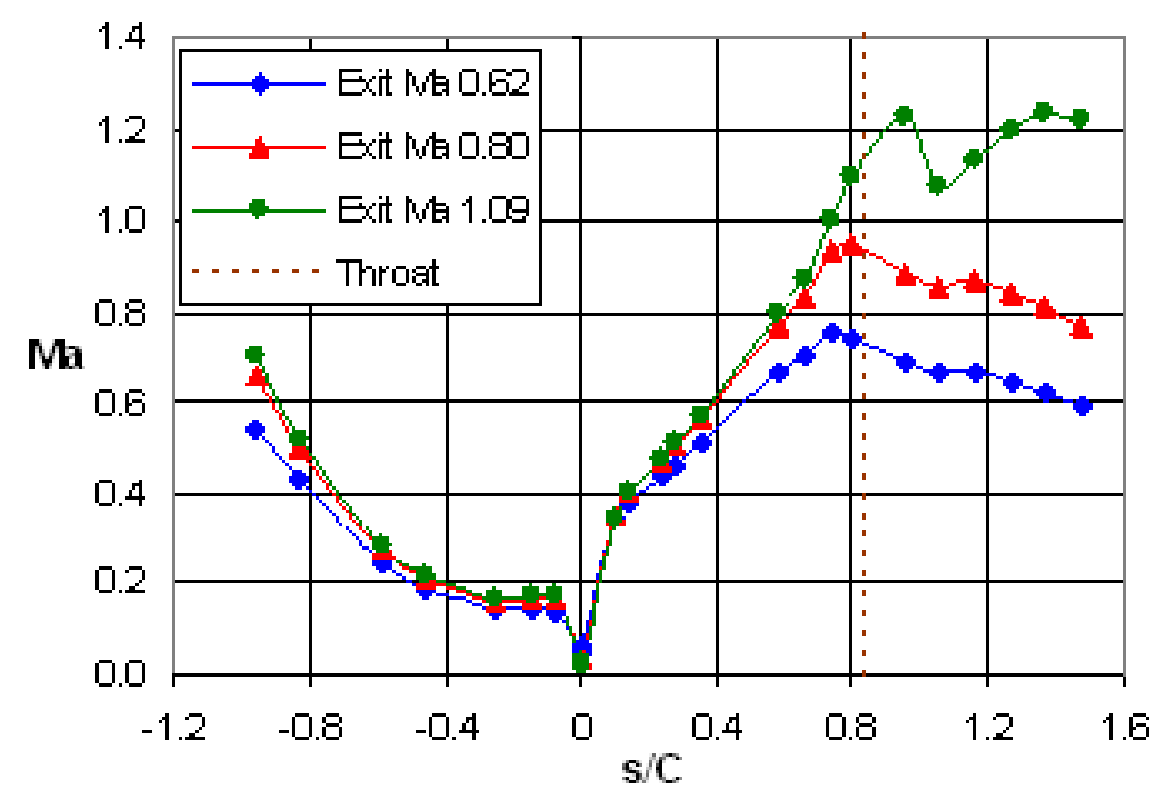

Figure 4.11. Local Mach number distribution

The periodicity of the flow at exit Mach 0.85 is provided in Figure 4.12. The flow periodicity is shown by comparing the local Mach number distribution over the blade surfaces. The suction side of blade 3 and blade 4 shows the same local Mach number distributions over the majority of the suction surface. There is only a slight variation in the local Mach numbers near the geometric throat. The pressure side of blade 4 and blade 5 shows almost identical local Mach number distributions. 


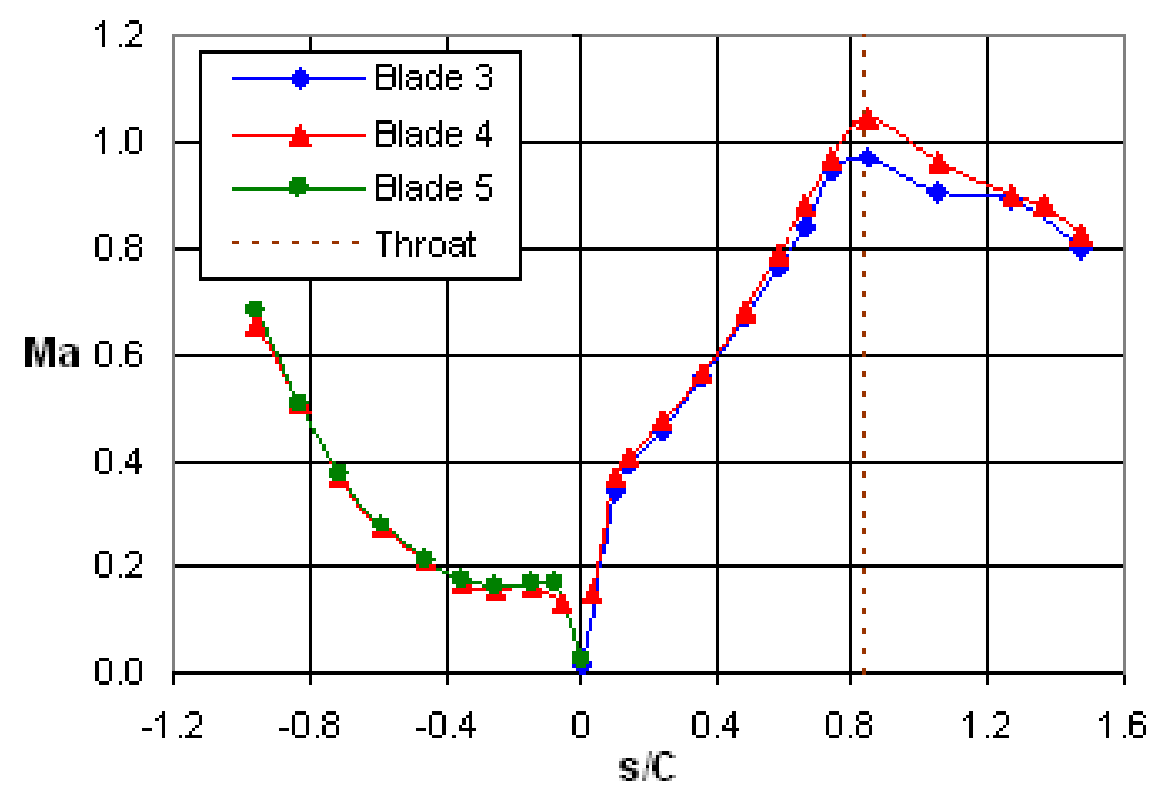

Figure 4.12. Flow periodicity through blade passages

The distribution of the acceleration parameter on the blade surface for each exit Mach number is provided in Figure 4.13. The acceleration parameter distribution shows the same trends as the local Mach number distribution. A positive acceleration parameter indicates that the flow is accelerating and a negative value indicates that the flow is decelerating. On the pressure side of the blade, the acceleration parameter is above the critical value of $3 \times 10^{-6}$ which has been observed by Jones and Launder [19] and reported in the transition study by Mayle [20] to relaminarize the boundary layer.

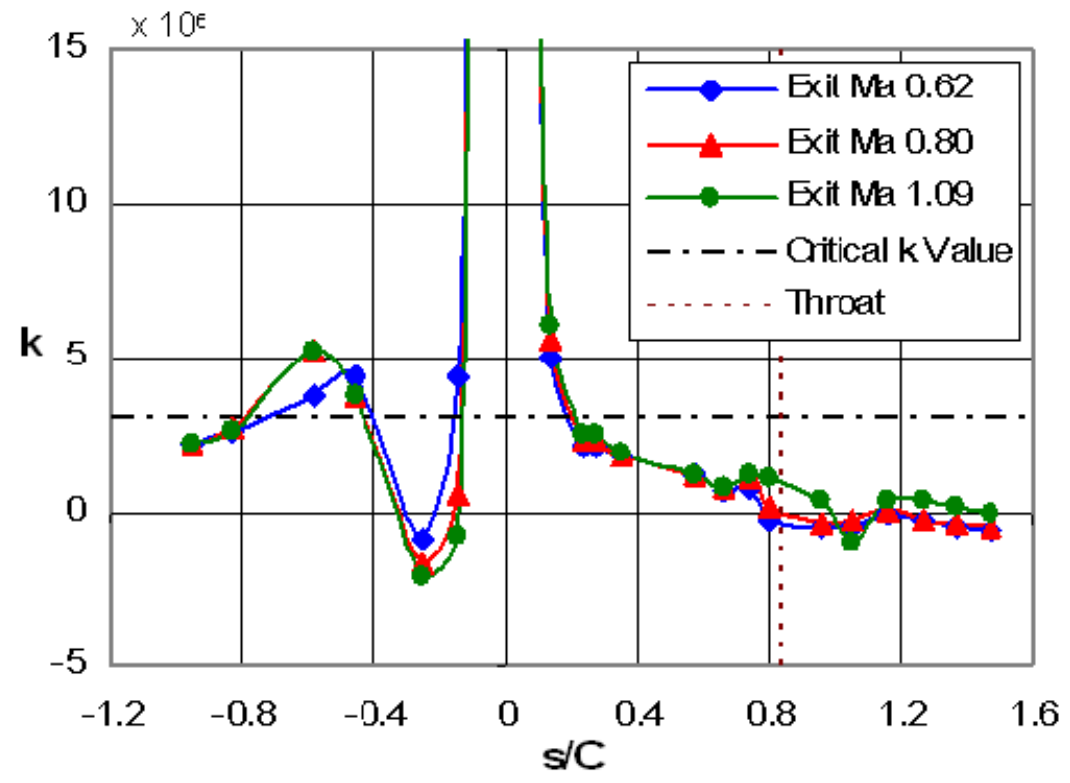

Figure 4.13. Acceleration parameter distribution 


\section{Blade Heat Transfer Distribution}

\section{Test Conditions}

Heat transfer measurements were performed at exit Mach numbers of $0.55,0.78$, and 1.03. The turbulence levels were varied between $2 \%, 12 \%$, and $14 \%$ at each exit Mach number. The test matrix resulted heat transfer data for nine different flow conditions. For each test condition, heat transfer measurements were performed at least three times to establish repeatability. Table 4.3 provides the flow and heat transfer conditions for each test. The exit Reynolds number coupled with the exit Mach number is based on blade chord and is defined by,

$$
\operatorname{Re}_{2}=\frac{\rho_{2} \cdot U_{2} \cdot C}{\mu_{2}}
$$

where the average pressure and temperature data during the test run were used to calculate the exit Reynolds number.

Table 4.3. Test conditions for each case

\begin{tabular}{|c|c|c|c|c|c|}
\hline & Exit Ma & $\mathbf{T u}$ & Exit Re & $\mathbf{T}_{\mathbf{0 1}}\left({ }^{\mathbf{0}} \mathbf{C}\right)$ & $\mathbf{T}_{\text {init,w }}\left({ }^{\mathbf{0}} \mathbf{C}\right)$ \\
\hline Case 1 & 0.57 & $2 \%$ & 640,000 & 106 & 25.0 \\
\hline Case 2 & 0.55 & $12 \%$ & 610,000 & 99 & 24.5 \\
\hline Case 3 & 0.55 & $14 \%$ & 600,000 & 102 & 26.5 \\
\hline Case 4 & 0.76 & $2 \%$ & 810,000 & 103 & 25.7 \\
\hline Case 5 & 0.78 & $12 \%$ & 790,000 & 108 & 26.8 \\
\hline Case 6 & 0.78 & $14 \%$ & 800,000 & 107 & 27.4 \\
\hline Case 7 & 1.03 & $2 \%$ & $1,090,000$ & 100 & 27.0 \\
\hline Case 8 & 1.03 & $12 \%$ & $1,060,000$ & 103 & 25.9 \\
\hline Case 9 & 1.01 & $14 \%$ & $1,070,000$ & 95 & 26.5 \\
\hline
\end{tabular}

\section{Effect of Freestream Turbulence}

This section discusses the effect that increasing the freestream turbulence has on the heat transfer distribution over the turbine blade surface. Plots are shown of the heat transfer distribution over the blade surface in terms of Nusselt number and the Nusselt number augmentation relative to the low freestream turbulence cases. The data is also compared with the flat plate correlations for laminar and turbulent boundary layers. Each of these plots is presented for each exit Mach number condition tested.

Figures 4.14, 4.15 and 4.16 provide the heat transfer distributions for each freestream turbulence level at exit Mach 0.55, 0.78 and 1.03, respectively. The turbulence augments the heat 
transfer at the leading edge, on the pressure side and the suction side of the blade for each exit Mach number condition. The general shape of the heat transfer distribution over the blade surface is the same for all cases. The highest heat transfer occurs at the leading edge and decreases as the flow proceeds down the suction and pressure sides. The heat transfer on the suction surface decreases until the boundary layer transitions, where a large increase in heat transfer occurs. The heat transfer on the pressure surface shows a decrease until s/C $=-0.40$ and then a slight increase afterwards.

On the suction side, the transition to a turbulent boundary layer occurs near the throat $(\mathrm{s} / \mathrm{C}=0.84)$ for each turbulence level at exit Mach numbers of 0.55 and 0.78 . The boundary layer transition length over the blade surface is short for the exit Mach 0.55 and 0.78 cases because the flow is decelerating after the throat. The boundary layer transition for the $2 \%$ turbulence at exit Ma 1.03 occurs at $\mathrm{s} / \mathrm{C}=0.58$. Since the flow is still accelerating at this point, the transition length increases. The effect of acceleration on the transition length was also noted in the study performed by Zhang and Han [21].

The start of transition for the $12 \%$ and 14\% turbulence tests at exit Mach 1.03 appears to begin at $\mathrm{s} / \mathrm{C}=0.58$. However, the increase in heat transfer is very gradual for both the $12 \%$ and $14 \%$ turbulence cases. A sharp rise in heat transfer occurs at $\mathrm{s} / \mathrm{C}=1.01$ which corresponds to where trailing edge shock from the adjacent blade is impinging on the suction surface. The slow transition could be attributed to the interaction of the shock. Once the boundary layer goes turbulent on the suction side, the effect of the freestream turbulence level on heat transfer diminishes.

On the pressure side, higher augmentation levels can be seen. The low freestream turbulence data show a local peak in the heat transfer data downstream of the leading edge on the pressure side at $\mathrm{s} / \mathrm{C}=-0.26$. Local peaks in heat transfer on the pressure side have been observed by Consigny and Richards [3], Arts et al. [4] and Giel et al. [5]. This location is corresponds to the location of the flow deceleration and has been hypothesized by Arts et al. [4] and Giel et al. [5] to be caused by local flow separation. At the higher turbulence levels, the local peak appears to be diminished. Unfortunately, the gauge located at the peak was damaged after completing the heat transfer measurements at low freestream turbulence. However, the gauges surrounding the damaged gauge do not appear to indicate that a peak is present at higher turbulence levels. 


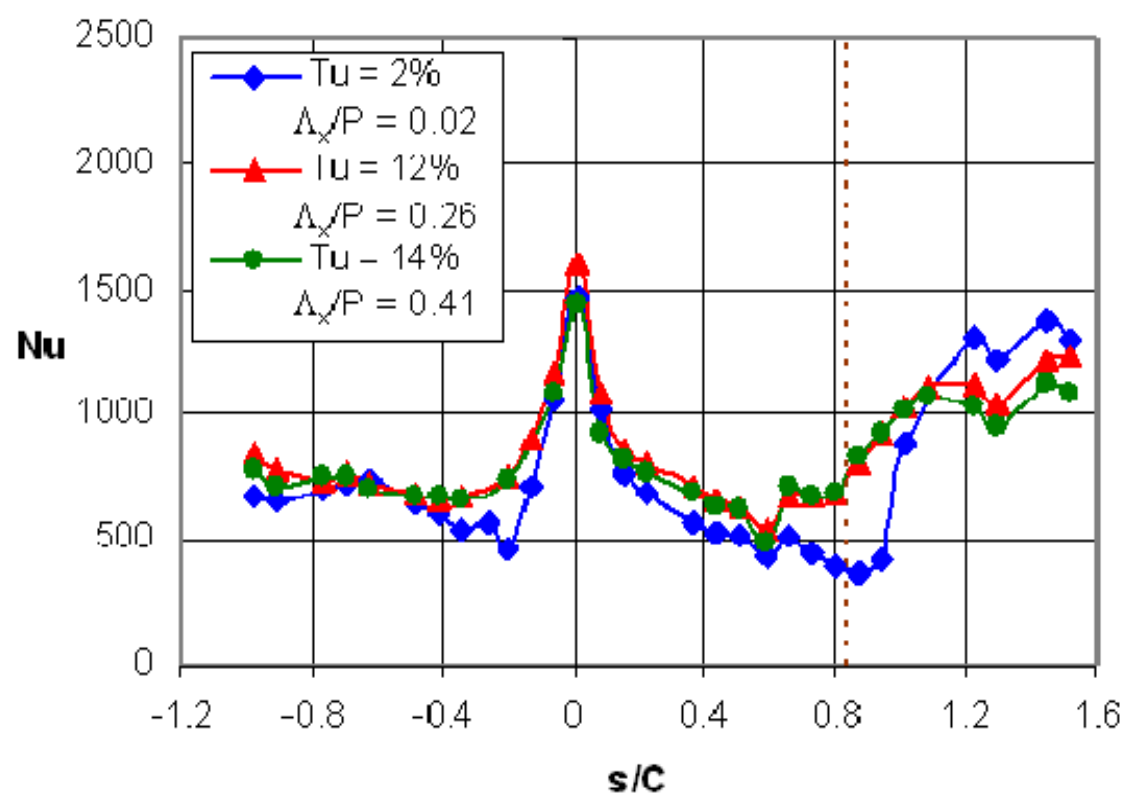

Figure 4.14. Heat transfer distribution at exit Ma 0.55

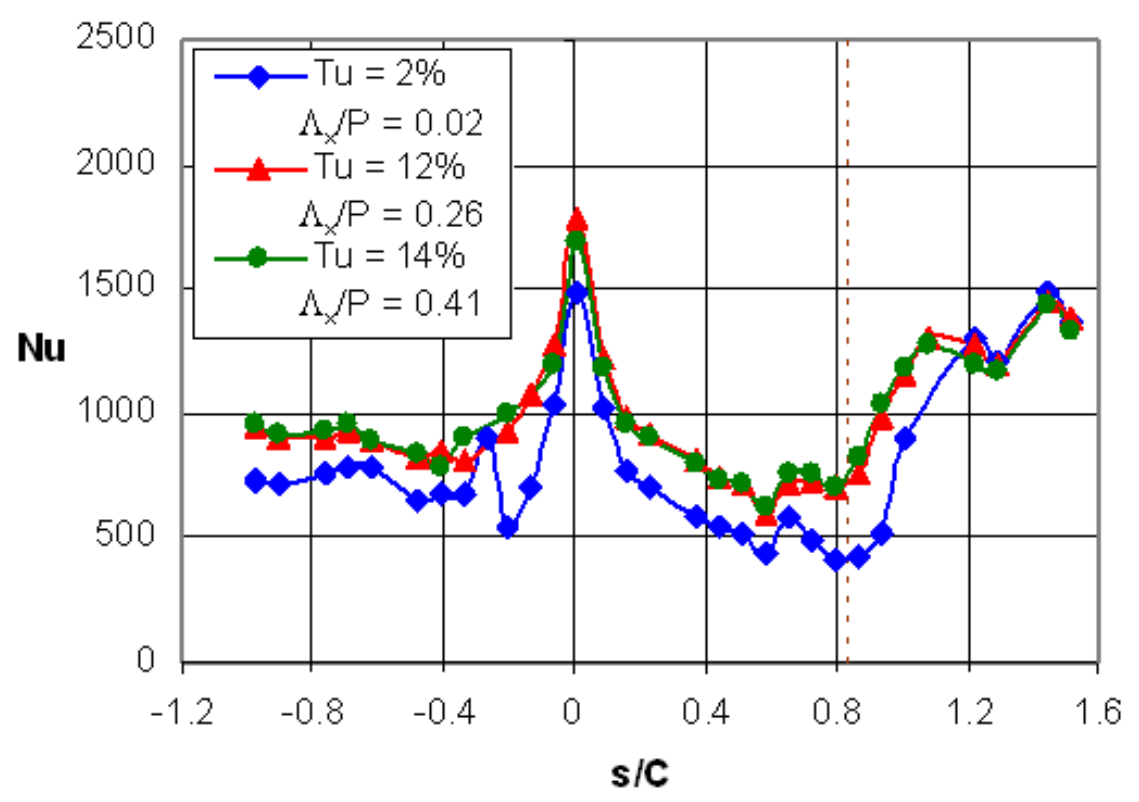

Figure 4.15. Heat transfer distribution at exit Ma 0.78 


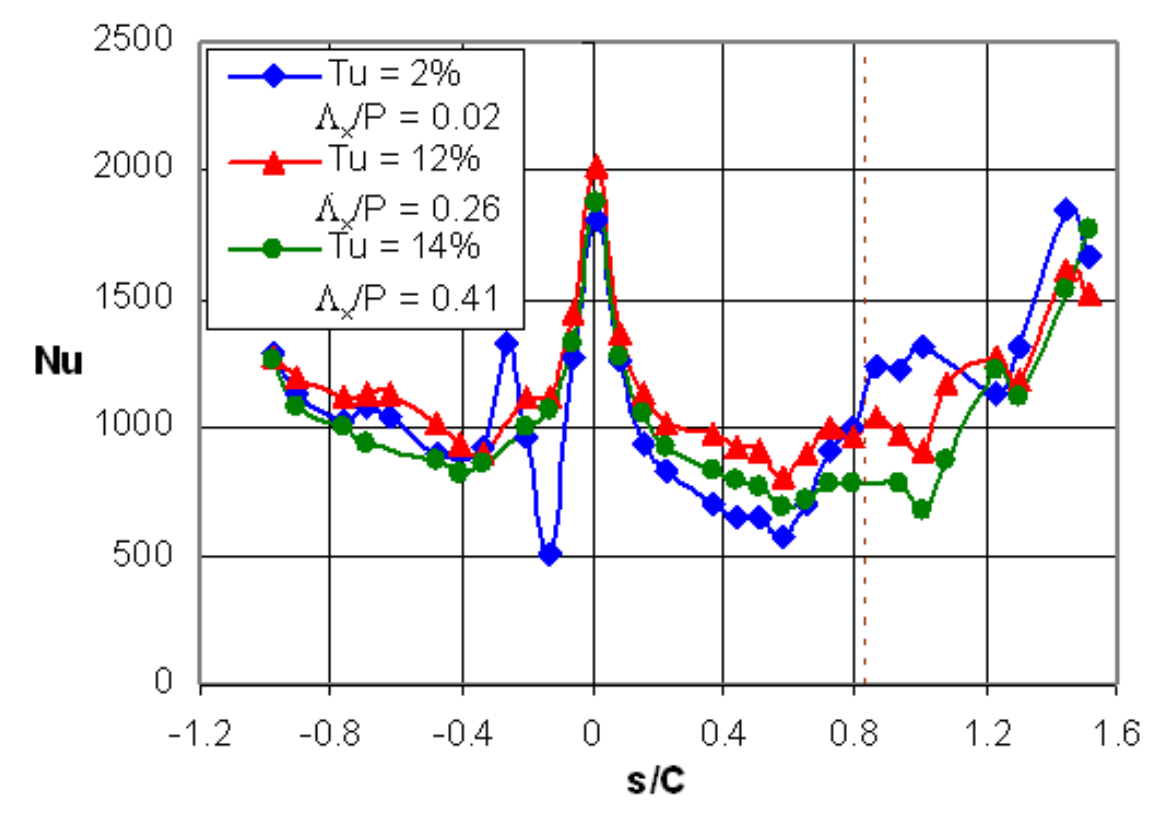

Figure 4.16. Heat transfer distribution at exit Ma 1.03

The heat transfer data at the high turbulence levels were also normalized with the $2 \%$ turbulence data to show the augmentation levels due to turbulence. The augmentation plots for exit Mach 0.55, 0.78 and 1.03 are shown in Figures 4.17, 4.18, and 4.19, respectively. There is a peak in the augmentation plot on the pressure side where the flow decelerates at $\mathrm{s} / \mathrm{C}=-0.26$. Another peak occurs just after the throat at $\mathrm{s} / \mathrm{C}=0.84$ since the transition occurs slightly earlier.

The augmentation levels for the $12 \%$ and $14 \%$ turbulence cases are almost exactly the same at exit Mach 0.55 and 0.78. At exit Mach 1.03, a difference in the augmentation levels for the $12 \%$ and $14 \%$ turbulence cases was observed. The $12 \%$ turbulence data show higher augmentation levels on both the pressure and suction sides of the blade than the $14 \%$ turbulence data. Since the turbulence levels for each high freestream turbulence test are approximately the same, the length scales are the only difference between the tests. It appears that for the exit Mach 1.03 tests, the smaller length scale augments the heat transfer more than larger length scale. 


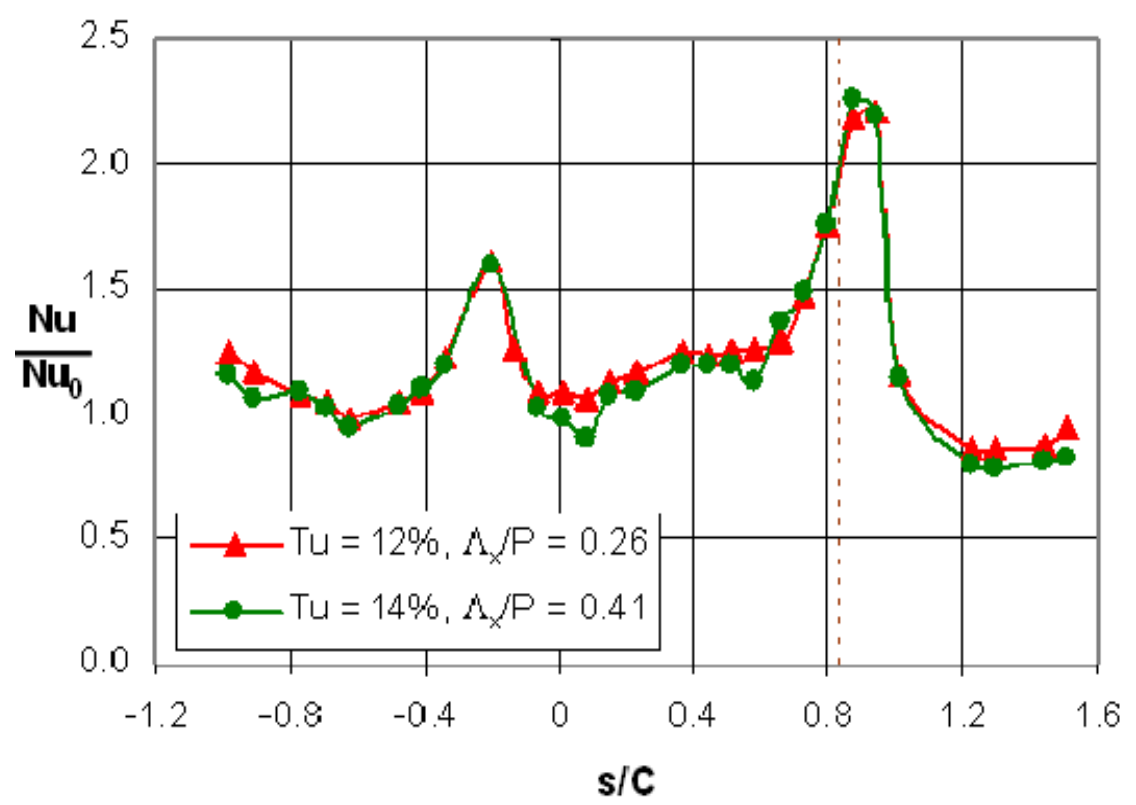

Figure 4.17. Heat transfer augmentation at exit Ma 0.55

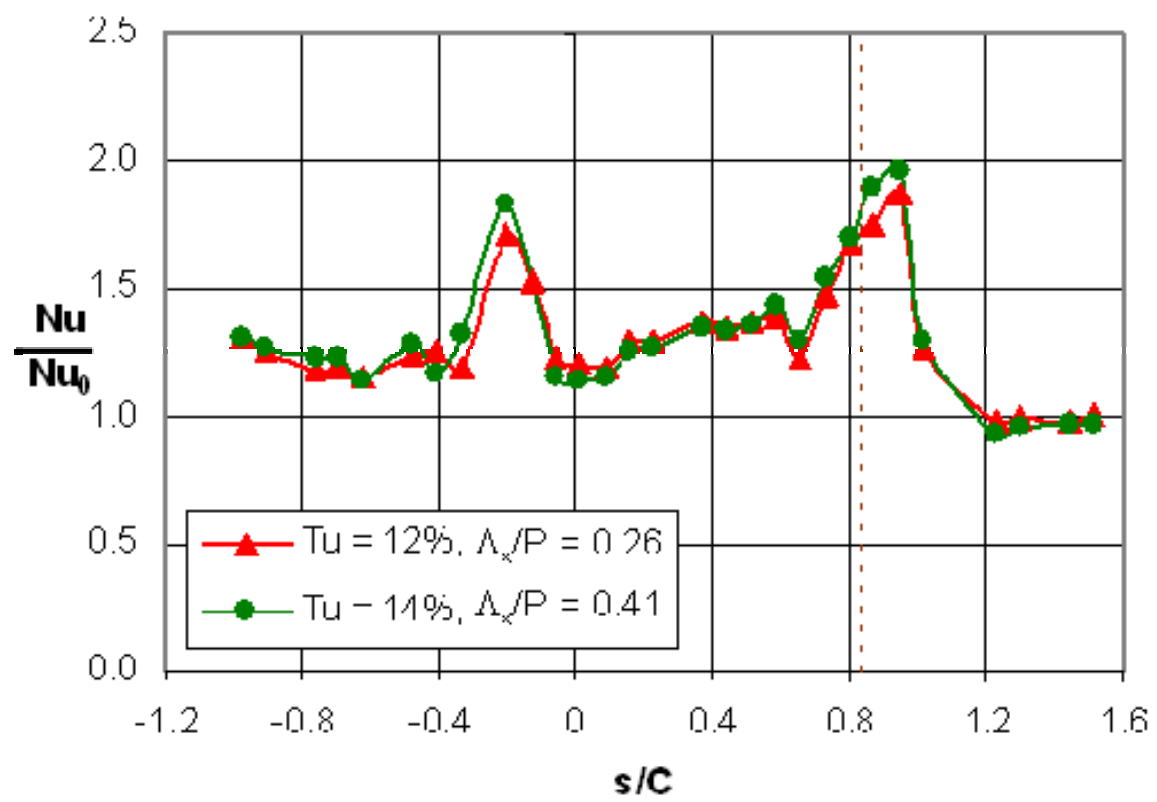

Figure 4.18. Heat transfer augmentation at exit Ma 0.78 


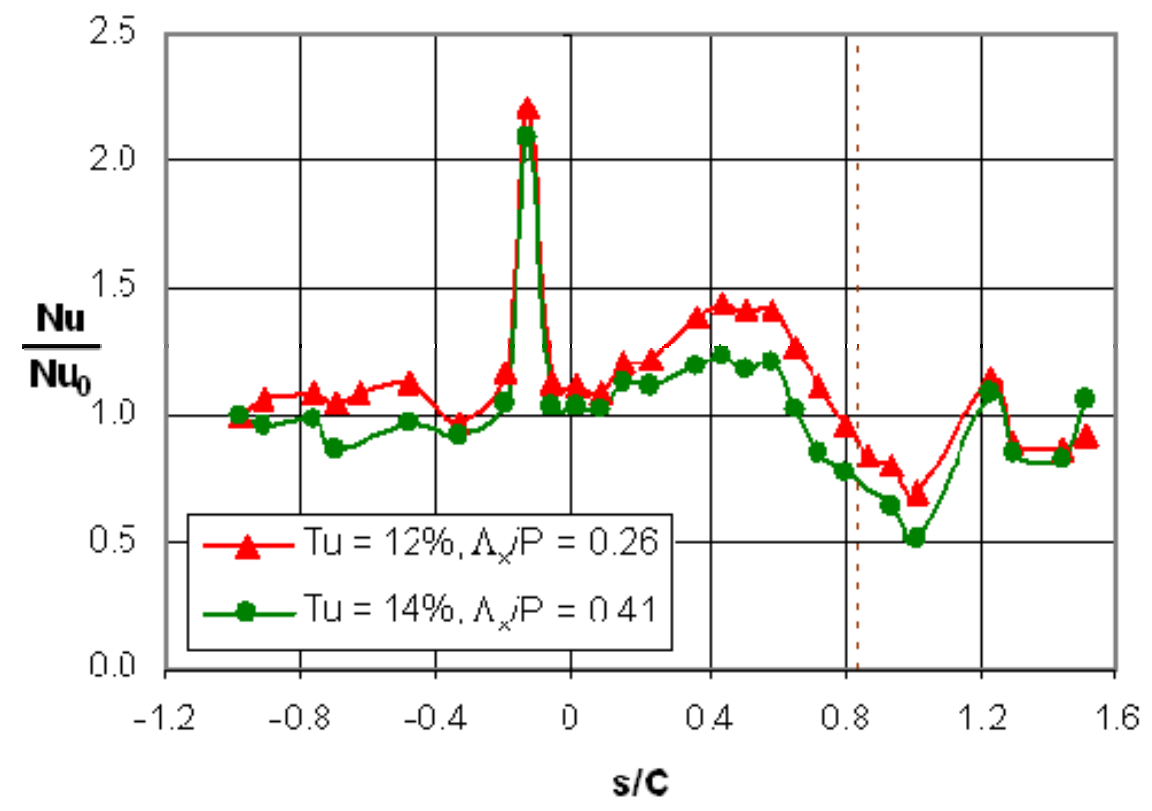

Figure 4.19. Heat transfer augmentation at exit Ma 1.03

The heat transfer data were also compared to the flat plate correlations for a laminar and turbulent boundary layer. While the flat plate correlations do not take into account the effect of pressure gradient or curvature on heat transfer, the correlations do provide insight on boundary layer behavior. The flat plate correlations reported by Incropera and DeWitt [22] in terms of the local Nusselt number are,

$$
\begin{array}{ll}
\text { Laminar: } & N u_{L}=0.332 \mathrm{Re}_{L}^{1 / 2} \cdot \operatorname{Pr}^{1 / 3} \\
\text { Turbulent: } & N u_{L}=0.0296 \mathrm{Re}_{L}^{4 / 5} \cdot \operatorname{Pr}^{1 / 3}
\end{array}
$$

The local Reynolds number given by,

$$
\operatorname{Re}_{L}=\frac{\rho_{L} \cdot U_{L} \cdot s}{\mu}
$$

was used to find the Nusselt number distribution of the correlation. Averaged pressure and temperature data taken during the test run were used to calculate the local Reynolds number. The local Nusselt number was converted into a heat transfer coefficient at each measurement location by using,

$$
h=\frac{N u_{L} \cdot k_{a}}{s}
$$

and then the Stanton number is calculated by using equation 4.4. 
Figures 4.20, 4.21 and 4.22 show how the experimental data compares with the turbulent and laminar flat plate heat transfer correlations on the suction side of the blade at exit Mach 0.55, 0.78 and 1.03, respectively. Before transition occurs, the boundary layer lies between the laminar and turbulent boundary layer correlations for each case and follows the trend of the laminar correlation before transitioning. The difference between the laminar correlation and the low freestream turbulence data in the laminar region can be attributed to the effect of favorable pressure gradient. The augmentation due to turbulence on the suction side can also be seen since the high turbulence levels fall closer to the turbulent correlation than the $2 \%$ turbulence case. Good agreement between the turbulent flat plate correlation and the experimental data is shown for all of the data once the flow goes turbulent on the suction surface.

The comparison between the experimental data compared with the laminar and turbulent flat late correlations on the pressure side is provided in Figures 4.23, 4.24, and 4.25. The measured heat transfer lies near the turbulent correlation indicating that the pressure side boundary layer is fully turbulent. The one exception is the point that lies close to the laminar correlation for the $2 \%$ turbulence data at exit Mach 1.03. This point is just upstream of the deceleration region. The heat transfer being close to the laminar correlation suggests that the flow is laminar at this location.

The data start above the turbulent correlation and then decay below the turbulent correlation. The data having a steeper slope than the turbulent correlation might suggest that the boundary layer is attempting to relaminarize. From the acceleration parameter in Figure 4.14, the acceleration parameter is above the critical value on the majority of the pressure side, which supports the possibility of relaminarization occurring. 


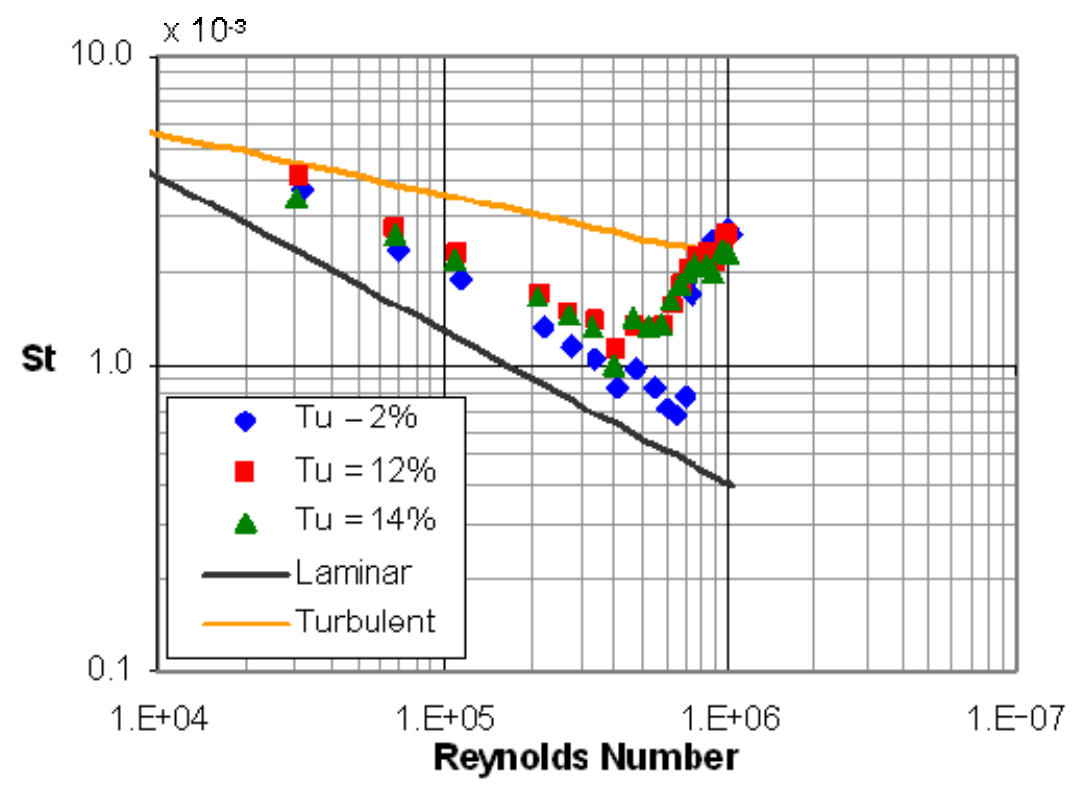

Figure 4.20. Suction side data compared to the flat plate correlations at exit Ma 0.55

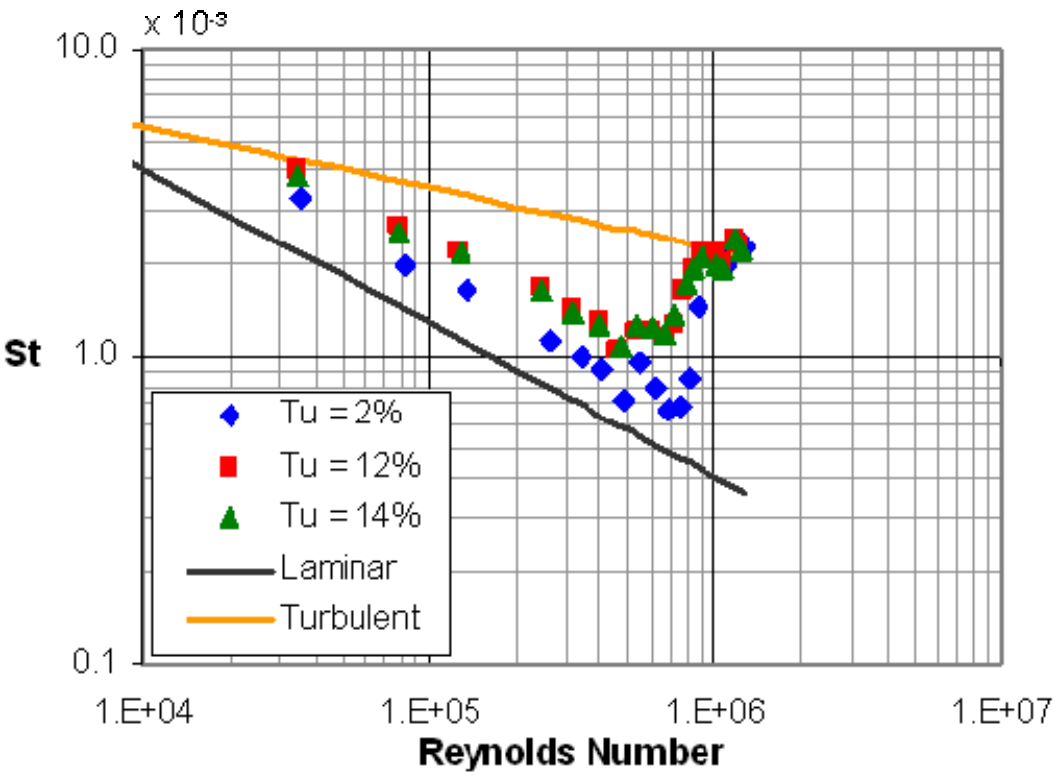

Figure 4.21. Suction side data compared to the flat plate correlations at exit Ma 0.78 


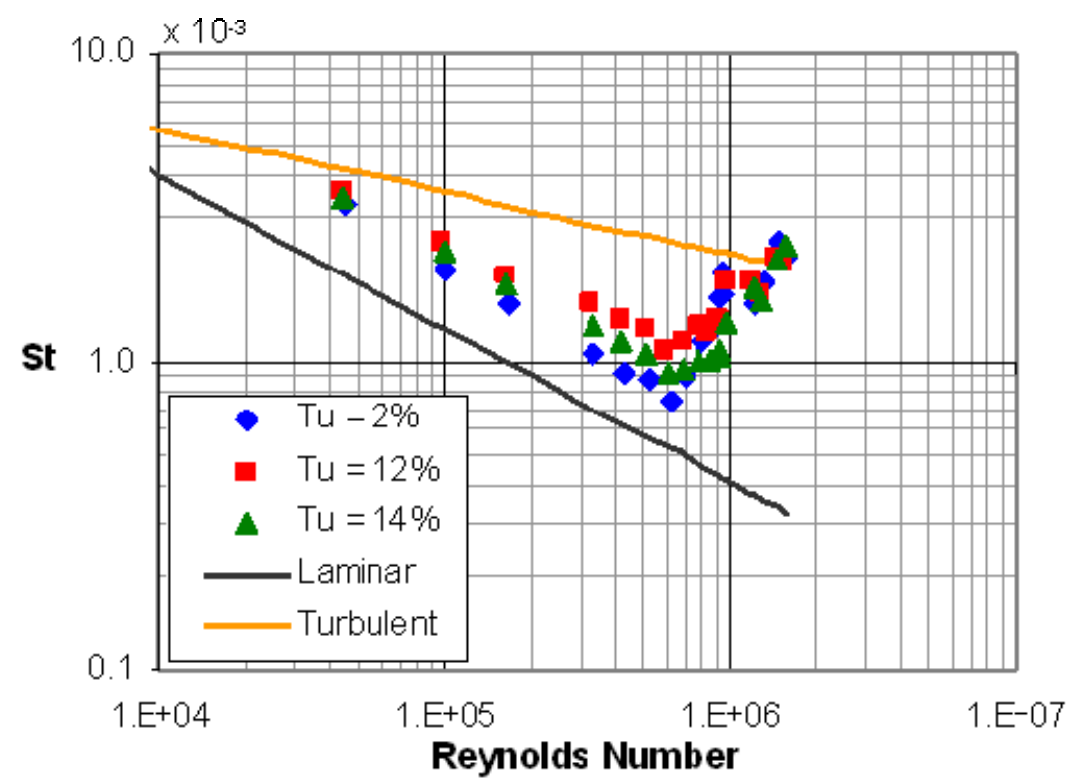

Figure 4.22. Suction side data compared to the flat plate correlations at exit Ma 1.03

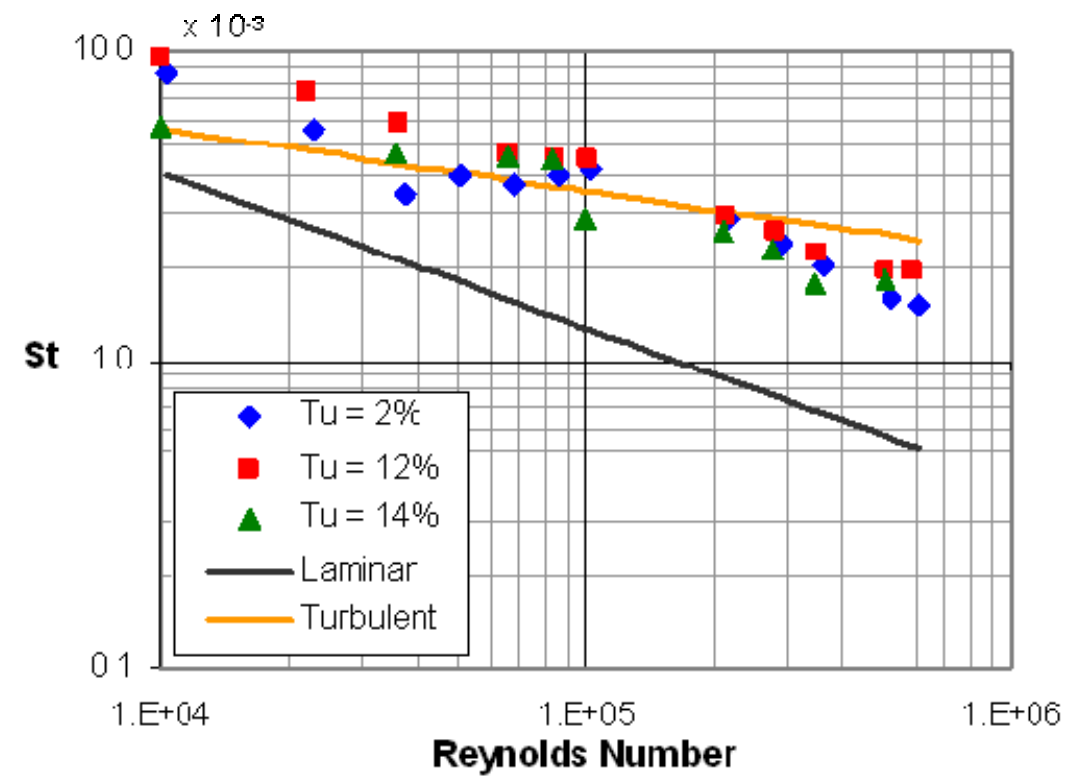

Figure 4.23. Pressure side data compared to the flat plate correlations at exit Ma 0.55 


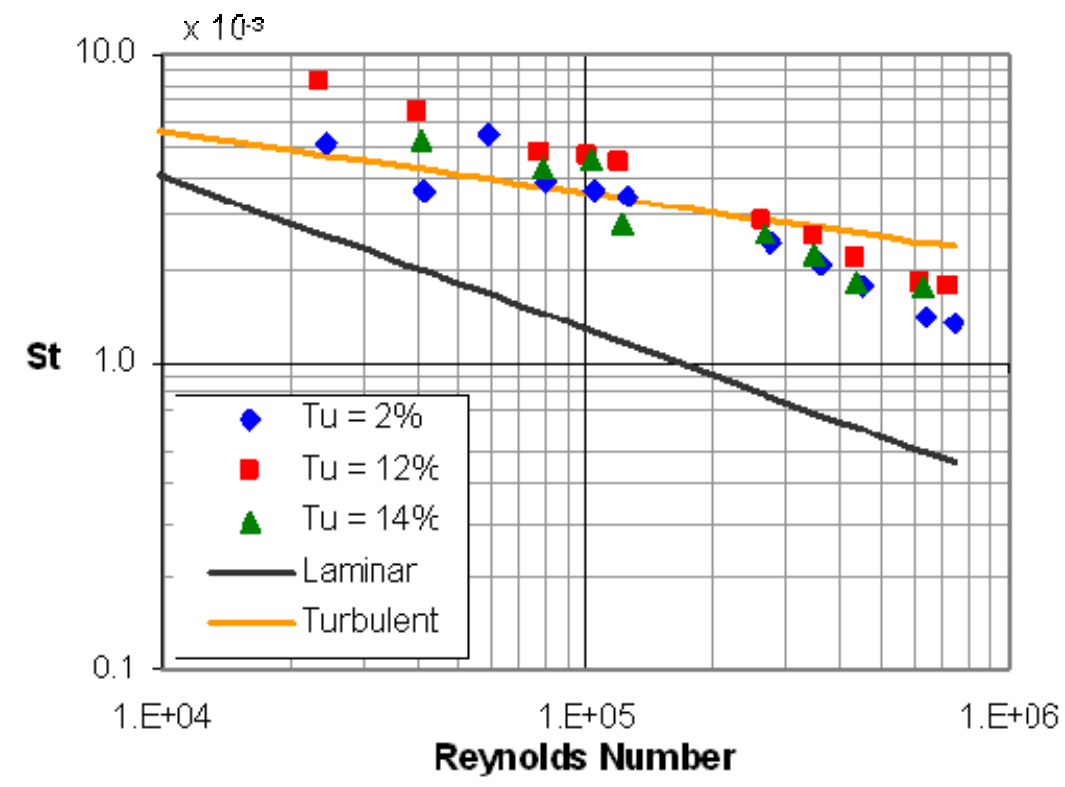

Figure 4.24. Pressure side data compared to the flat plate correlations at exit Ma 0.78

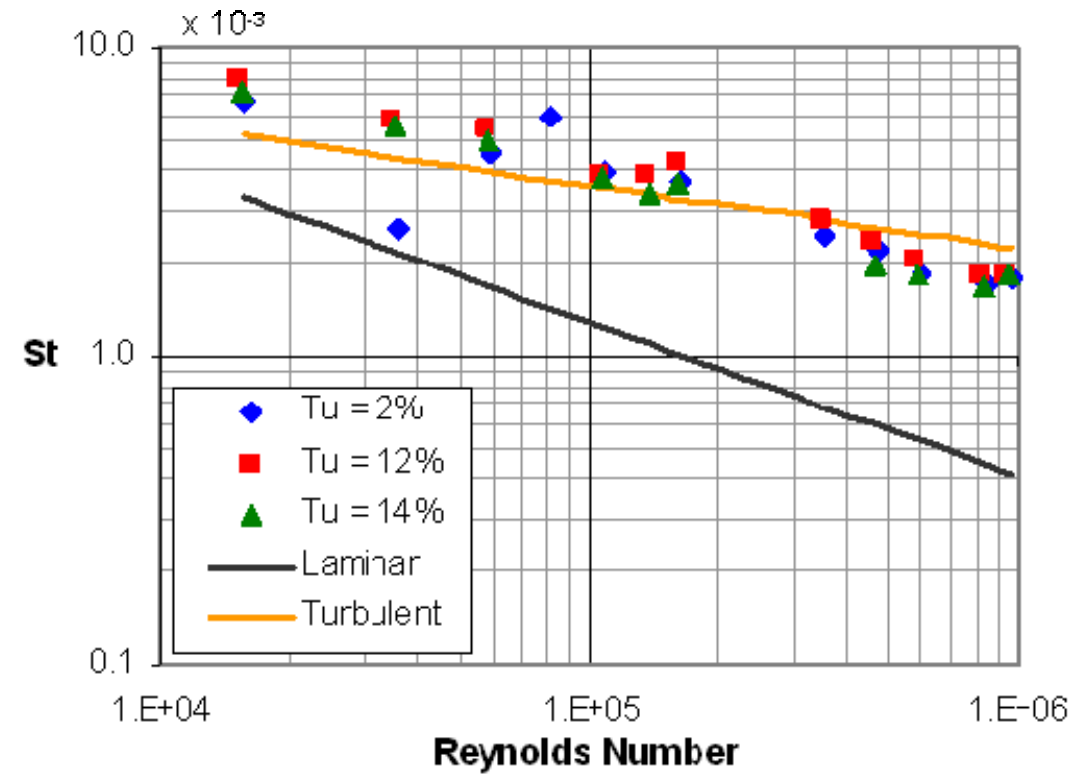

Figure 4.25. Pressure side data compared to the flat plate correlations at exit Ma 1.03 


\section{Effect of Length Scale}

As shown in Figures 4.14, 4.15, and 4.16, the heat transfer is augmented more at the leading edge with the $12 \%$ turbulence than the $14 \%$ turbulence. Since the turbulence levels are similar, the difference in heat transfer is caused by the size of the turbulence length scale. At similar turbulence levels, the heat transfer is augmented more at the leading edge if the size of the length scale is smaller. Van Fossen et al. [23] also observed that decreasing the length scale will increase the heat transfer augmentation at the leading edge. Both the turbulence intensity and the length scale size have an effect on the heat transfer in the stagnation region. The effect of the length scale also appears at the exit Mach 1.03 conditions as shown in Figures 4.16 and 4.19. On both the pressure side and suction side of the blade, the $12 \%$ turbulence shows higher augmentation levels than the $14 \%$ turbulence.

\section{Effect of Reynolds Number}

The primary objective of this work was to examine the effect of freestream turbulence at on heat transfer at three exit Mach number conditions. Because of this objective, the exit Mach number was not decoupled from the exit Reynolds number. An increase in exit Mach number corresponds to an increase in the exit Reynolds number. To remain consistent with the previous sections, the data will be compared by stating the Mach number. The actual exit Reynolds numbers measured for each test is provided in Table 4.3.

The Nusselt number distributions showing the effect of increasing the Reynolds number at turbulence levels of $2 \%, 12 \%$, and $14 \%$ are shown in Figures 4.26, 4.27, and 4.28, respectively. As expected, there is an overall increase in heat transfer due to the increase in Reynolds number. For the $12 \%$ and $14 \%$ turbulence tests, an increase in the heat transfer with Reynolds number is not seen near the throat since the boundary layer transition is gradual at exit Mach 1.03.

At $2 \%$ turbulence, the amplitude of the local peak on pressure side caused by local separation increases as the Reynolds number increases. The local peak increasing in amplitude with Reynolds number was also observed by Consigny and Richards [3]. 


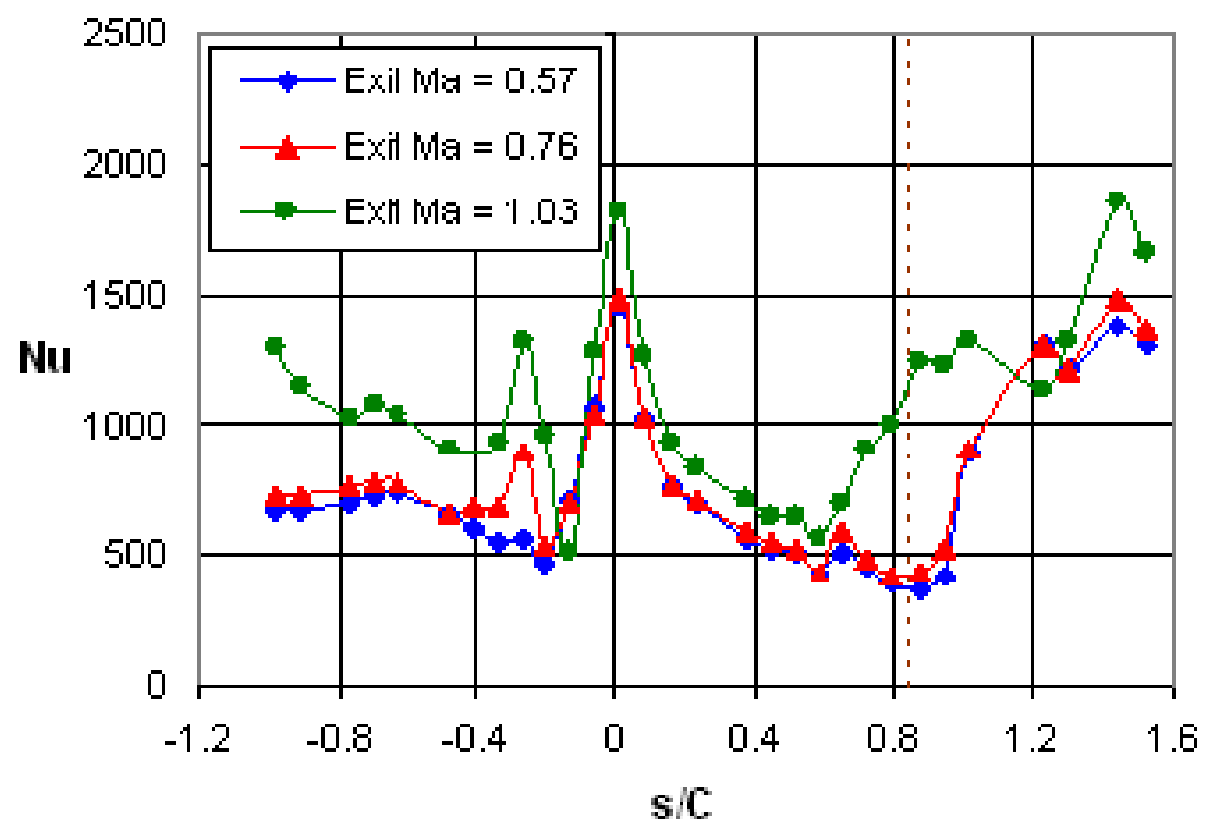

Figure 4.26. Heat transfer distribution at $\mathrm{Tu}=2 \%$

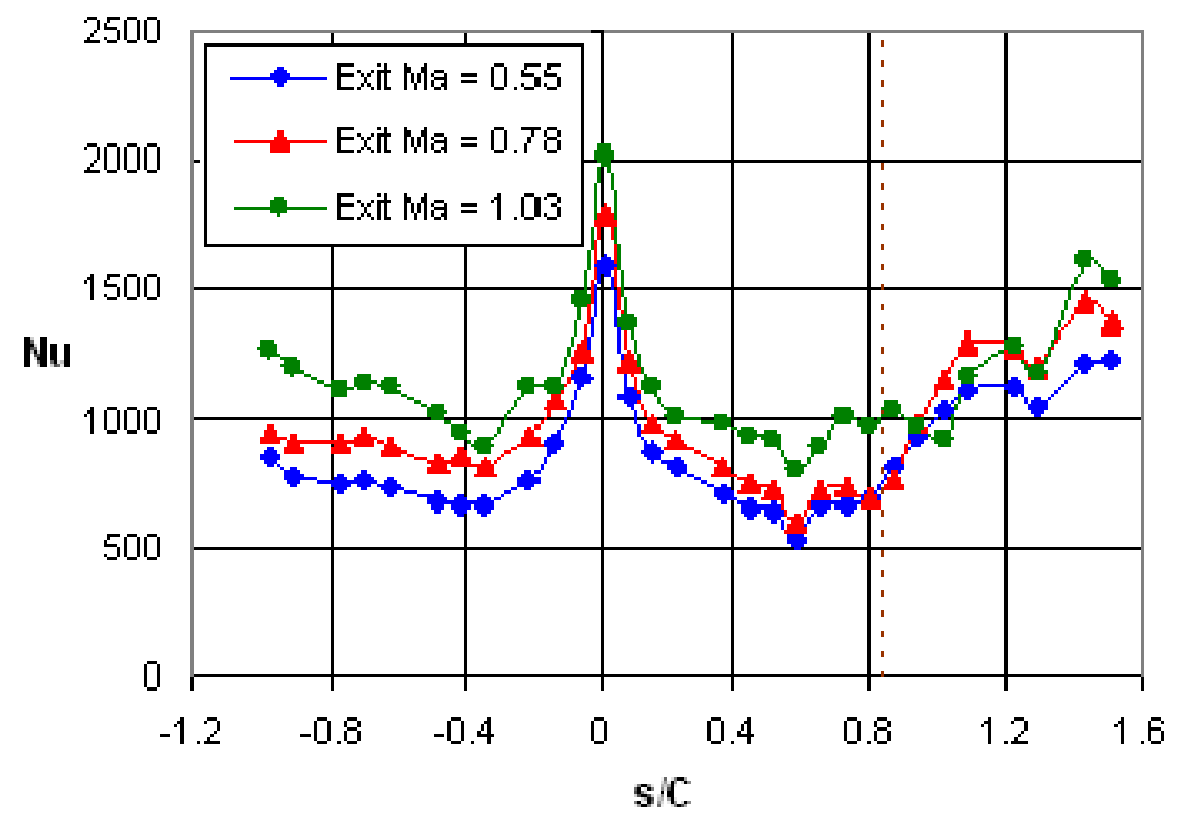

Figure 4.27. Heat transfer distribution at $\mathrm{Tu}=12 \%$ 


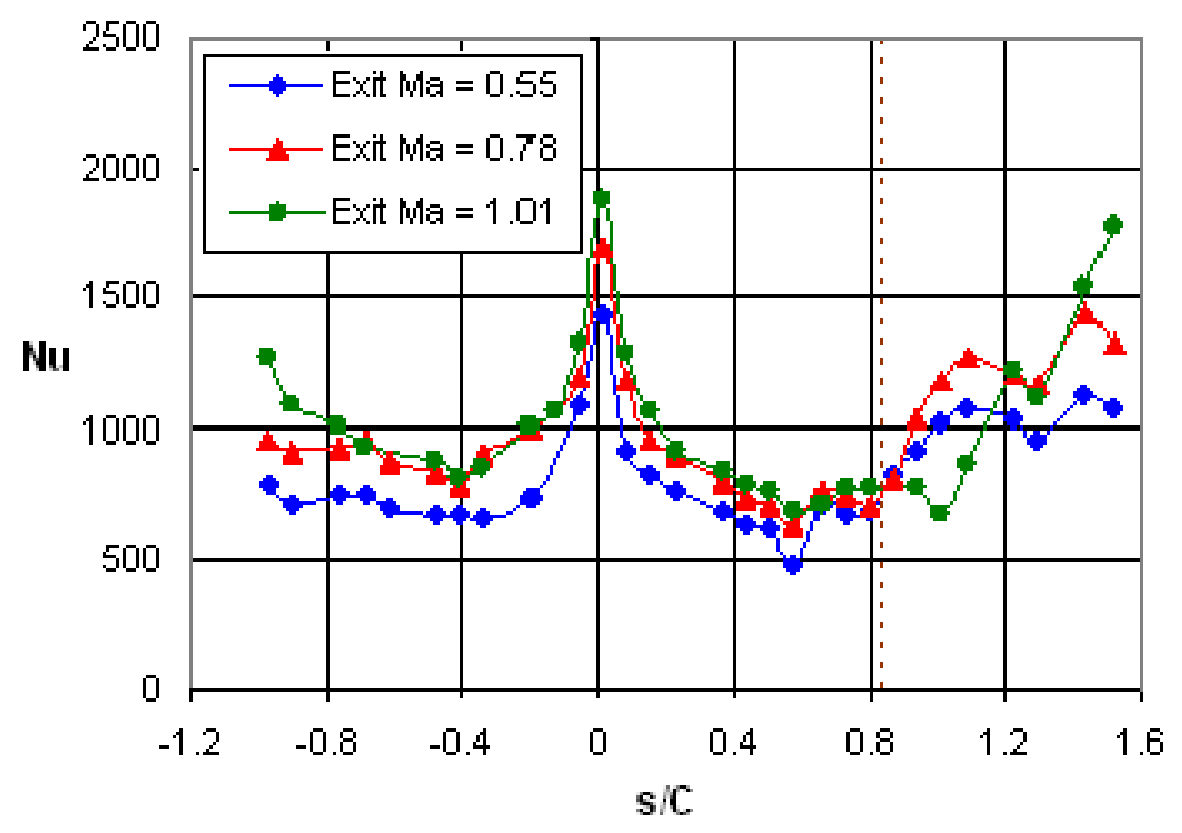

Figure 4.28. Heat transfer distribution at $\mathrm{Tu}=14 \%$

\section{Leading Edge Correlation}

The experimental data at the leading edge was compared to the stagnation region heat transfer correlation for elliptical leading edges developed by Van Fossen et al. [23]. The stagnation region heat transfer correlation takes into account the turbulence intensity, length scale, leading edge diameter, and Reynolds number and is provided by,

$$
\frac{F r_{T u}}{F r_{\text {lam }}}=0.00851 \sqrt{T u \operatorname{Re}_{d, \text { in }}^{0.8}\left(\frac{\Lambda_{x}}{d}\right)^{-0.574}}+1.0
$$

The plot of the correlation and the data are provided in Figure 4.29. The experimental leading edge heat transfer data was converted into a Frossling number given by,

$$
F r_{T u}=N u \cdot \frac{(d / C)}{\sqrt{\operatorname{Re}_{d, i n}}}
$$

From the blade geometry, the leading edge approximated to an ellipse with an aspect ratio of 1.5:1 where $\mathrm{Fr}_{\text {lam }}=0.87$. The experimental data at the leading edge compares rather well with the Van Fossen correlation. All of the data follows the same trend as the correlation and lies within $\pm 9 \%$ (bias error) of the Van Fossen correlation. The experimental data also shows good agreement with the results reported by Giel et al. [5]. 


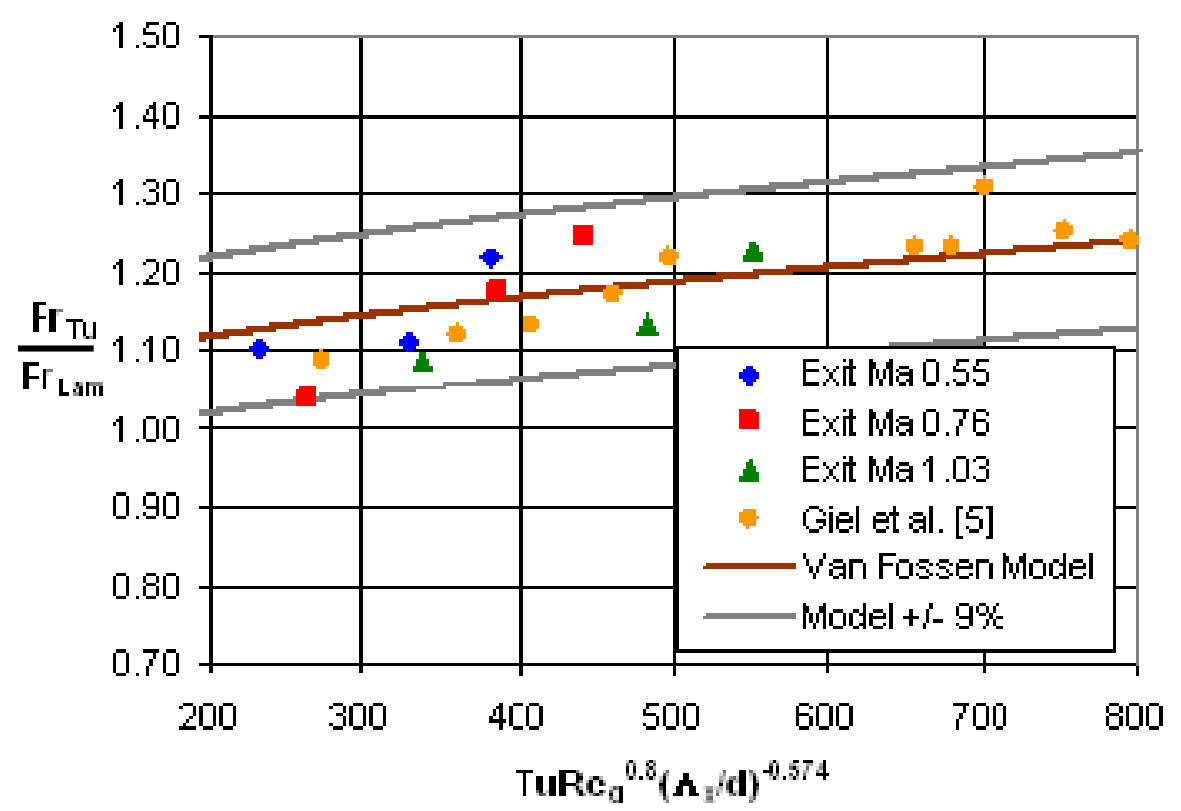

Figure 4.29. Van Fossen correlation comparison

\section{TEXSTAN Comparison}

The experimental data was compared with surface heat transfer predictions made using academic version of TEXSTAN developed by Crawford [24]. To model the flow through the blade passages, the two-equation Lam-Bremhorst turbulence model was used with the SchmidtPatankar transition model. A constant surface temperature boundary condition was applied to the blade and the constant turbulence kinetic energy was set throughout the computational domain by freezing the turbulence dissipation rate.

At low freestream turbulence, the TEXSTAN prediction matches the experimental data well as shown in Figure 4.30. The suction side heat transfer prediction matches levels and transition location of the data very well. On the pressure side, TEXSTAN slightly underpredicts the heat transfer and does not predict the local peak near the leading edge.

At higher turbulence levels, TEXSTAN overpredicted the heat transfer on both the pressure and suction sides as shown in Figure 4.31. The suction side prediction appears to be fully turbulent with the data only coming close to the prediction after the transition. The pressure side is also well overpredicted. As shown in Figure 4.24, the experimental data falls close to the turbulent flat plate correlation and the TEXSTAN prediction is well above the correlation. The 
leading edge heat transfer is also overpredicted. Similar trends were observed with the predictions at exit Ma 0.55 and 1.03 .

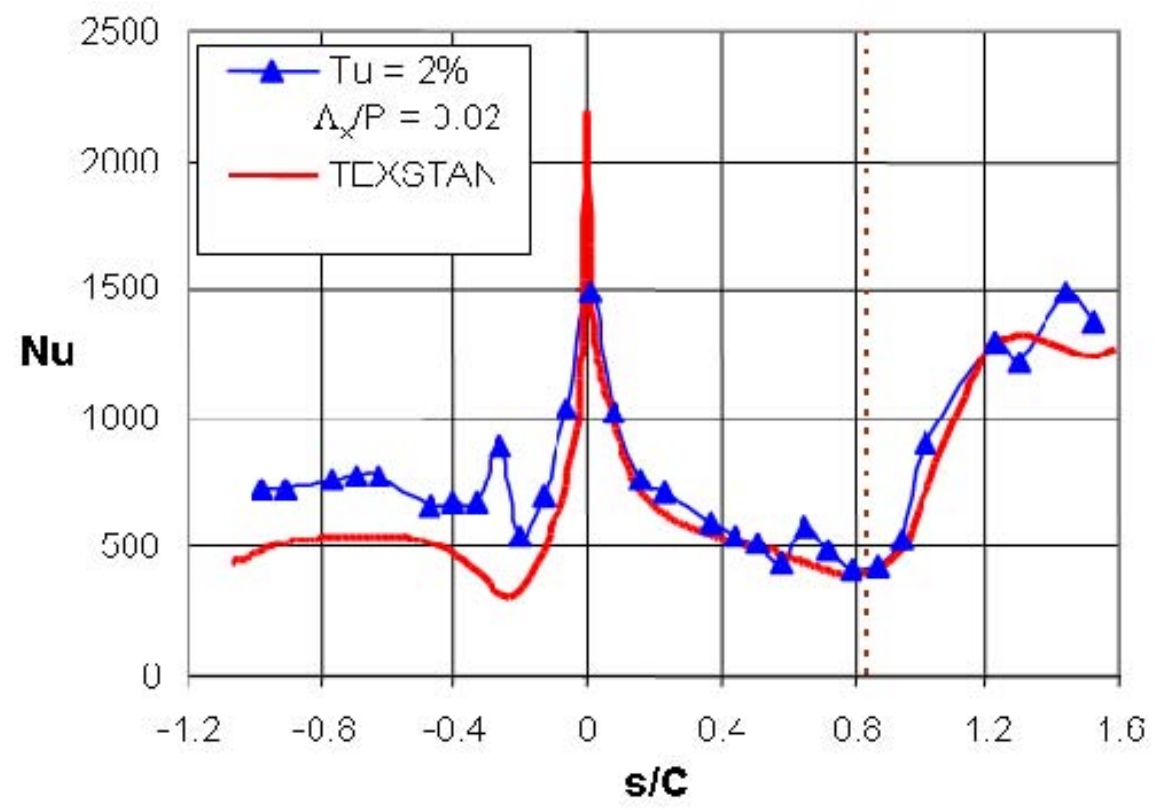

Figure 4.30. TEXSTAN prediction at exit Ma $0.78,2 \% \mathrm{Tu}$

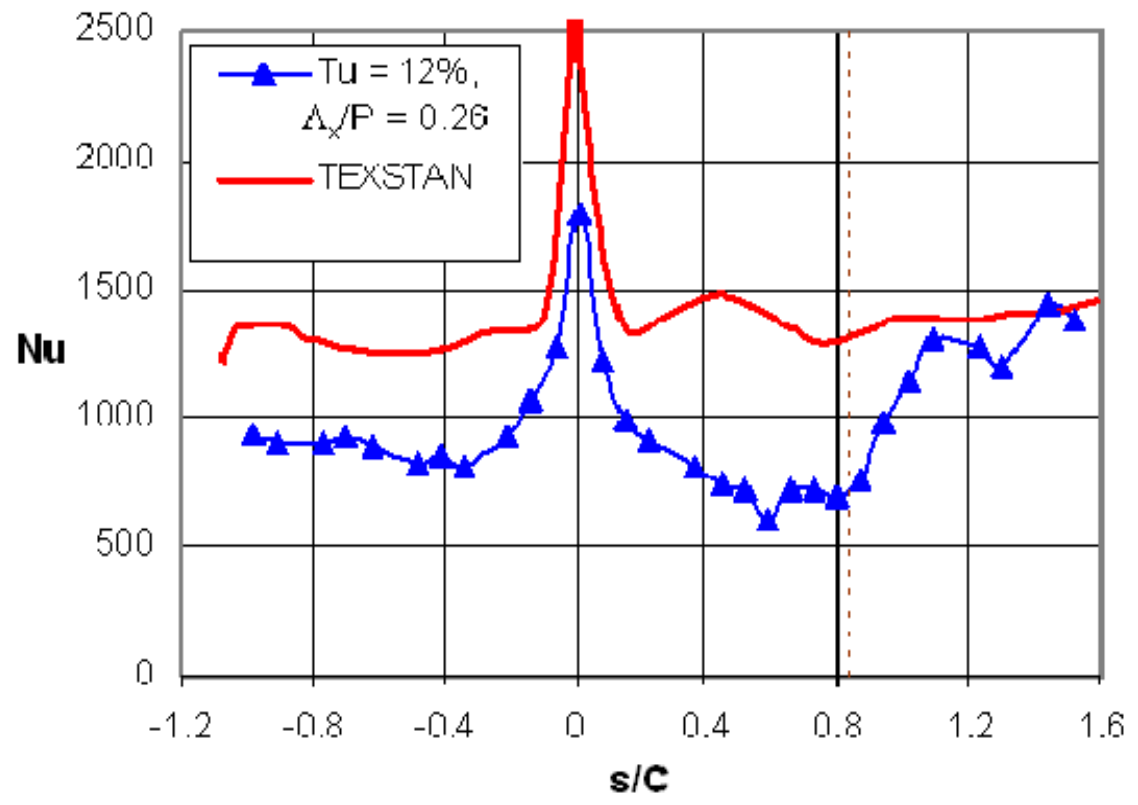

Figure 4.31. TEXSTAN prediction at exit Ma $0.78,12 \% \mathrm{Tu}$ 


\section{Conclusions}

Aerodynamic and heat transfer measurements were made on a turbine blade at flow conditions representative of engine operating conditions. High levels of freestream turbulence were generated by using passive turbulence grids that produced similar turbulence levels, but different length scales. Increasing the turbulence level was observed to augment the heat transfer over the blade surface.

The turbulence augmentations for the two high freestream turbulence levels with different length scales were almost identical except at the leading edge for the exit Mach 0.55 and 0.78 cases. For the exit Mach 1.03 cases, the turbulence was augmented more for the smaller turbulence length scale. Increasing the freestream turbulence was observed to not significantly influence the location of boundary layer transition.

As expected, increasing the exit Reynolds number was shown to increase the heat transfer levels and cause earlier boundary layer transition. The boundary layer transition was observed to be influenced primarily by the Reynolds number of the flow. An increase in the exit Reynolds (Mach) number caused the boundary layer to transition closer to the leading edge. The local peak on the pressure side increased with increasing the Reynolds number for the baseline case.

Several comparisons were made between the data using the analytical flat plate correlations, leading edge correlations developed by Van Fossen et al. [23] and the TEXSTAN predictions. The heat transfer data showed good agreement with Van Fossen's leading edge correlation. The TEXSTAN prediction accurately modeled the heat transfer at low freestream turbulence levels, but was found to significantly overpredict the heat transfer levels at high turbulence levels.

\section{Acknowledgements}

This work was sponsored by Solar Turbines Inc. We would also like to express our gratitude to Dr. Richard Anthony and Dr. Marcus Polanka of the Air Force Research Laboratory, Wright-Patterson AFB for their help with manufacturing and implementation of the thin film gauges. 


\section{References}

[1] Zimmermann, D.B., 1979, "Laser anemometer measurements at the exit of a T63-C20 combustor," NASA CR- 159623.

[2] Van Fossen, G. J. and Bunker, R. S., 2001 "Augmentation of stagnation heat transfer due to turbulence from a DLN can combustor," ASME J. Turbomach., 123, pp. 140-146.

[3] Consigny, H. and Richards, B.E., 1982, "Short Duration Measurements of Heat-Transfer Rate to a Gas Turbine Rotor Blade," ASME J. Eng. Power, 104, pp. 542-551.

[4] Arts, T., Duboue, J. M., and Rollin, G., 1998, "Aerothermal Performance Measurements and Analysis of a Two-Dimensional High Turning Rotor Blade," ASME J. Turbomach., 120, pp. 494499.

[5] Giel, P. W., Boyle, R. J., and Bunker, R. S., 2004, "Measurements and Predictions of Heat Transfer on Rotor Blades in a Transonic Turbine Cascade," ASME J. Turbomach., 126, pp. 110121.

[6] Holmberg, D.G., and Diller, T.E., 2005, "Simultaneous Heat Flux and Velocity Measurements in a Transonic Turbine Cascade," ASME J. Turbomach., 127, pp. 502-506.

[7] Nix, A.C., Diller, T.E., and Ng, W.F., 2007, "Experimental Measurements and Modeling of the Effects of Large-Scale Freestream Turbulence on Heat Transfer," ASME J. Turbomach., 129, pp. 542-550.

[8] Smith, D.E., Bubb, J.V., Popp, O., Grabowski, H.C., Diller, T.E. Schetz, J.A. and Ng. W.F., 2000, "Investigation of Heat Transfer in a Film Cooled Transonic Turbine Cascade, Part I: Steady Heat Transfer," ASME 2000-GT-202.

[9] Popp, O., Smith, D.E., Bubb, J.V., Grabowski, H.C., Diller, T.E. Schetz, J.A. and Ng. W.F., 2000, "Investigation of Heat Transfer in a Film Cooled Transonic Turbine Cascade, Part II: Unsteady Heat Transfer," ASME 2000-GT-203.

[10] Schultz, D.L., and Jones, T.V., 1973, "Heat Transfer Measurements in Short Duration Hypersonic Facilities," AGARD AG-165.

[11] Doorly, J.E., and Oldfield, M.L.G., 1987, "The Theory of Advanced Multi-Layer Thin Film Heat Transfer Gages," Intl. J. Heat and Mass Transfer, 30, pp. 1159-1168.

[12] Dunn., M.G., 1995, “The Thin-Film Gage," Von Karman Institute for Fluid Dynamics, Lecture Series 1995-01.

[13] Joe, C.R., 1997, "Unsteady Heat Transfer on the Turbine Research Facility at Wright Laboratory," Ph.D. Dissertation, Syracuse University. 
[14] Cress, R.D., 2006, “Turbine Blade Heat Transfer Measurements in a Transonic Flow Using Thin Film Gages," Master's Thesis, Virginia Polytechnic Institute and State University.

[15] Moffat, R. J., 1988, “Describing Uncertainties in Experimental Results," Exp. Thermal and Fluid Science, 1988, pp. 3-17.

[16] Baines, W.D. and Peterson, E.G., 1951, “An Investigation of Flow Through Screens," Trans. of the ASME, July 1951, pp. 467-480.

[17] Nix, A.C., Smith, A.C., Diller, T.E., Ng, W.F. and Thole, K.A., 2002, "High Intensity, Large Length-Scale Freestream Turbulence Generation in a Transonic Turbine Cascade," ASME GT2002-30523.

[18] Roach, P.E., 1987, "The Generation of Nearly Isotropic Turbulence by Means of Grids," Int. J. Heat and Fluid Flow, 2, pp. 82-92.

[19] Jones, W.P. and Launder, B.E., 1972, "The Prediction of Laminarization with a TwoEquation Model of Turbulence," Intl. J. Heat and Mass Transfer, 15, pp. 301-314.

[20] Mayle, R.E., 1991, "The Role of Laminar-Turbulent Transition in Gas Turbine Engines," ASME J. Turbomach., 113, pp. 509-537.

[21] Incropera, F.P. and DeWitt, D.P., 2002, Fundamentals of Heat and Mass Transfer, 5th Ed., John Wiley and Sons, New York.

[22] Zhang, J., and Han, J.-C., 1994, "Influence of Mainstream Turbulence on Heat Transfer Coefficient from a Gas Turbine Blade," ASME J. Heat Transfer, 116, pp. 896-903

[23] Van Fossen, G. J., Simoneau, R. J., and Ching, C. Y., 1995, "Influence of Turbulence Parameters, Reynolds Number, and Body Shape on Stagnation-Region Heat Transfer," ASME J. Heat Transfer, 117, pp. 597-603.

[24] Crawford, M.E., 1986, "Simulation Codes for Calculation of Heat Transfer to ConvectivelyCooled Turbine Blades," Convective Heat Transfer and Film Cooling in Turbomachinery, VKI Lecture Series 1986-06. 


\section{Conclusions of Research Work}

Aerodynamic and heat transfer measurements and calculations were made on a first-stage turbine vane (without and with showerhead film cooling) at flow conditions representative of engine operating conditions. The vane was arranged in a two-dimensional, linear cascade in a heated, transonic, blow-down wind tunnel. Three different exit Mach numbers of $\mathrm{M}_{\mathrm{ex}}=0.57$, 0.76 and 1.0 - corresponding to exit Reynolds numbers based on vane chord of $9.7 \times 10^{5}, 1.1 \mathrm{x}$ $10^{6}$ and $1.5 \times 10^{6}$, respectively — were tested with an inlet free stream turbulence intensity (Tu) of $2 \%$ and $16 \%$ and an integral length scale normalized by vane pitch $\left(\Lambda_{\mathrm{x}} / \mathrm{P}\right)$ of 0.05 and 0.23 , respectively. Single hot film probe was used to measure inlet freestream turbulence and integral length scale according to the procedure described by Nix et al. [1]. Surface heat transfer measurements were made at the midspan of the vane using single-sided thin film gauges.

\section{No-Cooling Measurements and Calculations}

The experimental results on a smooth vane (with no showerhead film cooling) showed that the large scale high freestream turbulence $(\mathrm{Tu}=16 \%)$ augmented the Nusselt number on both the pressure and suction sides of the vane as compared to the low freestream turbulence (Tu $=2 \%$ ) case and promoted slightly earlier boundary layer transition on the suction surface for exit Mach 0.55 and 0.75. At nominal conditions, exit Mach 0.75, average Nusselt number augmentations of $52 \%$ and $25 \%$ were observed on the pressure and suction side of the vane, respectively. An increased Reynolds number was found to induce earlier boundary layer transition on the vane suction surface and to increase Nusselt number levels on the suction and pressure surfaces. On the suction side, the boundary layer transition length was also found to be affected by increased changes in Reynolds number. Several comparisons were made between the data using the analytical flat plate correlations, leading edge correlation developed by Dullenkopf and Mayle [2], FLUENT $v^{2}-f$ model and TEXSTAN predictions. The Nusselt number or Stanton number data showed good agreement with flat plate and leading edge correlations. The $v^{2}-f$ model and TEXSTAN resulted in overall reasonable prediction of the Nusselt number at 
low freestream turbulence levels. At high freestream turbulence, FLUENT $v^{2}-f$ model and TEXSTAN was found to significantly overpredict the Nusselt number levels on the vane surface.

\section{Showerhead Film Cooling Measurements and Calculations}

Experimental measurements at high freestream turbulence $(\mathrm{Tu}=16 \%)$ were also performed on a showerhead film cooled vane with five rows of staggered cylindrical cooling holes in the leading edge region. A showerhead cooling scheme was tested at blowing ratios (coolant injection rate) of $B R=0,1.5,2.0$, and 2.5 and a density ratio of $D R=1.3$. The showerhead film cooled vane was instrumented with single-sided platinum thin film gauges to experimentally determine the Nusselt number and film cooling adiabatic effectiveness distributions over the surface from a single transient-temperature run. Baseline heat transfer distributions on the vane with showerhead cooling holes were established with no coolant injection $(\mathrm{BR}=0)$ data as compared to no-film cooling (smooth vane) data for similar exit flow condition because of the effect of film cooling holes as roughness elements on vane surface heat transfer as documented by Bolchoz et al. [3]. In showerhead film cooling experiments, instead of assuming local freestream recovery temperature based on local Mach number and recovery factor, it was measured in a high speed flow from the no film injection $(B R=0)$ case.

One of the primary effects of coolant injection was to augment Nusselt number downstream of the injection on the vane surface as compared to no film injection case $(B R=0)$ at all exit Mach number conditions. At exit Mach 0.57 and 0.76 , an increase in blowing ratio from 1.5 to 2.5 showed a noticeable Nusselt number augmentation on the pressure surface as compared to the suction surface. At exit Mach 1.0, an increase in blowing ratio from 1.5 to 2.5 showed negligible effect of Nusselt number augmentation on suction surface and showed partial/complete jet lift off downstream of coolant injection on the pressure surface. Film cooling injection also reduced adiabatic wall temperature downstream of the injection on the vane surface as compared to no film injection case $(\mathrm{BR}=0)$ at all exit Mach number conditions. At exit Mach 0.57 and 0.76, an increase in blowing ratio was observed to either result in similar or slightly higher adiabatic effectiveness values on each surface (pressure and suction). At exit Mach 1.0, an increase in blowing ratio (1.5 to 2.5) was observed to have an adverse effect on adiabatic effectiveness on the pressure surface but had a negligible effect on the suction surface. 
The adiabatic effectiveness trend on the suction surface was also found to be influenced by a favorable pressure gradient due to Mach number and boundary layer transition in the region $\mathrm{s} / \mathrm{C}$ $=0.28$ to $\mathrm{s} / \mathrm{C}=0.45$ at all blowing ratio and exit Mach number conditions. An increase in blowing ratio from 1.5 to 2.5 had a noticeable effect on net heat flux reduction and film coverage on the pressure surface as compared to the suction surface at all exit Mach conditions. Overall, the blowing ratio of 1.5 provided superior net heat flux reduction at all exit Mach number conditions. An increase in Reynolds number from exit Mach 0.76 to 1.0 increased heat transfer levels on the vane surface at all blowing ratio conditions. An increase in Reynolds number from exit Mach 0.76 to 1.0 adversely affected adiabatic effectiveness on the pressure surface at all blowing ratio conditions. On the suction surface, a large increase in Reynolds number from exit Mach 0.76 to 1.0 also affected adiabatic effectiveness in a favorable pressure gradient and boundary layer transition region.

The experimental study with showerhead film cooling was also complimented with a 3-D CFD effort to calculate and explain adiabatic film cooling effectiveness and Nusselt number distributions downstream of the showerhead film cooling rows at vane midspan at high freestream turbulence $(\mathrm{Tu}=16 \%)$, exit flow condition of $\mathrm{M}_{\mathrm{ex}}=0.76\left(\mathrm{Re}=1.1 \times 10^{6}\right)$ and blowing ratio conditions of $\mathrm{BR}=0$ and 1.5. The CFD calculation presented a three-simulations technique to calculate vane surface recovery temperature, adiabatic wall temperature, and surface Nusselt number to completely characterize film cooling performance in a high speed flow. The RANS based $v^{2}-f$ turbulence model, originally suggested by Durbin [4], was used in all numerical calculations.

On the pressure surface, at $\mathrm{BR}=1.5$, the $v^{2}-f$ model showed an overall good adiabatic effectiveness distribution comparison with the experimental data. On the suction surface, at $\mathrm{BR}=$ 1.5 , the $v^{2}-f$ model overpredicted adiabatic effectiveness but captured the experimental data trend on the entire surface. Also on the suction surface, the adiabatic effectiveness calculation on the suction surface is found to be influenced by favorable pressure gradient due to Mach number through changes in local adiabatic wall and recovery temperature. On the pressure surface, at BR $=0$ and 1.5 , the $v^{2}-f$ model overpredicted Nusselt number and showed negligible effect of coolant injection. On the suction surface, the $v^{2}-f$ model also overpredicted Nusselt number downstream of the stagnation region for $\mathrm{BR}=0$ and 1.5 , but unlike the pressure surface, it did show Nusselt number augmentation downstream of stagnation region due to coolant injection $(\mathrm{BR}=1.5)$. 
Similar to experimental results, the Nusselt number calculation on the suction surface showed a peak and a valley downstream of the film cooling rows in a favorable pressure gradient region for both tested blowing ratio conditions. The reason for this peak and valley is attributed to the effect of favorable pressure gradient to possibly relaminarize the pseudo-turbulent boundary layer by increasing the inner viscous sublayer thickness of the pseudo-turbulent boundary accompanied by a bypass transition again to a fully turbulent boundary layer. It is very difficult to match the Nusselt number and adiabatic effectiveness levels with the experimental data but current research work provides good foundation for future research.

\section{Contribution of Research Work}

The unique contribution of this research work is to experimentally investigate the effects coolant injection rate or blowing ratio and exit Reynolds number/Mach number on the film cooling performance of a showerhead film cooled first stage turbine vane at high freestream turbulence $(\mathrm{Tu}=16 \%)$ and engine representative exit flow conditions. A showerhead cooling scheme was tested at engine representative blowing ratios (coolant injection rate) but the density ratio was selected to be $1.3-1.4$. Film cooling performance of showerhead film cooled vane was characterized in terms of Nusselt number, adiabatic film cooling effectiveness, and net heat flux reduction. The vane used in these experimental measurements was a scaled up version of firststage turbine vane for the Taurus-65 Solar Turbines power generator set. The vane was arranged in a two-dimensional, linear cascade in a heated, transonic, blow-down wind tunnel. Experimental measurements were also performed to study the effects of large scale high freestream turbulence and exit Reynolds number/Mach number on smooth (without film cooling holes) turbine vane heat transfer at engine representative exit flow conditions.

The primary effects of coolant injection were to augment Nusselt number and reduce adiabatic wall temperature downstream of the injection on the vane surface as compared to the no film injection case at all exit flow conditions. Showerhead film cooling experiments performed at high freestream turbulence showed heat transfer coefficient augmentation comparable to the data of Turner et al. [5] at low freestream turbulence for the highest exit flow condition of $\mathrm{M}_{\mathrm{ex}}=1.0\left(\mathrm{Re}=1.5 \times 10^{6}\right)$. An important contribution of current research was to document the effect of favorable pressure gradient due to Mach number on the adiabatic wall and 
recovery temperature on the suction surface. The effect of favorable pressure gradient due to Mach number on recovery temperature was found to be significantly different from assumed recovery temperature based on local Mach number and turbulent boundary layer recovery factor $\left(\mathrm{r}=\operatorname{Pr}{ }^{1 / 3}\right)$. It may be due to the reason that for $\operatorname{Pr}<1$, the favorable pressure gradient due to Mach number can decrease the recovery factor, as hinted by Oudheusden [6]. To properly account for this effect, the recovery temperature in the experiments was measured from no film injection case $(B R=0)$ at each exit flow condition. Similarly, the CFD calculations presented a three-simulations technique to calculate vane surface recovery temperature, adiabatic wall temperature, and surface Nusselt number to completely characterize film cooling performance in a high speed flow.

The experimental data collected with no film cooling experiments is already being used by Solar Turbines engine designers [7] with identical flow and thermal boundary conditions to validate and improve their numerical calculation capabilities. The experimental data collected with showerhead film cooling will also be used to validate and improve numerical prediction capabilities. Beyond CFD code validation, the engine designer can also scale up the current experimental data for Nusselt number and adiabatic effectiveness to engine level values by correcting for the molecular (thermal) properties of the gases used in actual engine as documented by Guo et al. [8].

\section{References}

[1] Nix, A.C., Smith, A.C., Diller, T.E., Ng, W.F. and Thole, K.A., 2002, "High Intensity, Large Length-Scale Freestream Turbulence Generation in a Transonic Turbine Cascade," ASME GT2002-30523.

[2] Dullenkopf, K., and Mayle, R.E., 1995, “An Account of Free-Stream-Turbulence Length Scale on Laminar Heat Transfer," ASME J. Turbomach., 117, pp. 401-406.

[3] Bolchoz, T., Nasir, S, Ng, W.F., Zhang, L.J., and Moon, H.K., 2008, “An Experimental Investigation of Showerhead Film Cooling Performance in a Transonic Vane Cascade at Low Freestream Turbulence," Master's Thesis, Virginia Polytechnic Institute and State University.

[4] Durbin, P., 1991, "Near-Wall Turbulence Closure Modeling Without "damping functions"," Theor. Comput. Fluid Dyn., 3, pp. 1-13. 
[5] Turner, E.R., Wilson, M.D., Hylton, L.D., and Kaufman, R.M., 1985, "Turbine Vane External Heat Transfer: Vol. 1: Analytical and Experimental Evaluation of Surface Heat Transfer Distributions with Leading Edge Showerhead Film Cooling,” NASA CR-174827.

[6] van Oudheusden, B.W., 2004, "Compressibility Effects on the Extended Crocco Relation and the Thermal Recovery Factor in Laminar Boundary Layer Flow," ASME J. Turbomach., 126, pp. $32-41$.

[7] Luo, J., and Razinsky, E.H., 2008, "Prediction of Heat Transfer and Flow Transition on Transonic Turbine Airfoils Under High Freestream Turbulence,” ASME GT-2008-50868.

[8] Guo, S.M., Lai, C.C., Jones, T.V., Oldfield, M.L.G., Lock, G.D., and Rawlinson, A.J., 1998, "The Application of Thin-film Technology to Measure Turbine-Vane Heat Transfer and Effectiveness in a Film-Cooled, Engine-Simulated Environment," Intl. J. Heat and Fluid Flow, 19, pp. 594-600. 


\section{Appendix A Literature Review - Airfoil Film Cooling}

\section{Experimental Work}

Film cooling is a broad, mature topic and its various applications have been studied in literature for some time. The basic film cooling physics on flat plates are described by Goldstein [A-1]. Bogard and Thole [A-2] and Han et al. [A-3] have compiled much of the current work on film cooling as it applies to the gas turbine field. The literature review for the experimental work focuses on airfoils in both low and high speed environments. Literature is presented in increasing relevance beginning with low speed blade and vane studies and concluding with high speed blade and vane experiments.

\section{Low Speed Blade}

An experimental study of coolant density ratio and the impact of an upstream wake was conducted in a low speed, linear, fully film cooled blade cascade by $\mathrm{Ou}$ et al. [A-4] and Mehendale et al. [A-5]. Heat transfer coefficient is reported by [A-4], while effectiveness and heat load reduction are presented by [A-5]. Density ratio was varied by using air and $\mathrm{CO}_{2}$ as the two coolant gases, and a spoked wheel wake generator simulated blades passing an upstream wake. Film cooling increased heat transfer coefficient over the surface of the blade and it was found that cooling injection had a larger effect on heat transfer coefficient than the addition of the upstream wake. An increase in the mass flux ratio or blowing ratio from 0.4 to 1.8 was seen to increase heat transfer coefficient. The addition of the upstream wake reduced film cooling effectiveness. Different blowing ratios were seen to provide the highest effectiveness levels for air and $\mathrm{CO}_{2}$ injection. However, it was noted that effectiveness for the higher density $\mathrm{CO}_{2}$ case could be conservative due to the specific heat differences between air and $\mathrm{CO}_{2}$. In terms of heat load reduction, the best blowing ratio for air and $\mathrm{CO}_{2}$ was found to be 0.8 and 1.2 , respectively. The addition of grid turbulence on film cooling performance was studied in the same facility by Ekkad et al. [A-6]. Superimposing turbulence from a grid on a wake was found to increase heat transfer coefficients and further decrease film cooling effectiveness. However, at a high enough level of freestream turbulence, the unsteady wake was shown to have negligible effect on film cooling performance. 
Several studies have also investigated film cooling performance on a turbine blade in a low speed rotating turbine stage environment. Dring et al. [A-7] studied film cooling performance on a large scale model of a high-pressure, first stage turbine blade. Coolant was injected from a single hole on both the pressure and suction sides of the rotor blade. Density ratios from 1.0 to 4.0 were investigated, and flow visualization studies showed radial migration of the coolant, especially on the pressure side. The migration was found to be relatively insensitive to the coolant properties. Film effectiveness profiles were measured downstream of the holes. The suction surface effectiveness profiles were found to correlate well with flat plate data, while the pressure surface film effectiveness was significantly reduced. Takeishi et al. [A8] also measured film cooling effectiveness for a rotating turbine blade with showerhead, pressure, and suction surface rows of film cooling holes. Takeishi et al. [A-8] corroborated results of [A-7], as the pressure surface film effectiveness was found to decrease relative to cascade tests due to the radial flow and concave curvature. The suction surface film effectiveness was in good agreement with the stationary blade tests except far downstream where enhanced mixing reduced the film effectiveness.

Recently, Ahn et al. [A-9] conducted detailed film cooling effectiveness measurements on the leading edge of a rotating first stage gas turbine blade with two rows (pressure-side row and suction-side row on either side of the stagnation) using the pressure sensitive paint (PSP) technique. Film cooling effectiveness measurements were conducted with different rotation speeds and blowing ratio conditions. Results showed significant impact of rotation on the leading edge film cooling distributions with the average film cooling effectiveness in the leading edge region decreasing with an increase in the rotational speed. Ahn et al. [A-9] also found out that an increase in blowing ratio weakened each coolant trace but improved uniformity of coolant distribution in the leading edge region.

\section{Low Speed Vane}

Ames [A-10] studied the effects of turbulence $(\mathrm{Tu}=1 \%$ and $12 \%)$ and rate of coolant injection on a film cooled C3X vane in a low speed facility at two different Reynolds numbers. Several film cooling geometries were studied, but the showerhead cooled vane results are of interest to this study. Ames [A-10] used thermocouples to measure the surface temperature distribution with foil heaters on the vane surface supplying heat flux and a finite element analysis 
to correct for two-dimensional internal conduction. The results showed that film cooling augmented Stanton number in the both the laminar and turbulent regions of the vane with more augmentation in the laminar region. Increasing the rate of coolant injection increased the levels of Stanton number augmentation. The effect of coolant injection rate on effectiveness was shown to be greater than the effect of Reynolds number on effectiveness. The effect of freestream turbulence was observed to reduce the levels of film cooling effectiveness and also quicken the dissipation of cooling effectiveness.

Polanka et al. [A-11] and Witteveld et al. [A-12] also studied leading-edge film cooling experimentally at low and high freestream turbulence $(\mathrm{Tu}=0.5 \%$ to $22 \%$ ) for blowing ratios ranging from 0.5 to 2.9 on a turbine vane in a low speed facility. They had six rows of showerhead holes that were directed along the span of the vane and had a $25 \mathrm{deg}$ angle relative to the surface. Results from Polanka et al. [A-11] showed increasing adiabatic effectiveness with increasing blowing ratio. This was attributed to the small surface angle facilitating jet attachment. They also found that on the pressure side, the coolant from the stagnation row spreads more evenly at high freestream turbulence and results in higher effectiveness in the stagnation region. Further downstream of the stagnation region, high freestream turbulence reduced effectiveness at all blowing ratio conditions. On the suction side, Witteveld et al. [A-12] found that the effect of the freestream turbulence on effectiveness varied with different blowing ratios in the stagnation region but resulted in decrease in effectiveness downstream of stagnation.

Colban et al. [A-13] measured heat transfer coefficient and film cooling effectiveness levels in a scaled-up, two passage vane cascade with five-row showerhead and four rows of shaped holes on each surface in low speed facility. Heat transfer measurements indicated that the behavior of the boundary layer transition along the suction side of the vane showed sensitivity to the location of film cooling injection. Therefore, the transition was simulated by the use of trip wire placed on the vane suction surface. Single row adiabatic film cooling effectiveness without any upstream blowing showed jet lift-off prevalent along either surface of the vane. In the presence of upstream showerhead blowing, the jet lift-off for the first pressure side row was reduced, increasing local adiabatic effectiveness levels. 


\section{High Speed Blade}

Camci and Arts [A-14 to A-16] measured heat transfer coefficient over a film cooled VKI rotor in a short duration, high speed facility with thin film gages mounted on a semi-infinite, Macor blade. Measurements were performed at engine representative exit Mach, $\mathrm{M}_{\mathrm{ex}}=0.90$ and varying inlet freestream turbulence intensities from $0.8 \%$ to $5.2 \%$. They found that increasing the coolant mass flow decreased the heat transfer coefficient levels below the uncooled case. An increase in freestream turbulence did not have a significant effect on heat transfer coefficient and the existence of cooling holes without injection lead to an earlier boundary layer transition on the suction surface.

Rigby et al. [A-17] tested a range of film cooling geometries, blowing ratios, and the effect of upstream passing shocks and wakes on film cooling performance in a two dimensional linear transonic cascade. On the suction surface, increasing the blowing ratio was noted to decrease heat transfer coefficient below the uncooled case. Also on the suction surface, film coolant liftoff was assumed because of a drop of effectiveness between a blowing ratio of 1.0 and 1.5. Schlieren photography captured this coolant liftoff. Shock and bar passing were seen to decrease film cooling effectiveness.

The geometry studied by [A-17] was tested in MIT's blow-down turbine test facility in a full rotating stage by Abhari and Epstein [A-18]. Tests included the effect of upstream wake passing and upstream NGV trailing edge blowing. Hub, tip, and midspan of the blade were instrumented with thin film gages and time averaged and time resolved data were presented. A reduction in heat transfer coefficient was said to take place with the introduction of film cooling in both the time averaged and time resolved data. Of the two blowing ratios studied, the higher blowing ratio provided less effective cooling than the lower blowing ratio.

References [A-14 to A-18] report a decrease in heat transfer coefficient for the addition of film cooling because these experimental approaches do not define the heat transfer coefficient in terms of the adiabatic wall temperature. In these cases, a decrease in the heat transfer coefficient is interpreted as a decrease in heat flux due to film cooling.

Film cooling was studied on a highly turned blade in the linear, transonic, blow-down, Virginia Tech, wind tunnel by Smith et al. [A-19]. Heat transfer coefficient and film cooling effectiveness measurements were made with help of Vatell HFM-7 sensors on the suction side of a showerhead cooled blade with additional pressure side and suction side gill cooling hole rows. 
A method that allowed for the determination of both the heat transfer coefficient and either the recovery temperature (in uncooled runs) or the film cooling effectiveness (in film cooled runs) from one transient run was used. For a nominal pressure ratio of 1.04, the heat transfer coefficient was seen to increase with the addition of film cooling. The engine-realistic density ratio was provided by liquid-nitrogen-cooled air. Varying the pressure ratio in the range from 1.02 to 1.19 had only a weak effect on the heat transfer coefficient and slightly decreased the film cooling effectiveness at some measurement locations.

Heidmann et al. [A-20] experimentally investigated the effect of wake passing on a fiverow showerhead film cooled turbine blade in an annular stationary cascade with an inlet Mach number of 0.27 . The wakes were generated using a rotating bar mechanism rotating upstream of the cascade annulus. Nickel based thin-film gauges were used to determine local film effectiveness and Nusselt number values for various injectants $\left(\mathrm{CO}_{2}\right.$ and Air), blowing ratios, and Strouhal numbers. The Strouhal number was found to have a measurable effect on the flow split between the suction and pressure surfaces for showerhead cooling. A higher Strouhal number skewed the coolant flow toward the pressure surface, producing better cooling on the pressure surface and worse on the suction surface. Experimental results indicated a reduction in film effectiveness with increasing Strouhal number, as well as an expected increase in film effectiveness with blowing ratio. Nusselt numbers were found to remain fairly constant with changing Strouhal number but were higher for $\mathrm{CO}_{2}$ than for air injection.

Zhang and Moon [A-21] conducted effectiveness measurements on a showerhead film cooled turbine blade designed by Solar Turbines using the pressure sensitive paint (PSP) technique. The effectiveness of several cooling geometries was investigated. They found that reducing the injection angle or increasing the hole diameter slightly improved film effectiveness for a fixed total coolant flow. A showerhead cooling scheme with three rows of cylindrical holes was shown to provide the most uniform spanwise distribution of effectiveness. The effect of turbulence and Reynolds number on the heat transfer coefficient distribution of an uncooled version of the blade geometry used by [A-16] was completed by Carullo et al. [A-22].

Guy et al. [A-23] presented heat transfer coefficient distribution, film cooling effectiveness, and net heat flux reduction of the showerhead film cooled blade geometry described by [A-21] and compared to the uncooled measurements of [A-22]. The film cooling performance was studied over two exit Mach number conditions $\left(\mathrm{M}_{\mathrm{ex}}=0.78\right.$, and 1.0) and three 
different blowing ratios $(\mathrm{BR}=0.5,1.0$, and 1.5) in a linear, transonic environment with an engine representative coolant to freestream density ratio of 1.7. Guy et al. [A-23] found that the film cooling was found to increase Nusselt number over the entire measurement domain, and increasing the blowing ratio also increased the Nusselt number. Of the blowing ratios tested, a blowing ratio of 1.0 was found to have superior heat load reduction performance at both exit Mach number conditions.

Recently, Mhetras et al. [A-24] experimentally investigated the effect of flow parameter variations on film cooling effectiveness for a fully film cooled gas turbine blade in a three-blade high speed linear cascade. Tests were performed with two different exit Mach number conditions $\left(\mathrm{M}_{\mathrm{ex}}=0.51\right.$ and 0.68$)$ and freestream turbulence intensity at the cascade inlet of $6 \%$. Results showed that varying blowing ratios could have significant impact on film cooling effectiveness distribution. Large spanwise variations in film cooling effectives were also observed. Mhetras et al. [A-24] also observed longer and distinct coolant traces on the suction side as compared to the pressure side. Although secondary flows significantly impacted suction side film cooling effectiveness, overall film cooling effectiveness on the suction side was comparable to that of the pressure side even with fewer number of film rows at all blowing ratios and freestream conditions tested. Exit Mach number variation did not significantly affect the film coverage on the blade surface for a given blowing ratio at sub-sonic flow conditions.

\section{High Speed Vane}

The effects of varying Reynolds number, Mach number, coolant injection rate, and coolant to temperature ratio were studied on a showerhead cooled NASA C3X vane at freestream turbulence of $6.5 \%$ in a transonic, linear cascade wind tunnel by Turner et al. [A-25]. Increasing the rate of coolant injection was seen to increase the heat transfer coefficient. Increases in Reynolds number in the film cooled case were also seen to augment the heat transfer coefficient. It was noted that the addition of film cooling had a definite effect on heat transfer coefficient in the laminar region, but after transition the effect of film cooling was negligible. Film cooling was shown to move the location of laminar to turbulent transition slightly farther upstream.

Later, Nirmalan and Hylton [A-26] studied the effects of various operating parameters investigated by Turner et al. [A-25] on a fully film cooled C3X vane. This study did not have any instrumentation in the region between the showerhead and downstream rows. The 
downstream film cooling was shown to be a complex function of mainly two competing mechanisms: (i) the thermal dilution due to injection of relatively cold fluid, and (ii) turbulence augmentation due to injection process. The pressure surface showed higher variance in heat transfer reduction due to parameters such as thermal dilution, exit Mach number, and turbulence augmentation. This investigation was a fairly good representation of actual engine conditions.

Arts and Bourguignon [A-27] investigated the effect of exit Reynolds number, freestream turbulence, blowing ratio, and location of a pair of film cooling row locations on heat transfer coefficient and film cooling effectiveness along the pressure side of a high-pressure nozzle guide vane in a transonic linear cascade. They found that increasing blowing ratio from 0.4 to 2.0 increased film cooling effectiveness and heat transfer coefficient downstream of injection. For $\mathrm{BR}=1.0$ and exit Mach $=1.1$, an increase in freestream turbulence from $1 \%$ to $6 \%$ slightly decreased effectiveness downstream of injection but had a negligible effect on heat transfer augmentation. For $\mathrm{BR}=1.0$ and $\mathrm{Tu}=4 \%$, an increase in Reynolds number adversely affected film cooling effectiveness and reduced heat transfer augmentation downstream of injection.

Abuaf et al. [A-28] performed heat transfer coefficient and film cooling effectiveness measurements on a heavily film cooled nozzle guide vane in a linear cascade with realistic flow conditions. They had 14 rows of film cooling holes — nine in the stagnation region and five on the suction side. The cooling blowing ratio was as high as 2.7 in the showerhead region and as low as 1.2 on the suction surface. Thermocouples embedded in a thin-walled turbine vane were used to measure the transient surface temperature. Vane suction side heat transfer coefficient showed significant increase due to film cooling as compared to the pressure surface. The accumulated effect of the showerhead and suction side rows also produced significantly higher values of film effectiveness far downstream on the suction surface.

Drost and Bölcs [A-29] studied the effect of varying Mach number, density ratio, blowing ratio, and freestream turbulence on a high speed vane. The transient liquid crystal technique was used to determine heat transfer coefficient and film cooling effectiveness. For a single row of film cooling holes on the pressure surface, best effectiveness near the hole was obtained for blowing ratio of 1.3. For a pair of rows of film cooling holes on the suction surface, a jet lift-off was observed between blowing ratios of 1.11 and 1.77 . They also found that the film effectiveness was strongly influenced by the nature of incoming boundary layer. Variation in exit 
Reynolds number/Mach number was found to affect the film cooling performance on the suction side due to changes of boundary layer thickness and flow acceleration.

Guo et al. [A-30] used platinum thin film gauges on a semi-infinite substrate (Perspex) in a transonic annular cascade to measure the effect of film cooling on a fully cooled nozzle guide vane. Measurements were performed with cylindrical and fan shaped holes at exit Mach, $\mathrm{M}_{\mathrm{ex}}=$ 0.96 and freestream turbulence intensity at the cascade inlet of $13 \%$. Foreign gas with specific heat properties similar to air was used to match the density ratio seen in a gas turbine. For a nominal pressure ratio of 1.02, an augmentation of heat transfer coefficient due to cooling was observed over the entire pressure surface and some of the suction surface. Heat transfer coefficient levels below that of uncooled data are reasoned to be the result of a thicker boundary layer. Effectiveness was higher on the pressure side where more rows of coolant injection were present, and it decreased after the last row of cooling holes. Fan shaped holes resulted in a significant improvement of the film cooling effectiveness in the region immediately downstream of the cooling holes. Piccini et al. [A-31] developed a type of double-sided thin film gauge by adding a thermocouple beneath the thin film gauges used by [A-30]. A variation of this type of double-sided gauge was also used by Guy et al. [A-23] in turbine blade showerhead film cooling measurements.

Zhang et al. [A-32] researched vane film cooling at high freestream turbulence of $\mathrm{Tu}=$ $12 \%$ with one row of shaped holes on the suction side using the PSP technique in a high speed wind tunnel. They found that adiabatic film cooling effectiveness increased with an increase in blowing ratio from 0.5 to 1.5 . Zhang et al. [A-32] also reported that for a blowing ratio of 1.5 , a small separation region occurred downstream of the hole exit before the jet reattached. Despite high freestream turbulence at the nozzle inlet, a significant spanwise variation of film cooling effectiveness was observed. This spanwise variation was attributed to the effect of secondary flow and insufficient mixing on the suction surface. Other important conclusions from their study were that film cooling effectiveness decreased with an increase in exit Reynolds number and a decrease in exit Mach number. These flow condition effects (independent variation of exit Reynolds number and Mach number) were less pronounced at the highest blowing ratio.

Zhang and Pudupatty [A-33] investigated the effects of injection angle and hole exit shape on film cooling effectiveness on the same vane geometry researched by Zhang et al. [A33]. Tests were performed at exit Mach, $\mathrm{M}_{\mathrm{ex}}=0.72$ and freestream turbulence intensity at the 
cascade inlet of $12 \%$. They investigated a four-row showerhead and one row of holes on the pressure side using the PSP technique in a high speed wind tunnel. Three showerhead coolant injection angles $\left(45^{\circ}, 90^{\circ}\right.$, and $\left.135^{\circ}\right)$ and two pressure side injection angles $\left(20^{\circ}\right.$ and $\left.40^{\circ}\right)$ for the cylindrical holes and $40^{\circ}$ angle for the shaped hole were studied. The results indicated that $45^{\circ}$ spanwise angle injection for the showerhead regions and $20^{\circ}$ cylindrical hole injection for the pressure side provided best film coverage. In a combined showerhead and pressure side film hole study, at a low blowing ratio, showerhead geometry dominated effectiveness distribution even downstream from the pressure side injection. At a higher blowing ratio, $20^{\circ}$ cylindrical hole geometry resulted in overall higher film cooling effectiveness.

Reiss and Bölcs [A-34] studied the influence of boundary layer state and Reynolds number/ Mach number on the film cooling effectiveness and heat transfer on a cooled nozzle guide vane. They found that the incoming turbulent boundary layer decreased the effectiveness values for single injection location as compared to a laminar boundary layer at actual engine conditions. It was also shown that higher Mach and Reynolds number may increase or decrease the film cooling effectiveness, depending on the surface location and the intensity of injection. No uniform trend could be established that would be generally applicable for the entire vane surface and all injection locations.

Schnieder et al. [A-35] investigated the effect of approach boundary layer on vane film cooling effectiveness with showerhead blowing and three rows of fan-shaped film cooling holes on the pressure side in a high speed facility. They presented laterally averaged adiabatic effectiveness data for each row for three blowing ratios. Schnieder et al. [A-33] also investigated the superposition approach for individual rows, and found that it matched quite well with the complete coverage data.

Haldeman et al. [A-36] conducted aerodynamic and heat flux measurements on a fully film cooled, high-work, single stage HP turbine operating in a short duration blow-down rig at Ohio State University. Double-sided Kapton thin film gauges were used for both time-averaged and time-accurate heat flux measurements. Data was presented only for a low Reynolds number, low coolant mass flow case within a large experimental matrix. The vane measurements for the $50 \%$ span showed lower heat flux on the pressure side where the gauges were more heavily influenced by the cooling holes. The differences in the heat flux between the suction and pressure surfaces were minimal because of low cooling injection rates. 
Recently, Zhang and Moon [A-37] experimentally measured suction side film cooling effectiveness using PSP from a five-row showerhead and two rows of shaped holes on a first stage turbine nozzle with two different wall thicknesses and different blowing ratio conditions. They found that, in general, the film cooling effectiveness for the five-row showerhead increased with the blowing ratio before the first row of suction side injection. The wall thickness effect on the film cooling effectiveness was not significant for the five-row showerhead arrangement but for the showerhead combined with two suction side rows, the film cooling effectiveness increased with the increase in blowing ratio in general for a thinner wall case. The effect of turbulence and Reynolds number on the heat transfer coefficient distribution of an uncooled version of the vane geometry used by [A-37] was completed by Nasir et al. [A-38].

\section{Numerical Work}

Several computational studies have been performed to explain and predict film cooling on turbine blades and vanes at engine realistic flow conditions. Garg and Ameri [A-39] used 3-D RANS code with Coakley's $q-\omega$ model, Chien's $k$ - $\varepsilon$ model and Wilcox's $k-\omega$ model to predict heat transfer coefficient at low freestream turbulence on the film cooled VKI rotor with six rows of cooling holes including three rows in the showerhead and the NASA C3X vane with nine rows of holes including five rows in the showerhead. Later, Garg [A-40] used a multi-block 3-D RANS code with Wilcox's $k$ - $\omega$ model to study with-in hole and near-hole physics in relation to heat transfer on the showerhead film cooled VKI rotor blade. He found a reasonably good agreement with the experimental data over the whole surface but found that near hole heat transfer coefficient distribution was dependent on velocity and temperature distribution profiles inside the cooling holes.

Theodoridis et al. [A-41] developed a 3-D model, using $k-\varepsilon$ model, to investigate coolant air injection at the leading edge of a high pressure AGTB turbine blade. They calculated and compared the velocity and pressure fields and turbulence intensity in the vicinity of the showerhead region with the available experimental data. To avoid the non realistic increase of the near-wall turbulence intensity, they applied turbulence anisotropy correction of Bergeles et al. [A-42]. This correction led to better prediction in the span-wise direction on the pressure side of the blade. 
Heidmann et al. [A-43] performed 3-D coupled internal/external heat transfer simulation of Allied Signal's film cooled vane using the LeRC-HT code at engine representative exit Mach number condition of $\mathrm{M}_{\mathrm{ex}}=0.876$ and freestream turbulence intensity of $8 \%$. The turbulence closure was done by means of modified Wilcox's $k-\omega$ model as implemented by Chima [A-44]. Two computations were performed for different isothermal wall temperatures to allow independent determination of heat transfer coefficient and film cooling effectiveness values. The numerical results were not validated with the experiments but showed that the shaped holes on the pressure surface provided a reduction in heat flux through the reduction in heat transfer coefficient and increase in film cooling effectiveness as compared to showerhead region circular shaped holes.

Ginibre et al. [A-45] computed wall heat flux on a 3-D slice of high pressure film cooled NGV with multiple rows of injections to evaluate 3D Navier-Stokes solver developed by Snecma Moteurs. The turbulence closure was done by means of algebraic mixing length model and Spalart-Allmaras one-transport equation model. Ginibre et al. found that both the models predicted similar span averaged heat flux values but Spalart-Allmaras model was more appropriate for industrial use because of its generality and robustness.

Medic and Durbin [A-46] presented flow and heat transfer coefficient predictions for a high pressure film cooled VKI rotor blade with turbulent time-scale bound $k-\varepsilon$ model, standard and modified $k$ - $\omega$ model, and $v^{2}-f$ model. All the simulations were performed at exit Mach number condition of $\mathrm{M}_{\mathrm{ex}}=0.92$ and freestream turbulence of $5 \%$. They found that for low blowing ratios, the modified $k-\varepsilon$ model and $v^{2}-f$ model gave satisfactory predictions of overall heat transfer coefficient levels on the film cooled vane surface. For higher blowing ratios, on the suction surface, the modified $k-\varepsilon$ model and $v^{2}-f$ model overpredicted film cooling in the vicinity of film cooling holes. For higher blowing ratios, on the pressure surface, the $v^{2}-f$ model predicted stronger jet lateral spreading as compared to the other models.

Montomoli et al. [A-47] upgraded the finite volume CFD solver Hybflow, to perform conjugate heat transfer simulations of QinetiQ MT1 high pressure NGV at freestream turbulence of 5.5\%. The heat transfer coefficient distribution over the vane surface showed good agreement with the experimental data of Chana and Mole [A-48].

Recently, Laskowski et al. [A-49] obtained coupled 3-D CFD heat transfer simulations for a high pressure film cooled VKI rotor blade and high pressure film cooled vane with the 
shear stress transport (SST) turbulence model of Menter [A-50]. Laskowski et al. found that film cooling simulations consistently underpredicted heat transfer coefficient downstream of the film cooling holes. They also noted better lateral film cooling coverage for the VKI rotor as compared to the $\mathrm{C} 3 \mathrm{X}$ vane.

\section{References}

[A-1] Goldstein, R.J., 1971, “Film Cooling," Advances in Heat Transfer, 7, pp. 321-380.

[A-2] Bogard, D.G., and Thole, K.A., 2006, "Gas Turbine Film Cooling," ASME J. Propulsion and Power, 22, pp. 249-270.

[A-3] Han, J.-C., Dutta, S., and Ekkad, S.V., 2000, Gas Turbine Heat Transfer and Cooling Technology, Taylor \& Francis, New York.

[A-4] Ou, S., Han, J.-C., Mehendale, A.B., and Lee, C.P., 1994, "Unsteady Wake Over a Linear Turbine Blade Cascade with Air and $\mathrm{CO}_{2}$ Film Injection: Part I-Effect on Heat Transfer Coefficients," ASME J. Turbomach., 116, pp. 721-729.

[A-5] Mehendale, A.B., Han, J.-C., Ou, S., and Lee, C.P., 1994, "Unsteady Wake Over a Linear Turbine Blade Cascade with Air and $\mathrm{CO}_{2}$ Film Injection: Part II-Effect on Film Effectiveness and Heat Transfer Distributions," ASME J. Turbomach., 116, pp. 730-737.

[A-6] Ekkad, S.V., Mehendale, A.B., Han, J.-C., and Lee, C.P., 1997, “Combined Effect of Grid Turbulence and Unsteady Wake on Film Effectiveness and Heat Transfer Coefficient of a Gas Turbine Blade with Air and $\mathrm{CO}_{2}$ Film Injection," ASME J. Turbomach., 119, pp. 594-600.

[A-7] Dring, R.P., Blair, M.F., and Joslyn, H.D., 1980, “An Experimental Investigation of Film Cooling on a Turbine Rotor Blade,'’ ASME J. Eng. Power, 102, pp. 81-87.

[A-8] Takeishi, K., Aoki, S., Sato, T., and Tsukagoshi, K., 1992, "Film Cooling on a Gas Turbine Rotor Blade,' ASME J. Turbomach., 114, pp. 828-834.

[A-9] Ahn, J., Schobeiri, M.T., Han, J.-C., and Moon, H.K., 2006, “Film Cooling Effectiveness on the Leading Edge Region of a Rotating Turbine Blade with Two Rows of Film Cooling Holes Using Pressure Sensitive Paint,', ASME J. Heat Transfer, 128, pp. 879-888.

[A-10] Ames, F.E., 1996, "Experimental Study of Vane Heat Transfer and Film Cooling at Elevated Levels of Turbulence," NASA CR-198525.

[A-11] Polanka, M. D., Witteveld, V. C., and Bogard, D. G., 1999, "Film Cooling Effectiveness in the Showerhead Region of a Gas Turbine Vane Part I: Stagnation Region and Near Pressure Side," ASME GT-1999-48. 
[A-12] Witteveld, V. C., Polanka, M. D., and Bogard, D. G., 1999, "Film Cooling Effectiveness in the Showerhead Region of a Gas Turbine Vane Part II: Stagnation Region and Near Suction Side," ASME GT-1999-49.

[A-13] Colban, W., Gratton, A., Thole, K.A., and Haendler, M., 2006, "Heat Transfer and FilmCooling Measurements on a Stator Vane with Fan-Shaped Cooling Holes," ASME J. Turbomach., 128, pp. 53-61.

[A-14] Camci, C., 1985, "Theoretical and Experimental Investigation of Film Cooling Heat Transfer on a Gas Turbine Blade, Ph.D. Thesis, Von Karman Institute for Fluid Dynamics and University of Leuven, Belgium.

[A-15] Camci, C., and Arts, T., 1985a, "Short Duration Measurements and Numerical Simulation of Heat Transfer Along the Suction Side of a Film-Cooled Gas Turbine Blade," ASME J. Eng. Power, 107, pp. 991-997.

[A-16] Camci, C., and Arts, T., 1985b, "Experimental Heat Transfer Investigation around the Film-Cooled Leading Edge of a High-Pressure Gas Turbine Rotor Blade," ASME J. Eng. Power, 107, pp. 1016-1021.

[A-17] Rigby, M.J., Johnson, A.B., and Oldfield, M.L.G., 1990, "Gas Turbine Rotor Blade Film Cooling With and Without Simulated NGV Shock Waves and Wakes," ASME GT-1990-78.

[A-18] Abhari, R.S., and Epstein, A.H., 1994, "An Experimental Study of Film Cooling in a Rotating Transonic Turbine," ASME J. Turbomach., 116, pp. 63-70

[A-19] Smith, D.E., Bubb, J.V., Popp, O., Grabowski, H. C, Diller, T.E., Schetz, J.A., and Ng, W.F., 2000, "An Investigation of Heat Transfer in a Film Cooled Transonic Turbine Cascade, Part I: Steady Heat Transfer," ASME GT-2000-202.

[A-20] Heidmann, J.D., Lucci, B.L., and Reshotko, E., 2001, "An Experimental Study of Film Cooling in a Rotating Transonic Turbine," ASME J. Turbomach., 123, pp. 214-221.

[A-21] Zhang, L.J., and Moon, H.K., 2006, "Turbine Blade Film Cooling Study-The Effects of Showerhead Geometry,” ASME GT-2006-90367.

[A-22] Carullo, J.S., Nasir, S., Cress, R.D., Ng, W.F., Thole, K.A., Zhang, L.J., and Moon, H.K., 2007, "The Effects of Freestream Turbulence, Turbulence Length Scale, and Exit Reynolds Number on Turbine Blade Heat Transfer in a Transonic Cascade," ASME GT-2007-27859.

[A-23] Guy, A., Nasir, S., Bolchoz, T., and Ng, W.F., 2007, "Effect of Blowing Ratio on the Nusselt Number and Film Cooling Effectiveness Distributions of a Showerhead Film Cooled Blade in a Transonic Cascade," Master's Thesis, Virginia Polytechnic Institute and State University. 
[A-24] Mhetras, S., Han, J.-C., and Rudolph, R., 2007, "Effect of Flow Parameter Variations on Full Coverage Film-Cooling Effectiveness for a Gas Turbine Blade," ASME GT-2007-27071.

[A-25] Turner, E.R., Wilson, M.D., Hylton, L.D., and Kaufman, R.M., 1985, "Turbine Vane External Heat Transfer: Vol. 1: Analytical and Experimental Evaluation of Surface Heat Transfer Distributions with Leading Edge Showerhead Film Cooling,” NASA CR-174827.

[A-26] Nirmalan, N.V., and Hylton, L.D., 1990, "An Experimental Study of Turbine Vane Heat Transfer with Leading edge and Downstream Film Cooling," ASME J. Turbomach., 112, pp. 477-487.

[A-27] Arts, T., and Bourguignon, A.E., 1990, "Behavior of a Coolant Film with Two rows of Holes along the Pressure Side of a High Pressure Nozzle Guide Vane," ASME J. Turbomach., 112 , pp. 512-520.

[A-28] Abuaf, N., Bunker, R., and Lee, C.P., 1997, "Heat Transfer and Film Cooling Effectiveness in a Linear Airfoil Cascade," ASME J. Turbomach., 119, pp. 302-309.

[A-29] Drost, U., and Bölcs, A., 1999, "Investigation of Detailed Film Cooling Effectiveness and Heat Transfer Distribution on a Gas Turbine Airfoil," ASME J. Turbomach., 121, pp. 233-242.

[A-30] Guo, S.M., Lai, C.C., Jones, T.V., Oldfield, M.L.G., Lock, G.D., and Rawlinson, A.J., 1998, "The Application of Thin-film Technology to Measure Turbine-Vane Heat Transfer and Effectiveness in a Film-Cooled, Engine-Simulated Environment," Intl. J. Heat and Fluid Flow, 19, pp. 594-600.

[A-31] Piccini, E., Guo, S.M., and Jones, T.V., 2000, "The Development of New Heat Transfer Gauge for Heat Transfer Facilities," Meas. Sci. Technol., 121, pp. 342-349.

[A-32] Zhang, L. J., Baltz, M., Pudupatty, R., and Fox, M., 1999, "Turbine Nozzle Film Cooling Study Using the Pressure Sensitive Paint (PSP) Technique,” ASME GT-1999-196.

[A-33] Zhang, L. J. and Pudupatty, R., 2000, "The Effect of Injection Angle and Hole Exit Shape on Turbine Nozzle Pressure Side Film Cooling," ASME GT-2000-247.

[A-34] Reiss, H., and Bölcs, A., 2000, "The Influence of the Boundary Layer State and Reynolds Number on Film Cooling and Heat Transfer on a Cooled Nozzle Guide Vane," ASME GT-2000205 .

[A-35] Schneider, M., Parneix, S., and Wolfersdorf, J., 2003, "Effect of Showerhead Injection on Superposition of Multi-Row Pressure Side Film Cooling with Fan-Shaped Holes," ASME GT2003-38693.

[A-36] Haldeman, C.W., Mathison, R.M., Dunn, M.G., Southworth, S., Harral, J.W., and Heitland, G., 2006, "Aerodynamic and Heat Flux Measurements in a Single Stage Fully Cooled Turbine - Part II: Experimental Results,” ASME GT-2006-90968. 
[A-37] Zhang, L.J., and Moon, H.K., 2008, “The Effect of Wall Thickness on Nozzle Suction Side Film Cooling,” ASME GT-2008-50631.

[A-38] Nasir, S., Carullo, J.S., Ng, W.F., Thole, K.A., Wu, H., Zhang, L.J., and Moon, H.K., 2007, "Effects of Large Scale High Freestream Turbulence, and Exit Reynolds Number on Turbine Vane Heat Transfer in a Transonic Cascade," ASME IMECE-2007-44098.

[A-39] Garg, V.K., and Ameri, A.A., 1997, "Comparison of Two-Equation Turbulence Models for Prediction of Heat Transfer on Film-Cooled Turbine Blades," Numerical Heat Transfer, Part A $32,347-371$.

[A-40] Garg, V.K., 2001, "Modeling Film Coolant Flow Characteristics at the Exit of Shower Head Holes", Intl. J. Heat and Fluid Flow, 22, pp. 134-142.

[A-41] Theodoridis, G.S., Lakehal, D., and Rodi, W., 2001, "Three-Dimensional Calculations of the Flow Field around a Turbine Blade with Film Cooling Injection near the Leading Edge," Flow Turbulence and Combustion, 66, pp. 57-83.

[A-42] Bergeles, G., Gosman, A.D. and Launder, B.E., 1978, "The Turbulent Jet in a Cross Stream at Low Injection Rates: A Three-Dimensional Numerical Treatment," Numerical Heat Transfer, 1, 217-242.

[A-43] Heidmann, J.D., Rigby, D.L., and Ameri, A.A., 2000, “A Three-Dimensional Coupled Internal/External Simulation of a Film-Cooled Turbine Vane," ASME J. Turbomach., 122, pp. 348-359.

[A-44] Chima, R. V., 1996, “A k- $\omega$ Turbulence Model for Quasi-Three-Dimensional Turbomachinery Flows,', NASA TM-107051.

[A-45] Ginibre, P., Lefebre, and M., Liamis, N., 2001, "Numerical Investigation of Heat Transfer on Film-Cooled Turbine Blades", Annals New York Academy of Sciences, 934, pp. 377-384.

[A-46] Medic, G., and Durbin, P.A., "Towards Improved Prediction of Heat Transfer on Turbine Blades", ASME J. Turbomach., 124, pp. 193-199.

[A-47] Montomoli, F., Adami, P., Della Gatta, S., and Martelli, F., 2004, "Conjugate Heat Transfer Modeling in Film Cooled Blades," ASME GT2004-53177.

[A-48] Chana, K.S., and Mole, A.H., 2002, "Summary of Cooled NGV and Uncooled Rotor Measurements from the MT1 Single Stage High Pressure Turbine in the DERA Isentropic Light Piston Facility", Brite-EuRam Turbine Aero-Thermal External Flow project (BRPR-CT970519). 
[A-49] Laskowski, G.M., Tolpadi, A.K., and Ostrowski, M.C., 2007, "Heat Transfer Predictions of Film Cooled Stationary Turbine Airfoils," ASME GT2007-27497.

[A-50] Menter, F. R., 1994, “Two-Equation Eddy-Viscosity Turbulence Models for Engineering Applications," AIAA-Journal, 32, pp.1598-1605. 


\section{Appendix B Film Cooling System}

This appendix describes the construction and operation of the film cooling system in greater depth.

\section{Film Cooling System Setup and Operation}

The film cooling system used in this experiment is an adaptation of the one used by Smith et al. [B-1]. A diagram of the system is shown in Figure B.1, and a photograph can be seen in Figure B.2. Film cooling air is supplied by a 5-hp Ingersoll-Rand compressor located outside of the laboratory. Air from the compressor is dried below four percent relative humidity and then stored in a large tank within the laboratory. This storage tank is charged to a pressure of 120 psi to provide adequate pressure and mass flow for the experiment. Because the volume of the tank is large compared to the mass flow of the coolant during an experiment, there is minimal "blow-down" during a tunnel run. The flow rate of air to the vane is regulated by a control valve. After passing through the control valve, mass flow of coolant is measured by an orifice plate. The air then flows through a copper coil immersed in a water bath. This serves to heat the coolant air to a temperature that matches the vane's initial temperature-preventing internal conduction within the airfoil. After passing through the coil, the air flows into the vane via a fitting designed to pass air through the test section window. The fitting, shown in Figure B.3, is threaded through the test section window and uses an o-ring to form a face seal against the vane. Air then flows through the vane plenum and is ejected through the film cooling holes.

Air is supplied to the plenum at a constant pressure during the run. Before the run, the pressure is set by a Pitot-static probe installed in the aforementioned fitting. Once the desired

pressure is set, an operator starts the tunnel. This provides a constant blowing ratio during the blow-down tunnel run. 


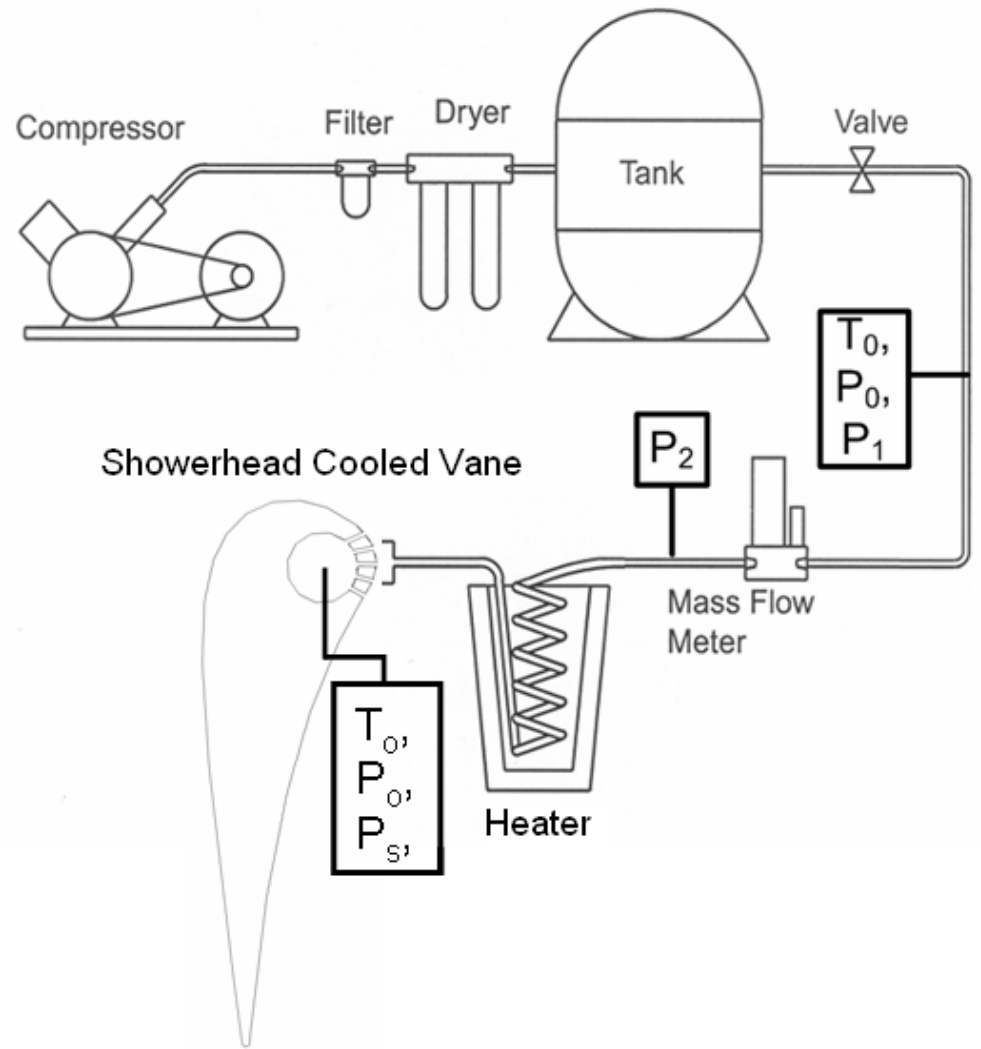

Figure B.1. Film cooling system schematic

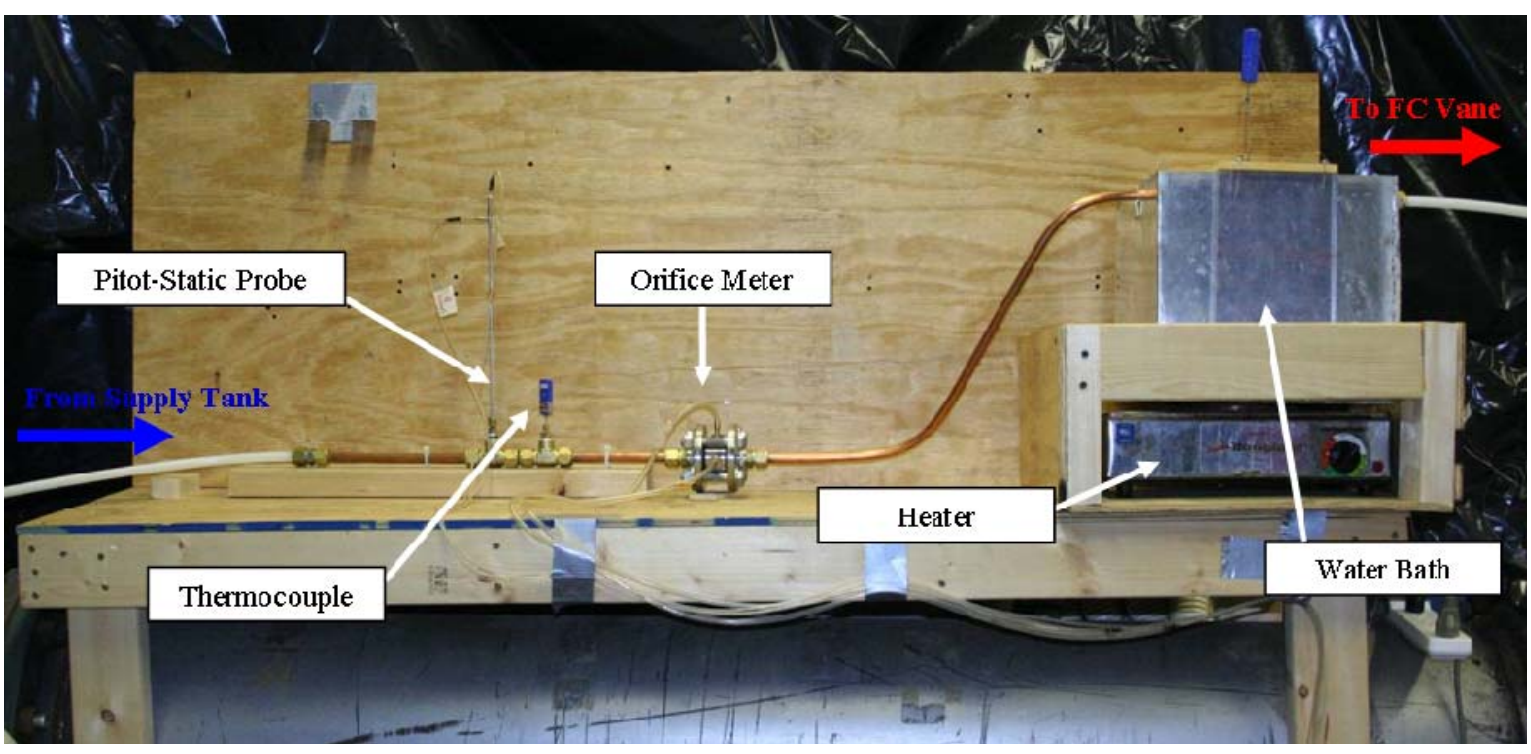

Figure B.2. Photograph of film cooling system 


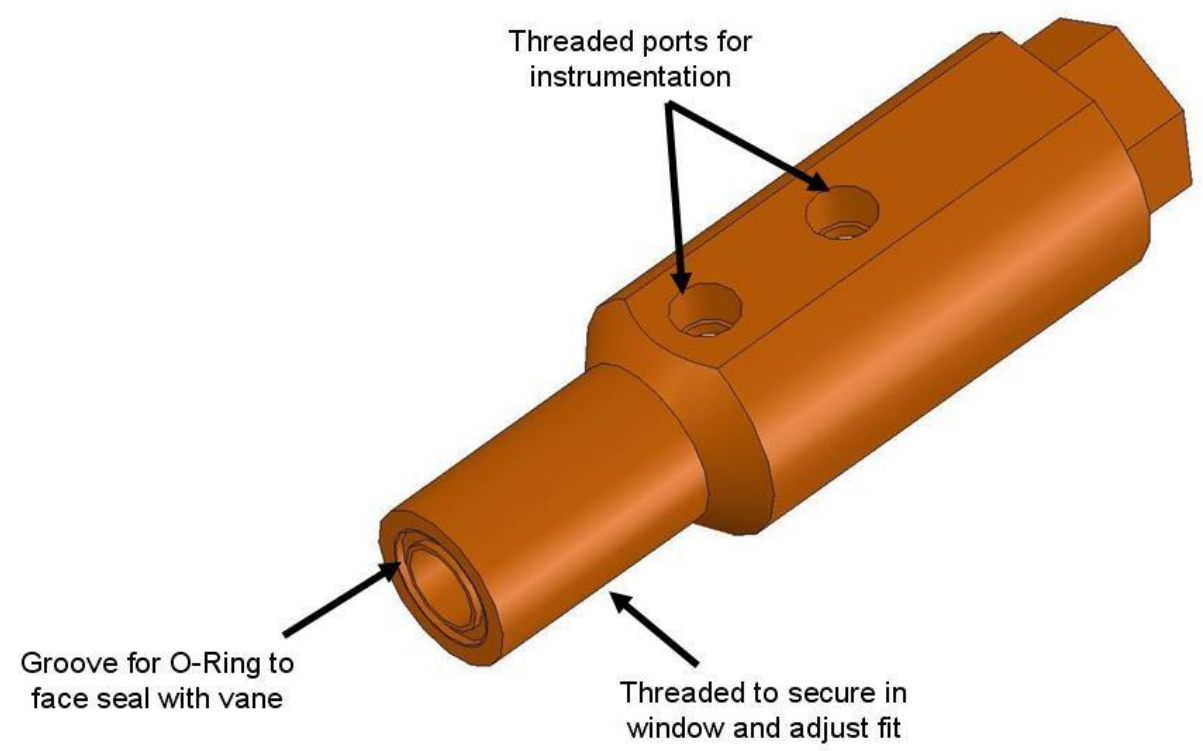

Figure B.3. Coolant supply fitting

\section{Measurements and Calculations}

To set and measure film cooling parameters such as blowing ratio and density ratio, the film cooling system has been adequately instrumented with temperature, pressure, and mass flow measurement devices. Blowing ratio is determined by Equation 2.2. Mass flow rate of the coolant is measured by an orifice plate using the following relation:

$$
\dot{m}_{c}=C_{d} A_{o p} \sqrt{2 \rho \Delta P}
$$

where $C_{d}$ is the discharge coefficient of $0.62, A_{o p}$ is the area of the orifice plate $\left(3.95 \times 10^{-5} \mathrm{~m}^{2}\right)$, $\rho$ is the density of air, and $\Delta P$ is the pressure drop across the plate. A Pitot-static probe and Ttype thermocouple upstream of the orifice plate provide the temperature and pressures needed to calculate the density of the air traveling through the orifice plate. Their location can be seen in Figure B.1.

Additionally, a Pitot-static probe was placed at the entrance to the film cooling plenum to provide the pressure measurement necessary to set the coolant flow prior to a test run. Pressure measurements from this probe were also used to calculate density ratio. Coolant temperature was measured by a T-type thermocouple inserted into the center of the plenum near the midspan of 
the vane. Because of the low thermal conductivity of the Macor vane, it was assumed that the temperature of the plenum was the same as the temperature of the coolant at the exit of the cooling holes.

Calibrated MKS pressure transducers with proper pressure ranges were used to measure all the pressure data for blowing ratio and density ratio measurements. The pressure data were sampled at $1 \mathrm{kHz}$ and recorded for 30 seconds using NI SCXI-1600 data acquisition system. The temperature data for blowing ratio and density ratio measurements were also sampled at $1 \mathrm{kHz}$ and recorded for 30 seconds using the cold junction compensation internal to the isolation amplifier (SCXI 1120) of NI SCXI-1600 data acquisition system

\section{References}

[B-1] Smith, D.E., Bubb, J.V., Popp, O., Grabowski, H. C, Diller, T.E., Schetz, J.A., and Ng, W.F., 2000, "An Investigation of Heat Transfer in a Film Cooled Transonic Turbine Cascade, Part I: Steady Heat Transfer,” ASME GT-2000-202. 


\section{Appendix C Thin Film Gauge Overview - Film Cooling Measurements}

\section{Thin Film Gauge Mounting on Vane}

The platinum thin film gauges used in film cooling experiments were manufactured by Air Force Research Laboratories. The gauges are the same type used by Carullo et al. [C-1] and Nasir et al. [C-2]. Each thin film gauge uses a platinum sensor approximately $3.18 \mathrm{~mm}(0.125$ in.) long attached to copper leads. The platinum sensor changes resistance with temperature and gives a fast response measurement with high spatial resolution between gauges. Twenty-five gauges are sputtered onto a Kapton sheet $(k=0.12 \mathrm{~W} / \mathrm{mK})$ with a $50 \mu \mathrm{m}$ thickness. Each sheet of gauges is given an adhesive backing approximately $20 \mu \mathrm{m}$ in thickness.

Before mounting the gauges on a low thermally conductive Macor $(k=1.46 \mathrm{~W} / \mathrm{mK})$ vane, the gauge sheet was cut to the appropriate size, and the Macor airfoil was thoroughly cleaned. The gauges were aligned with the midspan of the airfoil and the cooling hole rows, and then the sheet was carefully adhered to the pressure and suction surfaces. Air bubbles were eliminated beneath the sheet by using a soft paper towel to apply the sheet from the stagnation region toward the trailing edge.

After the sheet was applied, an $\mathrm{X}$-acto ${ }^{\circledR}$ knife was used to scrape away the copper leads and platinum sensors of four gauges that were covering the cooling hole rows. Once the gauges covering holes were removed, a hot soldering iron with a fine tip was used to pierce a hole in the Kapton at each hole location. Using a soldering iron to create holes prevented the Kapton sheet from tearing. Once the holes were made, excess Kapton was removed from the holes by hand using a pin-vise-mounted drill bit with a diameter equivalent to the cooling hole diameter. Each cooling hole was visually inspected to ensure uniformity between holes and eliminate the possibility of hole blockage. Figure C.1 shows the gauge sheet mounted on the film cooled vane. Figure C.2 shows the film cooling holes drilled through the thin film gauge sheet. 


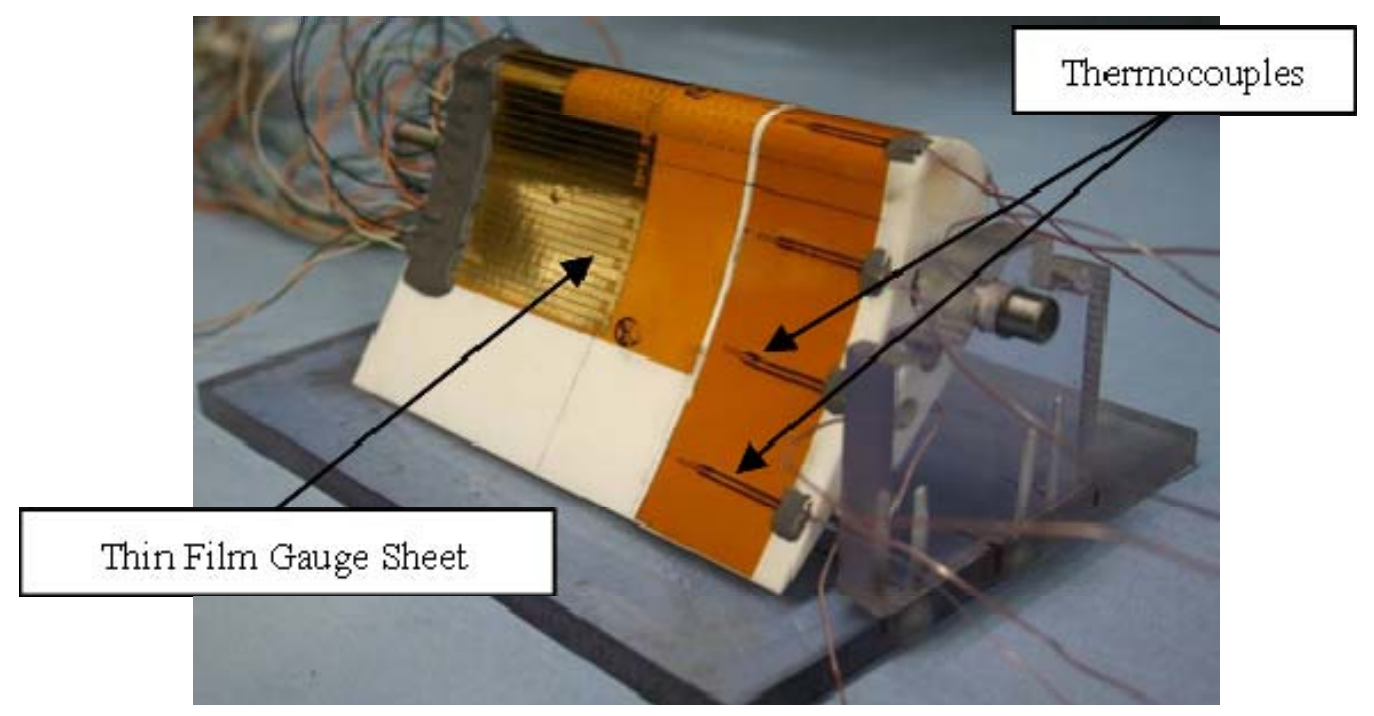

Figure C.1. Gauges mounted on the vane before installation in wind tunnel

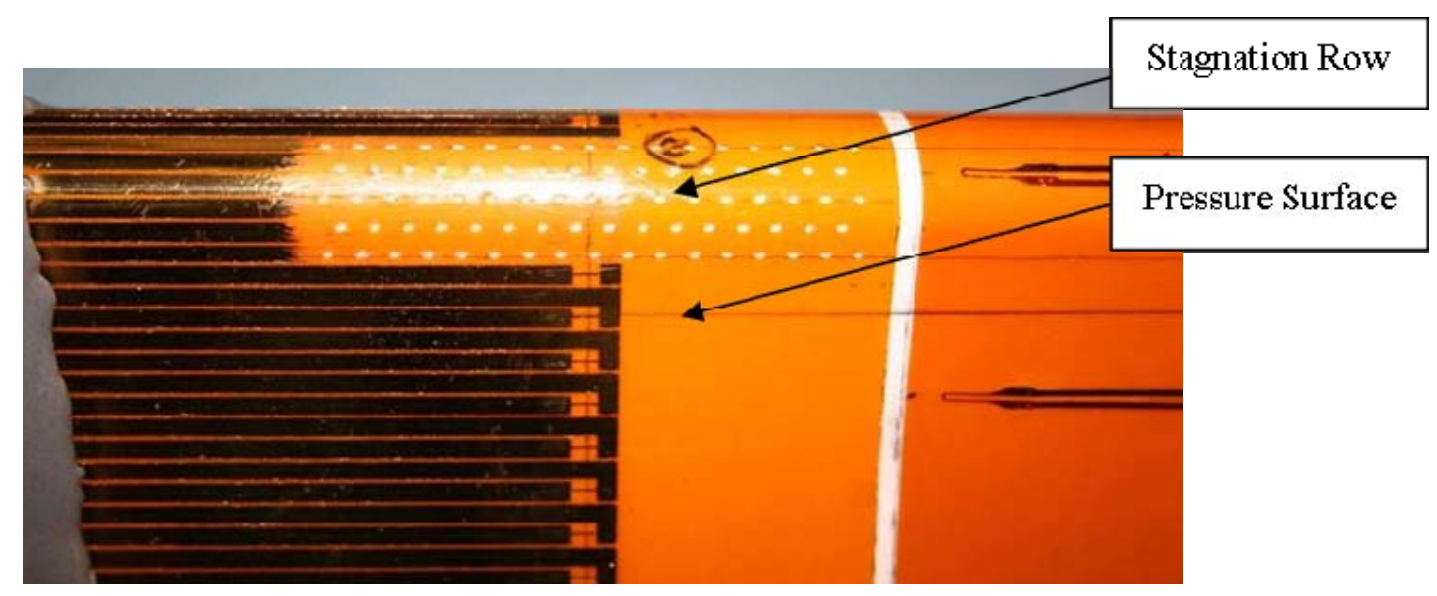

Figure C.2. Film cooling holes drilled through the thin film gauge sheet

\section{Extent of Vane Instrumentation}

The showerhead film cooled Macor vane was instrumented with a total of 21 active single-sided platinum thin film gauges. The vane had 12 gauges on the suction side and 9 gauges on the pressure side. The first gauge (gauge \# 10) downstream of the film cooling rows on the suction side was discarded later on because of highly unrepeatable results. The entire airfoil was not instrumented for film cooling measurements because it was found from literature survey that the selected extent of measurement should capture the full performance of vane showerhead film cooling at high freestream turbulence. Drost and Bölcs [C-3] showed that multiple injection locations (6 rows) resulted in high effectiveness values and extent of film cooling on suction side 
to $\mathrm{s} / \mathrm{C} \sim 1.0$, whereas on the pressure side, cooled by only two rows, low effectiveness values and extent of film cooling performance to $\mathrm{s} / \mathrm{C} \sim 0.25$ was observed. Ames [C-4] showed that the extent of film cooling performance with showerhead film cooling ( 3 rows) vane was found to be up to $\mathrm{s} / \mathrm{d} \sim 80$ on the suction side. A summary of the extent of vane instrumentation is shown in Table 2. Figure C.3 shows the location of each gauge on the vane.

Table C.1. Extent of vane instrumentation

\begin{tabular}{|c|c|c|c|}
\hline & $\begin{array}{c}\text { \# of Thin Film } \\
\text { Gauges }\end{array}$ & $\begin{array}{c}\text { Extent of } \\
\text { Measurement } \\
(\mathrm{s} / \mathrm{d})\end{array}$ & $\begin{array}{c}\text { Extent of } \\
\text { Measurement } \\
(\mathrm{s} / \mathrm{C})\end{array}$ \\
\hline Pressure Side & 9 & 68 & 0.58 \\
\hline Suction Side & 12 & 84 & 0.72 \\
\hline
\end{tabular}

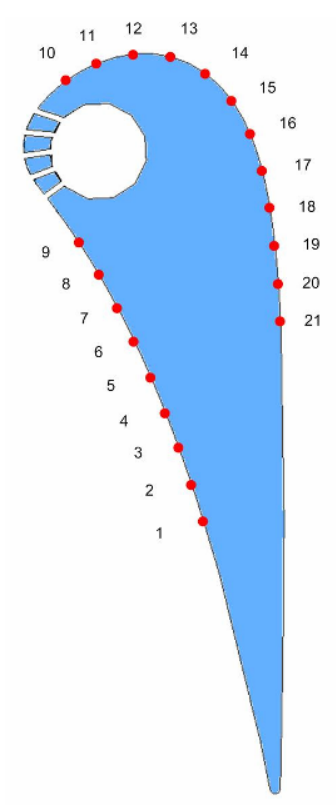

Figure C.3. Location of thin film gauges on the vane surface

\section{Thermocouple Mounting on Vane}

In addition to the thin film gauges, ten T-type thermocouples were installed on the film cooled vane. The purpose of these thermocouples was to measure temperature uniformity between runs and to monitor the initial core temperature of the Macor airfoil before and during a run. Figure C.4 shows the streamwise thermocouple locations. 
Eight miniature T-type (0.0005 in.) foil thermocouples manufactured by RDF were placed on the surface of the vane opposite the thin film gauges. To attach the thermocouples, an adhesive-backed strip of Kapton was placed on a table with the adhesive side facing upwards. The foil thermocouples were placed on the strip of Kapton aligning the sensors in the spanwise direction with one inch of space between each thermocouple and the leads oriented in the spanwise direction. The strip of Kapton was then adhered to the Macor surface with the first thermocouple located one inch from the trailing edge on the suction surface. Figure C.1 shows the thermocouples mounted on the film cooled vane.

Two miniature T-type thermocouples manufactured by Omega were placed in small holes drilled 1.5 inches deep from the vane endwall opposite the thin film gauges. The thermocouples were placed in the holes with the lead wires running out, and then a high-thermal-conductivity epoxy manufactured by Omega was used to fill the holes and secure the thermocouples in place.

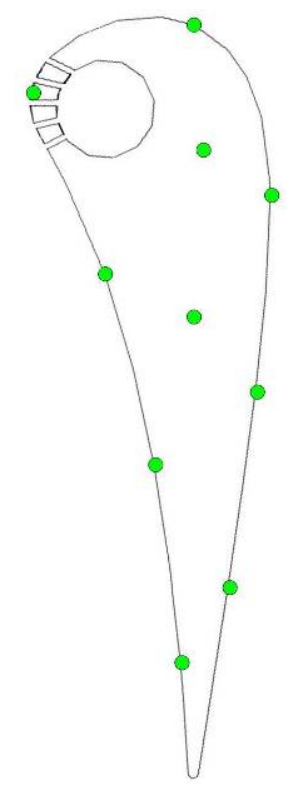

Figure C.4. Thermocouple locations

\section{Thin Film Gauge Lead Wire Attachment}

After mounting the thin film gauges and thermocouples to the vane surface and drilling holes in the Kapton for the film cooling holes, the thin film gauge lead wires were soldered onto the thin film gauge leads. They were soldered following the same procedure as Carullo [C-5], 
except the soldering iron was set at a lower temperature $\left(420^{\circ} \mathrm{C}\right.$ rather than $\left.575^{\circ} \mathrm{C}\right)$. The gauges used in this experiment appeared to have a different surface treatment than gauges used previously, and the temperature setting used before caused the gauge to burn through when soldering.

\section{Thin Film Gauge Calibration}

Once lead wires were soldered, the thin film gauges were calibrated for temperature coefficient of resistivity in a low temperature incubator over the range of temperatures encountered during a tunnel test. The calibration consisted of increasing the temperature of the incubator in five discrete steps from ambient temperature up to $\sim 57^{\circ} \mathrm{C}$ and recording the resistance of each gauge at that temperature. The temperature of the incubator was then decreased back to ambient in three discrete steps and again the resistance of each gauge was recorded at each temperature. Typically 2 hours was allowed to pass between calibration points so that the incubator could reach a steady temperature and to ensure that the vane was thermally soaked. Calibration points were recorded as the temperature increased and decreased to check for gauge hysteresis. Linear calibration fits were obtained by plotting the resistance versus temperature for each gauge. A calibration fit for two of the gauges is provided in Figure C.5.

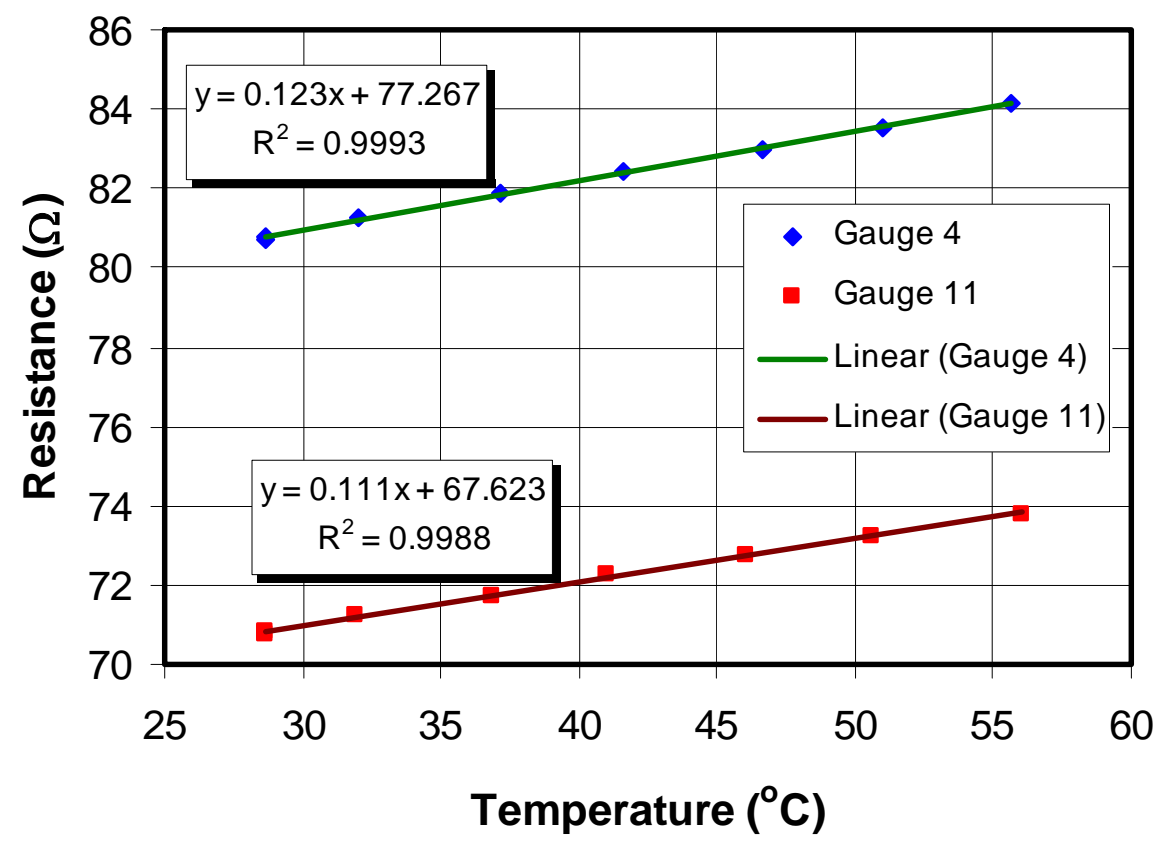

Figure C.5. Calibration curve for two of the thin film gauges installed on the turbine vane 
Each thin film gauge acts as one arm of an individual Wheatstone bridge circuit. The constant current supplied by the balanced Wheatstone bridge circuit ensures that a voltage change, rather than a direct measurement of resistance change, can be recorded by National Instruments (NI) data acquisition system as the vane surface temperature changes. From this time resolved voltage, the surface temperature history is calculated. Figure C.6 provides a schematic of the Wheatstone bridge circuit of the thin film gauges.

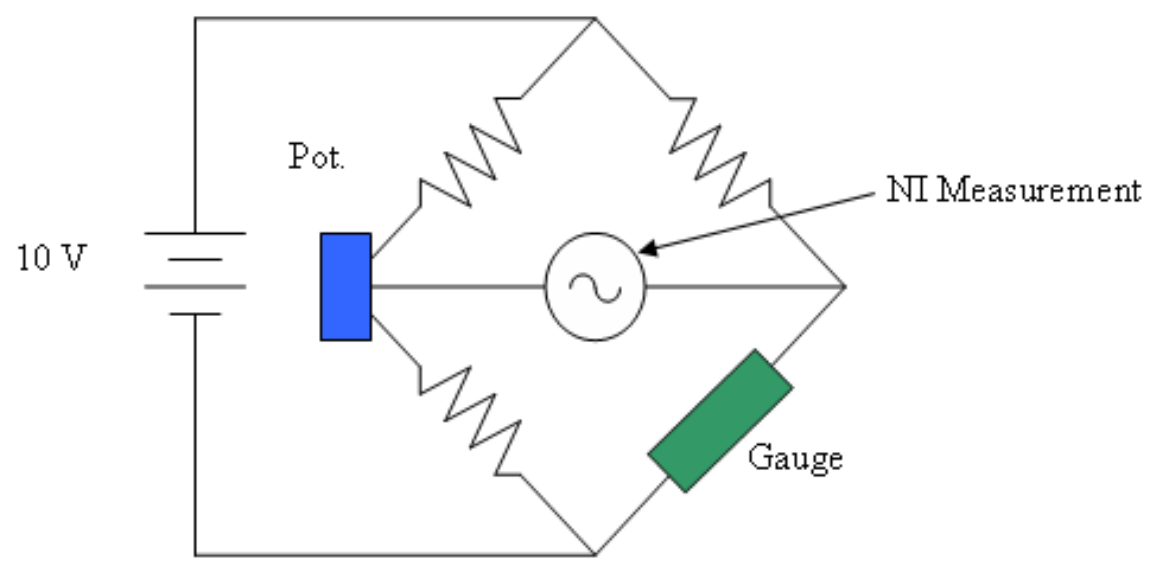

Figure C.6. Schematic of the Wheatstone bridge circuit for the thin film gauges

After calibration, the lead/thin film gauge junctions were covered with JB Weld to increase the robustness of the junction. At this point, the thermocouple lead wires were also soldered to the foil thermocouples and their junctions were covered with JB Weld. Figure C.1 also shows the lead wires and junctions.

\section{Test Section Installation}

After JB welding all lead wire junctions, the film cooled vane was mounted on the test section window where it remained for the remainder of the experiment. To do this, the film cooled vane was attached to a Lexan test section window using dowel pins inserted through the window and into the vane. The thin film gauge lead wires were pulled through holes drilled in the Lexan near the surface of the vane. Silicone caulk was used to cover the lead wires and seal the vane to the Lexan window.

An aluminum insert was attached to the other side of the vane, and the thermocouple lead wires were pulled through holes drilled in the aluminum near the vane surface. Again, silicone 
caulk was used to cover the lead wires and seal the vane to the insert. Figures C.7 and C.8 show the vane attached to the window and insert.

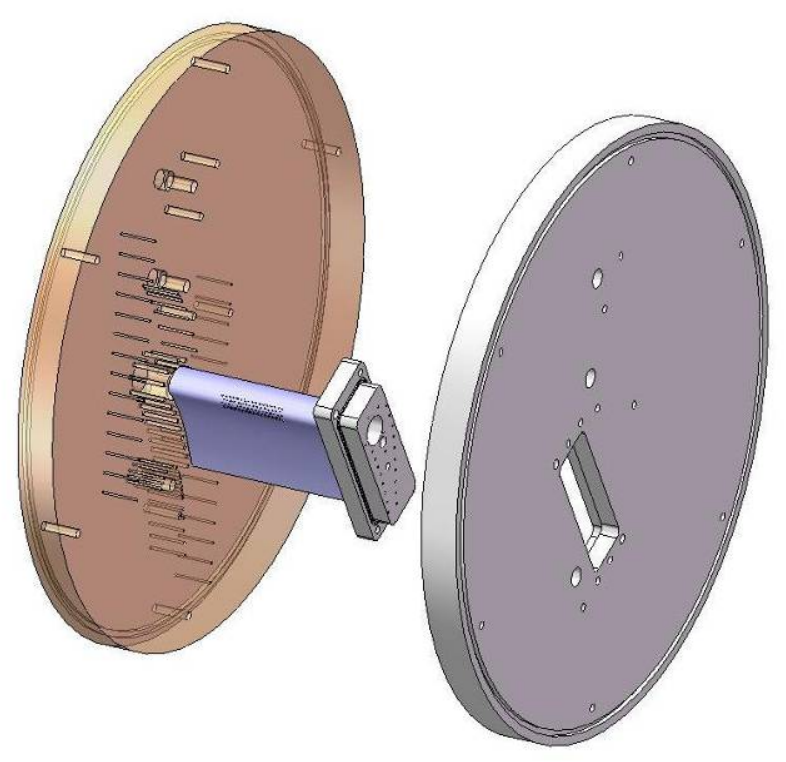

Figure C.7. Film cooled vane assembled with test section windows and insert

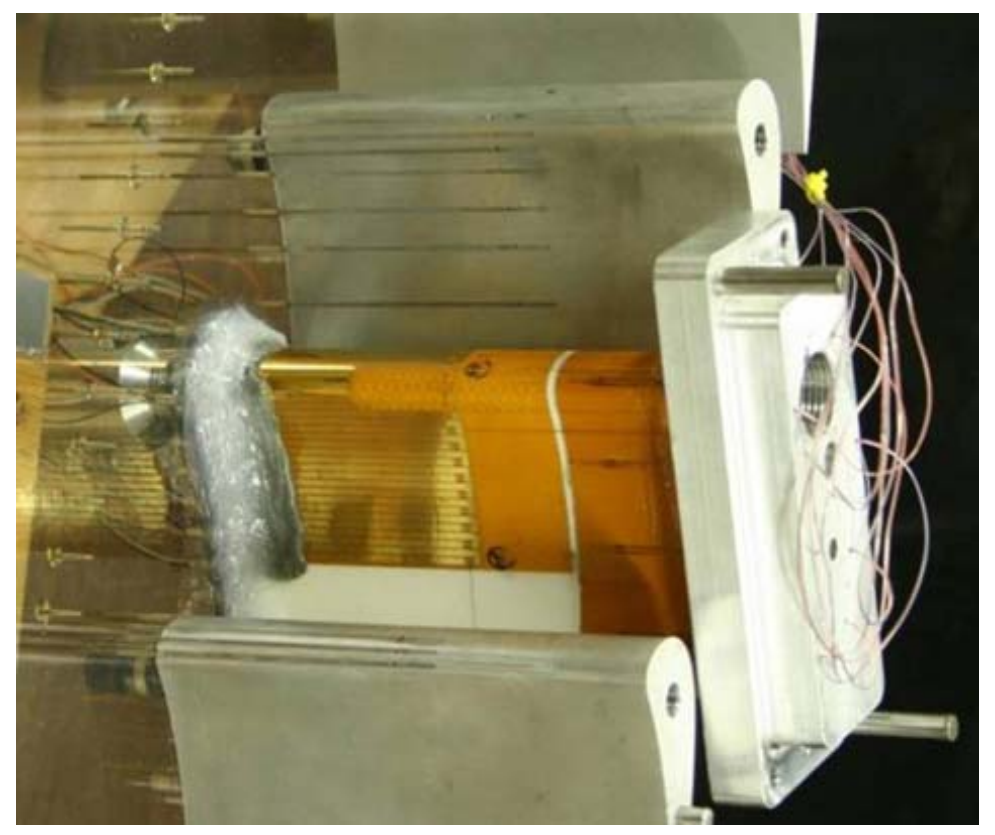

Figure C.8. Picture on instrumented vane installed in test section 


\section{Thin Film Gauge Data Collection}

The thin film gauge voltages from the Wheatstone bridge circuits were sampled at $1 \mathrm{kHz}$ and recorded for 30 seconds using NI SCXI-1600 data acquisition system. The data acquisition system consisted of a SCXI-1001 chassis and SCXI-1120 isolation amplifiers connected into it. The isolation amplifiers for the thin film gauge voltages were set to filter the voltage signals at 4 $\mathrm{Hz}$ or $10 \mathrm{kHz}$ and to apply a gain of 500. Each isolation amplifier was connected to a Wheatstone bridge through a SCXI-1320 terminal block. A total of 21 Wheatstone bridges were connected to the NI system. In addition to the filter settings with the isolation amplifiers, separate analog filters set at a cut-off frequency of $500 \mathrm{~Hz}$ were also used to remove aliasing noise in the thin film gauge voltage data.

The temperature data from the vane surface thermocouples were also sampled at $1 \mathrm{kHz}$ and recorded for 30 seconds using the cold junction compensation internal to the NI SCXI-1600 data acquisition system

\section{References}

[C-1] Carullo, J.S., Nasir, S., Cress, R.D., Ng, W.F., Thole, K.A., Zhang, L.J., and Moon, H.K., 2007, "The Effects of Freestream Turbulence, Turbulence Length Scale, and Exit Reynolds Number on Turbine Blade Heat Transfer in a Transonic Cascade," ASME GT-2007-27859.

[C-2] Nasir, S., Carullo, J.S., Ng, W.F., Thole, K.A., Wu, H., Zhang, L.J., and Moon, H.K., 2007, "Effects of Large Scale High Freestream Turbulence, and Exit Reynolds Number on Turbine Vane Heat Transfer in a Transonic Cascade,” ASME IMECE-2007-44098.

[C-3] Drost, U., and Bölcs, A., 1999, "Performance of a Turbine Airfoil with Multiple Film Cooling Stations Part I: Heat Transfer and Film Cooling Effectiveness," ASME GT-1999-171.

[C-4] Ames, F.E., 1996, "Experimental Study of Vane Heat Transfer and Film Cooling at Elevated Levels of Turbulence," NASA CR-198525.

[C-5] Carullo, J.S., 2006, "Effects of Freestream Turbulence, Turbulence Length Scale, and Reynolds Number on Turbine Blade Heat Transfer in a Transonic Cascade," Master's Thesis, Virginia Polytechnic Institute and State University. 


\section{Appendix D Sample Data Analysis - Film Cooling Measurements}

This appendix presents a sample data for the calculation of heat transfer coefficient and film cooling effectiveness for one gauge on the showerhead film cooled vane with freestream conditions of $\mathrm{M}_{\mathrm{ex}}=0.8, \mathrm{BR}=2.0, \mathrm{Tu}=16 \%$ and $\Lambda_{\mathrm{x}} / \mathrm{P}=0.23$. Data is presented for Gauge 7, which is located at $\mathrm{s} / \mathrm{C}=-0.25$ on the pressure surface.

Sample time traces of tunnel flow conditions are provided in Figure D.1. In order to make sure that the thin film gauges were satisfying semi-infinite boundary condition, heat transfer data is reduced conservatively over a three second time window as soon as freestream flow conditions reached quasi-steady state. This time period corresponds to the high tunnel to vane normal heat flux transfer during quasi-steady flow conditions. The transient temperature blow-down run permits the calculation of $h$ and $\eta$ from a single film cooling run. Blowing ratios are transient over the course of data reduction, but this change is small and average values are reported in the description of results. In the sample data presented in Figure D.1, blowing ratio decreases from a beginning value of 2.0 to 1.96 at the end of data reduction. Similarly density ratio changes from 1.34 to 1.31 over the course of the data reduction time. In Figure D.4, it can be observed that the heat transfer coefficient is steady; so, the small variability of density ratio and blowing ratio over the course of data reduction has a negligible impact on heat transfer coefficient.

\section{Determination of Surface Heat Flux}

Thin film gauge voltages output from each Wheatstone bridge are sampled at $1 \mathrm{kHz}$ and recorded for 30 seconds during the experimental run by a 16-Bit NI SCXI-1600 data acquisition system. Each recorded thin film gauge voltage is then converted into surface temperature using the gauge calibration and basic Wheatstone bridge operating principles. Next, the normal heat flux $\left(q^{\prime \prime}\right)$ for each gauge is calculated by using a finite-difference code developed by Cress [D1]. The finite-difference code uses the surface temperature history of the gauge as a boundary condition and solves the one-dimensional, transient heat conduction equation using semi-infinite boundary condition. The initial temperature of the Macor vane is determined by the 10 thermocouples prior to the run. 1-D semi-infinite heat conduction can be assumed since the 
gauges are installed on the low thermally conductive Macor vane and the coolant temperature in the vane plenum is controlled to match the initial vane temperature during the data reduction period as shown in Figure D.2. Figure D.3 shows the normal heat flux into the vane for Gauge 7 during the run.

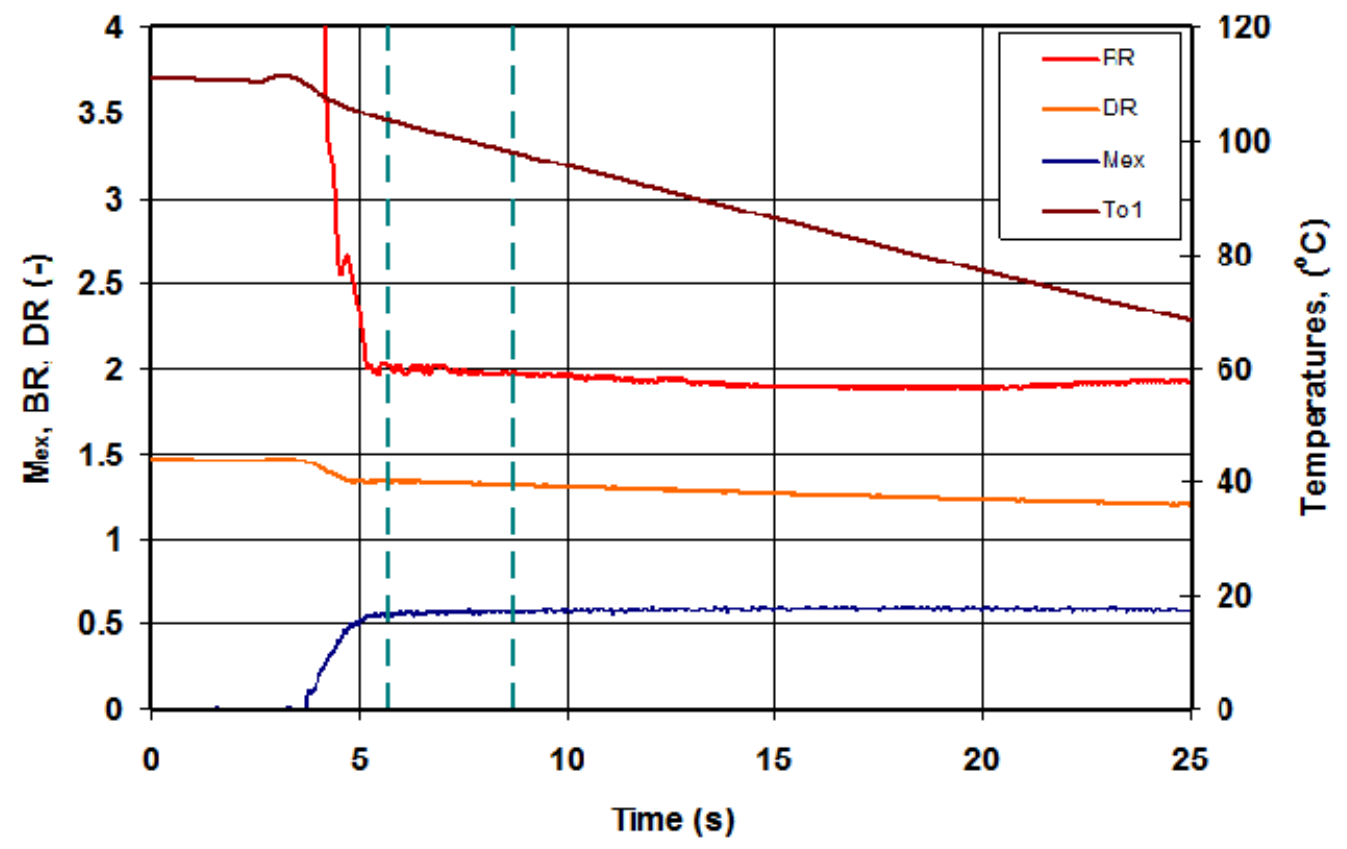

Figure D.1. Sample tunnel run

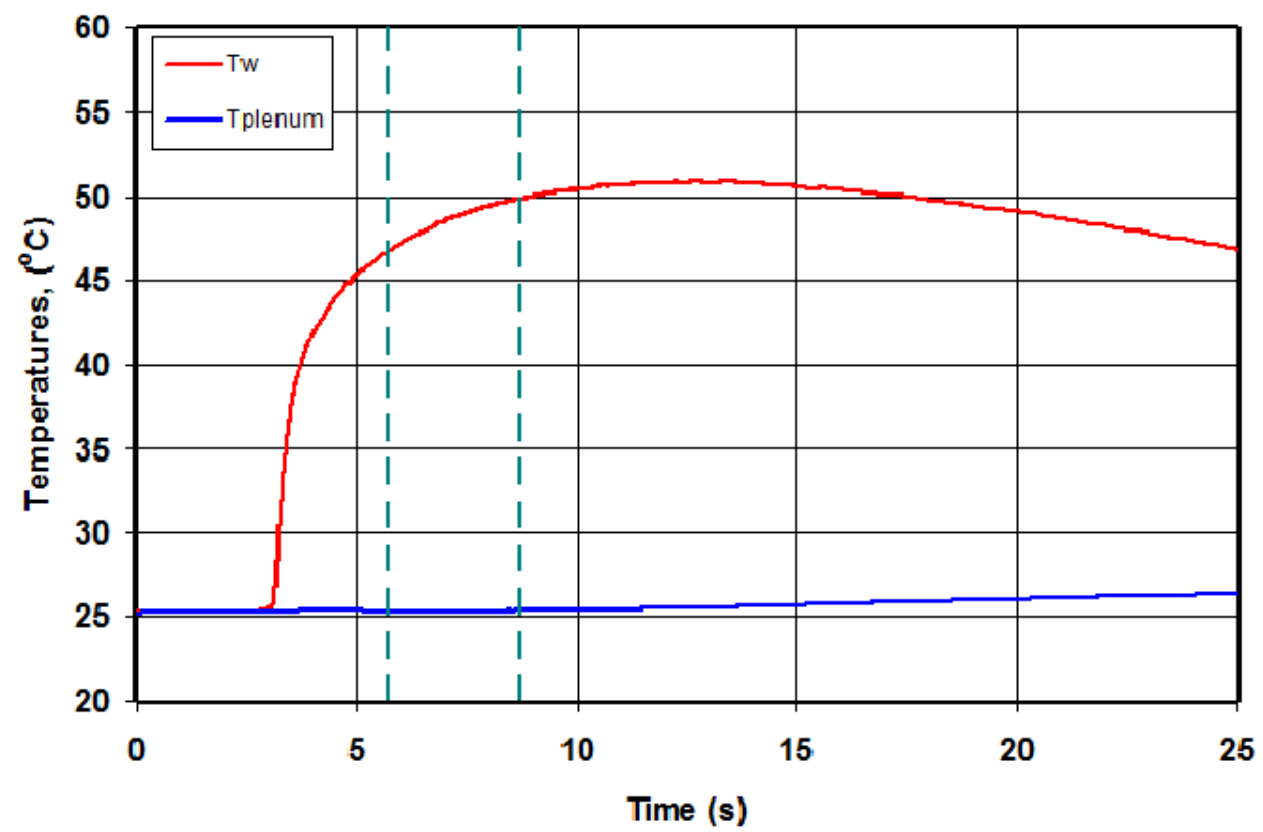

Figure D.2. Gauge 7 and plenum temperature history 


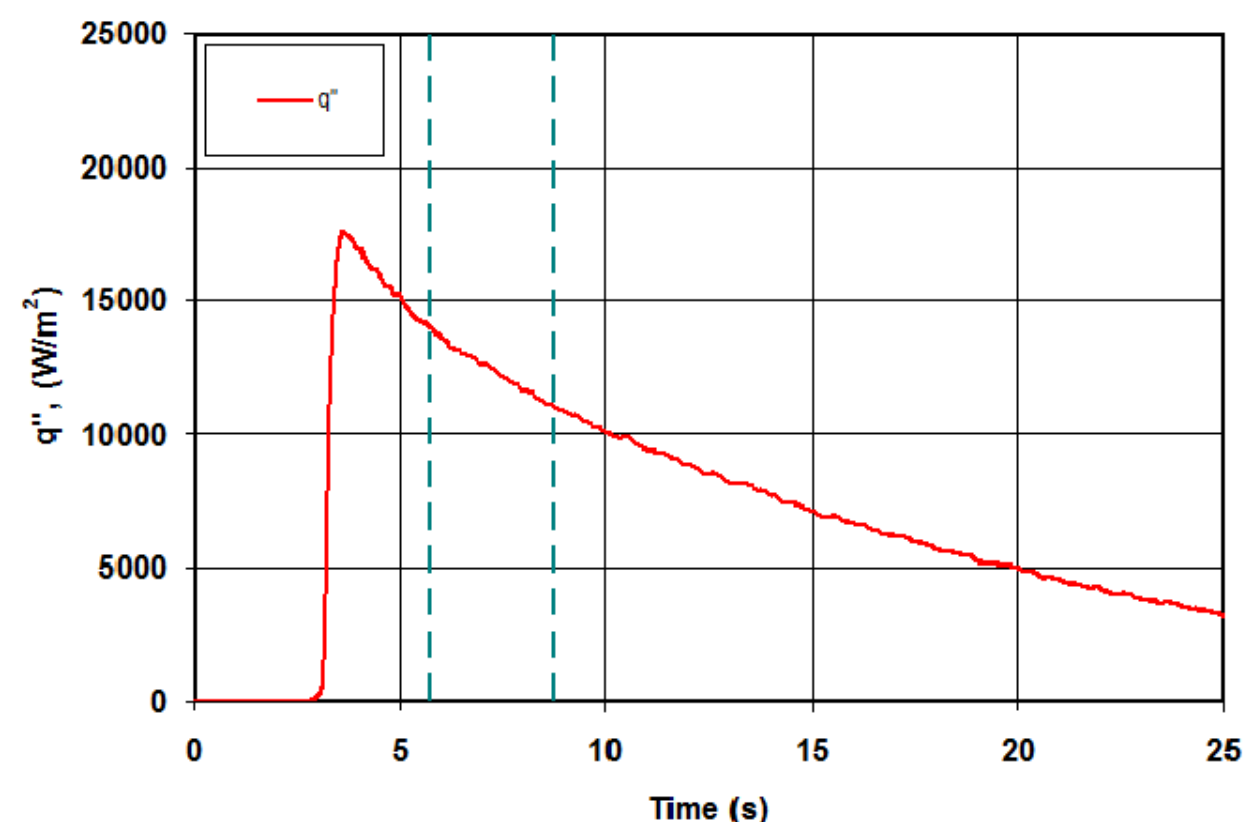

Figure D.3. Gauge 7 heat flux history

\section{Determination of Heat Transfer Coefficient and Adiabatic Effectiveness}

Once heat flux is calculated, the heat transfer coefficient and film cooling effectiveness can be found using the least squares linear regression fit of the following equation. This is Equation 2.5 of Paper 2 in the thesis.

$$
\frac{q^{\prime \prime}}{T_{r}-T_{c}}=h\left(\frac{T_{r}-T_{w}}{T_{r}-T_{c}}\right)-h \eta
$$

where $q$ " is calculated with the single-sided thin film gauge.

Equation D-1 is equivalent to the standard line equation of $y=m x+b$. The nondimensional temperature variable multiplied by $h$ in Equation 2.5 is plotted as the $\mathrm{x}$-axis and the left side of the equation is plotted as the y-axis for the quasi-steady portion of the sample run. The slope of the line fit is the heat transfer coefficient and the $\mathrm{x}$-intercept is the adiabatic film cooling effectiveness - where $q$ " goes to zero. A sample plot demonstrating this technique to measure heat transfer coefficient and film cooling effectiveness for Gauge 7 can be seen in Figure D.4. 


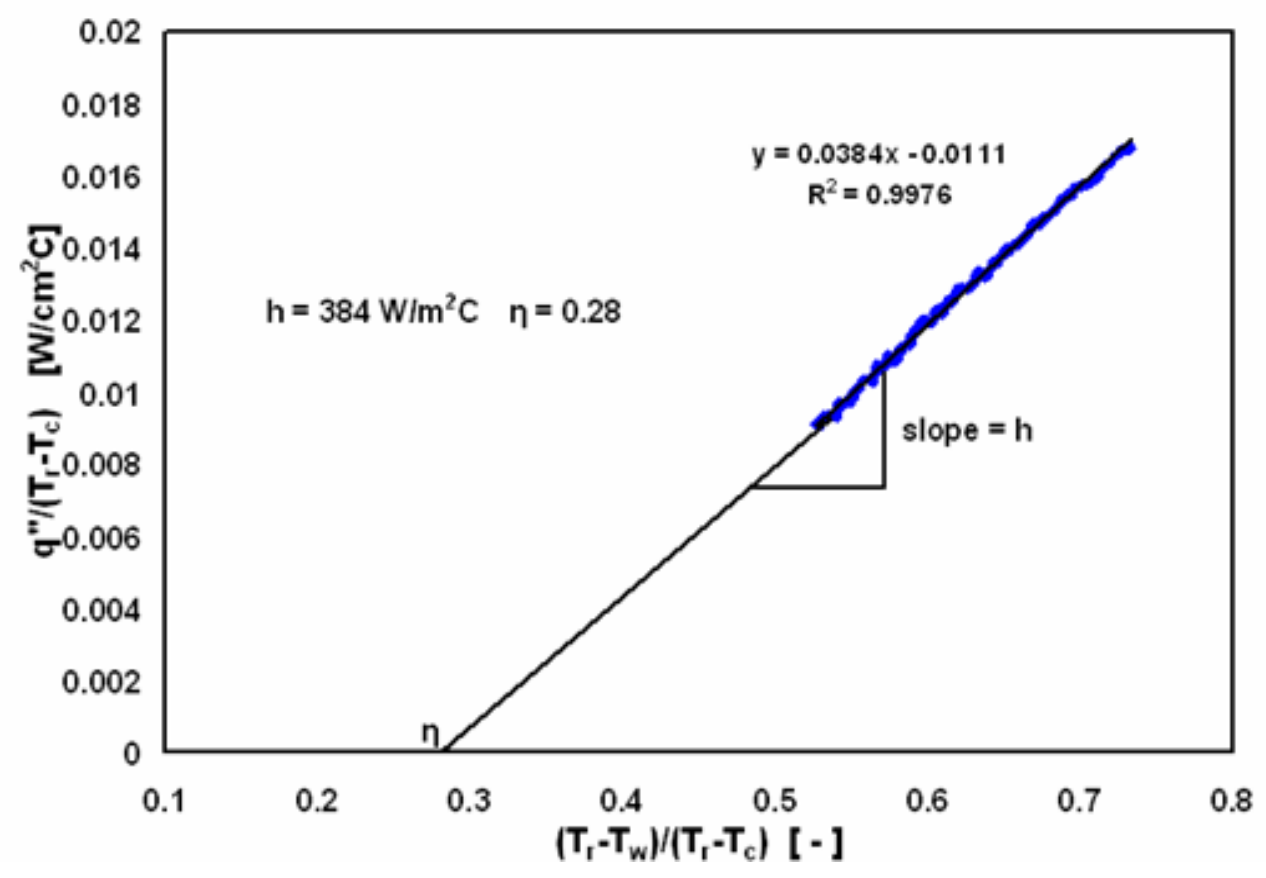

Figure D.4. Determination of $h$ and $\eta$

\section{Determination of Recovery Temperature}

The recovery temperature $\left(T_{r}\right)$ in Equation D-1 is experimentally measured in a high speed flow from the no film injection $(B R=0)$ case. With the $B R=0$ data, the following equation is used to determine $T_{r}$ for the film cooled runs.

$$
q_{0} "=h_{0}\left(T_{o, \infty}-T_{w}\right)-h_{0}\left(T_{o, \infty}-T_{r}\right)
$$

Using Equation D-2, we can determine $h_{0}$ and $T_{r}$ by plotting $q_{0}$ "versus $\left(T_{0, \infty}-T_{w}\right)$ for the quasi-steady portion of the run. The result gives us a line of the form $y=m x+b$ where the slope of the line is heat transfer coefficient without film cooling and the $\mathrm{x}$-intercept of the line is $\left(T_{o, \infty}{ }^{-}\right.$ $\left.T_{r}\right)$. $\left(T_{o, \infty}-T_{r}\right)$ was determined at each measurement location and then used to find the recovery temperature using $T_{o, \infty}$ from the film cooled runs. More explanation of this technique can be seen in Smith et al. [D-2] and Popp et al. [D-3]. A sample plot demonstrating this technique to measure $T_{r}$ for Gauge 7 is shown in Figure D.5. 


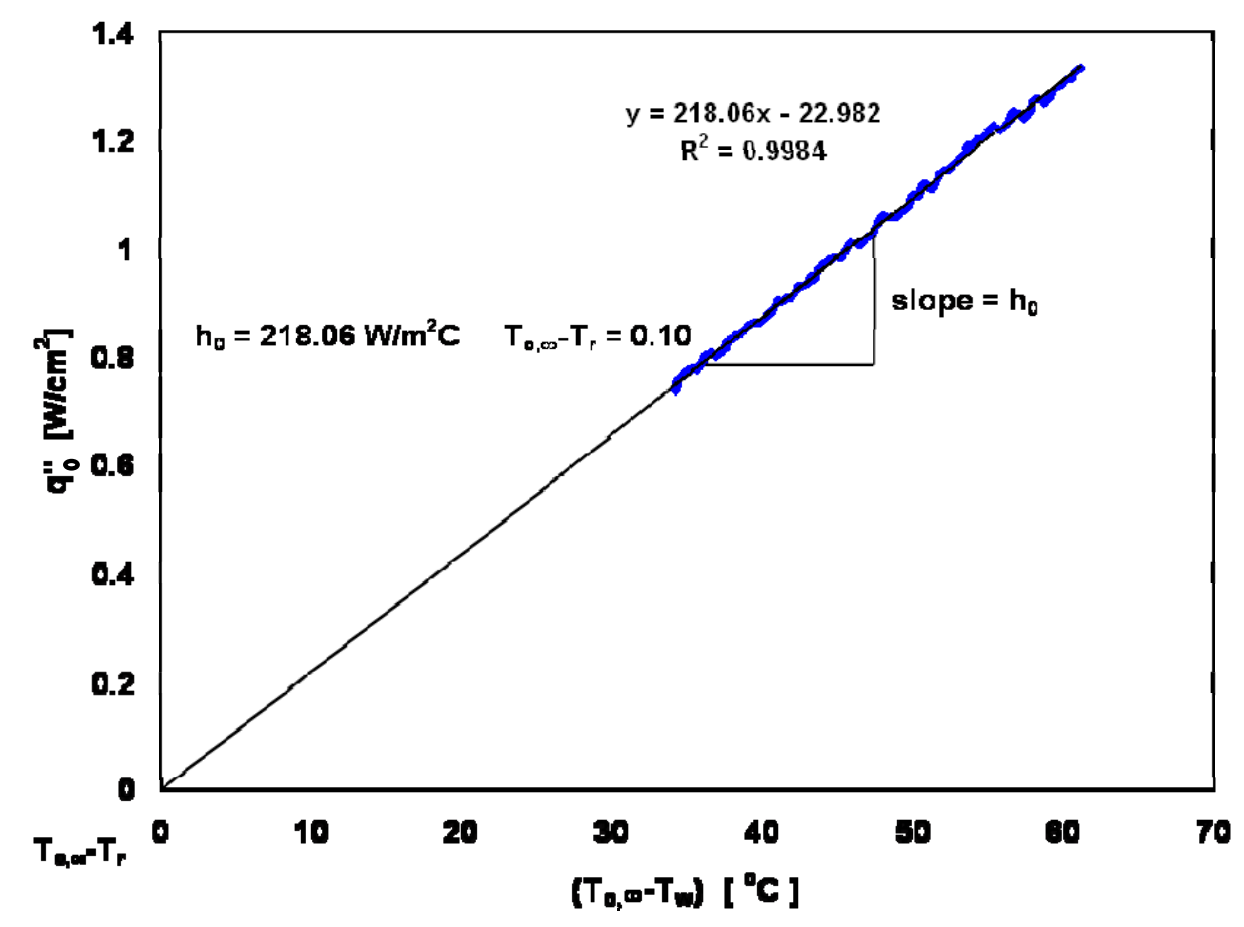

Figure D.5. Determination of $h_{0}$ and $\left(T_{o, \infty}-T_{r}\right)$

\section{References}

[D-1] Cress, R.D., 2006, "Turbine Blade Heat Transfer Measurements in a Transonic Flow Using Thin film Gages,” Master's Thesis, Virginia Polytechnic Institute and State University.

[D-2] Smith, D.E., Bubb, J.V., Popp, O., Grabowski, H.C., Diller, T.E. Schetz, J.A. and Ng. W.F., 2000, "An Investigation of Heat Transfer in a Film Cooled Transonic Turbine Cascade, Part I: Steady Heat Transfer," ASME GT-2000-202.

[D-3] Popp, O., Smith, D.E., Bubb, J.V., Grabowski, H.C., Diller, T.E. Schetz, J.A. and Ng. W.F., 2000, "An Investigation of Heat Transfer in a Film Cooled Transonic Turbine Cascade, Part II: Unsteady Heat Transfer," ASME GT-2000-203. 


\section{Appendix E Uncertainty Analysis - Film Cooling Measurements}

\section{Heat Transfer Coefficient and Adiabatic Effectiveness}

This appendix describes the method used to determine the experimental uncertainty in heat transfer coefficient and film cooling effectiveness for showerhead film cooled vane measurements. As discussed in Papers 2 and 3 of this thesis, the heat transfer coefficient and adiabatic effectiveness from a single transient-temperature blow-down experimental run was determined as the slope and $\mathrm{x}$-intercept of the least-squares line fit of the $\mathrm{x}$ and $\mathrm{y}$ coordinates as shown in Figure E.1.

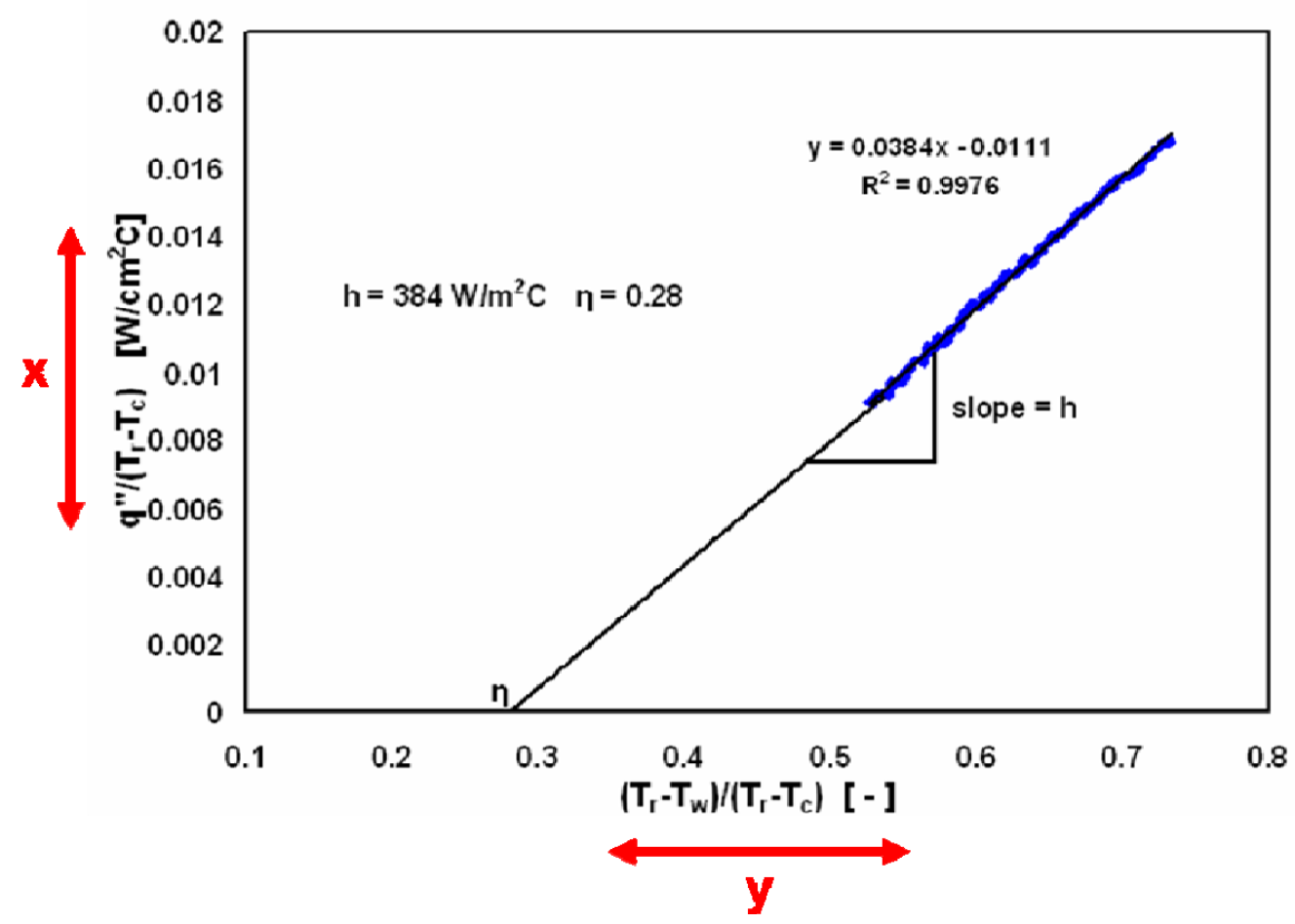

Figure E.1. Determination of $h$ and $\eta$

By the nature of the experiment, each data point shown in Figure E.1 has bias and precision uncertainty in both $x$ and $y$ coordinates. The bias uncertainty is the uncertainty that is constant for a set of measurements. Typical measurement bias uncertainties are due to calibration error, material properties error, thermocouple measurement and acquisition error. The bias uncertainties for the $x$ and $y$ coordinate were determined using the perturbation method described 
by Moffat [E-1]. This method takes into account the error associated with the measurement and tracks the error as it propagates through calculations. The precision uncertainties for the $x$ and $y$ coordinate were determined within a $95 \%$ confidence interval using variance from a line fit instead of the mean.

Knowing the bias and precision uncertainty in $x$ and $y$ coordinates, Brown et al.'s [E-2] method was used to determine the uncertainty in the linear regression. According to Brown et al. the most general form of the expression for the uncertainty in the slope of line, $m$, is:

$$
\begin{aligned}
& U_{m}^{2}=\sum_{i=1}^{N}\left(\frac{\partial m}{\partial Y_{i}}\right)^{2} P_{Y_{i}}^{2}+\sum_{i=1}^{N}\left(\frac{\partial m}{\partial X_{i}}\right)^{2} P_{X_{i}}^{2}+\sum_{i=1}^{N}\left(\frac{\partial m}{\partial Y_{i}}\right)^{2} B_{Y_{i}}^{2}+2 \sum_{i=1}^{N-1} \sum_{k=i+1}^{N}\left(\frac{\partial m}{\partial Y_{i}}\right)\left(\frac{\partial m}{\partial Y_{k}}\right) B_{Y_{i}} B_{Y_{k}} \\
& +\sum_{i=1}^{N}\left(\frac{\partial m}{\partial X_{i}}\right)^{2} B_{X_{i}}^{2}+2 \sum_{i=1}^{N-1} \sum_{k=i+1}^{N}\left(\frac{\partial m}{\partial X_{i}}\right)\left(\frac{\partial m}{\partial X_{k}}\right) B_{X_{i}} B_{X_{k}}+2 \sum_{i=1}^{N} \sum_{k=1}^{N}\left(\frac{\partial m}{\partial X_{i}}\right)\left(\frac{\partial m}{\partial Y_{k}}\right) B_{X_{i}} B_{Y_{k}}
\end{aligned}
$$

A similar expression for the uncertainty in the y-intercept, $c$, is

$$
\begin{aligned}
& U_{c}^{2}=\sum_{i=1}^{N}\left(\frac{\partial c}{\partial Y_{i}}\right)^{2} P_{Y_{i}}^{2}+\sum_{i=1}^{N}\left(\frac{\partial c}{\partial X_{i}}\right)^{2} P_{X_{i}}^{2}+\sum_{i=1}^{N}\left(\frac{\partial c}{\partial Y_{i}}\right)^{2} B_{Y_{i}}^{2}+2 \sum_{i=1}^{N-1} \sum_{k=i+1}^{N}\left(\frac{\partial c}{\partial Y_{i}}\right)\left(\frac{\partial c}{\partial Y_{k}}\right) B_{Y_{i}} B_{Y_{k}} \\
& +\sum_{i=1}^{N}\left(\frac{\partial c}{\partial X_{i}}\right)^{2} B_{X_{i}}^{2}+2 \sum_{i=1}^{N-1} \sum_{k=i+1}^{N}\left(\frac{\partial c}{\partial X_{i}}\right)\left(\frac{\partial c}{\partial X_{k}}\right) B_{X_{i}} B_{X_{k}}+2 \sum_{i=1}^{N} \sum_{k=1}^{N}\left(\frac{\partial c}{\partial X_{i}}\right)\left(\frac{\partial c}{\partial Y_{k}}\right) B_{X_{i}} B_{Y_{k}}
\end{aligned}
$$

The partial derivatives are

$$
\begin{gathered}
\frac{\partial m}{\partial Y_{i}}=\frac{N X_{i}-\sum_{i=1}^{N} X_{i}}{N \sum_{i=1}^{N}\left(X_{i}^{2}\right)-\left(\sum_{i=1}^{N} X_{i}\right)^{2}} \\
\frac{\partial c}{\partial Y_{i}}=\frac{\sum_{i=1}^{N}\left(X_{i}^{2}\right)-X_{i} \sum_{i=1}^{N} X_{i}}{N \sum_{i=1}^{N}\left(X_{i}^{2}\right)-\left(\sum_{i=1}^{N} X_{i}\right)^{2}} \\
\frac{\partial m}{\partial X_{i}}=\frac{N Y_{i}-\sum_{i=1}^{N} Y_{i}}{N \sum_{i=1}^{N}\left(X_{i}^{2}\right)-\left(\sum_{i=1}^{N} X_{i}\right)^{2}}-\frac{\left(N \sum_{i=1}^{N} X_{i} Y_{i}-\sum_{i=1}^{N} X_{i} \sum_{i=1}^{N} Y_{i}\right)\left(2 N X_{i}-2 \sum_{i=1}^{N} X_{i}\right)}{\left(N \sum_{i=1}^{N}\left(X_{i}^{2}\right)-\left(\sum_{i=1}^{N} X_{i}\right)^{2}\right)^{2}}
\end{gathered}
$$


and

$$
\frac{\partial c}{\partial X_{i}}=\frac{2 X_{i} \sum_{i=1}^{N} Y_{i}-\sum_{i=1}^{N} X_{i} Y_{i}-Y_{i} \sum_{i=1}^{N} X_{i}}{N \sum_{i=1}^{N}\left(X_{i}^{2}\right)-\left(\sum_{i=1}^{N} X_{i}\right)^{2}}-\frac{\left(\sum_{i=1}^{N}\left(X_{i}\right)^{2} \sum_{i=1}^{N} Y_{i}-\sum_{i=1}^{N} X_{i} \sum_{i=1}^{N} X_{i} Y_{i}\right)\left(2 N X_{i}-2 \sum_{i=1}^{N} X_{i}\right)}{\left(N \sum_{i=1}^{N}\left(X_{i}^{2}\right)-\left(\sum_{i=1}^{N} X_{i}\right)^{2}\right)^{2}}
$$

where

$\mathrm{B}=$ bias limit

$\mathrm{B}_{\mathrm{ik}}=$ covariance estimator

$\mathrm{c}=\mathrm{y}$-intercept of line

$\mathrm{m}=$ slope of line $(h)$

$\mathrm{N}=$ number of data points

$\mathrm{P}=$ precision limit

$\mathrm{U}=$ uncertainty interval

$\mathrm{X}=$ independent variable

$\mathrm{Y}=$ dependent variable

The uncertainty interval for the $\mathrm{x}$-intercept $(\eta)$ is

$$
U_{\eta}^{2}=U_{m}^{2}+U_{c}^{2}
$$

Covariance estimator was assumed to be negligible in these measurements. The result of Brown's analysis produces an uncertainty in the linear regression's slope and x-intercept which represent the uncertainty in heat transfer coefficient and film cooling effectiveness, respectively. For each test condition, measurements were performed at least three times to establish repeatability. Measurement repeatability for heat transfer coefficient and adiabatic effectiveness was based on a 90\% confidence interval and Student-t distribution. The overall average uncertainty of the heat transfer coefficient was determined to be $\pm 6.5 \%$. Because $\eta$ is determined from extrapolating the data shown in Figure E.1, its uncertainty is larger. The overall average uncertainty in $\eta$ is \pm 0.032 .

Uncertainties in the exit Mach number $\left(\mathrm{M}_{\mathrm{ex}}\right)$, density ratio (DR), and blowing ratio (BR) were determined with Moffat's [E-1] small perturbation method within the $95 \%$ confidence interval. Uncertainty values for intermediate and final results are shown in Table E.1. Samples of 
data plotted with the uncertainty band are provided for heat transfer coefficient and adiabatic effectiveness in Figures E.2 and E.3, respectively.

Table E.1. Uncertainty values

\begin{tabular}{|c|c|}
\hline Value & $\begin{array}{c}\text { Average } \\
\text { Uncertainty }\end{array}$ \\
\hline$q "$ & $\pm 7.6 \%$ \\
\hline$T_{r}$ & $\pm 3^{\circ} \mathrm{C}$ \\
\hline$h$ & $\pm 6.5 \%$ \\
\hline$\eta$ & \pm 0.032 \\
\hline $\mathrm{M}_{\mathrm{ex}}$ & $\pm 1.3 \%$ \\
\hline $\mathrm{DR}$ & $\pm 0.4 \%$ \\
\hline $\mathrm{BR}$ & $\pm 1.4 \%$ \\
\hline
\end{tabular}

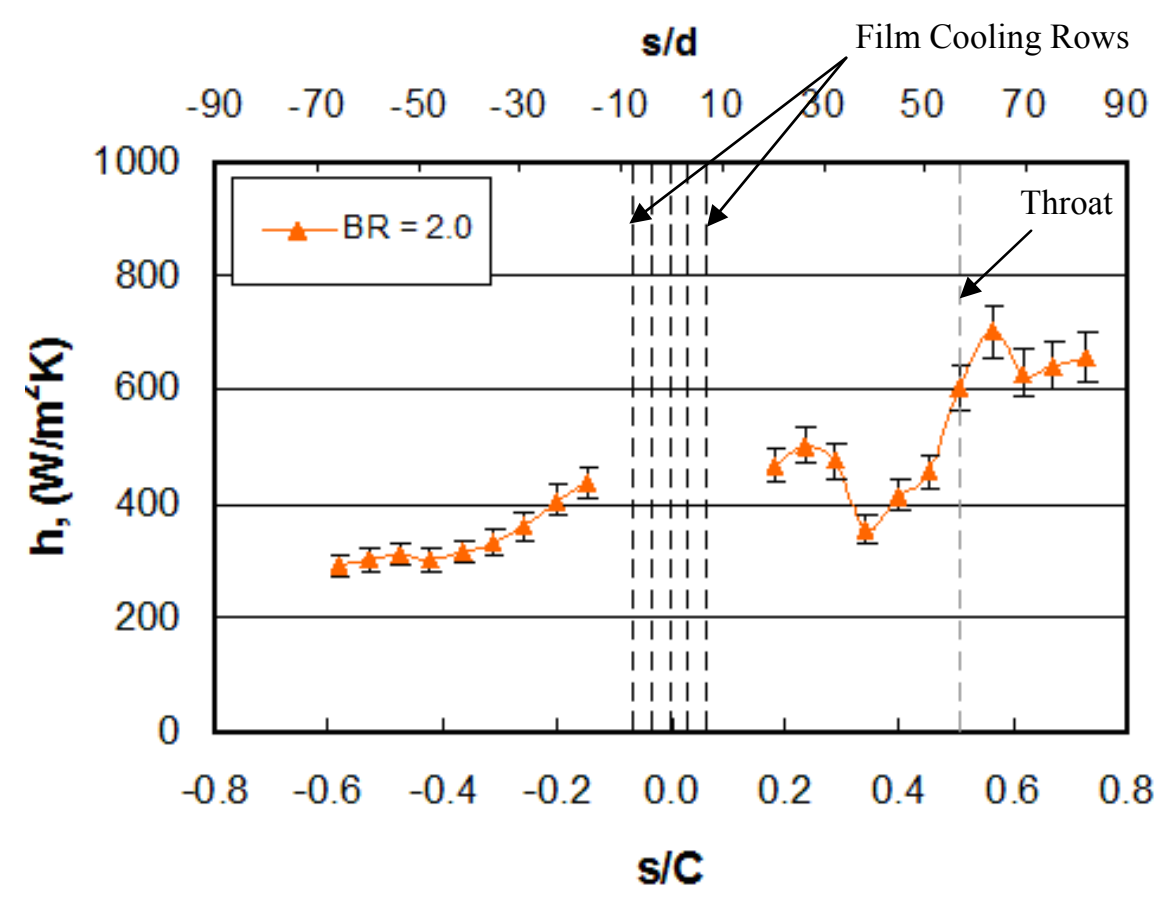

Figure E.2. Showerhead film cooled vane surface heat transfer coefficient distribution with uncertainty band. The data correspond to Figure 2.10 of the thesis 


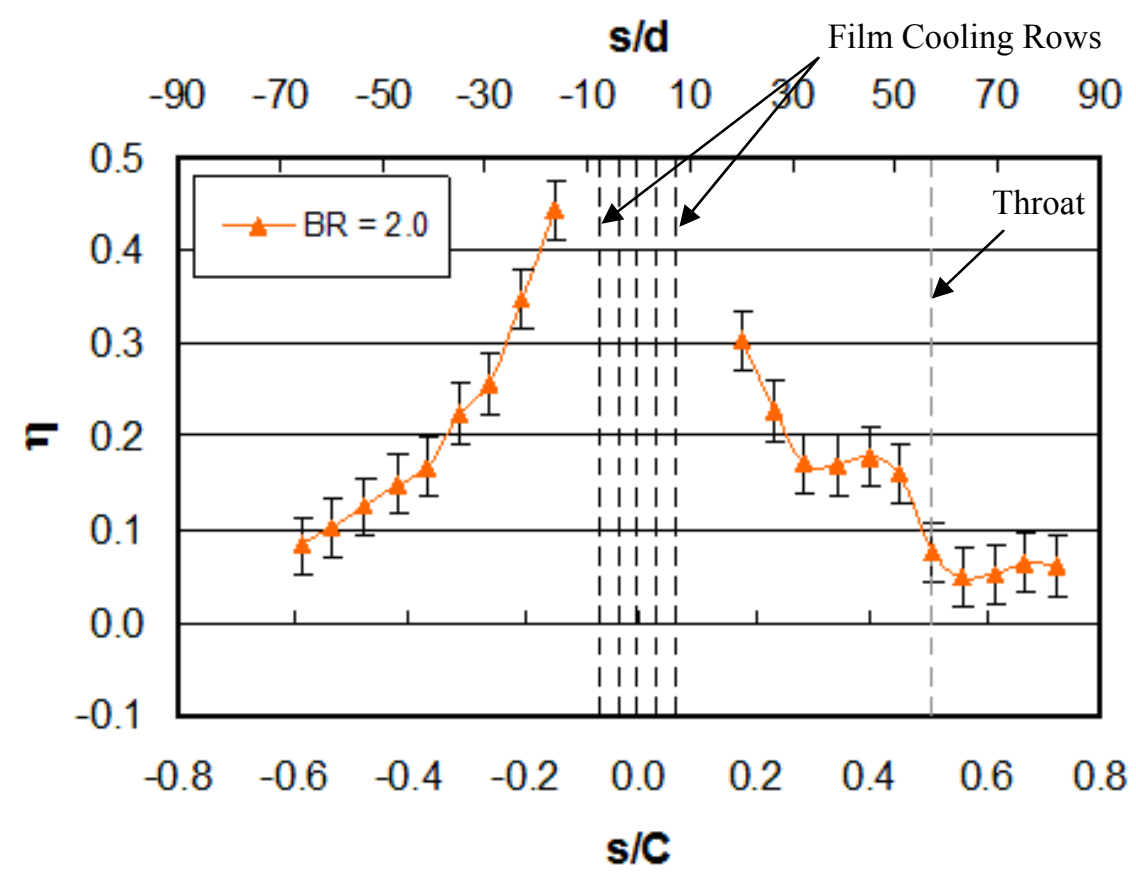

Figure E.3. Showerhead film cooled vane surface adiabatic effectiveness distribution with uncertainty band. The data correspond to Figure 2.13 of the thesis

\section{References}

[E-1] Moffat, R. J., 1988, "Describing Uncertainties in Experimental Results," Exp. Thermal and Fluid Science, 1, pp. 3-17.

[E-2] Brown, K.H., Coleman, H.W., and Steele, W.G., 1995, "Estimating Uncertainty Intervals for Linear Regression," AIAA-1995-0796. 


\section{Appendix F Turbulence Generation and Instrumentation}

This appendix is an updated version of the one reported by Carullo [F-1]. The appendix has been modified for turbine vane cascade turbulence measurements.

\section{Instrumentation}

Turbulence measurements were made with a single-wire hot film. The hot film probe that was used is a TSI 1201 hot film that was connected to a Dantec Type 55M01 anemometer that kept the temperature of the hot film constant by varying the voltage. Hot film and hot wire probes have the same exact operating principals with the wire construction and wire size being the primary difference between the probes. A hot film has a slightly slower response time than the hot wire probe, but is more robust since it has a larger wire size. The output from the Dantec system was passed through the signal conditioner portion of the TSI IFA-100 system. The IFA100 system performed the filtering and added a gain to the signal before the signal was recorded using a Nicolet BE256-LE system.

During hot film calibration, the hot film anemometer output signal was filtered at $400 \mathrm{~Hz}$ using the IFA-100 signal conditioner and sampled at $1000 \mathrm{~Hz}$ with the BE256-LE system. To make the turbulence measurements, the hot film anemometer output signal was filtered at $40 \mathrm{kHz}$ using the IFA-100 signal conditioner and sampled at $100 \mathrm{kHz}$ with the BE256-LE system. The sampling time was adjusted so that the number of samples collected would equal $2^{\mathrm{x}}$, where $\mathrm{x}$ is an integer. Typically data was collected for $0.65 \mathrm{sec}\left(2^{16}\right.$ samples at $\left.100 \mathrm{kHz}\right)$ or $1.31 \mathrm{sec}\left(2^{17}\right.$ samples at $100 \mathrm{kHz}$ ). This number of samples collected was done so that the hot film data could be properly frequency averaged.

\section{Hot Film Calibration}

A calibration of each hot film probe was performed prior to performing a turbulence measurement. The goal of the calibration is to correlate the voltage output of the hot film to the velocity of the flow. The calibration of the hot film was performed with no turbulence grid installed in the wind tunnel. This allowed for the smallest amount of velocity fluctuations in 
which to calibrate the hot film. Using a Pitot static probe, the total and static pressure of the flow were measured using MKS 223B pressure transducers. An air probe type-T thermocouple was used to measure the total temperature of the flow upstream of the test section. An ice bath was used as a reference temperature for the thermocouple. The voltage output of the hot film, pressure transducers and the thermocouple were all sampled at $1 \mathrm{kHz}$ using the BE256-LE system for 60 seconds. The tunnel was run for roughly 40 seconds so that hot film could be calibrated over a range of velocities.

The static and total pressures were used to calculate the Mach number of the flow using isentropic flow equation. With the Mach number and the total temperature, the static temperature of the flow is given by,

$$
T=\frac{T_{o}}{1+\frac{\gamma-1}{2} \cdot M a^{2}}
$$

where $\gamma$ is the specific heat ratio, Ma is the Mach number of the flow and $\mathrm{T}_{\mathrm{o}}$ is the total temperature of the flow. The Pitot probe flow velocity can be found as,

$$
U=M a \cdot \sqrt{\gamma \cdot R \cdot T}
$$

where $\mathrm{R}$ is the gas constant of air and $\mathrm{T}$ is the static temperature of the flow. The density of the flow was found by using the ideal gas equation as,

$$
\rho=\frac{p}{R \cdot T}
$$

where $p$ is the static pressure of the flow. Empirical correlations were used to estimate the dynamic viscosity as a function of temperature. With the flow data, the instantaneous film Reynolds number was found using,

$$
\operatorname{Re}=\frac{\rho \cdot U \cdot d_{w}}{\mu}
$$

where $d_{w}$ is the diameter of the hot film and $\mu$ is the dynamic viscosity.

The voltage output of the hot film was converted into a Nusselt number by using the following steps. The mean temperature of the hot wire was calculated by,

$$
T_{m}=\frac{T+T_{w}}{2}
$$


where $T$ is the static temperature and $T_{w}$ is the hot wire temperature. The flow properties are calculated at this mean temperature. The hot film temperature is given by,

$$
T_{w}=\frac{R_{o p}-R_{0}}{R_{c}} \cdot 100
$$

The hot film temperature is a function of operating resistance, $\mathrm{R}_{\mathrm{op}}$, the hot film probe resistance at $0^{\circ} \mathrm{C}, \mathrm{R}_{\mathrm{c}}$, and the change in hot film probe resistance from $0^{\circ} \mathrm{C}$ to $100^{\circ} \mathrm{C}, \mathrm{R}_{0} . \mathrm{R}_{\mathrm{c}}$ and $\mathrm{R}_{0}$ were supplied by the hot film manufacture and the operating resistance is set by the user. With the temperatures, probe voltage output and thermal conductivities of air, a modified Nusselt number can be calculated by using,

$$
N u^{\prime}=\frac{V^{2}}{k \cdot\left(T_{m}-T\right)} \cdot\left(T_{m}-T\right)^{-0.17}
$$

This Nusselt number is referred to as a modified Nusselt number because it is not nondimensionalized. The thermal conductivity, $k$, of air was calculated using an empirical equation that is a function of temperature,

The data from the hot film measurements were then used to plot a calibration curve of wire Reynolds number and the modified Nusselt number. The data was then curve fit with a power law to give a following equation:

$$
N u^{\prime}=A \cdot \operatorname{Re}^{B}
$$

where A and B are calibration constants. A calibration was performed for each probe. Probes were calibrated shortly before they were used to make turbulence measurements. This calibration procedure is similar to the procedure used by Nix [F-2]. A sample calibration curve is provided in Figure F.1. 


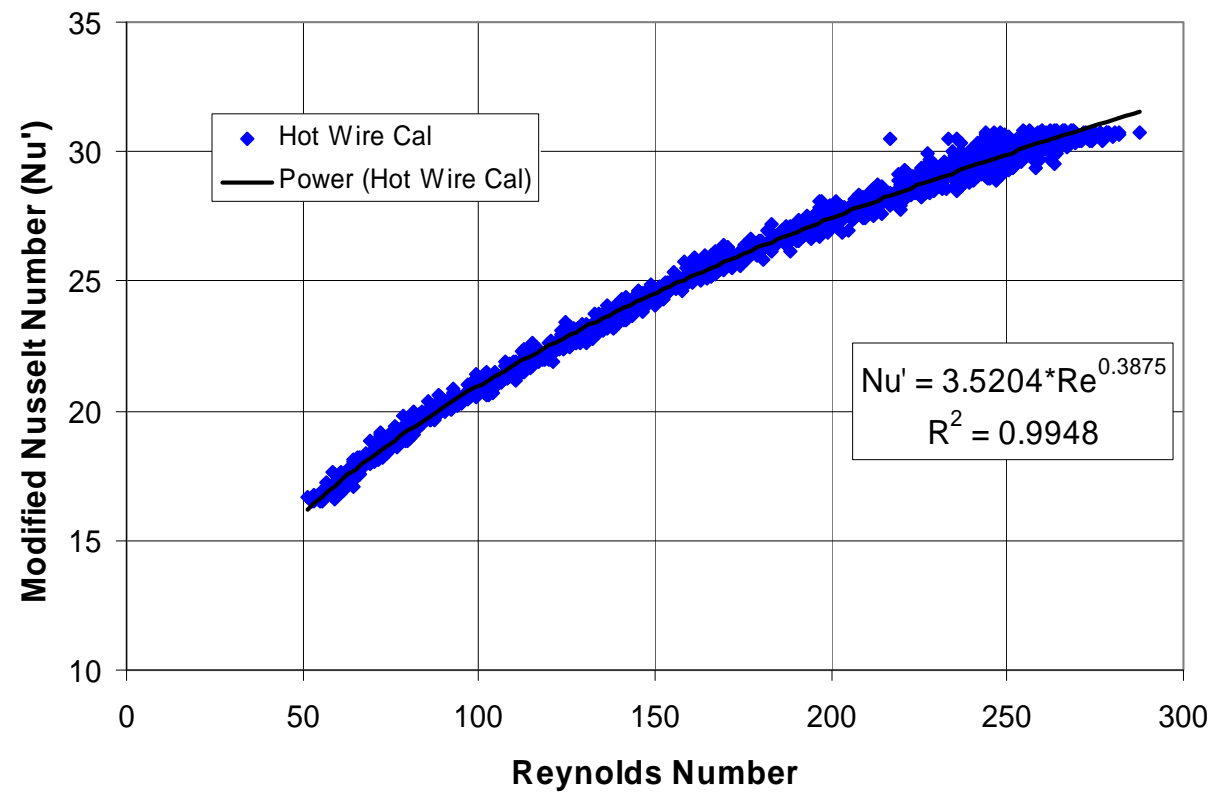

Figure F.1. Plot of the calibration curve of a hot film (Courtesy of Carullo [F-1])

\section{Turbulence Grid}

To generate freestream turbulence levels of $16 \%$, a passive square mesh turbulence grid was used. A schematic of the turbulence grid is provided in Figure F.2. The grid design was based on the correlations reported by Baines and Peterson [F-3] and research performed by Nix et al. [F-2] on turbulence grids in the VT cascade wind tunnel. The square mesh grid has bar widths of $\mathrm{B}=1.91 \mathrm{~cm}(0.75$ in.) and spaced to create $3.81 \mathrm{~cm} \times 3.81 \mathrm{~cm}(1.5$ in. $\times 1.5$ in.) square openings. The porosity of the square mesh grid is $52 \%$.

The location of turbulence grid relative to the test section is provided in Figure F.3. The turbulence grid is oriented so that the flow is perpendicular to the grid bars. The mesh grid was placed downstream of the two-dimensional contraction with a spacer (1.25 in. thick) placed between the contraction and test section. The nondimensional streamwise distance from turbulence grid to the turbulence measurement slot is given by $\mathrm{x} / \mathrm{B}=16$. 


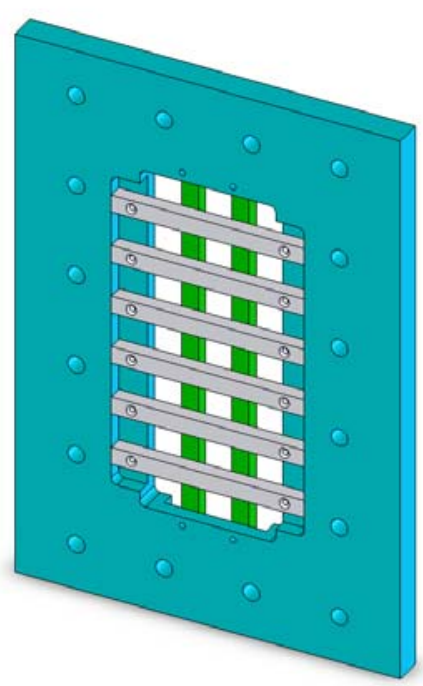

Figure F.2. Square mesh turbulence grid

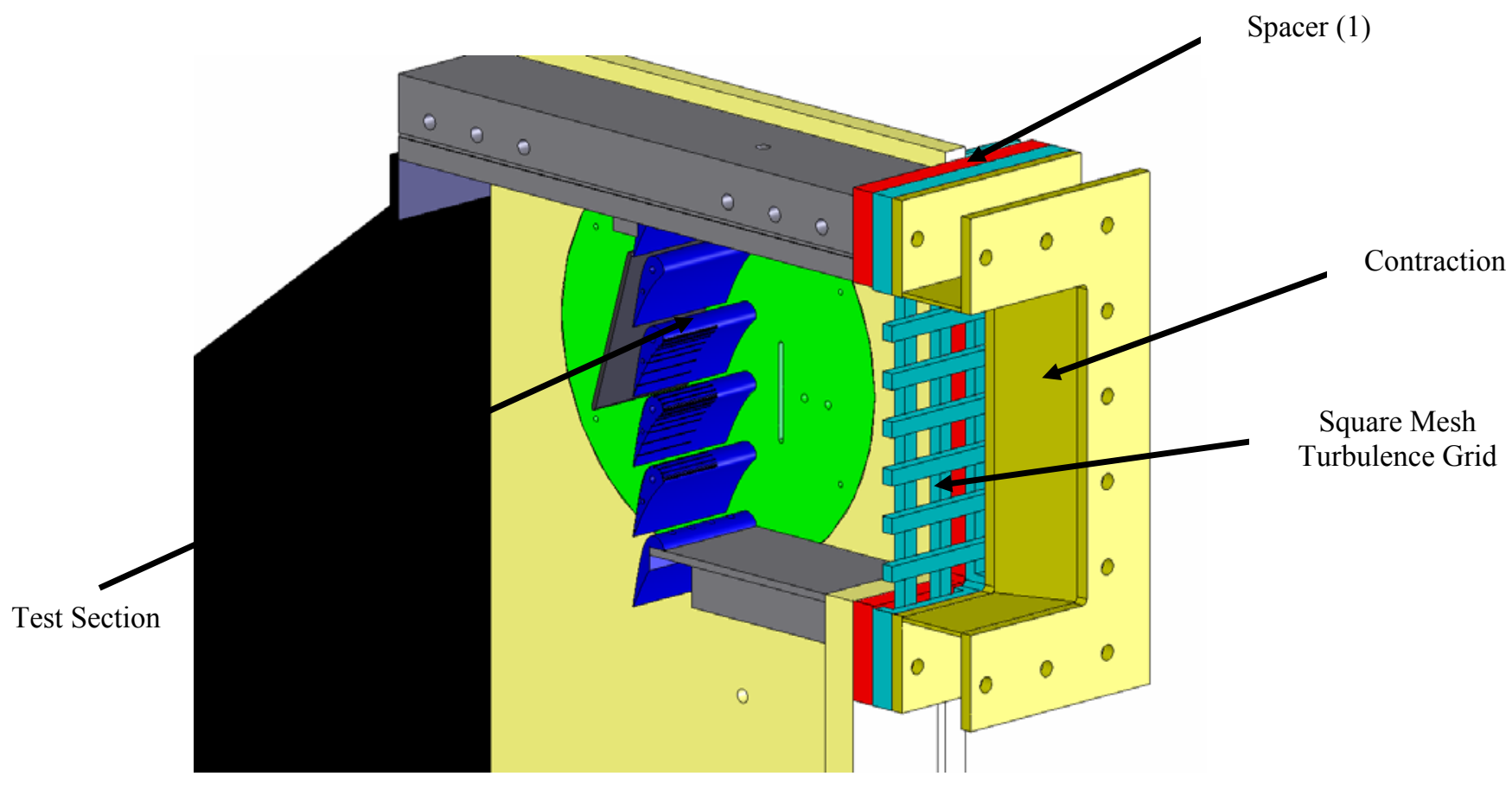

Figure F.3. Schematic showing the position of the square mesh turbulence grid relative to the test section 


\section{Turbulence Measurements}

Inlet freestream turbulence in the transonic turbine vane cascade with and without the square mesh grid is measured using a single hot film probe. To account for the compressibility effects, the hot film was calibrated in the transonic wind tunnel through a blow-down calibration method. The hot film measured the streamwise instantaneous velocity of the flow and from the instantaneous velocity, the freestream turbulence levels and turbulence integral length scales could be calculated. In a single run, the hot film probe was traversed to five discrete locations to measure the instantaneous velocity at each location. The probe traversed a full vane pitch with the center of the traverse located at the leading edge of the middle vane. Measurements were made in the single vertical slot upstream of the vane passage. The slot is spaced 0.45 chords upstream of the vane row. The chord of the $1.5 \mathrm{x}$ scale vane is $3.591 \mathrm{in}$. The location of the slot relative to the vanes is shown in Figure F.4.

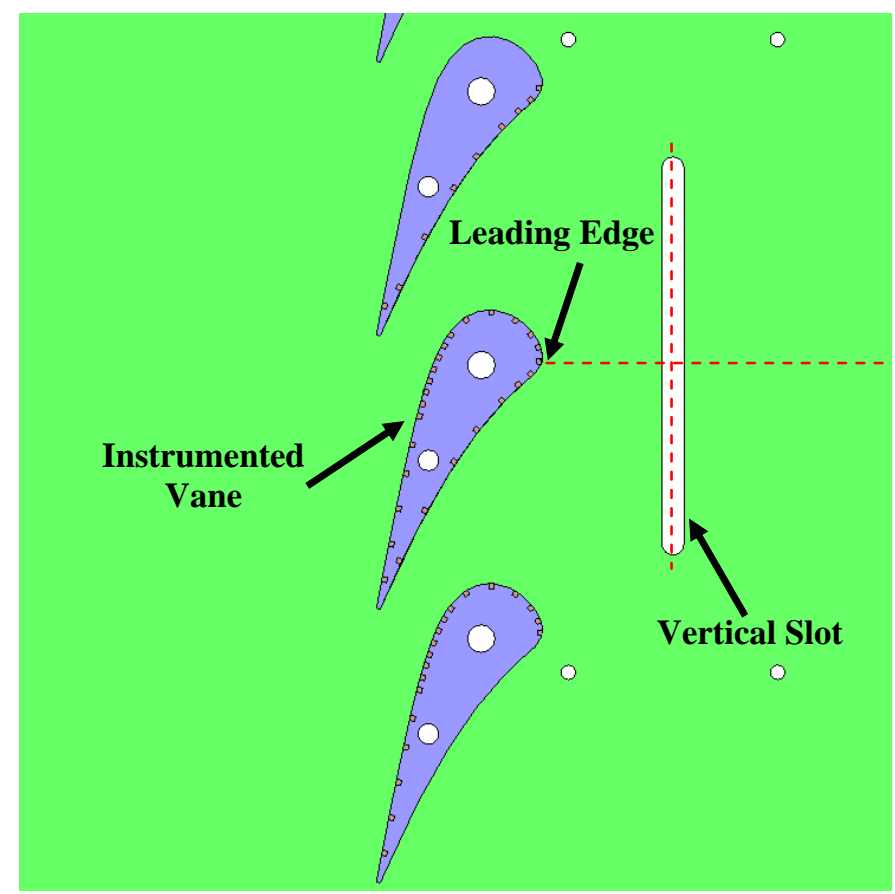

Figure F.4. Schematic showing the location of the measurement slot in the test section

After making the measurements with the hot film, the voltage signal was converted into an instantaneous velocity by applying the hot film calibration using the same procedure as described by Nix [F-2] and Sauer [F-4]. With the instantaneous velocity, the mean velocity could be calculated using, 


$$
U=\frac{1}{N} \cdot \sum_{i=1}^{N} \tilde{u}_{i}
$$

where $\mathrm{N}$ is the total number of samples and $\tilde{u}$ is the instantaneous velocity. RMS of the fluctuating velocity component was then calculated by,

$$
u^{\prime}=\sqrt{\frac{1}{N} \cdot \sum_{i=1}^{N}\left(\tilde{u}_{i}-U\right)^{2}}=\sqrt{\frac{1}{N} \cdot \sum_{i=1}^{N} u_{i}^{2}}
$$

With the mean velocity and the RMS of the fluctuating component of velocity, the streamwise turbulence intensity of the flow could be calculated as,

$$
T u=\frac{u^{\prime}}{U} \cdot 100
$$

A sample instantaneous velocity measurement is provided in Figure F.5 and the corresponding velocity histogram is show in Figure F.6.

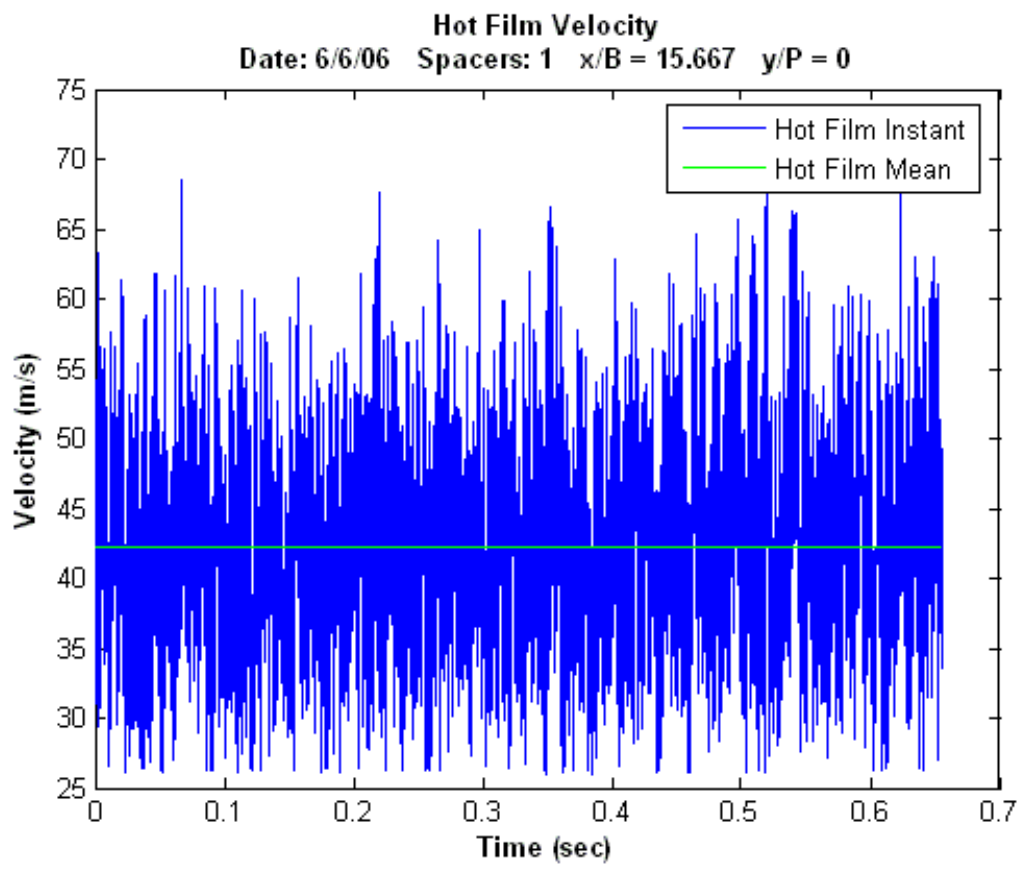

Figure F.5. Sample time history of the instantaneous velocity measured by hot film probe 


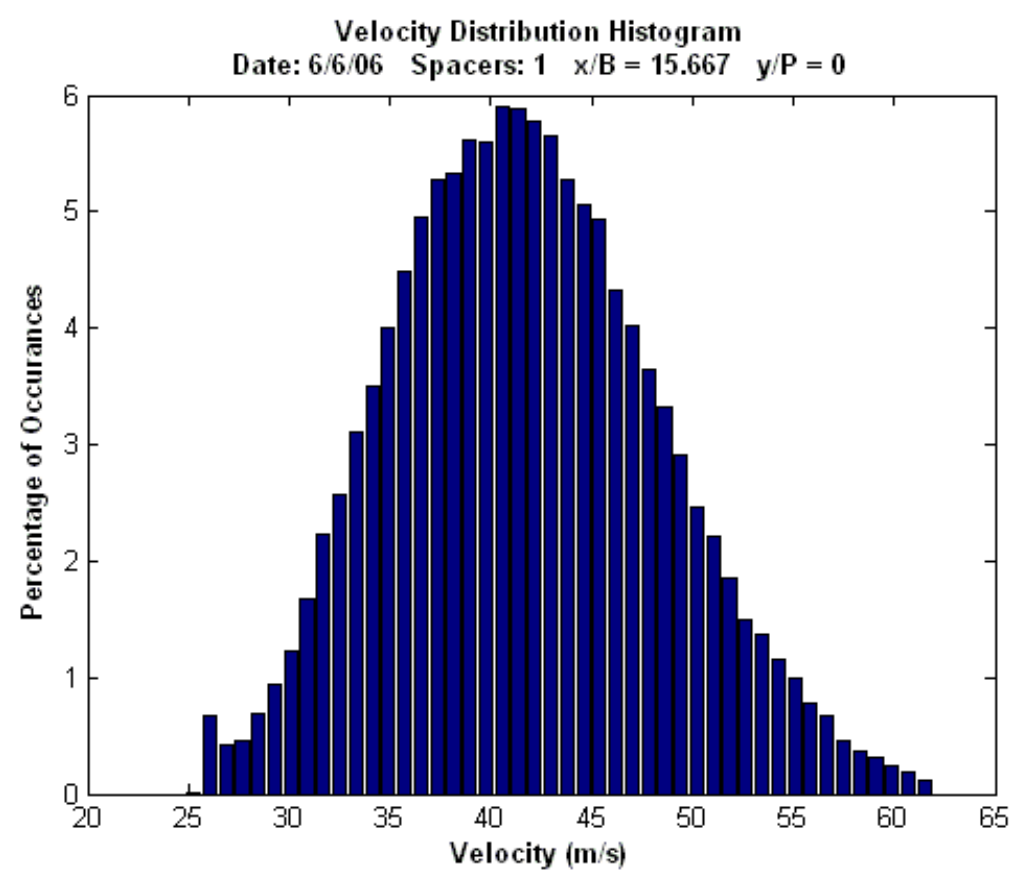

Figure F.6. Sample plot of the velocity histogram of the flow

The power spectral density (PSD) of the hot film velocity signal was also calculated to analyze the energy and frequency content of the flow. The PSD can also be used to estimate the integral length scale of the most energetic eddies in the flow field. The PSD was calculated by breaking the total number of samples into equal parts and performing a fast Fourier transform (FFT) on each part of the total signal using the FFT function (fft) in Matlab. The FFT on each part of the signal was then averaged to get the average FFT. The FFT is divided by the frequency resolution to get the power spectral density. The PSD of the hot film velocity signal measured at five discrete locations during a full vane pitch traverse along the vertical slot is shown in Figure F.7. The PSD levels and frequency content look very similar for all five discrete locations along the vertical slot located $0.45 \mathrm{C}$ upstream of the vane cascade. 


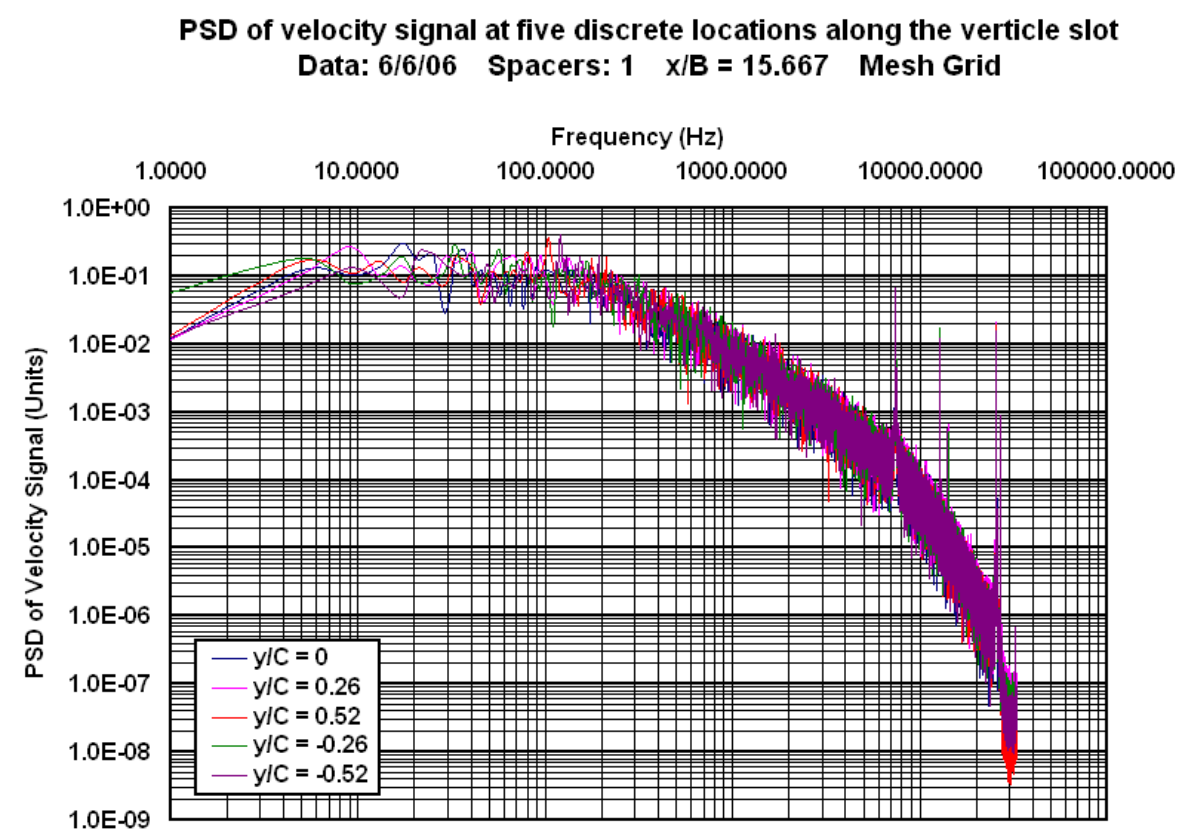

Figure F.7. PSD of velocity signal at discrete location along vertical slot

The PSD was also normalized and compared to the theoretical one dimensional isotropic Von Karman spectrum. According to McComb [F-5], 3-D isotropic flow occurs when each of the three fluctuating velocity components are invariant due to the arbitrary rotation of the defining principal axis i.e. $\overline{u v}=\overline{v w}=\overline{u w}$. The Von Karman relation for isotropic turbulence as reported by Hinze $[\mathrm{F}-6]$ and Nix $[\mathrm{F}-1]$ is provided by,

$$
\frac{E(f) \cdot U}{u^{\prime 2} \cdot \Lambda_{x}}=4 \cdot\left(1+\left(\frac{8 \pi f \cdot \Lambda_{x}}{3 \cdot U}\right)^{2}\right)^{-\frac{5}{6}}=4 \cdot\left(1+\left(\frac{\kappa}{\kappa_{e}}\right)^{2}\right)^{-\frac{5}{6}}
$$

where $\mathrm{E}(\mathrm{f})$ is the power spectral density of the fluctuating component of velocity, $f$ is the frequency, $\Lambda_{\mathrm{x}}$ is the turbulence length scale, $\kappa$ is the wave number, and $\kappa_{e}$ is the most energetic wave number. The wave number and the most energetic wave number are defined as,

$$
\begin{gathered}
\kappa=\frac{2 \pi f}{U} \\
\kappa_{e}=\frac{3}{4 \cdot \Lambda_{x}}
\end{gathered}
$$

Figure F.8 shows a sample plot of a normalized PSD compared to the theoretical Von Karman spectrum. The normalized PSD compares reasonably well to the theoretical Von 
Karman spectrum. Both spectrums begin to roll off at the same frequency and heave a very similar slope in the sub-inertial range up to $\kappa . \Lambda_{\mathrm{x}} \approx 1$.0. Isotropic turbulence should have a slope of $-5 / 3$ in the sub-inertial range of the PSD. This indicates that the flow generated by this particular turbulence grid tends to be isotropic. The three spikes in the signal in high frequency region are present for each turbulence measurement and occur at the same frequency in each run. These spikes are not caused by the flow but rather the anemometer or the hot film probe.

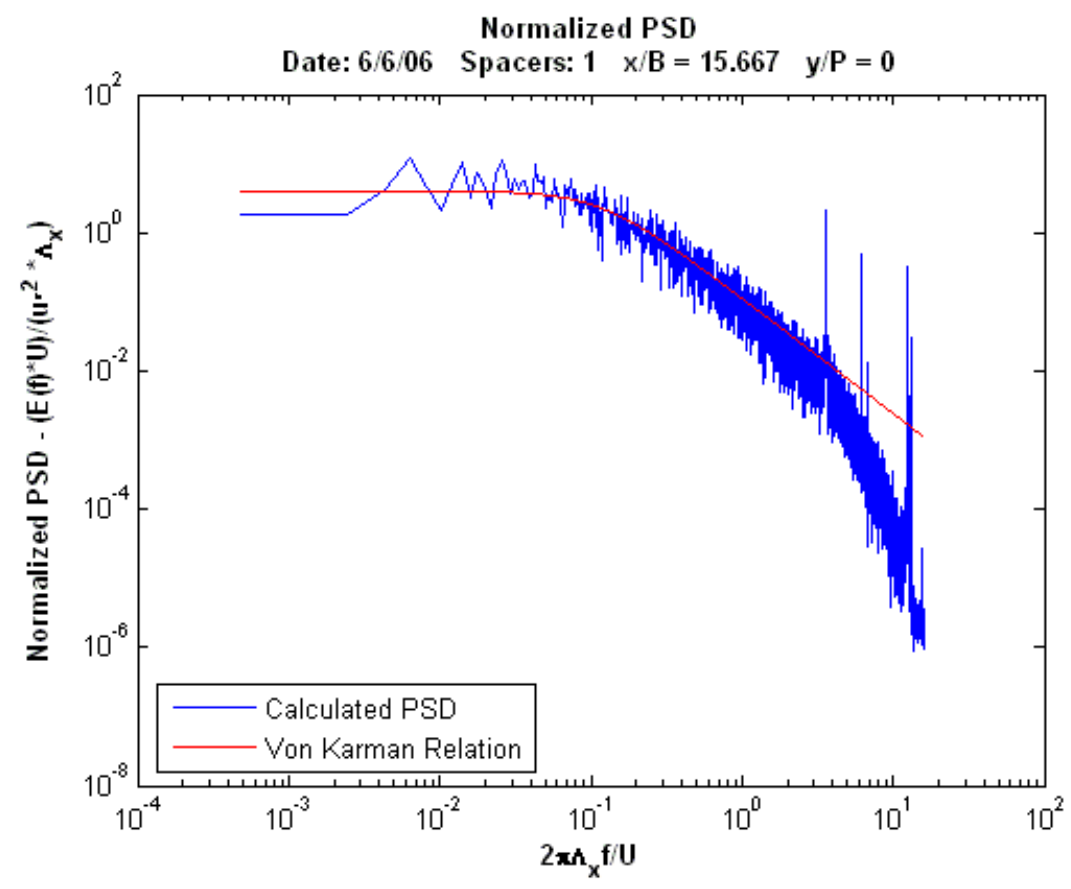

Figure F.8. Plot of the normalized power spectral density

Another way to ascertain isotropic grid generated turbulence is to examine the statistical measure of skewness of fluctuating velocity component [F-7]. According to McComb [F-5], skewness is defined as:

$$
\text { skewness }=\frac{\frac{1}{N} \cdot \sum_{i=1}^{N} u^{3}}{\left(u^{\prime 2}\right)^{3}}
$$

In statistical terms, skewness is a measure of asymmetry or tendency for a particular fluctuating value to be greater or less than the mean. In theory, the skewness of the fluctuating component of the hot film velocity should approach zero in an isotropic flow. A typical value of skewness of hot film fluctuating velocity was found to be 0.000909 . 
In addition to calculating the freestream turbulence at the vane cascade inlet, the integral turbulence length scale was also calculated. The integral turbulence length scale is representative of the size of the most energetic eddies in the flow field. The integral length scale is determined by evaluating the autocorrelation coefficient of the fluctuating component of the hot film velocity signal, which is given by,

$$
R_{11}(\tau)=\left(\frac{\overline{u(t) \cdot u(t+\tau)}}{u^{\prime 2}}\right)=\frac{1}{N}\left(\frac{\sum_{i=1}^{N} u_{i} u_{i+j}}{u^{\prime 2}}\right) \quad \text { where } \tau=j \cdot \Delta t
$$

In the limit as $\tau$ goes to zero (zero time lag), the value of the normalized autocorrelation is equal to the square of the RMS of the fluctuating velocity signal. The autocorrelation function (xcorr) in Matlab was used to perform the autocorrelation on the signal. A sample plot of the autocorrelation is provided in Figure F.9.

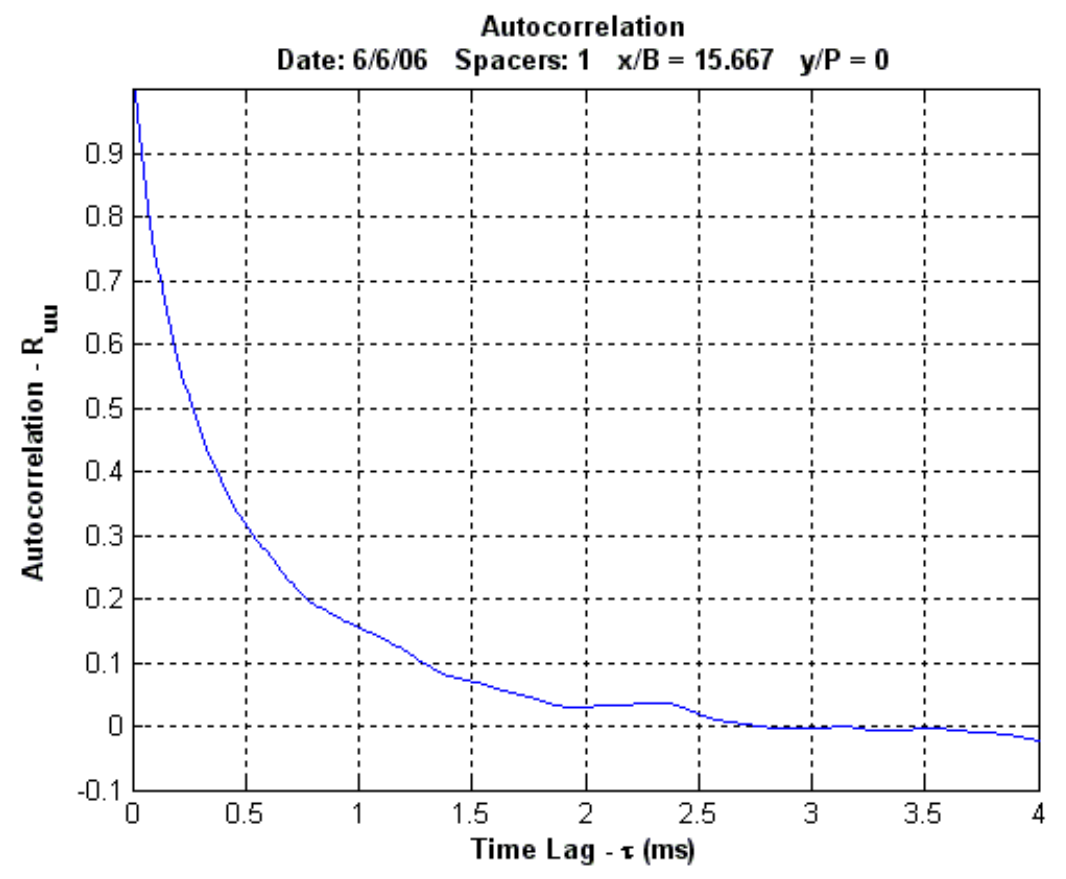

Figure F.9. Plot of the autocorrelation for the hot film signal

The integral time scale $(T)$ was determined by integrating the autocorrelation curve to the first zero crossing as,

$$
T=\int_{t=0}^{\infty} R_{11}(\tau) d \tau \cong \sum_{i=1}^{N_{0}} R_{11 i} \cdot \Delta \tau
$$


where $\mathrm{N}_{0}$ is the point of first zero crossing. Using Taylor's hypothesis of frozen turbulence, the streamwise integral length scale is determined by multiplying the mean velocity of the flow field to the integral time scale as,

$$
\Lambda_{x}=U \cdot T
$$

To normalize the integral length scale, the length scale was divided by the pitch of the vane. The turbulence levels and length scales were measured for the square mesh grid and a baseline case where no turbulence grid was installed in the tunnel.

\section{Turbulence Results}

The turbulence intensity and length scale variations along the inlet pitch for the baseline, square mesh grid and the bar grid are provided in Figures F.10 and F.11. Since there is variation in the turbulence levels and lengths scales across the inlet pitch, the data was averaged. The baseline case with no turbulence grid has a turbulence intensity of $2.1 \%$ and a nondimensional length scale of 0.05 . The square mesh grid generates a turbulence intensity of $15.7 \%$ and a nondimensional length scale of 0.23 . The summary of turbulence measurements is provided in Table F.1.

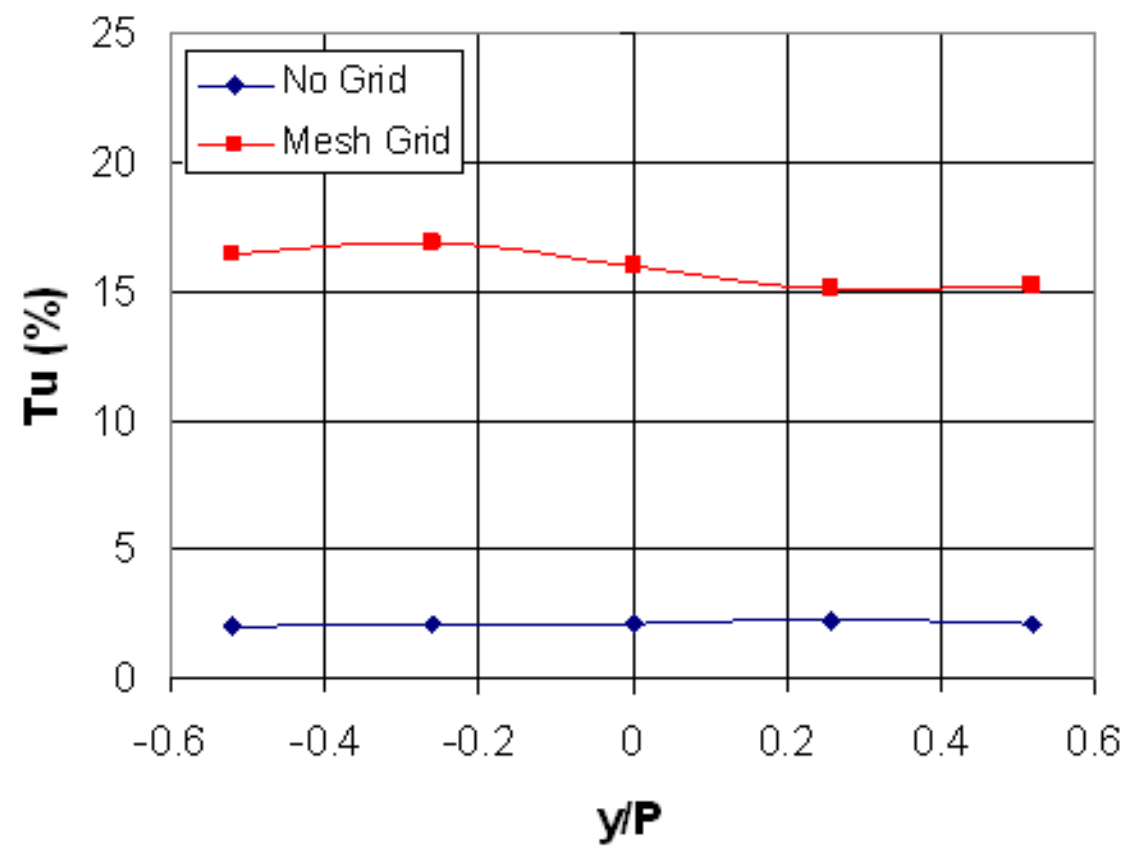

Figure F.10. Turbulence intensity along inlet pitch 


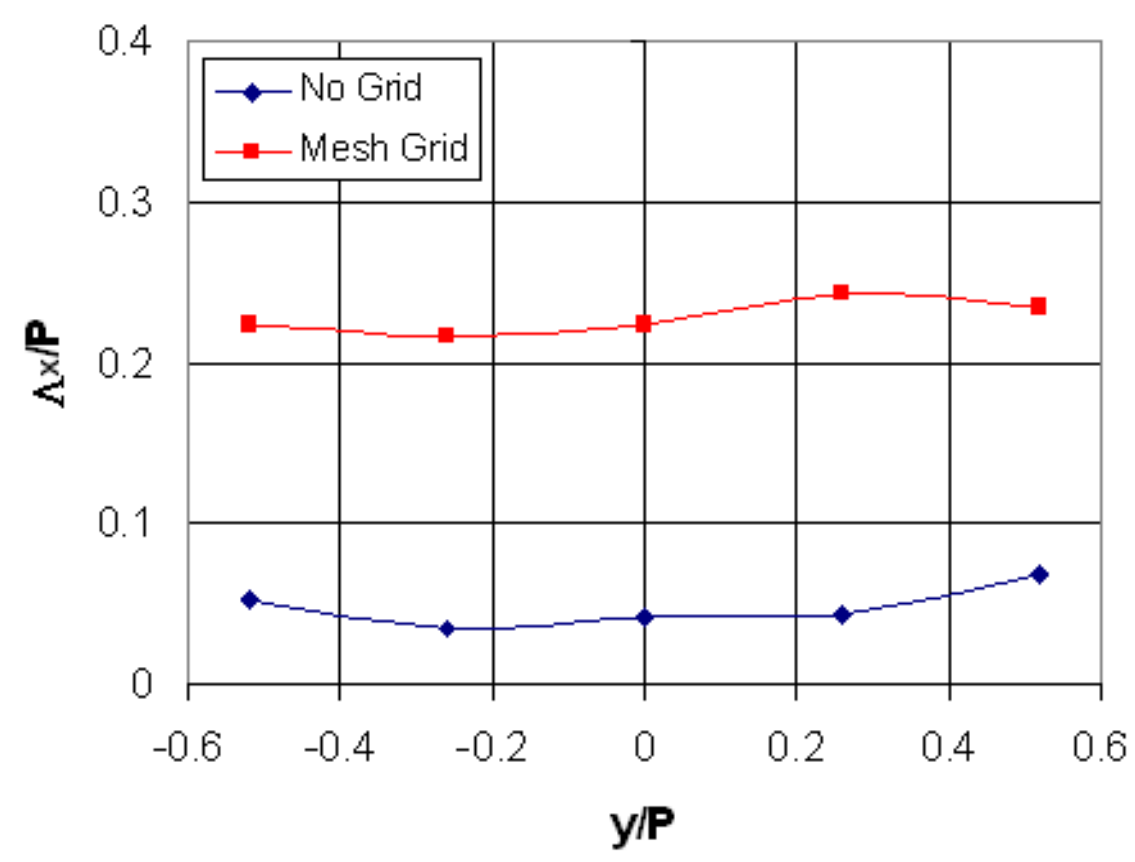

Figure F.11. Turbulence length scale along inlet pitch

Table F.1. Summary of grid generated turbulence

\begin{tabular}{|c|c|c|}
\hline & Tu Intensity & $\begin{array}{c}\text { Length Scale } \\
\left(\Lambda_{\mathrm{x}} / \mathrm{P}\right)\end{array}$ \\
\hline Baseline & $2 \%$ & 0.05 \\
\hline Mesh Grid & $16 \%$ & 0.23 \\
\hline
\end{tabular}

The turbulence intensity and length scale measurements were also compared to the literature correlations for grid generated turbulence in the streamwise direction using the coefficient values reported by Roach [F-8]. The turbulence decay correlation for the mesh grid geometry is given by,

$$
T u=1.13 \cdot\left(\frac{x}{B}\right)^{-5 / 7}
$$

and the length scale dispersion for the mesh grid geometry is provided by,

$$
\frac{\Lambda_{x}}{B}=0.2 \cdot\left(\frac{x}{B}\right)^{1 / 2}
$$

The turbulence decay for the two measurement locations seem to compare reasonably well with correlation as shown in Figure F.12. The dispersion of integral length scale for the two measurement locations downstream of the mesh gird is provided in Figure F.13. The measured 
turbulence length scales are above the correlation and do not show dispersion at the two measurement locations downstream of the grid. Nix [F-2] also observed that the measured turbulence length scales downstream of a bar grid $(B=2$ in) were above the correlation in the transonic wind tunnel facility.

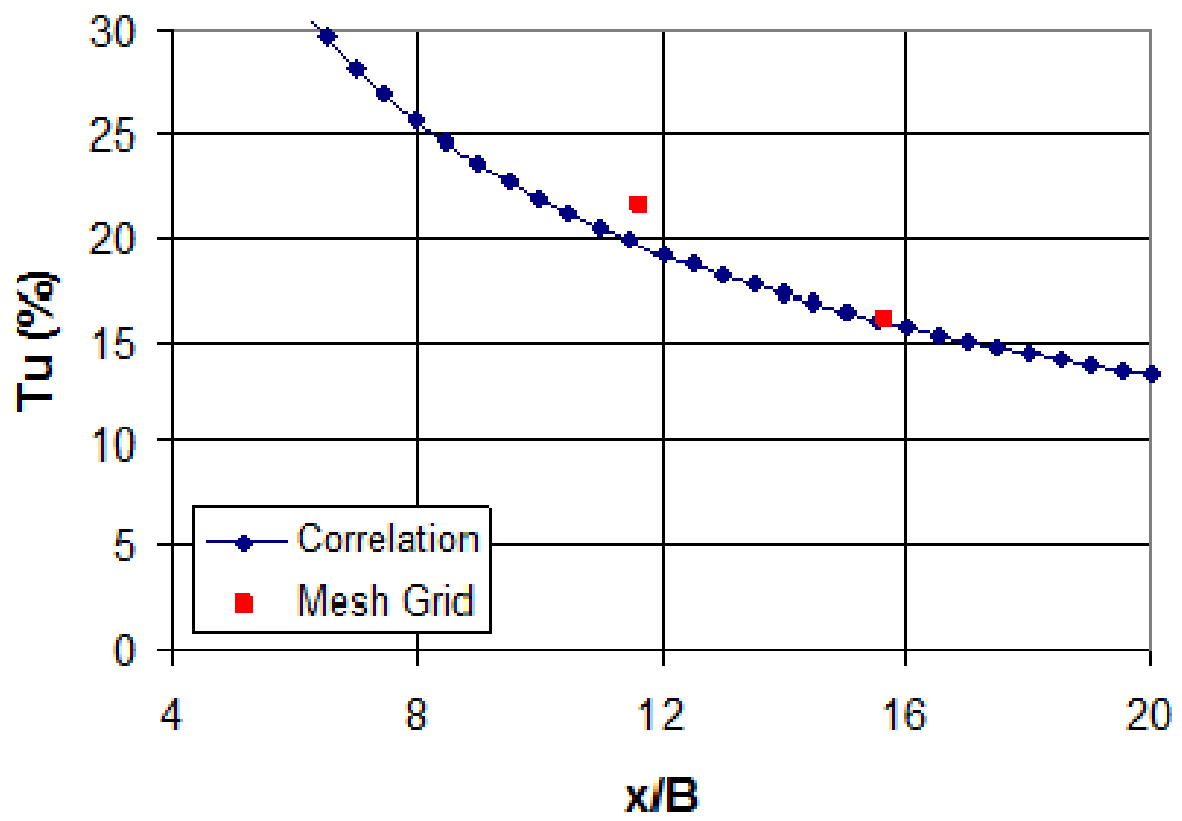

Figure F.12. Turbulence decay from the mesh grid

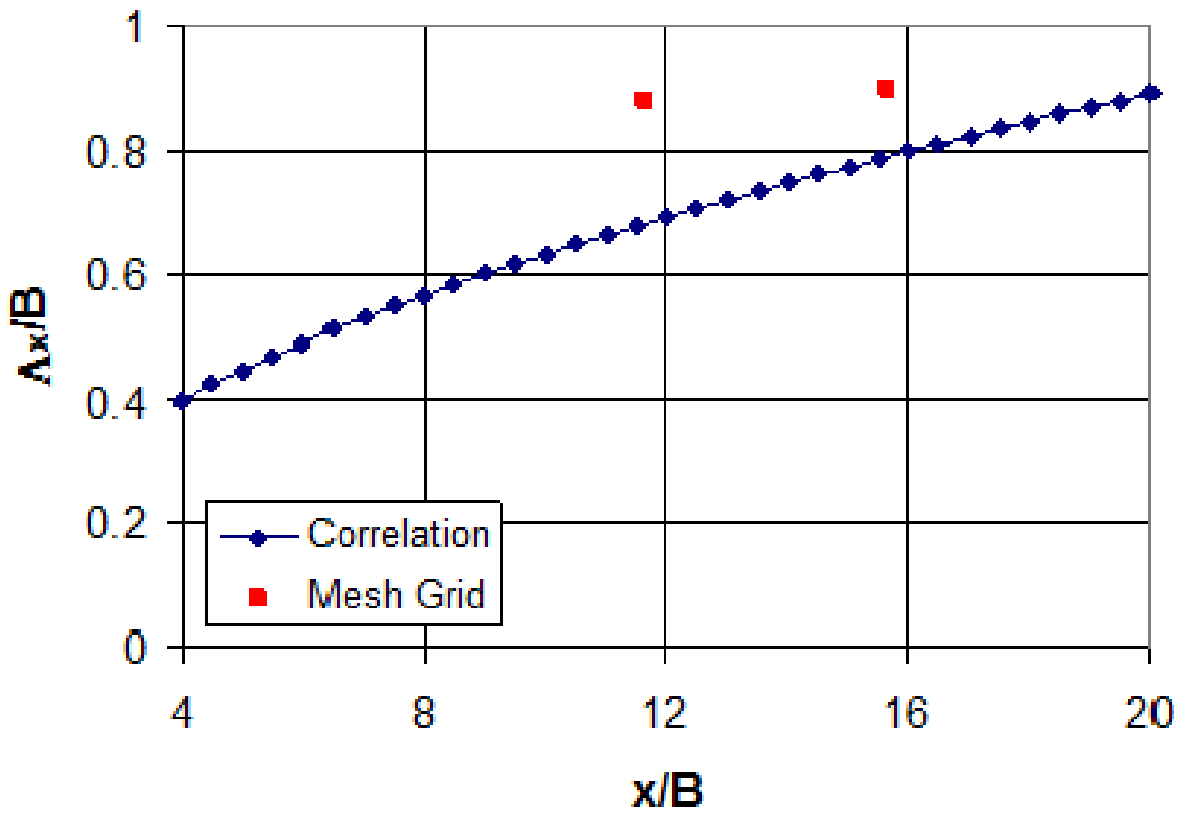

Figure F.13. Length scale dispersion from the mesh grid 
To check uniformity of the inlet flow to the vane passages, a Kiel probe was continuously traversed at low speed along the measurement slot shown in Figure F.4. The Kiel probe measured the total pressure along the measurement slot and a Pitot static probe located at cascade inlet measured total and static pressures of the flow at the cascade inlet. A velocity ratio or Mach number ratio was obtained by dividing the velocity measured from the Kiel probe to the velocity measured from a stationary Pitot probe using isentropic flow relations. The velocity ratio for the square mesh grid and a baseline configuration tested is provided in Figure F.14. The mesh grid shows reasonable flow uniformity at the cascade inlet.

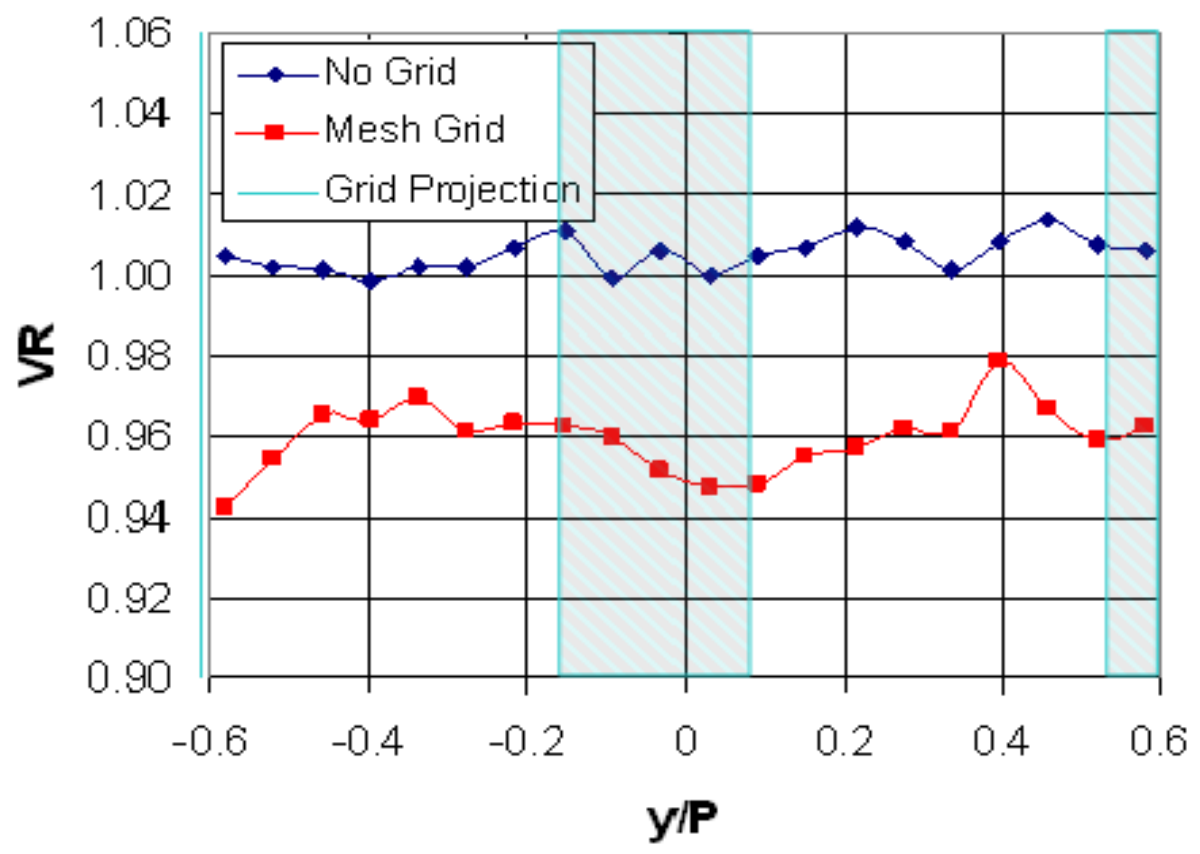

Figure F.14. Velocity ratio variation along inlet pitch

\section{References}

[F-1] Carullo, J.S., 2006, "Effects of Freestream Turbulence, Turbulence Length Scale, and Reynolds Number on Turbine Blade Heat Transfer in a Transonic Cascade," Master's Thesis, Virginia Polytechnic Institute and State University.

[F-2] Nix, A.C., 2003 "Effects of High Intensity, Large-Scale Freestream Combustor Turbulence on Heat Transfer in Transonic Turbine Blades," Ph.D. Dissertation, Virginia Polytechnic Institute and State University.

[F-3] Baines, W.D. and Peterson, E.G., 1951, "An Investigation of Flow Through Screens," Trans. of the ASME, July 1951, pp. 467-480. 
[F-4] Sauer, J., 1996, "The SUDI Turbulence Generator - A Method to Generate High Freestream Turbulence Levels and a Range of Length Scales," Thesis, University of Wisconsin/ University of Karlsruhe, Germany.

[F-5] McComb, W.D., 1990, “The Physics of Turbulence,” Oxford University press.

[F-6] Hinze, J., 1975, Turbulence, $2^{\text {nd }}$ Ed., McGraw-Hill, New York.

[F-7] Mohamed, M.S., and LaRue, J.C., 1990, "The Decay Power Law in Grid Generated Turbulence," J. Fluid Mech., 219, pp. 195-214.

[F-8] Roach, P.E., 1987, "The Generation of Nearly Isotropic Turbulence by Means of Grids," Int. J. Heat and Fluid Flow, 8, pp. 82-92. 


\section{Appendix G Vane Aerodynamic Tests}

Developing accurate aerodynamics is critical to producing a heat transfer data base for the turbine vane. The vane surface static pressures were measured in order to calculate the local Mach number distribution on the vane. The static pressures measurements were performed independently of the heat transfer measurements. The local Mach number distributions were measured for exit Mach numbers of 0.6, 0.8 and 1.0. In addition to the local Mach number distributions, the flow periodicity through vane cascade was also checked.

\section{Vane Local Mach Number Distribution}

To find the local Mach number distribution on the vane surface, static pressure taps were installed on the vane. A total of 26 pressure taps were instrumented at the midspan of the vane with 7 on the pressure side, 18 on the suction side and 1 near the leading edge. Tap locations were decided upon after predicting the local Mach number distribution on the vane surface by running a CFD model with Fluent. From Fluent, it was found that the flow stagnation location occurred on the pressure side of the vane and not at the geometric stagnation. Because of this, the leading edge tap was moved towards the pressure side from the geometric stagnation location. A PSI 8400 System with 32 channels was used to collect the static pressure data at $20 \mathrm{~Hz}$ during the experimental run. Figure G.1 provides the photographs of the instrumented middle vane in the test section and a schematic of the pressure tap locations on the vane is shown in Figure G.2.

The static pressure data from each pressure tap and the total pressure of the flow measured from a Pitot probe upstream were used to calculate a pressure ratio at each tap location. With the pressure ratio, the local isentropic Mach number could then be calculated by using,

$$
M a=\sqrt{\frac{2}{\gamma-1} \cdot\left(P R^{\frac{\gamma-1}{\gamma}}-1\right)}
$$

where PR is the pressure ratio and $\gamma$ is the specific heat ratio. It was assumed that there were no losses through the vane passages, so the total pressure remained constant. 


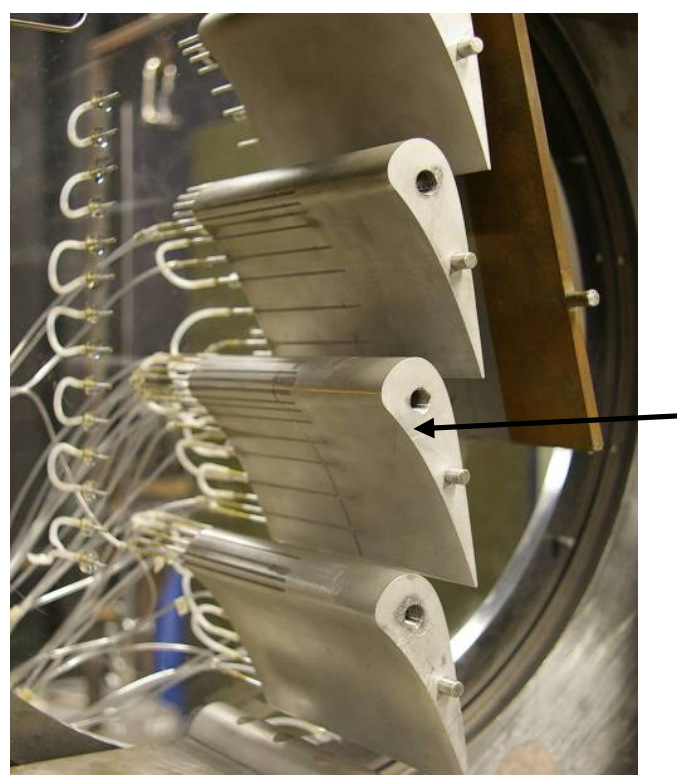

(a)

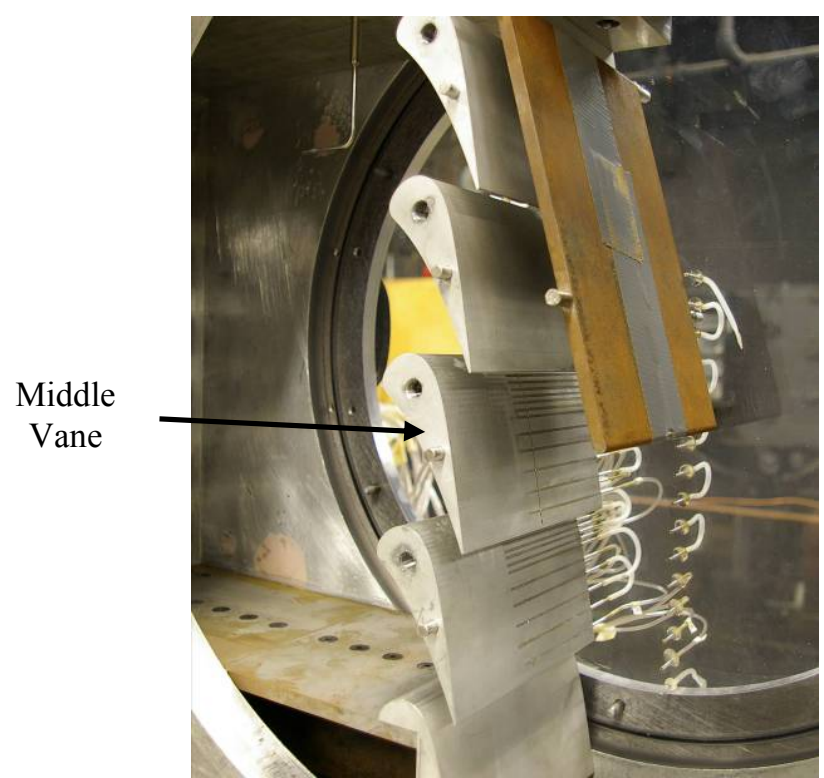

(b)

Figure G.1. Pictures showing the vane pressure taps (a) front view and (b) back view

Upper Vane (Vane 3) (PS instrumented)

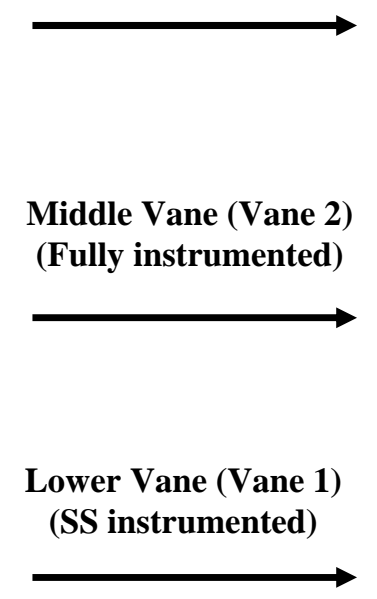

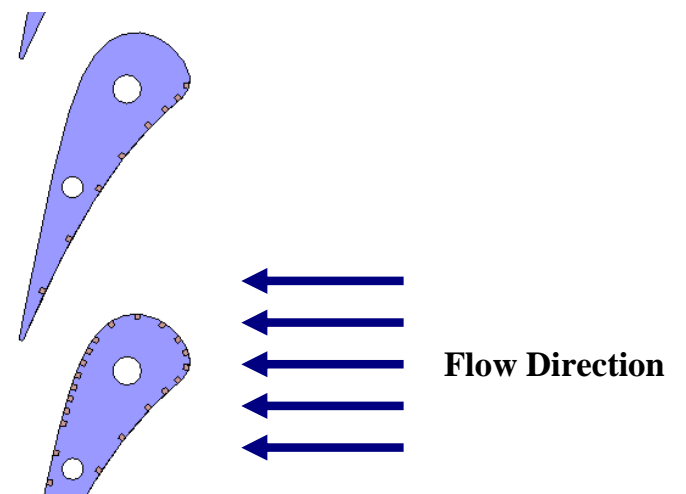

Figure G.2. Schematic of the pressure tap locations with the taps shown in red 
Experiments were performed several times at each exit Mach number to ensure that the vane surface Mach number distributions were repeatable. From the experiments, we observed that the each test had similar results. Figure G.3 provides a plot showing the run to run repeatability of the experiments for exit Mach 0.8 distribution.

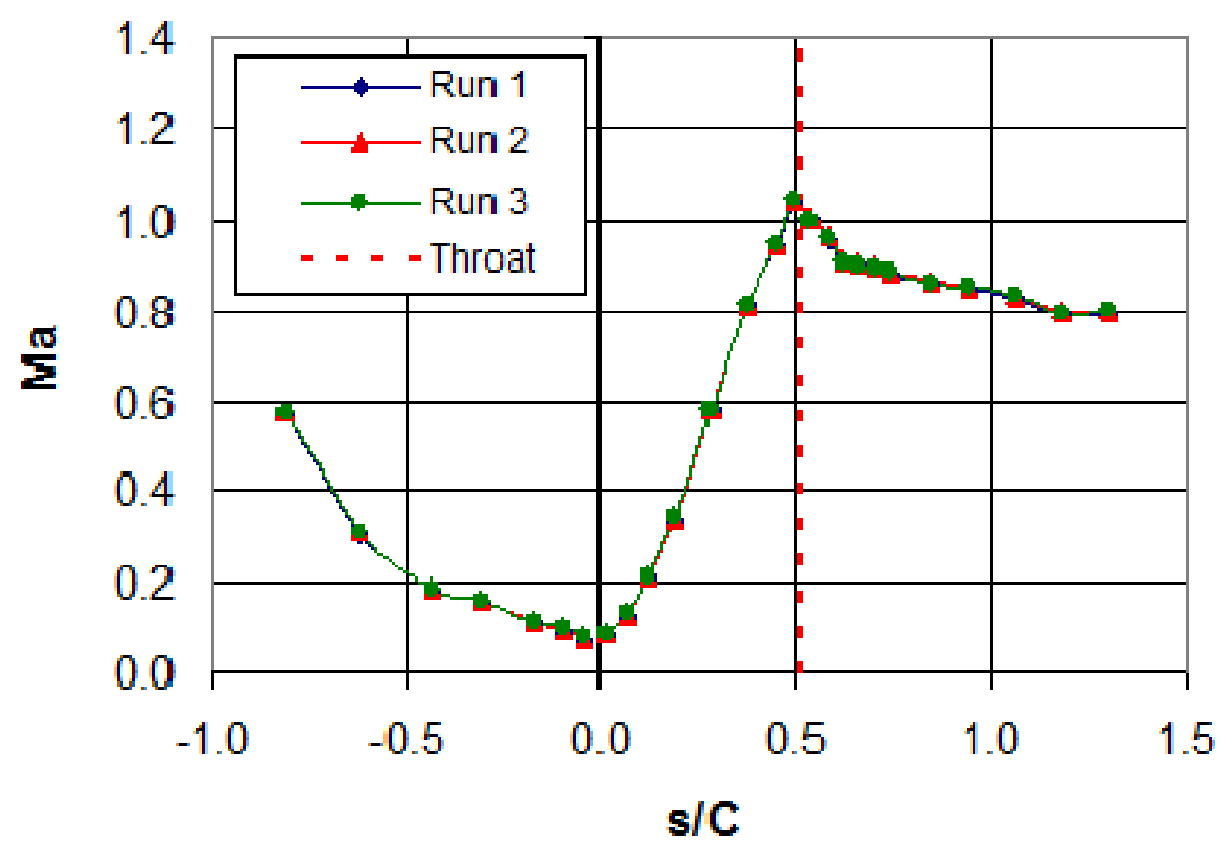

Figure G.3. Run to run repeatability of exit Mach 0.8 distribution

Figure G.4 shows the local Mach number distributions on the vane surface for three exit Mach number conditions. The Mach number distribution varies smoothly along the pressure side, and does not exhibit any velocity peak downstream of the stagnation region. The flow on the suction side continuously accelerates up to the geometric throat area $(\mathrm{s} / \mathrm{C}=0.51)$. The exit Mach 0.6 and 0.8 cases decelerate immediately after the throat, whereas the exit Mach 1.0 case continues to accelerate and becomes supersonic. A trailing edge shock from the adjacent vane impinging on the suction surface $(\mathrm{s} / \mathrm{C}=0.58)$ causes the multi flow decelerations after the throat for the exit Mach 1.0 case. 


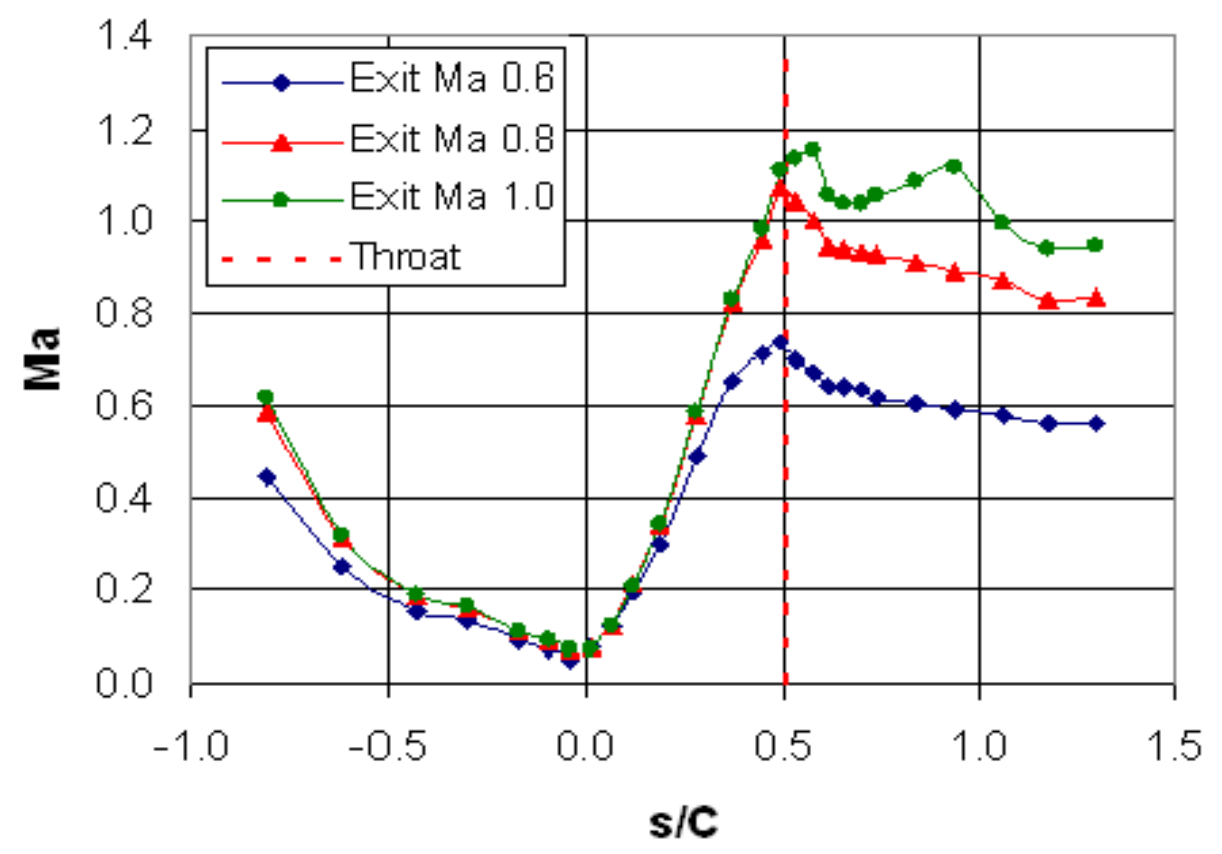

Figure G.4. Local Mach number distribution

The local Mach number distribution on the vane can also be examined in terms of the acceleration or pressure gradient parameter. The pressure gradient parameter is a nondimensional way of indicating how the flow is accelerating over the vane and is defined as,

$$
k=\frac{v}{U^{2}} \cdot \frac{d U}{d x}
$$

where $v$ is the kinematic viscosity based on local density, $\mathrm{U}$ is the local velocity and $x$ is the surface distance from the leading edge.

The distribution of acceleration parameter, $k$, on the vane surface for each exit Mach number is provided in Figure G.5. A positive acceleration parameter indicates that the flow is accelerating and a negative value indicates that the flow is decelerating. On the pressure side of the vane, the acceleration parameter for exit Mach 0.6 case barely reaches the critical value of 3 x $10^{-6}$ after $\mathrm{s} / \mathrm{C}=-0.43$. This critical value of $k$ has been observed by Jones and Launder [G-1] and Mayle [G-2] as a criterion for boundary layer relaminarization. 


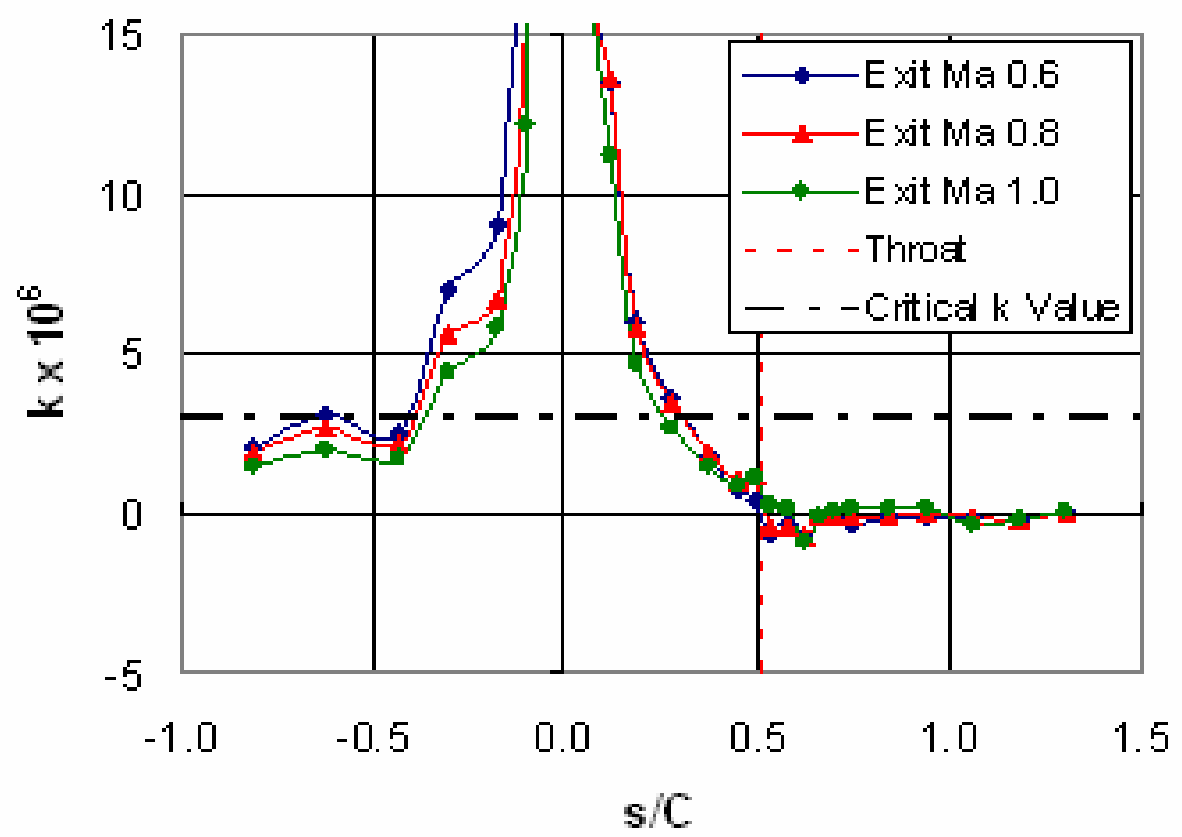

Figure G.5. Acceleration parameter distribution

\section{Vane Passage Periodicity}

In order to model the flow in a cascade, it is very important to have periodic inlet and outlet conditions. The flow periodicity was checked by instrumenting static pressure taps on the suction side of the vane below the middle vane (Vane 1) and the pressure side of the vane above the middle vane (Vane 3), as shown in Figure G.2. This gave us two passages that were fully instrumented with pressure taps. Due to the limited number of pressure transducers, the suction side periodicity had to be checked in a different set of tests than the pressure side periodicity. Tests were repeated several times to ensure that the experiments were repeatable. The periodicity of the flow at exit Mach 0.8 is provided in Figure G.6. The suction sides of vane 1 and vane 2 show the same local Mach number distributions over the majority of the suction surface. There is a slight variation in the local Mach numbers near the geometric throat. The pressure side of vane 2 and vane 3 shows almost identical local Mach number distributions with very small variation downstream of the stagnation region. 


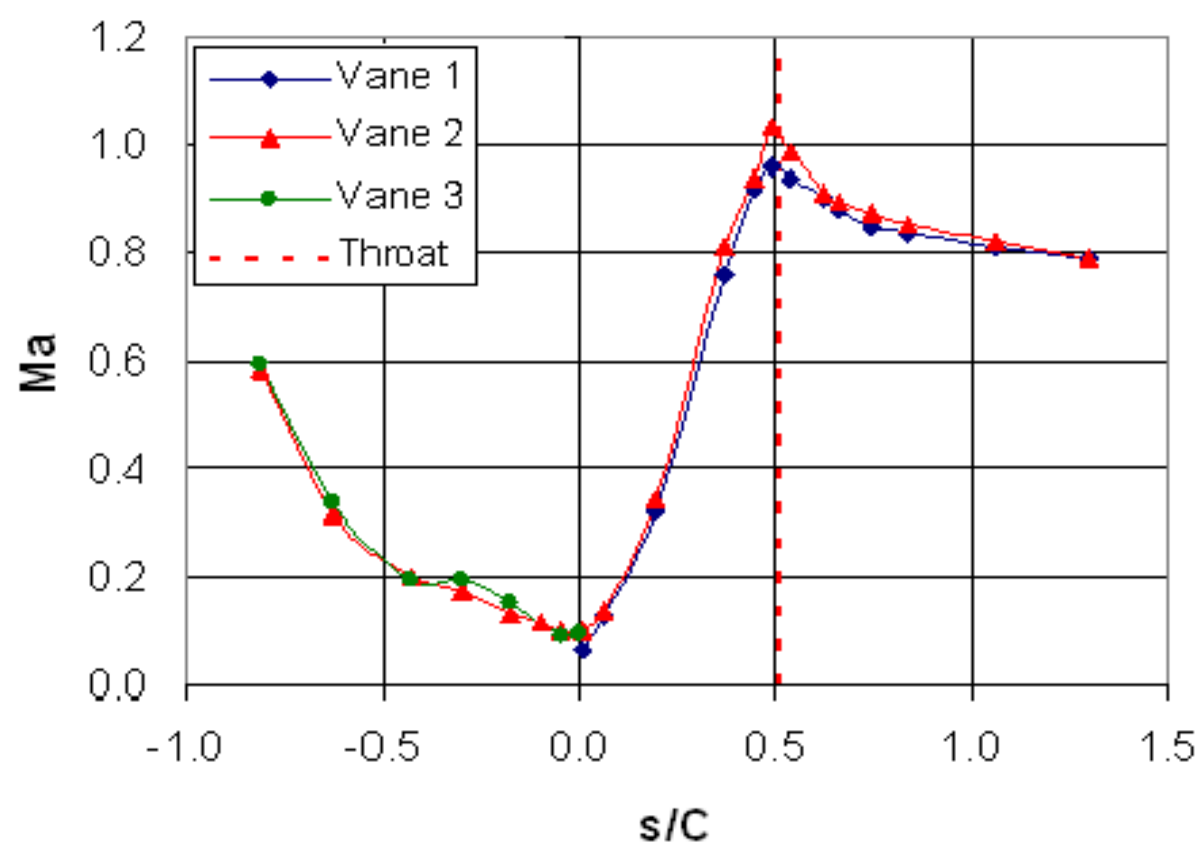

Figure G.6. Flow periodicity through vane passages

\section{References}

[G-1] Jones, W.P., and Launder, B. E., 1972, "The Prediction of Laminarization with a TwoEquation Model of Turbulence," Intl. J. Heat and Mass Transfer, 15, pp. 301-314.

[G-2] Mayle, R.E., 1991, "The Role of Laminar-Turbulent Transition in Gas Turbine Engines," ASME J. Turbomach., 113, pp. 509-537. 


\section{Appendix H Tabulated Results - Film Cooling Measurements}

\section{Vane Heat Transfer and Adiabatic Effectiveness at Exit Mach 0.57}

Table H.1. Nusselt number, $\mathrm{Nu}$, for $\mathrm{M}_{\mathrm{ex}}=0.57$

\begin{tabular}{|c|c|c|c|c|c|c|}
\hline \multirow{2}{*}{ Gauge } & \multicolumn{2}{|c|}{ Location } & \multicolumn{5}{c|}{ Nu Blowing Ratio: } \\
\cline { 2 - 7 } & s/d & $\mathbf{0 . 0}$ & $\mathbf{1 . 5}$ & $\mathbf{2 . 0}$ & $\mathbf{2 . 5}$ \\
\hline 1 & -0.585 & -67.7 & 713 & 807 & 825 & 887 \\
\hline 2 & -0.530 & -61.4 & 709 & 813 & 847 & 893 \\
\hline 3 & -0.476 & -55.1 & 711 & 820 & 871 & 920 \\
\hline 4 & -0.421 & -48.8 & 661 & 778 & 858 & 908 \\
\hline 5 & -0.366 & -42.5 & 667 & 799 & 912 & 954 \\
\hline 6 & -0.312 & -36.1 & 631 & 770 & 956 & 998 \\
\hline 7 & -0.257 & -29.8 & 635 & 805 & 1061 & 1147 \\
\hline 8 & -0.203 & -23.5 & 614 & 885 & 1200 & 1304 \\
\hline 9 & -0.148 & -17.2 & 591 & 965 & 1444 & 1546 \\
\hline 10 & 0.125 & 14.5 & & & & \\
\hline 11 & 0.179 & 20.8 & 849 & 1095 & 1215 & 1372 \\
\hline 12 & 0.234 & 27.1 & 1087 & 1232 & 1465 & 1552 \\
\hline 13 & 0.288 & 33.4 & 1231 & 1265 & 1454 & 1456 \\
\hline 14 & 0.343 & 39.7 & 962 & 1000 & 1163 & 1185 \\
\hline 15 & 0.398 & 46.1 & 1107 & 1222 & 1406 & 1434 \\
\hline 16 & 0.452 & 52.4 & 1322 & 1439 & 1585 & 1581 \\
\hline 17 & 0.507 & 58.7 & 1884 & 1851 & 1940 & 1865 \\
\hline 18 & 0.561 & 65.0 & 2089 & 1941 & 2006 & 1941 \\
\hline 19 & 0.616 & 71.4 & 2002 & 1885 & 1938 & 1887 \\
\hline 20 & 0.671 & 77.7 & 1994 & 1914 & 1949 & 1901 \\
\hline 21 & 0.725 & 84.0 & 2007 & 1916 & 1936 & 1888 \\
\hline
\end{tabular}


Table H.2. Nusselt number augmentation, $\mathrm{Nu} / \mathrm{Nu}_{0}$, for $\mathrm{M}_{\mathrm{ex}}=0.57$

\begin{tabular}{|c|c|c|c|c|c|}
\hline \multirow[b]{2}{*}{ Gauge } & \multicolumn{2}{|c|}{ Location } & \multicolumn{3}{|c|}{$N u / N u_{0} @$ Blowing Ratio: } \\
\hline & s/C & s/d & 1.5 & 2.0 & 2.5 \\
\hline 1 & -0.585 & -67.7 & 1.13 & 1.16 & 1.24 \\
\hline 2 & -0.530 & -61.4 & 1.15 & 1.20 & 1.26 \\
\hline 3 & -0.476 & -55.1 & 1.15 & 1.22 & 1.29 \\
\hline 4 & -0.421 & -48.8 & 1.18 & 1.30 & 1.37 \\
\hline 5 & -0.366 & -42.5 & 1.20 & 1.37 & 1.43 \\
\hline 6 & -0.312 & -36.1 & 1.22 & 1.51 & 1.58 \\
\hline 7 & -0.257 & -29.8 & 1.27 & 1.67 & 1.81 \\
\hline 8 & -0.203 & -23.5 & 1.44 & 1.95 & 2.12 \\
\hline 9 & -0.148 & -17.2 & 1.63 & 2.44 & 2.62 \\
\hline 10 & 0.125 & 14.5 & & & \\
\hline 11 & 0.179 & 20.8 & 1.29 & 1.43 & 1.62 \\
\hline 12 & 0.234 & 27.1 & 1.13 & 1.35 & 1.43 \\
\hline 13 & 0.288 & 33.4 & 1.03 & 1.18 & 1.18 \\
\hline 14 & 0.343 & 39.7 & 1.04 & 1.21 & 1.23 \\
\hline 15 & 0.398 & 46.1 & 1.10 & 1.27 & 1.30 \\
\hline 16 & 0.452 & 52.4 & 1.09 & 1.20 & 1.20 \\
\hline 17 & 0.507 & 58.7 & 0.98 & 1.03 & 0.99 \\
\hline 18 & 0.561 & 65.0 & 0.93 & 0.96 & 0.93 \\
\hline 19 & 0.616 & 71.4 & 0.94 & 0.97 & 0.94 \\
\hline 20 & 0.671 & 77.7 & 0.96 & 0.98 & 0.95 \\
\hline 21 & 0.725 & 84.0 & 0.95 & 0.96 & 0.94 \\
\hline
\end{tabular}


Table H.3. Film cooling effectiveness, $\eta$, for $\mathrm{M}_{\mathrm{ex}}=0.57$

\begin{tabular}{|c|c|c|c|c|c|}
\hline \multirow{2}{*}{ Gauge } & \multicolumn{2}{|c|}{ Location } & \multicolumn{2}{c|}{$\boldsymbol{\eta} @$ Blowing Ratio: } \\
\cline { 2 - 6 } & s/C & s/d & $\mathbf{1 . 5}$ & $\mathbf{2 . 0}$ & $\mathbf{2 . 5}$ \\
\hline 1 & -0.585 & -67.7 & 0.09 & 0.08 & 0.11 \\
\hline 2 & -0.530 & -61.4 & 0.10 & 0.10 & 0.11 \\
\hline 3 & -0.476 & -55.1 & 0.10 & 0.11 & 0.12 \\
\hline 4 & -0.421 & -48.8 & 0.11 & 0.14 & 0.15 \\
\hline 5 & -0.366 & -42.5 & 0.13 & 0.16 & 0.16 \\
\hline 6 & -0.312 & -36.1 & 0.14 & 0.21 & 0.20 \\
\hline 7 & -0.257 & -29.8 & 0.18 & 0.26 & 0.25 \\
\hline 8 & -0.203 & -23.5 & 0.27 & 0.34 & 0.32 \\
\hline 9 & -0.148 & -17.2 & 0.39 & 0.46 & 0.43 \\
\hline 10 & 0.125 & 14.5 & & & \\
\hline 11 & 0.179 & 20.8 & 0.25 & 0.31 & 0.35 \\
\hline 12 & 0.234 & 27.1 & 0.17 & 0.25 & 0.26 \\
\hline 13 & 0.288 & 33.4 & 0.13 & 0.20 & 0.20 \\
\hline 14 & 0.343 & 39.7 & 0.13 & 0.21 & 0.21 \\
\hline 15 & 0.398 & 46.1 & 0.14 & 0.21 & 0.21 \\
\hline 16 & 0.452 & 52.4 & 0.13 & 0.18 & 0.17 \\
\hline 17 & 0.507 & 58.7 & 0.09 & 0.13 & 0.10 \\
\hline 18 & 0.561 & 65.0 & 0.07 & 0.11 & 0.09 \\
\hline 19 & 0.616 & 71.4 & 0.08 & 0.11 & 0.09 \\
\hline 20 & 0.671 & 77.7 & 0.08 & 0.11 & 0.09 \\
\hline 21 & 0.725 & 84.0 & 0.08 & 0.10 & 0.08 \\
\hline
\end{tabular}


Table H.4. Net heat flux reduction, NHFR, for $\mathrm{M}_{\mathrm{ex}}=0.57$

\begin{tabular}{|c|c|c|c|c|c|}
\hline \multirow{2}{*}{ Gauge } & \multicolumn{2}{|c|}{ Location } & \multicolumn{3}{c|}{ NHFR @ Blowing Ratio: } \\
\cline { 2 - 6 } & s/C & s/d & $\mathbf{1 . 5}$ & $\mathbf{2 . 0}$ & $\mathbf{2 . 5}$ \\
\hline 1 & -0.585 & -67.7 & 0.04 & 0.00 & -0.01 \\
\hline 2 & -0.530 & -61.4 & 0.04 & 0.00 & -0.02 \\
\hline 3 & -0.476 & -55.1 & 0.04 & -0.01 & -0.04 \\
\hline 4 & -0.421 & -48.8 & 0.05 & 0.00 & -0.04 \\
\hline 5 & -0.366 & -42.5 & 0.06 & 0.01 & -0.05 \\
\hline 6 & -0.312 & -36.1 & 0.07 & 0.02 & -0.06 \\
\hline 7 & -0.257 & -29.8 & 0.11 & 0.05 & -0.06 \\
\hline 8 & -0.203 & -23.5 & 0.22 & 0.15 & 0.00 \\
\hline 9 & -0.148 & -17.2 & 0.42 & 0.43 & 0.24 \\
\hline 10 & 0.125 & 14.5 & & & \\
\hline 11 & 0.179 & 20.8 & 0.25 & 0.30 & 0.34 \\
\hline 12 & 0.234 & 27.1 & 0.18 & 0.21 & 0.19 \\
\hline 13 & 0.288 & 33.4 & 0.20 & 0.22 & 0.21 \\
\hline 14 & 0.343 & 39.7 & 0.19 & 0.21 & 0.20 \\
\hline 15 & 0.398 & 46.1 & 0.16 & 0.17 & 0.15 \\
\hline 16 & 0.452 & 52.4 & 0.14 & 0.16 & 0.14 \\
\hline 17 & 0.507 & 58.7 & 0.16 & 0.19 & 0.18 \\
\hline 18 & 0.561 & 65.0 & 0.19 & 0.21 & 0.21 \\
\hline 19 & 0.616 & 71.4 & 0.18 & 0.20 & 0.20 \\
\hline 20 & 0.671 & 77.7 & 0.17 & 0.20 & 0.19 \\
\hline 21 & 0.725 & 84.0 & 0.17 & 0.19 & 0.19 \\
\hline
\end{tabular}


Vane Heat Transfer and Adiabatic Effectiveness at Exit Mach 0.76

Table H.5. Nusselt number, $\mathrm{Nu}$, for $\mathrm{M}_{\mathrm{ex}}=0.76$

\begin{tabular}{|c|c|c|c|c|c|c|}
\hline \multirow{2}{*}{ Gauge } & \multicolumn{2}{|c|}{ Location } & \multicolumn{4}{c|}{ Nu @ Blowing Ratio: } \\
\cline { 2 - 7 } & s/C & s/d & $\mathbf{0 . 0}$ & $\mathbf{1 . 5}$ & $\mathbf{2 . 0}$ & $\mathbf{2 . 5}$ \\
\hline 1 & -0.585 & -67.7 & 722 & 825 & 885 & 859 \\
\hline 2 & -0.530 & -61.4 & 718 & 852 & 910 & 894 \\
\hline 3 & -0.476 & -55.1 & 712 & 873 & 942 & 932 \\
\hline 4 & -0.421 & -48.8 & 664 & 852 & 920 & 923 \\
\hline 5 & -0.366 & -42.5 & 673 & 884 & 961 & 982 \\
\hline 6 & -0.312 & -36.1 & 633 & 909 & 1007 & 1047 \\
\hline 7 & -0.257 & -29.8 & 644 & 986 & 1089 & 1193 \\
\hline 8 & -0.203 & -23.5 & 636 & 1080 & 1230 & 1393 \\
\hline 9 & -0.148 & -17.2 & 602 & 1107 & 1323 & 1745 \\
\hline 10 & 0.125 & 14.5 & & & & \\
\hline 11 & 0.179 & 20.8 & 942 & 1237 & 1417 & 1321 \\
\hline 12 & 0.234 & 27.1 & 1131 & 1394 & 1527 & 1556 \\
\hline 13 & 0.288 & 33.4 & 1210 & 1396 & 1441 & 1500 \\
\hline 14 & 0.343 & 39.7 & 925 & 1047 & 1080 & 1159 \\
\hline 15 & 0.398 & 46.1 & 1001 & 1206 & 1259 & 1341 \\
\hline 16 & 0.452 & 52.4 & 1098 & 1336 & 1382 & 1437 \\
\hline 17 & 0.507 & 58.7 & 1736 & 1870 & 1830 & 1930 \\
\hline 18 & 0.561 & 65.0 & 2309 & 2163 & 2133 & 2197 \\
\hline 19 & 0.616 & 71.4 & 2084 & 1960 & 1907 & 2014 \\
\hline 20 & 0.671 & 77.7 & 2082 & 2002 & 1955 & 2074 \\
\hline 21 & 0.725 & 84.0 & 2104 & 2047 & 1990 & 2136 \\
\hline
\end{tabular}


Table H.6. Nusselt number augmentation, $\mathrm{Nu} / \mathrm{Nu}_{0}$, for $\mathrm{M}_{\mathrm{ex}}=0.76$

\begin{tabular}{|c|c|c|c|c|c|}
\hline \multirow{2}{*}{ Gauge } & \multicolumn{2}{|c|}{ Location } & \multicolumn{2}{c|}{$N \mathbf{N} \mathbf{N} \mathbf{u}_{0} @$ Blowing Ratio: } \\
\cline { 2 - 6 } & s/C & s/d & 1.5 & 2.0 & 2.5 \\
\hline 1 & -0.585 & -67.7 & 1.14 & 1.23 & 1.19 \\
\hline 2 & -0.530 & -61.4 & 1.19 & 1.27 & 1.25 \\
\hline 3 & -0.476 & -55.1 & 1.23 & 1.32 & 1.31 \\
\hline 4 & -0.421 & -48.8 & 1.28 & 1.38 & 1.39 \\
\hline 5 & -0.366 & -42.5 & 1.31 & 1.43 & 1.46 \\
\hline 6 & -0.312 & -36.1 & 1.43 & 1.59 & 1.65 \\
\hline 7 & -0.257 & -29.8 & 1.53 & 1.69 & 1.85 \\
\hline 8 & -0.203 & -23.5 & 1.70 & 1.93 & 2.19 \\
\hline 9 & -0.148 & -17.2 & 1.84 & 2.20 & 2.90 \\
\hline 10 & 0.125 & 14.5 & & & \\
\hline 11 & 0.179 & 20.8 & 1.31 & 1.50 & 1.40 \\
\hline 12 & 0.234 & 27.1 & 1.23 & 1.35 & 1.38 \\
\hline 13 & 0.288 & 33.4 & 1.15 & 1.19 & 1.24 \\
\hline 14 & 0.343 & 39.7 & 1.13 & 1.17 & 1.25 \\
\hline 15 & 0.398 & 46.1 & 1.20 & 1.26 & 1.34 \\
\hline 16 & 0.452 & 52.4 & 1.22 & 1.26 & 1.31 \\
\hline 17 & 0.507 & 58.7 & 1.08 & 1.05 & 1.11 \\
\hline 18 & 0.561 & 65.0 & 0.94 & 0.92 & 0.95 \\
\hline 19 & 0.616 & 71.4 & 0.94 & 0.92 & 0.97 \\
\hline 20 & 0.671 & 77.7 & 0.96 & 0.94 & 1.00 \\
\hline 21 & 0.725 & 84.0 & 0.97 & 0.95 & 1.02 \\
\hline & & & & & \\
\hline 17 & & & \\
\hline
\end{tabular}


Table H.7. Film cooling effectiveness, $\eta$, for $\mathrm{M}_{\mathrm{ex}}=0.76$

\begin{tabular}{|c|c|c|c|c|c|}
\hline \multirow{2}{*}{ Gauge } & \multicolumn{2}{|c|}{ Location } & \multicolumn{2}{c|}{$\boldsymbol{\eta} @$ Blowing Ratio: } \\
\cline { 2 - 6 } & s/C & s/d & $\mathbf{1 . 5}$ & $\mathbf{2 . 0}$ & $\mathbf{2 . 5}$ \\
\hline 1 & -0.585 & -67.7 & 0.06 & 0.08 & 0.05 \\
\hline 2 & -0.530 & -61.4 & 0.08 & 0.10 & 0.07 \\
\hline 3 & -0.476 & -55.1 & 0.11 & 0.12 & 0.10 \\
\hline 4 & -0.421 & -48.8 & 0.14 & 0.15 & 0.13 \\
\hline 5 & -0.366 & -42.5 & 0.16 & 0.17 & 0.15 \\
\hline 6 & -0.312 & -36.1 & 0.23 & 0.22 & 0.21 \\
\hline 7 & -0.257 & -29.8 & 0.28 & 0.26 & 0.26 \\
\hline 8 & -0.203 & -23.5 & 0.36 & 0.35 & 0.33 \\
\hline 9 & -0.148 & -17.2 & 0.45 & 0.44 & 0.47 \\
\hline 10 & 0.125 & 14.5 & & & \\
\hline 11 & 0.179 & 20.8 & 0.27 & 0.30 & 0.31 \\
\hline 12 & 0.234 & 27.1 & 0.21 & 0.23 & 0.25 \\
\hline 13 & 0.288 & 33.4 & 0.16 & 0.17 & 0.19 \\
\hline 14 & 0.343 & 39.7 & 0.16 & 0.17 & 0.20 \\
\hline 15 & 0.398 & 46.1 & 0.17 & 0.18 & 0.21 \\
\hline 16 & 0.452 & 52.4 & 0.16 & 0.16 & 0.18 \\
\hline 17 & 0.507 & 58.7 & 0.09 & 0.07 & 0.10 \\
\hline 18 & 0.561 & 65.0 & 0.06 & 0.05 & 0.07 \\
\hline 19 & 0.616 & 71.4 & 0.06 & 0.05 & 0.07 \\
\hline 20 & 0.671 & 77.7 & 0.06 & 0.06 & 0.09 \\
\hline 21 & 0.725 & 84.0 & 0.06 & 0.06 & 0.09 \\
\hline & & & & & \\
\hline 14 & & \\
\hline
\end{tabular}


Table H.8. Net heat flux reduction, NHFR, for $\mathrm{M}_{\mathrm{ex}}=0.76$

\begin{tabular}{|c|c|c|c|c|c|}
\hline \multirow[b]{2}{*}{ Gauge } & \multicolumn{2}{|c|}{ Location } & \multicolumn{3}{|c|}{ NHFR @ Blowing Ratio: } \\
\hline & $s / C$ & s/d & 1.5 & 2.0 & 2.5 \\
\hline 1 & -0.585 & -67.7 & -0.01 & -0.04 & -0.08 \\
\hline 2 & -0.530 & -61.4 & -0.01 & -0.04 & -0.09 \\
\hline 3 & -0.476 & -55.1 & 0.00 & -0.04 & -0.09 \\
\hline 4 & -0.421 & -48.8 & 0.02 & -0.04 & -0.09 \\
\hline 5 & -0.366 & -42.5 & 0.04 & -0.04 & -0.10 \\
\hline 6 & -0.312 & -36.1 & 0.10 & -0.01 & -0.08 \\
\hline 7 & -0.257 & -29.8 & 0.16 & 0.02 & -0.08 \\
\hline 8 & -0.203 & -23.5 & 0.30 & 0.18 & 0.01 \\
\hline 9 & -0.148 & -17.2 & 0.53 & 0.43 & 0.35 \\
\hline 10 & 0.125 & 14.5 & & & \\
\hline 11 & 0.179 & 20.8 & 0.19 & 0.16 & 0.24 \\
\hline 12 & 0.234 & 27.1 & 0.13 & 0.08 & 0.12 \\
\hline 13 & 0.288 & 33.4 & 0.14 & 0.13 & 0.13 \\
\hline 14 & 0.343 & 39.7 & 0.16 & 0.15 & 0.15 \\
\hline 15 & 0.398 & 46.1 & 0.11 & 0.08 & 0.09 \\
\hline 16 & 0.452 & 52.4 & 0.08 & 0.04 & 0.05 \\
\hline 17 & 0.507 & 58.7 & 0.05 & 0.04 & 0.04 \\
\hline 18 & 0.561 & 65.0 & 0.11 & 0.11 & 0.12 \\
\hline 19 & 0.616 & 71.4 & 0.15 & 0.16 & 0.15 \\
\hline 20 & 0.671 & 77.7 & 0.15 & 0.16 & 0.15 \\
\hline 21 & 0.725 & 84.0 & 0.14 & 0.16 & 0.14 \\
\hline
\end{tabular}


Table H.9. Nusselt number, $\mathrm{Nu}$, for $\mathrm{M}_{\mathrm{ex}}=1.0$

\begin{tabular}{|c|c|c|c|c|c|c|}
\hline \multirow{2}{*}{ Gauge } & \multicolumn{2}{|c|}{ Location } & \multicolumn{4}{c|}{ Nu B Blowing Ratio: } \\
\cline { 2 - 7 } & s/d & $\mathbf{0 . 0}$ & $\mathbf{1 . 5}$ & $\mathbf{2 . 0}$ & $\mathbf{2 . 5}$ \\
\hline 1 & -0.585 & -67.7 & 1244 & 1374 & 1398 & 1387 \\
\hline 2 & -0.530 & -61.4 & 1219 & 1356 & 1376 & 1380 \\
\hline 3 & -0.476 & -55.1 & 1199 & 1346 & 1350 & 1360 \\
\hline 4 & -0.421 & -48.8 & 1119 & 1246 & 1254 & 1310 \\
\hline 5 & -0.366 & -42.5 & 1108 & 1250 & 1268 & 1292 \\
\hline 6 & -0.312 & -36.1 & 1046 & 1216 & 1253 & 1241 \\
\hline 7 & -0.257 & -29.8 & 1054 & 1255 & 1273 & 1264 \\
\hline 8 & -0.203 & -23.5 & 1032 & 1324 & 1203 & 1229 \\
\hline 9 & -0.148 & -17.2 & 991 & 1512 & 1210 & 1252 \\
\hline 10 & 0.125 & 14.5 & & & & \\
\hline 11 & 0.179 & 20.8 & 1307 & 2150 & 2235 & 2171 \\
\hline 12 & 0.234 & 27.1 & 1970 & 2558 & 2559 & 2486 \\
\hline 13 & 0.288 & 33.4 & 2194 & 2657 & 2606 & 2591 \\
\hline 14 & 0.343 & 39.7 & 1697 & 2115 & 2068 & 2092 \\
\hline 15 & 0.398 & 46.1 & 2417 & 2934 & 2808 & 2904 \\
\hline 16 & 0.452 & 52.4 & 2742 & 3079 & 2993 & 2968 \\
\hline 17 & 0.507 & 58.7 & 2731 & 2995 & 3023 & 2945 \\
\hline 18 & 0.561 & 65.0 & 2562 & 2874 & 2887 & 2828 \\
\hline 19 & 0.616 & 71.4 & 2209 & 2450 & 2325 & 2316 \\
\hline 20 & 0.671 & 77.7 & 1214 & 1016 & 745 & 1118 \\
\hline 21 & 0.725 & 84.0 & 2516 & 2810 & 2383 & 2601 \\
\hline
\end{tabular}


Table H.10. Nusselt number augmentation, $\mathrm{Nu} / \mathrm{Nu}_{0}$, for $\mathrm{M}_{\mathrm{ex}}=1.0$

\begin{tabular}{|c|c|c|c|c|c|}
\hline \multirow[b]{2}{*}{ Gauge } & \multicolumn{2}{|c|}{ Location } & \multicolumn{3}{|c|}{$\mathrm{Nu} / \mathrm{Nu} \mathrm{u}_{0} @$ Blowing Ratio: } \\
\hline & s/C & s/d & 1.5 & 2.0 & 2.5 \\
\hline 1 & -0.585 & -67.7 & 1.10 & 1.12 & 1.11 \\
\hline 2 & -0.530 & -61.4 & 1.11 & 1.13 & 1.13 \\
\hline 3 & -0.476 & -55.1 & 1.12 & 1.13 & 1.13 \\
\hline 4 & -0.421 & -48.8 & 1.11 & 1.12 & 1.17 \\
\hline 5 & -0.366 & -42.5 & 1.13 & 1.14 & 1.17 \\
\hline 6 & -0.312 & -36.1 & 1.16 & 1.20 & 1.19 \\
\hline 7 & -0.257 & -29.8 & 1.19 & 1.21 & 1.20 \\
\hline 8 & -0.203 & -23.5 & 1.28 & 1.17 & 1.19 \\
\hline 9 & -0.148 & -17.2 & 1.53 & 1.22 & 1.26 \\
\hline 10 & 0.125 & 14.5 & & & \\
\hline 11 & 0.179 & 20.8 & 1.64 & 1.71 & 1.66 \\
\hline 12 & 0.234 & 27.1 & 1.30 & 1.30 & 1.26 \\
\hline 13 & 0.288 & 33.4 & 1.21 & 1.19 & 1.18 \\
\hline 14 & 0.343 & 39.7 & 1.25 & 1.22 & 1.23 \\
\hline 15 & 0.398 & 46.1 & 1.21 & 1.16 & 1.20 \\
\hline 16 & 0.452 & 52.4 & 1.12 & 1.09 & 1.08 \\
\hline 17 & 0.507 & 58.7 & 1.10 & 1.11 & 1.08 \\
\hline 18 & 0.561 & 65.0 & 1.12 & 1.13 & 1.10 \\
\hline 19 & 0.616 & 71.4 & 1.11 & 1.05 & 1.05 \\
\hline 20 & 0.671 & 77.7 & 0.84 & 0.61 & 0.92 \\
\hline 21 & 0.725 & 84.0 & 1.12 & 0.95 & 1.03 \\
\hline
\end{tabular}


Table H.11. Film cooling effectiveness, $\eta$, for $\mathrm{M}_{\mathrm{ex}}=1.0$

\begin{tabular}{|c|c|c|c|c|c|}
\hline \multirow{2}{*}{ Gauge } & \multicolumn{2}{|c|}{ Location } & \multicolumn{2}{c|}{$\boldsymbol{\eta} @$ Blowing Ratio: } \\
\cline { 2 - 6 } & s/C & s/d & 1.5 & $\mathbf{2 . 0}$ & $\mathbf{2 . 5}$ \\
\hline 1 & -0.585 & -67.7 & 0.05 & 0.04 & 0.01 \\
\hline 2 & -0.530 & -61.4 & 0.05 & 0.04 & 0.02 \\
\hline 3 & -0.476 & -55.1 & 0.06 & 0.03 & 0.00 \\
\hline 4 & -0.421 & -48.8 & 0.06 & 0.03 & 0.02 \\
\hline 5 & -0.366 & -42.5 & 0.07 & 0.03 & 0.01 \\
\hline 6 & -0.312 & -36.1 & 0.10 & 0.06 & 0.02 \\
\hline 7 & -0.257 & -29.8 & 0.13 & 0.08 & 0.01 \\
\hline 8 & -0.203 & -23.5 & 0.21 & 0.10 & 0.02 \\
\hline 9 & -0.148 & -17.2 & 0.35 & 0.20 & 0.12 \\
\hline 10 & 0.125 & 14.5 & & & \\
\hline 11 & 0.179 & 20.8 & 0.28 & 0.31 & 0.30 \\
\hline 12 & 0.234 & 27.1 & 0.16 & 0.18 & 0.17 \\
\hline 13 & 0.288 & 33.4 & 0.15 & 0.16 & 0.15 \\
\hline 14 & 0.343 & 39.7 & 0.17 & 0.17 & 0.16 \\
\hline 15 & 0.398 & 46.1 & 0.12 & 0.11 & 0.11 \\
\hline 16 & 0.452 & 52.4 & 0.08 & 0.09 & 0.08 \\
\hline 17 & 0.507 & 58.7 & 0.09 & 0.11 & 0.10 \\
\hline 18 & 0.561 & 65.0 & 0.11 & 0.12 & 0.11 \\
\hline 19 & 0.616 & 71.4 & 0.11 & 0.11 & 0.10 \\
\hline 20 & 0.671 & 77.7 & -0.12 & -0.32 & -0.07 \\
\hline 21 & 0.725 & 84.0 & 0.12 & 0.08 & 0.10 \\
\hline & & & & & \\
\hline 14 & & & \\
\hline 19 & & & \\
\hline
\end{tabular}


Table H.12. Net heat flux reduction, NHFR, for $\mathrm{M}_{\mathrm{ex}}=1.0$

\begin{tabular}{|c|c|c|c|c|c|}
\hline \multirow{2}{*}{ Gauge } & \multicolumn{2}{|c|}{ Location } & \multicolumn{3}{c|}{ NHFR @ Blowing Ratio: } \\
\cline { 2 - 6 } & s/C & s/d & $\mathbf{1 . 5}$ & $\mathbf{2 . 0}$ & $\mathbf{2 . 5}$ \\
\hline 1 & -0.585 & -67.7 & -0.02 & -0.04 & -0.09 \\
\hline 2 & -0.530 & -61.4 & -0.02 & -0.06 & -0.10 \\
\hline 3 & -0.476 & -55.1 & -0.01 & -0.06 & -0.14 \\
\hline 4 & -0.421 & -48.8 & -0.01 & -0.07 & -0.13 \\
\hline 5 & -0.366 & -42.5 & 0.00 & -0.08 & -0.15 \\
\hline 6 & -0.312 & -36.1 & 0.02 & -0.08 & -0.15 \\
\hline 7 & -0.257 & -29.8 & 0.07 & -0.05 & -0.18 \\
\hline 8 & -0.203 & -23.5 & 0.16 & 0.02 & -0.16 \\
\hline 9 & -0.148 & -17.2 & 0.36 & 0.20 & -0.01 \\
\hline 10 & 0.125 & 14.5 & & & \\
\hline 11 & 0.179 & 20.8 & 0.11 & 0.16 & 0.17 \\
\hline 12 & 0.234 & 27.1 & 0.05 & 0.08 & 0.10 \\
\hline 13 & 0.288 & 33.4 & 0.09 & 0.12 & 0.11 \\
\hline 14 & 0.343 & 39.7 & 0.10 & 0.13 & 0.10 \\
\hline 15 & 0.398 & 46.1 & 0.02 & 0.06 & 0.03 \\
\hline 16 & 0.452 & 52.4 & 0.03 & 0.07 & 0.07 \\
\hline 17 & 0.507 & 58.7 & 0.07 & 0.10 & 0.10 \\
\hline 18 & 0.561 & 65.0 & 0.08 & 0.11 & 0.11 \\
\hline 19 & 0.616 & 71.4 & 0.10 & 0.14 & 0.13 \\
\hline 20 & 0.671 & 77.7 & -0.01 & 0.06 & -0.02 \\
\hline 21 & 0.725 & 84.0 & 0.10 & 0.18 & 0.14 \\
\hline & & & & & \\
\hline 14
\end{tabular}




\section{Appendix I Tabulated Results - No-Cooling Measurements}

\section{Smooth Vane Heat Transfer at Exit Mach 0.55}

Table I.1. Nusselt number, $\mathrm{Nu}$, for $\mathrm{M}_{\mathrm{ex}}=0.55$

\begin{tabular}{|c|c|c|c|}
\hline \multirow[b]{2}{*}{ Gauge } & \multirow{2}{*}{$\begin{array}{c}\text { Location } \\
\text { s/C } \\
\end{array}$} & \multicolumn{2}{|c|}{ Nu@Tu: } \\
\hline & & $2 \%$ & $16 \%$ \\
\hline 1 & 1.35 & 1290.0 & 1379.6 \\
\hline 3 & 1.24 & 1422.6 & 1478.8 \\
\hline 5 & 1.13 & 1659.2 & 1679.5 \\
\hline 7 & 1.01 & 1490.9 & 1518.0 \\
\hline 9 & 0.90 & 1619.9 & 1654.4 \\
\hline 11 & 0.79 & 1535.7 & 1548.4 \\
\hline 13 & 0.68 & 1446.2 & 1529.5 \\
\hline 14 & 0.63 & 1130.8 & 1414.0 \\
\hline 15 & 0.57 & 567.7 & 1080.6 \\
\hline 16 & 0.52 & 795.2 & 756.4 \\
\hline 17 & 0.46 & 627.5 & 735.3 \\
\hline 18 & 0.41 & 633.8 & 733.2 \\
\hline 20 & 0.30 & 772.6 & 927.4 \\
\hline 21 & 0.24 & 787.0 & 948.5 \\
\hline 22 & 0.19 & 762.3 & 926.8 \\
\hline 23 & 0.13 & 784.1 & 963.6 \\
\hline 24 & 0.08 & 837.5 & 1017.2 \\
\hline 25 & 0.02 & 954.5 & 1177.9 \\
\hline 26 & -0.03 & 845.9 & 1101.8 \\
\hline 27 & -0.08 & 515.4 & 766.3 \\
\hline 28 & -0.14 & 421.3 & 667.7 \\
\hline 30 & -0.25 & 384.1 & 626.5 \\
\hline 32 & -0.37 & 409.0 & 674.9 \\
\hline 34 & -0.48 & 447.3 & 723.0 \\
\hline 35 & -0.53 & 490.8 & 766.5 \\
\hline 36 & -0.59 & 518.1 & 792.2 \\
\hline 37 & -0.64 & 550.5 & 786.8 \\
\hline 38 & -0.70 & 636.7 & 866.9 \\
\hline 39 & -0.75 & 677.9 & 907.8 \\
\hline 41 & -0.86 & 954.2 & 1297.7 \\
\hline 43 & -0.97 & 806.1 & 1151.2 \\
\hline
\end{tabular}


Smooth Vane Heat Transfer at Exit Mach 0.75

Table I.2. Nusselt number, $\mathrm{Nu}$, for $\mathrm{M}_{\mathrm{ex}}=0.75$

\begin{tabular}{|c|c|c|c|}
\hline \multirow[b]{2}{*}{ Gauge } & \multirow{2}{*}{$\begin{array}{c}\text { Location } \\
\text { s/C } \\
\end{array}$} & \multicolumn{2}{|c|}{ Nu@Tu: } \\
\hline & & $2 \%$ & $16 \%$ \\
\hline 1 & 1.35 & 1201.2 & 1497.7 \\
\hline 2 & 1.29 & - & 1541.5 \\
\hline 3 & 1.24 & 1544.6 & - \\
\hline 4 & 1.18 & - & 1815.2 \\
\hline 5 & 1.13 & 1749.6 & 1807.9 \\
\hline 7 & 1.01 & 1609.9 & 1657.0 \\
\hline 8 & 0.96 & - & 1747.5 \\
\hline 9 & 0.90 & 1738.5 & - \\
\hline 10 & 0.85 & - & 1620.9 \\
\hline 11 & 0.79 & 1610.7 & 1633.7 \\
\hline 13 & 0.68 & 1281.1 & 1560.9 \\
\hline 14 & 0.63 & 928.6 & 1403.6 \\
\hline 15 & 0.57 & 555.1 & 1054.9 \\
\hline 16 & 0.52 & 687.6 & 817.2 \\
\hline 17 & 0.46 & 621.5 & 745.8 \\
\hline 18 & 0.41 & 642.4 & 787.9 \\
\hline 20 & 0.30 & 818.4 & 985.2 \\
\hline 21 & 0.24 & 840.0 & 1052.3 \\
\hline 22 & 0.19 & 830.9 & - \\
\hline 23 & 0.13 & 861.8 & 1028.5 \\
\hline 24 & 0.08 & 930.3 & 1100.5 \\
\hline 25 & 0.02 & 1065.5 & 1205.9 \\
\hline 26 & -0.03 & 934.6 & 1165.3 \\
\hline 27 & -0.08 & 568.4 & 808.8 \\
\hline 28 & -0.14 & 465.2 & 708.9 \\
\hline 29 & -0.19 & - & 688.9 \\
\hline 30 & -0.25 & 420.1 & - \\
\hline 32 & -0.37 & 445.8 & 721.9 \\
\hline 34 & -0.48 & 472.8 & 797.5 \\
\hline 35 & -0.53 & 520.0 & - \\
\hline 36 & -0.59 & 562.0 & - \\
\hline 37 & -0.64 & 615.0 & 895.3 \\
\hline 38 & -0.70 & 704.1 & - \\
\hline 39 & -0.75 & 770.8 & 1061.5 \\
\hline 41 & -0.86 & 957.5 & 1487.6 \\
\hline 43 & -0.97 & 690.9 & 1254.7 \\
\hline
\end{tabular}


Smooth Vane Heat Transfer at Exit Mach 1.01

Table I.3. Nusselt number, $\mathrm{Nu}$, for $\mathrm{M}_{\mathrm{ex}}=1.01$

\begin{tabular}{|c|c|c|c|}
\hline \multirow[b]{2}{*}{ Gauge } & \multirow{2}{*}{$\begin{array}{c}\text { Location } \\
\text { s/C }\end{array}$} & \multicolumn{2}{|c|}{ Nu@Tu: } \\
\hline & & $2 \%$ & $16 \%$ \\
\hline 1 & 1.35 & 1757.1 & 1677.2 \\
\hline 3 & 1.24 & 1936.7 & 1848.0 \\
\hline 5 & 1.13 & 2055.4 & 2001.6 \\
\hline 7 & 1.01 & 1886.1 & 1694.9 \\
\hline 9 & 0.90 & 1989.7 & 1891.6 \\
\hline 11 & 0.79 & 1883.2 & 1788.9 \\
\hline 13 & 0.68 & 1708.2 & 1700.2 \\
\hline 14 & 0.63 & 1370.6 & 1288.4 \\
\hline 15 & 0.57 & 1312.7 & 1386.5 \\
\hline 16 & 0.52 & 1536.6 & 1231.9 \\
\hline 17 & 0.46 & 1031.2 & 1080.8 \\
\hline 18 & 0.41 & 943.2 & 976.4 \\
\hline 20 & 0.30 & 1130.7 & 1208.9 \\
\hline 21 & 0.24 & 1135.8 & 1240.2 \\
\hline 22 & 0.19 & 1022.0 & 1183.0 \\
\hline 23 & 0.13 & 1071.5 & 1237.1 \\
\hline 24 & 0.08 & 1124.0 & 1295.8 \\
\hline 25 & 0.02 & 1275.3 & 1503.1 \\
\hline 26 & -0.03 & 1126.8 & 1390.9 \\
\hline 27 & -0.08 & 688.6 & 965.3 \\
\hline 28 & -0.14 & 573.4 & 858.3 \\
\hline 30 & -0.25 & 527.0 & 829.5 \\
\hline 32 & -0.37 & 563.5 & 905.4 \\
\hline 34 & -0.48 & 606.6 & 975.8 \\
\hline 35 & -0.53 & 660.7 & 1040.5 \\
\hline 36 & -0.59 & 736.1 & 1146.0 \\
\hline 37 & -0.64 & 863.1 & 1188.7 \\
\hline 38 & -0.70 & 1119.9 & 1498.4 \\
\hline 39 & -0.75 & 1441.6 & 1593.4 \\
\hline 41 & -0.86 & 1949.9 & 2006.1 \\
\hline 43 & -0.97 & 1595.0 & 1478.5 \\
\hline
\end{tabular}


Smooth Vane Mach Number Distribution

Table I.4. Vane local Mach number

\begin{tabular}{|c|c|c|c|c|}
\hline \multirow[b]{2}{*}{ Tap } & \multirow{2}{*}{$\begin{array}{l}\text { Location } \\
\text { s/C }\end{array}$} & \multicolumn{3}{|c|}{ Ma @ Exit Mach: } \\
\hline & & 0.60 & 0.80 & 1.0 \\
\hline 1 & -0.809 & 0.449 & 0.590 & 0.621 \\
\hline 2 & -0.620 & 0.253 & 0.312 & 0.319 \\
\hline 3 & -0.431 & 0.154 & 0.188 & 0.193 \\
\hline 4 & -0.302 & 0.133 & 0.162 & 0.164 \\
\hline 5 & -0.174 & 0.089 & 0.112 & 0.111 \\
\hline 6 & -0.098 & 0.074 & 0.093 & 0.092 \\
\hline 7 & -0.044 & 0.055 & 0.071 & 0.072 \\
\hline 8 & 0.010 & 0.082 & 0.082 & 0.075 \\
\hline 9 & 0.064 & 0.123 & 0.124 & 0.122 \\
\hline 10 & 0.116 & 0.195 & 0.213 & 0.211 \\
\hline 11 & 0.189 & 0.299 & 0.341 & 0.342 \\
\hline 12 & 0.279 & 0.494 & 0.584 & 0.590 \\
\hline 13 & 0.373 & 0.657 & 0.824 & 0.831 \\
\hline 14 & 0.448 & 0.715 & 0.961 & 0.981 \\
\hline 15 & 0.492 & 0.734 & 1.073 & 1.109 \\
\hline 16 & 0.535 & 0.699 & 1.047 & 1.136 \\
\hline 17 & 0.579 & 0.678 & 1.000 & 1.154 \\
\hline 18 & 0.620 & 0.647 & 0.946 & 1.056 \\
\hline 19 & 0.659 & 0.642 & 0.940 & 1.039 \\
\hline 20 & 0.701 & 0.636 & 0.934 & 1.041 \\
\hline 21 & 0.743 & 0.620 & 0.927 & 1.059 \\
\hline 22 & 0.841 & 0.607 & 0.906 & 1.084 \\
\hline 23 & 0.939 & 0.599 & 0.893 & 1.116 \\
\hline 24 & 1.060 & 0.583 & 0.872 & 0.993 \\
\hline 25 & 1.180 & 0.566 & 0.831 & 0.937 \\
\hline 26 & 1.300 & 0.567 & 0.835 & 0.943 \\
\hline
\end{tabular}




\section{Appendix J Sample TEXSTAN Input Files}

Smooth vane (no film cooling holes) surface heat transfer measurements were also compared with the numerical predictions of academic version of TEXSTAN developed by Crawford [J-1]. Freestream total pressure, total temperature, turbulence intensity and turbulence dissipation rate were given as inputs as well as smoothed local free-stream velocities along the vane surface. For the high freestream turbulence cases, Lam-Bremhorst two-equation turbulence model along with the Schmidt-Patankar transition model was selected. This transition model requires the specification of momentum thickness Reynolds number at which point the effects of turbulent kinetic energy production in the boundary layer were included. For the low freestream turbulence cases, the TEXSTAN was forced to transition at the location where the experimental data indicated transition by using abrupt transition model. In all TEXTSAN predictions, a constant surface temperature boundary condition was applied to the vane. This appendix displays two sample input files for the suction side at exit Mach 0.75. One is for the low freestream turbulence level of $\mathrm{Tu}=2 \%$ and the other for the high freestream turbulence level of $\mathrm{Tu}=$ $15.7 \%$.

\section{Suction Side, $\mathrm{Tu}=2 \%$}

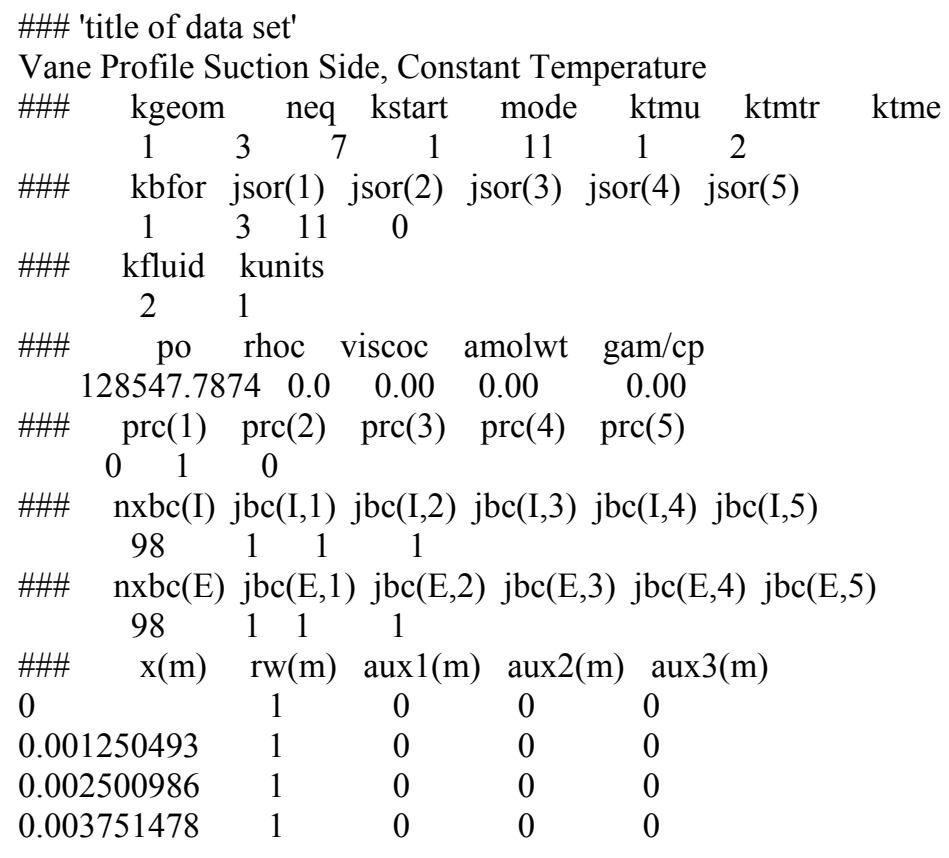




$\begin{array}{lllll}0.005001971 & 1 & 0 & 0 & 0 \\ 0.006252464 & 1 & 0 & 0 & 0 \\ 0.007502957 & 1 & 0 & 0 & 0 \\ 0.00875345 & 1 & 0 & 0 & 0 \\ 0.010003942 & 1 & 0 & 0 & 0 \\ 0.011254435 & 1 & 0 & 0 & 0 \\ 0.012504928 & 1 & 0 & 0 & 0 \\ 0.013755421 & 1 & 0 & 0 & 0 \\ 0.015005914 & 1 & 0 & 0 & 0 \\ 0.016256406 & 1 & 0 & 0 & 0 \\ 0.017506899 & 1 & 0 & 0 & 0 \\ 0.018757392 & 1 & 0 & 0 & 0 \\ 0.020007885 & 1 & 0 & 0 & 0 \\ 0.021258378 & 1 & 0 & 0 & 0 \\ 0.02250887 & 1 & 0 & 0 & 0 \\ 0.023759363 & 1 & 0 & 0 & 0 \\ 0.025009856 & 1 & 0 & 0 & 0 \\ 0.026260349 & 1 & 0 & 0 & 0 \\ 0.027510842 & 1 & 0 & 0 & 0 \\ 0.028761334 & 1 & 0 & 0 & 0 \\ 0.030011827 & 1 & 0 & 0 & 0 \\ 0.03126232 & 1 & 0 & 0 & 0 \\ 0.032512813 & 1 & 0 & 0 & 0 \\ 0.033763306 & 1 & 0 & 0 & 0 \\ 0.035013798 & 1 & 0 & 0 & 0 \\ 0.036264291 & 1 & 0 & 0 & 0 \\ 0.037514784 & 1 & 0 & 0 & 0 \\ 0.038765277 & 1 & 0 & 0 & 0 \\ 0.04001577 & 1 & 0 & 0 & 0 \\ 0.041266262 & 1 & 0 & 0 & 0 \\ 0.042516755 & 1 & 0 & 0 & 0 \\ 0.043767248 & 1 & 0 & 0 & 0 \\ 0.045017741 & 1 & 0 & 0 & 0 \\ 0.046268234 & 1 & 0 & 0 & 0 \\ 0.047518726 & 1 & 0 & 0 & 0 \\ 0.048769219 & 1 & 0 & 0 & 0 \\ 0.050019712 & 1 & 0 & 0 & 0 \\ 0.051270205 & 1 & 0 & 0 & 0 \\ 0.052520698 & 1 & 0 & 0 & 0 \\ 0.05377119 & 1 & 0 & 0 & 0 \\ 0.055021683 & 1 & 0 & 0 & 0 \\ 0.056272176 & 1 & 0 & 0 & 0 \\ 0.057522669 & 1 & 0 & 0 & 0 \\ 0.058773162 & 1 & 0 & 0 & 0 \\ 0.060023654 & 1 & 0 & 0 & 0 \\ 0.061274147 & 1 & 0 & 0 & 0 \\ 0.06252464 & 1 & 0 & 0 & 0 \\ 0.063775133 & 1 & 0 & 0 & 0 \\ 0.065025626 & 1 & 0 & 0 & 0 \\ 0.066276118 & 1 & 0 & 0 & 0 \\ 0.067526611 & 1 & 0 & 0 & 0 \\ 0.068777104 & 1 & 0 & 0 & 0 \\ 0.070027597 & 1 & 0 & 0 & 0 \\ 0.07127809 & 1 & 0 & 0 & 0 \\ 0.072528582 & 1 & 0 & 0 & 0 \\ 0.073779075 & 1 & 0 & 0 & 0\end{array}$




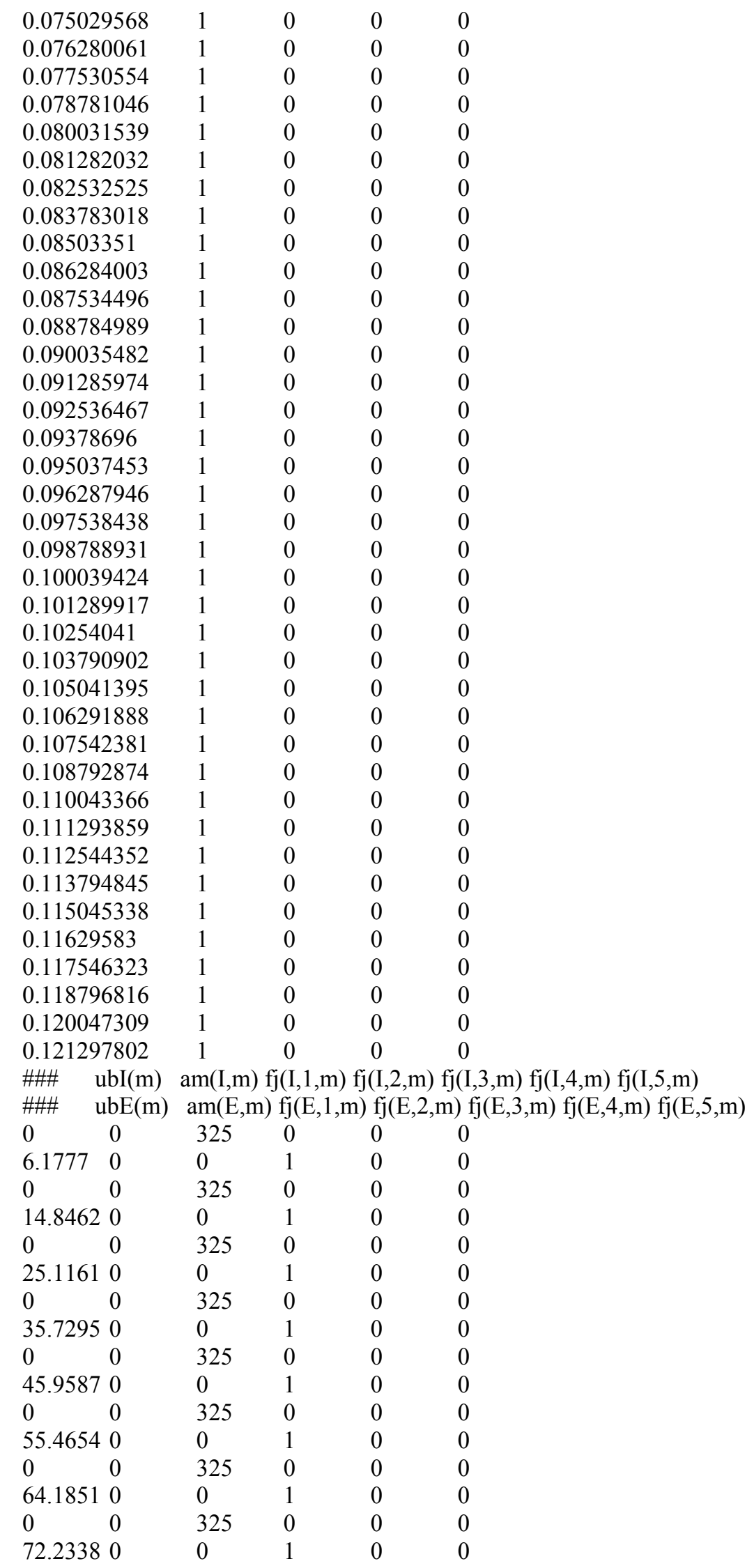




\begin{tabular}{|c|c|c|c|c|}
\hline 0 & 0 & 325 & 0 & 0 \\
\hline 79.8351 & 0 & 0 & 1 & 0 \\
\hline 0 & 0 & 325 & 0 & 0 \\
\hline 87.2632 & 0 & 0 & 1 & 0 \\
\hline 0 & 0 & 325 & 0 & 0 \\
\hline 94.8001 & 0 & 0 & 1 & 0 \\
\hline 0 & 0 & 325 & 0 & 0 \\
\hline 102.705 & 0 & 0 & 1 & 0 \\
\hline 0 & 0 & 325 & 0 & 0 \\
\hline 111.196 & & 0 & 1 & 0 \\
\hline 0 & 0 & 325 & 0 & 0 \\
\hline 120.432 & 0 & 0 & 1 & 0 \\
\hline 0 & 0 & 325 & 0 & 0 \\
\hline 130.514 & 0 & 0 & 1 & 0 \\
\hline 0 & 0 & 325 & 0 & 0 \\
\hline 141.479 & 0 & 0 & 1 & 0 \\
\hline 0 & 0 & 325 & 0 & 0 \\
\hline 153.304 & 0 & 0 & 1 & 0 \\
\hline 0 & 0 & 325 & 0 & 0 \\
\hline 165.916 & 0 & 0 & 1 & 0 \\
\hline 0 & 0 & 325 & 0 & 0 \\
\hline 179.194 & 0 & 0 & 1 & 0 \\
\hline 0 & 0 & 325 & 0 & 0 \\
\hline 192.982 & 0 & 0 & 1 & 0 \\
\hline 0 & 0 & 325 & 0 & 0 \\
\hline 207.099 & 0 & 0 & 1 & 0 \\
\hline 0 & 0 & 325 & 0 & 0 \\
\hline 221.347 & 0 & 0 & 1 & 0 \\
\hline 0 & 0 & 325 & 0 & 0 \\
\hline 235.520 & 0 & 0 & 1 & 0 \\
\hline 0 & 0 & 325 & 0 & 0 \\
\hline 249.415 & 0 & 0 & 1 & 0 \\
\hline 0 & 0 & 325 & 0 & 0 \\
\hline 262.838 & 0 & 0 & 1 & 0 \\
\hline 0 & 0 & 325 & 0 & 0 \\
\hline 275.611 & 0 & 0 & 1 & 0 \\
\hline 0 & 0 & 325 & 0 & 0 \\
\hline 287.576 & 0 & 0 & 1 & 0 \\
\hline 0 & 0 & 325 & 0 & 0 \\
\hline 298.602 & 0 & 0 & 1 & 0 \\
\hline 0 & 0 & 325 & 0 & 0 \\
\hline 308.585 & 0 & 0 & 1 & 0 \\
\hline 0 & 0 & 325 & 0 & 0 \\
\hline 317.452 & 0 & 0 & 1 & 0 \\
\hline 0 & 0 & 325 & 0 & 0 \\
\hline 325.158 & 0 & 0 & 1 & 0 \\
\hline 0 & 0 & 325 & 0 & 0 \\
\hline 331.688 & 0 & 0 & 1 & 0 \\
\hline 0 & 0 & 325 & 0 & 0 \\
\hline 337.056 & 0 & 0 & 1 & 0 \\
\hline 0 & 0 & 325 & 0 & 0 \\
\hline 341.300 & 0 & 0 & 1 & 0 \\
\hline 0 & 0 & 325 & 0 & 0 \\
\hline 344.482 & 0 & 0 & 1 & 0 \\
\hline 0 & 0 & 325 & 0 & 0 \\
\hline 346.682 & & 0 & 1 & 0 \\
\hline
\end{tabular}




\begin{tabular}{|c|c|c|c|c|}
\hline 0 & 0 & 325 & 0 & 0 \\
\hline 347.997 & & 0 & 1 & 0 \\
\hline 0 & 0 & 325 & 0 & 0 \\
\hline 348.533 & & 0 & 1 & 0 \\
\hline 0 & 0 & 325 & 0 & 0 \\
\hline 348.405 & 0 & 0 & 1 & 0 \\
\hline 0 & 0 & 325 & 0 & 0 \\
\hline 347.731 & 0 & 0 & 1 & 0 \\
\hline 0 & 0 & 325 & 0 & 0 \\
\hline 346.628 & 0 & 0 & 1 & 0 \\
\hline 0 & 0 & 325 & 0 & 0 \\
\hline 345.210 & & 0 & 1 & 0 \\
\hline 0 & 0 & 325 & 0 & 0 \\
\hline 343.584 & 0 & 0 & 1 & 0 \\
\hline 0 & 0 & 325 & 0 & 0 \\
\hline 341.848 & 0 & 0 & 1 & 0 \\
\hline 0 & 0 & 325 & 0 & 0 \\
\hline 340.087 & 0 & 0 & 1 & 0 \\
\hline 0 & 0 & 325 & 0 & 0 \\
\hline 338.374 & 0 & 0 & 1 & 0 \\
\hline 0 & 0 & 325 & 0 & 0 \\
\hline 336.767 & 0 & 0 & 1 & 0 \\
\hline 0 & 0 & 325 & 0 & 0 \\
\hline 335.309 & 0 & 0 & 1 & 0 \\
\hline 0 & 0 & 325 & 0 & 0 \\
\hline 334.030 & 0 & 0 & 1 & 0 \\
\hline 0 & 0 & 325 & 0 & 0 \\
\hline 332.945 & 0 & 0 & 1 & 0 \\
\hline 0 & 0 & 325 & 0 & 0 \\
\hline 332.053 & 0 & 0 & 1 & 0 \\
\hline 0 & 0 & 325 & 0 & 0 \\
\hline 331.347 & 0 & 0 & 1 & 0 \\
\hline 0 & 0 & 325 & 0 & 0 \\
\hline 330.804 & 0 & 0 & 1 & 0 \\
\hline 0 & 0 & 325 & 0 & 0 \\
\hline 330.398 & 0 & 0 & 1 & 0 \\
\hline 0 & 0 & 325 & 0 & 0 \\
\hline 330.094 & 0 & 0 & 1 & 0 \\
\hline 0 & 0 & 325 & 0 & 0 \\
\hline 329.854 & 0 & 0 & 1 & 0 \\
\hline 0 & 0 & 325 & 0 & 0 \\
\hline 329.640 & 0 & 0 & 1 & 0 \\
\hline 0 & 0 & 325 & 0 & 0 \\
\hline 329.414 & 0 & 0 & 1 & 0 \\
\hline 0 & 0 & 325 & 0 & 0 \\
\hline 329.140 & 0 & 0 & 1 & 0 \\
\hline 0 & 0 & 325 & 0 & 0 \\
\hline 328.788 & 0 & 0 & 1 & 0 \\
\hline 0 & 0 & 325 & 0 & 0 \\
\hline 328.335 & 0 & 0 & 1 & 0 \\
\hline 0 & 0 & 325 & 0 & 0 \\
\hline 327.764 & 0 & 0 & 1 & 0 \\
\hline 0 & 0 & 325 & 0 & 0 \\
\hline 327.065 & 0 & 0 & 1 & 0 \\
\hline 0 & 0 & 325 & 0 & 0 \\
\hline 326.238 & & 0 & 1 & 0 \\
\hline
\end{tabular}




\begin{tabular}{|c|c|c|c|}
\hline 0 & 325 & 0 & 0 \\
\hline 325.292 & 0 & 1 & 0 \\
\hline 0 & 325 & 0 & 0 \\
\hline 324.242 & 0 & 1 & 0 \\
\hline 0 & 325 & 0 & 0 \\
\hline 323.1110 & 0 & 1 & 0 \\
\hline 0 & 325 & 0 & 0 \\
\hline 321.924 & 0 & 1 & 0 \\
\hline 0 & 325 & 0 & 0 \\
\hline 320.715 & 0 & 1 & 0 \\
\hline 0 & 325 & 0 & 0 \\
\hline 319.514 & 0 & 1 & 0 \\
\hline 0 & 325 & 0 & 0 \\
\hline 318.354 & 0 & 1 & 0 \\
\hline 0 & 325 & 0 & 0 \\
\hline 317.264 & 0 & 1 & 0 \\
\hline 0 & 325 & 0 & 0 \\
\hline 316.269 & 0 & 1 & 0 \\
\hline 0 & 325 & 0 & 0 \\
\hline 315.386 & 0 & 1 & 0 \\
\hline 0 & 325 & 0 & 0 \\
\hline 314.625 & 0 & 1 & 0 \\
\hline 0 & 325 & 0 & 0 \\
\hline 313.985 & 0 & 1 & 0 \\
\hline 0 & 325 & 0 & 0 \\
\hline 313.457 & 0 & 1 & 0 \\
\hline 0 & 325 & 0 & 0 \\
\hline 313.020 & 0 & 1 & 0 \\
\hline 0 & 325 & 0 & 0 \\
\hline 312.646 & 0 & 1 & 0 \\
\hline 0 & 325 & 0 & 0 \\
\hline 312.298 & 0 & 1 & 0 \\
\hline 0 & 325 & 0 & 0 \\
\hline 311.935 & 0 & 1 & 0 \\
\hline 0 & 325 & 0 & 0 \\
\hline 311.515 & 0 & 1 & 0 \\
\hline 0 & 325 & 0 & 0 \\
\hline 310.996 & 0 & 1 & 0 \\
\hline 0 & 325 & 0 & 0 \\
\hline 310.347 & 0 & 1 & 0 \\
\hline 0 & 325 & 0 & 0 \\
\hline 309.544 & 0 & 1 & 0 \\
\hline 0 & 325 & 0 & 0 \\
\hline 308.582 & 0 & 1 & 0 \\
\hline 0 & 325 & 0 & 0 \\
\hline 307.472 & 0 & 1 & 0 \\
\hline 0 & 325 & 0 & 0 \\
\hline 306.249 & 0 & 1 & 0 \\
\hline 0 & 325 & 0 & 0 \\
\hline 304.967 & 0 & 1 & 0 \\
\hline 0 & 325 & 0 & 0 \\
\hline 303.696 & 0 & 1 & 0 \\
\hline 0 & 325 & 0 & 0 \\
\hline 302.514 & 0 & 1 & 0 \\
\hline 0 & 325 & 0 & 0 \\
\hline 301.489 & 0 & 1 & 0 \\
\hline
\end{tabular}




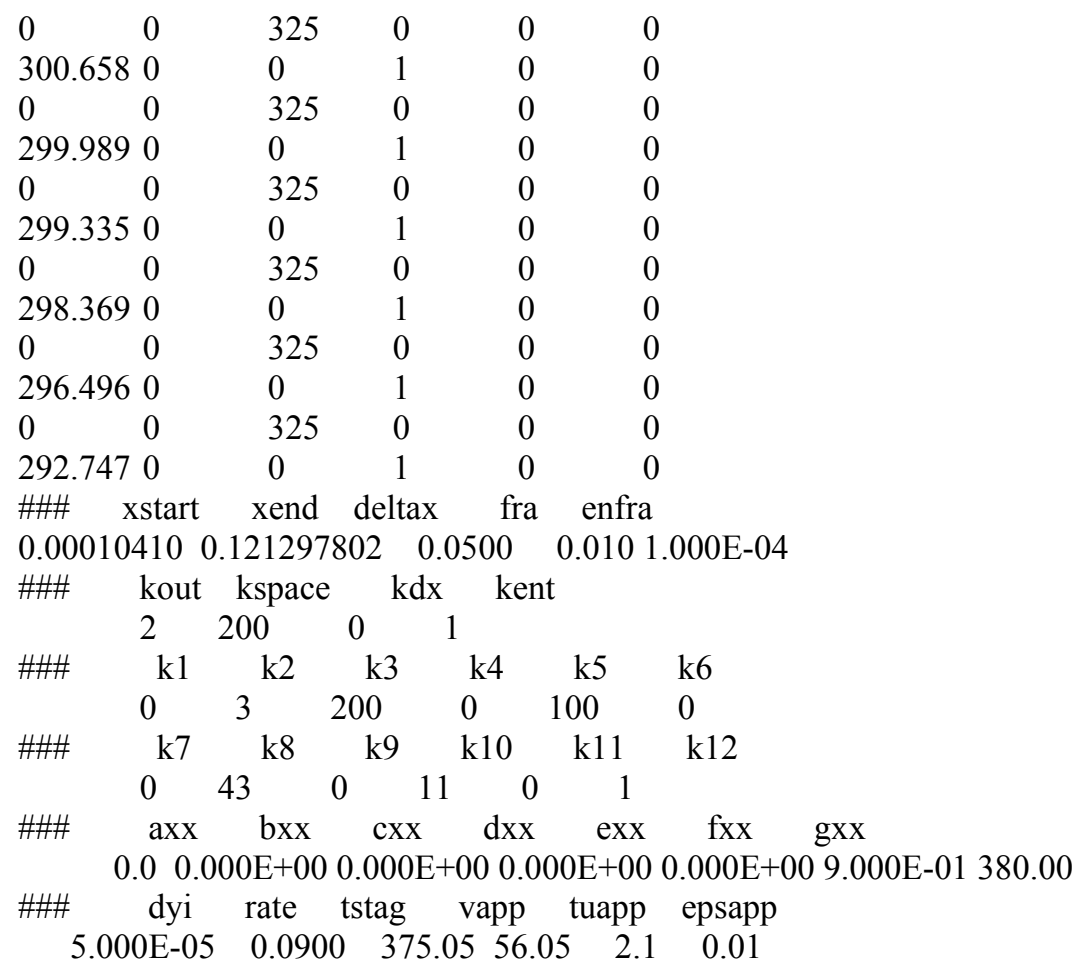

\section{Suction Side, $\mathrm{Tu}=15.7 \%$}

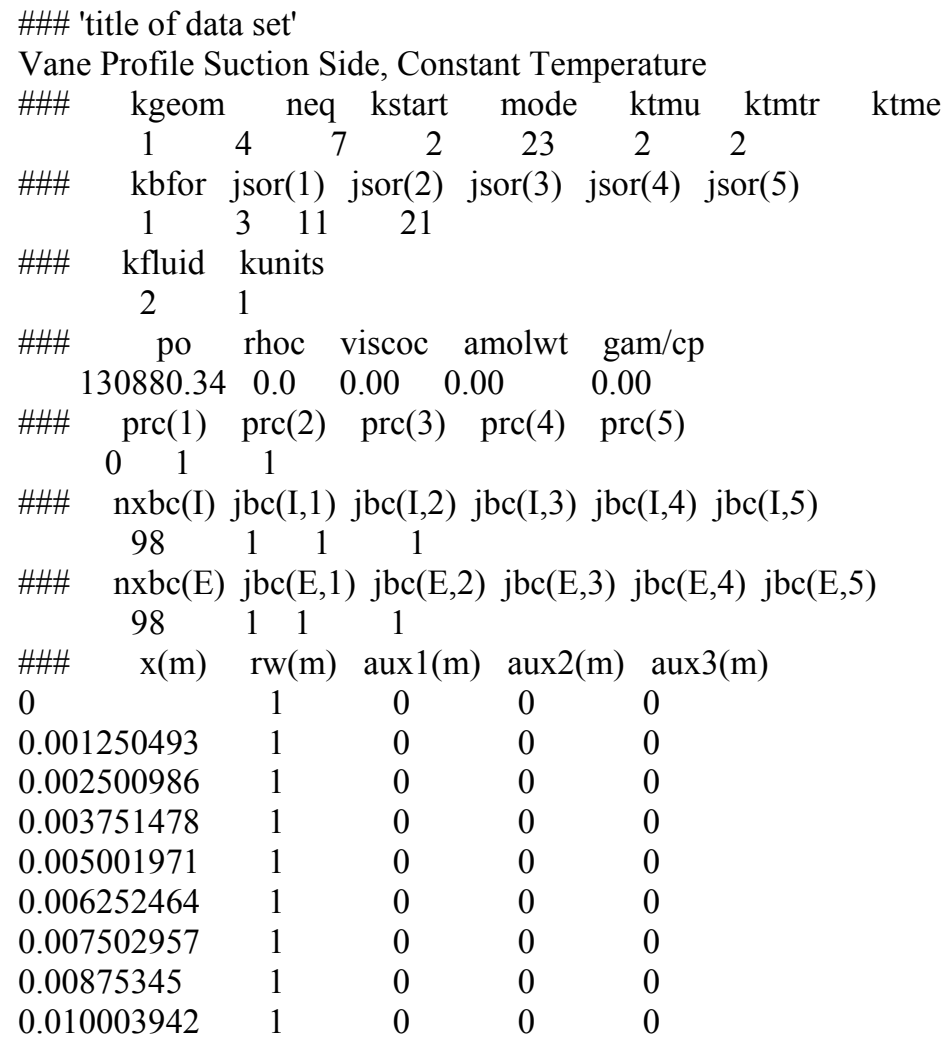




$\begin{array}{lllll}0.011254435 & 1 & 0 & 0 & 0 \\ 0.012504928 & 1 & 0 & 0 & 0 \\ 0.013755421 & 1 & 0 & 0 & 0 \\ 0.015005914 & 1 & 0 & 0 & 0 \\ 0.016256406 & 1 & 0 & 0 & 0 \\ 0.017506899 & 1 & 0 & 0 & 0 \\ 0.018757392 & 1 & 0 & 0 & 0 \\ 0.020007885 & 1 & 0 & 0 & 0 \\ 0.021258378 & 1 & 0 & 0 & 0 \\ 0.02250887 & 1 & 0 & 0 & 0 \\ 0.023759363 & 1 & 0 & 0 & 0 \\ 0.025009856 & 1 & 0 & 0 & 0 \\ 0.026260349 & 1 & 0 & 0 & 0 \\ 0.027510842 & 1 & 0 & 0 & 0 \\ 0.028761334 & 1 & 0 & 0 & 0 \\ 0.030011827 & 1 & 0 & 0 & 0 \\ 0.03126232 & 1 & 0 & 0 & 0 \\ 0.032512813 & 1 & 0 & 0 & 0 \\ 0.033763306 & 1 & 0 & 0 & 0 \\ 0.035013798 & 1 & 0 & 0 & 0 \\ 0.036264291 & 1 & 0 & 0 & 0 \\ 0.037514784 & 1 & 0 & 0 & 0 \\ 0.038765277 & 1 & 0 & 0 & 0 \\ 0.04001577 & 1 & 0 & 0 & 0 \\ 0.041266262 & 1 & 0 & 0 & 0 \\ 0.042516755 & 1 & 0 & 0 & 0 \\ 0.043767248 & 1 & 0 & 0 & 0 \\ 0.045017741 & 1 & 0 & 0 & 0 \\ 0.046268234 & 1 & 0 & 0 & 0 \\ 0.047518726 & 1 & 0 & 0 & 0 \\ 0.048769219 & 1 & 0 & 0 & 0 \\ 0.050019712 & 1 & 0 & 0 & 0 \\ 0.051270205 & 1 & 0 & 0 & 0 \\ 0.052520698 & 1 & 0 & 0 & 0 \\ 0.05377119 & 1 & 0 & 0 & 0 \\ 0.055021683 & 1 & 0 & 0 & 0 \\ 0.056272176 & 1 & 0 & 0 & 0 \\ 0.057522669 & 1 & 0 & 0 & 0 \\ 0.058773162 & 1 & 0 & 0 & 0 \\ 0.060023654 & 1 & 0 & 0 & 0 \\ 0.061274147 & 1 & 0 & 0 & 0 \\ 0.06252464 & 1 & 0 & 0 & 0 \\ 0.063775133 & 1 & 0 & 0 & 0 \\ 0.065025626 & 1 & 0 & 0 & 0 \\ 0.066276118 & 1 & 0 & 0 & 0 \\ 0.067526611 & 1 & 0 & 0 & 0 \\ 0.068777104 & 1 & 0 & 0 & 0 \\ 0.070027597 & 1 & 0 & 0 & 0 \\ 0.07127809 & 1 & 0 & 0 & 0 \\ 0.072528582 & 1 & 0 & 0 & 0 \\ 0.073779075 & 1 & 0 & 0 & 0 \\ 0.075029568 & 1 & 0 & 0 & 0 \\ 0.076280061 & 1 & 0 & 0 & 0 \\ 0.077530554 & 1 & 0 & 0 & 0 \\ 0.078781046 & 1 & 0 & 0 & 0 \\ 0.080031539 & 1 & 0 & 0 & 0\end{array}$




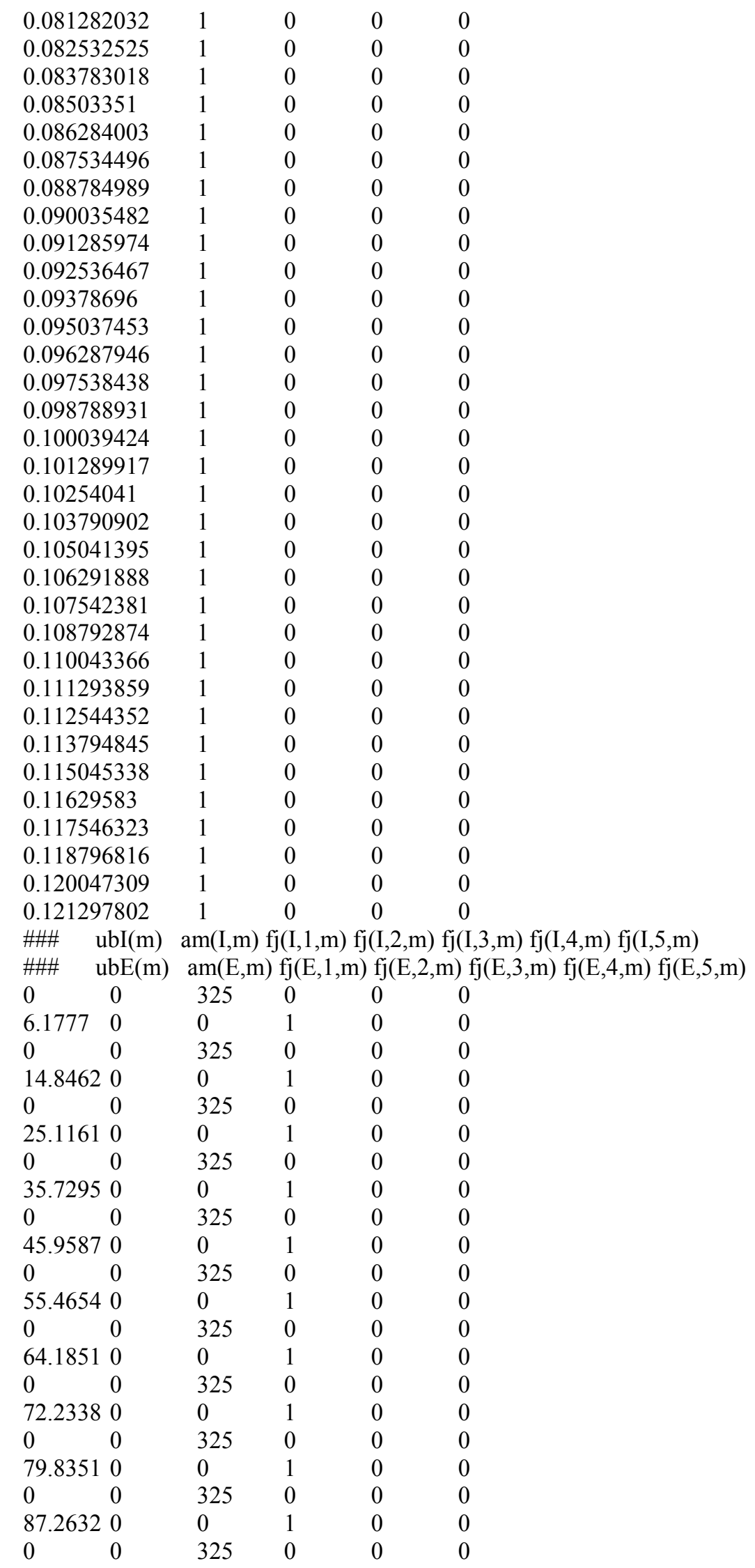




\begin{tabular}{|c|c|c|c|c|}
\hline 94.8001 & 0 & 1 & 0 & 0 \\
\hline 0 & 325 & 0 & 0 & 0 \\
\hline 102.705 & 0 & 1 & 0 & 0 \\
\hline 0 & 325 & 0 & 0 & 0 \\
\hline 111.196 & 0 & 1 & 0 & 0 \\
\hline 0 & 325 & 0 & 0 & 0 \\
\hline 120.432 & 0 & 1 & 0 & 0 \\
\hline 0 & 325 & 0 & 0 & 0 \\
\hline 130.514 & 0 & 1 & 0 & 0 \\
\hline 0 & 325 & 0 & 0 & 0 \\
\hline 141.479 & 0 & 1 & 0 & 0 \\
\hline 0 & 325 & 0 & 0 & 0 \\
\hline 153.304 & 0 & 1 & 0 & 0 \\
\hline 0 & 325 & 0 & 0 & 0 \\
\hline 165.916 & 0 & 1 & 0 & 0 \\
\hline 0 & 325 & 0 & 0 & 0 \\
\hline 179.194 & 0 & 1 & 0 & 0 \\
\hline 0 & 325 & 0 & 0 & 0 \\
\hline 192.982 & 0 & 1 & 0 & 0 \\
\hline 0 & 325 & 0 & 0 & 0 \\
\hline 207.099 & 0 & 1 & 0 & 0 \\
\hline 0 & 325 & 0 & 0 & 0 \\
\hline 221.347 & 0 & 1 & 0 & 0 \\
\hline 0 & 325 & 0 & 0 & 0 \\
\hline 235.520 & 0 & 1 & 0 & 0 \\
\hline 0 & 325 & 0 & 0 & 0 \\
\hline 249.415 & 0 & 1 & 0 & 0 \\
\hline 0 & 325 & 0 & 0 & 0 \\
\hline 262.838 & 0 & 1 & 0 & 0 \\
\hline 0 & 325 & 0 & 0 & 0 \\
\hline 275.611 & 0 & 1 & 0 & 0 \\
\hline 0 & 325 & 0 & 0 & 0 \\
\hline 287.576 & 0 & 1 & 0 & 0 \\
\hline 0 & 325 & 0 & 0 & 0 \\
\hline 298.602 & 0 & 1 & 0 & 0 \\
\hline 0 & 325 & 0 & 0 & 0 \\
\hline 308.585 & 0 & 1 & 0 & 0 \\
\hline 0 & 325 & 0 & 0 & 0 \\
\hline 317.452 & 0 & 1 & 0 & 0 \\
\hline 0 & 325 & 0 & 0 & 0 \\
\hline 325.158 & 0 & 1 & 0 & 0 \\
\hline 0 & 325 & 0 & 0 & 0 \\
\hline 331.688 & 0 & 1 & 0 & 0 \\
\hline 0 & 325 & 0 & 0 & 0 \\
\hline 337.056 & 0 & 1 & 0 & 0 \\
\hline 0 & 325 & 0 & 0 & 0 \\
\hline 341.300 & 0 & 1 & 0 & 0 \\
\hline 0 & 325 & 0 & 0 & 0 \\
\hline 344.482 & 0 & 1 & 0 & 0 \\
\hline 0 & 325 & 0 & 0 & 0 \\
\hline 346.682 & 0 & 1 & 0 & 0 \\
\hline 0 & 325 & 0 & 0 & 0 \\
\hline 347.997 & 0 & 1 & 0 & 0 \\
\hline 0 & 325 & 0 & 0 & 0 \\
\hline 348.533 & 0 & 1 & 0 & 0 \\
\hline 0 & 325 & 0 & 0 & 0 \\
\hline
\end{tabular}




\begin{tabular}{|c|c|c|c|c|}
\hline 348.4050 & 0 & 1 & 0 & 0 \\
\hline 0 & 325 & 0 & 0 & 0 \\
\hline 347.7310 & 0 & 1 & 0 & 0 \\
\hline 0 & 325 & 0 & 0 & 0 \\
\hline 346.6280 & 0 & 1 & 0 & 0 \\
\hline 0 & 325 & 0 & 0 & 0 \\
\hline 345.2100 & 0 & 1 & 0 & 0 \\
\hline 0 & 325 & 0 & 0 & 0 \\
\hline 343.5840 & 0 & 1 & 0 & 0 \\
\hline 0 & 325 & 0 & 0 & 0 \\
\hline 341.8480 & 0 & 1 & 0 & 0 \\
\hline 0 & 325 & 0 & 0 & 0 \\
\hline 340.0870 & 0 & 1 & 0 & 0 \\
\hline 0 & 325 & 0 & 0 & 0 \\
\hline 338.3740 & 0 & 1 & 0 & 0 \\
\hline 0 & 325 & 0 & 0 & 0 \\
\hline 336.7670 & 0 & 1 & 0 & 0 \\
\hline 0 & 325 & 0 & 0 & 0 \\
\hline 335.3090 & 0 & 1 & 0 & 0 \\
\hline 0 & 325 & 0 & 0 & 0 \\
\hline 334.0300 & 0 & 1 & 0 & 0 \\
\hline 0 & 325 & 0 & 0 & 0 \\
\hline 332.9450 & 0 & 1 & 0 & 0 \\
\hline 0 & 325 & 0 & 0 & 0 \\
\hline 332.0530 & 0 & 1 & 0 & 0 \\
\hline 0 & 325 & 0 & 0 & 0 \\
\hline 331.3470 & 0 & 1 & 0 & 0 \\
\hline 0 & 325 & 0 & 0 & 0 \\
\hline 330.8040 & 0 & 1 & 0 & 0 \\
\hline 0 & 325 & 0 & 0 & 0 \\
\hline 330.3980 & 0 & 1 & 0 & 0 \\
\hline 0 & 325 & 0 & 0 & 0 \\
\hline 330.0940 & 0 & 1 & 0 & 0 \\
\hline 0 & 325 & 0 & 0 & 0 \\
\hline 329.8540 & 0 & 1 & 0 & 0 \\
\hline 0 & 325 & 0 & 0 & 0 \\
\hline 329.6400 & 0 & 1 & 0 & 0 \\
\hline 0 & 325 & 0 & 0 & 0 \\
\hline 329.4140 & 0 & 1 & 0 & 0 \\
\hline 0 & 325 & 0 & 0 & 0 \\
\hline 329.1400 & 0 & 1 & 0 & 0 \\
\hline 0 & 325 & 0 & 0 & 0 \\
\hline 328.7880 & 0 & 1 & 0 & 0 \\
\hline 0 & 325 & 0 & 0 & 0 \\
\hline 328.3350 & 0 & 1 & 0 & 0 \\
\hline 0 & 325 & 0 & 0 & 0 \\
\hline 327.7640 & 0 & 1 & 0 & 0 \\
\hline 0 & 325 & 0 & 0 & 0 \\
\hline 327.0650 & 0 & 1 & 0 & 0 \\
\hline 0 & 325 & 0 & 0 & 0 \\
\hline 326.2380 & 0 & 1 & 0 & 0 \\
\hline 0 & 325 & 0 & 0 & 0 \\
\hline 325.2920 & 0 & 1 & 0 & 0 \\
\hline 0 & 325 & 0 & 0 & 0 \\
\hline 324.2420 & 0 & 1 & 0 & 0 \\
\hline 0 & 325 & 0 & 0 & 0 \\
\hline
\end{tabular}




\begin{tabular}{|c|c|c|c|c|}
\hline 323.111 & 0 & 1 & 0 & 0 \\
\hline 0 & 325 & 0 & 0 & 0 \\
\hline 321.924 & 0 & 1 & 0 & 0 \\
\hline 0 & 325 & 0 & 0 & 0 \\
\hline 320.715 & 0 & 1 & 0 & 0 \\
\hline 0 & 325 & 0 & 0 & 0 \\
\hline 319.514 & 0 & 1 & 0 & 0 \\
\hline 0 & 325 & 0 & 0 & 0 \\
\hline 318.354 & 0 & 1 & 0 & 0 \\
\hline 0 & 325 & 0 & 0 & 0 \\
\hline 317.264 & 0 & 1 & 0 & 0 \\
\hline 0 & 325 & 0 & 0 & 0 \\
\hline 316.269 & 0 & 1 & 0 & 0 \\
\hline 0 & 325 & 0 & 0 & 0 \\
\hline 315.386 & 0 & 1 & 0 & 0 \\
\hline 0 & 325 & 0 & 0 & 0 \\
\hline 314.625 & 0 & 1 & 0 & 0 \\
\hline 0 & 325 & 0 & 0 & 0 \\
\hline 313.985 & 0 & 1 & 0 & 0 \\
\hline 0 & 325 & 0 & 0 & 0 \\
\hline 313.457 & 0 & 1 & 0 & 0 \\
\hline 0 & 325 & 0 & 0 & 0 \\
\hline 313.020 & 0 & 1 & 0 & 0 \\
\hline 0 & 325 & 0 & 0 & 0 \\
\hline 312.646 & 0 & 1 & 0 & 0 \\
\hline 0 & 325 & 0 & 0 & 0 \\
\hline 312.298 & 0 & 1 & 0 & 0 \\
\hline 0 & 325 & 0 & 0 & 0 \\
\hline 311.935 & 0 & 1 & 0 & 0 \\
\hline 0 & 325 & 0 & 0 & 0 \\
\hline 311.515 & 0 & 1 & 0 & 0 \\
\hline 0 & 325 & 0 & 0 & 0 \\
\hline 310.996 & 0 & 1 & 0 & 0 \\
\hline 0 & 325 & 0 & 0 & 0 \\
\hline 310.347 & 0 & 1 & 0 & 0 \\
\hline 0 & 325 & 0 & 0 & 0 \\
\hline 309.544 & 0 & 1 & 0 & 0 \\
\hline 0 & 325 & 0 & 0 & 0 \\
\hline 308.582 & 0 & 1 & 0 & 0 \\
\hline 0 & 325 & 0 & 0 & 0 \\
\hline 307.472 & 0 & 1 & 0 & 0 \\
\hline 0 & 325 & 0 & 0 & 0 \\
\hline 306.249 & 0 & 1 & 0 & 0 \\
\hline 0 & 325 & 0 & 0 & 0 \\
\hline 304.967 & 0 & 1 & 0 & 0 \\
\hline 0 & 325 & 0 & 0 & 0 \\
\hline 303.696 & 0 & 1 & 0 & 0 \\
\hline 0 & 325 & 0 & 0 & 0 \\
\hline 302.514 & 0 & 1 & 0 & 0 \\
\hline 0 & 325 & 0 & 0 & 0 \\
\hline 301.489 & 0 & 1 & 0 & 0 \\
\hline 0 & 325 & 0 & 0 & 0 \\
\hline 300.658 & 0 & 1 & 0 & 0 \\
\hline 0 & 325 & 0 & 0 & 0 \\
\hline 299.989 & 0 & 1 & 0 & 0 \\
\hline 0 & 325 & 0 & 0 & 0 \\
\hline
\end{tabular}




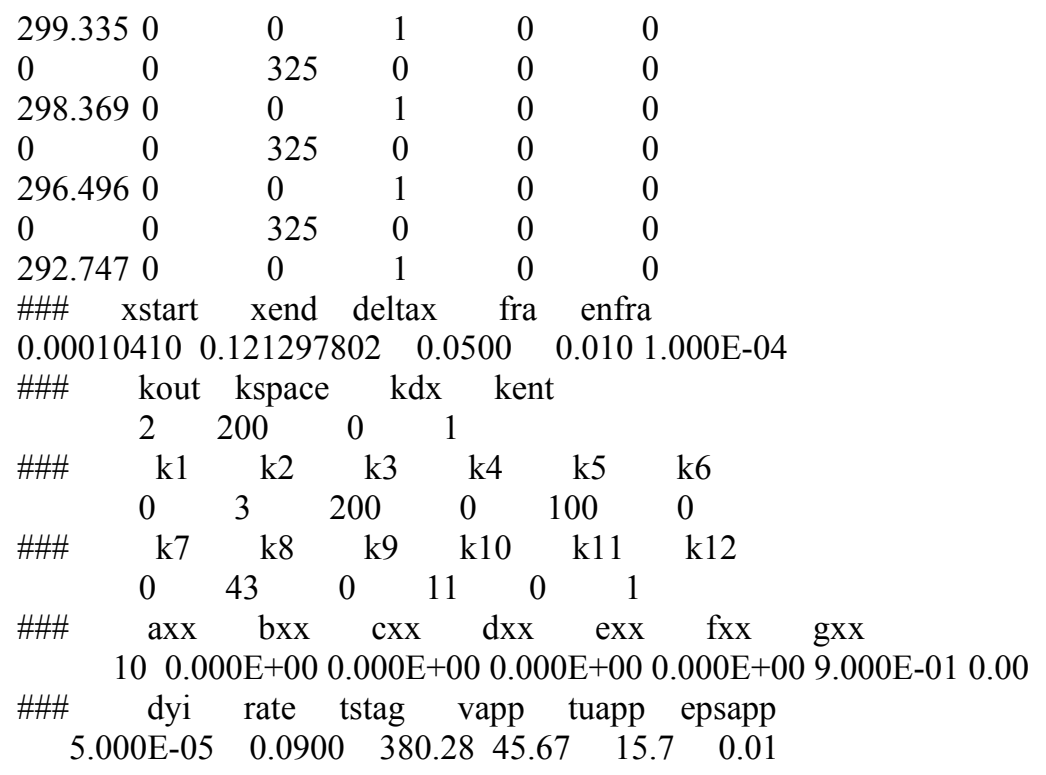

\section{References}

[J-1] Crawford, M.E., 1986, "Simulation Codes for Calculation of Heat Transfer to Convectively-Cooled Turbine Blades," Convective Heat Transfer and Film Cooling in Turbomachinery, VKI Lecture Series 1986-06. 